A mmeher ensavaun Colligue

$$
\text { a Drfirang }
$$

Sonvenir affentucus

Labucclbin

4

ancir 1867 . 


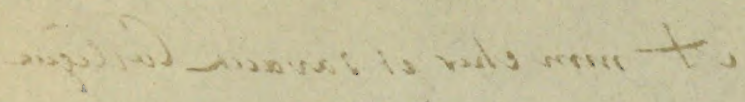

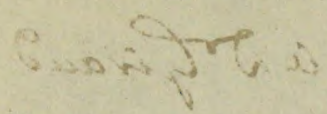

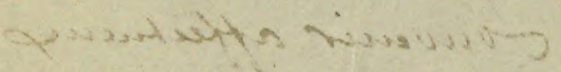

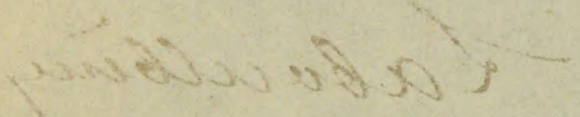

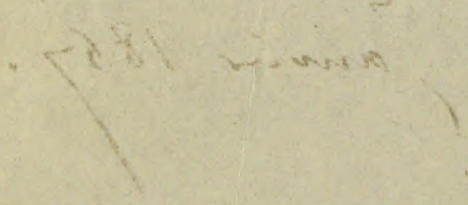





\title{
TRAVAUX D'ENTOMOLOGIE
}

\author{
du Dr A. Laboulbène, \\ Membre et ancien Président de la Société entomologique de Fra zce, \\ Professeur agrégé à la Facnlté de médecine, \\ Médecin des hôpitarx, etc.

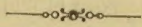

1. Description d'une nouvelle espèce française de Lamophlous ( $L$. $\dot{D} u-$ fourii).

(Annales de la Société entomologique de France, 2* série, t. VI, p. 295-300, figure sur bois, 1848.)

2. Note sur la matière pulvérulente qui recouvre la surface du corps des Lixus et de quelques autres insectes (en commun avec M. E. Follin). (Ann. ent. France, 1848, p. 301-306, fig. sur bois.)

3. Études sur le genre Æpus de Leach et description d'une nouvelle espèce française (T'rechus- IEpus-Robinii).

(Ann. ent. France, 1849, p. 23-37, planche 2, $\mathrm{n}^{\circ}$ I.)

4. Détails anatomiques sur deux larves de Coléoptères, les Anobium abietis et pertinax.

(Comptes Rendus de là Société de Biologie, t. I, p. 97-98, 1849, - Ann. ent. France, 1849, p. 311-313.)

5. Description de deux Insectes polyméliens.

(C.-R. Soc. Biologie, t. I, p. 83, 1849.) 
6. Monstruosités des antennes chez les Insectes,

(C.-R. Soc. Biologie, t. 1, p. 94-95, 1849.)

7. Nole sur un palpe monstrueux observé sur un Bembidium par Jacquelin-Duval, etc.

(Ann. ent. France, 1850 , p. 534.)

8. Réponse à la note de $\mathbf{M}$. Ch. Coquerel sur la prétendue poussière cryptogamique qui recouvre le corps de certains Insectes.

(Ann. ent. France, 1850, p. 17-19. - Rectification finale, 1854, Bulletin, p. Xvir.)

9. Description de quelques Acariens et d'une Hydrachne.

(Ann. ent. France, 1851, p. 295-303, pl. 9, fig. 1, 2, 3, 5.)

10. Description et figure du Tyroglyphus (Cheyletus) Mericourti.

(Ann. ent. France, 1851, p. 301-302, pl. 9, fig. 4. - Vid. MoquinTandon, Éléments de Zoologie médicale, p. 314-315, fig. 119, Paris, 1862, et Dictionnaire encyclopédique des Sciences médicales, t. I, p. 267-268, 1864.)

11. Notes sur l'anatomie des Insectes.

(Ann. ent. France, 1852, p. 335-348.)

12. Sur la physiologie de l'aiguillon des insectes Hyménoptères,

(C.-R. Soc. Biologie, $1^{\text {re }}$ série, t. IV, p. 17-18, 1852.)

43. Sur la physiologie des organes annexés au conduit des æufs chez les Insectes femelles.

(C.-R. Soc. Biologie, $1^{\text {re }}$ série, t. IV, p. 18-19, 1852.)

14. Note sur le cocon du Bombyx paphia.

(Ann. ent. France, 1852, p. 535-537, pl. 15, n 1v. - C.-R. Soc, Biologie, $1^{\text {re }}$ série, t. IV, p. 12/4-125, 1852.) 
15. Note sur une galle végétale développée sur le Draba verna.

(C.-R. Soc. Biologie, $\mathbf{t}^{\text {re }}$ série, t, IV, p. 39-40, 1852.)

16. Description de plusieurs nouvelles espèces du genre Gyretes (Coléoptères-Gyriniens.)

(Ann. ent. France, 1853, p. 47-59, pl. $1^{\mathrm{re}}, \mathrm{n}^{\circ}$ II.)

17. Sur le foie des Insectes.

(C.-R. Soc. Biologie, $1^{\text {re }}$ série, t. V, p. 17-18, 1853.)

18. Note sur une Galle végétale africaine (en commun avec M. Louis Amblard).

(C.-B. Soc. Biologie, $\mathrm{t}^{\text {re }}$ série, t. V, p. $82,1853 .-$ Ann. ent. France, 1853, Bull., p. xxvI-XxviI.)

19. Histoire des métamorphoses d'un Ceutorhynchus qui produit une galle sur le Draba verna.

(Ann. ent. France, 1856, p. 145-168, pl. 4, fig. 1-11. -Mémoires de la Société de Biologie, $2^{\circ}$ série, t. III, p. 147-161, 1856.)

20. Note sur le système nerveux de la Nemoptera lusitanica.

(Ann. ent. France, 1856, Bull., xxv et XcviI.)

21. Faune entomologique française, ou description des Insectes qui se trouvent en France (en collaboration avec M. Léon Fairmaire).

(Un volume in-12, de xxxv-665 pages, Paris, 1854-1856.)

22. Métamorphoses de la Cecidomyia papaveris et remarques sur plusieurs espèces du genre Cecidomyia.

(Ann. ent. France, 1857, p. 565-585, pl. 12, fig. 1-21; et rectifications, Bull., p. GLXIV-cLXv.)

23. Note sur la nymphe de l'Anthrax sinuata.

(Ann. ent: France, 1857, p. 781-790, pl. 15, $n^{\circ}$ 11.) 
24. Note sur des Siliques de Colza attaquées par des insectes.

(Ann. ent. France, 1857, p. 791-797. - C.-R. Soc. Biologie, $2^{\mathrm{e}}$ série, t. IV, p. 66-70, 1857.)

25. Note sur les Galles du Calligonum comosum et du Limoniastrum Guyonanum trouvées en Algérie.

(Ann. ent. France, 1857, Bull., p. LX-LXI.)

26. Sur des Helminthes trouvés dans l'Asilus crabroniformis.

(Ann. ent. France, 1857, Bull., p. cxuIII-cxLv.)

27. Détails anatomiques sur le Bacillus gallicus.

(Ann. ent. France, 1857, Bull., p. cxxxvi-cxxxvir.)

28. Lettre sur la larve de la Cicindela hybrida.

(Archives entomologiques de Thomson, t. I, p. 105-108, 1857.)

29. Recherches sur les appareils de la digestion et de la reproduction du Buprestis (Anthaxia) manca.

(Archiv. entomol. Thomson, t. I, p. 204-236, planches 11 et 12 , 1857. - Mémoires Soc. Biologie, $2^{\mathrm{e}}$ série, t. IV, p. 139-162, 1857.)

30. Recherches sur l'anatomie du Buprestis gigantea.

(Archiv. entomol. Thomson, t. I, p. 465-487, pl. 15, fig. 8-24, 1857.)

31. Sur les mœurs et l'anatomie de la Micralymma brevipenne.

(Ann. ent. France, 1858, p. 73-110, pl. 2 et 3.)

32. Histoire des métamorphoses de la Gelechia (Parasia) Carlinella (en commun avec M. le colonel Goureau).

(Ann. ent. France, 1858, p. 263-278, pl. 7, n I.)

33. Histoire des métamorphoses du Larinus carlinx.

(Ann, ent. France, 1858, p. 279-285, pl. 7, $n^{\circ}$ II.) 
34. Histoire des métamorphoses de l'Orchestes rufus.

(Ann. ent. France, 1858, p. 286-297, pl. 7, n 1II.)

35. Description des métamorphoses du Dasytes caruleus.

(Ann. ent. France, 1858, p. 513-521, pl. 13, nº 1.)

36. Note sur les caroncules thoraciques, ou cocardes rouges, du Malachius bipustulatus.

(Ann. ent. France, 1858 , p. 522-528, pl. 13, n ${ }^{\circ}$ II.)

37. Rapport sur la Session extraordinaire tenue à Grenoble au mois de juillet 1858.

(Ann. ent. France, 1858, p. 819-900.)

38. Métamorphoses du Gymnetron campanulx.

(Ann. ent. France, 1858 , p. $900-904$, pl. $17, n^{\circ}$ I.)

39. Histoire d'un Ichneumon parasite des Araignées (Pimpla Fairmairii).

(Ann. ent. France, 1858, p. 797-817, pl. 17, n ${ }^{\circ}$.)

40. Note sur un Acarus trouvé dans l'urine d'un malade.

(C.-R. Soc. Biologie, 2 série, t. V, p. 140, 1858.)

41. Examen anatomique de deux Melolontha vulguris trouvés accouplés et paraissant du sexe mâle.

(Ann. ent. France, 1859, p. 567-570.)

42. Note sur une monstruosité de l'Oryctes Silenus.

(Ann. ent. France, 1859, p. 645-646.)

43. Rapport sur une larve d'OEstride, extraite de la peau d'un homme à Cayenne.

(Mémoires de la Société de Biologie, $3^{\mathrm{e}}$ série, t. II, p. 161-166, 1860.)

44. Métamorphoses d'une Mouche parasite (Tachina villica).

(Ann. ent. France, 1861, p= 231-248, pl. 7.) 
45. Description et figure d'une larve d'OEstride de Cayenne, extraite de la peau d'un homme (voyez $n^{\circ} 43$ ).

(Ann. ent. France, 1861, p. 249-253.)

46. Description de la larve du Callicnemis Latreillei.

(Ann. ent. France, 1861, p. 607-614.)

47. Note pour servir à l'histoire des parasites de la Noclua (Hadona) brassicz.

(Ann. ent. France, 1861, p. 612.)

48. Note sur des larves d'insecte Diptère trouvées dans les tuniques de l'estomac, les replis péritonéaux et la paroi abdominale chez des grenouilles.

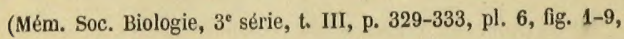
1861.)

49. Note sur un Ver parasite, de la famille des Gordiacés et du genre Mermis, sorti du corps d'un Gryllus domesticus.

(G.-R. Soc. Biologie, $3^{e}$ série, t. III, p. 254, 1861.)

50. Sur des Mermis (Helminthes-Gordiacés) parasites du Dytiscus marginatis.

(C.-R. Soc. Biologie, $3^{\text {e }}$ série, t. III, p. 255-256, 1861.)

51. Sur les stigmates de la larve du Nosodendron fasciculare.

(Ann. ent. France, 1862, p. 149-152, pl. 2, fig. 3, c.)

52. Description de l'Acurus (Tyroglyphus) cntomophagus et observations anatomiques sur le genre Tyroglyphus (en commun avec M. le professeur charles Robin).

(Ann. ent. France, 1862, p. 317-338, pl. 10.)

53. Descriptions de plusieurs Larves de Coléoptères, avec remarques.

(Ann. ent. France, 1862, p. 559-575, pl. 13.) 
5\%. Note sur des IIelminthes parasites du genre Mermis sortis du corps du Gryllus domesticus et du Dytiscus marginalis.

(Ann. ent. France, 1862, p. 576-578.)

55. Sur des larves de Dipteres trouvées dans les tuniques de l'estomac, les replis péritonéaux et la paroi abdominale chez des grenouilles (voyez $n^{\circ} 48$ ).

(Ann, ent, France, 1863, p. 14-16.)

56. Description et figure d'une Chenille mincuse des feuilles du bouleau, (Ann. ent. France, 1863, p. 99-104, pl. 1, fig. 1.)

57. Description du Sciara Bigoti, de sa larve et de sa nymphe.

(Ann. ent. France, 1863, p. 105-110, pl. 2, fig. 5.)

58. Note sur la phosphorescence des larves et des nymphes du genre Lampyris.

(Ann. ent. France, 1863, p. 470.)

59. Observations sur les Insectes tubérivores, avec réfutation de l'erreur qui, attribuant les Truffes a la piquure d'un insecte, les a fait assimiler aux galles végétales.

(Ann. ent. France, 186a, p. 69-114, pl. 2. - Id., 1865, Bull., p. LXII-LXIIL.)

60. Note sur un Helminthe parasite, du genre Mcrmis, sorti du corps d'un Orthoptère à la Nouvelle-Calédonie.

(Ann. ent. France, 1864, p. 678.)

61. Sur l'organe musical de la Chelonia pudica.

(Ann. ent. France, 1864, p. 689-704, pl. 10, fig. 4 et 5.)

62. Recherches sur l'Anurida maritima, iasecte thysanoure de la famille T des podurides.

(Ann. ent. France, 1864, p. 705-720, pl. 11. - Mém. Soc. Biologie, $4^{e}$ série, t. I, p. 189-206, 1864.) 
63. Note sur un habitat remarquable de l'Ephestia elutella.

(Ann. ext. France, 1864, p. 733.)

64 Notice nécrologique sur Emile Charre.

(Ann. ent. France, 1848, Bull., xxxix-xz.)

65. Allocution prononcée aıx funérailles de M. Dunéril, au nom de la Société entomologique de France.

(Ann. ent. France, 1860, p. 651-652.)

66. Paroles d'adieu adressées à M. Lếon Dufour, au nom de la Société entomologique de France.

(Ann. ent. France, 1865, p. 214-215.)

67. Liste des travaux d'entomologie publiés de 1811 à 1864 par M. Léon Dufour.

(Ann. ent France, 1865, 216-252.)

26 décembre 1866.

panis, - Typog. Fíl.IX MaLTESTE et Cie, rue des Deux-Portes-St-Sauseur, 22. 




\section{EXTRAIT DES ANNALES}

UE $\mathbf{L} \wedge$

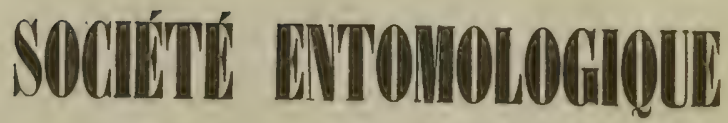

\section{IDE THBANCW.}

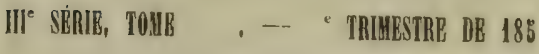




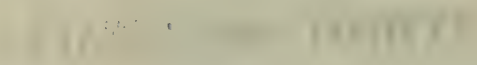

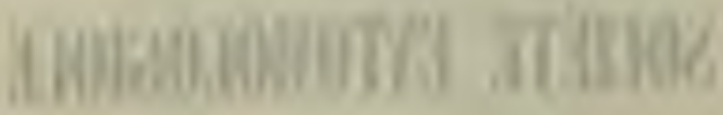

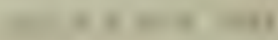

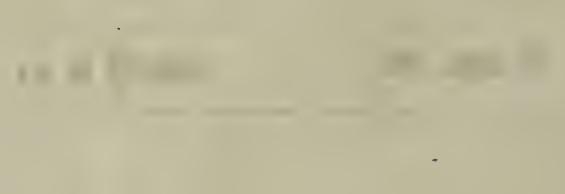

$$
-\frac{1}{a}=-
$$




\title{
NOTES
}

\section{SUR L'AHATOMIE DES INSECTES.}

\author{
Par M. ALEXANiRE LABOULBÈnE.
}

(Séance du 14 Janvier 1852, )

Depuis deux ans jétudie l'organisation intérieure des insectes, et j'ai pu examiner quelques espèces encore non disséquées, ou dont l'anatomie est restée obscure malgré les travaux si recommandables de nos maîtres. En m'aventurant sur ce terrain scabreux, "sur ce vaste champ hérissé de ronces vivaces, ") suivant l'expression de M. Léon Dufour, je ne me suis pas dissimulé les difficultés des recherches, les erreurs que je m'exposais à commettre. Toutefois, animé d'un sincère amour de la science et appelant à mon aide toute l'acuité de ma vue, i'ai, sans préventions, cherché à voir ce qui est; j'ai contrôlé ensuite avec soin ce que j'avais rencontré sous le scalpel et je le transcris dans ces simples notes.

\section{Orthoptènes.}

Gryllus domesticus. - En disséquant le Gryllus domesticus L. j'ai trouvé chez cet insecte, contrairement à ce que pensait Rhamdor, un foie exactement pareil à celui que $\mathbf{M}$. 
Léon Dufour a décrit dans ses recherches sur les Orthoptères (Mém. des savants étranger's vi, 336) et figuré ( $\Lambda$ nn. Sc. Nat. 1843, xıx,Pl. 6), d’après le Gryllus campestris L. Ce foie est composé d'une grande quantité de tubes biliaires aboutissant tous à un petit calice commun et suivi lui-même d'un canal cholédoque.

Les bourses, ou plutôt les dilatations ventriculaires, sont au nombre de deux supéricures, latérales et assez développées. En les ouvrant, on les trouve plissées à leur surface interne, ainsi que M. L. Dufour l'a indiqué pour la Courtilic̀re mais en outre j'ai découvert qu'elles présentent des endroits élevés, ovalaires et bordés d'aspérités brunâtres. Ces petits organes sont très probablenent destinés à achever la trituration des aliments, déjà faite en grande partie par le gésier, car il est impossible d'admettre là un appareil sécrétoire. On ne trouve du reste jamais des vaisscaux biliaires couronnant les poches du ventricule chylifique des Gryllus, comme cela a lieu dans les Locustaires.

Locustaires. - J'ai reconnu dans la Locusta (Meconema) varia $\mathrm{F}$. que l'insertion des vaisseaux biliaires à l'extrémité inférieure du ventricule chylifique n'est point exactement verticilléc, mais a lieu par deux houppes latérales. C'est un fait nouveau d'insertion biliaire, qui doit prendre place à côté de celui que M. L. Dufour a signalé et figuré pour l'E phippigera, dont le foic s'abouche dans le canal intestinal par cing faisceaux distincts. (Voy. Ouv. cités 350 et Ann. Sc. Nat. 1843, xix, 147. Pl. 6, fig 1).

J'ai constamment rencontré dans les Locustaires l'extrémité des vaisseaux du foic accollée aux dilatations supérieures du ventricule chylifigue, mais ces extrémités m'ont toujours paru y adhérer sans s'y ouvrir en aucune façon. 
La fernelle du Decticus verrucivorus L., disséquée avec soin, m'a permis de constater que les annexes du conduit vaginal sout bien séparés (1) coinıne l'indique M. L. Dufour. Ils consistent en un corps réniforme à parois épaisses et en un tube distinct fort allongé. J'ai découvert des sperinatozoïdes daus le premier organe qui a son insertion rapprochuée de l'ovaire, ct dans le second, dont l'insertion est plus inférieure, je n'ai pas constatéde tube inclus corné, mais de simples parois comme aux vaisseaux biliaires, par exemple.

Je me contente, en ce moment, de prendre boune note de ces faits anatomiques dont je discuterai la physiologie dans un prochain travail sur les annexes du conduit vaginal, dans l'appareil génital femelle des insectes de tous les ordres.

\section{Colfoptères.}

Staphylinus olens. - J'ai déjà annoncé à la société que le gésier du $S$. olens $\mathbf{F}$. était garni à son intéricur de séries de poils sans lames cornées. M. Aubé a, de son còté, constaté le même fait.

II. L. Dufour a indiqué la coloration rouge fort remarquable de l'enveloppe testiculaire chez le $S$. punctatissimus (Ann. Sc. Nat. 1825, vi, 164), mais il ne fait pas mention de la couleur des testicules des autres espéces qu'il a disséquées. J'ai constamment trouvé à l'enveloppe de ces organes, au pérididyme, une belle couleur rose dans le $S$.olens et je dois ajouter que si je ne suis pas parvenu à démêter la véritable structure tubuleuse (ou en grappe?) des testi-

(1) La figure 31 de la planche 3 (ouvrage cité) représentant l'ap. pareil génital femelle de l'Acanthus Italicus, rend assez bien compte de cette disposition. 
cules j'ai constaté qu'ils renfermaient dans leur intérieur une prodigieuse quantité de spermatozoïdes.

Enfin l'appareil des sécrétions excrémentitielles du S.olcns m'a toujours paru (sur dix individus au rnoins) composé de deux vésicules séparées, oblongues, en forme de cornue à goulot court. Une seule fois j'ai cru trouver un tube sécréteur, mais je me suis convaincu que cétait un conduit biliaire qui venait adhérer au sommet de l'un des organes par un bout recourbé en hameçon. Si je ne lisais pas ( $A n n$. Sc. Nat. 1826, vı, 17), "le vaisseau sécréteur unique(il y a cependant deux réservoirs distincts) a un tube inclus et une enveloppe bien constatée " je serais tenté de croire qu'un vaisseau biliaire en a imposé à M. L. Dufour. De nouvelles recherches me paraissent nécessaires pour décider cette question.

Elatérides. - M. L. Dufour m'a recommandé d'étudier altentivement dans les femelles des Elater de grande taille l'organe si extraordinaire qu'il a décrit et représenté (Ann. Sc. Nat. 11, 223 Pl. xi fig. 3.) comme pouvant être une glande spéciale, fournissant les matériaux d'un cocon pour préserver les œufs de l'insecte. J'ai disséqué toutes Jes femelles d'Elater que j'ai pu me procurer, surtout celJes de l' $E$. murinus $\mathbf{L}$. mais je suis encore loin d'avoir une opinion arrêtée à ce sujet. Je puis toutefois ajouter un fait de détail à ce que M. I. Dufour a vu le premier. C'est que, si l'arbuscule de la glande sébaccé? de l'Elater murinus o a généralement des dilatalions triangulaires (Voy. les figures Ann. Sc. Nat. Pl. xvi fig. 8 du tome v1, 1825) j'en ai vu plusieurs néanmoins qui étaient quadrangulaires, en forme de rectangle assez allongé.

Le tube digestif de l'Elater murinus a été parfaitement. décrit et figuré par M. L. Dufour, je n’ajouterai qu'une 
ligne a ce qu'il en a dit: cet insecte a un gésier dont lin. térieur est garni de quatre doubles séries de poils assez espacés.

Anobium et Dermestes. - I. J'ai signalé à la Société, en 1849, que dans l'Anobium abietis F. je n'avais su trouver que six vaisseaux biliaires et depuis j'ai mentionné dans le Bulletin que sur deux Anobium tesselatum F., obligeamment donnés par M. Aubé, $\mathrm{j}$ 'a vais constaté de la manière la plus évidente l'existence de six vaisseaux hépatiques. Ces vaisseaux étaient d'un jaune verdâtre, peu variqueux.

Sur huit nouveaux individus de la même espèce donnés par M. Rouzet ou que j'ai recueillis ınoi-même, j'ai retrouvé exactement le niême nombre de vaisseaux et j’ai maintenant acquis la certitude que les Anobium n'ont réellement que six vaisseaux hépatiques comme beaucoup d'autres coléoptères et ne forment point une exception unique par un foie it huit vaisseaux.

Jusqu'à présent le mode de terminaison des vaisseaux biliaires m’avait échappé. Etaient.ils libres à leur extrémité et en cocum flollant, ou bien se réunissaient-ils pour se porter dans la partic inférieure du tube digestif? J'ai trouvé, à ma vive salisfaction, la solution du problème. Il m’a été permis de constater de la manière la plus évidente que les vaisseaux biliaires se portent près du renflement cœcal de l'intestin et que là, ils ne s'ouvrent pas dans ce mềme intestin, mais seulement soulèvent sa tunique externe, formant d'abord un bourrelet et se terminant insensiblement en cœecum.

Il faut avoir poursuivi des heures entières une dissection ardue en contrôlant chaque coup de ciseaux, chaque déchirure de membranes par l'exainen à la plus forte loupe et au microscope pour bien comprendre les joies que procure un pareil résultat. 
Du reste, j’avais déjà trouvé dans l'A. abielis et signalé dans nos Annales (1849, 313), l'existence d'un corps ovoïde où les vaisseaux biliaires semblent se rendre, corps placé à la partie inférieure de l'intestin. Il s'agissait très probablement d'une fausse insertion de ces vaisseaux. On le voit clairement le fait de la terminaison des tubes hépatiques en vaisseaux aveugles, ou en cœcum se confirme de plus en plus, alors même que ces tubes paraissent s'ouvrir dans l'intestin d'une manière évidente. Voy. dans les Ann. Sc. Nat. 1840, xiv, 231, la découverte de ce fait important par M. L. Dufour.

J'ai à peu près vu les organes génitaux des Anobium qui sont encore à décrire. Les testicules des of sont composés d'une vingtaine de tubes spermatiques, ovales, allongés, aboutissant tous au sommet d'un canal déférent. Il ma paru y avoir deux paires de vésicules séminales lobulées.

J'ai compté de vingt à vingt-quatre gaînes ovigères pour chaque ovaire de la fenelle. Elles renfermaient chacune un wuf assez gros et deux à trois autres très petits superposés. J'ai constaté l'existence $1^{\circ}$ d'une utricule en forme de trèfle ou trifolicéc à parois épaisses et de couleur cornce annexée à l'oviducte, et ' $2^{\circ}$ d'une autre utricule milnie d'un canal excréteur également annexéc au conduit les œufs.

II. Il est impossible de mienx décrire le tube digestif des Dermestes que M. L. Dufour ne l'a fait pour le D. lardarius L. et le D. undulatus, Brahm.; tesselatus Oliv. J'ai éprouvé un véritable bonheur en retrouvant dans le D. Frischii, Kugel. (ancien D. vulpinus des auteurs) Ia fidele représentation des figures clonnées dians les Antales des Sciences nalurelles (1834, I, pl. 2, fig. 1. 2). 
J'ai vu parfaitement les six bourses à la partic supéricure du ventricule chylifique, seulement, dans cette espèce qu’on n'avait point encore disséquée, elles sont proportionnellement plus courtes que dans le Dermestes lardarius. Le filet brun cornéde l'intestin existe aussi.

L'ovaire du $D$. Friscliii o m'a paru renfermer douze a quinze gaînes ovigères. J'ai bien vu une utricule cornéc, annexée à l'ovaire, et pourvue d'un tube replié inséré sur elle-même.

Phyllopertha horticola. - Les lesticules des mâles des $S c a$ rabcides sont formés par une réunion variable de capsules spermatiques a yant un pédicelle cornme les feuilles peltées de la capucine (Tropueolum majus). On peut voir dans les Annales Sc. Nat. (1825 T.VI. PI.VII.) que ces capsules sont parfaitement arrondies.

J'ai trouvé une disposition différente sur la Phylloperlha horticola $\mathrm{L}$. Chaque capsule spermifique m’a paru denteléc sur les bords par vingt-quatre petites entailles, ou, en d'autres termes, elle représente la coupe médiane d'une mûre à vingt-quatre grains.

Bruchus cisti E. - Le ventricule cliylifique de cet insecte n'est point lisse comme celui des autres Bruchiles, car je l'ai trouvé hérissé de longues papilles comme celui de la plupart des Charansoniles (ouv. cilé. 1825; IV, 103).

Chrysomélines. - I. J'ai reconnu dans la Galleruca tanaceti L. l'exactitude de la figure et de la description données par M. L. Dufuur, j’ai de plus constaté l'existence d'un gésier renfermant dans son intérieur six courtes rangées de poils très écartés el peu nombreux.

Voici la description des organes génitaux femelles de cet insecte qui nont pas encore été décrits, à ma connaissance. 
Les ovaires se composent chacun de cinquante à soixante gaînes ovigères uni ou biloculaires, courles, remplies d'œufs jaunes; elles sont insérées sur un calice ovale très considérable, de telle sorte que chaque ovaire ressemble assez à un fruit de conifère dont les écailles seraient prolongées : le col des calices est trés court. L'oviducte ou vagin est assez allongé, épais, et il a pour annexes: $1^{\circ}$ une utricule à parois épaisses, cornées, munie d'un canal excréteur. Celui-ci est commun à l'utricule et à un vaisseau terminé en cœecum, pourvu d'un tube inclus et dont les fonctions doivent ĉtre liées à celles de l'utricule; $2^{\circ}$ d'un autre vaisseau enroulé sans tube inclus inséré sur l'oviducte bieu au dessous du premier canal excréteur. J'ai constaté que l'utricule cornée renfermait des spermatozoïdes et le vaisseau à parois simples, des curpuscules d'un asprect graisseux.

II. Plusieurs C'hrysomela Banksii F. qui m'ont été apportées vivantes de Bordeaux, ne m'ont offert rien de particulier dans leurs organes digestifs, à part un gésier à six rangées de poils intérieurs; mais c'est sur elles que j'ai été témoin pourla première fois de l'existence des spermatozoïdes dans cet annexe de l'oviducte qui se présente ordinairement dans les colćoptères sous la forme d'un petit réservoir cornéo-membraneux pourvu d’un vaisseau (renfermant lui-même un tube inclus); ce vaisseau terminé en cœcum s'ouvre directement dans le réservoir ou tout au moins il est en communication avec lui par le tube excréteur. J'ai vu des milliers de spermatozoides s'agilant dans le canal excréteur de l'utricule dont je viens de parler et passant par les fêlures de la mêrne utricule cornéo-membraneuse brisée entre deux lamelles de verre sous le microscope.

Le nombre des gaînes ovigères est de vingt à vingt-cinı 
au moins, le calice est grand, aplati et il supporte ces gaînes à la manière du réceptable des fleurs synanthérées. (Comparez arec les figures 6 et 11, $a$ de la Pl. XX. An. Sc. Nat. 1825, T. VI.)

Coccinelles. - Les Cocinella 7-punctata L. que j'ai disséquées mont offert un gésier très petit qu'on distingue déjà dans la planche donnée par M. L. Dufour, quoique le texte n'en fasse pas mention. Si on l'ouvre avec soin on le trouve constitué par quatre rangées de poils disposés en écusson dont les pointes inférieures forment une valvule. Le ventricule chylifique lisse, sans papilles, est dilaté en haut, excavé pour recevoir le gésier; en bas il présente un tubercule pour l'insertion des vaisseaux biliaires. J'ai bien vu ceux de ces vaisseaux qui au nombre de deux sont plus courts et plus pâles que les autres.

Je n'ai pas encore démêté le mode d'arrangement des organes génitaux de cette Coccinella.

\section{IIYMÉNoPtĖngs.}

La forme des parties qui constituent l'appareil du venin chez beaucoup d'insectes hyménoptères est curieuse à étudier. Swammerdam a fait connaître l'aiguillon dentelé des abeilles, M. L. Dufour dans ses recherches anatomiques (Ouv. cit. Pag. 410 a 418) a consacré un chapitre spécial à l'appareil vénénifique, et il a divisé les aiguillons des hyménoptères, en ceux qui sont dentelés en fer de flèche ou armés de dents dirigées en arrière et en ccux qui sont lisses sur leurs bords et vers la pointe, mais il n'indique point la forme spéciale dans l'article traitant de chacque famille en particulicr.Aucun naturaliste, à ma connaissance, n'a cherché la raison physiologique de la présence ou de 
l'absence de ces dentelures; je crois être arrivé à une solution raisonnable, au moins en ce qui concerne l'aiguillon du groupe des Sphégides.

En étudiant à Agen au mois de juin 1850 une espèce d'Ammophile très probablement la sabulosa $\mathbf{E}$., je trouvai un aiguillon parfaitement lisse dans toute l'étendue des bords. Un grossissement de 400 et de 500 diamètres ne montrait pas la moindre dentelure. Or, comme j'avais disséqué l'Ammoplieile devant un de mes amis et que j'avais, d'après l'analogie de l'aiguillon des Abeilles et des Scolies, annoncé un dard à dentelures, je fus singulièrement désappointé. Ma préocupation ne cessa que lorsque, réfléchissant au genre de vie des Spltégides et de l'Ammophile en particulier, je me rappelai que ces hyménoptères fouisseurs, après avoir creusé un petit terrier, vont à la recherche d'insectes vivants pour nourrir les larves qui sortiront de leurs œufs. lls percent de leur aiguillon la proie qu'ils capturent et celle-ci est tuéc par linoculation du venin qui en même temps a préserve de toute putréfaction. Ce dernier fait, si insolite, si piquant, est mis hors de doute par les travaux de M. L. Dufour sur le Cerceris bupresticida (1) d'A udouin et sur l'Odynerus spinipes F. Or, il faut si l'Ammophile prend dix, vingt insectes, qüil les pirjue tous et par conséquent qu'il retire son aiguillon à chaque fois. Cet organe est pour lui, non seulement une arme contre les ennemis qu'il peut avoir (Voy. Ann. Se. Nat. $1811, x v .353$ et suiv.) à redouter mais surtout un instrument nécessaire; indispensable pour assurer l'existence des larves destinées à propager son espèce. Que serait-il arrivé si l'aiguillon eut été dentelé ? II serait resté dans les partics molles comme celui de l'Abcille qui a piqué, et

(1) Voy. Ann. Sc, nat, 1841, XV. 352 et suiv. 
cette mutilation aurait entraîné la mort de l'insecte ou bien, dans le cas de survivance, l'aurait privé d'un organe indispensable.

Il me paraît donc évident que les hyménoptères dont l'aiguillon est une arme exclusivement défensive, ont ce inême aiguillon dentelé, disposé de manière à pénétrer profondément dans les chairs, mais aussi très difficile it retirer pour l'insecte qui vient de faire usage de cette arme. Au contraire les hyménoptères dont l'aiguillon est un dard, un instrument, qu'on me passe le mot, inoculateur avant d'être une arme défensive, doivent avoir cet aiguillon lisse.

J'appelle l'attention des entomologistes sur le fait que je viens de signaler et dont je poursuivrai l'étude.

Je dois ajouter, relativement à l'anatomie del'Ammophile que j'ai parfaitement constaté six ganglions nerveux abdominaux dont les trois derniers sont très rapprochés mais néanmoins distincts. J'ai, en outre, noté quatre gaînes ovigères pour chaque ovaire, par conséquent la femelle de cet insecte aurait un ovaire constitué comme les Bombus, Xylocopa et Chrysis et non comme les Bembex, Crabro et Philanthus. 'Toutefois comme M. L. Dufour admet des. ovaires à trois gaînes aux Splégicides, je ferai de nouvelles dissections qui pourront seules me faire persister dans ma. manière de voir.

\section{Lépidoptianes.}

Je dois à l'extrême obligeance de MI. Bellier de la Chavignerie d'avoir pu disséquer le rare lépidoptère suivant. éclos chez lui et quil m'a domné. Je rapporterai à sis. description ce que mont offert les autres insectes du. même ordre que j’ai étudiés.

Thaïs lypsipyle F. polyxana Ilubn. - Tube digestif. 
Je n'ai pas pu voir les glandes salivaires. Le tube digestif a un osophage allongé a la partie supérieure duquel s'accole l'extrémité antérieure du vaisseau dorsal. On trouve latéralement sur cet œsophage un canal qui aboutit à une véritable panse assez dévelop- pée (estornac de succion de Siébold).

Le ventricule chylifique commence après l'insertion du canal de la panse, sans gésier et sans rétrécissement marqué. Il est parfaitement lisse, et à son extrémité inférieure existe un bourrelet pour l'insertion de six vaisseaux hépatiques, jaunâtres, flottants, terminés en cœecum et qui convergent de manic̀re à s'ouvrir par deux vaisseaux cholédoques seulement. L'intestin grêlequi suit est très étroit, le rectum s'est trouvé, au contraire, très développé, fort ample, encore rempli de cette matière rougeâtre que les lépidoptères rendent en grande abondance après être parvenus à leur dernier élat.

Le tube digestif a une fois et demie environ la longueur du corps de linsecte, et le rectum ou le cœcum est superposé à l'intestin grêle, comme cela arrive constamment dans les larves des $S$ carabéides(Oryctes, C'ctonia,).

Le tube digestif des Pieris cratagi L., Acherontia atropos L., de l'A rctic urtica Lsper et de l'Amphidasis hirtaria L. m'a paru différer très peu du mode que je viens de signaler dans la Thaïs. Je n'ai su voir une panse que chez l' $A$ cherontia atropos dont le ventricule chylifique était plissé transversalement dans l'individu ơ que j’ai eu sous les yeux. Tous les autres lépidoptères signalés avaient six vaisseaux biliaires flottants à leur cxtrémité, réunis à deux canaux cholédoques, tous enfin présentaient un rectum ou cocum? énormément distendu. Cette partie de l'intestin m'a paru garnie d'une appendice, d'une espèce d'éperon dans l'Acherontia atropos et l'Aretia urtica. Etait-ce une disposition accidentelle? 
Vaisseau dorsal. Je n'ai rien vu nettement sur les connexions de cet organe, soit à son extrémité antérieure ou postérieure, soit avec les vaisseanx afférents qu'on lui a donnés.

Organes génilaux mâles. J'ai assez bien vu ces organes; j'ai trouvé que chez la Picris cratagi, le Satyrus magera L., le Polyommatus phlocas L. et l'Acherontia atropos, les deux testicules étaient réunis en un seul corps; il était rose chez le Satyrus, vert chez le Polyommatus. J'ai constaté qu'ils renfermaient dans I' $A$. atropos et le $S$. magera de beaux spermatozoïdes.

Organes génitaux femelles. La Thaïs et tous les autres lépidoptères que j’ai énumérés m'ont offert constamment quatre gaînes ovigères à chaque ovaire. Elles sont disposées en très long chapelet décroissant, contournées ou entortillées d'une façon désespérante quand il faut les étaler. Une ligament suspenseur d'une ténuité extrême les termine et les réunit. Leur couleur varie suivant celle des wufs qu'elles renferment. Le calice ovarien n'offre rien de particulier; le col qui lui fait suite s'est trouvé assez peu allongé dans les espèces que j'ai vues; le vagin ou oviducte qui succédeà leur réunion est épais, nusculo-membraneux ; j'ai entrevu les annexes de ce conduit. Chez la Thaïs, il existe d'abord $1^{\circ}$ une petite poche à parois épaisses et un conduit terminé en coccum dont les connexions exactes m'ont échappé ; $2^{\circ}$ un organe symétrique formé par deux vésicules réunies ayant ensemble la forme d'une samaridie, du fruit de l'érable par exemple, terminées par un tube fermé en cœcum. Les deux vésicules réunies à leur base avaient un seul eonduit excréteur et étaient d'un jaune de chlore. J'ai retrouvé la disposition de deux vésicules doubles, jaunâtres, unies par un connectif, a vec un scul canal 


\section{ANNALES DE LA SOCIÉTÉ ENTOMOLOGIQUE.}

excréteur et terminées par un tube dans l'Amphidasis hirtaria. Ce dernier tube examiné avec soin se terminait en deux on trois cœecums.

Systime nerveux. Incomplètement reconnu. Dans la Thaïs hypsipyle, Pieris cratagi, Acherontia atropos il y avait guatre ganglions abdominaux séparćs les uns des autres.

\section{Diptères.}

Presque toutes les femelles des Diptères ont pour annexes du conduit de leurs $œ u f s$ des organes qui doivent être distingués en deux catégories.

La première eatégorie comprend des vésicules ou orbicelles dont le nombre varie de une à trois; elles sont rondes ou à peu près rondes, noires ou noirâtres; d'une consistance cornée, constituées par une petite boîte ou capsule enveloppée d'un tissu plus mou et transparent. Ces vésicules ont un conduit éférent droit ou flexueux renfermant un tube inclus, épais et une cnveloppe extéricure extensible et plissée. La deuxième catégoric est constituée par deux organes pairs, deux bourses, deux utricules à col allongé ou presque sessiles, parfois deux arbuscules rameux.

Je me contente de signaler ici que jai constamment trouvé dans les Muscides des genres Calliphora, Musca et Sarcophaga les orbicelles remplies de spermatozoides le plus souvent vifs et remuants dans le champ du microscope. Ces spermatozoïdes manquaient chez des o vierges, écloses chez moi et dont j’avais parqué les pupes. 




\section{DESGRIPTION}

\section{DE PLUSIEURS NOUVELLES ESPĖCES}

DU GENRE GYRETES.

(Colèoptères. - Gyrinicns).

Par M. ALEXANDRE LABOULBËNE.

(Séance du 23 Février 1853.)

Les Gyretes forment dans le species des IJ drocanthares et Gyriniens de M. Ch. Aubé un petit groupe de huit espèces reconnaissables à leur forme gyrinienne, à leur écusson indistinct, leurs antennes presque pointues, et surtout leur dernier segment abdominal allongé en pyramide triangulaire. Toutefois, ces caractères, à part l'absence de l'écusson, les différencient à peine des Orectochilus, mais un fait d'une grande importance pour la géographie entomologique peut les faire isoler. C'est l'habitation exclusive des Gyretes dans le Nouveau-Monde, tandis que les Orectochilus sont propres à l'ancien continent.

Parmi les huit espèces qui composaient le genre Gyretes, plusicurs sont remarquables par l'espace ou la plaque lisse des élytres; d'autres présentent à l'extrémitê de ces mêmes organes des prolongements épincux, ou bien encore une troncature arrondie, caractéristiques. En outre, notre collègue, M. le docteur Ch. Robin, a trouvé sur l'une d'elles, d'après les indications de M. Guérin-Méneville, des parasites végélaux qu'il fera bientôt connaître dans la deuxième 
idition de son ouvrage sur les végétaux parasites des Animaux vivants.

En faisant des recherches pour connaître l'espèce qui portait des Cryptogames, j'ai trouvé dans plusieurs collections, entr'autres dans celles de MMI. Chevrolat et Sallé, non seulement cette meme espèce en grand nombre, mais encore deux autres qui sont comme elle tout à fait nouvelles pour la science.

$\Lambda$ près avoir consulté les différents ouvrages oủ ces insectes pouvaient être signalés, j’ai demandé à MM. Ch. Robin, Chevrolat et Sallé la permission de les décrire dans nos Annales. Ils y ont obligeamment consenti, je les en remercie bien sincèrement.

J'aurais voulu conserver aux especes le nom que M. Chevrolat leur avait donné dans sa collection, mais comme M. Ch. Robin avait déjà fait dessiner et déterminé lui-meme la première, j'ai cru devoir prendre le nom qu'il lui avait imposé.

Genre GYRETLS, Brullé.

(Aubé, Species des Iydrocanthares et Gyriniens, 747.)

Gyretes sericeus, Ch. Robin et Laboulbènc.

$$
\text { (Pl. 1, No II, fig. } 1 a, 1 b . \text { ) }
$$

Oblongo ovalis, convexus, nigro-ceneus, dense reticulato punctatus, ochro sericeus; capite, thorace postice medio, elytris plaga minore dorsali suturaque levibus; sublus nigropiceus; pedibus rufis; elytris apice oblique truncatis, angulis externis acutis, internis rotundatis.

Long. 8 à 9, 5 millim. Larg. 3,4 à 5 millim. 
Lorps orale, allongé, assez peu convexe; dessus d'un noir bronzé brillant, avec un reflet verdatre un peu irisé, densément et finement ponctuć, très finement réticulé dans les intervalles et couvert d'un duvet couleur d'oere et soyeux, correspondant à la ponctuation; dessous d'un noir de poix.

Têtc bronzée, lisse, brillante, finement reticulée-ponctuée de chaque côté, en dehors des yeux supérieurs, oủ elle est couverte d'un duvet jaunatre; labre noinatre, avec une légère élévation médiane, fortement ponctué, velu; antenvess noires, à base brune; palpes ferrugineux, arec leur dernier article rembruni.

Corselet de la couleur du corps, marqqué d'une légère dépression médiane transversale, finement et densément ponctué, couvert d'un duvet jaunatre, excepté en arrière: sur le milicu, où se trouve un espace triangulaire lisse, a yant le sommet vers le disque et la base vers le bord postérien.

Elytres assez régulièrement ovalaires, tronquées obliquement à leur extrémité, dont l'angle externe est aigu, mais non épineux, et l'inierne arrondi, relevé, saillant. Elles sont verdatres, légèrement irisées, brillantes, très légèrement rebordées, densément et finement réticulées-poncluées, avec: un duvet jaundtre soyeux. On remarque chez le ơ une petile plaque et une ligne juxta-suturale lisses, allant se joindre à l'espace lisse déjà indiqué pour le corselet. Chez la $f$ li ligne suturale est plus large, et la plaque lisse, également plus grande, atteint presque la moitié de la longueur de d'élytre.

La portion réfléchic des élytres est d'un noir de poix, is peine ferrugineuse. Palles ct bord des segments abdominaux ferrugineux, extrémité du segment anal ciliée de poils roux. зе Série, томг i. 
II. Cet insecte se trouve au pied des Cascades, à Caracas (Amérique du Sud), d'oủ il a été rapporté par M. Sallé. Il existe dans les collections de MM. Chevrolat, Sallé, GuérinMéneville, Deyrolle, etc.

J'en ai eu une trentaine, au moins, d'exemplaires sous les yeux, tant $\delta^{*}$ que + . Un très grand nombre portait sur le corselet et les élytres des végétaux noirs, mais de très petite taille.

Colte espèce vient se placer auprès du Gyretes melanarius (Aubé, loc. cit. 748), mais elle est bien distincte par sa forme plus étroite, plus allongée, sa convexité moindre, sa coloration verdatre, le peu d'étendue de l'espace lisse des élytres. En outre, la troncature de ces dernières et la forme des angles postérieurs ne sont pas les mêmes dans les deux espèces; enfin, la dilatation des tarses antérieurs des of est bien plus prononéée dans ce Gyreles que daus le Gyretcs sericeus.

Variété. J'ai vu plusieurs individus de cette espèce qqui, au premier coup d'œil, paraissent en différer par une coloration noiratre, terne, avec un très léger reflet verdalre ou bronzé, et surtout l'absence presque complète de poils soyeux. A peine existe-t-il quelques rares poils d'un grisjaunatre sur les bords et vers l'extrémité des élytres.

Je me suis convaincu, avec M. Sallé, que ces individus ne constituaient qu'une variété, que l'on peut produire artificiellement en frottant arec rudesse le dessus du corps des Gỵretes sericcus les plus normaux. M. Sallé s'est assuré, en outre, que les Gyretes les plus ternes et les plus épilés étaient les plus vieux, les plus agés de tous ceux qu'il ramassait à Caracas, ceux qui avaient le plus longtemps été exposés à frotter leur corps. 


\section{Gyretes Saluet.}

Oblongo-ovalis, convexus, nigro-e'neus, angustissime $\mathrm{fer}$ rugineo marginatus, nitidissimus; thoracis elytrorumque lateribus reticulato punctatis, ochro scriccis; subtus lirunneur; elytris apice paulo oblique truncatis angulis externis fere rectis, internis obtusis; margine inflexo; pedibus anoque ferrugineo testaceis.

Long. 5 à 5,5 millim. Larg. 2,75 à 3 millim.

Corps ovale, peu allongé, assez convexe, d'un noir-bronzé très brillant en dessus, brunatre en dessous.

Téte lisse, très brillante, finement réticulée de chaque côtẻ en dehors des jeux supérieurs, où elle est couverte d'un duvet couleur d'ocre; labre noiruttre; antennes noiràtres. avec la base d'un testacé un peu ferrugineux; palpes de cette couleur.

Corselet très lisse, excepté sur les côtés, où il est finement réticulé-ponctué, et couvert d'un duvet couleur d'ocre, plus largement en avant qu'en arrière.

Elytres ovalaires, très étroitement bordúes de ferrugineux, tronquées un peu obliquement à leur extremité dont l'angle externe est presque droit, non émoussć, et l'angle interne un peu obtus. Elles sont très brillantes, finement ponctuéesréticulées, et recouvertes d'un duvet couleur d'ocre le long de leur bord externe. Cette bordure, étroite à la jonction des élytres et du corselet, s'élargit peu à peu jusqu'aux trois quarts postéricurs; en cet endroit, clle se porte lrusquement en dedans et arrive largement sur le bord apical, et très peu sur la suture, en suivant une ligne parallèle au bord externe. En d'autres termes, la ligne interne qui borde l'es. 
pace soyeux se dilate vers les trois quarts postérieurs de l'élytre en y formant une saillie considérable en dedans.

Dessous du corps brun, avec la poitrine et le bord des segments abdominaux d'une couleur plus claire. Pattes et anus d'un testacé teint de ferrugineux.

Habite Caracas. - Je n'ai vu que deux individus o de cette espèce, dans la collection de l'intrépide et intelligent entomologiste voyageur auquel je l'ai dédiée.

Cette espèce ressemble au $G$. morio, Aubé, dont elle diffire par la taille et par l'absence d'un prolongement interne sur la bordure duveteuse des élytres. Elle est, en outre, extrêmement voisine du G. levis, Brullé, mais elle en est récllement distincte par sa forme moins régulièrement ovalaire, élargic aux épaules, la bordure élytrale dilatée, comme je l'ai dit, en formant un prolongement anguleux et pointu, enfin par les angles postéro-externes des élytres non émoussés, non arrondis.

NI. Sallé a bien voulu me donner les détails qui suivent sur les Gyretcs sericeus et Sallei. Je les transcris fidèlement, en le remerciant ici de ces renseignements précieux, tout à fait nouveaux pour la science. " J'ai pris le Gyrctes sericeus à Caracas, capitale de la République de Venezuela, dans le Rio de Catuche, torrent très rapide qui descend de la Cordillière et qui fournit l'eau à la ville. Comme le lit de ce torrent est semé d'énormes roches, il y a une suite de cascades, et la chute de l'eau forme au bas de ces énormes pierres des petits réservoirs ou bassins dont l'eau est plus ou moins agitée. C'est dans ces bassins qu'on trouve notre insecte par groupes d'une vingtaine au plus, nageant très vite, avec force, et remontant quelquefois contre le courant. Pendant leur vie ils ont l'abdomen beaucoup plus allongé que dans 
l'état sec, où nous les conservons dans nos collections; aussi s'en servent-ils lorsqu'ils sont jetés par l'eau sur le rivage pour d'un bond s'y précipiter de nouveau, en faisant avec la pointe arc-boutant et se lançant comme avec un ressort, à une hauteur de quelques pouces, et parfois d'un pied. J'ai surtout observé les sauts de ces insectes lorsque je les prenais dans mon filet. Beaucoup d'individus ont sur les élytres un nombre plus ou moins grand de petits champignons ou clavaires noires d'une longueur de deux millimètres, et terminées par un petit bouton. J'attribue la croissance de ce cryptogame sur ces insectes à la vapeur continuelle du torrent qui, dans ses chutes, forme une pluie excessivement fine, et qui retombe souvent sur eux. On les trouve plus particulièrement en octobre, novembre et décembre, dans les régions froides et tempérées.

) ...... Quant à la petite espèce (Gyr. Sallei), je n'en ai pris que deux exemplaires, pendant le mois de juin, dans te Rio-Guaire, rivière qui coule dans la vallée de Caracas, près de la ville: ils nageaient à la surface de l'eau, qui est très rapide. "

Grotes nitidulus, Chevrolat et Isaboulbène.

(Pl. 1, No II, fig. $2 a, 2$ b.)

Elongatus, ellipticus, valde convexus, nigro-ceneus, nitidissimus, anguste luteo marginatus; thoracis elytrorumque lateribus dense reticulato-punctatis, griseo sericcis; subtus rufo-brunneus; clytris apice oblique truncatis, angulis externis acutis, intrrnis oblusis fere rectis; margine inflexo, pedibus, anoque luteo-rufis.

Long. 5,5 millim. Larg. 2,75 millim.

Corps allongé, de forme elliptique, fortement convexs, 
d'un noir-bronzé très brillant en dessus, brun-rougeâtre en dessous.

Tête lisse, très brillante, finement réticulec de binque côté, en dehors des yeux supéricurs, où elle est couverite d'un duvet grisatre; labre noiratre, ponctué, velu; antennes noiratres, brunatres à la base; patpes d'un brun-jaunatre.

Corselet marqué de deux dépressions transversales, très. lisse, excepté sur les cútés, oú il est finement réticuléponctué et couvert d'un duvet grisatre, un peu plus largement en avant qu'en arrière.

Elyires allongées, clargies au-delà de leur base, tronquées obliquement à leur extrémité, dont l'angle externe est aigu et l'interne émoussé, presque droit. Elles sont très brillantes, ponctuées-réticulées, plus fortement vers leur sommet, et recouvertes d'un duvet grisatre le long du bord externe, étroitement en avant, largement en arrière (sans touclier la suture) et près du milieu, où la portion ponctuée, duveteuse, forme une espèce de crochet.

La portion réfléchie des élytres, les pattes et l'anus sont d'un jaunatre teint de ferrugineux et de brun.

II. Le seul individu + sur lequel cette description a été faile provenait de la rivière des Amazones (Amérique du Sud).

Ce Gyretes est distinct du Gyretes levis, Brullé (Aubé, loc. cit. 757), par sa taille plus grande, sa forme plus allongće, la troncature, les angles saillants et la bordure jaune-rougedtre des élytres.

Avec les caractères qui viennent d'etre assignés à ces trois nouvelles espèces, on peut former le tableau synoptique suivant de tous les Gyretes connus jusqu'd ce jour. 
A. Taille grande (pour les insectes du genre). $-\mathbf{1 0}$ millimètres environ.

$q$ différant des ơ par leurs tarses antérieurs simples et par l'espace lisse plus considérable du corselet et des élytres.

* Angle postéro-interne des élytres terminé en pointe très allongée, aigue.

Corps noir, très brillant, convexe, réticulé-ponctué sur les cotés du corselet et le bord externe des élytres, duvet grisâtre; dessous du corps et portion réfléchie des élytres, d'un noir de poix; pieds antérieurs brunatres, les autres ferrugineux, ainsi que l'anus. - Long. 10 mill. - Gyrinus bidens, Oliv. Ent. HI , 41, p. 13. - Aubé, Sp. Hydrocanthares, Gyr. 751. . . . . . . G. BiDENS.

"* Angle postéro-externe des élytres plus ou moins aigu, mais non terminé en pointe très allongée.

a. Elytres bordées de jaunatre ou de rougedtre.

Corps oxale, fortement convexe, brun-bronsć brillant, étroitement bordé de jaunâtrce, réticulé-ponctué sur les colés du corselet el les élytres, à l'cxception de leur disque, duvet. couleur d'ocre; bord réfléchi des èlytres jaunätre; dessous du corps ferrugineux; pattes testaccess. Angle postéro-externe des élytres aigu, épincux. - Long. 10 mill. - Brullé, Voyage de M. d'Orbigny dans l'Amérique méridionale, vi, 52 . Aubé, loc. cit. 749. . . . . . . . G. ponsat.ss.

Corps ovale, convexe, noir-bron $*$, brillant, très étroitement bordé de ferrugineux, réticulé-ponctué sur les côtés du corselet et le bord externe des élytres, duvet coulcur d'ocre; bord réflechi des élytres rongciure; dessons du corpss noir 
69) Ir. Iaboulnène. - Gyreles sericeus el vulheralus.

de poix; abdomen et paltes ferrugineux. Angle postérom externe des élytres un peu obtus, légèrement ouvert. Long. 10,5 mill. - Aubé, loc. cit. 748. . G. MrLanaries.

\section{Elytres sans bordure colorée.}

Corps ovale, allongé, assez peu convexe, noir-bronzé brillant, avec un reflet verdâtre un peu irisé, réticulé-ponctué sur le corselet et les élytres, duvet coulcur d'ocre, soycux; dessous noir de poix; pattes et bord des segments abdominaux ferrugincux. Tete, un espace triangulaire à la partic postérieure du corselet, sulure, ainsi qu'une petile plaque sur chaque élytre, lisses; angle postéro-externe, aigu, épineux. - I.ong. 8 à 9,5. mill. - Ch. Robin et Laboulbène.

G. Sericeos.

$B$. Taille moyenne. -6 millimètres.

* Corps des $\sigma$ très lisse, celui des + très finement réticulé, terne, avec deux côtes élevées sur les élytres, effacées en avant et en arrière.

Corps ovale, convexe, noir-bronzé, très brillant, bordé de jaune, côtés du corselet et des élytres réticulés-ponctués, duvet jaunâtre; bordure des élytres étroite en arrière, n'atteignant pas la suture; bord rélléchi jaunatre, dessous du corps roux-lestacé, ainsi que les pattes. Côtes des élytres des ‡ bien marquées; angle postéro-externe un peu saillant, aigu. - Long. 6 mill. - Aubé, loc. cit. 752. G. vulneratus.

Corps ovale, convexe, noir-bronzé, très brillant, suns boralure jaune, côtés du corselet et des élytres réticulésponctués, duvet jaundtre; bordure des élytres élargie en arrière, bord réflechi jaunatre; dessous du corps noir de 
poix, abdomen ferrugineux, pattes testacé-fcrrugineux. Côtes des élytres des 우 à peine marquées; angle postéroexterne obtus, arrondi. - Long. 6 millim. - Aubé, loc. cit. 753 .

G. Leionotus.

* Corps très lisse dans les deux sexes; + ne différant des $\sigma^{*}$ que par leurs tarses antérieurs simples, non dilatés.

a. Bord externe des élytres non réliculé-ponctué dans toute son étendue.

Corps ovale-allongé, convexe, noir-bronzé, très brillant, irisé, bordé de jaune; labre noirûtre; côtés du corselet et extrémité postéro-externe des élytres réticulés-ponctués, duvet jaunatre, dessous du corps noir de poix; pattes et anus roux-testacé; angle postéro-externe des élytres presque droit. - Long. 6 mill. - Gyrinus cinctus, Germ. Ins. Nov. Sp. 33. - Aubé, loc. cil. 755. . . . . . G. cinctus.

b. Bord externe des élytres réticulé-ponctué dans toute son étendue.

Corps ovale-allongé, convexe, noir-bronzé très brillant, peu ou point irisé, non bordé de jaune, labre testacé; cótés du corselet et des élytres réticulés-ponctués dans toute leur étendue, plus largement en arrière sur les élytres, jusqu'à la suture, duvet jaunâtre; dessous du corps et patles ferrugineux; angle postéro-externe des élytres droit, non émoussé. Long. 6 d̀ 6,75 mill. $-\Lambda$ ubé, loc. cit. 756. . G. Monı.

Corps elliptiquc, allongé, convexe, noir-bronzé, très brillant, non irisé, étroitement bordé de jaunâtre ; labre noirâtre; côtés du corselet et des élytres réticulés-ponctués dans toute leur étendue, plus fortement vers leur sommet, la bordure des élytresest étroite en avant, large en arière, où elle n'at- 
58 Ar. Labouldìne. - Cygreles nilidulus, Sallei el levis.

teim pas la suture, et elle forme vers le milieu du bord cxtcrne une espèce de crochet; duvet grisûtre; portion réftéchic, pattes et anus, jaunâtres, teints de ferrugineux. Dessous du corps brunatre. Angle postéro-cxterne des élytres aigu, épineux. - Long. 5,5 millimètres. - Chevrolat et Laboulbène.

G. Nitidulus.

Corps ovale-allongé, convexe, noir-bronzé très brillant, très étroitement bordé de ferrugineux et non irisé; labre noirdtre; côtés du corselet et des élytres réticulés-ponctués dans toute leur étendue, bien plus largement vers les troisquarts postérieurs, oủ la partie dilatée s'avance en formant un prolongement interne. La bordure ponctuée-duveteuse ne touche la sulure qu'à l'extrémité. Dessous du corps brunâtre; portion réfléchie des élytres, anus et pattes, testacés, teints de ferrugineux; angle postéro-externe des élytres presque droit, non émoussé. - Long. 5 à 5,5 . . . . G. SALIEI.

\section{c. Taille petite, 4,75 millim.}

Corps ovale, à peine allongé, convexe, noir-bronzé, très brillant, légèrement irisé sur les élytres, non bordé de jaune; cotés du corselet el les élytres réticulés-ponctués ; bordure duveteuse ne touchant la suture qu'à l'extrémité; duvet jaunatre, dessous du corps roux-testacé, pieds et anus jaunatres, angle postéro-externe des élytres arrondi. Long. 4,75 mill. - Brullé, Voy. de M. d'Orbigny dans l'Am. mérid. VI, 52. - Aubé, loc. cit. 757. . . . G. LEYIS.

J'ajouterai, pour terminer ce qui se rapporte au genre Gyretes pris dans son ensemble, quelques renseignements destinés d̀ ceux qui voudront l'étudier ultérieurement.

J'ai vu dans la collection de M. L. Buquet un Gyretes indiqué de Cayenne, et venant de M. Lepricur. Ce Gyreles 
pourrait constituer une nouvelle espèce, mais l'individu unique est en très mauvais état. II a été brisé, puis reconstruit avec de la gomme, aussi a-t-il une forme aplatie, tout à fait anormale. Peut-etre trouvera-t-on dans la collection de M. Lepricur, ou dans celle de quelques autres entomologistes, un nombre suffisant d'individus bien conservés qui permettront oui ou non d'établir une espèce légitime.

Voici les caractères, à ce qu'il me semble, assignables à ce Gyretes :

Corps très brillant, d'un noir-bronzé, bordé de jaune, paraissant devoir êlre peu convexe, avec une bordure ponctuéeduveleuse assez large, régulic̀re, alteignant largement cn arrière la suture élytrale. Troncature des ćlytres paraissant. devoir être droite; angle postéro-externe élytral droit, un peu ouvert. Labre noir. Antennes noires, à base testacée, ainsi que les pattes. Dessous du corps brunàtre. (Individu $\sigma^{*}$.)

Ce Gyretes a de l'analogie pour les couleurs avec le G. vulneratus et le $G$. cinctus; il se rapproche pour la taille du $G$. levis, et c'est le nom qu'il porte dans la collection de M. Buquet.

S'il y a lieu, je propose de le nommer G. PARvolus.

Explication des figures de la planche I, No II.

Fig. 1. Gyretes sericeus, vu en dessus.

a. Je male.

b. La femelle.

Fig. 2. a. Gyretes nitidulus, vu en dessus.

b. Le meme, vu de profil. 



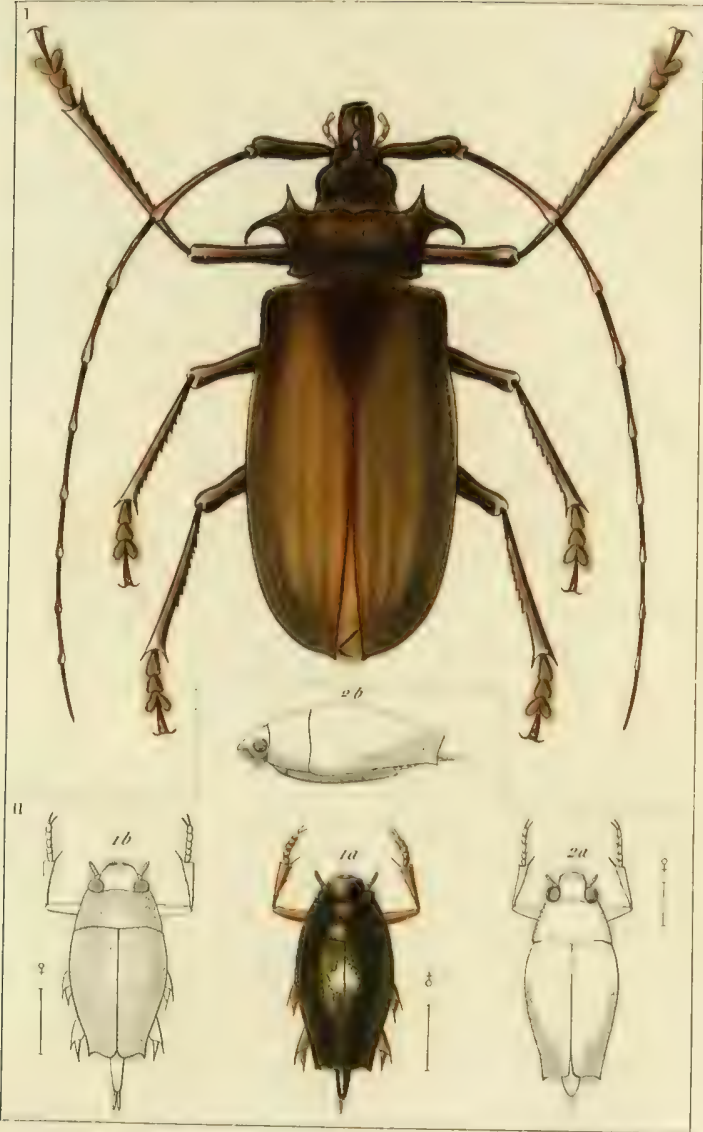

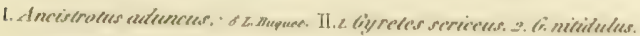





\section{MÉTAMORPHOSES DE LA CECIDOMYIA PAPAVERIS}

ET

Remarques sur plusieurs esperes du genre Cecidomyia.

Par M. le Dr ALEXANDRE LABOULBìne.

(Séance du 21 Septembre 1856.)

Vers le milieu du mois de juillet 1856, tout en remplissant les devoirs de mon service médical auprès de S. A. I. le prince Jérôme, alors dans son domaine de Villegenis (situé dans la vallée de la Bièvre, près de Verrières), je n’ai point négligé les recherches d'entomologic. Je viens de compléter l'une d'elles par des renseignements bibliographiques, et je l'offre aussitôt à la Société.

IIon attention s'est portée plus spécialement sur les insectes qui attaquent les plantes indigènes, et parmi celles que j'observais, se trouvaient des l'apaver rhaets de semis, dont les fleurs larges et doubles produisaient un bel effet. Je cherchais sur elles les larves du Centorhynclus macula 3e Séric, Tone v. 
alba HERBSt, sans négliger les mémes plantes venues naturellement dans les champs; mais les fleurs étaient passées, les capsules pleines de graines leur avaient succédé sans avoir rien présenté d'anormal. Toutes les plantes examinées étaient d'une belle venue, aucune ne paraissait maladive ou attaquée par des insectes.

Un matin cependant (10 juillet), par un temps couvert, j'aperçus quelques très petites mouches sur une capsule presque desséchée, mais dont la teinte n'était pas uniforme et jaunatre comme à l'ordinaire. $\Lambda$ yant saisi le frele Diptère, je reconnus en lui une petite espèce voisine des Tipula, et sa constance à venir se poser sur la tête du pavot quand on l'avait fait envoler, me fit immédiatement ouvrir la capsule. Or, cette capsule, parsemée de taches livides et brunatres, offrait dans son intérieur, au lieu des graines normales, des graines avariées noiràtres, ramollies, et parmi elles des larves d'un rougeatre ou d'un jaune-orange, et des nymphes d'une teinte plus foncée.

Sur d'autres capsules j'eus vite découvert, au point de la déhiscence avec le disque supérieur, des dépouilles de nymphe, transparentes et restées moilié en dedans, moitié en dehors, abandonnées en cet endroit par l'insecte parfait. Il était, par conséquent, probable que ces larves et nymphes produisaient l'insecte q̨ue j'avais d'abord aperçu.

Pour avoir une certitude à cet ȩ́ard, j'ai recueilli les capsules tachées de noir et toutes celles qui me paraissaient anormales, et je les ai placées dans les boites à observation, dont le couvercle est formé par un verre. Il est éclos dans ces boites une grande quantité (200 individus environ) du Diptère que j'arais trouvé. Après m'etre assuré de l'identité de l'espèce et ayoir dessiné les deux sexes de l'insecte par- 
fait, j’ai examiné à diverses reprises la larve, la nymphe et la dépouille dont j'ai parlé.

J'avais pensé que la Cécidomyie du pavot était connue, et j'étudiais son oryanisation et ses premiers états pour moiméme et non pour les publier. Je m’étais altaclié à certains détails sans en connaître d'avance tout l'intérè, et heureusement quelques-uns d'entre cux avaient éé négligrés; d'autres confirmeront des assertions émises saus preuves.

La Cecidomyia papaveris a été décrite pour la première fois par WIskertz, dans les Linna entomolog ica (Beilray zu einer Monographic der Gallmüclien, 1853, p. 229). L'auteur n'a donné aucune fiģ⿻ure de cet insecte, ni aucun détail anatomique lui appartenant.

On ne trouve aucune mention de celte Cecidomyia dans les trois volumes de M. Macquart sur les arbres. arbrisseaux et plantes herbacées d'Europe et leurs insectes, ni daus le récent ouvrage de Grste (Die Mysterien der curopäschen Insectenwelt, 1856).

Je dois à mes chers amis et collègues, MIM. Léon Fairmaire et Bigot, des indications précieuses ou la communication des principaux travaux qui ont élé fait sur les Tipulaires gallicoles ou Cécillomyies. J'ai consulté les auvres de IIII. Macquart, Rondani, Brémi, Lœw et Winnertz, dont la monographie résume presque toutes nos connaissances sur ce genre intéressant d'insectes. J'aurai sosn, en décrivant les trois états de la Cecidomyia papaveris, d'en mentionner plusieurs passages. J'aurai encore á citer divers travaux de II. Léon Dufour et des mémoires récents entre autres, celui de MI. C. Bazin, sur la Cécidomyie du froment (C. tritici Kunby, Tipul(t), de M. L. Amblard sur la galle et la 
nymphe de la Cécidomyie du Tamarix (C. tamaricis), et celui de M. Edouard Perris, renfermant la description de la Cecidomyia entomophila.

\section{LARVE.}

$$
\text { (Pl. 12, fig. } 2 \text { à 4). }
$$

Larva apoda, pseudocephala, ovato-oblonga ; aurantiaca; glabra, asperula; antice subattenuata; antennis biarticulatis; corporis segmento ultimo emarginato; stigmatibus novem paribus. - Long. 2 mill.

LARve allongée, un peu aplatie, apode, presque glabre; d'un rouge orangé, à côtés translucides. Corps de douze segments, la tete non comprise (fig. 2).

Tête, ou plutot pseudocéphale, petite, un peu brunatre, rétractile, ayant sa base entourée d'un faux segment transversal où elle peut se cacher en entier. Anicnnes composées de deux articles, le premier court, le second allongé, plus grele.

Corps à tégument chagriné, diaphane. Premier segment (après le faux segment de la tete), plus large en arrière qu'en avant, très fortement arrondi sur les côtés un peu avant le milieu; les segments suivants, transversaux, arrondis en arrière loin du milieu; le onzième un peu trapézoïdal, son bord postérieur le moins larg̨e, échancré; douzième segment arrondi. Portion anale siluze en dessous. Chaque segment a sur les còtés un ou deux poils peu allongés, faibles, le dernier segment seul a un bouquet de trois poils latéraux (6ig. 4). 
Dessous du corps presque plan, avec un trail brun, visible aussi en dessus et tenant ì une pièce brunâtre, paraissant à travers les téguments et appartenant à la partje supéricure du tube digestif.

Tissu adipeux splanchnique lobulé, d'un jaune orangé, domnant à la larve sa coloration; les pelotons graisseux forment deux ou trois contours festonnés le long de chaque segment assez loin du bord externe.

Stigmates au nombre de neuf paires. Celle du premier segment est latérale et postéricure; celles des segments suivants, la dixième comprise, sont latérales et plus médianes sur les cótés, enfin la dernière paire située sur le onzième segment est placée en dessus et près du bord postéricur (lig. 2 et 4).

La larve de la Cecidomyja papaveris est franchement apode et n'a pas de poils ou de pseudopodes tenant lieu de pieds. De Géer avait cru trouver des pattes à une larve de Tipule qui vit sur le pin et qui n'est autre que la C. pini De Géer (Winnentz loc. cit. 270), observée aussi par Ratzeburg (Fortinsckten III, 159); Brémi en citant De Géer (Beilrage «u einer Honographic der Gullmeiecken, Neuenburg 1846, p. 8), dit expressément qu'il n’a jamais vu de pattes à des larves de Cécidomyies, et croit que le Réaumur suédois a admis comme pattes des pseudopodes.

Notre larve n'a donc ni les appendices figurés, à tort ce nous semble, pour la Cecidomyja tritici (BAzis, Notice sur la Cécidomyic du froment 1856, fig. 3), ni les poils de quelques autres espèces, entr'autres de la C. dauci (pericarpiicola), BnEm loc. eit. 58, pl. x, fig. 10; C. cracece et quercus LOEw (Dipterologische Beitræge, vierter Theil 1850, p. 22); C. entomophila Ed. PEnms (Hétcmorphoses 
de divers Insectes, Liége 1855, pl. v bis, fig. 101 et 103), etc., etc. Les seuls poils dignes d'attention sont en arrière, ainsi que l'indique la fig. 4 quue j'en ai donnée, qui me dispense d'autres détails.

M. Léon Dufour a parfaitement fait connaitre les curieux pseudopodes d'une larve de Cecidomyia (C. Pini maritime L. Dufoun, Anm. Sc. Nat. 2e série, xvi, 258, pl. xiv, fig. 2). Elte porte " sept paires d'appendices saillants que l'on prendrait volontiers pour des pattes. Ces curieux appendices raides, inarticulés, oblongs, divisés en deux digitations inégales terminées par une soie, m’ont paru insérés comme les pattes ordinaires. »Je crois pouvoir assurer que ces pseudopodes sont analoģues aux organes observés par De Géer, représentés t. 6 de ses Mémoires, pl. 26, fig. 13, et décrits de la manic̀re suivante : a Jai cru observer sur ces larves deux rangs de pattes charnues ou tout au plus cartila jineuses en forme de pointes coniques, un peu courbées el refendues au bout. Mém. vi, 418. »

Je ne puis m'empecher de faire remarquer la grande ressemblance de la larve du pavot avec celle d'une Lasioptera (gence démembré des Cécidomyies), publiée par M. Léon Dufour dans les Mémoires de la Société royale des sciences de Lille (année 1845, p. 215, fig. 2, 3 et 4). Leur corps a le ineme aspect grenu à un fort grossissement, leur forme est semblable. Mieux servi par les circonstances, j'ai constate deux articles aux antennes (fig. 3), tandis que M. Léon Dufour les croyait d'un seul article en forme de soie, de pointe roide dans la larve soumise à son observation, et ne savait si on devait les appeler antennes ou palpes (loc. cit.). Il est difficile d'ailleurs de donner un nom catégorique à ces appendices du pseudocéphale. M. P'erris les 
nomme antennes dans la larve de la $C$. entomophila, et leur donne deux articles. M. Léon Dufour, ce me semble, les regarde comme des palpes dans les $C$. pini maritima et populi où il les figure avec deux articles (loc. cil. pages 258 et 260); plus tard en décrivant la larve de la $C$. verbasci (Ann. Sc. Nat. 3e sćrie, v, page, 12), il dit qu'on lui trouve de chaque coté, un palpe (ou si l'on veut une antenne) biarticulé. ")

La pièce brune située en avant et en dessous du corps a été trouvée par M. Léon Dufour dans plusieurs larves; il la considère comme un vestige de ces mandibules rétractiles qui s'observent dans plusieurs larves dépourvues de véritable tête. Réaumur avait connu et décrit cette pièce sous le nom de trait brun comé. Brémi (loc. cit. 8), le signale pour toutes les larves sans préciser la position exacte.

Les stigmates réclament une attention soutenue pour etre bien appréciés. M. Léon Dufour n'en arait pu apercevoir que huit sur la $L_{a}$ asioptera, il en figure neuf pour les $C$. pini maritima et verbasei; la $C$. populi scule aurait onze paires de stigmates. M. Perris en a trouvé neuf pour la C. entomophila et j'en ai parfaitement vu le meme nombre sur ma larve du pavot, en la faisant rouler entre deux lamelles de verre, sous l'objectif du miscoscope. Je renvoie pour leur situation aux figures 2 et 3 , en mème temps qu'à la description générale. J'ai en outre représenté le stigmate postérieur grossi (fig. 5).

Dans un travail sur les insectes nuisibles au colza, M. Focillon (Annales de l'Institut agronomique, 1852) a décrit et figuré sous le nom de ver blanc une larve qu'il ne savait a quel insecte rapporter et qui appartient à la $C$. Irrassice WInNElTz, loc. cit. 231. La ligure grossic (PI. III, fig. 29) 
donnée par M. Focillon est assez exacte; mais il a représenté onze a douze paires de stigmates, ce qui est évidemment une erreur. J'ai observé un grand nombre de ces larves du colza el je n'ai jamais vu que neuf paires d'ostioles respiratoires. L'auteur que je cite admet deux articles aus antennes et il a bien rendu les lobules latéraux du tissu graisseux.

M. Bazin a fait figurer des sortes d'appendices de chaque coté des segments de la larve de la C. tritici (loc. cit. fig. 3). Je crois que cette figure est fautive. J'ai examiné avec soin les larves d'un jaune orangé ou d'un jaune de soufre, des épis de blés, suivant les indications de l'auteur, et je puis affirmer que sur aucune on ne trouve un appendice. J'ai, au plus, vu la saillie des stigmates dont je ne trouve pas l'indication dans le travail de M. Bazin et j'ai figuré cette disposition (fig. 18 et 21 ) en ajoutant le contour 4-lobé du dernier sergment abdominal qui est remarquable. Je désire que mes observations soient vérifices à leur tour, et je le répète, c'est dans ce but que jai figuré cette larve. Il est plus fréquent de ne pas voir les stigmates saillant sur le bord des segments. M. Low a indiqué la saillie des segments chez quelques larves de Cecidomyia, M. Winnertz a donné comme règle neuf paires de stigmates (loc. cit. 193 et 195).

Les larves de la Cecidomyia papaveris ne quitteni pas les capsules du pavot; elles y vivent en sociétés nombreuses. Tirées de leur retraite et placées au grand air sur un plan uni, elles sont lentes, contractées; elles s'allongent pour marcher, mais sans beaucoup de vivacité. C'est dans celte attitude que j’en ai représenté unc (fig. 2).

Je me suis assuré qu'elles ne sautaient point conme 
celles de la C. populi l.. Drfour Ann. Sc. Nat. 20 Séric XVI, 261 et pl. 14 figg. 10) ei celle de la C. tritici KunB dont les mours sont rapportées par M. Bazin(loc. cit. Page 9). Ces larves ont en efiet peu de mouvements à exécuter, elles sont sédentaires, vivent dans un petit espace, au sein d'une nourriture abondante et y subissent lcur transformation en nymphe. Elles n'ont pas à sauter comme celles de la $C_{\text {. }}$ tritici qui va en terre subir sa transformation, suivant M. Bazin.

Je n'ai pas cherché spécialement à voir la filière ou l'organe qui en tient lieu ct dont la larve doit etre pourvue, car parıni les graines avariées du pavot et les divers débris on trouve des sortes de trames làches blanchatres, sans que les nymplies y soient exactement placées. Il y a plutòt un ouvrage d'ensemble pour relier et assembler les différentes parties internes de la capsule et non les coques propres a chaque larre en particulier.

Notre Cecidomyie du pavo n'est pas la seule du genre qui ne produit pas de galle; de Géer, Brémi, MII. Léon Dufour, Macquart, Lœw, Winnertz, elc., ont signalé un bon nombre de faits semblables; mais souvent alors les larves de Cecidomyies s'enveloppent d'une coque de soie. M. Perris nous a fait connaitre la $C$. cnlomophila qui vit parmi les Acarus sur les insectes des collections, et cet observateur si consciencieux a souvent trouvé des larres de Ciciulominic sous les écorces, parmi les excréments d'autres larves xylophages qui les avaient précédées; dans les ulcères, les écoulements sanieux ou sèveux des arbres, dans les tigres creuses de plusieurs plantes mortes ou sur le déclin (loc. cit.). 


\section{NYMPHE.}

(PI. 12, fig. 6 et 7).

Nympha mula, obvoluta, oblonga; fuscescens, abdomine pectoreque pallide aurantiacis; capite antice bifido, vertice setis duabus instructo; thorace gibbo, cormubus duobus fore rectis armato; abdomine 8-articulato, apice fisso.-Long. 2 mill.

J'ajouterai à cette phrase diagnostique et à la figure de celte nymphe, que les antennes offrent des traces légères de division, que le corselet et les étuis des ailes sont noirâtres, que les pattes sont allongées, rapprochées, les extérieures étant les plus longues de toutes.

La nymphe de la Cecilomyia papaveris ressemble ainsi que je viens de l'exposer, à celles des Tipulaires en général. Tous les auteurs qui ont étudié ces nymplies les ont trouvées à peu près semblables aux insectes dont elles recouvraient les diverses parties, différant ainsi d'unc manière considérable de celles des Muscites qui sont de véritables Pupes.

Aussi, n'est-ce point sans étonnement que dans le mémoire de M. Bazin, j’ai vu décrite et figuréc sous la dénomination de nymphe une des formes d'un insecte trouvé dans les glumes du blé oủ il hiberne. Cette forme ne saurait convenir à une véritable nymphe de Cecidomyie. Il me paraît y avoir là une fausse interprétation; M. Migneaux II'a exactement dessiné que ce qu'il a vu, M. Bazin n’a décrit que ce qu'il a observé, mais il m'a toujours paru impossible que la fig. 4 de la planche de son mémoire 
représentat la véritable nymphe de la $C$. tritici. Je me suis bien souvent demandé ce qu'étail cette forme insolite. Etait-ce une larve saine restée dans l'épillet?

J'ai cu recours de mon côté à l'ubservation directe, et j’ai vu une larve incluse dans la peau séparée de son corps. Est-ce dans cette enveloppe sèche et ridée que la métamorphose a lieu? Je ne puis décider la question; mais le Professeur Low (Diplerologische Beitrege, vierter Theil, 1850 p. 8 et 23) cite d'après M. Asa Fitch le fait très exceptionnel de la métamorphose en nymphe dans la peau de la larve elle-méme pour la $C$. destructor Say. Je son coté M. Winnertz a vu la C. graminicola (loc. cit. 292) dont la larve blanchatre vit sur le Poa nemoralis, se transformer dans sa propre peau de larve. Or, la larve observée par M. Bazin et par moi-meme se tenant dons les glumes du blé n'est point celle de la $C$. destructor qui vit contre les noeuds de la tige dans la gaîne des feuilles, mais elle a peutetre comme elle une nymphe transformée dans la peau de la larve.

M. Bazin pense que les larves restent pendant l'hiver à l'état dormant dans la terre; leur transformation en nymphe doit être promptement suivie de leur éclosion. Dans tous les cas la véritable nymphe est restée inconnue à MI. Bazin qui n'a encore pu rencontrer dans la terre que la larre (loc.cit, pages 9 et $\mathbf{1 1}$ ).

La forme ordinaire des nymples de Cecitomyia a servi i M. Jouis Amblard dans un travail récent ( $\Lambda n n$. Société Entom. France, 1856,) à rapporter à un de ces insectes la production d'une galle observée sur le Tamerix brachystilis de nos possessions d'Afrique. Je crois comme M. Amblard 
que la nymphe qu'il a fait connaitre appartient à une Cecilomyia.

La coloration de notre nymphe du pavot est d'abord d'un jaune rougeatre, plus tard la teinte passe au brunatre sur le dos et le fourreau des ailes. Les yeux deviennent les premiers d'une teinte brune, puis noire.

Cette nymphe n'a point d'épines marquées sur ses huit segments; elle n'a que deux mamelons à l'extrémité, qui ne doit pas compter pour un neuvième segment, à mon avis. Les deux appendices de la tete et du thorax (sans parler des saillies frontales) méritent de nous arrêter.

Les cornes ou saillies frontales paraissent servir aux nymphes des Cecidomyia pour percer leur prison, qu'elle soit une galle ou une coque soyeuse; je pense qu'il en est ainsi pour la Cécidomyie du Tamarix L. AsBLARD, comme pour les Cecidomyia entomophila PEuris. Les cornes et l'espèce de hure de la C. verbasci Vallot (Lion Dufouh, loc. cil. Pl. 2, fig. 10 et 11), sont très remarquables, ainsi que celles des C. fagi et sarolhamni, représentées par Winnentz, loc. cit. Pl. 1, fig. 5 et 6 ).

On trouve des poils sétiformes situés près du front sur quelques Cecidomyia ou de Lasioptera, mais je ne connais qu'un autre exemple bien net des cornes thoraciques que j'ai ligurées (fig. 6 et 7), c'est celui fourni par M. Léon Dufour dans sa description de la nymphe d'une Lasioptera (Mém. Soc. Roy. Lille, 1845, fig. 5.)

J'avais à plusicurs reprises examiné sous divers grossissements les poils cervicaux et les cornes, tant sur la nymphe non éclose de la $C$. papaveris que sur la dépouille après la sortic de l'insecte parfait. Les soies cervicales étaient simples, mais les cormes dorsales mont paru renfermer un tube 
inclus, et ce tube a les apparences d'une trachéc. J'ai représenté celte disposition par une figure (fig. 7).

Ce detail remarquable me paraissait devoir etre connu. MM. Low et Winnertz parlent de soies tubuleuses et respiratoires (WINNERTZ, loc. cil., p. 194 et 198). M. Léon J)ufour doute de l'usage physiologique de ces cornes, et il cite De Géer comme ayant cru à un organe de respiration. Or, De Géer ne parle que des cornes du vertex et non des cornes thoraciques de la $C$. du gínevrier (p. 409 du tome VI de ses Mémoires).

" La nymphe porte sur la tete deux petites pointes coniques en forme de cornes droites qui sont sans doute les organes de la respiration: )

J'appelle l'attention des entomologistes sur ces organes respiratoires. Je désire que de nouvelles recherches confirment une observation que je voudrais moi-même répéter encore.

Quand le moment de la métamorphose en insecte parfait est arrivé, la nymphe de la Cecidomyia papaveris s'avance jusqu'au haut de la capsule qui, par une harmonie admirable, devient déhiscente à la même époque, à cause de sa maturité. La nymphe s'y engage a moitié, la ligne dorsale médiane se fend dans toute sa longueur et l'insecte parfait prend son essor.

La fixation de la nymphe dans un point ou elle se trouve arretée n'est pas indispensable à l'éclosion. Plusicurs insectes sont nés de capsules ouvertes et de nymphes libies sur un plan uni.

La dépouille laissée par l'insccte parfait est d'un beau blane un peu diaphane; elle présente tonjours les antennes isolées et la déhiscence dorsale. 
La Cecidomyia papaveris reste peu de temps á l'êtat de nymphe.

\section{Insecte parfait.}

(Pl. 12, fig. 8 à 15).

Cecidomyia papaveris Wivnertz Lin. Ent. vir, 229 (1853).

— Watker, Insecla Britannica Diptera III, 78 (1856).

Nigrescens, griseo squamoso-tomentosa; antennis fuscis 16-17 articulatis, articulis in mare spheroideis pedicellatis ; oculis nigris in mare connexis; thoracis et abdominis lateribus, ventreque rufis vel rufescentibus; alis diaphanis, tricostatis; halteribus fulvis; pedibus fuscis, subtus argenteis, libiis tarsisque rufescentibus, tarsorum articulo primo brevissimo. — Long. 2 à $21 / 2$ mill.

Corps brunatre varié de rougeatre plus ou moins sombre et revetu d'écailles d'un gris satiné ou d'un blanc soyeux.

Tête avec les yeux noirs, grands et contigus ơ ; écartés, distants $\%$.

Antennes paraissant composées de dix-sept articles chez le $\sigma^{7}$, et de seize chez la + ; égalant la longueur du corps et recourbées en haut, of; premier article grand, presque glabre, ainsi que le deuxième. Les suivants allongés, pédicellés, renflés à la base en forme d'ovoïde court et portant un verticelle de poils isolés (figg. 10,11 et 12), article terminal sans pédicule, sessile. Pétiole de la longueur du renflement à la base des antennes et vers leur milieu, de la moitié de leur longueur sculement vers les derniers articles. Chez le of , les articles trois à quinze sont presque carrés, un peu transversaux, sans verticelles de poils (fig, 13). 
Bouche laissant apercevoir deux corps en forme de lobes arrondis, correspondant à des machoires supportant chacune un palpe visiblement $\mathbf{4}$-articulé.

Thorax brunatre avec les còtés rougedtres et trois bandes sur le disque, longitudinales, plus foncées, produites par les poils ou écailles moins lisses.

Ailes diaphanes, irisées sous un certain jour, avec trois nervures, leur bord antérieur et postérieur noir, et des poils noirs sur leur surface; frange du bord antérieur serrée, la postérieure longue et plus fine. Trois nervures longitudinales et une transwersale petite et difficile à voir. Cette dernière est située au milieu de la première nervure longitudinale ${ }^{*}$ (fig. 14) et un peu plus en dedans of (fir. 15). La deuxième se recourbe un peu en haut depuis sa naissance et s'approche de la première nervure (c'est sur ce point que tombe la nervure transversale), puis elle forme une courbe à convexité inférieure et atteint le bord externe bien avant le couvercle externe de l'aile, sur le bord supéricur. La troisieme presque droite à la base, se courbe légèrement sans atteindre le bord postérieur, sa division secondaire bien visible.

Balanciers rougeatres couverts de poils d'un blanc argenté.

Abdomen de huil segments, l'armure génitale rougeatre avec une large bande transversale noiratre ou brunätre sur chaque segment, en dessus atteignant le bord postérieur.

Dessous du corps d'un jaune rougeatre.

L'abdomen porte à l'extrémité, chez le $\sigma^{*}$, une pince ou tenaille brunatre très mobile, pouvant se recourber en haut, assez semblable à celles des Panorpes; chez la $q$, une tarière d'un jaune rougeatre, presque glabre, de trois pièces pouvant s'allonger démesurément et dépasser la longueur du 
corps. La dernière pièce de la tarière n'offre pas de valves ou lames appréciables.

Pattes trìs longues, greles; brunatres, rougedtres à l'extrémité, revêtues surtout en dessus, d'écailles satinées, plus serrées sur les jambes et les tarses. Ceux-ci, avec le premier article très court. Ils sont terminés par deux ongles, ou crochets greles, pouvant se cacher en se redressant dans une sorte d'avancement oblique du dernier article, et pourvus dans leur milieu d'une petite pelote se relevant elle-même en haut.

Après la mort, l'insecte devient brunatre, le dessous de l'abdomen est rougeatre. On voit clairement, chez la $q$ surtout, la partie antérieure des segments rougeâtre, la tarière de la 우 est de la longneur du corps.

Brémi, MM. Lœw et Winnertz donnent l'exellent conseil de décrire les Cécidomyjies sur linsecte vivant ou venant de mourir et de ne pas altendre la dessication qui les rend souvent difficiles á reconnaître en détruisant leur forme et leurs couleurs. Je dois dire que j'ai eu un grand avantage pour étudier les détails des antennes, des ailes, des tarses, etc., en plaçant l'insecte dans l'cau ou dans l'huile entre deux lames de verre.

Les antennes arqueces et relevées en haut pendant la vie, surtout celles du male, sont très élégantes dans ce dernicr sexe. J'ai bien vu la manière dont les articles sont unis entre cux. L'extrémité de chaque article est grêle, en forme de pédicule, la base est globuleuse, garnie de poils verticellés. Ces dispositions n'ont pas encore été suffisamment signalées, je les ai représentées (fig. 11). La plupart des figures anciennes données par les auteurs exprimaient défectueusement les verticilles de poils qui ne sont entièrement visibles 
que sur l'insecte frais. MM. Lew et Winnertz les ont bien représentés. (V. Winnertz, loc. cil. Pl. ur et IV).

Les antennes sont d'une grande frarrilité. C'est un rude labeur que de compter leurs articles dans la plupart des Cecidomyia. Les deux premiers sont gros et presiue glabres, servant de support aux autres dont la configuration est differente en général.

Il y a dix-sept articles à l'antenne $\sigma^{*}$ de la C. papaveris, le dernier est sessile, arrondi au bout; une seule fois il m'a semblé trouver chez une $q$ du mème insecte un article pareil et surajouté. Y avait-il sculement une scission du seizième? Je signale le fait comme exceptionnel. Je n'en ai pas tenu compte dans la description générale.

On sait que les Cecidomyia ont un nombre très variable d'articles aux autennes. Meigen croyait que les of avaient vingt-quatre articles et les + douze seulement. Aujourd hui on s'accorde à dire que le nombre varie beaucoup plus, de dix à vingt-six (LoEw, loc, cil. 16), de treize a trente-sis (Winnentz, loc. cil. 181), el les différences de nombre et de iorme chez les ô et les of sont généralement très marquées.

La $C$. populi $\mathrm{L}$. Duwour a vingt-cing arlicles oux antennes ot et $q$; celle du verbascum, d'apres le meme auteur, quatorze articles ot et o.

La C. tritici, d'après M. Bazin, (loc. cil. 25), aurait treize articles $\sigma^{1}$ et douze articles $q$ aux antennes, non compris le point d'attache (ordinaircment de deux articles), ce qui ferait quinze pour les o el quatorze pour les q; mais je trouve sur la figure un pédicule terminant chaque antenne, et je crains fort que celle-ci n’ait éti brisée et que des articles soient in3e Série, томе v. 
complets; car les antennes ont ordinairement leur dernier article arrondi ou globuleux.

La C. entomophila Perms (loc. cit. 49) a vingt-quatre articles of et quatorze sculement + . Les deux articles de la base sont incomplétement rendus sur la planche V bis, figure 104.

Les C. hyperici Géné et la C. Woldicliii Contarini paraissent en avoir un très grand nombre (voy. Memoria per servire alla storia naturale di una specie di Cecidomyia che vive sugli Iperici, del prof. GIUSEPPE GÉni. - Acad. dell. science di Torino, xxxvi, 287. - Memoria sopra una nuova specie di Cecidomyia ed alcune observazioni sopra quella dell Iperico, etc. Letla all'Ateneo di Venezia, dal signor Conte N. B. Contarini, 1840, vol. 111, 122).

C'est en ayant égard aux nervures des ailes et au nombre et à la forme des articles des antennes, que MII.C. Rondani, Low et Winnertz ont fondé des genres pour l'étude du grand genre Cecilomyia. La C. papaveris rentre dans la première division ou sous-genre Cecidomyia proprement dite.

La bouche m'a paru composée d'un labre avancé, peu arrondi en avant (fig. 16) et de deux sortes de machoires lobées portant des palpes de quatre articles (fig. 13).

M. Bazin a, comme moi, trouvé les palpes 4-articulés (loc. cil. fig. 10). Brémi dit que les pałpes sont de tro s articles, et les figure ainsi dans la C. subpalula. il. Léon Dufour donne deux articles aux palpes de la C. veibasci (loc. cil. PI. 14, fig. 14). MMI. Loew et Winnertz adrnettent des palpes de quatre articles comme caractère génírique.

Les anneaux de l'abdomen sont arrondis latéralement. M. Dufour a figurí de meme ceux de la C. verbasci. M. Mi- 
gneaux a représenté autrement ceux de la $C$. tritici, peutêtre n'a-t-il eu sous les yeux que des insectes desséchés et déformés.

Les males de la $C$. papaveris sont plus petits et bien plus rares que les femelles. M. Winnertz avait remarqué leur rareté dans les éclosions qu'il avait obtenues de capsules de Papaver rhaeas et dubium, envoyées d'Aix-la-Chapelle par M. Fœrster. Il y a plusieurs espèces de Cecilomyia oủ l'un des sexes est seul connu. La f de Lasioptera dont M. L. Dufour a décrit les métamorphoses, et que Réaumur n'avait pu élever (Mém. Soc. Roy. sc. de Lille, 1845), me paraît, d'après la description, devoir etre rapportéc it la L. rubi Scuranck, et non d la L . picta Meigen qui d'ailleurs vit sur' le génevrier.

Je n'ai observé dans les insectes éclos des capsules du Papaver rhceas que la $C$. papaveris. Je n'ai vu aucun individu de la C. callida Winnentz (loc. cit. 255).

Le frele diptère dont jai essayé de retracer les métamorphoses, vole par petites saccades. Le o est très vif, il saisil la femelle avec les pinces de son forceps pendant l'accouplement qui a lieu en sens opposé et sur une ligne droite, les extrémités des deux abdomens étant accolées bout à bout.

La recidomyia papaveris m'a paru vivre pzu de temps sous sa dernière forme. I'ignore de quelle manière les oufs sont pondus, et comment les jeunes larres éclosent et se développent.

\section{EXPLICATION DES FIgURES DE LA PLANCHE XII.}

Fig. 1. Capsule de Papaver riheas, de grandeur naturelle, 
tacliée de brun, ouverte, montrant dans son intérieur des graines, des larves et des nymphes de Cecidomyia papaveris, et la déhiscence de son bord supérieur.

2. Larve de la C. papaveris prete á se transformer, et à côté mesure de sa grandeur naturelie.

3. Antenne très grossie de cette larve.

4. İxtrémité de l'abdomen très grossie, aspect granulé du corps, stigmates postéricurs et poils du dernier segment, qui est légèrement échancré.

5. Stigmate postérieur encore plus grossi.

6. Nymphe de la C. papaveris et mesure de sa grandeur naturelle.

7. Une des cornes thoraciques grossie montrant la trachée interne.

8. Cecidomyia papaveris of et mesure de sa grandeur naturelle.

9. Cecilomyia papaveris $q$ avec les ailes écartíes et mesure de sa grandeur naturelle.

10. Antenne du ơ grossie.

11. Trois articles de cette antenne très grossis et sćparés pour mettre en évicence leur mode d'articulation.

12. Un de ces articles encore pl is grossi et montrant dans le renflemeut de la sase une ligne qui parait etre une trace de division. Cette division n'est qu'apparente.

13. Antenne de la ㅇ grossie.

14. Aile grossie de la $C$, papaveris $\sigma^{\prime}$. 
15. Nile grossic de la $C$. papuveris 우

16. Tete et organes buccaux très grossis.

17. Extrémité d'un tarse extrêmenent grossi, montrant les crochets terminaux et l'unique pelotte située entre eux.

18. Larve de la C. trilici Kınny, vivant dans les glumes du blé et très grossie. On remarque la saillie légère et non constante des stigmates latéraux.

19. Extrémité du huilième segment; le neuvième est quadridenté et oftre en outre deux poils de chaque côté.

20. P'ièce cornéc annexée is la partic supéricure du tube digestif, chez la meme larve.

21. Un des segments médians extrêmennent grossi, montrant la disparition des lobules du corps graisseux et les stigmates de chaque coté. 



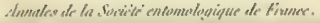

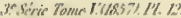

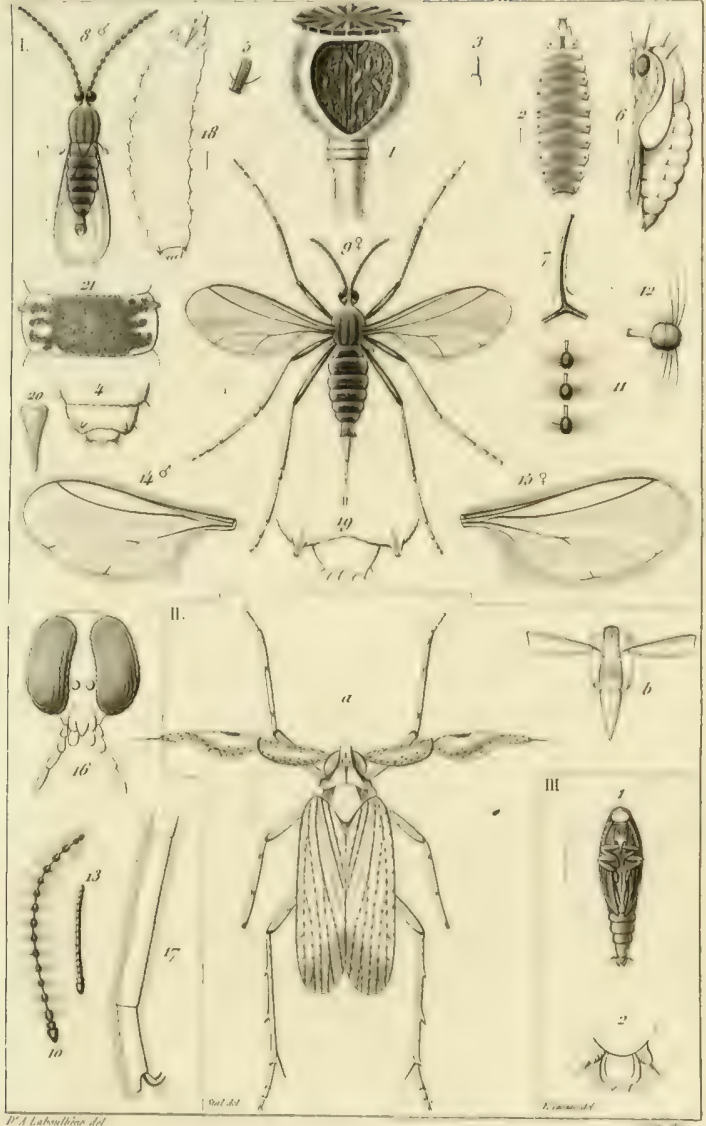

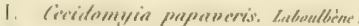

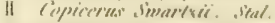

III limenewhis capucinus. Ahrous. 



\title{
NOTS
}

\section{SUR LA NYMPIE DE L'ANTHRAX SINUATa.}

\author{
Par M. le $\mathrm{D}^{\mathrm{r}}$ Alesandre LABOULBÈNE.
}

(Séance du 22 Juillet 1857.)

Pendant une excursion entomologique, faitc le 5 mai 1857 , à Bouray, près d'Étampes, avec mon ani ct collìgue M. Louis Amblard, nous ayons trouvé, contre le mur d'un pare, plusieurs nids d'H yménopteres batis avec de la terre et forts durs. Ces nids, dans lesguels on voyait des loges voisines les unes des autres, ovales, lapissées par une sorte de toile mince, furent díposés dans des boîtes à observation, en meme temps que d'autres insectes trourés dans la mème journée, entre autres des larves de Cicindèles (V. Archives entomologiques de M. J. Thonsos, 1857, I, 105). Au lieu des IIyminoptères, que nous nous attendions à voir paraître, ct qui très probablement devaient appartenir au genre Megachile et ì l'espèce muraria, il est éclos, un mois après environ, d'abord un Anthrax simuata, et quinze jours après un second de ces Diptères. Je dois dire d'ailleurs que dès l'apparilion du premier insecte, nous avions constaté l'existence de sa dé- 
pouille de nymphe et recherché s'il ne s'en trouvait point d'autre dans les cellules déjà signalées. Or, nous n'avons vu aucune larve ou nymphe d'llyménoptères, mais nous avons recueilli une nymphe de Diptère d'une forme insolite, courbée en arc, ressemblant un peu à certaines chrysalides de Lépidoptères diurnes et dont il est sorti le deuxième Anthrax, pareil au premier.

Voici la description de la nymphe qui est représentée pl. 15, no $^{1}$, fig. 1 et 2 , grossie, ayant à cóté la mesure de sa grandeur naturelle.

\section{NyMPIE D'ANTHRAX SINUATA.}

Corps d'un jaune pâle et blanchatre, courbéen arc, prêsentant à la tete, et à l'extrémité du dernier segment des saillies brunatres ou noiratres. Il est fourni de poils fauves très longs sur l'abdomen.

Tête grosse, comme enfléc ou vésiculeuse, ayant en avant, au-dessus des yeux, une sorte de crète découpée en six dentelures ou dents brundtres (fig. 3). Vers le milieu des yeux, de chaque côté de la ligne médiane deux autres saillies antérieures brunes, dentiformes rapprochees; deux dernières saillies très petites sur l'étui des parties de la bouche.

Thorax de la grandeur de la tête environ, formé presque entièrement par le mésothorax très développé, ne laissant apercevoir le prothorax et le mésothoras que sur les cotés en haut et en dessous de lui. Etui des ailes peu grand, embrassant le corps, ses deux moiliés presque réunies en avant sur la ligne médiane. Etui des pattes occupant entre la base de la tete et les ailes un espace triangu- 
laire; leurs deux pattes postérieures débordent en bas les ailes et se dirigent par coté et en dehors.

Abdomen de huit segrments, le premier ayant en arrière une range transversale, interrompue au milieu de très longs poils à base renflée; les deuxième, troisième, quatrième et cinquième segments ayant en arriere sur leur convexité de onze à treize crochets siillants et libres à leurs deux bouts, arqués en forme de C, el tenant par leur convexité au milieu du segment (fig. 5). Au-dessous de la ligne dorsale des crochets sont de longs poils dirigés obliquement et en bas. Dernier segment (figr. 2 et 1), relevé en avant et un peu en haut, à cause de la courbure du corps; sou extrémité avec deux dents fortes, rapprochées et trois autres dents plus petites de chaque côté près des principales.

Stigmates grands, arrondis, au nombre de huit. Le premier, situé sur le prothorax on, all mnins, entre lui et le mésolhorax, pıés de la tète; le deuxième, sur la partic supérieure et latérale du premier segment abdominal très près du mélathorax; les autres, au bord supérieur et latéral des deusième, troisième, quatrième, cinçuicme, sixieme et septième segments de l'abdomen. Le huitièms anneau seul en est dépourvu. Je ne crois pas qu'on doive admettre un neuvieme segment qui ne serait formé que par les saillies terminant le huitième.

Labdomen offre sur les cótés de ses segments de longs poils a peine dirigés en bas, il en porte aussi en avant du côté de la concavilé, mais ils sont bien moins longr.

Cette nymphe paraît assez vive, et elle exécute des mouvements quand on l'inquiete. II est probable que les curieuses saillies de la tele, les crochets dorsaux et les dents terminales lui servent pour s'érhapper de la prison oi la 
larve a dù se nourrir aux dépens de l'Hyménoptère dont elle est parasite. La sortie de l'Anthrax doit cependant etre bien difficile, car la cellule qui les renferme est dure comme la pierre.

L'insecte parfait quitte sa déponille par une ouverture céphalique et dorsale qui se trouve sur la pellicule de la nymphe dans sa partie médiane et postérieure. L'enveloppe de la tête est clle-méme fendue sur les cótés au-dessous de la crete frontale.

Je pense qu'on n'a pas conservé à cette espèce le nom de morio, sous lequel Linné l'avait décrite, ainsi que De Géer, et plus tard Latreille, parce qu'on n'a pas la certitude que sous le meme nom, ils n'aient compris plusieurs espèces dislinctes. Ia figure 11, 12 et 13 de la planche II, tome vi des mémoires de De Géer est trop peu soignée pour lever toute incertitude. Meigen lui-meme n’a pas fidèlement représenté, dans son ouvrage sur les Diptères (II, pl. 17, fig. 18), l'aile de l'Anthrax sinuata. Le dessin de Macquart (I, pl. 10, fig. 4), est encore moins reconnaissable. Pour ne laisser aucun doule et bien faire connaitre l'insecte dont je parle, j'ai pris le parti de figurer l'aile de l'Anthrux qui fait le sujet de cette note, et qui est l'A. sinuata de Fallen, de Meigen, de Macquart, de Zetterstedt, de Zeller, etc. Je l'ai vu dans la collection de M. J. Bigot, portant ce nom écrit par notre regrettable Mlacquart (fig, 6).

La science, sans etre très riche, sur la connaissance des premiers états des Anthraciens offre cependant des matériaux précieus. J'ai pu, avec mon cher ami et collègne, M. J. Bigot, en réunir la majeure partie. Je les transcris, espérant qu'ili pourront servir pour dles travaux ultérieurs. 
Premiers étals des antunaciens (Macquant).

LATReille (Genera Cruslaceorum et Insectorum 1V, p. 307, 1809), famille des Antlıraciens, dit : a Larva parasita? Pupa nuda, incompleta, spinosulo annulata. ”

Faleev (Antracides Suecio, pagre 3, année 1814) exprime l'opinion suivante sur les mocurs de la famille ou de la tribu : "Larva verisimiliter rhizophagæe, in terra uliginosá metamorphosin forsitan sæpius subeunt, , mais arrivant au genre Anthrax, p. 6, on trouve (Metamorphosis latet. ")

MEIGEN (Systematische Beschreibung der bekannten europaischen Zweifluegeligen Insecten, II, 142, 1820), pense qu'ils se développent dans le bois vermoulu. "Von den ersten Stæenden der Trauerlicgen ist noch nichts bekannt, wahrscheinlich Ieben die Larven im faulen IIolze. »

Maceunat (Suites à Buffon. Diptères I, 398, 1834), n'a pas observé par lui-meme et dit : " suivant M. Latreille leurs nymphes sont nues, incomplètes, avec les segments munis de petites pointes. $)$

WAHLBERG (Kongl. Vetensliaps Academiens Ilandlingar fer an 1838, Stockholm 1839) a recueilli un Anthrax fava Meigen sorti, sans aucun doute possible, de la chry salide de la Mamestra brassice. Pour lui "Larra Anthracis pupam Mamestrae sine dubio Tachinarum more perforaverat, el haud multo post ipsa transformationem subierat. Nescio tamen quamdiu Anthrux in larve vel in pupæ statu restat, neque larva facies mihi cognita” (page 10). Suit la description détaillée de la nymphe de cet Anthrax. Elle ma paru identique avec celle de 3 . Mulsant dont je rais bientôt parler. 
ZetTenstedt (Insecta Lapponica, Diptera, p. 520, 1840), dit a Plerasque species ova in terra arenosa (corpore scilicet fere perpendiculariter erecto, vaginaque anali elongata in arena emissa) deponere sæepe observavi. " En parlant de l' $\boldsymbol{\Lambda}$. sinuata, page 521, il ajoute * Sub lapide loco montoso ad Hamzangeberg gestricia inveni etiam pupas $7 \mathrm{vel} 8$, singulam circiter 6 lineas longam, cylindricam, paulo incurvam, livido-pellacidam, multiannulatam, et in singulo annulorum 4-mediorum in dorso serie duplici denticulorum brevissimorum basi connexorum; subtus inprimis fasciculis pilorum præditam et antice corona e dentibus 6, subulatis, nigro brunneis ornatam. Ex lis pupis intra folia Betule nana, in formam cylindrorum conglomerata, occultis et dic 14 maji captis deinde diebus sequentium mensium 25 jun. 6 jul. et 2 aug. imagines declaratas prevenire vidi. „

Zeller (Isis, 1840, p. 25) réfute Meigen et Schrank q̨ui avaient cru, d'après une fausse interprétation de Ríaumur, que les larves d'Anthrux vivaient dans le bois. Il a vu les A. mucida Zeclen et capucina FAB. enfoncer leur abdomen dans la terre, ainsi que l'a indiqué Zetterstedt.

ZetTerstedr(Diptera Scandinavice, $1,195,1812$ ) s'cxprime ainsi : « Larva aut in terra degunt, ovis à matre (corpora ferè perpendiculariter erecto et oviducto in arena emisso) depositis, exclusis ; aut parasitx in larvis Lepidopterorum vivunt. "Il divise le genre Anthrax en deux sections. Les insectes de la première ont le corps jaunatre et les ailes hyalines, leurs larves sont parasites des larves de Lépidoptères (page 195); ceux de la deuxième section ont le corps noir, les ailes variées, leurs larves vivent dans le sable (page 198).

Le MÊME Auteun, dans le tome vư du méme onrragr. 
1849, page 2979, ligne dernière, répète " Ova in Lepidopterorum larvis deponuntur, ) et plus loin, p. 2981, il ajoute:

6. A. sinuala I, p. 199 (Ex Ilispania à Léon Dufour missa)• Obs. Larvæ in nido Megachilce muraria prædentes vivunt, teste von Bremi.

WheKer (Insecta Britannica, Diptera 1, 77, 1851. a Some of their larva live in the earth; other in Lepidopterous larvæ. D

JacQuelin-Duval (Annules de la Société entomologique de France, 2e série IX, Bull. $\mathbf{L x x x}, 1851)$ \& dit quelques mots sur les mours de l'Anthrax sinuala qu'il a va sortir de la nymphe d'un IIyménoptère qu'il croit etre celle du Megachile muraria. D

Mulsant (Note pour servir à l'histoire des Anthrax, présentéc à l'Académic des sciences de Lyon le $\mathbf{1 7}$ février 1852, Opuscules entomologifues 1 er cahier, 178, 1852) annonce que M. Roux, eutomologiste du midi de la France, lui a envoyé un Anthrax flava MEsGev, sorti au mois de juillet de la chrysalide de l'Argiopis aprilina Lisvé. - Description ditaillée de la nymphe de cet Anthrax.

ZetTeistedT (Op. cil. t. Xil, p. 4584 en note, 18j.j) rapporte le fait de $\mathbf{1 1}$. J. Duval, " Quoque observante $D$. Jacquelin-Duval imago hujus specici e pupa hymenopteri Meyachile murarie exclusa. "

Premiers états des Bombruens (Macelant).

Latreiled $\{(0, c u .311,1809)$ famille des Bombyliers. "Larva parasitica? "

Mrigk (Op. cil. 11, 187, 1820.) " Von den ersten Stæn- 
den der Schwebfliegen ist noch nichts bekannt. Fallen vermuthet dass die Larven in der Erde von Pflanzenwurzeln leben.

Macouart (Op. cit. I, 376, 1831) dit: - Leurs larves ne sont pas encore connues, il est probable qu'elles vivent dans la terre. ")

Zetterstent (loc. cit. 1, 188, G. Bombylius, 1812). "Larve plantarum radicibus victitant."

Walker (loc. cit. 1, 81, 1851), a The larva are supposed to live in the roots of plants."

II. Lucas (Am. Soc. Ent. France, 18;2, page 2, pl. 1) figure et décrit la nymphe du Bombylius bogharicnsis qu'il a Irouvée sous une pierre aux environs de Boghar.

J'ajouterai que celte année, vers la fin du mois d'octobre, j'ai vu avec mon ami M. Edouard Perris, dans le cabinet de M. Léon Dufour ì Saint-Sever plusicurs nymphes d'où étaient éclos des Bombylius major et une larve qui était très probablement celle de cet insecte. Elles avaient été trouvées dans un tertre sableux oủ nichaient soit des Andrènes, soit des Colletes hirsuta.

Les nymphes du $B$, major ont de très grands rapports avec celle de l'Anthrax sinuata. M. Léon Dufour nous a fait remarquer en outre lcur analogie avec celles des As:liqnes. Ces dernières sont figurées daus un mémoire qu'il a publić, en 1850, sur ces insectes dans les Annales des sciences naturelles.

liéaumur, dans son mémoire sur les abeilles maçonnes (T. vir, p. 57 et suir.), n'a pas trouvé les Anthrax parmi les parasites de ces insectes. II signale (p. 80) plus de trente pe- 
tits vers blanes qui " avaient crû aux dépens de la propre substance de l'habitant naturel du lieu. Dans d'autres cellules, j'ai ru que le ver de la maçonne avait seulement servi à nourrir dix à douze vers, mais plus gros que les précédents. Dans telle autre cellule je n'ai pu apercevoir que les restes du ver pour qui elle avait été faite et un seul ver blanc comme les derniers, mais bien autrement gros. ") Il joute plus bas « les vers étrangers se iransformaient en des mouches à quatre ailes du genre Ichneumon. " Il représente et décrit ensuite, comme parasile et très dévastatrice, la larve du Trichodes alvearius FAB, dont l'insecte parfait est reconnaissable (t. vi, pl. 8, fig. 9 et 10) à la tache carrée de l'écus. son et à la disposition de la première bande bleue des élytres. La dernic̀re est représentée apicale, à tort certainement, à moins qu'on n'ait voulu rendre l'cffet en raccourcide l'élytre. Je partage l'opinion que II. Jacquelin-Duval a exprimée à ce sujet dans ces Annales (1857, p. 94).

Réaumun, à ma connaissance, ne parle qu'une fois des Anthrax. Il a figuré (t. vi, pl. 27, fig. 13) l'A. morio de Fallen, Panzer, Zetterstedt, ou A. semiatra de Meigen et de Mac. quart, avec d'autres mouches trouvées comme cette espèce, dians des branches de chêne oủ les avait empilées une guèpe ichneumon ( $\rho .272)$. - Ces différents morceaux de bois, et quelquefois le mème, avaient plusieurs nichées remplies de six différentes sortes d'insectes mis en pile, mais tous ceux de la même nichéc étaient de la même espèce. "Loc, cit. p. 271.

J'ai rapporté ce dernier fait pour faire voir que les $A n-$ thrax qui paraissent, au moins dans des cas bien authentiques, etre parasites à l'état de larve, sont dévorés à leur tour à l'état parfait par d'autres larves. 
Enfin, pour en finir avec l'Anthrax sinuata dont Bremi, M. J. Duval, M. Amblard et moi-meme avons constaté le parasitisme et dont M. Zetterstedt a trouvé la nymphe sous une pierre, ainsi que nous l'avons rapporté, dirons-nous qu'il a deux manières de vivre sous le premicr état de larve? De nouvelles recherches décideront, fiat tux !...

Explication des figures.

(Pl. 15, No 11, fig. 1-5).

1. Nymphe d'Anthrax sinuata vue de profil et mesure de sa grandeur naturelle.

2. La meme nymphe vue de face et par la partie antérieure du corps.

3. Saillies de la tete très grossies.

4. Saillies du dernier segment abdominal encore plus grossies.

5. Crochets dorsaux des $2^{e}, 3^{e}, 4^{e}$ et $5^{e}$ segments de l'abdomen.

6. Aile d'Anthrax sinuata montrant la disposition des nervures au sommet. 


\section{NOTE}

รขน

des Siliques de Colza atraquées pan des Insectes.

Par M. le D' Alexandre LABOULBËNE.

(Séanoe du 23 Septembre 1857.)

J'ai observé cette année, à Villegenis, dans le domaine de S. A. I. Monseigneur le prince Jérome Napoléon, des colzas sur pied altaqués par des insectes, et j'ai pu faire l'examen de siliques pareillement attaquées provenant du département du Calvados. Ces dernières ont été mises à ma disposition par le savant président de la Société de Biologie, M. Rayer. J'ai l'honneur de communiquer le résultat de cette double étude.

Je passerai en revue successivement l'état maladif des siliques et des graines, et j'indiquerai ensuite les insectes qui sont les auteurs du mal.

Les siliques malades examinées à l'extérieur présentent généralement une déformation qui consiste soit en une courbure anguleuse sur une de leurs faces, soit une sorte d'atrophie générale ou partielle. En outre, leur couleur au lieu 
d'être verte (ou jaundtre à l'époque de la malurité) est brunatre ou roussatre parfois, avec une teinte plus foncée sur un de leurs points. Toutefois la couleur extéricure pent rester normale, malgré la déformation.

On remarque sur ces mémes siliques, des trous, des perforations, ou plus rarement, de simples pertes de substance n'intéressant qu'une partie peu étenduc de leur surface et ne pénétrant pas à l'intéricur.

Les trous paraissent produits ou bien de l'incérieur à l'cxtéricur, ce dont il est facile de s'assurer sur la silique ouverte, car on voit alors une surte d'entonnoir évasé en dedans et la paroi interne est refoulée vers l'intérieur de la silique.

Il y a deux espèces de trons faits du dedans en dehors.

$1^{\circ}$ Ceux de la premic̀re espece sont grands, arrondis, et correspondent à la place oủ se trouvent une ou deux graines dévorées dans leur parlie interne, leur enveloppe ou écorce restant en grande partic intacte.

$2^{\circ}$ Les trous de la scconde espèce sont moins grands, moins régulièrement arrondis et ne se trouvent pas exactement situés près d'un groupe de graines et de débris, celleslà élant dévorées à peu près en totalité.

Il n'y a qu'une seule espèce de trous faits de dehors en dedans.

$3^{\circ}$ J'ai constamment trouvé les trous de celte troisième espèce petits ou même très petits, ne correspondant pas à des graines mangées, mais bien à des graines avortées ou non développées.

En ouvrant les siliques malades pour en visiter l'intérieur, voici ce que l'on constate.

$1^{\circ}$ Celles qui présentent une teinte foncée sur un de leurs points m'ont offert en cet endroit une larve blanchâtre courbée en urc, ayant douze anneaux, la tete non comprise, ct les 
parties buecales des Jarves de Charançonites. Celte larve se nourrit de l'intéricur des graines, et c'est elle qui doit percer la silique d'un gros trou rond ou de la première espèce. L'insecte ne restant point dans la silique doit se métamorphoser dans la terre. Je ne puis dire quel est le Coléoptère que cette larve produit, mais je ne crois point que ce soit un Ceutorhynchus ou un Grypidius, comme on l'a assuré.

$2^{\circ}$ On voit dans d'autres siliques une chenille (non une vraic larve) reconnaissable à ses pattes au nombre de seize. Sa couleur est verte avec des poils noirs. Près d'elle sont des graines presqu'entièrement dévorées. J'ai vu cette chenille atlaquant la paroi interne de la silique assez loin du point oủ existaient les débris des graines; c'est donc cette chenille qui produit les trous de la deuxième espèce.

Ces deux insectes, larve et cherilie, ne font que percer la silique pour en sortir et ne se nourrissent pas de sa substance, mais bien de la graine du colza. La chenille verte file une coque en dehors sur un rameau et s'y change en chrysa. lide. II sort de cette enveloppe un petit papillon. J'ai Irouvé cetle coque, mais je n'en ai point vu sortir l'insecte parfait qui du reste est bien connu et dont je reparlerai plus bas. Il n'est éclos que le parasite.

3० Enfin, le plus grand nombre des siliques malades, celles qui sont mal développées ou anguleuses, présentent dans le point coudé un trou fait de dehors en dedans. Ces siliques renferment un grand nombre (15, 20 et plus) de larves longues de deux à trois millimètres d'un blanc grisâtre ou à peine jaunatre. Ces larves déterminent par leur présence ou leurs succions dans la silique une exsudation humide qui tapisse les parois. Les graines sont avortées ou mal venues, parfois moisies; la couleur est changée.

3e Série, Tomk v. 
Par leurs caractères divers qui sont : un corps composé de douze segments, la tete non comprise; celle-ci formée d'une sorte de museau rétractile avec deux antennes biarticulées, peu visibles ; le dernier segment du corps légèrement échancré avec quelques poils raides dirigés en arrière; neuf paires de stigmates, etc.; ces larves appartiennent à un insecte diptère du genre Cccidomyia. Elles doivent, pour le plus grand nombre, tomber en terre à l'époque de la déhiscence de la silique, et là se métamorphoser en une petite mouche. Le fait a, du reste, été parfaitement observé.

C'est la mouche femelle qui, avec sa longue tarière, doit forer le trou de dehors en dedans et pondre les œufs dans la silique lorsqu'elle est encore très peu développée. On voit que je ne pense pas que ce soit un Coléoplère qui perce la silique d'un trou pour manger les graines.

40 Enfin, en dernier lieu, il existe des parties de la silique oủ la paroi externe est rongée. Ces dégats sont produits par des insectes Coléoptères parvenus à l'état parfait. Je les nommerai bientôt.

Pour ne pas compliquer cet exposé, j'ai négligé de dire que pour chacun des trois habitants de la silique, il y a une larve parasite qui produit un IIyménoplère. J'en ai vu plusieurs parmi les larves de Diptère, et un autre avec une larve forant les trous ronds de la première espèce.

Fn résumé, j'ai trouvé sur les colzas du Calvados et des environs de Paris :

10 Une larve assez grosse, blanchatre, appartenant à un Curculionite, mangeant l'intérieur des graines, forant la silique en cet endroit.

20 Une chenille verte, à poils noirs, mangeant à peu près toute la graine sans respecter l'épiderme, et allant percer la 
silique dans un endroit souvent éloigné du lieu où elle s'est nourric.

3o Une larve de Diptère, blanchatre, sans mandibules, produisant une extravasation des sucs et empechant les graines de se développer convenablement.

En outre, les parasites de ces trois larves. Il me reste d donner les noms des insectes parfaits et à faire remarquer quelques travaux antérieurs.

La larve du Curculionite ou Charançon a été observée et décrite par M. Focillon (Annales de l'Institut agronomique dé Versailles, Paris, 1852, p. 152, pl.1, fig, 5), qui la rapporte à l'insecte qu'il nomme Grypidius brassica, nouveau d'après lui, pour la science. Il y a là, ce me semble, une double erreur. Le Grypidius est un insecte (Ceutorhynchus) fort commun, parfaitement connu, décrit par Gyllenirac sous le nom de C. assimilis. Sa larve se trouve constamment dans les racines ou au collet de la tige des plantes cruciferes, entre autres du navet, ainsi que Krnby et Spevce l'ont démontré. J'ai signalé leurs observations dans les Annules de la Société entomologique de France, année 1856, page 165.

Je ne puis savoir encore quel est l'insecte produit par la larve qui fait ces trous ronds de la première espèce, mais ce ne peut etre le $C$. assimilis qui vit sous sa première forme dans les galles des Crucifères au collet de leurs racines.

J'ai déjà dit, et je le répète, qu'il me parait peu probable que le $C$. assimilis perce les siliques pour manger leurs graines.

20 Le papillon provenant de la chenille verte étudièe plus haut, est la Tinea xylostella LnNé, Ypsolophus xylostci FABricius, ou Teigne à bandeletle blanche de Geoffroy. M. Focillon l'a bien observéc. Cette Teigne ne vit pas d'ailleurs 
exclusivement sur le colza, mais aussi sur la plupart des plantes crucifères potagères ou d'ornement.

$3^{\circ} \mathrm{La}$ larve blanchatre d'insecte diptère qui produit les plus grands dégâts et que MI. Focillon (loc. cit. p. 165 pl. II, fig. 22, et pl. III, fig. 29) ne savait à quel insecte rapporter, est le premier état de la Cecidomyia brassice Vinnentz (Linnea entomologica, Beitrag zu einer Monographie der Gallmuecken, vili, 231). Cet auteur dit expressément que cet insecte nuit beaucoup au colza, qu'on trouve parfois cinquante ou soirantelarves dans une seule silique, que ces larves se métamorphosent dans la terre où il les a vues se transformer en nymphes et éclore huit ou dix jours après leur changement d'état.

40 Les insectes qui rongent la cuticule et le parenchyme externe des siliques sont des Coléoptères du genre Altica. Il y a longtemps que leurs ravages sont connus, mais il faut dire qu'ils ont lieu sur les feuilles des plantes très jeunes auxquelles les Alica nuisent beaucoup, tandis que le tort fait aux siliques est insignifiant. Ces Altica ne sont pas, du reste, propres au colza, pas plus que la chenille ou la Cecidomyia. Elles vivent sur la plupart des plantes crucifères des potagers.

Les Altica observées sur les colzas sont les A. brassica FAB.; A. nemorum Lins.; A. nigrocenea Manshiм; $\boldsymbol{A}$. chrysocephala Linn.; A. napi ENT. HeFT.

Je terminerai celte note en énumérant les travaux suivants :

M. Plieninger a fait connaitre les mours d'un insecte ( $B a-$ ridius chloris Fabricius) dont la larve déterminerait dans la partie où se détachent les racines du colza, la formation de galles dans lesquelles elle subit ses tranformations. 
Il se pourrait fort bien qqu'on observat plus tard sur le colza d'autres insectes qui, à l'état de larve se nourrisent sur des crucifères.

M. Léon Dufour a signalé le Baridius piceus dans les vieilles tiges des choux (Annales de la Société entomologique de France 1847).

MI. Guérin-Méneville et moi-même ayons observé sur le chou et sur le Sinapis arvensis les larves du Ceutorhnychus sulcicollis (loc. cil. 1815, Bull. XxxiI, et 1856, Bull. LXXXv).

J'ai fait connaitre, 'dans nos Annales de 1856, les mours d'une curieuse et nouvelle espèce, le Ceutorhynchus draboe.

Enfin, M. Jacquelin du Val a communiqué récemment à notre Société les dégatts occasionés au colza dans le département de l'Oise par la larve du Mcligethes ceneus Fab.

M. Heeger a le premier fait connaître cette larve comme nuisant aux crucifères potagères (Sitzungsber. der. $\mathbf{K K}$. Akad. in Wien, 1854, page 278, pl. 3).

J'ai cherché avec le plus grand soin la larve du Meligethes sans pouvoir la trouver. 



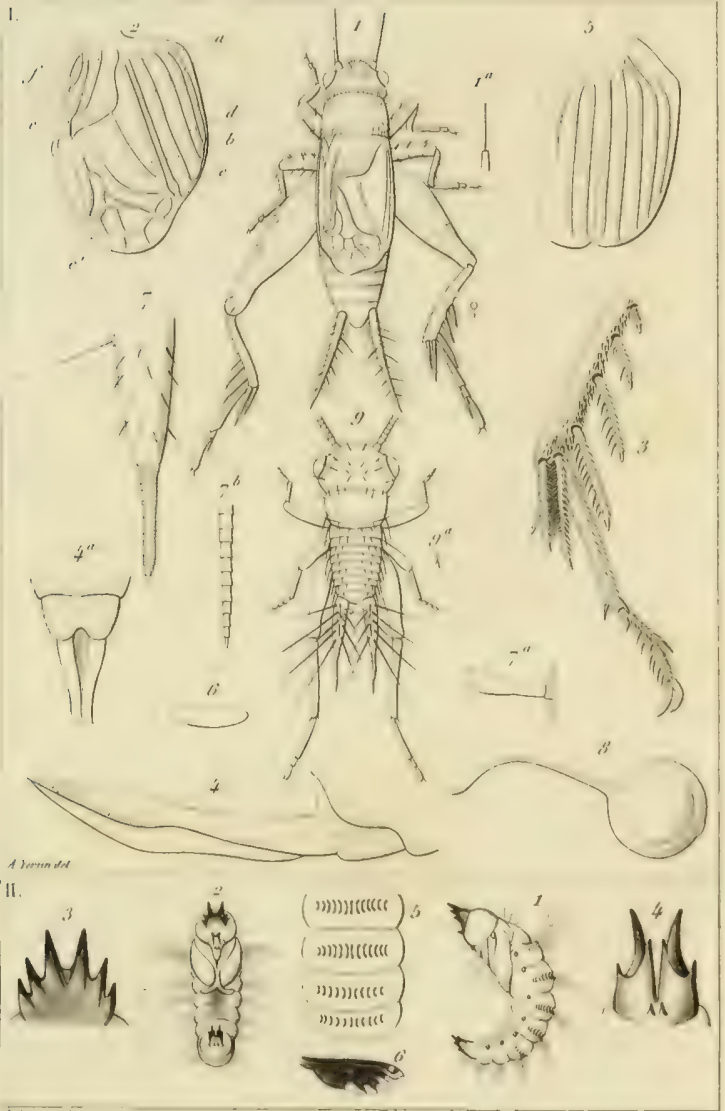

1. Giryllus Meydenie. Fisen. Fr.

II. Nymples de L'Mnthros sinunta. 


\section{SUR LES MEURS ET L'ANATOMIE}

DB LA

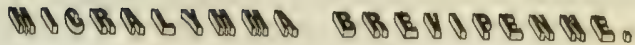

Par M, le $\mathrm{D}^{*}$ Alexandre LABOULBË́ne.

(Séance du 23 Septembre 1857.)

L'intérêt qui s'attache à l'étude anatomique et physiologique des insectes, redouble quand on se trouve en pré. sence des conditions d'existence spéciales qui sont le partage d'un petit nombre d'entre eux. Pendant deux années consécutives j'ai observé au Mavre la Micralymma brevipenne. On sait que ce petit Staphylinide offre le curieux phénomène d'une vie passée, tantòt à l'air libre de l'atmosphère, tantôt sous les vagues pendant tout le temps que dure la pleine mer.

Je me suis déjà occupé des insectes sous-marins. J'ai fait connaitre dans nos Annales (1849, page 23, pl. II), le Trechus (EDus) Robinii, espèce très voisine du T. fulvescens, sur lequel Audouin a publié un mémoire dans les Nouvelles Annales du Muséum, 1834, page 117. A cette époque(1849), je pensais qu'il était inutile d'invoquer l'endosmose et l'exosmose de Dutrochet pour expliquer la respiration de l'insecte 
enveloppé d'eau et placé dans une petite bulle d'air appliquée autour de son corps.

Il me semblait suffisant d'admettre que l'insecte recouvert par la mer respire un air moins riche en oxygène et que sa respiration va s'amoindrissant de plus en plus (loc. cit, p. 28). Je faisais remarquer d'autre part que les animaux supérieurs (Mammifères, Oiseaux), vivent très longtemps daus un air qui ne renferme qu'une très petite quantité d'oxygène, quand on a le soin d'enlever l'acide carbonique produit continucllement par la respiration. C'est d'ailleurs la condition dans laquelle les insectes sous-marins se trouvent placés, car l'eau dissout l'acide carbonique produit dans la bulle d'air qui les environne, aussitôt que ce premier gaz s'est formé.

Mon collègue et ami M. le docteur Ch. Coquerel, en découvrant plus tard (Nole pour servir à l'Histoire de l'Apus Robinii et Description de sa larve, Annales Soc. Ent. France, 1850, p. 529) la larve de l'Lipus Robinii, a confirmé par ses observations ma manière de voir. Mon illustre maître et notre vénéré doyen M. Léon Dufour a, dans un remarquable exposé “ Des divers modes de respiration aquatique dans les insectes) (Comptes-rendus de l'Institut, 1849, xxxix,703), mentionné le genre de vie sous-marin des Blemus (Epus) fulvescens et Robinii. Il a fait connaître en outre les mocurs très curieuses du Phytobius hydrophilus (1) qui vit constamment immergé, sans couche d'air autour de son corps.

D'après mes nouvelles recherches, je crois aujourd'hui qu'il n'est plus nécessaire d'invoquer l'indispensable, la rigou-

(1) Je crois citre sûr que cet insecte doit ètre rapportí au Phylobüus velatus Schoznnumbir. 
reuse nécessité d'une atmosphère bulleuse autour de l'insecte. J'ai vu des Micralymma rester immobiles sous l'eau, privées de la petite bulle d'air qui les enveloppe ordinairement, car je l'enlevais avec les poils d'un pinceau très fin, et les insectes se mouvaient dès qu'ils étaient mis à l'air libre. J'ai pu en laisser quelques-uns jusqu'à cinq jours sous l'eau, et ils n'en sont point morls.

On connaît les expériences de Malpighi, de Réaumur, de M. Straus-Durckheim, etc., sur l'asphyxie des insectes (Consid. sur l'anat. comp. des animaux articulés 1828, 308). Cette asphiyxie est très difficile (1) à obtenir. J'ai rapporté des exemples de cette difficulté dans ma note précitée sur le T. Robinii (p. 30). L'espéce de résurrection qu'éprouvent les insectes noyés sous l'cau, tels que les IIarpulus semiviolaccus, Limonius nigripes, etc., sur lesquels j'ai expérimenté cette année, paraît moins extraordinaire quand on pense aux faits d'un autre ordre, à la reviviscence des Tardigrades des"

(1) M. le professeur Clande Bernard m'a dit que M. Ie professcur Biot, faisant dans un cours les expérjences ordinaires de la unachine pneumatique, avait placé sous le récipient une Blatta orientalis afin de montrer aux elèves la mort de cet animal dès que te vide serait produit. L'insecte ne pas ut pas succomb r, loin de lì, et on en conclut que la machine opérait ntal et quil y avait une issue par où arrivait l'air. La Blatte fut laissée sous le récipient. Le lendemain on s'assura que la machine fonctionnait très bien et que l'insecte était encore vivant. On recommença, on s'obstina poutr fiare périr la Blate dans le vide et on ne put jamais y parvenir. Je ne conclus pas de ce fait à l'impossibilité d'asphyxier les insectes, mais simplement a la résistance très grande qu'ils oflirent à l'asphyxie sous l'eau et dlans le vide. Réaumur avait constaté des faits semblables sur des chenilles. 
séchés et à celle des larves de l'Anguillule du blé niellé, qui ont fourni à mon ami, M. le docteur Davaine, le sujet d'un mémoire plein d'intérêt (Mémoires de la Société de biologie, 20 série, t. III, 201, 1857).

Je vais exposer ce que je sais des mœurs de la Micralymma, observée à l'éłat de liberté, ou bien pendant que je la gardais chez moi emprisonnée dans des tubes de verre.

On trouve assez abondamment, vers la fin du'mois d'août et pendant le mois de septembre, la Micralymma brevipcrne au Cap-la-Пève près du Havre. Je l'ai capturée à cette époque et à plusieurs reprises, ainsi que sa larve et sa nymphe. Il faut attendre que la marée baisse et laisse à découvert les gros blocs de roches qui sont au-dessous des phares pour aller la chercher dans les fentes de ces roches. Deux fois seulement j'ai vu l'insecte parfait et sa larve courant hors de leur retraite ordinaire. La marche de l'insecte n'est pas très vive, il relève à peine l'abdomen si on l'inquiète et il tache de se blottir dans la fissure qu'il habite ou sous un coquillage collé auprès. L'Achorules maritimus, espèce de Podurclle d'un gris ardoisé, est plus hardie et se trouve gà et là en assez grand nombre. Quelle que puisse etre la cause qui empeche la Micralymma de se hasarder hors de son gîte de prédilection, je puis assurer que celui qui la rechercherait au IIarre exclusivement sur les pierres ou les roches, n'en trouverait que fort peu.

Le moyen par excellence est d'avoir un ciseau ordinaire d'ouvrier, ou de tailleur de pierres, dit ciseau à froid; les galets qui sont beaucoup trop multipliés sous les pieds de l'entomologiste servent de marteau. Il faut chercher avec soin une fente, une fissure sur la roche que la mer vient de quitter, y introduire l'extrémité du ciseau, puis frapper 
pour faire éclater la pierre et regarder vite sur les deux parties disjointes. On trouve à la fois de petits coquillages, des Annélides roulées sur elles-mêmes, des Acariens maritimes, des Podurelles et leurs ocufs, enfin la Micralymma. Les Podurelles sont très abondantes, la Micralymma est plus rare, ainsi que les $\boldsymbol{\Lambda}$ cariens. Elle est en quelque sorte collée à la roche, elle se met à fuir dès qu'on veut la prendre. Le doigt ou une pince à mors très doux suffisent pour cela; c'est mieux encore de placer sous les insectes un flacon ̀̀ ouverture assez grande, et dans laquelle on fait fomber rapidement tous ceux qu'on a mis à découvert.

On peut constater que la Micralymma qui n'exlsale aucune odeur quand elle est tranquille, en répand une très mauvaise et très pénétrante dès qu'on la prend.

Je n'ai pu trouver d'autres Coléoptères dans les endroits qu'habite le Micralymma. J'ai cherché sous les galets el sur le sable au pied des roches ou de leurs débris, je n'ai rencontré aucun autre insecte que ceux déjà signalés. Les larves identiques prises pendant ces deux années consécutives sont donc, à coup sûr, celles de la Micralymma, puisqu'il n'y avait qu'clle, arec l'insecte parfait, et parce qu'en outre ce sont des larves de Staphylinide. J'espère qu'on partagera ma conviction à cet égard.

La larve est plus agile que l'insecte parfait.

La recherche de ces insectes n'est productive qu’à la condition de ne point ménager les coups de galet sur le ciseau et d'explorer soigneusement toutes les fissures que l'on rencontre. La récolte se fait, qu'on me passe l'expression vulgaire, à la force du poignet et à la sueur du front. On doit se hater d'ailleurs et ne point songer à faire d'autres captures, car le flot gagne, aprís un laps de temps rigourcuse- 
ment fixé, les rivages qu'il avait laissés à découvert. L'écume des lames vient entourer le pied des roches, les gouttes d'eau retombent sur leurs parois, le vent s'élève ou souffle avec plus de violence et entraine vers la terre plusieurs Muscides qui se reposaient sur les rares fucus de la côte. II soulève leurs ailes et elles sont impuissantes à rester accrochées par leurs tarses, elles s'envolent vers la terre. La mer a bientôt recouvert la place oủ les Micralymma se tiennent blotties et immobiles.

Dès que j’avais placé dans un tube de verre un certain nombre de Micralymma, en ajoutant quelques algues pour entretenir une sorte d'atmosphère marine, les insectes couraient et finissaient apress avoir reconnu ce terrain nouveau pour eux, par se blottir contre le bouchon. Existait-il un espace d'un demi-millimetre vers le sommet de celui-ci et la paroi, cinq ou six Micralymma s'y logeaicnt à l'envi, s'y pressaient l'une contre l'autre. Il n'était point facile de déboucher le tube ou le flacon sans les écraser.

Quand on place l'insecte sur un plan uni, il marche assez vite et cherche à gagner un abri, il se glisse sous une feuille de papier et s'y blottit. La larve est plus vagabonde; elle court en s'appuyant sur le dernier segment du corps, prolongé ou saillant en dessous. J'ai mis dans l'eau de mer restée dans un creux de rocher, ou bien chez moi dans un verre, les larves et les insectes parfaits. Ils s'abritent, ne font plus de mouvement et attendent qu'ils puissent etre à découvert.

La larve n'exhale pas d'odeur particulière, mais l'insecte parfait en répand une très pénétrante, très forte relativement à sa petite taille. J'ai cherché avec un soin minuticux, à voir s'il faisait saillir un appendice à l'extrémité de l'ab- 
domen, je n'en ai aperçu aucun destiné ì cet usage. J'ai vu, au plus, une très petite goutte de matière sourdre près de l'orifice anal quand je pressais l'abdomen. L'organe produisant cette odeur m'est resté inconnu, malgré toutes mes recherchies. Je me suis assuré que les ot les + la répandent également; je l'avais crue d'abord particulière à l'un des sexes, mais il n'en est rien.

J'ai gardé des larves et insectes parfaits vivants pendant huit, dix et meme quinze jours, en ayant soin de renouveler les algues des tubes. Je n'ai pas observé l'accouplement, ni vu pondre des œufs.

Je vais présentement exposer dans un premier chapitre la description des trois états de la Micralymma brevipenne. Le deuxième chapitre sera destiné à l'anatomic de la larve et de l'insecte parfait.

CHAPITRE Ier.

DESCRIPTION DES TROIS ÉTATS DE LA

Micralymma brevipenne.

S 1. Larve.

(Voy. pl. II, fig. 1 à 7).

LARva capitata, hexapoda, antennata, oblongo-clongata, piligera, grisea seu livida. Capite corneo; antennis quadriarticulatis; stemmatibus punctis quinque compositis. Segmentis corporis dorsalibus ferè coriaccis, partim obscuris; ultimo 
segmento bicaudato. Stigmatibus novem paribus. - Long. 3 mill.

Corps allongé (fig. 1), à peine élargi aux 2/3 postérieurs, presque parallèle; composé de douze segments, la tête non comprise. Coulcur brunatre en dessus, avec les bords latéraux, les intervalles des segments et le dessous du corps plus pales, d'un jaune grisâtre ou grisatres. La tête et le dessus des segments présentent une résistance marquée, le dessous est mou, plus membraneux.

Tête ovale, brune, offrant un trail jaunatre en forme d'Y à branches supérieures sinuées, allant de l'occiput sur le front, où il se bifurque, pour se rendre au dela de la base des antennes, près du labre (voy. fig. 1 et_6).

Antennes de quatre articles, le premier large et très court, le troisième le plus long, pourvu en dedans d'un appendice allongé; le quatrième petit, avec des poils à l'extrémité (fig. 2).

Yeux très petits, paraissant formés de cinq très petits ocelles situés latéralement sur le milieu de la longueur de la tete ( fig. $3, d$ ).

Les parties de la bouche seront décrites dans le clıapitre II.

Segments du corps d'inégale longueur. Les trois qui suivent la tête ou thoraciques, les plus grands, ayant dans leur milieu une ligne longitudinale qui fait suite à celle de l'occiput; premier segment le plus grand de tous, ses côtés peu arrondis, angles antéricurs et postérieurs assez peu marqués. Les deuxième el troisième segments à peu près d'égale longueur, arrondis sur les cotés. Chacun de ces trois segments porte une paire de pattes (fig. 4), composées de cinq articles, 
le premier ou la hanche, épais, arrondi, cylindrique, le deuxième très court, le troisième le plus long, le quatrième muni de poils raides, surtout en dessous et rappelant un peu une palte ravisseuse comme chez les Manis; le cinquième formant un crochet ou ongle simple, légèrement recourbé, très fort.

Segments abdominaux, quatrième à dixième, arrondis sur les côtés; les onzième et douzième plus allongés, leurs côtés presque parallèles; le douzième terminé par deux longs appendices, articulés à leur base, obscurément formés de deux pieces (fig. 1 et 7 ).

Anus saillant en dessous, prolongé en bas, et formant un pseudopode (fig. 5).

Le dessus du corps offre des poils nombreux. On en trouve plusieurs rangées longitudinales sur les segments, et on observe d'autres poils divergents sur les cotés (fig. 1).

Stigmates au nombre de neuf paires. La première est exactement placée sur la membrane qui unit le segment prothoracique au segment mésothoracique; les deuxième, troisième, quatrième paires sur les quatrième, cinquième, sixième segments, sur les côtés, un peu en avant du milieu. Les cinquième, sixième el septième paires sur les septième, huitième, neuvième segments sur les côtés, exactement au milieu de leur longueur; enfin les septième, huitième et neuvième paires sur les dixième et onzième segments, un peu au delà du milieu (fig. 7).

M. Westwood a décrit (Notes upon subaquatic Insecls, with the description of new genus of British Staphylinidae. - Magazine of Zoology and Botany conducted by Jardine, Selby and Johnston, II, 124, 1838), une larve qu'il a rap3e Série, томе vi. 
portée (1) à la Micralymma Johnstonis, qui n'est autre que la M. brevipenne de Gyllenhal. L'habileté, le rare talent d'observation du savant entomologiste anglais, sont un sûr garant qu'il a dessiné ce qu'il a vu. Les dessions de M. Westwood sont signés par lui. On ne peut croire qu'il aurait méconnu ou altéré des caractères de c'ette larve, lors mème qu'il n'aurait eu à sa disposition que des individus ou desséchés, ou raccornis par une liqueur conservatrice.

Les figures de la larve, des parties de sa bouche et des pattes données par .1. Westwood diffèrent beaucoup de celles que j'ai représentées moi-même. Ceci me portait, à priori, à penser que nous avions eu chacun sous les yeux une larve différente. Si j'ai regretté de n'avoir rencontré au IIavre que la Micralymma brevipenne, je suis heureux présentement de cette circonstance, car l'insecte auquel elle se rapporte ne peut etre douteux.

Or, il faut remarquer que sur les côtes d'Angleterre on trouve à la fois, dans les mêmes lieux, et les Micralymma et les Epus; on est naturellement porté à se demander si la larve figurée par M. Westwod ne serait point celle d'un

(1) Voiciles paroles de M. Westwood : "Hence I feel but little hesitation in regarding these larve and pupæ as those of Micralymma Johnstonis, loc. cit., 131. " Plus tard, dans son Introduction to modern classification of Insects, I, 169, 1839, nous trouvons: " $\mathrm{D}^{\mathrm{r}}$ Johnston of Berwick-upon-Tweed has communicated to me specimens of the larvx (fig. 16, 15) and pupx (fig. 16, 16) of a Sta. phylinideous Insect, which 1 have not the least hesitation in considering as those of Micralymma Johnstonis (having been found in company with that species far below highwater mark on the sca coast), and of which I have published figures and descriptions in the Mag. Zool. and Bot., vol. II. N 
ALpus. La réponse est facile à faire, puisque mon cher ami et collègue N. le docteur Charles Coquerel a décrit la larve de l'A pus Robinii Laboulbène, prise par lui à Brest, dans l'anse des gardes marines, ou il n'a pas vu une seule Micralymma. Comparons la planche Iv du Magazine of Zoology and Botany, 1838, à la planche Xvi, no in des Annales de la Société entomologique de France, 1850, et nous trouvons qu'il existe plus que de la ressemblance entre les larves représentées en Angleterre et en France, c'est presque, sinon complétement, de l'identité.

La forme de la tête, des parties de la bouche, des pattes sont les memes. La tete est énorme, les mandibules sont crochues, très aiguës avec une dent interne, avancée, aigut, recourbée, les machoires ont un lobe interne de deux articles (M. Coquerel dit : mâchoires portant deux palpes de trois articles, mais la figure rectifie l'erreur du texte, p. 532). La lèvre offre des palpes triarticulés, etc.

Concluons de tout ceci que la larve décrite par MI. Westwood est celle d'un Epus, probablement du fulvescens et non celle de la Micralymma. Je crois qu'on devra rectifier sur les catalogues des larves la citation de M. Westwood, qu'Erichson, MM. Chapuis et Candeze, M. Jacquelin.Duval avaient adoptée.

Pour mieux faire juger cette question, je donne fig. 1, A, le calque de la larve figurée dans le Mag. Zool. and. Boi., pl. IV. fig. 2, par ir. Westwood, dont j'apprécie infiniment les travaux. Les parties de la bouche sont représentées fig. 3, C, une patte fig. 4, D.

Notre larve est manifestement celle d'un Staphylinide, mon savant ami M. Perris le pense comme moi-meme. Je n'exposerai pas ici les raisons qui étayent mon opinion, 
renvoyant, entre autres, aux larves de cette famille déjà di crites par mon ami, dans son admirable travail sur les Insectes du pin maritime (voy. Ann. Ent. Fr., 1853, pl. Xvir, et surtout fig. 14). Je ferai remarquer encore l'analogie de ma larve du IIavre avec celle de l'Oxytelus sculpius Gravennonst, décrite par MM. Chapuis et Candèze (Calalogue des larves de Coléoplères, p. 60, pl. II, fig. 2). Elles ont toutes les deux des machoires à lobe interne fixe, non articulé, et une lèvre inférieure semblable.

\section{$\$ 2$ 2. NxMPHE. \\ (Voy. pl. 1I, fig. 8 et 9).}

NympHa muda, obvoluta, oblonga, grisea seu luteo-albida; capite oculto, inflexo. Thorace setis duabus longissimis antice, lateribus quinque minutis. Abdominis lateribus nec non apice setis longissimis instructis. - Long. 2 1/2 mill.

NyMpie d'un jaune grisatre, avec de très longs poils sur la tete et les cotés de l'abdomen, offrant repliées sur cllesmemes les formes des diverses parties de l'insecte parfait.

Tête penchée sur la poitrine, tout à fait cachée et fléchie sous le prothorax.

Yeux et extrémité des mandibules brunatres.

Antennes dirigées en arrière sur la première paire de pattes.

Prothorax débordant la tete en haut, pourvu en cet endroit de deux poils très longs, à base élargic ou placés sur des mamelons, et de plusieurs autres (cinq au moins) sur les 
côtés. Fourreau des ailes très petit. Mésothorax et métalhorax bien visibles en arrière.

Paltes à jambes fléchies sur les cuisses, leurs tarses étalés longitudinalement.

Abdomen divisé en sept segments, le dernier appendiculé, pourvu de quatre longs poils, chacun des autres ayant pareillement un poil très long sur les côtes. Tous ces poils à base mamelonnće. On remarque en avant une ombre brunatre transversale sur l'antépénultième segment. Elle est peut-ctre accidentelle, mais elle est évidente dans la nymphe observée.

Je n'ai eu qu'une seule nymphe pour faire cette description, je n'en ai pas pu obtenir l'éclosion, et j'ai dû la mettre dans l'alcool après l'avoir décrite.

M. Westwood (loc. cit. pl. IV, 1838) a figuré une nymphe qu'il regarde comme appartenant à la $\boldsymbol{M} \boldsymbol{L}$. Johnstonis. Elle se rapproche beaucoup de celle que j'ai observée. Elles offrent toutes les deux ces poils allongés de la tete et de chaque segment abdominal, mais je n'ai pas vu les deux appendices terminaux très saillants et détachés de l'abdomen, représentés par le savant entomologiste anglais (voyez pl. II, fig. 8, E et 9, F).

Les fourreaux des ailes sont très petits, autre preuve en faveur de la ressemblance des deux nymphes observées en Angleterre et au IIavre. On remarquera cependant la position des antennes et la forme différente des segments abdominaux.

Je n'oserais pas affirmer ici, comme pour la larve dejà décrite, la différence très marquée des objets observés. J'espère 
qu'on fera à ce sujet de nouvelles recherches. Peut-être sur la larve et la nymphe décrites par M. IVestwood, la nymphe scule appartient-elle à la Micralymma brevipenne.

J'ai donné, fig. 8 , F, et 9, F, le calqque de la nymphe figurée par MI. Westwood (Mag. Zool. and Bot. Pl. IV, fig. 3).

\section{S 3. Insecte parfakt.}

(Voy. Pl. 11, fig. 27).

Omalium brevipenne GycLenHal, Ins. Suec. 11, 234 (1810).

Micralymma Johnstonis WesTwooD, Mag. of. Zool. and Bot. II, 130 (1838).

M. brcvipenne Encuson, Gen. et Spec. Staphyl. 820 (1840).

M. brevipenne Fairanile et Laboulbène, Faun. Ent. Franc. I, 625 (1856).

Nigrum, subnitidum, dense breviter pubescens; capite, thorace, elytris abdomineque creberrime reticulosis. Os piccum. Mentum distincte reticulosum, fulcrum labii mento sesqui brevius, membranaccum, exsertum, apice late rotundatum. Caput depressum; fronte clypeorue foveolis binis impressis. Stcmmata minulissima. Pronolum planiusculum; angulis omnibus obusis; linea media longitudinali, subelevata, levi. Elytra longitudine pronoti, parce punctata, apice singula Leviler rotundata. Aldomen crebrius punctulatum. Ped's nigro-picei. - I.ong. 2 à $21 / 3$ mill. 
Le nom du genre Mieralymma a été donné par M. West-

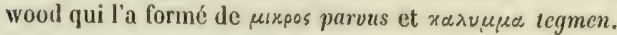

J'ai emprunté presque textuellement cette description à M. Schindte (Ueber die Gallung Micralymma, in Linnea entomol. I, 162, 1846). Je l'ai toutefois mise en rapport avec les observations que j'ai failes sur les insectes pris au IIAvre.

On sait que M. Schiœdte a décrit (loc. cit., 163) une deuxième espèce de Micralymma à laquelle il a donné le nom de brevilingue, et qui provient du Groënland, oủ elle a été trouvie sous la mousse dans des tombeaux par le capitaine Iolbœll. Elle differe de la M. Urevipenne, principalement par la pièce intermédiaire de la lèvre inférieure non saillante, de telle sorte que le menton cache la base des palpes labiaux. Sa taille est plus petite, sa forme plus allongée, un peu convexe. Les antennes sont plus épaissies, ainsi que les palpes maxillaires. Les stemmates sont situés sur une ligne placée en arrière des yeux, loin de leur bord postérieur. Les élytres sont un peu plus longues que le corselet. Le corps est à peine visiblement réticulé, le menton lisse, etc.

Cette espèce vivrait à l'air libre, bien différente en cela de la M. brevipenne. 


\title{
CIIAPITRE II.
}

ANATOMIE DE LA LABVE ET DE L'INSECTE PARIAT.

\author{
S 1er. Lanve. \\ (PI. 1I, fig. 3 et 6 ).
}

Tune vigestrif de la longueur du corps, droit, ou presque droit.

Les diverses parties de la bouche offrent la forme suivante:

Labre arrondi sur les côtés et largement échancré au milieu, bord corné avec six à huit longues soies (fig. 3).

Mandibules fortes, allongées, assez aiguës à l'extrémité, courbées, concaves au côté interne avec plusieurs dents bien marquées en cet endroit (fig. $3, a$ ).

Mâchoires avec un lobe interne fixe, irrégulièrement triangulaire, ayant des poils disposés en dent de peigne et un palpe externe de trois articles; le premier gros et long, le deuxième plus petit, le troisième étroit, de la longueur du premier (fig. 3, b).

Lève inféricure avancée, menton subarrondi au bord antérieur; pièce intermédiaire ayant un peu la forme d'un sablier supportant les palpes labiaux (fig. 3, c); languette très petite, munie de deux poils. Palpes de deux articles, le premier élargi et court, le deuxième grele et deux fois plus long. 
OLsophaye peu allongé, arrondi, s'ouvrant dans le ventricule chylifque sans jabot ni gésier intermédiaire (fig. 6. ८).

Ventriculechylifífuc pas très allongé, droit, ou sans flexuosités, cylindrique. Surface lisse, dépourvue de papilles (Gig. 6, c).

Vaisseaux hépatiques au nombre de quatre, insérés à l'extrémité du ventricule, leur extrémité libre, en cœecum, peu renflé (fig. 6, $c$ ).

Gros intestin sans dilatation cœcale marquée, rempli d'une pulpe noiratre ou brunâtre (fig. $6, f$ )

Anus très saillant, froncé sur les bords (fig. $6, h$ ).

J'ai eu à ma disprosition une douzaine de ces larves. J'en ai disséqué la moitié. J'ai été beureux de déposer les autres dans la belle collection de larves de mon cher et savant ami II. Edouard Perris.

\section{S 2. InSECte PARFAit.}

Tune Digestif. (P. III, figo 15 à 22). Les diverses parties de la bouche présentent:

Un labre (fig. 16) ou lèvre supéricure, coriace, transversal, trois fois aussi large que long, largement échancré en avant dans toute sa longueur, pourvu en cet endroit de longs poils; à cotés largement arrondis.

L'épistôme qui lui fait suite est membraneux, transversal, très étroit.

J.es mandibules (fig. 17 et 18), peu allongées, en pointe 
un peu mousse à l'extrémité, arquées, aplaties, larges, convexes extérieurement, concaves à leur partie interne et supérieure, ayant une membrane ciliée près de leur base depuis le milieu environ de leur longueur, et terminćes par une surface élargie. Mandibule droite (fig. 17), unidentée ì l'extrémité, ayant au milieu du bord interne une dent marquée. Mandibule gauche (fig. 18) bidentée au sommet, la deuxième dent située en haut.

Mâchoires (fig. 19) cornées, pen avancées, lobe interne terminé par un crochet, son bord à poils élargis et recourbés; lobe externe obscurément de trois articles, le dernier membraneux, poilu. Les palpes maxillaires de trois articles: le premier très court; le deuxième renflé à l'extrémité, allongé; le troisième le plus long (fig. 19, a), son extrémité obliquement et légèrement tronquée.

Lèvre inférieure (fig. 20) composée de trois parties, le menton, la pièce intermédiaire, la languette.

Menton transversal (fig. 20,a).

Pièce intermédiaire membraneuse (fig. 20, b), élargie, arrondie, recouvrant en dessous une partie seulement de la base des palpes labiaux. Ceux-ci de trois articles, les deux de la base larges. Ils sont tous cornés, ainsi que leur base qui est irrégulièrement trapézoïde, échancrée en haut(cette base insérée sur la pièce intermédiaire).

Languette (fig. 20, d), à lobes irrégulièrement arrondis en avant, sinués en dedans, rapprochés, ayant leur ensemble ì un peu près cordiforme. Paraglosses paraissant sur le bord externe des lobes de la languette, ciliées.

OEsophage assez court (fig. 5, 6 et fig. 21), très visiblement pourvu de poils roux situés dans son intérieur et dirigés de 
haut en bas. Si ces poils n'étaient pas placés plutot vers te haut, je verrais là nettement un gésier, mais j'admets son existence comme rudimentaire.

Ventricule chylifique allongé (fig. 15, c), un peu recourbé, entièrement recouvert dans toute son étendue de papilles allongées, creuses, de diverticules en doigt de gant.

Vaisseaux biliaires au nombre de quatre (fig. 15, $d, d$ ), ̀̀ contenu légèrement violacé; extrémité torminée en coecum (fig. 22) à peine renflée.

Intestin grêle un peu recourbé sur le gros intestin, à parois épaisses, peu allongé (fig. 15, $c$ ).

Gros intestin assez dilaté dans la partie du colon (fig. 15, $f$, renfermant une pulpe verdatre. Ses parois offrent l'apparenee de colonnes charnues, musculeuses, perpendiculaires.

Anus superposé à l'orifice génital, soit pénien, soit vulvaire.

appareil de la gínération male et femele (fig. 23 à 26, etc.). L'apparcil génératcur ơ est le premier à examiner. Il est constitué par :

Les testicules (fig. 23, a, a), dont la forme est quadrilobéc, composés de quatre capsules spermatiques venant s'insérer sur un canal déférent, assez long (fig. 23, $৮$ ).

Les organes annexés (vésicules séminales Lìon Dufoun) sont au nombre de deux paires (fig. $23, c, c$ ), l'une plus petite, à deux branches convergentes, formant une sorte de parenthèse, l'autre plus allongée et flottante, repliée. Leurs connexions sont rendues par la fig. 24. Ils mont paru s'in- 
sérer sur le canal déférent comme les deux canons d'un fusil double, par deux orifices rapprochés.

Je ne donne pas le nom de vésicules séminales en toute assurance à ces glandes, parce que je doute qu'elles renferment du sperme élaboré. Je crois plutôt, par analogie avec ce que j'ai déjà constaté (Recherches sur les appareils de la digestion el de la reproduction de l'Anthaxia manca. Archives entomologiques de $M$. Thomson, I, 225, 1847), qu'elles contiennent une humeur propre à fluidifier ou à servir d'une manière quelconque à l'élaboration du sperme.

Les dcux réservoirs situés en haut du canal éjaculateur après la réunion des deux canaux déférents et de lcurs annexes me paraissent plutot des réservoirs séminaux. M. Léon Dufour désigne ces organes, sous le nom de vésicules séminales principales. Ce sont elles qui concourent à former le canal éjaculateur.

Le canal éjaculateur (fig. 23, d), formé de la réunion des deux canaux déférents et de ceux des organes ci-dessus, est résistant, élastique. Il commence aux deux dilatations déjá signalées, devant renfermer le vrai sperme élaboré ; il vient se rendre à un pénis dur, corné, dont l'extrémité livre passage à une véritable verge membraneuse, terminée ellemème par une sorte de gland bien marqué.

Le pénis ou verge (fig. 23 et 25) offre sous l'étui corné deux appendices articulés très près l'un de l'autre et qui s'écartent ou se rapprochent pour embrasser l'étui corné de la verge (lig. $25, g$ ). On comprend très bien que l'armure copulatrice $\sigma^{*}$, introduite fermée dans les organes de la + , s'y développe ainsi que je l'ai figurée (fig. 25), et assure, de la sorte, avec celte espèce de forceps, l'acte de la reproduction. 
Outre le pénis, l'armure génitale comprend d'autres pièces terminant l'abdomen du ot et dont nous parlerons plus tard longuement.

La dissection de l'armure génitale du male est ardue ; j'ai, après un grand nombre d'essais, acquis la certitude que sous le sixième segment portant une paire de stigmates (voy. pl. II, fig. 10) on trouve un segment formant un anneau presque complet (pl. II, fig. 11) fendu en arrière, où il est muni en haut de deux apophyses (fig. 12). It résulte de cette disposition que ce segment peut s'élargir au besoin et revenir ensuite sur lui-même. En dessus, il existe (fig. 11, c) une pièce glissant sous lui, c'est une lame en triangle arrondi, ciliée, formant le dernier demi-segment supérieur. On trouve enfin, en dessous, pour couvrir la partie fendue du grand segment (fig. 12, d), une lame moins large que la première et pourvue des deux longs poils qu'on voil à l'abdomen des ơ . Cette lame est située, je le répète, en dessous et recourre la fente du segment (fig. 13, $d$ ).

Ainsi donc, la verge et son étui corné pourvu des deux branches de son forceps glissent dans un segment fendu en dessous et pourvu de deux lames, l'une supéricure terminant l'abdomen, l'autre inférieure munie de deux longs poils.

Par la pression des doigts, l'abdomen laisse échapper le pénis, qui se recourbe en haut, dont les branches du forceps s'écartent, et on voit la verge elle-meme faisant saillie et le plus souvent coudée a angle presque droit (pl. III, fig. 25, h).

L'apparcil générateur + (fig. 26) est très simple. Il se compose de deux ovaires (fig. 26, $a, a$ ) formés par la réunion de six gaînes ovigères allongées renfermant un, ou 
au plus, deux ovules. Le premier est gros, le deuxième est très petit ou invisible. Les gaînes s'insèrent sur des calices latéralement et au sommet de chaque trompe.

Les trompes (fig. 26, $b, b$ ) sont assez courtes et convergent pour former un oviducte dont la partie supérieure renllée doit servir de poche copulatrice (fig. 23, c).

Le reccplaculum seminis (capsule séminale) est arrondi et forme un réservoir résistant, blanchâtre, pourvu d'un tube excrétcur (fig. 23, d).

Ie vagin fait suite à l'oviducte, sans ligne de démarcation tranchée.

L'armure gínilale ou copulatrice of (fig. 14 et 26) se compose d'un long tube membraneux altaché au sixième segment abdominal (voy. fig. 14) rentrant sur lui-meme, formé de membranes plissées en travers, et terminć par deux appendices de deux pièces, ou articles, le premier très gros et très long, le deuxième très petit, surmonté d'un long poil (fig. 26, b, b). Il offre dans son intérieur un tube trachéen latéral et une plaque en $\mathrm{V}$ irrégulier un peu cornée, jaunatre, rudiment d'un demi-segment dorsal (fig. 14 et $26, a)$.

\section{S 3. Remarques.}

Les difficultés qu'on rencontre pour disséquer la MicraIymma sont fort grandes. Le corps est résistant et on a de la peine à l'attaquer parce qu'il fuit sous le scalpel. J'ai eu recours à plusieurs moyens pour le fixer. La gromme ne peut le retenir, il s'y imprime puis s'en détache à la moindre 
traction, quand elle est sèche. La cire est bonne, mais elle dessèche les viscères par le calorique dégagé quand elle est liquide. J'ai éthérisé l'insecte, je l'ai placé sur un vernis siccatif.

Une lancette fine, dite a langue de serpent, des aiguilles à cataracte très tranchantes m'ont principalement servi. Je me suis bien trouvé pour apprécier certains détails, après avoir laissé l'insecte dans une atmosphère d'éther ou de chloroforme, d'arracher soit la tete ou l'abdomen, en tout ou en partie, soit l'armure génitale, etc. On attire ainsi au dehors, soit l'œsophage ou le ventricule, ou bien le canal déférent et les vésicules séminales, soit l'oviducte ou d'autres organes attachés à la partie arrachée et dont on saisit micux de la sorte les connexions ou les détails.

Je ne me flatte point d'avoir fait un travail sans défauts, mais j'indique les précautions que j’ai prises pour arriver à connaitre la véritable forme des organes internes et pour eviter des erreurs trop faciles à commettre.

J'ai enfin placé dans des verres de montre, sous l'eau, puis dans d'autres liquides, alcool, huile, essence de térébenthine, etc., les divers organes. J'ai pu de la sorte apprécier quelques détails qui sont difficiles à constater par les moyens ordinaires.

Voici les points principaux que j'ai cru devoir discuter ou faire remarquer au sujet de l'anatomie de la Micralymma.

\section{LaRve.}

J'ai vu des ocelles de chaque cóté de la tele (voy. pl. in, 
fig. $3, a)$. Je crois qu'il en existe cinq de chaque côté. Ce nombre a été vérifié par M. Perris.

Les antennes ont positivement quatre articles, le troisième est muni en dedans d'un appendice.

La forme de la lévre est remarquable. Elle n'offre pas la complication de celle de l'insecte parfait. On voit nettement la pièce intermédiaire portant les palpes labiaux de deux articles et la languette terminant le tout, sans paraglosses.

Les stigmates sont placés comme d'ordinaire, il en existe neuf paires (voy. fig. 7); la première est sur la membrane du premier et du deuxième segment ou proto-mésothoracique. Ils répondent d̀ des trachées uniquement lubuleuses.

Erichson a recherché ce que devenaient ces stigmates des larves dans les insectes parfaits en mème temps que la métamorphose des divers segments de leur abdomen; or, le nombre des segments abdominaux est de neuf chez les larves de Colćoptères, tandis qu'il y en a sept, au plus, dit-it, chez les insectes parfaits. Il en manque deux chez ces derniers, et pour les retrouver le professeur de Berlin a proposé l'explication suivante. L'un des segments de la larve est venu former le premier segment dorsal de l'abdomen (qui est en réalité un huitième serment) de l'insecte parfait et l'autre segment de la larve vient former une partie de la région dorsale du métathorax de l'insecte développé. Ces deux segments portent des stigmates chez la larve et l'insecte qui en provient. De lia leur analogie (voy. Erichson, Archives II, 1846).

Cette idée est ingénieuse, mais le segment de la région métathoracique de l'insecte parfait, comparable au segment médiaire des IIyménoptères, est-il réellement thoracique 
ou abdominal 9 Je me propose de reprendre prochainement cette question sur un gros insecte, le Buprestis giganca.

Munie de cet appareil respiratoire complet, comme chez une autre larve quelconque de la meme famille, la larve de la Micralynima brevipenne reste sans asphyxie sous l'eau pendant le reflux de la mer. Ce fait, en apparence si extraordinaire, doit être rapproché des expériences de Malpighi, de Réaumur, de Lyonet, etc., qu'il rappelle sans leur etre identique (voy. la note, p. 75). On sait que le premier de ces observateurs éminents n'avait pu asphyxier sous l'euu les chenilles du ver à soie (Bombyx mori); Réaumur, après avoir vérifié ce fait, avait expérimenté au moyen du vide de la machine pneumatique sans pouvoir tuer des chenillesqu'il y avait placées (Mémoircs sur les Insectes, t. Ier, $3^{\mathrm{C}}$ mémoire). Lyonet avait pu laisser plusieurs heures une chenille dans le vide "Sous le récipient dont il avait pompé l'air, sans qu'elle en parùt aucunement incommodée, ni que cela eût mis pendant ce temps ou après aucun obstacle à ses mouvements, et même ensuite à sa transformation. " (Lyonet, OEuvres posthumes, dans Mémoires du Muséum, t. XIX, p. 78.)

Les paltes sont comme dans toutes les larves de Staphylinides connues jusqu'à ce jour terminées par un ongle simple. Cet ongle a pu contribuer à induire M. Weswood en erreur. Il est prouvé aujourd'hui que l'Epus Robinii et le Cillenum laterale proviennent de larves dont les pattes ont un seul ongle terminal. (Voy. Fairmaire, Ann. Sor. Ent. France, 185\%, 673.)

\section{Insecte panfait.}

J'ai jugé inutile de donner une description détaillée de la зе Série, томе vi. 
Micralymma brevipeme, page 86 , parce que cet insecte est aujourd'hui sufisamment connu d'après les travaux de Gyllenhal, Westwood, Erichson. Schiœedte, etc. Je désire seulement appeler l'attention sur les points qui suivent.

Extéricur du corps. Tête. MM. Westwood et Eirichson n'avaient pas remarqué les deux stemmates ou yeux lisses qui se trouvent dans la $M$. brevipenne en arrière du front sur le vertex, suivant une ligne qui passerait derrière les yeux. Les deux stemmates sont très apparents à un grossissement convenable et à la lumière réfléchie. Ils ont l'aspect de deux petits points brillants, de deux petites perles noires. Ils le sont encore plus si on a séparé la partie supérieure de la tete, l'épicrâne, de la boîte inférieure, et si on l'a placée entre deux plaques de verre dans le baume du Canada ou la térébenthine. Ces deux stemmates sont alors comme deux petits cercles parfaitement transparents, tandis que les parties voisines ont une opacité prononcée.

Il y a cnfin une circonstance de préparation qui m'a fait penser que peut-être il existe un troisième stemmate placé en avant des deux autres sur la ligne médiane et encore plus petit. J'ai placé dans le baume du Canada une Micralymma récemment éclose, j'ai obtenu ainsi une magnifique préparation que je conserve et où les moindres détails se voient bien mieux que dans l'insecte très coriace et brun. Mais ce stemmate, s'il existe, est, je le répète, plus pelit, moins appréciable encore que les deux autres, sur l'existence desquels il ne peut exister aucun doute.

Thorax. Le stigmate antérieur ou proto-mésothoracique est très évident, le deuxième ou méso-métathoracique doit exister chez la Micralymma, puisque Erichson l'a vu et signalé dans les grandes espèces de Staphylinides /Gen, et 
Species Staphylinorum, page 14, 1840). Je ne puis l'apercevoir convenablement. Mais le troisième, quoique caché par les élytres, est assez facile à mettre en évidence par l'arrachement de ces organes.

Abdomen. Le nombre des demi-segments abdominaux supérieurs est de huit, portant tous des stigmates; le premier trìs petit est entièrement caché sous les élytres (1).

En outre, il existe un neuvième segment placé en majeure partic sous le huitième, qu'il déborde et qui est visible chez le $\sigma^{\prime}$. Ce neuvième segment est suivi par une lame arrondie en dessus qui forme un dixième demi-segment. Je les ai décrits et figurés en parlant de l'armure génitale mule, qui est fort singulière et ressemble peu ì celle des autres Sta. phylins. (Voy, Erichson, loc.cit. 12.)

L.es stigmates abdominaux sont au nombre de scpt paires, sans comprendre dans ce nombre le stigmate thoraco-abdominal, qui est pour moi un troisième stigmate thoracique. Ils sont exactement situés près de la membrane qui unit les

(1) Ce premier segment est celui qu'Erichson regarde comme étant formé par un des segments surnuméraires de la larve.

Le nombre des segments abdominaux donne lieu à de grandes contestations. Il y a souvent plus de demi-segments en dessus qu'en dessous, et il est très difficile de les compter sur les pelites espèces. Je dis ici ce qui est; je constate, je n'explique pas. Il y a certincment un grand intérèt à comparer les faits, à connaître les nombres divers des demi-segments et à les rapporter à un type. Quant au schment médiaire situé contre le métathorax, il est peu visible dans la Micralymma. On ne peut décider d'après cet insecte s'il doit être regardé comme un demi-segment thoracique ou bien abdominal, mais par analogie, je suis pour cette dernière opinion. (Voyez une note de M. J. Duval, Gener a des Staphylinides, p. 1.) 
demi-segments supérieurs et inférieurs. Leur petitesse est fort grande; leur forme est arrondic. Ils sont très apparents sur la préparation dont j'ai parlé, leur péritrème est corné, arrondi.

M. IVestwood avait trouvé cinq articles à tous les tarses de la $M$. Johnsionis. Erichson admettait ce même nombre. M. Schiœdte, dans sa note sur le genre Micralymma (loc. cit., 160) ne donne que quatre articles aux tarses antérieurs. Je puis affirmer qu'il en existe cinq comme aux tarses intermédiaires et postéricurs. Il y a un article épais et court à la base, suivi de trois autres lobes et du dernier, avec deux crochets lisses en dessous (fig. 28). Le premier article n'est pas constitué par un prolongement de la jambe sur lequel les autres articles seraient posés. Il est lui-meme articulé à sa base. Mon cher ami M. Léon Fairmaire a contrôlé ces détails sans idée préconçue, et il partage mon opinion.

Organes internes. Quelques particularités sur l'appareil digestif me paraissent dignes d'être mentionnées.

On sait combien est recommandable le travail précité de M. Schiodte sur le genre Micralymma. Ce savant entomologiste a figuré avec soin les diverses parties de la bouche. Je ne suis en désaccord avec lui que sur peu de points. Le labre de l'insecte parfait est représenté ( $\mathrm{pl} .4$, fig. 2, $f$ ) par M. Schiœedte arec des expansions membraneuses, une antérieure bilobée et deux latérales, M. Westwood avait indiqué aussi un labre arrondi en avant en trois lobes. Je dois dire que j'ai cxaminé le labre sur les insectes dans l'alcool et sur d'autres desséchés, et je n'ai vu que ce que j'avais constaté el dessiné au Havre, a l'état frais. Je ne nic pas que les expansions membraneuses existent, je dis seulement que je ne les ai pas vues. Loin de croire à mon infaillibilité et plein 
d'estime pour les travaux de savants recommandables, je me défie de mon résultat et je regrette de n'avoir pas constaté ces expansions que j’ai vues d'ailleurs sur d'autres espèces, entre autres le $S$. olens. Le trait figuré au labre de la larve (pl. II, fig. 3) a l'air d'ailleurs de borner une expansion membraniforme.

M. Schiœedte indique huit poils à la partie antérieure du labre. M. Westwood, plus généreux, en a mis dix-huit à dixneuf dans son dessin. Je crois que la vérité est qu'il y a un grand nombre de poils parmi lesquels huit ou dix plus longs que les autres.

M. Schioedte dit expressément que les mandibules sont inermes. Il figure (loc, cit.) la mandibule droite de la M. brevilingue, sans dent saillante. M. J.-Duval dit comme II. Schiœdte : c mandibules mutiqques intérieurement. 》) (Genera des Col. d'Europe. Staphylinides, p. 67.) Or, il existe une dent très évidente au milieu de la mandibule droite, au bord interne de la $\boldsymbol{M}$. brevipenne. La mandibule gauche n'en a point, cela est vrai, mais ce caractère n'en est pas moins inexact.

La membrane finement ciliée des mandibules ne m'a pas offert les brosses de poils que M. Schicedte a figurées. Il existe simplement une membrane ciliéc.

Enfin la languette sur laquelle on discutera encore, et que M. Kraatz vient d'étudier récemment (Zur Terminologie der Paraglossen, in Berliner Entomol. Zcitschrift, Band. I, 1857), m'a paru composée de trois pièces. Je partage l'avis de MM. Schiœdte, Jacquelin-Duval et Kraatz à ce sujet. Je ne pense pas qu'on doive admettre avec Erichson une pièce uniquement formée par le support coriace ou corné des palpes labiaux. Il est d'ailleurs assez singulier qu'Erichson 
qui a distingué cette pièce ne l'ait pas représentée dans son Genera et Species des Staphylinides.

En comparant les figures que je donne pour les organes buccaux de la Mycralymma brevipenne avec ceux que M. J. Duval représente chez le meme insecte, on trouvera quelques légères différences. (Voy. Gener. Staphyl., pl. xxiv, fig. $118, a$, et $118, b$.) Je crois que ces différences viennent de ce que M. J. Duval n'a eu à observer que des insectes desséchés.

Le tube digestif est droit dans la larve, plus long dans l'insecte parfait. Les mandibules de la première sont arquées et plus dentées au côté interne. Le ventricule cliylifique n'est point papilloire, la pulpe du gros intestin est brunatre. Ces caractères indiquent qu'elle est plus carnassière que l'insecte parfait, que sa nourriture est purement animale el séjourne peu de temps dans le tube digestif. La pulpe verte de l'intestin de l'insecte parfait indique un régime plus végétạl.

Les vaisseaux biliaires sont terminés en coecum à peine renflé (pl.11, fig. 6, $d$, $d$ et pl. 11, 6ig. $15, d, d$ ) sur la larve et l'insecte parfuit. J'en ai acquis la preuve répétéc. J'ai vu une fois un petit filament, un prolongement dont j'ignore l'usage terminant un des vaisseaux hépatiques de l'insecte parfait. Je l'ai figuré sans y attacher d'autre importance (pl. 11i, fig. 22).

Organes génitaux. Les capsules spermifiques sont remarquables par leur forme quadrilobéc. C'est dans leur intérieur que doivent se former les Spermatozoides, mois je n'en ai pas eu la preuve, je n'ai point fait l'histologie de cet organe dont j'oi eu beaucoup de peine à reconnaitre les formes et les connexions. 
Il m'a semblé que les deux vésicules séminales, les deux tubes ainsi nommés par M. Léon Dufour s'ouvraient cote à cote sur le canal déférent.

Le trait le plus remarquable de l'appareil générateur $\delta$, est la dilatation du canal éjaculateur à son origine. Il y a là un réservoir et peut-etre une poche contractile destinée à la projection de la liqueur séminale.

La disposition des gaines ovariennes uniloculaires et la simplicité du conduit des œufs sont ordinaires chez les Staphylins. Remarquons la plaque en $\mathbf{V}$ de l'oviducte, vestige du neuvième segment abdominal du ot .

Il est bien extraordinaire que la Micralymma répande une odeur très forte sans que l'organe qui la produit soit gros ou au moins possible à trouver.

L'appareil respiratoire interne se compose, chez l'insecte parfait comme chez la larve, de trachées uniquement $t u b u$ leuses ou élastiques. Elles ne sont point très multiptićes. On comprend très bien l'absence de ballons aériens chez un insecte absolument aptère et d'un genre de vie si singulier. Les Staphylinus olens et maxillosus qui volent n'ont également que les memes trachées, ainsi que je l'ai constaté. II est vrai que le vol n'est pas chez ces insectes un exercice habituel.

Le système nerveux ne m'a rien offert de spécial ou digne d'être noté. Les ganglions destinés aux organes générateurs sont volumineux.

Le tissu adipeux splanchnique est d'un blanc de lait, granuleux. Son abondance est assez considérable, mais non excessive.

Pour terminer nos remarques sur cet insecte, nous compa 
rerons son organisation viscérale à celle des Staphylinides dont l'anatomie est déjà connue.

Remarquons les poils œesophagiens. Ces poils ont été signalés dans le Staph. politus par Ramdohr, dans les $S$. coesareus (erythropterus), et tous les Staphylinides disséqués par II. Léon Dufour (Ann. Scienc. nat. 1re série 11, 219). J'ai montré dans le gésier du $S$. olens des séries de poils (Ann. Ent. France, 1850, XLvil et 1852, 337), mais dans tous ces Staphylinides, ces poils forment les parois d'un vrai gésier.

Le ventricule chylifique est très papillaire dans la Micralymma. On trouve qu'il l'est aussi dans le $S$. politus (Ramdolır, Abhandhung ueber die Verdaungs werkzeuge, etc., pl. III, fig. 6). Tous les autres insectos de cette famille disséqués par M. I,éon Dufour ont des papilles ventriculaires plus ou moins saillantes, St. olens, ccesareus (eryihropterus FAB $)$, maxillosus, punctatissimus. Les Paderus riparius et ruficollis les ont à peine marquées.

Les testicules sont oblongs et mamelonnés (multicapsulaires) dans les St. olens, casareus, maxillosus, punctatissimus. Ils ont la forme d'un sac arrondi dans les Paderus (Voy. L. Dufour, Ann. Scienc. Nat. vi, 162, pl. v, fig. 4 à 9). Ces Staphylins ont deux paires de vésicules séminales, les Paderus trois paires. Le Staphylinus olens, fig. 4, a te canal déférent renflé à son origne comme la Micralymma.

Enfin les ovaires ont six gaines ovigères. Nous en trouvons le même nombre aux Staphylinus maxillosus d'après M. Icéon Dufour (Ann. Scienc. Nat. v1, 436); les Philonthus varius et Paderus riparius d'après M. Stein (Vergleichende An. und Phys. der Ins. Die weiblichen Geschlechisorgane der

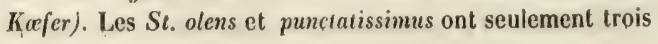


gaines ovigères (Léon Dufour). L'Oxytelus rugosus en prísente dix (Stein). Le Boletobius atricapillus douze (Stein).

Le receptaculum seminis n'est 'pas toujours simple comme dans la Micralymma, il offre des formes plus compliquées dans les Paderus riparius, Tachyporus chrysomelinus, Tachinus rufipes (Stein).

MI. Lacaze Duthiers n'a point parlé de l'armure génitale of des Staphylins, dans son travail sur res armures chez les insectes Coléoptères (Ann. des Scien. Nat., $3^{\mathrm{e}}$ série, xIx, 1853), mais M. J. Duval a décrit arec soin, suivant son habitude, celles du S. maxillosus, tant malle que femelle (Intro. duction au Genera des Coléoptères d'Europe, CXI et cxir).

M. Stein a représenté l'extrémité de l'abdomen chez les $q$ des $S$. eryihropterus (ou casareus?), Tachinus rufipes, Paderus riparius, Philonthus varius, Myrmedonia canalicu. lata (loc. cit., pl. 1II, fig. 7, 11, 12, 14 et 15).

Il faudrait employer le crayon pour faire l'exposé comparatif de ces dessins, j'aime mieux y renvoyer qu'en donner un aperçu toujours incomplet.

Les gaines ovigères de la Micralymma ne renfermaient pas d'œufs, mais une pulpe blanchatre. La plupart des figures données par les auteurs n'indiquent pas, non plus, des œufs dans les gaines. On doit remarquer le fait prouvé aujourd'hui de la grosseur relative des oufs des Staphylinides et leur petit nombre. 
Explication des figures des planches II et $\mathbf{I I}$.

\section{PI. II.}

Fig. 1. Larve grossie de la Micralymma brevipenne GyLLenina, et, à côté d'elle, à droite, mesure de sa grandeur naturelle.

A. Larve figurée par M. Westwood comme étant celle de la $\boldsymbol{M}$. Johnstonis et, à gauche d'elle, mesure de sa grandeur naturelle.

2. Antenne gauche d'une larve de $\boldsymbol{M}$. brevipenne, très grossie, ainsi que toutes les figures qui suivent.

B. Antenne droite de la larve figurée par Mr. Westwood.

3. Parties de la bouche d'une larve de M. brevipenne: $a$, mandibule droite; $b$, mâchoire gauche; $c$, lèvre inferieure; on distingue en dessus le labre et une ligne sinuéc indiquant des expansions membraneuses, 3 , $d$; ocelles.

C. Parties de la bouche figurées par M. Westwood.

4. Patte de la larve de la M. brevipenne; elle est terminée par un ongle unique, robuste.

D. Une patte de la larve figurée par M. Westwood.

5. Dernier segment abdominal vu de profil pour montrer le prolongement anal, faisant l'office de pseudopode chez la larve de la $M$. brevipenne.

6. Appareil digestif de celte larve: $a$, tete; $b$, œso- 
phage; $c$, ventricule chylifique; $d d$, vaisseaux hépatiques; $c$, intestin grele; $/$, gros intestin ; $g$. dernier segment abdominal; $h$, anus.

7. Côté gauche du corps de la même larve, très grossie, pour mettre en évidence la position des stigmates; $a$, premier stigmate ou protomésothoracique.

8. Nymphe très grossie de la Micralymma brevipenne, vue par la face ventrale, et, a coté d'elle, à droile, mesure de sa grandeur naturelle.

$\boldsymbol{E}$. Nymphe figurée par M. Westwood comme étant celle de la M. Johnstonis.

9. La mème nymphe vue par la face dorsale.

F. Nymphe figurée par M. Westwood vue de même par la face dorsale. Entre ces deux nymphes $(E, F)$ mesure de leur grandeur naturelle.

10. Abdomen très grossi de la Micralymma brevipenne ơ à l'état parfait, montrant en $a$ un dernier segment terminé par deux longs poils.

11, 12, 13. Parties composant le segment $a$ de la figure précédente. Les figures plus grossies : 11, 6 segment en demi-anneau, ouvert par derrière, ayant en avant une lame $c$ qui le termine en glissant sous lui. 12, le mêne segment en demianneau $b$ vu en arrière avec la lame $d$, qui le complete et terminée par deux longs poils. Ces trois pièces $b, c, d$, font partic de l'armure génitale $\delta^{*} .13$, lame $d$ représentée séparément.

14. Dernier segment abdominal + , avec le prolonge- 
ment membraneux de l'armure génitale ․ $a$, plaque en $\mathbf{V}$, un peu coriace, ambrée, indice d'un demi-segment supérieur; 66, appendices terminaux vulvaires.

P]. III.

Fig. 15. Appareil digestif de la Micralymma brevipenne + , à l'état parfait.

$a$, Tete ayant quatre impressions et, entre le bord postérieur des yeux à réseau, deux stemmates très visibles (peut-ctre un troisième entre ceux-ci et plus en avant); $b$, œsoplage; $c$, ventricule chylique garni de papilles; $d d$, vaisseaux hépatiques; $c$, intestin grêle; $f$, gros intestin; $g$, derniers segments abdominaux.

16. Labre suivi en arrière d'un épistome membraneux, très étroit. Le labre est très grossi, ainsi que les autres parties de la bouche.

17. Mandibule du côté droit de la bouche.

18. Mandibuie du coté gauche.

19. Machoire droite; $a$, palpe maxillaire.

20. Lèvre inféricure; $a$, menton; $b$, pièce intermédiaire; $c$, palpes maxillaires, et leur support coriace; $d$, languette et ses paraglosses visibles sur les côtés qu'elles recouvrent, ciliés intérieurement. 
Fig. 21. OEsophage, pour montrer la disposition de ses poils internes, dirigés en arrière et en bas.

22. Terminaison d'un vaisseau hépatique.

23. Appareil de la génération du male.

$a a$, Testicules 4-lobés; $b$, canal déférent; $c c c^{\prime} c^{\prime}$, en. semble des glandes annexes (vésicules séminales Léon Durour); $d$, canal éjaculateur renflé à son origine en $c ; f$, pénis avec un étui corné, son forceps $g$, la verge $h$.

24. Figure schématique montrant la disposition des divers canaux déférents et excréteurs avant l'origine du canal ejaculateur. Memes Iettres que pour la figure 23.

25. Ensemble du pénis ou verge du male.

$f$, étui corné; $g$, forceps; $h$, verge proprement dite terminée pur une sorte de gland $i$.

26. Appareil de la génération de la femelle. $a a$, gaines de l'ovaire, monoloculaires ou biloculaires; $b b$, trompes; $c$, poche copulatrice (vésicule séminale); $d$, reccptaculum seminis et son canal; $e$, oviducte; $f$, armure génitale (voy. fig. 14).

27. Micralymma brevipenne + , dessinée au trait, pour montrer la disposition générale des diverses parties du corps et les stigmates abdominaux.

28. 'Tarse antérieur gauche de cet insecte.

29. Tarse intermédiaire. 
A. Laboulbène. - Micralymma brevipeme.

30. Tarse postérieur.

31. Un des deux ongles terminant chaque tarse. Il est lisse en dessous avec une seule dent près du point d'articulation.

32. Portion d'une élytre pour montrer la fine réticulation transversale et la ponctuation pilifère qu'offre le corps de cette Micralymma. 


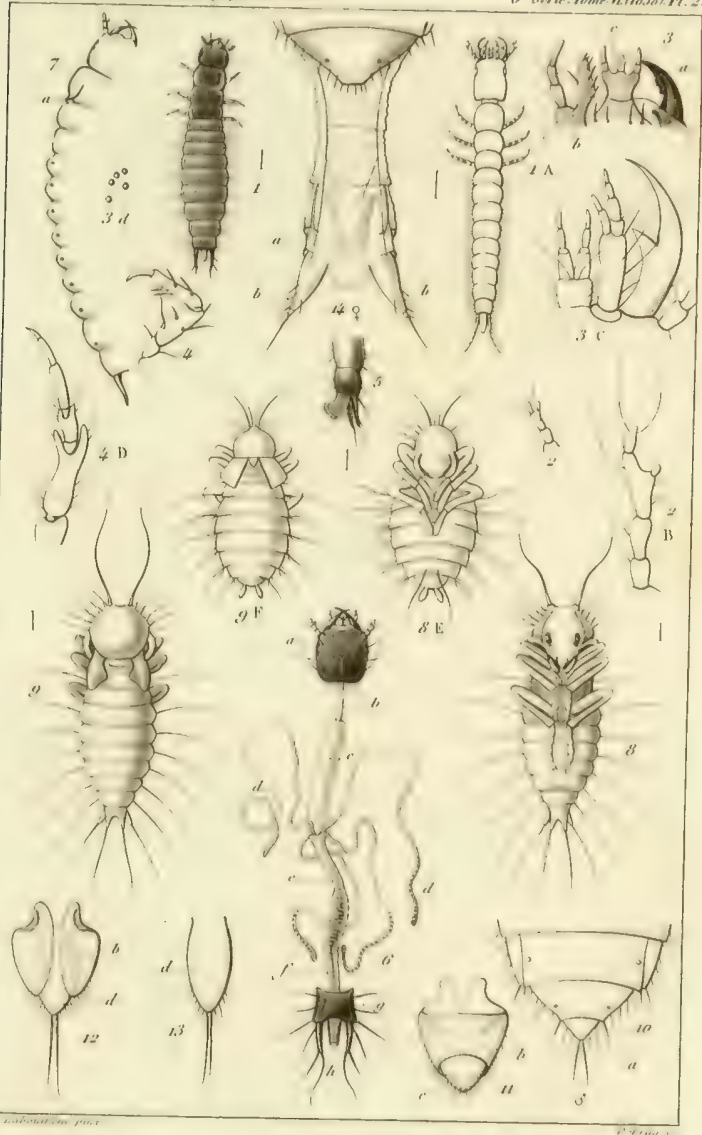

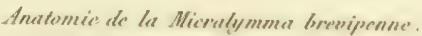




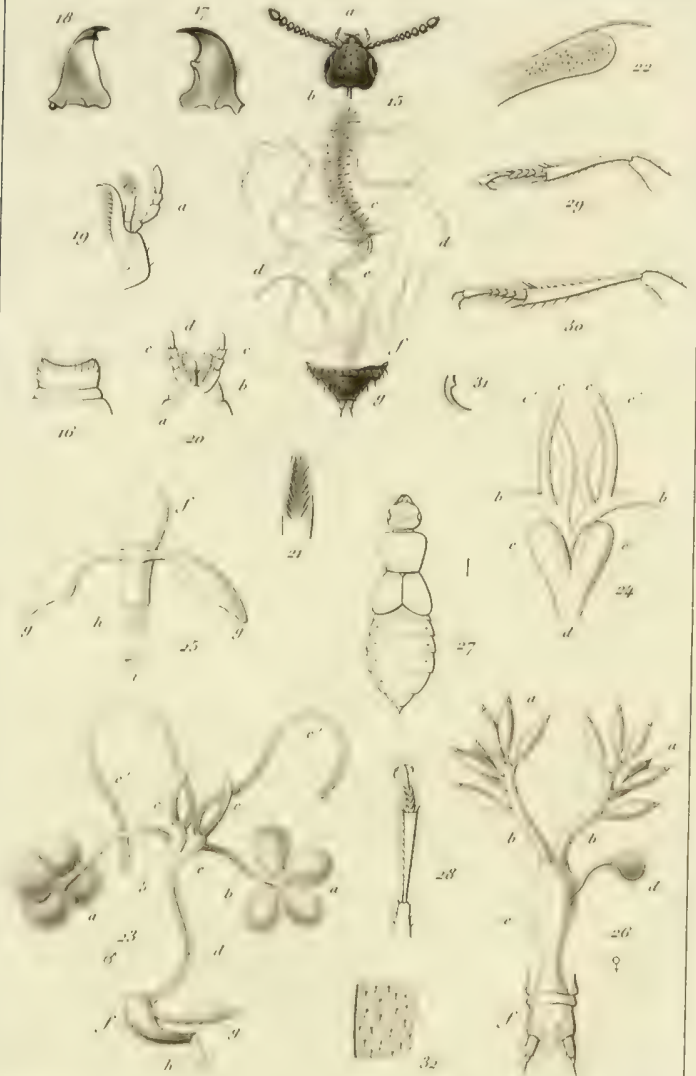

$=7$
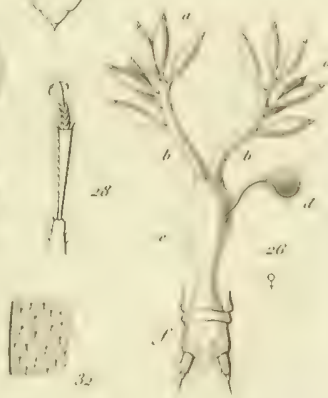

3

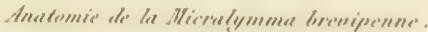





\section{IISTOIRE}

vES

\section{MÉTAMORPHOSES DE LA GELECHIA CARLINELLA,}

Par MM. le $\mathrm{C}^{\text {el }}$ GOUREAU et le $\mathrm{D}^{\mathrm{r}}$ LABOULbËNE.

(Seance du 10 Mars 1858.)

Les entomologistes qui cherchent à connaitre les premiers états des insectes savent combien il est difficile, dans de certaines circonstances, de rapporter avec certitude un insecte parfait à une larve bien connue.

Nous avons éprouvé cette perplexité pendant plusieurs années; nous avions étudié séparément une larve qui vit dans les capitules de la Carlina vulgaris Linvé, et nous arrivions aux mèmes résultats négatif's après avoir eu les memes préoccupations. Cette année seulement, la vérité nous a été dévoilée, et on va voir, par l'exposé de nos recherches, quelle peine elle a eu à sortir de son puits qui était, cette fois, un capitule de la Carlina vulgaris.

Voici les différents détails de nos bbservations. L'un de nous (M. le colonel Goureau) les a faites à Santigny, dans le département de l'Yonne, l'autre (II. Ie docteur Laboulbène) aux environs de Paris.

Le 27 septembre 1851, des capitules de Carlina, recueillis sur le bord d'un chemin à Santigny, ont offert une petite larve se tenant \& la base des aigrettes et rongeant, pour se 
nourrir, la substance charnue du réceptacle. Sa Iongucur était de quatre millimètres. Sa forme était atténuée vers l'extrémité, sa couleur blanchatre avec la tête d'un brun marron. Elle était pourvue de pattes thoraciques; absence de paltes abdominales; pattes anales apparentes. M. Ie colonel Goureau pense qu'il a peut-ctre sous les yeux une chenille.

Le 19 mai de l'année suivante, il trouve des larves mortes dans le fond de la boîte où il avait renfermé les tetes de Carlina. Ces larves étaicnt allongées, atténuées, paraissant apodes, courbées en arc, le dernier segment prolongé en mamelon. La conclusion tirée est que ce sont probablement des larves de Curculionite (Larinus ou Rhinocyllus). Dans les capitules ou tetes de Carline, on aperçoit obscurément des chenilles vivantes, mais renfermées chacune dans un tuyau de soie blanche et fine, ou cocon. Ce cocon est placé verticalement entre les aigrettes et enfoncé à moitié dans une galerie creusée par la chenille dans le réceptacle de la fleur desséchée. Les chenilles se tenaient immobiles, la tete en haut, altendant le moment de leur transformation en chrysalide et puis en insecte parfait. Lo premier de ces changements s'est opéré en juillet et le deuxième en aoùt.

Le 23 octobre et le 17 novembre 1855, l'examen de tetes de Carline récoltées dans le meme endroit n'apprend rien de nouveau. Elles ne présentent que des larves de Diptère dont l'éclosion n'a pas lieu. Le 2 juin 1856, nouvelle récolte dans l'espérance de trouver les insectes sur le point d'arriver à unc heureuse mélamorphose. On ne voit qu'imparfaitement une chenille contractée, peu éloignée de sa transformation, renfermée dans une sorte de cocon ou fourreau de soie blanche, placée verticalement au milieu de la fleur. 
Le lendemain, M. Goureau cueille des tetes de Carlina. Il trouve des larves vivantes, il les examine avec soin; chaque larve paraît solitaire dans une cellule qui arrive du réceptacle á la base des paillettes. La larve remplit cette cellule. On lui voit une tete écailleuse, jaunatre, un labre brun, deux mandibules de cette couleur. Le corps est fusiforme, mou, blanchatre, composé de douze segments, les trois pre-

- miers présentent des mamelons presque effacés, il n'en paraît pas sur le corps, mais il existe un mamelon anal. On conjecture qu'elle appartient à un Curculionite.

Le 17 juillet, plusieurs tetes de Carline ouvertes montrent des chrysalides de Lépidoptères contenues dans les cocons de soie déjà signalés et placés entre les aigreltes. Le 20 juillet il éclot des Lépidoptères.

En résumé, M. le colonel Goureau observe, en septembre 1851, uno jeune chenille, dont il voit en mai de l'année suivante le cocon et dont il obtient la transformation en août. En 1856, il observe de nouveau les cocons de cet insecte.

Mais, et c'était le point capital, en meme temps qu'il avait trouvé les cocons de Lépidoptère en 1856, comme le 19 mai 18:52, M. Goureau, avait remarqué dans les tetes de Carline l'existence de larves ressemblant tout à fait a celles d'un Curculionite, et il ne savait quel insecte elles pouvaient produire.

D'autre part, le 8 juin 1856, pendant l'excursion de la Société, à Bouray, plusieurs têtes de Carline vulgairc furent recueillies et examinées ensuite par M. Laboulbìne. Il constata de la manière la plus positive l'existence de une et parfois deux larves dans la partic charnue du réceptacle arrivant jusqu'aux paillettes. Ces larres arquées, blanchatres à 
corps mou, offraient six paltes très courtes sous les segments thoraciques. Il fallait le microscope pour les démontrer. Il n'existait point de pattes abdominales, sculement un prolongement du dernier segment. La bouche était remarquable par deux mandibules fortes, 1-dentées, des malchoires à lobe interne soudé à la tige, et à palpes au moins triarliculés. La lèvre inféricure offrait un prolongement médian, une filière et de chaque côté un paIpe, etc. En meme temps que ces larves, on trouva une seule chrysalide enveloppéc dans une coque de fine soie blanche, allongée, située perpendiculairement entre les paillettes.

Ces renseignements recueillis, la larve fut regardée comme appartenant á ún Curculionite, et habitant avec une chenille inconnue, mais dont on avait la chrysalide sous les yeux, dans la meme tête de Carlina.

En juillet, on vit paraitre, dans un grand bocal de verre où étaient enfermées les capitules de Carline, des Ichneumonides fort nombreux et se rapportant à l'Agathis malvacearum. Plus tard, vers la fin du mois, un grand nombre de Lépidoptères de la tribu des Tinéites se montrèrent. Mais, à la grande surprise de l'observateur, aucun Curculionite ne parut.

Le fait de la présence dans la Carlina d'une larve de Curculionite et d'un Microlépidoptère fut annoncé à la Societé, les 11 juin et 24 septembre (Bulletin, Lvur et Lxxxvi, 1856.)

En 1857, nouvelles recherches, à Santigny et à Bouray. M. Gourcau, le 4 mai, récolte des tetes de Carline desséchées, il en ouvre trois. L'une renfermait une chenille enveloppée ct cachée dans un fourreau de soic. L'observateur peut reconnaitre en elle la fausse larve de Curculionite, car la seconde tete offrait un cocon semblable au premier abri- 
tant une chrysulide de Lépidoptère. Une troisieme tele de Carline contenait un fourreau tout pareil aus deux précédents et renfermant une chrysalide d'Ichneumonide.

Le 15 juillet, les Ichncumonides appartenant au genre Agathis etふ l'espèce malvacearum LATR. se montrent; le 25, les Lépidoptères obtenus dans les années précédentes apparaissent à leur tour.

Ayant eu connaissance des premières observations de M. Gourcau, communiquées à la Société Entomologique le 25 février 1857 (Annales Soc. Ent. France, Bull., xxvi, 1857), son collègue avait récolté, à Bouray, le 5 mai, des têtes de Carline (1). Les larves présumées de Curculionite y étaient très nombrcuses. Il en existait jusqu'à trois dans le meme réceptacle. Les dessins faits l'année précédente étaient exacts. On remarquait comme antérieurement des pattes thoraciques et le dernier segment avait en dessus quelques élévations grenues, brunatres. Aucune chrysalide ne fut trouvée, ni aucune chenille. L'idée de l'éclosion du Curculionite prit plus de force que jamais; des capitules furent déposés sur du sable dans des flacons et dans des boites, toutes les précautions furent assurées et on attendit l'apparition des insectes parfaits.

M. Édouard Perris, dont la science et le talent d'observation, sont si remarquables, consulté par le docteur Laboulbène, pensa sur le vu des dessins que la larve était celle d'un Curculionite, mais le fait de la présence des pattes,

(1) C'est dans cette excursion, faite avec M. Louis Amblard, qu'ont été trouvées les larves de Cicindèles, dont il a été fait mention dans les Archives de M. Thomson, tome I ${ }^{\text {er }}$, page 105 , et la nymphe de l'Anthrax sinuata (Annales Ent. Fr., 1857, 781). 
des palpes maxillaires de trois articles au moins, la lui faisaient regarder comme anormale, comme aberrante.

Il parut d'abord dans les boites et dans des bocaux, au commencement de juillet une multitude de parasites, d'Agathis, puis une très grande quantité de Microlépidoptères et pas un seul Curculionite.

C'était vraiment désespérant. Mais une ciconstance fortuite vint mettre sur la trace de la vérité. Des larves avaient étẻ disposées duns un flacon étroit, contre le verre, de manière à les pouvoir observer par l'enlèvement d'une portion de leur loge. Ces larves, avant d'ctre introduites dans le tube, étaient en partie tombées de leur demeure, et il sortait de leur bouche un fil qui en avait tenu quelques-unes suspendues. Ce fai metlait hors de doute la propriété de la filière déjà constatée. Enfin, l'une de ces larves si semblables à celles des Curculionites, fut aperģue filant une coque dont la paroi était altachée contre le verre du flacon, et cette espèce de coque renferma plus tard une cInYSALIDE. Le mot de l'énigme élait trouvé comme à Santigny, et la présumée larve de Curculionile n’était autre que cette première chenille observée par M. Goureau, en automne, et qui, au moment de sa transformation, offrait une apparence si insolite.

Celle longue histoire nous a paru utile pour faire comprendre combien on doit s'armer de patience et insister sur l'étude d'un fait avant de pouvoir le résoudre. Les entomologistes passionnés nous comprendront. Ces derniers résultats ont été annoncés à la Société Entomologique le 10 mars (Am. Soc. Ent. France, Bull. xxx, 1858).

11 nous reste présentement à faire connaitre les trois êtats du Microlépidoptère dont la chenille a cité si difficile à 
reconnaftre au inoment ou elle a pris tout son accroissement. Nous devons à l'obligeance de notre collegue, M. Stainton, la détermination précise de l'insecte parfait, et nous avons cru devoir le figurer, d'après un dessin fait à notre demande, par notre collègue et ami, M. Bruand d'Uzelle.

description des trois états de la parasia Carlinella. S Ier. Chenille (voyez pl. 7, no I, fig. 1 à 11).

Cinenilete (sur le point de se transformer, fig. 1 et 2), molle, blanchâtre, à tête rousse ou brune, avcc les parties de la bouche brunatres.

Corps composé de douze segments, la tête non comprise, s'atténuant vers l'extrémité, très fortement courbé en arc. Surface du corps finement grenue à un fort grossissement, offrant des poils très ras et d'autres visibles à la loupe, mous, blanchâtres, peu allongés (fig. 1 et 2).

Tête petite dans son ensemble, enfoncée à moitić dans le premier segment thoracique, bouche inclinée en bas.

Antennes composées de trois articles, le premier grand, presque carré, le deuxième supportant un long poil et un très petit article. Ce dernier terminé par une soie (fig. 7).

Labre fortement échancré au milieu, arrondi aux angles latéraux (fig. 3).

Mandibules fortes, brunatres ou noirâtres, quadridentées (fig. 4).

Mâchoires composées d'un lobe interne fixe, avec des 
saillics en dents de peigne et des poils à son extrémité supérieure, et d'un palpe externe de trois articles, le premier large, le dernier petit (fig. 5).

Nous devons ajouter qu'il semble parfois exister à la base un quatrieme arlicle, mais son existence n'est pas constante, tandis que les trois que nous admettons ont leurs bords nets, assez faciles à trouver.

Lève inférícure (fig. 6) composée d'une filière allongée, médiane, cylindrique, élargie à sa base; de deux palpes latéraux biarticulés, terminés par une soie. La filière et les palpes s'insìrent sur une pièce basilaire arrondie en avant, molle, charnue.

Segments thoraciques n'étant pas sensiblement plus gros que les médians, le premier ou prothoracique montre en dessus une ombre roussâtre ou brunatre, formée par deux traits obliques, plus écartés en arrière. Chaque segment porte une paire de paltes à peine visibles, quadriarticulées (fig. 9). Le dernier article furmé par un ongle ou crochet simple.

Segments abdominaux s'atténuant légèrement en arrière, mais moins sur la larve vue de dos, le dernier offrant, en dessus, une sorte de plaque ou se trouvent des saillies grenues, roussatres ou brunatres; et en dessous un prolongement bifide ou pseudopode, visible surtout quand la larve cherche à s'allonger (fig. 1 et 2).

Stigmates au nombre de ncuf paires, la première située sur le prothorax, très près du métahorax, les autres disposés comme à l'ordinaire sur les quatrième, cinquième, sixième, septième, huitiène, neuvième, dixième et onzième segments. Péritrême arrondi (fig. 2 et 8). 
Dans le jeune âge, la forme de la chenille est bien plus reconnaissable (fig. 10 et 11). L'animal se tient moins recourbé, les pattes thoraciques sont plus saillantes, l'extrémité du corps plus droite, plus eflilée, le pseudopode arral fonctionne plus aisément et fait plus de saillic.

D'après ce que nous avons dit, la chenille passe l'hiver et se transforme en juin et juillet en chrysalide pour paraître sous forme d'insecte parfait en juillet et août. Pendant l'au. tomne, elle est reconnaissable pour une chenille, mais, après l'hiver, au printemps suivant, elle ressemble tout à fait à une larve de Curculionite.

Dans le premier cahier des Annales de notre Société pour l'année 1848, p. 164, M. Stainton, en parlant des larves des Parasia, dit qu'elles sont courtes, grosses, lourdes et ne marchent jamais volontiers. Ce fait est très exact.

SII. Chrysalide. (Voy. fig. 12.)

Très luisante, de couleur d'ambre, ou un peu plus foncée, à yeux noirs. Elle est remarquable par le fourreau des ailes qui atteint l'extrémité de l'abdomen. Cetle disposition nous semble peu commune. La figure nous dispense d'autres détails.

Cette chrysalide est, comme nous l'avons dit, enveloppée d'un cocon de soie blanche, trìs fine, lache, et placé debout, dans l'intervalle des paillettes. La chrysalide a la tete située en haut, et le papillon sort facilement par le bout supéricur qui est très faiblement tissé. 
\$ III. Insecte parfait. (Voy. fig. 13 à 20.)

Geleciua Carlinella Douglas, Trans. Ent. London, I, 245 (1852).

G. Lapella, var. $\beta$. Zeller.

Parasia Carlinella Stainton, Insecta Britannica, Lépidopt. Tineina, p. 141 (1854).

P. Astivella, Herrich-Schæffer, Schmetterlinge von Europa, V, p. 207, pl. 74, fig. 558, 559 (1855).

Longueur, 5 à 6 mill. de la tête à l'extrémité des ailes plięes; envergure, 12 à 14 millimètres.

D'un jaune ou d'un testacé couleur d'ocre on un peu ferrugineux.

Tête d'un blanc roussatre ou d'un jaune d'ocre, parfois presque blanche. Yeux noirs.

Antcnes filiformes, à peine de la longueur du corps et finement dentelées en dessous o : noiratres en dessus, roussâtres en dessous à la base (fig. 18).

Palpes roussatres ou quelquefois d'un jaune ocrcux (fig. 19).

Thorax roussatre, avec deux lignes longitudinales plus pâles; les épaulettes d'un jaune d'ocre blanchâtre.

Ailcs supéricures d'un testacé lerrugineux avec deux raies étroites, longitudinales, jaunatres. Tantôt la couleur du fond est ferrugineuse avec les raies d'un jaune pâle, tantôt le fond est brun avec les raies d'un roussatre ferrugineux. Une frange de longs poils bruns au bord interne et au bord pos- 
térieur où elle tourne parfois soit au jaune, soit au roux (fig. 15 et 16).

Ailes inféricures presque de méme largeur que les premières et d'un gris noiratre, plombé, avec une longue frange d'un brun roussatre (fig. 17).

Dessous des ailes d'un gris foncé, soyeux et luisant, avec la frange d'un gris jaunatre.

Poitrine d'un jaune plus ou moins intense.

Pattes testacées, les postéricures armées de deux paires d'éperons, leurs tibias frangés de poils blonds ou jaunatres en dessus (fig. 20).

Abdomen d'un gris noiratre soyeux, terminé chez le of, par un faisceau de prils blonds, plus ou moins jaunes ou roux (fig. 14).

I.e male se distingue de la femelle par sa taille un peu moindre, ses couleurs un peu plus tranchées, ses antennes un peu plus dentelées et généralement plus sombres; enfin, par le pinceau de poils terminant l'abdomen (1).

(1) Voici les descriptions de MM. Douglas et Herrich-Schxffer. Ces deux estimables auteurs ont soin de différentier la G. Carlinella de l.s G. Lappella.

\section{G. Carlinella Dovglas \{loc, cit.)}

Alce antica angustce, fulvo ochracece, apice saluratiori, fascia postica valdè obliqua pallidè ochracea. Ala postica fusco grisea, ciliis ochraceis. -- Expansion of wings 6-7 1/2 lines.

This species is very close to $G$. Lappella, from which it may be distinguished by its less average expansion, narrower anterior wings, which are also of a brighter, almost fulvous, yellow, and spotless; the palpi shorter and thinber, the terminal joint especially being much finer. The posterior wings are lighter than in G. Lapella. 3е Série, томе уг. 
M. Stainton qui publie un magnifique ouvroge sur les Tinéides, range la G. Carlinella dans le genre Parasia. Dans son Exposé sur les mueurs des chenilles des Tinéides, (Ann. Soc. Ent. de France 1858, 164) il parle de la chenille de la Carlinclla qui a dévore le réceptable de la Carlina vulgaris. $D$

Nous avons d'autre part été frappés des remarques de M. Bruand d'Uzelle, qui nous a fait observer que la Carlinella présentait les caractères du genre Gelechia, tel qu'il l'a réduit dans la classification des Tinéides, pour les espèces qui ont les ailes inférieures terminées en pointe plus ou moins aiguë, émarginées au sommet. Il laisse dans le genre Lita de Duponchel les espèces analogues dont les secondes ailes sont cultriformes ou terminées en s'arrondissant et non en pointe. Or la G. carlinella n'offre point les caractères que Duponchel a assignés à son genre Parasia dont le type est Nevropterella.

Bred abundantly in July and Angust 1850, from seed beads of the Carline thistle (Carlina vulgaris), gathered at Folkestone, during the preceding winter.

Parasia astivella Hennicu-Snxfrer. - G. Carlinclla Dovglas.

Ferruginea, alis anterioribus inter costas plumbeis, vitta ante limbum obliqua pallidiore, punctis typicis nullis.

Düsterer als Lapella, mit welcher sie in der Form, namentlich der Hinterflügel übereinstimmt. Die rostgelbe Farbe bleibt nur in Längsstrahlen übrig, weil die Zwischenraüme der Rippen gleichmässig bleigrau beschuppt sind. Nur längs des Saumes bleibt ein Schrägstreif etwas bleicher als die Grundfarbe. Die typischen Punkte fehlen ganz.

Von Regensburg und Frankfurt a. M., in England, lebt die Raupe vom Oktober bis zum Februar in den Köpfen der Carlina vulgaris. 
Nous croyons comme M. Bruand qu'il faut partir de l'ctat parfait des insectes pour l'établissement des genres, mais nous tenons en grand compte les premiers états. Dès lors, rien ne s'opposerait àce que Carlinella formâ tavec ses congénères Metzneriella, Bifractella, Lappella, ctc., à chenilles lourdes, arquées, semblables à des larves de Curculionites une bonne division du genre Gelechia. Peut-être aussí, notre savant collègue M. Stainton comprend-il le genre Parasia autrement que Duponchel?

Du reste, cette question est pour nous secondaire. Elle doit être jugée en dernier ressort par des Lépidoptérologistes. Nous avons voulu seulement apporter notre tribut de recherches au sujet d'une chenille fort anormale assurément.

\section{S4. Parasites.}

Nous avons dit qqu'iléclotavant les Lépidoptères un Parasite, un ennemi qui sait atteindre les chenilles dans leur retraite et qui en détruit un grand nombre. Cet ennemi est un Ichneumon de la division des Braconides; il apparticnt au genre Agallis de Latreille ct à l'espèce $\boldsymbol{A}$. malvacearum.

Nous devons faire remarquer les ressemblances qqu'offrent les deux sexes de cet Agathis au premier aspect. Nees d'Esembeck, avait déjà dit que le mâle ressemblait beaucoup à la femelle (femince simillimus). Nous avons cependant trouvé quelques rares individus måles dont l'abdomen est presque entièment noir et dont les cuisses sont rembrunies. On voit, en y regardant de près, qu'ils doivent etre rapportés à l'A. malvacearum et non à l'A. nigra. La disposition de leurs cellules alaires et de leurs formes générales ne saurait 
laisser de doutes à cet égard. Nees d'Esembeck a connu cette variêté (loc. cit., 138).

Agathis malvacearum Latneilee, Mist. Nat., Crust. et Insect., Buffon-Sonnini, XIII, 175 (1802) et Gen. Crust. et Ins. IV, 9.

Neiss D'Esembeck, Hymenopt. Ichneumon, aff. Monogr. I, 137.

․ Long. 5 mill.; sans la tarière. - D'un noir luisant; Tete noire ainsi que les parties de la bouche prolongées en trompe. Antennes noires, filiformes, moins longues que le corps. Thorax noir, dorsulum trilobé; métathorax rugueux, canaliculé au milieu. Abdomen sessile, ovalaire, de la longueur de la tete et du thorax réunis; noir, avec une large ceinture fauve comprenant une partie des deux premiers segments. Pattes fauves avec les hanches, les trochanters, la base des cuisses et l'extrémité des jambes noirs; tarses noirs. Ailes obscures en dehors, mais néanmoins transparentes en dedans à la base, nervures et stigma noirs, une tache blanchatre sous le stigma, deuxième cellule cubitale, petite, en triangle tronqué ou quadrangulaire. Tarière plus longue que le corps.

$\checkmark$, Long. 4 mill. Semblable à la + , mais plus petit; tête plus large que le corselet. Abdomen ayant la bande fauve généralement plus étroite. Cette bande varie du reste beaucoup pour la largeur.

Explication des figures de la planche 7, no I.

Fig. 1. Chenille de la Gelechia Carlinella Dodglas, ayant pris tout son accroissement, vue par la face dorsale, et à côté d'elle mesure de sa grandeur naturelle. 
Fig. 2. Cette même chenille vue de profil, très grossie.

3. Labre et épistome de cette chenille, très grossis ainsi que les figures suivantes.

4. Mandibule du côté droit de la bouche.

5. Máchoire du côté gauche de la houche, avec son palpe externe.

6. Lèvre inférieure, avec la filière médiane et les palpes latéraux.

7. Antenne.

8. Un des stigmates dont le péritrême est arrondi.

9. Une des pattes, terminée par un crochet simple.

10. Chenille de la Gelechia Carlinella, encore jeune. vue de profil.

1i. La meme vue par la région dorsale et à côté d'elle mesure de sa grandeur naturelle.

12. Chrysalide du même insecte et à côté d'elle mesure de sa grandeur naturelle.

13. Gelechia Garlinella Docglas, à l'état parfait, de grandeur naturelle et représentée au repos (cette figure et les suivantes ont été peintes par M. Bruand d'Uzelle).

14. Corps du mâle du meme insecte grossi du double. 15 et 16. Aile supérieure de la Gelechia Carlinella fort grossie ainsi que toutes les figures qui suivent.

17. Aile inférieure.

18. Antenne gauche.

19. Palpe.

20. Patte postérieure gauche. 
278 Goureau et Laboulbène. - Gelechia Carlinella.

\section{NOTE ADDITIONHELLE.}

Les capitules de la Carlina vulgaris ne renferment pas seulement la Parasia carlinclla. L'un de nous (M. Goureau) y a trouvé pendant l'automne des larves et pupes de Diptères.

Le 27 septembre 1851, des têtes de Carlina prises à Santigny, renfermaient entre les aigrettes de la fleur deux pupes noires ressemblant à celles des Siphonelles, mais elles ne sont point écloses.

L.e 17 novembre 1855 , il existait dans des capitules récoltés dans le meme endroit, de nombreuses larves réunies sur le réceptacle et sous les aigrettes qu'elles araient soulevées. Ces aigrettes sont noiratres et leur saillie fait reconnaitre les fleurs habitées. Ces larves d'un Diptère, blanches, apodes, glabres, rétractiles, coniques, ont $\mathbf{4}$ millimètres de longueur et 6 lorsqu'elles s'étalent pour marcher.

On leur trouve deux crochets noirs à l'extrémité de la tète, ils leurs servent à ratisser, à racler leur nourriture et à la porter dans leur bouche, ils leur servent aussi de grapin pour avancer. Le corps formé de dix ou onze segments est terminé sur le dernier par deux petits tubercules d'un blanc jaunatre, stigmatiques.

Ces larves se nourrissent de la substance du réceptacle qu'elles rongent, et probablement aussi des graines de la plante. Ces larves ont quitté les capitules et se sont répandues dans les boites à observation où elles sont mortes. Elles doivent probablement se métamorphoser dans la terre. 


\section{HISTOIRE}

\section{DES \\ MÉTAMORPHOSES DO LARINUS GARLINR,}

Par M. le D' Alexandre LABOULBÈNE.

Réunlon extraordinalro annuelle de 1858.

(Séance du 14 Avril.)

J'ai trouvé la larve de cet insecte dans le mois de juillet 1857, à Villegenis, dans le domaine de S. $\Lambda .1$. Monseigneur le prince Jéròme Napoléon en ouvrant les capitules prêts à fleurir, ou dont la floraison s'effectuait, de la Serratula arvensis LINNÉ.

Il est facile de s'apercevoir si un capitule de Scrratula est attaqué par une larve, car on voit alors sur un des colés, un avortement, une sorte d'atrophie de quelques ćcailles du calice et de plusieurs fleurons qui ont pris une teinte brunâtre. La fleur composée est de la sorte infléchie sur une de ses faces. La piqûre faite, probablement par l'insecte parfait au moment où l'œuf est déposé, occasionne cette altération particulière.

On trouve la larve, à divers degrés de développement au fond de la fleur composée, sur ou dans le réceptacle dont elle se nourrit. Après avoir crû, aux dépens de co réceptacle charnu, la larve se fait une loge qu'elle construit avec la partie inférieure des paillettes nombreuses qui sont à sa portée. Elle les réunit, les tasse, les enduit d'une substance 
agglutinative, et c'est dans cette loge, ou cocon, qu'elle subit sa transformation en nymphe et d'ou elle sort sous la forme d'insecte parfait.

Après avoir constaté la présence d'une larve sur plusicurs fleurs de Serratuli, je les avais enfermées dans des boltes, j'avais ajouté de la terre où elles pouvaient aller se transformer; je pensais néanmoins, par analogie, qu'elles devaient, comme celles da $L$. maurus rester dans la fleur complosée. Ayant laissé ces larves le 12 juillet, 1857, je n'ai pu les revoir que vers le milieu du mois de septembre. A cette époque, j’ai trouvé trois insectes parfaits du Lurinus carlince bien développés et morts, trois lchncumonides (de deux especes), parasites de cet insecte, enfin des nymphes mortes, desséchées. L'insecte parfait a dû éclore en août.

J'ai constaté la forme de la coque que la larve avait fabriquée et qui ressemble fort quand elle est ouverte à certains nids faits de brins d'herbe, je n'ai pas vu de fils de soie, de trame formée pour relier les pailleltes du réceptacle des graines de Scrratula. J'ai examiné à cet effet le cocon après l'avoir fait tremper dans l'eau. Cette coque est brunatre et lisse en dedaus, ovale, revetue en dehors d'un feutrage de paillettes.

Description des trois états du Larinus carlina.

S ler Larve. (Voy. pl. 7, no. II fig. 1 à 8.

Larve (fig. 1) très fortement recourbée sur elle-même, formant environ les sept huilièmes d'un cercle complet; thorax n'étant guère plus épais que le reste du corps. Couleurgrise, téguments diaphanes laissantapercevoir les organes 
internes, ce qui donne parfois à toute la larve la coloration des derniers segments abdominaux des grosses larves de Lamellicoınes.

Tête brune ou fauve antérieurement surtout, avec quelques poils rares, silués en avant.

Antennes situées à la base et un peu en dehors des mondibules, paraissant formées de deux arlicles très petits, le dernier terminé par un poil (fig. 7).

Epistôme et labre un peu échancrés au milieu, surtout ce dernier qui a quelques poils antéricurement (fig. 3).

Mandibules noiratres, fortes, bidentées à l'extrémité (fig.4).

Mâchoires à lobe interne large, fixe, ayant en dedans une série de poils courts, en dent de peigne; en dehors chaque machoire porte (fig. 5) un palpe de deux articles, le premier épais, aussi large que long, le deuxième allongé, terminé par trois poils.

Lèvre inférieure (fig. 6) arrondie sur les côtés, arquéc en avant, ayant de chaque coté un palpe de deux articles, le premier épais beaucoup plus grand que le deuxième.

Segments du corps très plissés ainsi que l'indique la fign. 1 ; doublement mamelonnés sur les côtés; très difficiles à compter; au nombre de douze, la tête non comprise; tégument luisant, presque glabre. Segments thoraciques absolument apodes.

Stigmates petits, à péritreme rond (fig. 8); au nombre de neuf paires, situés les premiers au bord du prothorax sur la membrane qui l'unit au deuxième segment du corps, les autres sur les quatrième, cinquième, sixième, septième, huitième, neuvième, dixième et onzième segments, vers le milieu de leurs bords latéraux. 
On n'éprouve aucune peine pour reconnaltre les deux articles des palpes maxillaires de cette larve. J'ai dejà dit, dans la description de la larve du Ceutorhynchus drabae dans ces Annales, 1856, p. 158, que les palpes maxillaires ont deux articles seulement $\dot{a}$ bords nets, et un troisième basilaire, membraneux, rétractile. Cet article basilaire m'a paru indistinct dans la larve du $L$. carlina.

Le nombre des articles des palpes maxillaires parait d'ailleurs etre de deux chez toutes les larves de Curculionides et de Bostrichides (1).

Je n'ai trouvé qu'une seule figure dans Ratzeburg où il y en ait trois représentés nettement. C'est pour la larve du du Curculio pini L. (IIylubius abietis). (Voy. RATzeburg Die Forstinsecten, Coléoptères, pl. IV, fig. 11, $\gamma$ et $x$.)

\section{S12. Nymphe (Voy. pl. 7, no II, fig. 9).}

Nympпe blanchatre, glabre ou presque glabre; luisante, offrant les formes de l'insecte parfait. Segments thoraciques sans poils allongés ; les abdominaux n'étant pas très mamelonnés. Extrémité postérieure sans prolongements. Les fourreaux des antennes, des ailes et des pattes ne paraissent devoir offrir rien de spécial.

(1) M. Edouard Perris a parfaitement exposé ces faits dans son beau travail sur les Insectes du Pin maritime ( $\mathrm{Ann}$. de la Soc. Ent. de France, 1856, 437). M. Burmeister a trouvé deux articles seulement aux palpes maxillaires et labiaux sur une grosse larve de $\mathrm{Ca}$ landra, mais il existe la trace d'un troisième article à la base des maxillaires (Zur Naturgeschichte der Gattung Calandra, etc., fig, 12, Berlin, 1837). 


\section{\$3. Insecte parfait.}

Larinus carlince Ouvien, Ent. V, page 280, genre 83, no 30 , pl. 21, fig. 282 (Lixus).

Scroensuen, Curcul. III, 133, no $\mathbf{4 5 .}$

Allongé, presque parallèle. Noir, à écailles grisâtres. Rostre plus court que le corselet, arqué, cylindrique, entier. Corselet très finement ruguleux. Elytres ponctuées-striées, intervalles larges, plans finement rugueux, à mouchetures grisâtres disposées presqu'en damier. Cuisses muliques GyLleniall.

L'un des trois individus éclos dans mes boltes appartenait à la varićté $B$ dont la coulcur est d'un brun clair.

Deux des parasites me paraissent pouvoir être rapportés au Caelinius viduus IIAliday ; le dernier est une Pimpla $q$, que je n'ai pu déterminer.

Mon cher et savant ami M. Perris, a observé aux environs de Mont-de-Marsan, la larve du Larinus carline vivant dans le réceptacle des fleurs du Cirsium palustre. IIon savant collègue, M. le colonel Goureau l'a trouvée dans cette même plaute à Santigny, dans le département de l'Jonne.

La science ne possède sur les métamorphoses des Larinus que la description de la larve du Larinus maurus Otivier, prise à Montpellier dans le Buphtalmum spinosum L. par M. Jacquelin-Duval et décrite par MM. Chapuis et Candèze dans leur Catalogue des larves de Coléoptires, page 212, pl. VII, fig. $\boldsymbol{\tau}$. (Voyez pour les changements de couleur de ce Larinus en rougeatre et en verdatre, les Annales de la Société entom., de France, 1852, page 732.) 
Mi. Jacquelin-Duval a trouvé aussi d̀ Montpellier la larve du Larinus maculosus Schoennnen, dans les capilules de l'Echinops ritro. Elle s'y creuse une vaste cellule et s'y transforme en nymphe vers la fin de juillet ou le commencement d'août. Elle se nourrit comme celle du $\boldsymbol{L}$. carlince de la partie charnue du réceptacle. Elle construit une coque assez résistante, formée de fibrilles végétales, agglutinées par le produit d'une sécrétion. On ignore le temps qu'elle passe sous les formes de larve et de nymphe. L'insecte parfait parait en aoùt et septembre. Sa ponte n’a pas été observée, mais il est probable que la femelle perce avec son rostre la partie verte du périanthe et y dépose ses œufs dans la substance charnue (loc. cit. et Ann. Soc. Ent. Fr., 1852, 731).

La larve du Larinus maculosus n'a pas encore été décrite, à ma connaissace.

Enfin M.M. Goureau et Léon Dufour ont observé la larve d'un insecte voisin des Larinus, c'est celle du Rhinocyllus latirostris; le premier l'a décrite dans nos Annales (1845, p. 77 et suiv. et figurée pl. II, fig. 4); elle vit dans le Carduus nulans. M. L. Dufour l'a trouvée avec une foule d'autres insectes dans les capitules de la Centaurea nigra. (Voy. Ann. Ent, de France, 1857, page 49.)

Explication des figures de la planche 7, no II.

Fig. 1. Larve du Larinus carline OLivien, grossie.

2. Cette larve de grandeur naturelle.

3. Labre et épistème. 
Fig. 4. Mandibule du côté droit de la bouche.

5. Machoire du même coté.

6. I.ère inférieure.

7. Antenne.

8. Un stigmate, pour montrer le péritrême arrondi.

8. Nymphe du Larinus carlinoe et à côté d'elle mesuro de sa grandeur naturelle. 


\section{HISTOIRE}

\section{DES \\ MÉTAMORPHOSES DE L'ORCHESTES RUFUS,}

Par M. le D' Alexandre LABOULBENE.

Réunion extraorilnafre annuelle do 1858.

(Séance du 14 Avril.)

Une monographie des Coléoptères du genre Orchestes et de leurs larves serait un travail rempli d'intérêt. Les formes et les couleurs de ces petits Curculionides, à cuisses postérieures renflées, propres au saut, n'offrent pas une grande variété, mais elles sont agréables. Leur synonymie d'ailleurs est très embrouillée. Quant à leurs larves, elles sont mineuses de feuilles et ont fourni à Réaumur, De Géer, Ratzeburg, Bouché, Héeger, etc., le sujet d'observations remarquables.

J'ai suivi pendant deux années les métamorphoses de l'Orchestes rufus Ocivien. Sa larve se trouve dans les feuilles récemment développées, ou encore tendres, de l'orme. J'en ai recueilli une grande quantité dans le domaine de Villegenis, près de Verrières.

Je dois dire qu'il est éclos des feuilles du meme arbre les deux Orchestes rufus et mclanocephalus.

Je crois toutefois pouvoir assurer que la larve et la nymphe des fig. 4, 5 et 11 se rapportent au rufus, car j’ai trouvé cet insecte dans les boîtes oủ j'avais laissé la nymphe que j'ai dessinéc. 
Les métamorphoses d'un Orchestes de l'orme ont déjà été suivics. Réaumur et de De Géer les ont rapportées dans leurs Mémoires pour servir à l'histoire des insectes. Ce doit etre un devoir de citer les précieux travaux de ces grands Natu. ralistes. Ils ont souvent épuisé le sujet et les observations ultérieures ne peuvent alors que confirmer les leurs, en ajoutant à peine quelques détails.

RÉAumur s'exprime ainsi dans le cinquième volume de ses Mémoires:

- Il nous reste à faire connaître quelques-unes des espèces de vers mineurs qui se transforment en scarabées; il y en a une qui en veut aux feuilles d'orme et qui y est très aisée à trouver. Si on observe les feuilles de plusirurs de ces arbres à la fin du printemps, on en apercevra, qui, quoique très vertes partout ailleurs, ont quelque part près de leurs bords, une partie desséchée, mais plus renflée que le reste. Un ver blanchatre qui a rongé l'intérieur de la feuille dans cet endroit est cause du desséchement qui y parait ; celui-ci se tient à peu près à égale distance du dessus et du dessous de la feuille, et il oblige les parties qu'il a séparées à prendre chacune de la convexité vers le dehors. Ce ver se métamorphose dans un très petit scarabée brun, qui est de la classe de ceux que nous appellerons dans la suite des scarabées à tete en trompe... page 31 . »

Nous trouvons dans DE GÉer, tome V, page 260 de ses Mémoires sur les insectes:

Charançon sauteur de l'orme. - Charançon sauteur à longue trompe, à corps ovale, d'un jaune d'ocre foncé et à yeux noirs.

"Les larves de ces Charançons vivent dans les feuilles de l'orme, qu'elles minent en grand, ou en grandes aires, se 
nourrissant de la substance intérieure de la feuille, qu'elles rongent en ménageant adroitement les deux membranes. Les endroits où elles se trouvent placées, se représentent comme des taches circulaires (fig. $a, b, c$ ) renflées dans le milieu des deux côtés de la feuille, en forme de petites vessies; ces plaques sont composées des deux membranes de la feuille qui se sont desséchées, la substance quise trouvait entre elles deux, ayant été consumée par la larve ; c'est pourquoi leur couleur est brune ou feuille morte, comme une feuille sèche. L'élévation de l'endroit miné n'est pas seulement produite par la larve qui s'y trouve placée et qui par sa grosseur excède déjà l'épaisseur de la feuille, mais elle est encore augmentée par une coque que la larve file en dedans de la feuille dans l'endroit miné, et tout cela avant que les membranes de la feuille se soient entièrement desséchées et tandis qu'elles sont encore susceptibles de quelque extension. Ces espèces de vessies sont ordinairement placées près des bords de la feuille, parce que les nervures y sont plus tendres et par conséquent plus faciles ì etre rongées par la larve. C'était à Utrecht au mois de mai et de juin de l'année 1736, que je découvris ces larves et leurs nids, mais je ne les ai pas encore rencontrées en Suède.

n Ces larves sont très petiles, de couleur blanc-jaunatre, avec plusieurs points obscurs (pl. 8, fig. 7), mais la tête et le premier anneau du corps sont d'un brun obscur. Le corps est divisé en douze anneaux, dont les séparations ou incisions sont profondes; les colés sont un peu ridés et le derrière est conique. On voit tout le long du dos à travers la peau, le grand canal des aliments, qui parait noir quand l'insecte a bien mangé. La tête est écailleuse et assez semblable à celle des chenilles, mais elles n'ont point de pattes. 
Parvenues au dernier degré d'accroissement, elles filent une petite coque très mince dans la feuille meme, et prennent ensuite la forme de nymphhes (fig. 9 et 10), qui sont d'un beau jaune à yeux d'un brun clair, et sur lesquelles on voit toutes les parties du Charançon arrangées avec beaucoup d'ordre. Vers la fin de juin les Charançons quittent la peau de nymphe et percent la feuille pour en sortir. Ils continuent encore de manger la feuille de l'orme et j'aj observé qu'ils survivent l'hiver, les ayant souvent trouvés en hiver sous la vieille écorce à demi détachée des arbres où ils séjournent pour se mettre à l'abri du froid et c'est au printemps suivant qu'ils se multiplient de nouveau."

Les auteurs qui ont parlé des Orchestes de l'orme après Réaumur et De Géer ont copić leurs ocuvres littéralement comme Herbst pour De Géer, ou bien n'ont rien fait connaître de plus.

J'ajouterai seulement, pour ma part, les réflexions suivantes:

Feuilles d'Orme. Je n'ai jamais trouvé ces feuilles mineses autre part que sur leurs bords (Voy.pl. 7, no III, fig. 1, 2,3). J'en ai vu de très peu développées renfermant des larves déjà près de se transformer. Ils est probable que l'œuf éclot dès qu'il est pondu et que la petite larve se hate de pénétrer dans l'intervalle des deux lames de la feuille. De Géer a représenté(loc. cit.) une feuille d'Orme minée dans le milieu, mais son texte donne ce fait comme exceptionnel. II parle de la préférence marquée des larves pour le bord des feuilles.

Coque. Je n'ai rien à ajouter à la description fidèle des deux Auteurs, sur la boursouflure creuse et d'un roux-branatre ou se trouve la nymphe, sur les bords de la feuille. Réaumur n'avait point remarqué l'existence d'une coque on зe Séric, Tоме vi. 
cocon en cet endroit, mais cette coque n'avait point échappé à De Géer qui la regarde comme étant filée par la larve.

J'ai le regret de n'avoir pu observer complétement comment s'y prennent les larres de cet Orchestes de l'Orme pour construire leurs coques. J'ai essayé d'enlever une des parois de la feuille minée et de la remplacer par une lamelle de verre; mais les insectes troublés, ou peut-être se trouvant dans des conditions défavorables, n'on pas voulu filẹ. Je me propose d'essayer à l'occasion d'enlever sur le cocon déjà commencé une partic que je remplacerai par le fon! concave d'un verre de montre en collant la feuille en eet endroit.

Tout ce que j’ai vu se réduit à des mouvements des deux extrémités ủu corps, et je pense, vu l'absence de filière buccale, que l'organe producteur de la matière du cocon est situé à l'extrémité ou près de l'extrémité de l'abdomen. Dans le compte-rendu de sa Première excursion dans les GrandesLandes (Lyon 1850, page 44). M. E. Perris dit: a Avant de passer à l'état de nymphe, elles (les larves d'Orchestes) s'enveloppent d'une coque soyeuse d'un tissu lache. La filière qui produit celte coque, se trouve à l'extrénilé postérieure du corps. Cette particularité assez bizarre n'a été, je crois signalée nulle part. $D$

L'habile naturaliste a vuet publié depuis (dans les Mémoires de l'Acalémie des sciences, belles-'ettres et arts de Lyon), les mancuvres de la larve du Phylonomus vicie Grildevihl. C'est en prenant, avec les parties de la bouche, la liqueur' sortie d'un mamelon situé à la base dorsale du douzicine segment, que les larves de ce Phytonomus construisent Ieurs coques à larges mailles. M. Perris est parvenu a faire filer ces larves sous des verres de montre et les a suivies pendant cette opération en les examinant à la loupe. 
Je tiens de M. le colonel fourenu qui a suivi les mélamorphoses de plusicurs larres d'Orchestes qu'avant de se changer en nymplies, elles tapissent leur demeure avec une matière liquide qui paraît sortir des derniers segments de l'abdomen.

Quoi qu'il en soit de la manière dont la coque de l'O. vrufus est formée par la larve, on trouve qu'clle est composée d'une sorte de membrane mince, fauve, qu'on a de la peine à détacher des deux lames écartées de la feuille, à moins qu'elle ne soit bien desséchée.

La coque forme, dans son ensemble, un petit corps ovoïde, lisse en dedans. Examinée à la loupe et su microscope, elle se trouve bâtic avec de gros fils. Il ne parait pas exister de trame soyeuse, mais un enchevetrement de filaments bruns ou fauves, gros et placés, surtout à angrle aigu, les uns contre les autres.

J'ai fait bouillir des feuilles msinées, j'ai recherché ensuilc sur l: coque devenue plus souple si je parviendrais à dévider les fils réunis par une matière gommeus? et j'ai pu y parnir, quoiqu'arec peine. Je conclus de la que cefle coque est formée par une matière tirée en gros filaments el nou par des fils de soie, fins, proprement dits, sortis d'ut:e liliere labiale. L'analogie me porte à croire que les palpes et d'aulres pièces buccales doivent servir à étendre la matìre du cocon. cette matière étant fouruis par un organe situé a l'extrémité de l'abdomen.

On trouve sur la feuille et la coque, après la sortic de l'insecte, un trou arrondi, assez régulier, usie perte de substance. L'Orchestes a commencé à l'étit parfait par détruire l'obstacle qui le retenait captif, puis il a paru au dehors (fig. 3). 
Larve. De Géer a représenté la larve au repos et la figure qu'il en donne est assez exacte ainsi que sa description. Toutefois, j'ai pensé qu'une nouvelle figure représentant la larve allongée et une autre vue de profil ne feraient point double emploi.

J'ai insisté sur les parties de la bouche que les auteurs ont généralement négligées, par excmple Ratzeburg pour l'Orchestes fagi. Héeger a fait connaitre les pières buccales de l'Orchestes populi dons ses Beitrage zur Naturys sch chte der Insecten (Sitzungsb.der K. Akad.der Wissenschaften au Wicn; XI, Band., Heft I, 1853, Raf. VI). Cet auteur représente fig. 6, la lèvre inférieure, sans pâlpes et avec une filière au milieu. J'ai déjà dit que je n'ai vu rien de semblable. (Voy. fig. 9.)

Nymphe. J'ai éprouvé un vif sentiment de plaisir en trouvant dans les Mémoires de De Géer, le portrait d'une uymphe ressemblant beaucoup à celui que j'avais dessiné moi-méme pour le meme insecte. La nature ne change pas et à un siècle re distance ses productions ont une adinirable conformité. J'ai pu ajouter cependant aux connaissances que nous devons au Réaumur suédois quelques détails, entr'autres ceux du dernier segment abdominal.

MM. Ratzeburg et IIéeger n'ont rien signalé de spécial aux derniers segments abdominaux de la nymphe des Orchestes fagi et populi. Mais, mon savant ami M. Perris, m'écrit qu'il possède les larves et les nymphes des Orchestes crinitus, pubescens, quercûs et iola; ces nymphes ont toutes le mamelon que j'ai observé vers la base du dernier segment ventral, mamelon surmonté de tubercules piligères. 
Insecte parfait. Il est impossible de décider si Réaumur a observé l'Orchestes rufus ou l'Orchestes melanocephalus, dont les mours sont analogues et les larves peut-etre à peine distinctes, ainsi que le's nymphes. Miris il est sûr que De Géer a cu réellement sous les yeux l'O. rufus. C'est pour fixer l'attention, à ce sujet, que j'ai rapporte la phrase descriptive de De Géer. Je n'ai rion à mettre après ce qu'il dit des mœurs de cet insecte, sinon que les œufs sont presqu'arrondis et d'un blane jaundtre.

Description des trois états de L'ORCHESTES Rufus.

S 1. Larve. (Voy, pl. 7, $\mathrm{n}^{\circ}$ III, fig, 4 à 9.)

Lanve d'un jaune très clair ou d'un jaune à peine rougeatre, allongée; un peu élargie au delà du milieu à l'état de repos; alténuée en arrière; presque plane en dessus et en dessous. Corps de douze segments, la tete non counprise, non plus qu'un prolongement articulé du dernier segment.

Tête (fig. 1 et 6 ) brune, peu avancie, rentrant en partie dans le premier segment.

Mandibules (fig. 7) arquées au côté externe, à peu près droites et sinuées, avec une ou deux dents peu aigües an côté interne.

Mâchoires (fig. 8) avec le lobe interne arrondi en haut, pourvu de gros cils. Elles ont en dehors un palpe de deux articles: le premier gros, le deuxième grêle et terminé par trois ou quatre poils. 
Lèvre inférieure (fig. 9) demi-circulaire ell avant, supportant deux palpes biarticulés.

Antennes (fig. 6) très petites, situées à la base des mandibules et paraissant formées d'un, peut-ctre de deux articles, terminées par un poil.

Segments thoraciques (fig. 4 et 5) plus larges que les abdominaux; le premier ou prothoracique subarrondi en avant, ayant en dessus deux traits arqués, brunatres. Le deuxième ou mésolhoracique, le plus grand de tous, arrondi sur les cotés; Ic troisième ou mélathoracique, moins long, également arrondi sur les côtés.

En dessous, le premier segment offre une teinte brundtre presque médiane, bien prononcée; les deux suivants présentent de chaque côté du milicu deux petites places obscures, à l'endroit ordinaire où s'insèrent les pattes, dont on ne voit dans cette larve, aucune trace.

Segmentsabulominaux, au nombre de neuf, plans en dessus, peu arrondis sur les côtés, mais offrant en dehors un prolongement saillant, lobaire, au point de réunion des demisegments supéricurs et inférieurs; le derniers segment terıniné par une saillie conique, articulée à sa base.

Quand la larie s'allonge elle prend la forme que j'ai représentée (fig. 4).

I. corps examiné à un fort grossissement est granuleux. On distingue deux ou trois poils courts, au bord de chaque segment et sur les cotés de la tete.

Stigmates au nombre de neuf paires; le premier situé au bord postérieur du prothorax, près du deuxième segment; les autres sur les quatric̀me à onzième segments. Le douzième en est dépourvu, comme d'habitude (

Je n'ai pas remarqué les ocelles de cette larve. J'ai omis 
le dessiner la forme du labre, mais je trouve dans mes notes qu'il est, à peu près arrondi en avant.

S2. Nymphe. (Voy. pl. 7, fig. 10 et 11).

Nrmpie jaunâtre comme la larve, ovale, allongée, offrant emmaillotées les formes de l'insecte parfait.

Tête débordée par le corselet en haut, courbée. liostre appliqués sur la poitrine. Ycux brunatres. Antennes coudees, s'appuyant de chaque côté, en haut sur la première paire de pattes.

Prothorax avec deux fortes saillies supérieures terminées par un gros poil ; arrondi sur les cotés. Mésothorax ayant ses angles antérieurs saillants. Pattes à cuisses et jambes repliées, renflées au milieu; tarses à divisions peu nettes, mais indiquées assez fortement.

Elytres recourbées, couvrant les cuisses postérieures; ailes débordant les ślytres en bas et en dedans.

Abdomen avec les articles presque droits, peu arrondis sur les cotés; terminé par deux saillies, offrant chacune un prolongement articulé, aigu (fig. 10 et 11). Le dernier segment présente en avant un espace ovale, muni de huit saillies pointues, ou huit mamelons, terminées par un poil court, les deux supéricures rapprochées, les autres obliques, convergeant en bas.

Je dois faire remarquer les poils gros et courts dont la tete est munie, ainsi que ceux du thorax, de l'extrémité externe des cuisses et sur les bords des segments abdominaux. En outre, j'ai vu, sur cette nymphe une saillic, un prolongement inférieur à l'extrémité de chaque patte, près de 
larticulation de la cuisse sur la jambe, et je l'ai figurée. Je n’attache pas à ce détail plus d'importance qu'il n’en mérite. Le fourreau des antennes et des larves est épaissi, noueux, mais sans diverticules aussi marqués que sur les palles. Nous ne devons pas, du reste, ctre étonnés de ces prolongements, quand nous voyons certaines chrysalides de Lépidoptères diurnes pourvues d'appendices extraordinaires; mais trouvant cette disposition sur les pattes de cette nymphed'Orchestes, j’ai dû y insister.

\section{S3. Insecte parfait.}

Orchestes rufus OLivier, Ent. V, page 101, genre 83, no 40 , pl. 32 , fig. 485 .

Schoennienk, Curcul. III, 492, geure 250, 5.

oblong, subconvexe. D'un roux testacé, a pubescence et poils grisatres; yeux et poitrine noirs. Corselet convexe, pointillé. Écusson concolore, presque dénudé. Elytres amples, distinctement ponctuées-striees, les points assez arrondis. Cuisses postérieures épineuses.

J'ai traduit cette description donnée par Gyllenhall dans l'ouvrage de Schoennmenr. Elle s'applique parfaitement à notre insecte. J'ai eu avec le type la variété $B$ de Schœnnherr, à poitrine de la couleur du corps.

Ratzeburg a mentionné dans son ouvrage sur les Ichneumons parasites faisant suite à ses $F$ orstinsecten, vingt-quatre espèces d'Iyménoptères parasites de l'Orchesles quercûs et treize parasites de l'Orchestes fagi. J'ai obtenu pendant deux années quatre espèces distinctes, vivant au dépens des larves de l'Orchestes rufus, mais je ne les ai pas encore déterminées. 
Explication des figures de la pl. 7, no 1 III.

Fig. 1. Feuilles d'orme récemment développées dont l'une minée présente déjà une coque formée par la larve de l'Orchestes rufus.

2. Une feuille du meme arbre, minée à l'extrémilé et sur son bord droit, montrant par transparence une larve d'Orchestes.

3. Une feuille encore plus développée, minéeà l'estrémité, avec le trou de sortie pratiqué par l'insecte parfait.

4. Larve d'Orchestes rufus OLIvien, vue au moment où elle s'allonge pour ramper, et mesure de sa grandeur naturelle.

5. La même vue de profil mais plus contractée.

6. Ensemble de la tete.

7. Mandibules.

8. MIachoire du côté gauche de la bouche.

9. Lèvre inférieure.

10. Nymphe de l'O. rufus et à côté d'elle mesure de sa grandeur naturelle.

11. Dernier segment abdominal de la nymphe vue de profil. 



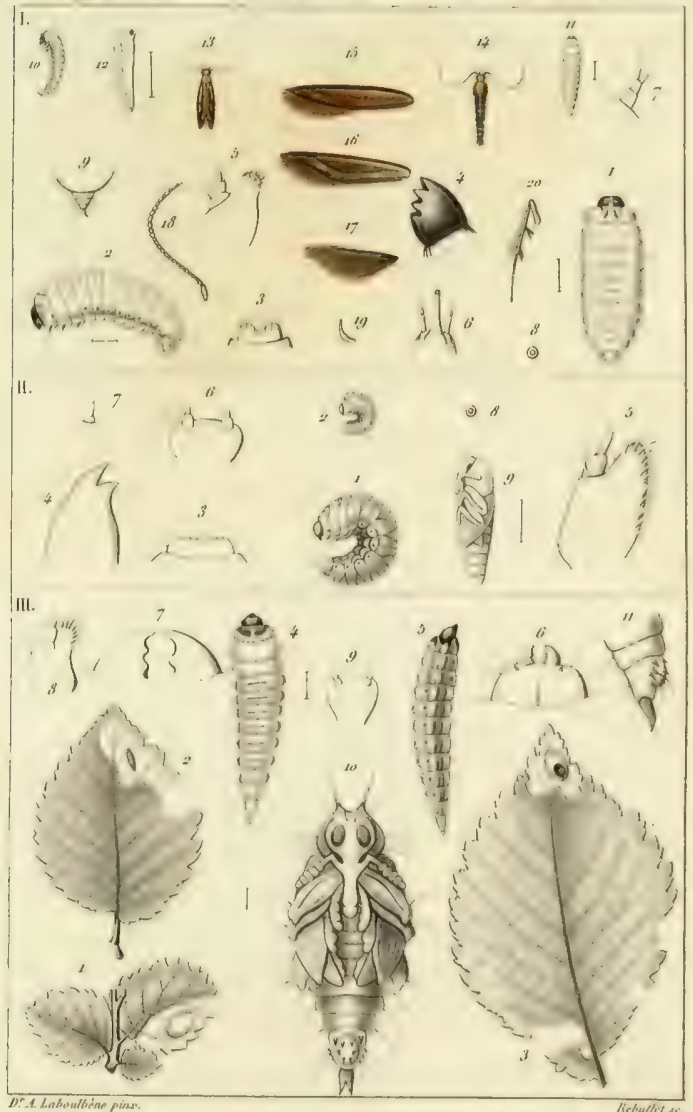

1. Mémmorphoses ate la Cielechin enrlinella. Donghes

II. " du Larimas indina" Otio.

III. " de l'Orchestes rufus. Otio. 



\section{CONGRËS}

DE

GRENOB L E 
PAnis. - Typ. FÉl.IX MALTESTE BT Ge, 22, rue des Deux-Portes-St-Sauveur. 


\title{
CONGRÈS
}

DE LA

\section{SOGLÉTÉ ENTOHOLOGIQUE}

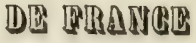

TENU A GRENOBLE EN 1858.

Extrait des ANMALES des $3^{e}$ et 4 e trimestres 1858.

A PARIS,

CHEZ LE TRÉSORIER DE LA SOCIÉTÉ,

BUE HAUTEPEULLE, 19.

1858 



\section{CONGRÈS}

DE $\mathbf{1 4}$

\section{SOCrÉTÉ ENTOMOLOGIQUE DE FRANGE}

TENU A GRENOBLE EN 1858.

\section{EXTRATTS DES PROGĖS-VERBAUX DES SÉANGES.}

\section{Session extratorilnaire annuelle de anris. \\ (Séance du .14 Avril 1858.)}

Présidence de M. le docteur BOISDUVAL.

Décision. La Société, à l'unanimité des voix, décide que la cession extraordinaire provinciale de 1858 se tiendra à Grenoble, et que les chasses entomologiques auront lieu dans les environs de Grenoble, dans les Hautes-Alpes, et principalement à la Grande-Chartreuse. L'époque précise de cette réunion sera fixée ultérieurement.

Une commission, composée de MM. le docteur Boisduval, E. Desmarest, $\mathbf{\Lambda}$. Doüé et le docteur Sichel, est chargée de l'organisation de ce Congrès.

(Słance de Paris du 23 Juin 1858.)

Présidence de M. le $\mathrm{D}^{\mathrm{x}} \mathrm{LABOULBÈNE}$, 2* vice-président.

Communications. M. E. Desmarest, secrétaire, fait connaître la circulaire, en date du 17 juin, qu'il a, de concert 
avec $\mathbf{M}$. le président, adressée à plus de $\mathbf{2 5 0}$ de nos collègues, tant en France que dans les pays voisins, tels que l'Angleterre, la Belgique, l'Allemagne, la Suisse, l'Italic et l'Espagne, pour annoncer le Congrès de Grenoble, et engager le plus grand nombre possible de nos confrères à s'y rendre. Il donne également communication des répouses, à ce sujet, d'un assez grand nombre de nos membres.

- M. Ie Secrétaire parle également des démarches que, conjointement avec M. l'Archiviste, $M$. Doüé, il a fait relativement à l'excursion extraordaire dans les Alpes, et donne lecture de diverses lettres des directeurs des administrations de chemin de fer de Paris à Lyon, Lyon à la Méditerranée et du Dauphiné, d'où il résulte que les membres de la Société qui se rendront à Grenoble jouiront sur toutes ces lignes d'une réduction de moité sur les prix de transport, a partir du 3 juillet jusqu'au 5 août, et qu'il auront la faculté de scinder le parcours et de s'arreter en route, soit en allant, soit en revenant.

Décisions. La Société décide : $1^{0}$ que le Congrès de Grenoble sera ouvert le 7 juillet et durera jusque et y compris le 18 du même mois ; $2^{\circ}$ que MM. E. Desmarest et H. Lucas étant retenus à Paris, M. le docteur Laboulbine, viceprésident, remplira à Grenoble les fonctions de secrétaire.

Elle règle, en outre, l'ordre du jour de la session extraordinaire qui doit être tenue à Grenoble (voy. page 13).

(Séance de Grenoble du 7 Juillet 1858.)

Présidence de M. le docteur BOISDUVAL.

La Société se réunit à huil heures du soir, dans unc 
des salles de la Faculté des sciences, au Jardin botanique do Grenoble. M. le professeur Bouteille, conservateur du Musée, avait fait prendre toutes les dispositions nécessaires pour l'installation de la Société entomologique de France dans ce local, désigné pour elle par M. le Maire de Grenoble.

Vingt-six membres de la Société sont présents à l'ouverture de la séance, à laquelle assistent un grand nombre de naturalistes étrangers. Parmi eux se trouvent MM. le professeur Bouteille, conservateur du Musée, le professeur Verlot, Goumain, secrétaire général de la mairie du $12^{\circ}$ arrondissement, Maillard, Servant, Malet, Locré, Lhuys, docteur Perréal, Plessis père et fils, Robinet, Iubert, Tronson, Fontannes, etc., etc.

M. le docteur Laboulbène, Vice-Président, remplit les fonctions de Secrétaire.

M. le Président déclare la session ouverte, puis il prononce le discours suivant :

Messieurs,

L'année dernière, à pareille époque, la Sociêté entomologique de France sc réunissait pour la première fois en session extraordinaire à Montpellier. Vous avez tous conservé le souvenir de l'accueil bienveillant dont elle fut l'objet de la part des autorités et des diverses Facultés du département. La préférence donnée à cette ancienne cité si renomméc autrefois comme le centre scientifique de notre patrie, n'a dú étonner personne. N'était-ce pas là le lieu où les Sociétés de Botanique et Entomologique de France devaient faire leur premier pèlerinage ? La tradition leur avait appris que Limné, ce grand maitre, le premier des naturalistes modernes, je dirais presque avec le général Dejean, des temps passés, préscnts et futurs, avait quitté 
momentanément sa chaire d'Upsal, à une époque où les moyeus de transport étaient rares et difficiles, pour traverser une partie de l'Europe et venir visiter les environs de Montpellier, dont la flore et la faume sont si différentes de celles des régions du Nord. Déjì en ce temps des savants de premier ordre y enseignaient les sciences naturelles, Dodart, Gouan, Broussonnet, dont les chaires ont eté successivement occupées par des hommes non moins illustres, tels que Decandolle, Delite, Dunal, etc. Nous pourrions même ajouter, si nous ne craignions de blesser la modestie de nos collègues, qqu'aujourd'hui même la Faculté des sciences de Montpellier soutient dignement son antique réputation.

Grâce à la bienveillance éclairéc de nos administrations de chemins de fer, la Société entomologique de France vient cette année visiter ces contrées qu'exploraient jadis Allioni et Villars, et demander l'hospitalité à cette vieille ville de Grenoble, qui a bien aussi ses souvenirs et ses parchemins, pour y tenir sa deuxième session extraordinaire.

Ici, Messieurs, au lieu d'une faune exclusivement méditerranéemne sous une température presque constante, en passant suecessivement par divers climats, vous rencontrerez les planies et les insectes de l'Europe moyenne, de quelques parties de la Provence et des régions septentrionales. Dans cette belle vallée du Grésivaudan, à Alievard, vous vous croirez presque à Fontainebleau; dans les plaines au sud de Grenoble, rous retrouverez çì et là de nos vieilles connaissances de Montpellier, que vous reverrez encore dans les gorges chaudes du bourg d'Oysans en compagnie d'espèces alpines; ì la GrandeChartreuse, dans les vastes prairies qui entourent le couvent et dans ces bois de hètres et de sapins, dont certains arbres sont si vieux qu'ils tombent de vétusté, apparaitront les espèces propres aux montagnes alpines proprement dites, mais ce n'est que lì, où la végétation frutescente disparait, comme sur le grand Som, les montagnes du mont Lans, de Champ-Rousse, de Villars-ès-Monts, de VillarsSaint-Jean, de Saint-Christophe, du Haut-Richard, du mont Viso, du Galibier, sur les glaciers de la Grave, etc., que vous trouverez les insectes et les plantes du haut nord. Plusieurs d'entre vous, Messicurs, ont admirć plus d'une fois les loeautés sauvages de ces hautes inon- 
tagnes et savent sans doute mieux que moi quelle ample moisson ils rapporteront de leur voyage. Plusieurs aussi, sans avoir parcouru ces hautes régions, ont visite le couvent de Saint-Bruno et ont encore présent à la mémoire l'accueil affable et bienveillant que faisait aux voyageurs ce vénérable frère Jean-Marie, qui dort aujourd'hui du sommeil du juste sous les dalles glacées de la Chartreuse.

Les personnes érrangères aux sciences naturelles se demandent sans doute à quoi sert l'entomologic et considerent ceux qui s'occupent de son étude comme des gens déswuvrés employant leur temps aił des futilités. Nous pourrions leur répondre : In natura nil inane, dans la nature rien n'a été fait en vain; vous admirez un Eléphant ou un Rhinocéros aux proportions gigantesques, et rous ne vous doutez pas que l'organisation des insectes est tout aussi compliquée et tont aussi admirable que celle de ces animaux, que leurs instincts sont en géneral beaucoup plus merveilleux, et que celui qui leur a donné la vie lient également et sans distinction de classe, à la conservation de l'espèce de tous les êtres, et qu'ì chaque insecte comme à tout autre animal il a donne le droit de s'asseoir au banquet de la création. Leur rappelleronsnous qu'il y a certaines espèces dont l'homme a sut tirer parti ? S'il n'y avait pas une Société d'apiculture, nous citerions ces IIyménoptères, connus de la plus haute antiquité, qui, au temps des Philistins, déposaient des rayons de miel dans la gueule d'un lion assommé par Sanson, et qui dans liìle de Crète fournissaient le sucre destiné à édulcorer le lait de la chère Amalthée pour son nourrisson. Mais nous laissons à cette Societé le soin d'expliquer comment les anciens et les poètes ont pu confondre avec des abeilles ces Muscides qui se nourrissent de matieres animales en décomposition. Leur parferons-nous de ces clıenilles importées de la Chine et de l'Inde, qui filent nos étofles de luxe, de ces Colćoptères vésicanıs qui, depuis Hippocrate jusqu’à nous, ont rendu tant de services à l'bumanité, de ces liémiptères tincloriaux que l'on élève aujourd'hui avec succès sur les Opuntia, en Algérie, de cet autre Coccus, jadis si célèbre en mérlecine et servant encore maintenant à colorer celte liqueur florentine gue l'on vend an poids de l'or aux voyageurs, dans te couvent de Sainte-Maric- 
Nouvelle? Nous ne leur parlerons pas d'avantage du Cossus des anciens, qui était pour les romains une friandise de luxe, du Charançon palmiste des Antilles, que les créoles mangent comme un mets très délicat; des Sauterelles voyageuses dont St-Jean se nourrissait dans le désert el qu'Olivier et Bruguères ont vu vendre à la fin du siècle dernier sur les marchés de Bagdad, par sacs conme des céréales; de cet autre insecte qui, dans les contrées arides et incultes de l'Arabie, détermine par' sa piqûre sur les rameaux d'un T'amarix cette manne qui servit de nourriture aux Ilébreux, ni même de cet Hémiptère aqquatique dont les oufs sont si abondants aux bords de quelques laes du Mexique que les indigènes les recueillent pour s'en nourrir et les conservent dans des sacs comme de la semoule. Non, mais ce que nous voudrions, c'est que l'histoire des insectes fût plus connue des gens du monde et surtout des horticulteurs et des agriculteurs, et qu'ils sussent au moins distinguer leurs ennemis de leurs amis, c'est-ì-dire les espèces qui leur rendent des scrvices de celles qui leur sont nuisibles, s'il en était ainsi, ils respecteraient ces Carabes dorés et généralement tous les Colcoptères de la mème famille qui se promènent dans leurs bois, leurs champs et leurs jardins, se livrant à une chasse incessante aux lombrics, aux limaces et aux chenilles des Agrotis, appelées vulgairement vers-gris, etc. Ils respecteraient aussi religieusement ces Coccinclles, que le peuple appelle betes à bon Dieu, et dont les larves dévorent si vite les Puçerons de nos arbres fruitiers. Ils ne mettraient pas sur le compte des Fourmis la maladie de leurs pêchers quuand les feuilles sont recoquevillées par les Puçerons; ils sauraient, au contraire, que les Fournis viennent là pour les titiller avec leurs antennes et recueillir la matière mielleuse sécrétée par ces Itémiptères, et que souvent même elles les emportent et les soignent dans leur fourmillière comme des sortes de vaches ì lait. lls considéreraient comme leurs meilleurs auxiliaires ces Ilyménoptères qui crensent des trous dans le sable et dans la terre sèche pour y inhumer de nombreuses chenilles qui doivent servir de pâture à leur postérité, et surtout ces Iclmeumonides et ces nombreuses Chalcidites qui déposent Jeurs œufs dans le corps mème des chenilles, et dont les races s'accroissent en raison de l'abondance de ces dernières, ils sauraient en même 
temps que c'est au développement de ces parasites qu'il faut attribuer la disparition complete tle la Pyrale de la vigne rui mallieureusement depuis a été remplacée par un autre fléan qui tient à l'état pathologique, dont plusieurs de nos végétaux souffrent depuis quelques années sans qu'il ait encore êté possible d'en apprécier les causes. Ils auraient constate comme no:ts ce fait positif, que lorsqu'une espèce se multiplie outre mesare, les parasites se multiplient dans les mêmes proportions, de manière à ce que l'équilibre reste tonjours le même dans la nature. Ils comprendraient, enfin, que ces mouches qui nous importunent en venant se réfugier dans nos labitations ont aussi leur raison d'être, que les unes ont pour mission de détruire d'énormes quantités de chenilles en déposant leurs ouf́s dans leur substance arlipeuse, et que la plupart des attres espèces sont chargées d'anéantir les restes des matièies organiques, qui, sans ce secours hygiénique, se réduiraient à leurs ćléments et se répandraient en miasmes pestilentiels dans l'atmosphère. Linné a donc pu dire avec vérité que trois mouches feront disparaître plus promptement le cadavre d'un cheval, qu'un lion ne pourrait le faire en employant le même temps.

Messieurs, s'il est à désirer que les agriculteurs connaissent bien les mours des insectes qui leur sont utiles et dont nous venons de vous signaler seulement quelques espèces, ì la hâte, il n'est pas moins nécessaire pour eux de faire connaissance avec leurs ennemis afin de les attaguer plus surement. Depuis longtemps ils ont observé les mours du Bombyx chrysorrhée, et le seul échenillage qu'ils pratiquent consiste à enlever, à la fin de l'hiver, ces nids que l'on apercoit au bout des branches des arbres comme des paquets de feuilles sèches, mais ils ne font nulle attention aux espèces qui passent l'hiver à l'état d'cufs. Ils laissent inapercus ces trainées d'oufs du Bombyx dispar qui ressemblent à des morceaux d'amadou appliqués sur le tronc des arbres des promenades publiques, et dont les nom. breuses chenilles qui en sortent au printemps ne tardent pas à les dénuder de leurs feuilles. Nous pourrions dire ha mème chose du Bombyx du Saule, dont les paquets d'œufs se font remarquer sur le tronc des peupliers par la coulcur blanche, luisante, spumeuse, des plaquıes qui les renferment et du Bomby.x noustrien appelé livrée, 
dont les œufs sont disposés autour des jeunes branches de nos arbres fruitiers comme ane large bague. Bien ne serait plus facile que de se préserver de la voracité des chenilles de certaines Phalènes appelées Geometra brunaria, defoliaria et aurantiaria, dont les femelles sont depourvues d'ailes et ressemblent presque à des Araignćes. Toutes ces espèces se métamorphosant en terre, il suffirait d'entourer le tronc des arbres, au mois de novembre, époque de l'éclosion, d'une couche annulaire de goudron de gaz pour les empècher d'y monter et d'y déposer des milliers d'œufs qui éclosent au moment de l'évolution des bourgeons. Si l'anriée dernière on eût fait usage de ce procédé au bois de Boulogne, nous n'eussions pas eu, cet été, le triste spectacle de Chènes complétement dépourvus de feuilles comme au milieu de l'hiver. Il n'est encore venuà l'idée de personne de détruire ces Cossus, et ces Longicornes qui perforent nos plus gros arbre comme avec une tariere; la chose n'est pourtant pas impossible, il sufirait d'injecter dans leurs trous ou sous les écorces malades une solution étendue de sulfate de cuirre. Les jardiniers pourraient facilement aussi, en détruisant ces Criocères dès qu'ils commencent à paraitre, préserver les différentes espèces de Lys de la saleté et de la voracité de leurs larves. Enfin, nous voudrions ne plus entendre dire, par des agriculteurs d'ailleurs fort liabiles, que leurs arbres ont reçu des vents roux, lorsque leurs pommiers sont enveloppés comme dans des toiles d'araignées par de nombreuses fanilles d'Yponomeutes qui rongent tranguillement sous leur tente le parenchyme des feuilles et les tleurs à peine épanouies, ou lorsque les fleurs de ces arbres ressemblent à des clous de girolles, parce que, dans chacune d'elle, il y a la larve d'un Anthonome dont l'wuf a été pondu avant l'inflorescence. Ou bien encore lorsque les fruits de leurs poiriers nouvellement noués prennent cette forme désignée sous le nom de calcbasse, parce que au moment de l'êpanonissement des fleurs une Cécidomyic y a déposé des oufs qui produisent ces petites larves qui rougent l'intérieur de l'ovaire et donnent aux poires rudimentaires une forme plutot giobuleuse que turbinée. Mais il faut esperer maintenant que l'histoire naturelle est cnseignée partout, dans les lycées, dans les colléges, daus les séminaires et dans les hautes ecoles, que ces vérilés seront mieux comprises, et qu’en faisant une 
plus large part à l'entomologie on rendra un véritable service à l'agriculture et à l'horticulture.

Ce discours remarquable, qui met en lumière les principales applications de l'Lntomologie, est plusieurs fois accueilli par des marques unanimes d'approbation.

Jès qu'il l'a terminé, M. Ie Président se lève et offre la présidence d'honneur à M. le professeur Bouteille, qui s'excuse d'abord et finit par accepter l'insigne honneur qui lui est décerné; mais il désire que M. le docteur Boisduval continue à diriger l'ordre de la séance el demeure Président réel.

M. le docteur Laboulbène émet le vou que l'assembléc vote des remercîments aux organisateurs du Congrès de Grenoble et aux autorités de la ville, qui ont si dignement et si généreusement accueilli la Société entomologique de France. Cette proposition est votée par acclamations.

M. le Secrétaire donne ensuite lecture de l'ordre du jour de la session extraordinaire, arreté à Paris par la Société dans la séance du 23 juin 1858.

ORDRE DU JOLR DK HA SESSIOS EXTRMORDINAILE

T'enue is Grenoble.

\section{Constipution du Congrès.}

En vertu d'une décision prise dans la séance extraordinaire du 14 avril dernier, sur la proposition de M. le docteur Boistluyal, la 
Société Emtumologique de France se réunit en session extraordinaire à Grenoble, le 7 juillet 1858 .

MN. le docteur Bojsduval, président. Ie docteur Lamoulbène, Vice-Président, remplissant les fonctions de Secritaire. LÉon Fainmane, Trésorier-Adjoint. Doüe, Archiviste.

La durée de la session extraordinaire, tenue à Grenoble en 1858 , est de douze jours, à partir du 7 juillet jusques et y compris le $18 \mathrm{du}$ mème mois.

Pendant le Congrès, plusieurs excursions seront dirigées dans les environs de Grenoble ainsi que dans les Ilautes-Alpes.

Il sera tenu deux séances dans l'une des salles de la Faculté des Sciences :

La première, le 7 juillet, à huit heures du soir ;

La seconde, le 18 juillet également à hutit heures du soir.

Les personnes étrangères à la Société, et présentées par un de ses membres, seront admises aux excursions et aux séances.

Ordre du jour de la première síance.

$1^{0}$ Lecture des noms de MM. les membres de la Société Entomologique et des personnes assistant à la séance;

$2^{\circ}$ Lecture de la correspondance;

3 Réception des ouvrages offerts à la Société;

$4^{\circ}$ Lecture de mémoires et travaux scientifiques;

$5^{\circ}$ Communications verbales;

$6^{\circ}$ Discussion sur la direction à donner aux excursions. 
Ortre de jour de la seconde séance.

$1^{\circ}$ Lecture et vote du procès-verbal de la séance précédente;

$2^{\circ}$ Lecture des nous de MM. les membres et des personnes assistant à la séance.

$3^{\circ}$ Lecture de la correspondance.

$4^{\circ}$ Compte-rendu des excursions faites par la Socićté entre les deux séances ;

5. Lecture de mémoires et travaux scientifiques ;

$6^{\circ}$ Communicutions verbales;

$7^{\circ}$ Lecture et vote du procès-verbal de la seconde séance.

Dispositions communes aux deux séanecs.

Le peu de temps dont les societaires présents à Grenoble pourront disposer, à l'effet de se réunir en séances pendant le Congrès, dont le but principal est l'exploration des montagnes alpines et l'examen des travaux entomologiques, ne permettent pas de s'uccuper des questions qui peuvent être soumises à la Société dans ses séances ordinaires, les présentations de candidats et toutes les propositions etrangères au but de cette session, purement explorative et scientifique, seront renvoyées à l'examen de la Société à Paris.

M. le Secrétaire lit les noms de Messieurs les membres de la Société ayant écrit qu'ils assisteraient d̀ la session extraordinaire tenue à Grenoble. Il fait ensuite connaitre les noms des naturalistes qui assistent à la séance et qui ont signé la feuille de présence déposée sur le bureau.

Correspondance. Lettre de M. E. Desmarest, Secrétaire de la Société, retenu à Paris, et témoignant de ses vifs 
regrets de ne pouvoir remplir ses fonctions ordinaires d Grenoble.

Sur la proposition de M. Bruand d'Uzelle, la Société charge M. le Secrétaire de témoignner à M. E. Desmarest sa vive sympathie.

- Lettre de M. IIenri Delamain, qui écrit de Jarnac, qu'un accident imprévu, lui rendant la marche impossible, l'empeche de pouvoir prendre part au Congrès.

Lectures. M. Bruand d'Uzelle lit un travail sur plusieurs espèces de Lépidoptères : Phlogophora scita, Sericoris atrana ct Gelechia vicinella.

- M. le docteur Laboulbène fait connaitre ses recherches anatomiques sur les organes que les Malachius font sortir chaque de côté de leur corps, près du thorax, et qui sont vulgairement connus sous le nom de Cocardes rouges.

- Le meme membre fait ensuite passer sous les yeux de la Société, une longue suite de dessins représentant les organes internes des Lépidoptères. Ces recherches ont pour but, dit M. Laboulbène, de servir de matériaux à l'anatomie des Lépidoptères que prépare mon vénéré maître, M. Léon Dufour. Je m'estimerai heureux de lui servir de manœuvre. Je prie mes collègues de penser à moi pendant les excursions de ce congrès, et de vouloir bien me réserver les Lépidoptères dont les ailes usées par le vol n'enrichiraient pas leurs collections. Ils seront utilisés soigneusement pour des recherches anatomiques.

Communications. M. le docteur Kraatz donne quelques 
détails sur les insectes Coléoptères pris dans une excursion faite ce jour même á Saint-Nizier.

M. L. Fairmaire ajoute plusieurs particularités à la communication de M. Kraatz.

- M. Bruand d'Uzelle annonce qu'il a trouvé la Tortrix dumicolana, Zeller, espéce nouvelle pour la Faune francaise. Il l'a prise à Parizet, dans une grotle, sur des licrres.

Décision. M. le Secrétaire invite M. le Président à vouloir bien consulter la Société pour fixer l'ordre des excursions qui auront licu pendant la session extraordinaire.

Après une discussion animée, il est décidé : que la Société explorera, outre les environs de Grenoble, les muntagnes de la Grande-Chartreuse, du Bourg-d'Oisans et du Lautaret. Les membres de la Société entomologique et les naturalistes présents au Congrès se diviseront par groupes pour faire leurs recherches. Plusieurs d'entre cux manifestent l'intention d'aller en outre à Uriage, Allevard, à la Chartreuse de Prẻmolle, etc.

M. le professeur Bouteille, MII. Boisduval, DucoudrayBourgault, Thibézard, Perroud, Léon Fairmaire, Martin et plusieurs autres naturalistes donnent des indications relatives aux localités à esplorer.

La séance est levée d̀ dix heures.

(Séance de Grenoble du 18 Juillet 1858.)

Présidence de M. le docteur BOISDUVAL.

Les membres de la Société encore présents à Grenoble et 
plusieurs naturalistes étrangers assistent à la séance. Quel ques membres de la Société qui n'avaient pu arriver à temps pour se trouver a la première réunion font parlie de la seconde.

M. Laboulbène, secrétaire, lit le procès-verbal de la séance tenue le 7 juillet, et donne de nouveau lecture de l'ordre du jour de la deuxième séance, tel qu'il a été arrêté à Paris par la Société.

M. le Président met ensuite aux voix le procès-verbal de la séance précédente et sa rédaction est adoptée.

M. Ie Secrétaire fait connaitre les noms de MM. les membres de la Société présents à la séance, ainsi que ceux des naturalistes étrangers.

Correspondance. Lettre de M. Bellier de la Chavignerie, qui explore les montagnes des Basses-Alpes et regrette de n'avoir pu venir à Grenoble. Il annonce que plusicurs localités des environs de Larche ont été assaillies cette année par une chenille qui a presque causé des dégats. Cette chenille est celle de l'Ueterogynis penella, qui vit habituellement sur différentes espèces de genêts. Ne trouvant pas ces plantes, qui manquent presque entièrement, elle s'est jetée sur les prairies, où elle vit polyphage, affection nant toutefois les trèfles et les sainfoins.

Communications. M. le Président expose le résumé des explorations entomologiques faites par la Société à SaintNizier, à la Grande-Chartreuse, dans les montagnes du Bourg-d'Oisans et au Lautaret. Il appelle l'attention des entomologistes sur la grande quantité de Zygona exulans qu'on voyait au Lautaret. Cette Zygène s'y trouvait par milliers, tandis qu'il y a déjà longtemps M. Boisduval ne 
l'avait rencontrée dans ces memes localités qu'en petit nombre et sur les prairies les plus élevées oủ crolt le Phaca glacialis.

En terminant cefte revue, M. le Président fait remarquer d'une manière toute particulière la présence d'innombrables Acrydium migratorium qui sont venus, portés par le vent, s'abattre sur le Bourg-d'Oisans. Ces Orthoplères, bien autre. ment redoutables que les chenilles de l'lleterogynis penella, ont dévoré la plupart des récoltes, ils attaquent meme les Arundo phragmites.

M. le Secrótaire général de la préfecture de l'Isère a consulté M. le Président et M. le Secrétaire du Congrès sur les moyens à prendre pour s'opposer à ce fléau.

M. E. Martin a été frappé comme tous les membres de la Société qui ont fait l'excursion du Lautaret, du grand nombre de Zygana exulans qu'on y a vues. Notre collègue avait déjà trouvé très abondamment cette Zygène aux environs du lac de la Magdeleine, dans les Basses- $\Lambda$ lpes, mais en bien moindre quantité.

M. Bruand d'Uzelle montre plusieurs Acrydium d l'élat de larve et de nymphe, ceux-ci ayant deux taches bleuAtres de chaque côté du thorax. Il demande s'il est bien sûr que ces larves el nymphes, qu'on observe par myriades et qui causent tant de dommages au Bourg-d'Oisans, appartiennent bien à l'Acrydium migratorium.

Une discussion s'engage sur ce point. M. le docteur Boisduval affirme le fait. D'autres le nient. M. le docteur Laboulbène pense qu'un examen approfondi de ces larves et de ces nymphes est nécessaire pour résoudre la question.

- MM. Emmanuel Martin, docteur Paul Lambert, docteur 
Titon, Bruand d'Uzelle, etc., font plusieurs communications relatives aux insectes de divers ordres, qu'ils ont pris dans leurs excursions et dont ils donneront une liste à M. le Secrétaire pour le rapport général.

-M. Bellevoye communique des observations qu'il a faites à Metz, sur les mours du Brachytarsus varius, dont les larves, selon lui, se nourriraient du bois de vieux poiriers, à l'endroit où les branches ont été coupées ras du tronc.

M. le docteur Laboulbène fait remarquer à M. Bellevoye qque les habitudes des Brachytarsus déjà observées ne sont pas toujours aussi inoffensives. Le parasitisme de leurs larves a été démontré. Il engage M. Bellevoye à s'assurer si ces larves étaient seules dans le bois de poirier et si elles n'y ont pas vécu aux dépens de quelques autres.

-Avant de clore la session extraordinaire, M. le Président propose de voter des remercîments aux autorités municipales et scientifiques de la ville de Grenoble, pour l'accueil bienveillant fait par elles à la Société entomologique de France, ainsi qu'aux Savants et aux Naturalistes qui ont bien voulu assister à nos séances et prendre part à nos excursions.

Ces remercîments sont votés à l'unanimité.

- M. le Secrétaire lit ensuite le procès-verbal de la deuxième séance, qui est mis aux voix et adopté.

La séance est levée à neuf heures et demie. 
(Séance de Paris du 28 Juillet 1858.)

Présidence de M. le $\mathrm{D}^{\mathrm{r}} \mathrm{LABOULBËNE}, 2^{*}$ vice-président.

Communication. Immédiatement après la lecture du procès-verbal de la précédente séance tenue à Paris, M. le docteur Laboulbène, vice-président, ayant rempli à Grenoble les fonctions de secrétaire, fait connaitre les procès-verbaux des deux séances des 7 et 18 juillet, tenues à Grenoble par la Société, lit le discours d'ouverture de l'excursion prononcé par le président, M. le docteur Boisduval, donne quelques détails sur les courses scientifiques qui ont eu lieu, et annonce qu'il communiquera dans quelque temps son rapport général sur le Congrès de 1858, dans lequel il insérera les listes qui doivent lui etre adressées par plusieurs de nos colleggues, relativement aux insectes qui y ont été recueillis.

Après avoir entendu cette communications, la Société, comme en 1857 au sujet de l'excursion extraordinaire de Montpellier, décide que des extraits des procès-verbeaux, en ce qui concerne le Congrès de Grenoble, le rapport de M. le docteur Laboulbène et les listes des insectes qui ont été pris dans les diverses courses entomologiques, seront tirés à deux cents exemplaires outre le tirage ordinaire des Annales.

Vingt-sept membres de la Société ont assisté au Congrès de Grenoble : ce sont MM. Bellevoye, venu de Metz; docteur Boisduval, de Paris; Th. Bruand d'Uzelle, de Besan- 
çon; docteur Cartercau, de Bar-sur-Seine; Constant fils, d'Autun; Charles Dat, de Carcassonne; Chambovet, de Saint-Etienne; Daube, de Montpellier; Delamarche, de Paris; Doüé, de Paris; L.-A. Ducoudray-Bourgault, de Nantes; L.-II. Ducoudray-Bourgault, de Nantes; L. Fairmaire, de Batignolles; Gougelet, de Montmartre; Guenée, de Chateaudun; Knechlin, de Darnach; docteur Kraatz, de Berlin; docteur Laboulbène, de Paris; docteur Paul Lambert, de Saumur; Legrand, de Troyes; E. Levrat, de Lyon; Emmanuel Martin, de Paris; Millière, de Lyon; Perroud, de Lyon; Rattet, de Paris; Thibézard, de Laon, et le docteur Titon, de Chalons-sur-Marne. 


\title{
RAPPORI
}

SUR LA

\section{SESSION EXTRAORDINAIRE TENUE A GRENOBLE,}

\author{
Au mols de Jullet 1858. \\ Par M. le $D^{r}$ Alexandre LABOULBËE.
}

(Séance du 22 Décembre 1858.)

\section{Messieurs,}

Vous avez accueilli, avec une faveur marquée, le Rapport dans lequel M. Léon Fairmaire vous décrivait, en historien fidèle, la première session extraordinaire de la Société Entomologique de lirance. Mon cher ami et savant collègue avait constaté le succès du Congrès de Montpellier. Il applaudissait aux utiles, aux excellents résultals de ces réunions nouvelles, car elles viennent rapprocher des collègues séparés par la distance, ou bien, elles cimentent de vives amitiés que les mèmes goûts scientifiques araient fait naître, depuis longues années, entre des naturalistes qui ne s'étaient jamais vus précédemment.

C'est qu'en effet, Messieurs, le but de ces excursions éloignées est à la fois de rattacher les membres de la Société les uns aux autres par les liens d'une affectueuse confraternité, et d'explorer tour à tour les diverses contrées de notre admirable pays. Les collections s'enrichissent par la récolte 
des insectes, par les échanges rendus plus faciles. Si les espèces rares qui nécessitent, pour être trouvées, un long séjour dans la contrée qu'elles habitent ne sont pas découvertes par nous-memes, nous aurons stimulé l'esprit de recherches, montré un zèle utile et bien mérité de la science.

La réunion des entomologistes avait été nombreuse à Montpellier, elle l'a été pareillement à Grenoble, et un grand nombre de Savants étrangers à notre Société sont venus prendre part à nos excursions.

L'organisation du Congrès avait été parfuitement établie par notre honorable président, M. Ie docteur Boisduval, et par notre secrétaire, M. Eugène Desmarest, dont le dévouement vous est bien connu. Je ne dois point oublier de signaler le concours de plusieurs membres de la Société, concours d'autant plus méritoire que ceux qui l'avaient donné étaient obligés de rester à Paris.

Les diverses compagnies de chemins de fer ont eu pour nous leur libéralité accoutumée. Nous tenons à constater cette bienveillance que l'un de nos collègues, venu de Berlin, donnait récemment comme modèle aux administrations des chemins de fer de l'Allemagne.

Dès le 6 juillet, la majeure partie des entomologistes voyageurs était rendue à Grenoble, par la voie de Lyon et de Saint-Rambert. Cet itinéraire est trop connu pour que je le répète ici, mais ceux qui voyaient pour la première fois le Dauphiné ont admiré les paysages de Voiron et la situation de Grenoble au milieu des montagnes qui l'entourent.

Après les visites officielles faites par le Président et les inembres du Bureau aux autorités de la Ville qui donnait 
l'hospitalité à notre Société, les premiers arrivés ont exploré aux portes de Grenoble les bords de l'Isère et du Brac. Mais la première excursion entreprise en commun a été celle de la montagne de Saint-Nizier; les autres ont cu lieu successivement à la Grande-Chartreuse et au Lautaret. Je vais, Messieurs et chers collègues, essayer de vous en rendre compte.

\section{SAINT-NIZIER DE PARISET.}

Le 7 juillet, dès sis heures du matin, une corbeille (1) pouvant donner place à un grand nombre de voyageurs, stationnait devant l'hotel des 'Trois-Dauphins, où la plupart d'entre nous avaient pris gite. Le temps s'annonçait peu favorable, d'épais nuages couronnaient toutes les cimes autour de Grenoble.

Nous nous sommes mis en route, néanmnins, en partie sur le véhicule, et le plus grand nombre à pied. Vers sept heures et demie, la voiture arrivait au terme où par suite des difficultés du terrain elle devait s'arreter. C'était sous la grande avenue de tilleuls séculaires qui forment un beau couvert devant le chateau de M. Félix Réal, ancien député du département. Notre Présiảent sachant que le propriétaire présidait aussi une Société savante, s’adjoignit l'Archiviste, et tous deux allèrent rendre visite à M. F. Réal, qui leur fit le plus gracieux accueil, ainsi qu'à la troupe pédestre de nos collègues qui arriva peu après.

(1) On désigne sous ce nom les chars-à-bancs servant aux escursions dans les environs de Grenoble: 
Celle-ci, sous la conduite de M. le professeur Verlot, qui avait bien voulu la diriger, avait suivi les magnifiques boulevards de la ville; elle y constatait les dégâts causés aux ormes par la Galleruca calmariensis et une immense quan. tité de chenilles du Liparis dispar, qui, huit jours plus tard, s'étaient métamorphosées. Elle atteignit les bords du Drac par une pluie battante; on ne put, ce jour là, rechercher les chenilles du Deilcphila hippophaes sur l'arbrisseau qui les nourrit et qui croit si abondamment au bord de cette rivière torrentueuse (1). Bientôt elle commença à gravir la montée de Pariset et trouva une Faune et une Flore bien différentes de celles des plateaux du nord de la France. Les nuages s'éclaircissaient, la pluie cessait de tomber; les premiers rayons de soleil joyeusement accueillis permettaient de voir voler quelques Lépidoptères diurnes, et les males du Rhizotrogus ater. Nos collègues, après avoir atteint un pelit plateau sur le sommet duquel on aperçoit la vallée du Graisivaudan, arrivaicnt devant le château de M. F. Réal.

Nous avions reçu, avec un accueil cordial, d'utiles renseignements sur les moyens de gravir la montagne en partie couverte de roches au milieu desquelles il n'était pas toujours facile de trouver un passage. Mais la tache, quoique rude, était loin de nous décourager; on soulevait des pierres et les insectes de la zone sous-alpine commençaient à etro pris. Dans de petites grottes et sur les rochers du parc, les lépidoptéristes recueillaient la Gnophos pullata, la G. fur-

(1) Le mauvais ıemps empêcha plusieurs de nos collègues d'aller à Seyssins pour y recueillir les chenilles des Sphinx vespertilio et anothera sur l'Epilobium angustifolium. 
vata, et les Larentia tophaccata et olivata. On fit une halte au petit hameau de Pariset, pour y prendre un modeste repas qu'un bon appétit rendit excellent.

Pourquoi ne consignerais-je point ici un fait qui nous a frappés? Il prouve que les montagnards ont gardé un reste des vertus et de la bonne foi primitives dont, trop souvent, on cherche en vain la trace chez les habitants de la plaine bien plus avancés en civilisation.

Après avoir payé notre déjeuner, dont le prix étail fort modéré, nous donnames, à notre vieille hotesse, la moitié d'un saucisson volumineux, apporté par précaution de Grenoble. La bonne femme voulait absolument réduire la carte déjà soldée, et ce ne fut qu'à grand'peine que nous avons pu lui faire accepter, comme don gratuit, cet échantillon des produits culinaires de la ville.

Le repas terminé, les nuages avaient disparu, un soleil radieux brillait sur nos têtes, nous partîmes pleins d'ardeur. Une vaste grotte située auprès du hameau fut explorée dans toutes ses profondeurs, et les amateurs de Géométrides et de ces Microlépiloptères, si intéressants à étudier, nous signa. lèrent la prise, par MM. Millière et Bruand, d'une jolie Platyomide, Tortrix dumicolana. On trouva dans cette grotte une variété d'un gris-blane de la Gnophos pullata, les Acidalia contiguaria, incanaria vor. Canteneraria, et bon nombre d'autres espèces dont j'aurai soin de vous donner plus tard la liste exacte.

Mais la chasse aux insectes, la recherche des plantes, avaient commencé de toutes parts en quittant les maisons, ou plutot les chaumières de Pariset. Nous nous disposions à gravir la montagne de Saint-Nizier jusqua'au sommet tridenté. appelé les Trois-Pucelles. II ne pouvait plus y avoir 
d'ensemble dans nutre pérégrination; dispersés par petits groupes, nous ne devions plus nous réunir que pour le retour. On ramasse autour de Pariset, quelques Coléoptères, Aphodius scrutator, Staphylinus fossor et lutarius etc., M. Daube trouve la Capnodis tenebricosa; dans une sorte de défilé, entre des roches, les Saryrus IIcımione et cordula étaient très abondants.

Nous visitons un petit plateau où se trouvent les ruines d'une Tour, appelée Tour-sans-venin, batic, dit la légende, par Roland, et que devaient fuir tous les animaux venimeux. Près de là est un cimetière où la rareté des tombes indique à la fois le petit nombre d'habitants du hameau et leur longévité.

Aux environs de la Tour-sans-venin, nous aurions pu prendre abondamment le Parnassius A pollo qui planait ou volait doucement parmi une myriade de sombres Satyrus cordula; ils formaient de la sorte un singulier mélange de blane et de noir.

En continuant l'ascension, nous atteignîmes la faune exclusivement alpine. Les noirs Erebia faisaient à leur tour ressortir les teintes dorées des Polyommatus virgaurea et eurydice. Puis les prairies pastorales nous offraicnt le Lycona damon, la gracieuse Acidatia faveolaria. Sur la Scabiosa sylvatica nous observames une assez grande quantité de Zygana trifolii. Tout en butinant, et après avoir traversé les zones de sapins, où nous voyions les travaux de l'Anobium abietis, nous avons atteint la base des inaccessibles dentelures dont j'ai parlé. Nous trouvons alors, en soulevant des pierres, les Cymindis axillaris, Feronia Hagenbachii, Amara picea, etc.

La journéc s'avaņ̧ait, il fallait penser à regragner 
Grenoble, où notre première séance devait avoir lieu. Ln descente ne fut pas faite sans profit, car les Géomètres commençaient à sortir de leurs retraites. M. E. Martin prenait, près de Pariset, la Typhonia lugubris, mais il ne put trouver le fourreau de la chenille, malgré toutes ses recherches.

Ceux qui n'avaient point gravi les hauteurs et qui revenaient les premiers reçurent, chez M. Iréal, un accueil non moins bienveillant que celui du matin. Il leur fit visiter sa belle propriéte, d'où la vue des montagnes et de la magnifique vallée du Graisivaudan est vraiment admirable; il les conduisit, tout en leur communiquant ses expériences et ses recherches sur la conservation des vers à soie et leurs maladies, jusqu'à l'Hermitage de Jean-Jacques Rousseau, faisant partie de son domaine. Plusieurs Sphinx pinastri furent trouvés venant d'éclore au pied des arbres qui avaient nourri leurs chenilles. Vers six heures du soir notre réunion était effectuéc et nous partions pour Grenoble, oủ la première séance fut tenue; vous en connaissez déjà les détails par le procès-verbal que j'ai eu l'honneur de vous soumettre.

\section{LA GRANDE-CHARTREUSE.}

Notre visite au célèbre couvent fondé par Saint-Bruno, avait été décidée par acclamations. Il n'y eut pas de retartiires au moment du départ. On était heureux de se mettre en route el on le témoignait. Pour les uns, c'était là satis- 
faction de revoir le Monastère et le sévère dísert qui l'entoure, pour les autres, l'attrait de la nouveauté el la certitude de trouver la réalité à la hauteur des espérances; pour tous, le plaisir d'ctre réunis. Nous nous plaçames gaiement dans les voitures disposées à la file qui devaient nous conduire à Saint-L_aurent-du-P'ont.

Les touristes ont célébré à l'envi le chemin qui conduit à la Grande-Chartreuse. Je ne répéterai pas leurs descriptions. Vous préférez aux détails sur l'étendue de la route, ou sur son altitude, le souvenir des insectes ou des plantes qu'elle vous a offerts.

Notre caravane sortit de Grenoble en traversant l'Isère, et se dirigea sur Voreppe. Les montagnes étaient encore a demi-cachées par le brouillard du matin. Nous eûmes bientot dépassé St-Martin, St-Égrève; nous avions hate d'alteindre Yoreppe. Nous y sommes descendus, et, quoique certains de trouver a Saint-Laurent du-Pont des cannes solides pour nos courses montagnardes, la plupart se munirent aussitôt de forts batons ferrés. Plusieurs d'entre nous ont rapporté à Paris ces utiles comparnons de voyage. Notre Président en avait un terminé par une sorte de crosse, ce qui lui donnait un air abbatial qui était de bon augure.

$\Lambda$ près Voreppe, la route monte et nous avons mis pied à terre pour allégrer nos véhicules et leurs montures, ou plutot pour commencer nos recherches. Nous jetons un regard sur le couvent des Dominicains, situé entre ciel et terre, sur le flanc du Pic-de-Chalais qui domine Voreppe. Le torrent, le Royje, était presque desséché, mais sa pente rapide et les grosses pierres dont il est encombré, indiquent assez quelle impéluosité il doit avoir pendant la mau. 
vaise saison. Son lit est large, et, sur la rive gauche, on trouve une scierie qui met en planches le bois descendu de la montagne.

Le soleil s'était levé. On cherchait avec ardeur betes et plantes. L'entomologic n'eut guère de captures. Le Satyrus Ilermione volait moins communément qu'à Saint-Nizier, et seul, peut-etre, je ne le dédaignai point. Je le plongeai dans l'esprit de vin en compagnie de quelques Arge et Polyommates, destinés à des recherches anatomiques.

Nous allions vers Saint-Laurent-du-Pont en suivant un chemin sinueux bordé, de chaque coté, de gros noyers et de chataigniers. Nous traversons le vallon de Pommier et dépassons successivement plusieurs villages. $\Lambda$ notre droite apparaissent les montagnes qui vont de Chalais au dela de Saint-Laurent. Nous apereevons enfin ce dernier. La première occupation en y arrivant fut de faire une reconnaissance, un appel général, et de commander un déjeuner substantiel. Jentends dire que les Sulmo thymalus et fario y figureront pour la forme; nous les retrouverons it la Chartreuse, où les aliments gras nous seront interdits.

En traversant les maisons disséminées de Saint-Laurentdu-Pont pour arriver jusqu'au fond du village, nous avions remarqué des constructions nouvelles, des toitures neuves que le temps n'avait pas encore recouvertes de celte couche byssoïde noire ou brunatre qu'il leur donne si vite dans les pays de montagnes. On nous apprit que ce village avait été incendié pendant l'été, il y a quatre ans. Une voiture chargée de paille s'enflamma par accident, et pendant qu'on l'éloignait du village, qu'elle dut traverser, les flammèches mirent le feu partout où elles tombèrent. Les Pères Chartreux ont puissamment aidé à la reconstruction du village 
incendié. Sans avoir aujourd'hui rien de bien remarquable, il est intéressant par sa position; les environs sont trés productifs pour l'Entomologie et la Botanique.

Au sortil de Saint-Laurent, plusieurs mulets portaient nos bagages, ils prirent les devants; nous les suivions à pied avec notre attirial de recherches entomologiques et botaniques. Notre caravane s'avançait le long du ruisseau du Guiers, qui coulait assez doucement dans un lit incliné. Sur ses bords et dans l'eau peu profonde nous avons pris les IIydroporus Sammarkii, septentrionalis, Davisii, les Elophorus arvernicus, Bembidium eques, Poederus longicornis La solitude commençait, les conversations étaient animées. M. Charles Dat parlait d'un Pristonychus nouveau découvert au fond d'une caverne souterraine, à Sorrèze, par M. Nauziel. Notre Président nous racontait son premier voyage à la Chartreuse, fait, il y a trente ans, en compagnie de MM. Rambur el de Brébisson. Mais le Guiers, assez calme naguère, est devenu plus bruyant, bientot c'est le bruit d'une chute d'eau. Sur la rive droite sont des forges, des bâtiment enfumés, dans leur intérieur brille la teinte rouge de la flamme; devant nous, une seule arche de pierre traverse le torrent, l'eau tombe et bouillonne en formant une cascade. Quelques pas encore et nous nous trouvons en face d'une scissure immense, entre deux rochers gigantesques dont la route entaille la base; le Guiers tumultueux coule au fond, et, par l'ouverture étroite, on aperçoit une verdure luxuriante.

Sans etre d'un enthousiasme novice ou d'un étonnement complaisant, il est impossible de n'être pas frappé de l'aspect grandiose de ce lieu. C'est l'entrée du désert de la Chartrcuse, et certes il y avait un contraste saisissant entre 
ce bruil des forges de Fourvoirie, ces traînées de feu qui s'en échappaient, et ce calme, cette sérénité de la nature qui leur succède.

Chacun de nous avait admiré celte entréc du désert et franchi la porte surmontée des armes de l'Ordre des Chartreux (1). Les recherches avaient commencé. On ne rencontrait toutefois, sous les pierres, que des Carabiques de la plaine; le Byrrhus ornatus fut pris sous la mousse. Mais le temps s'êtait assombri; la pluie tombait, et, en cherchant un abri sous le rocher creusé en demi-voûte, nous avons trouvé quelques Bembidium et les vulgaires Anchomenus angusticollis et pallipes. Un pretre venant de la Chartreuse et des paysans des environs se réfugient avec nous sous le meme rocher.

La route, très belle aujourd'hui et qu'on rend aussi douce que possible en rectifiant les montées trop raides, est d'abord à droite du Guiers, et la pente n'est pas trop sensible. Cependant nous trouvons bientot des sapins mêlés aux hêtres. Il est rare de voir d'aussi beaux rideaux de verdure que ceux qui revêtent les parois de cette vallée de rochers. Gráce à sa situation de l'est à l'ouest, le désert de Chartreuse est constamment d'une grande humidité, très favorable à la végétation.

L'entomologie n'avait point à espérer de belles prises avant d'arriver au couvent; toutefois, nous avons récolté contre les pierres, la Machilis amnulicornis, le Glomeris guttata, ainsi que des IIelix, Bulimes et Clausilies de ces régions alpestres. Des 'Tïéitcs, des Geomètres saxicoles

(1) Elles consistent en un globe surmonté d'une croix entourée de sept étoiles. La devise était : Stat crux dum volvitur orbis. 
étaient appliquées sur les rochers, entr'autres, les Gnophos pullata, Nudaria mundana; mentionnons seulement, parmi la flore de cette route, si digne d'etre parcourue par le naturaliste, les Saxifraga aizooides, le Prenanthes purpurea et le Cihrysosplenium alternifolium.

Nous voici dans un endroit où les sapins dominent. Le chemin est au bord du précipice; le Guiers coule au fond avec un bruit sourd. Le tronc des sapins s'elance droit à une grande hauteur; les branches latérales s'étendent au loin. Les monts se dénudent à leur cime et forment des sommets ou som, des arêtes découpées, des sierras en miniature. La ruute traverse le torrent, sur un pont hardi, d'une seule arche (pont de Saint-Bruno ou pont Parant), bati en dolomie, qui est la pierre la plus répandue dans les gorges du désert.

Des ouvriers travaillent à la route qui s'est éboulée en plusieurs endroits sous l'effort des avalanches. Il y a grande abondance de pierres. Nous les soulevons sans prendre autre chose que les Feronia striola ou concinna. Nous passons sous de petits tunnels creusés en trois endroits dans le roc vif.

Un rocher en forme d'aiguille, de cône très pointu et très escarpé s'élève à notre droite, près de l'abîme taillé à pic. Contre lui est une porte ou plutot la ruine d'une porte. Lá existait le fort de l'Aiguille ou de l'OEillette. Une croix formée de deux branches de sapin a été placéc sur le sommet de l'Aiguille. De hardis montagnards ont accompii celte périlleuse escalade, mais l'un d'eux est resté, dit-on, trois jours sans pouvoir parvenir à descendre.

Une grande corde attire notre altention au sortir de celte deuxième porte du désert. Elle est fixée au rocher opposé 
et traverse la vallée. On y suspend les trones des sapins, qui, glissant à l'aide de poulies, viennent tomber sur la route, car, de notre côté, la corde est attachée à un anneau fortement scellé dans le rocher-paroi.

Plusieurs arbres abattus et dans l'état de vétusté furent dépouillés de leur écorce sans grands résultats; en continuant à marcher nous fouillames des souches de hetre à demi-décomposées qui nous offrirent des larves aplaties de Pyrochroa. L'Eurebia ligoca commençait à paraitre. Sur les rochers, il eût été facile de prendre une grande quantité de chrysalides du Bombyx monaca et plusieurs chenilles de Lithosies saxicoles.

La pente devient de plus en plus raide, en certains endroits la route est couverte de menus débris. Nous entendons un bruit sourd, prolongé par les échos, et semblable ì un coup de tonnerre, c'est l'explosion d'une mine qui vient d'éclater. Les pierres roulent de rocher en rocher, jusque dans l'abîme.

Nous touchons presque aux murs du couvent. Nous trouvons plusieurs entrepóts de bois; nous arrivons enfin aux batiments de la Correric. M. Boisduval nous fait remarquer et froisser entre les doigts une belle et aromatique Ombellifire, le Myrhis odorata; un Apollo est pris au repos sur une plante Synanthéréc.

La journée s'avançait et la tenspérature commençait à baisser quand nous entrons dans le Couvent, qui a l'air d'une petite ville. Après avoir traversé une vaste cour, nous trouvons au fond d'un corridor une salle où brille un bon feu. Un frère Chartreux en vetement blanc nous accueille et nous offre la liqueur de Chartreuse, que nous acceptons de grand coeur. C'est ainsi qu'a commencé l'hospitalité du frère 
Gérasime, dont la complaisance et la cordialité à notre égard ont été parfaites.

Le diner nous attendait. Quels fruits savoureux et parfumés que ceux du Fragaria alpina, d'oủ proviennent les fraises cultivées des quatre saisons! Je tiens encore à yous rappeler le Salmo alpinus et le Sium sisaron, dont la racine frite avait un goût assez agréable. Tout fut mangé et de grand appétit. Consignons ici, avec justice, que nous avons fait de bons diners maigres à la Chartreuse.

Vous savez, Messieurs et chers collègues, qu'on nous reproche d'aimer les descriptions parce qu'on nous voit étudier et faire connaître un monde merveilleux qui, par sa petitesse, échappe aux regards du vulgaire. Pour moi surtout, médecin et entomologiste, la remarque risque d'etre vraie. J'espère, cependant, rester dans de convenables limites. Je venais d'ailleurs pour la première fois à la Grande-Chartreuse et dans les $\Lambda$ lpes du Dauphinć, et, si je leur paie ici notre tribut d'admiration collective, qui de vous penserait à mien blamer.

Le repas fini, les nouveau-venus entourent le Président. On le questionne sur les environs de la Grande-Chartreuse; il est entraîné au dehors et fait aux derniers rayons du jour une reconnaissance devant le Monastère. Nous remarquons la porte simple du couvent, les deux statues de Chartreux à côté d'elle, les clochers quui dominent les batiments. Nous rentrons dans la salle où nos amis parlent et se chauffent. On discute sur les projets du Iendemain, sur les excursions à faire.

$\Lambda$ ssis au coin du feu de la grande salle et crayonnant mes notes, je remarque les solives brunes et rapprochées du plafond, les larges croisées, les solides assises de pierre des 
murailles, l'immense cheminée en marbre du pays, les trois tables que nous remplissions il y a un instant. Les parois de la salle sont blanchies à la chaux, et, le dirai-je, rajées de trop de noms et de trop de dates qu'un nouveau badigeon fera disparaitre avec justice. Quelques gravures anciennes et non sans mérite, jaunies ou plutot roussies par les années, décorent seules les murs blanchis.

Nous demandons à présenter, le lendemain matin, nos respectueux hommage au Révérend Père Général, supérieur de l'Ordre. On nous conduit dans nos cellules. J'examine aussitôt la mienne. Elle est presque carrée; un lit, une table, une chaise, un prie-Dieu, le tout en bois de sapin. Encore ces solives rapprochées au plafond, et brunies par le temps. Une seule croisée aux petits vitraux enchassés dans le plomb. Je me hate de soufler... non point la lampe fumeuse, non point la chandelle de suif, mais la bougie qu'on m'a donnée. Notre dîner lui-meme a eu lieu aux bougies. L'hospitalité des Chartreux est aussi confortable que cordiale.

Après une bonne nuit, bien calme, je vais frapper à la porte du Président. Sa cellule contiguë à la mienne est beaucoup plus grande; elle a deux croisées, une tablebureau, une cheminée et un bon feu, une vaste armoire avec trois flacons à liqueurs blanche, jaune et verte, qui sont restés intacts, et deux paires de larges et chaudes pantoufles qui ont été chaussées avec plaisir. Le quartier-général présidentiel a été, comme vous le pensez, très apprécié et très fréquentó.

Rentré chez moi, je commence, avec $\mathbf{1 1}$. Perroud, la dissection d'un A pollo pris à Saint-Nizier. Je le place sur une planchette de liége immergée dans un verre ordinaire. 
C'était probablement la première fois qu'on fouillait les entrailles des Insectes dans une cellule de la Chartreuse.

Le Président et le Secrétaire ont été admis dans la matinće chez le Révérend Père Général, supérieur del'Ordre; il connaissait l'arrivée de la Société à Grenoble, oú le Journal de l'Isère l'avait annoncée. La bienveillance du Révérend Père Général est extrême.

Peu après, je revoyais la façade et les murs du Couvent: j'avais rencontré dans la cour d'entrée plusieurs collègues qui avaient pris des IIydroporus dans les deux grands bassins pleins d'eau qu'y s'y trouvent. Le religieux ayant un vetement blanc et portant la barbe, le mème qui nous avait si cordialement accucillis, donnait des instructions à des ouvriers prêts à partir et à un autre religicux vetu de brun. On me dit à l'oreille que les religieux bruns ne sont que des serviteurs, des frères donnés n'ayant fait aucun vœu, les religieux vetus de blanc et laissant croître leur barbe, ou frères convers, ont prononcé des vœux, mais ne sont pas pretres. Les Pères Chartreux seuls ont l'habit blanc, le visage et la tete rasés, et sont tous entrés dans les ordres sacrés.

Notro déjeuner finissait à peine, quand on est venu nous annoncer que le kévérend Père Général venait, en personne, nous chercher pour nous faire les lionneurs de la GrandeChartreuse. Vous avez été, Messieurs et chers collègues, vivement touchés de cette marque de haute faveur. La Société a été présentée au Revérend Père Général par le Président. A peine est-il besoin de vous rappeler le calme et le respect avec lesquels notre visite a été faite.

Il existe dans divers ouvrages, plusieurs descriptions exactes du Couvent des Chartreux, et je ne dois ni ne veux 
les répéter. Mais puis-je ne point vous rappeler celte fongue galerie des Cartes oủ sont représentées toutes les maisons de l'Ordre et oủ Ie Révérend Père Général voyait avec plaisir plusicurs de nos collègues, venus de loin, reconnaitre des lieux qui leur étaient familiers ? Et la salle capitulaire avec la statue de Saint-Bruno, les portraits des cinquante premiers Généraux des Chartreux et la copie retouchée par Le Sueur, de la vie de Saint-Bruno, dont yous avez tous admiré au Louvre la belle collection originale? Pour moi, je l'avoue, j'ai regretté de les avoir vus trop vite, j'y suis revenu avec M. Goumain, nous y avons meme copié plusieurs inscriptions, que je reproduis dans une note (1).

Faut-il passer sous silence, la chapelle de Saint-Louis, si richement ornée, fondée par Louis XIII, la chapelle des morts et le buste remarquable en marbre blanc, qui est sur la porte d'entrée? Je tiens à vous rappeler d'une manière toute spéciale, la chapelle dans laquelle le Révérend Père Général dit sa messe habituelle, et où if a eu la bonté de nous introduire. Le maltre-autel est un curieux ouvrage de

(1) La sentence qui occupe la place où ne se trouvera pas de longtemps, nous l'espérons bien, le portrait du R. P. Général, est la suivante: Judicium durissimum his qui prasunt, fict.

Voici quelques-unes des inscriptions placées sur la porte des Chartreux. Cellule C. Ibit homo in domum aternitatis suce. Omni momento ad ostium aternitatis sto. - Gellule E. Vanitas vanitatum et omnia vanitas proter amare Deum et illi soli servire. - Cellule G. Domine si sine te nitil, totum in te. - Cellule M. Quam amabilis est locus iste: non est hic aliud nisi domus Dei et porla cali. - Cellule O. Pax huic domui. - Cellule X. II ane in secreto et fruere Deo tuo. - Cellule LL. Dum non es in patria, cella tua sit paradisus. 
marqueterie fait avec les racines de divers bois du désert de Chartreuse et très artistement ajustés. Il n'y a que deux stalles située l'une et l'autre de chayue coté devant l'autel; elles sont destinées gux grands personnages qui ont seuls le privilége d'assister à cette messe.

Quel touriste n'a pas été frappé d'admiration en parcourant le vieux cloître éclairé par cent trente fenetres et où les chapiteaux des colonnes sont d'une ciselure si délicate. Nous sommes passés respectueusement devant le champ du repos situé au milieu de ce cloltre. Deux de nos collègues qui avaient vu le portrait d'un oncle parmi les Généraux de la salle capitulaire, ont retrouvé dans le cimetière le nom qu'ils cherchaient, sur la croix de pierre qui indique seule les tombes des supérieurs.

Il nous a été permis de voir un vénérable Père Chartreux dans sa retraite. Il réclamait les secours de la médecine, et réunis en consultation MM. les docteurs Boisduval, Cartereau et moi-même avons été heureux de les lui donner. Sa cellule, comme toutes celles des Pères, offrait une première pièce ou oratoire, et, á l'étage inférieur, un atelier et un petit jardin.

En revenant par les cloitres, le silence que nous gardions a cessé un instant, une légère animation s'est manifestée dans notre petite troupe. C'était la découverte d'une A pamea captiuncula, espèce considérée júsqu'à ce jour comme exclusive aux Alpes de la Styrie et de l'Oural, et qui doit faire dorénavant partie de la Faune française.

Elle venait d'etre prise dans le cloitre meme, sur la muraille, auprès de l'une des fontaines oủ l'eau en tombant rompt seule le silence de cette solitude.

Le liévérend Père Général a bien voulu nous laisser péné- 
trer dans la cuisine où s'apprêtaient les repas auxquels nous faisions si bien honneur. Nous y avons remarqué des dalles gigantesques en dolomic, servant de tables et une exquise propreté. Dans la grande salle du réfectoire, nous avons touché les humbles objets qui servent aü vénérables Pères dans les repas que la règle leur permet de prendre en commun.

Le Révér. Père Général a eu encore l'extrême obligeance de nous montrer plusieurs manuscrits précieux renfermés dans sa propre cellule et de placer sous nos yeux les richesses de la bibliothèque du Monastère. Nous avons, M. Léon Fairmaire et moi-meme, sollicité l'honneur de lui offrir la Faune Entomologique Française, et j'espère, Messieurs et chers collègues, que vous donnerez un souvenir à l'ouvrage qui vous est dédié lorsque vous retournerez à la Grande-Chartreuse.

Après avoir remercié le Révérend Père Général, notrc petite troupe se répandit au dehors et s'y dispersa dans toutes les directions. Ce jour li et pendant ceux qui suivirent, malgré un temps peu favorable, nous avons exploré la bergerie de Vallombrey, la ferme de Chartreusette, la montagne du Col d'oú l'on découvre le lac du Bourget, le mont Bovinant, le mont Aliénard.

En soulevant des pierres, près de la bergeric et de Bovinant, nous avons trouvé les Feronia Prevostii cuivreuses, et leurs variétés noires ou bronzèes, Feronia IIagenbachii, cxternepunctata, Yvanii, l'Athous Dejeanii ot et + , le Corymbites cupreus, les Otiorhynchus armadillo el tencbricosus, etc. Sur les fleurs, et, entrautres, sur la Spiraca aruncus, qu'on pourrait appeler la plante des précipices, 
étaient posées la Pachyla virginea, la $P$. octomaculata, et beaucoup d'autres espèces moins spéciales aux montagnes.

Nous nous sommes à plusieurs reprises rendus a la chapelle de Saint-Bruno, en passant devant Notre-Dame de Casalibus. Toutes les fois que le soleil brillait nous avons pu prendre, en fauchant dans les clairières ou les petites prairies, le Molorchus umbellatorum et diverses espèces d'Anthophagus et d'Oreina.

M. Bellevoye a trouvé le rare Trigonurus Mellyi dans la mousse recouvrant un vieux trone de sapin. L'Erebia Pyrrha se reposait sur les épis de l'Orchis globosa. La Geometra tinctaria n'était pas rare dans ces localités.

La prairic qui domine le Monastère nous a offert, au milieu de plantes superbes de végétation, des Lilium martagon, une grande quantité de Lépidoptères diurnes; parmi les autres insectes, je ne ferai que mentionner une très grande quantité de Locusta verrucivora, d'Acrydide, tels que les Stenobothrus scalaris, variegatus, et de la Tipula varipennis.

Autour du monastère, plusieurs espèces de Lépidoptères ont été prises; je dois vous signaler plus spécialement les Eupithecia semigraphata, Larentia infidata, flavicinclata, la variété citrinata de la Gnophos glaucinata, Tinea Cartusianella, etc.

Dans les bois de sapins qui se trouvent contre les rochers, M. Boisduval a remarqué sur la Dentaria pinnata, la che. nille d'une Piéride, probablement la $P$. rape, qu'il ne s'attendait point à trouver à une pareille hauteur et sur celte plante.

L'ascension du grand Som n'a pu ctre faite par la majeure 
partie d'entre nous. Quclques-uns plus privilégiés ont attendu le beau temps pour atteindre ce sommet élevé. l.curs récoltes entomologiques n'ont pas eté extraordinaires. L'exploration des sommets de Charmanson, de Chamechaude n'a pas donné de grands résultats.

La veille du départ officiel, plusieurs de nos collègues sont revenus à Grenoble, par la route du Sappey. Ils nous ont fait part de leurs impressions. En passant près de SaintPierre-de-Chartreuse, dont les maisons sont espacées au pied du mont de Chamechaude, jusqu'au col d'Entremont, et, en traversant le col de Portes, ils ont pris quelques Lépidoptères saxicoles. Je citerai la rare Polia dumosa trouvée par M. E. Martin, près du hameau du Sappey.

Notre Président avait été obligé, par suite de la disparition, pour ne pas dire plus, des plantes vivantes et destinées à son jardin qu'il avait recueillies sur le mont Bovinant, de revenir les chercher; il avait gravi les hauteurs d'Aliénard. Il a rapporté avec les mêmes plantes plusieurs Coléoptères de ces régions alpines, Feronia et Otiorhynchus, et une galle de Rhododendron, dont l'habitant, à mon grand regret, ne s'est point développé.

Quelques collègues retardataires étaient arrivés à la Chartreuse, dans les derniers jours. J'avais entendu dire que l'un d'eux était venu tout exprès de Saint-Étienne pour chercher la larve du Ceruchus tarandus. J'ai vu, en effet, les. captures que $\mathrm{M}$. Chambovet était venu faire en toute assurance, grace d la connaissance qu'il avait des mœurs de celte larve. Je tiens meme à vous donner ici les renseignements que j'ai écoutés avec tant de plaisir à la Grande-Chartreuse,

Ces faits ont été observés par un collègue aussi modeste que zélé. 
Les larves de Ceruchus tarandus que N. Chambovet a élevées, ont mis quatre années pour se transformer en insectes parfaits. Il est probable, cependant, que ce terme doit être réduit de moitié dans l'état de nature, car, dans les éducations que l'on fait artificiellement, on retarde souvent les larves dérangées dans leur accroissement.

Les larves élevées provenaient d'œufs récoltés le $\mathbf{1 5}$ août 1854, et c'est à la fin du mois de mai de la présente année 1858 que M. Chambovet a obtenu l'éclosion d'une femelle. Les autres larves ne se sont pas développées complétement.

Ce n'est qu'en juin et juillet qu'on trouve à la GrandeChartreuse, mais non pas toutes les années, des males et des femelles de $C$. turandus; plus tard, du 10 au 20 août, on ne rencontre plus que des femelles occupées à pondre. A cet effet, elles perçent les trones de sapins, renversés d̀ terre et décomposés, d'un trou perpendiculaire d'abord
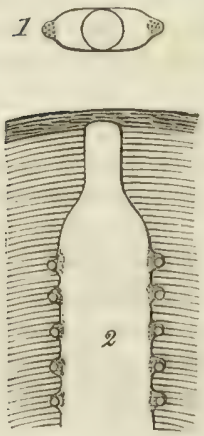
rond dans sa parlie supérieure, puis ovale dans le reste de sa profondeur. La partie ronde a le diamètre de la largeur de l'insecte; la partic ovale en a la largeur et la longueur, et quelquefois trois ou quatre fois la longueur lorsque deux ou trois femelles s'y sont réunies. Quant à la profondeur, elle atteint le centre de l'arbre et souvent le dépasse de beaucoup. J'indique par un dessin cette disposition facile a comprendre. 1. Coupe transversale. 2. Coupe longitudinale.) 
C'est dans la partie ovale que les femelles déposent leurs œufs, dans des entailles faites les unes au-dessus des autres aux deux pôles extremes de la cavilé ovalaire et dans toute la hauteur. Les ocufs sont d'un jaune ferrugineux, sans éclat, presque tomenteux. Ils sont recouverts avec soin dans leur loge d'un peu de sciure de bois bien lassée.

Après la ponte, il est sûr que les femelles meurent dans les trous qu'elles ont creusés, car, dans presque tous et à toutes les époques de l'annéc, on trouve leurs corps ou leurs débris.

Je m'abstiendrai de parler de la larve dont yous connaissez la description donnée par M. Mulsant, dans son Histoire naturelle des Lamellicornes de France, page 593.

M. Chambovet a remarqué encore que les larves, en petit nombre, qui ont atteint tout leur développement à la fin du mois d'août se changent en nymphe à cette époque et donnent l'insecte parfait en octobre. Notre collègue m'a écrit qu'il a vu éclore dans le courant de ce mois une des larves que j'avais vues à la Grande-Chartreuse; elle a produit un insecte femelle. Il est probable que ces insectes précoces passent l'hiver dans l'intérieur des troncs de sapins et n'en sortent qu'avec les autres éclos plus tard. On ne peut, en effet, trouver des individus avant le mois de juin.

M. Chambovet a observé les deux larves du Callidium rufipes et du Molorchus umbcllatorum qui vivent dans les tiges mortes de la Ronce. La première après avoir acquis tout son développement entre l'écorce et le bois, pénétre dans la moelle pour s'y changer en nymphe; la seconde passe toute sa vic dans la moelle, où elle trace une longue galerie. Les deux insectes parfaits éclosent du 20 au 25 mai.

Voici quelques détails intéressants sur les larves de l'Ilyle- 
coetus dermestoides. Elles vivent dans les souches de Hetre encore saines et revêtues de leur écorce. Elles perçent une galerie droite et horizontale de 20 d̀ 25 centimètres de profondeur, d'égale largeur à peu près partout. Celte galerie, qu'elles élar'rissent à mesure que leur corps grossit, se termine à la surface de l'écorce par une très petite ouverture. Ce pertuis a probablement servi à l'introduction de l'œuf; la larve en profite pour nettoyer sa galerie, et ce sont les débris déblayés par cette voie qui dévoilent sa présence. Cette larve met deux années pour atteindre son développement complet; l'insecte parfait éclot du 5 au 15 mai.

Le fait le plus curieux de l'histoire de cette larve est la manière dont elle avance dans sa galerie. Son corselet se dilate ou se contracte latéralement, suivant la volonté de l'animal, non pas en se gonflant ou en se dégonflant tour' à tour, mais bien en s'aplatissant ou en se creusant en tuile à canal, ses bords se relevant en haut. Elle prend de la sorte un point d'appui antérieur en aplatissant son corselet, le second point d'appui est fourni par la pointe cornée et fortement rapeuse qui termine son corps. Veut-elle avancer, elle arcboute sa pointe terminale et s'étend le plus possible; elle dilate alors son corselet et, se raccourcissant, elle arcboute de nouveau la pointe cornée, pour étendre de nouveau son corps et ainsi de suite. Ces mouvements sont très rapides, et, quoique la larve de l'IIylecœus soit privée de pattes, elle s'enfonce rapidement au fond de son trou.

Une des larves que M. Chambovet a le plus facilement élevées, est celle de la Pyrochroa coccinea. Vous savez que mon vénéré maltre, M. Léon Dufour, en a publié la description et l'anatomie dans les $\Lambda$ nnales des Sciences naturelles (20 série, tome XIII, page 321,1840 ). M. Chambovet 
a constaté qu'elle se contente du liber décomposé et humide des arbres les plus opposés, tels que Peuplier, Chene, Pommier, Noyer et Frene. Il suffit, pour en avoir constamment, d'établir les unes au-dessus des autres, dans un grand pot à fleurs de jardinier, des couches de vieilles écorces garnies de leur liber et de combler les joints avec celte espèce de sciure produite par les larves des gros Longicornes. Quand le pot est presque rempli, on y met les premieres larves de Pyrochioa qu'on a pu se procurer, puis on le recouvre d'une gaze métallique. Les insectes qui naîtront s'y propageront indéfiniment si on laisse quelques femelles fécondées.

La durée totale de la vie de ces larves est de deux années. L'époque de leur éclosion est très irrégulière, mais c'est du 15 mai au 15 juin que paraît le plus grand nombre d'individus.

$\Lambda$ près avoir eu les renseignements qui précèdent, nous allons faire une dernière promenade sur les prairies qui dominent la Chartreuse. Chemin faisant, je trouve la Strangalia aurulenta dans une souche de sapin. Sur les deux espèces de Cacalin nous prenons les Oreina, qui y sont abondantes. La Grande-Chartreuse attire nos regards et nous paraît, en quelque sorte, en relief avec son immense cloître rectangulaire, ses batiments d'entrée surmontés aux quatre angles par un toit aigu, ses clochers, son grand mur d'enceinte. En revenant par la prairie, je cueille plusieurs pieds de Campanula rhomboillatis qui me paraissent anormaux. Les fleurs offrent un gonflement de l'ovaire, et je constate qu'il est habité par des larves ou des nymphes. Je vous donnerai, en terminant mon Rapport, 
I'histoire de celte galle de la Campanula rhomboidalis produite par un Curculionite.

Pendant celte dernière journée de notre séjour à la Chartreuse, et c'était un dimanche, nous avions assisté à l'office du matin, comme le lendemain de notre arrivée nous avions assisté d̀ l'office de la nuit.

Vous vous rappelez, Messieurs, que l'église de la GrandeChartreuse n'offre rien de saillant, au point de vue de l'architecture. Les Pères Chartreux occupent seuls le chœur, une séparation en boiserie surmontée d'un groupe sculpté, les isole des frères convers et donnés. L'office est psalmodié simplement; quand il touche à sa fin, les religieux se couchent à terre. Pendant sa durée, ils relèvent et abaissent plusieurs fois leurs capuchons blancs.

Les matines, ou l'office de la nuit, ont un caractère sépulcral. Les religieux arrivent successivement avec une lanterne, dont la lumière disparait aussitôt qu'ils ont pris place dans leurs stalles. On n'aperçoit que vaguement les vètements blancs au milieu des ténèbres, rendues visibles par la tremblante clarté de la lampe du chour. Les chants s'élèvent et se poursuivent dans l'obscurité, puis ils cessent tout à coup pour recommencer sur le même mode lent et grave.

Les préparatifs du départ ont été faits, en mettant à contribution la pharmacie du couvent, oủ nous avons trouvé du chloroforme pour asphyxier nos captures entomologiques et les empecher de s'entre-dévorer. Nous y avons remplacé les flacons, qui ne se brisent que trop souvent pendant les chasses. De cette pharmacie assez complète sortent 'n foule des médicaments distribués gratuitement à tous les nécessiteux, et la liqueur si connue de la Chartreuse. Les rayons 
offrent de curieux vases à médicaments d'une forme an. tique, et portant l'indication de leur contenu pharmaceutique, tracéc en vieux caractères. Le frère jardinier a eu besoin de nos conseils pour les pieds d'Angélique couverts d'A phis, qui leur étaient fort nuisibles. Appelé auprès de ces malades d'un nouveau genre, j'ai prescrit pour traitement les lotions savonneuses, et je sais que les plantes ont été débarrassées de leurs parasites.

Nous avons pris congé du Révérend Père Général des Chartreux en lui têmoignant combien nous avions été touchés de l'accueil qui nous avait été fait, et nous avons quitté les bons Religieux, dont l'hospitalité restera toujours présente à notre souvenir.

En revenant par Saint-Laurent-du-Pont, et en suivant le cours du Guiers, j'ai eu pour compagnon M. Chambovet. J'étais sûr qu'il ne m'avait encore fait connaître qu'une partie de ses remarques entomologiques. Cet obligeant collègue m'a communiqué, de grand cœur, ses observations faites à Saint-Étienne, et l'intérêt que j'ai eu à les entendre m'engage à les rapporter.

Vous savez, Messieurs, que les femelles de l'Hoplia corrulea sont difficiles à trouver; M. Mulsant signale ce fait, sur lequel M. Íéon Dufour a pareillement insisté (1). M. Chambovet est parvenu à en prendre un grand nombre, et voici comment. Il avait essayé bien des fois de chercher, sur les bords de la Loire, la femelle de ce joli insecte au pied des plantes sur lesquelles les males étaient extremement communs. Je creusais la terre, me disait-il, je retournais les pierres

(1) Voyez Mulsant, Lamellic, de France, p. 517, et L. Déroun, Ann, Sc, naturelles, $4^{\circ}$ série, IX, p. 5. 
sans rien trouver. Découragé, j’abandonnai ce système ct me mis à étudier l'allure des mâles, qui, placés de manière à ctre bien éclairés par le soleil, se tenaicnt cramponnés au sommet des Saules nains au moyen de leurs quatre pattes antérieures, tandis qu'ils avaient leurs deux grandes pattes libres, relevées au-dessus de leurs élytres.

Insensibles à mon passage ou à mon approche, ces. IIoplia $\mathrm{c}^{*}$ ne donnaient aucun signe de cette crainte, que l'instinct de la conservation produit chez la plupart des autres insectes. Or, comme ils n'étaient point endormis, mais en éveil, leur attitude n'était point indifférente ou prise en vain. Pour m'en assurer, j'en ramassai un grand nombre que j'établis autour de moi, et j'attendis. Bientot, je vis passer au vol un insecte peu brillant, que j'atteignis d'un coup de filet, e'était une femelle de cette espèce d'Hoplia, bientot j'en eus pris une seconde, en une heure, j'en avais, par ce moyen, recueilli une douzaine.

J'étais curieux de savoir comment la réunion des sexes s'effectuait dans ce sérail de males où la femelle jetait le mouchoir. Je ne perdis pas de vue la première qui parut. Elle vint, après quelques détours, se poser sur un male aux aguets, qui, la saisissant aussitôt avec ses longues pattes élevées au-dessus de ses élytres, la fit glisser sous lui et s'en rendit maitre.

Mais les choses ne se passent pas toujours aussi simplement. Il arrive parfois qu'au moment oủ une femelle s'abat sur un male un peu trop lent, elle s'envole de suite, ou bien un male, voisin du premier, ayant vu la femelle se poser, s'en empare sur le corps meme du premier male. II s'ensuit alors une lutte pendant laquelle d'autres malles arrivent et les combattants ne forment plus qu'une boule 
vivante d'un azur brillant, jusqu'au moment où l'un d'eux est resté vainqueur.

La même femelle s'accouple plusieurs fois, puis elle s'enfonce dans la terre pour lui confier sa progéniture.

M. Chambovet a élevé un grand nombre de larves. Les habitudes de la plupart d'entr'elles sont connues. Mais comme les faits de cette nature ne perdent pas à ctre constatés plusieurs fois, je les consigne tels que notre collègue me les a communiqués:

Les larves des Pogonocherus pilosus et Grammoptera ruficornis vivent dans le canal médullaire du Lierre, et ne creusent une loge dans le bois que pour s'y métamorphoser. Elles éclosent du 10 au 30 mai.

Les Hallomenus fuscus, Orchesia micans, Mycetophagus multipunctatus et Dorcatoma Dresdensis, vivent et subissent toutes leurs métamorphoses dans l'intérieur du Potyporus sulphurcus desséché. Les insectes parfaits éclosent tous du 15 mai au 10 juin.

Les Lycoperdons morts ont fourni à notre collègue, les Pocadius ferrugineus, Golgia succinta, Lycoperdina bovista et Dorcatoma boviste. Tous ces insectes sont éclos au premier printemps. Cependant, il lui est souvent arrivé de prendre, vers la fin d'octobre, des Pocadius et des Lycoperdina à l'état parfait.

Le Peuplier nourrit les larves du Melanophila decastigma et de l'Agrilus sexguttatus. Le premier est éclos du ter au 15 août, l'Agrilus, du 25 au 30 juin. Ces insectes déposent leurs aufs sur les arbres récemment abattus. La larve du Melanophila vit entre l'écorce et le bois, et, lorsque le moment de la transformation en nymphe approche, elle établit 
sa loge dans l'écorce. La larve de l'Agrilus passe sa vie entière dans l'épaisseưr de l'écorce du Peuplier.

La route m'a paru courte, grace à la causerie. Nous avons vemarqué, à plusieurs reprises, le volume accru des eaux du Guiers; nous trouvions souvent des cascades descendant des rochers, et qui n'existaient pas à notre premier passage. La pluie qui avait duré longtemps n'expliquait que trop cette exubérante humidité.

Notre rentrée à Grenoble ne fut pas directe, à partir de Saint-Laurent; nous nous fimes transporter à Sassenage, dont nous voulions visiter les grottes et cuves. Un guide fort peu intelligent nous y précéda muni d'une chandelle qui menaçait à tout instant de s'éteindre. Or, cette promenade dans des anfractuosités de rocher, dans des sortes de tuyaux de pierre entrecoupés d'abimes où l'eau bouillonne, n'est pas sans danger. Je ne la conseille point aux personnes ankylosées. On s'étonne à bon droit que l'autorité, qui permet la visite de ces grottes, n'en facilite pas le passage au moyen d'anneaux de fer placés de distance en distance, et qui ne gateraient point l'originalité du lieu. Disons, enfin, qu'une Larcntia dubitaria a été prise par M. Millière, au fond de ces cavernes.

En quittant Sassenage, nous trouvions, sur notre droite, des roches calcaires disposées comme des fortifications, et formées d'assises d'une grande régularité qui augmentait la ressemblance. Tantot ces assises étaient parfaitement horizontales, d'autres fois eiles avaient une inclinaison oblique. Alrivés à Grenoble, nous avons arreté, pour le lendemain, notre départ pour le Lautaret. 


\section{LE LAUTARET.}

Tous les entomologistes qui avaient pris part à l'excursion de la Grande-Chartreuse n'ont pu venir dans les HautesAlpes. Ils ont employé le temps dont ils pouvaient disposer, en explorant Uriage, Allevard, la Chartreuse de Prémolles, en un mot, la plupart des environs de Grenoble. Je citerai, parmi les Insectes récoltés dans ces localités, les Cymindis humeralis, Licinus Hoffmanseggii, Feronia cxternepunctat, Ocypus atcr, Podabrus alpinus et Par. mena Solieri, pris à Uriage par plusieurs de nos collègues, et plus particulièrement par M. Bellevoye; le Carabus nodulosus, trouvé à la Chartreuse de Prémolles par M. Charles Dat. L.es bords du Drac avaient offert les chenilles du Dci. lephila hippophaes, et, sur les fleurs composées, les Zygocna crythrus et sarpedon; en outre, les Apion et Tychius meliloti, Pachybrachys hippophacs, Sciaphilus viridis, etc.

M. Léon Fairmaire, qui avait remonté le cours de l'Isère, jusqu'à Conflans avait rapporté de cette localité, les Lampra rutilans et conspersa, le Coniatus repandus, qui se trouvait abondamment sur les Tamarix des sables de l'Isère, l' $A l$ tica hippophaes, très commune sur l'Ilippophac rhamnoidcs, le Bembidium bisignatum, assez rare sous les graviers, la Xanthochroa carniolica, prise le soir pendant qu'elle volait autour des fleurs de Jasmin. Il avait capturé le Cerceris arenaria, emportant entre ses pattes un Otiorhynchus sulcatus. Vous avez, comme moi, Messieurs et chers collègues, admiré les travaux de MM. Léon Dufour et II. Fabre, sur l'instinct des Cerceris, et vous connaissez les moeurs de l'arenaria, qui fail une guerre acharnée aux Curculionites. 
Une voiture spéciale et assez commode devait nous conduire à petites journées jusqu'au Lautaret. Quittant Grenoble de grand matin, nous avons pris une route opposée à celle de Voreppe. Elle est large et droite, jusqu'au moment oủ nous apercevons le pont de Claix, jeté sur le Drac par Lesdiguières; mais alors, laissant le Drac sans le traverser, nous nous sommes dirigés sur Vizille. Le pays que nous parcourions ainsi est d'une grande fertilité; tantôt de belles prairies, parfois un peu humides, tantôt de riches moissons, de beaux arbres, des vignes, des champs de Solanum, de Cannabis. Les Vanessa Antiopa, Papilio Podalyrius, l'Apatura Ilia, viennent se reposer sur la route et s'envolent à l'arrivée de la voiture. Ces Lépidoptères sont très communs en cet endroit. J'éprouve un grand plaisir à écouter le chant des Cigales; je l'ai bien vite reconnu, quoiqqu'il n'eut pas frappé mon oreille depuis plus de douze ans.

Vizille a été notre première étape. Après y être restés le temps d'un repas, nous continuons notre route. Traversant la Romanche, nous trouvons une suite de collines qui vont s'étageant les unes sur les autres, mais le fond large des vallées est toujours couvert d'une belle végétation, de moissons et d'arbres fruitiers. Bientot, cependant, après avoir dépassé Séchilienne, la vallée se rétrécit et nous apercevons à l'horizon un haut sommet et de la neige. Profitant du ralentissement forcé des chevaux qui conduisent au pas notre maison roulante, nous montons et descendons bien souvent par la portic̀re toujours ouverte. M. Paul Lambert prend le Dolichus flavicornis sous une pierre, on trouve encore les Chlonius tibialis, Carabus intricatus, elc. Les rochers commencent à etre tapissés du charmant Sempervivum arachnoideum. Ils nous offrent aussi l'Asplenium sep- 
tentrionale, et dans les parties schisteuses et humides, la Primula viscosa. L'Erebia euryale, des Polyommates et d'autres Lépidoptères alpins viennent se reposer sur les parties humides des rochers et au bord des petites flaques d'eau que les infiltrations produisent sur la route.

Nous avons rencontré, après avoir dépassé Séchilienne, des cantonniers brisant des pierres granitiques sur une sorte d'enclume cylindrique et creuse, formee d'un tronc d'arbre, évasée en haut, cerclée de fer. L'un d'eux nommail cet appareil, une guise, si je l'ai bien compris.

Après avoir traversé un défilé assez large, nous entrons dans un véritable cirque de montagnes et, par une route d'une rectitude et d'une longueur désespérantes, nous arrivons enfin au Bourg-d'Oisans. L'aspect en est sombre, les maisons sont brunatres et enfumées.

Nous avions résolu de passer an Bourg-d'Oisans la fin de cette journée et celle tout entière du lendemain. Nous traversons la Romanche pour nous rendre au pied de la cascade, située en face du Bourg; clle arrive et tombe entre deux rochers escarpés, dont la base est nue, semée de débris, oủ se plaisent les Vipères. Avant d'atteindre la cascade, on voit des cultures bien arrosées, entourées de fossés bordés de saules.

Au pied même de la cascade, nous prenons une grande quantité de Bembidium, parmi lesquels je ne mentionnerai que l'eques; les Nebria picicornis, Heterocerus sericans. Je trouve le Parnassius A pollo endormi sur une Carduacéc. Les Verbascum, fort nombreux parmi les pierres éboulées, m’offrent en grand nombre les Cionus ungulatus et Gymnetron thapsicola.

Le soir, au crépuscule, la chasse des Microlépidoplères 
nous donne un grand nombre de Pyrausta sanguinalis et de Pterophorus, tels que : adactyla, megadactyla, nemoralidactyla, tristidactyla, paludidactyla. Quand nous rentrons au Bourg-d'Oisans, les sommets couverts de neige des montagnes environnantes étaient seuls éclairés de ces teintes rosées, violatres ou dorées, d'une délicatesse extrême que se rappellent toujours ceux qui les ont vues une fois.

Le Jendemain, notre troupe s'est divisée en deux camps. L'un, sous la direction de M. Boisduval, a parcouru les monlagnes du Sud, jusqu'i Villard-Eymund et Villard-Reymond ou St-Jean. Ces localités sont extremement intéressantes. Elles offrent presque l'Entomologie et la Flore du Lautaret. Notre Président y a retrouvé le Lycoena Donzelii, qu'il y avait découvert il y a trente ans; il y a pris, en outre, une variété de cette espice sans points marginaux, le Polyommatus Eurydice, les espèces alpines d'Erebia, etc. Un montagnard lui a montré des Carabus nodulosus qu'il avait ramassés sur les hauteurs; M. P. Lambert a pris les Cychrus attenuatus et Feronia metallica; M. Boisduval a rapporté, dans sa boîte d'herborisation, les Pinguicula grandiflora et alpina, Corallorhiza IIalleri, Goodyera repens, Orchis albida, Artemisia Bocconi, Sibbaldia procumbens et un grand nombre d'autres plantes rares.

La petite froupe qui suivait notre Président et qui s'était égarée dans ces régions alpestres conservera le meilleur souvenir de l'hospitalité cordiale de M. le curé de VillardEymond.

De notre côté, en compagnie de MM. Martin, Bruand, Constant, Bellevoye, etc., nous avons exploré les montagnes du Nord. M. Martin et moi-meme gravissons, non sans peine, ni danger, un des rochers de la cascade ou croissait 
l'Asclepias vinceloxicum, émaillé, comme de coutume, de nombreux Chrysochus pretiosus. Après avoir frugalement déjeuné au bord du torrent, dans un endroit où voltigeait par essaims le Lycocna damon, nous continuons notre ascension jusqu'au village d'Iluez. Les prairies nous avaient abondamment offert sur ces hauteurs les Polyommatus Eurydice, virgaureo, Argynnis Niobe, Ino, et une quantité vraiment considérable d'A pollo. Près d'Huez, j’ai pris au vol l'Anilirax capucina.

En arrivant dans ce malheureux village d'Iluez, incendić depuis un mois à peine, nous avons trouvé le plus triste spectacle. Sur unc centaine de maisons, disposées en amphithêdre et rapprochées les unes des autres, quelquesunes á peine étaient restíes debout, les autres avaient été dévorées par les flammes. Ce n'étaient plus que toits renversés, murailles noircies et tenant à peine sur un sol encombré de débris ralcinés. Nous avons parcouru ces ruines. Un villageois nous a appris, non sans doléances, et elles n'étaient que trop justes, qu'une batiture de fer partic d'une forge élait tombée sur un toit en chaume, où elle avait porté l'incendie qui avait couvé lentement.

Les flammes, poussées par un vent frès fort et favorisées par une température élevée avaient enveloppé tout le village; les habitants, dispersés dans les champs et revenus a la hate n'ont pu qu'assister à celte scène de désolation. L'eau manquait, tout a été rapidement consumé.

On se hátait de rebàtir quelques maisons et nous avons vu des mulets portant des ardoises sur le dos arriver jusqu'à Huez. Il serait indispensable de supprimer dans les villages les toitures en chaume qui propagent si vite l'incendie.

Notts dépassons Huez et atteignons les sommets. En face 
de nous est la montagne limitrophe du Piémont. On en extrait une houille abondante, mais de mauvaise qualité.

Sous les pierres, nous trouvons en grand nombre, avec Ies Cymindis humeralis, Calathus fulvipes, alpinus, une belle variété d'un vert-bronzé foncé du Carabus cancellatus, l'Amara rufocincta, le Cryptocephalus imperialis à taches confluentes, la Chrysomela limbata et la commune Forficula bipunctata. Je dois mentionner le Capsus trigutlatus, à cause de la taille qu'offre cet IIémiptère dans cette localité, il est du double plus grand que celui des environs de Paris.

Plusieurs Aphodius alpins fouissaient dans leur demeure ordinaire. J'ai pris au vol les Rhizotrogus ochraceus et assimilis. M. Bellevoye a trouvé le $R$. cicatricosis. Le Stenobothrus variegatus était fort commun.

Nous sommes revenus au Bourg par un chemin moins pénible que celui de l'ascension, mais néanmoins très fatiguant par ses zig-zags interminables.

C'est par une route moins longue que celle de notre arrivée, mais droite comme elle, que nous quittons le cirque de montagnes, oú est situé le sombre Bourg-d'Oisans. II est infiniment probable que l'espace renfermé entre ces monts a été jadis occupé par un vaste lac dont les eaux se seront écoulées du côté de Vizille. La ronte que nous suivons s'élève et nous traversons un défilé. Bientôt elle est tracée sur le flanc du rocher et bordée, à notre gauche, d'affreus précipices au fond desquels la Romanche coule dans un lit torrentueux. Le Centranthus angustifolius, la Lavandula spica nous offrent quelques Zygènes et des Lépidoptères diurnes alpins qui vont se reposer sur les sommités fleuries. A plusieur's reprises, nous passons sous de petits tunnels creusés dans le rocher. Cette route est 
très accidentée; elle avait parfois des aspects vertigineus, quand, lancés à toute vitesse, nous regardions à notre coté, sans troltoirs, ni garde-fous, le torrent, dont le lit rempli de blocs ou de pierres énormes, grondait sourdement au fond d'abîmes taillés à pic ou hérissés de pointes aiguës.

Derrière nous sont le Pémoutet (mont du pied de mouton) et mont de Lans sur' notre droite. En nous éloignant d'eux, je dois mentionner certaines cultures particulières aux Alpes et que nous avions, du reste, observées dans le département de l'Isère avant d'arriver au Bourg-d'Oisans. Elles donnent un aspect tout spécial au paysage.

Sur le bord des rochers, sur les pentes les moins escarpées, partout oú se trouve de la terre végétale, on remarque des sortes de zones, de bandes transversales, couvertes de moissons et de cultures diverses. Quelques-unes arrivent au bord meme lu précipice, et il faut un pied montagnard pour aller les recueillir.

Près du Freney, on vient de construire un tunnel assez long, au sortir duquel la route sera considérablement élevée sur une terrasse bien bátie. L'ancienne route est en mauvais état.

Nous atteignons le Pont-du-Dauphin, presque détruit par les inondations de $\mathbf{1 8 5 6}$, et nous passons la Romanche qui coulera désormais à notre droite. Sur le bord des eaux, nous prenons la Cicindela transversalis, des Chlcenius, des. Bembidium; l'A pollo vole en grand nombre, les Lycœna, les Polyommates alpins se reposent sur les fleurs déjà signalées. Plusieurs cnscades tombent et s'effilent en longues traînées vaporeuses du haut des arêtes de rochers. D'autres forment de petites bandes sinueuses et argentées, qui 
roulent avec bruit et conduisent à la Romanche le tribut provenant de la fonte des neiges.

Le pays que nous traversons est de plus en plus désert et sauvage; ce ne sont plus les aspects des environs de Grenoble et de la Chartreuse, la route a été emportée en plusieurs endroits, nous en profitons pour descendre et butiner en marchant. Des arbres jetés en travers sur la Romanche servent de pont aux montagnards. Les cascades se multiplient; nous apercevons meme sur les rochers a droite, opposés à ceux que nous cotoyons, de grands espaces couverts de neige provenant d'avalanches non fondues. Ils semblent rapprochés de nous, mais on sait combien les distances sont trompeuses dans les pays de montagnes. Nous remarquons dans un talus de pierres et de fragments éboulés à notre gauche, sur les Lavandula, les Centranthus, les Thymus alpinus, Centaurca paniculata, Artemisia camphorata, bon nombre d'espèces alpines de Lépidoptères et d'Hyménoptères. Parmi elles, nous reconnaissons parfaitement la Thais Medesicaste.

Quelques chétives cabanes, situées au pied de la montagne, de l'autre côté de la Romanche, consistent en murs de pierre sèche adossés au rocher-paroi, leur toit est incliné pour ne pas céder sous le poids de la neige; elles sont groupées les unes auprès des autres, et leur aspect est misérable.

Nous remarquons, sur les hauteurs et sur le flanc des montagnes de droite, les bois d'Efraux, composés en grande partie de Mélèzes. On y fait la chasse aux grands coqs de Bruyère (Tetrao urogallus) et aux Tétras à queue fourchue (Tetrao tetrix). 
D'énormes blocs de rocher se sont détachés et ont roulé jusque sur la route, qui a dû se détourner devant ces obstacles. Nous découvrons de loin un sommet neigeux, un véritable glacier. La couche est considérable, éternelle. Nous touchons à La Grave-en-Oisans, village très heureusement situé pour le naturaliste.

Il est décidé que nos montures se reconforteront à La Grave et nous pareillement. Nous y avions été annoncés et nous y sommes convenablement reçus. On cultive á La Grave, dans quelques champs en zone dont j'ai déjà parlé, le Secale cereale et le Solanum tuberosum qui ne peuvent pas toujours y mûrir ou s'y multiplier. On y fait aussi un pain en forme de pavé cubique, composé de seigle, d'orge et de très peu de blé moulus. On le fait cuire pendant longtemps et pour la majeure partie des habitants à la fois; il est d'une longue conservation. Sa dureté est celle du biscuit de mer; nous en avons vu de trois années de date et qui ne paraissait point altéré. Pendant qu'on nous montrait ce pain, un petit garçon s'occupait à en grignoter un morceau.

Sur la terrasse de l'hôtellerie de La Grave on jouit d'un coup d'œil magnifique, la Romanche coule au bas, en face sont de vertes prairies, des sapins et des mélèzes espacés ou groupés en petites masses, le glacier couronne le tout. C'est un des sites les plus intéressants que nous ayons vus dans les Alpes. Je donnerai encore un souvenir à La Grave.

Les bords de la Romanche nous ont offert, sous les pierres, quelques Carabiques, la Nebria picicornis et une grande quantité de Bembidium.

Au sortir de La Grave, nous trouvons un tunnel considérable, sa longueur est de 800 mètres; il n'est pas droit, mais un peu recourbé; en pénétrant au fond des ouvertures 
latérales qui ont servi aux déblais, la vue tombe sur d'effrayants précipices. On terminait les travaux de maçonnerie de ce tunnel du cóté de La Grave; à l'époque de notre pas. sage.

La route continue à s'élever, chacun de ses détours est marqué par un long polean de bois, pareil à ceux des télégraphes électriques sur les lignes de chemins de fer. Ils sont destinés à indiquer la route dans la saison des neiges. Le paysage devient de plus en plus sauvage. Les monts ont leur cime dépouillée, leurs flanes sont grisâtres, raboteux, et n'offrent plus d'arbres, de sapins éparpillés. 'Toute végétation frutescente a disparu. Par contre, le long de la route, à notre gauche, l'œil se repose sur de belles prairies alpines.

Nous apercevons le clocher incliné de Villar-d'Arène. La route s'élève toujours. Nous la faisons à pied, el, en cherchant sous les pierres, MM. Bellevoye et Lambert prennent la Cicindela chloris qui s'y était réfugiée.

Enfin, avançant toujours, et après une montée exfrêmement raide, nous apercevons de loin un batiment fort bas, situé à l'extrémité d'une magnifique prairie. La route fait un détour pour s'y rendre. Nous sautons tous dans l'herbe et arrivons au Lautaret, à travers les plantes bautes d'un mètre en plusieurs endroits.

En soulevant les pierres des sentiers qui traversent la prairie, $\mathrm{j}$ 'ai trouvé quelques intéressants Carabiques, Cymindis axillaris et coadunala, Ilarpalus lovicollis, Amara monticola, et dans leur gîte habitucl, les Aphodius obscurus et alpinus.

L'impression que produit à première vue l'ancien Hospice du Lautaret n'est pas des plus attrayantes. Le batiment 
se compose d'un rez-de-chaussée et d'un étage peu élevé, solidement construits, ayant la forme rectangulaire. Il est placé sur le point le plus élevé de la route de Turin, et toutes les voitures s'y arretent en passant.

Pénétrons dans l'intérieur. C'est d'abord une sorte de vestibule obscur, à sol inégal; dans un recoin à droite se trouve une fontaine où coule une eau abondante; nous cherchons à gauche et à tatons la porte d'entréc. Nous voici dans une salle assez vaste, mais sombre, chauffée par un poele. Elle est voûtée, avec les arêtes de la voûte simples, sans ornements. Autour d'une longue et solide table sont nos colle gues et quelques montagnards, qui bientot nous cèdent la place. La famille Amieu, qui hahite le Lautaret, nous reçoit avec bonheur et nous comble de prévenances.

A la suite de cette pièce en est une autre, voûtée comme ellc, où s'est déjà établi notre collègue, M. Thibézard, qui nous a précédés au Lautaret. Je pourrais l'appeler chambre présidentielle, parce qu’elle a reçu notre Président. II y a trouvé un bon lit, mais, en outre, une collection de Pulc $x$ et une grande humidite.

J'ai toujours aimé à voir les objets dans leur ensemble; je suis plusieurs collègues qqui grimpent déjà sur un monticule, en face de l'ancien Hospice. En soulevant les pierres, nous prenons en grand nombre la Feronia llonnoratii, la Cymindis axillaris; des Rhododendron ferrugineum rabougris couvrent le sol autour de nous, ainsi que l'Empetrum nigrum et l'Arnica montana en pleine floraison. La Zygona exulans se trouve par milliers sur toutes les plantes. Elle est d'une abondance excessive.

Vu de notre observatoire, le Lautaret forme le seul relief de la route sinueuse qui s'élève du côté de Villar-d'Arène, 
et qui va s'abaissant du côté de Briançon. Le premier étage va toucher le sol sur notre droite, d'oủ nous pouvons conclure que les animaux domesliques, les bestiaux, peuvent s'y rendre quand le rez-de-chaussée a disparu sous la neige. Derrière nous est le mont IIaut-Richard, devant nous le Galibier, que nous gravirons demain; à droite, au loin, un poste de douaniers établi dans une maisonnette et formant un point dans cet espace désolé, encombré de montagnes nues et grisatres, étagées, amoncelées les unes sur les autres.

La nuit arrive subitement dans ces hautes régions, hatonsnous de revenir. Nous nous assurons que le toit du Lautaret, vu horizontalement, est au-dessus de ces grandes plaques de neige qui revetent le IIaut-Richard. Entrons de nouveau au Lautaret. Prenons gaiment notre repas d'une simplicité rustique. Le Génépi des Alpes a remplacé la liqueur de la Chartreuse. J'apprends que l'ancien Hospice du Lautaret a été construit pour recueillir les voyageurs pendant l'hiver.

On y avait placé une cloche qui était sonnée pendant les tourmentes et quand la neige tombait, mais on a été obligé de l'enlever parce que le son de cette cloche répété par les échos des montagnes trompait souvent le voyageur et l'égarait au lieu de le diriger. Ces longs poteaux, qui indiquent la route et qui me paraissaient fort élevés, sont parfois enfouis sous la neige. Alors on en place d'autres a l'endroit qu'occupaient les premicrs, et ils servent de guide aux courriers qui vont en traineau sur la route et auxquels il arrive peu d'accidents. Quand l'usage des poteaux superposés est devenu indispensable, les habitants du Lautaret gagnent Villar-d'Arène et laissent leur domicile enfoui dans la neige. 
Le moment du rcpos élant venu, je cherchais des yeux oủ pourraient etre les lits de notre troupe. J'ai été bientôt satisfait. Nous repassons dans le vestibule, et là, grimpant à une échelle assez droite, nous nous trouvons dans le premier étoge, grenier et remise, tout à la fois, oủ nous nous étendons dans des couvertures et sous des couvertures, sur les graminées desséchées de la prairie. La même couverture sus-enveloppante recouvrait de deux à trois d'entre nous, suivant son ampleur. Quelles gaies réflexions avant le som. meil! Nous navons pas eu le lit de la chambre du rez-dechaussée, mais l'humidité ne nous a point incommodés et nous n'avons pas constaté la présence des Pulex, Cimex, etc.

Sur pied avant l'aube, après les ablutions ordinaires, nous commençons l'ascension du Galibier en traversant de stperbes prairies. Nous y remarquons, entre autres plantes, parmi le Veratrum aux larges feuilles, les Gentiana bavarica, Anemone narcissiflora, Brassica Richeri, Aquilegia alpina, etc., un Narcissus voisin du poeticus et qui constituera peut-etre, suivant $\mathbf{M}$. Boisduval, une nouvelle espèce. Nous franchissons un torrent peu profond, mais assez large, puis par un sentier raide, nous arrivons aux chalets qui dominent le Lautaret, et au-dessus desquels la montagne devient de plus en plus escarpée. Au soleil levant, nous avons pris les Purnassius Plicebus, Lycoena optilete, orbitilus, eros, pheretes, eumedon, etc. Autour des chalets, nous trouvons une collection fort singulière, et parfaitentent alignéc en quinconces, de stercus bovinum séchant à l'air sur la terre ou sur des toits inclinés. Il élait évident que ces étranges produits avaient été soigneusement ramassés dans les prairies ou le long des sentiers et transportés de là et de l'étable au séchoir commun, où ils avaient été disposés avec 
ordre. Quelle pouvait etre leur utilité? On me l'expliqua et j'y ai cru plus tard, de visu, en apercevant les petites masses avec lesquelles le feu du foyer était entretenu au Lautaret. L'odeur elle-même avait quelque chose de spécial qui révélait la nature du combustible. Le bois n'existe pas à plusieurs lieues à la ronde. Le stercus bovinum desséché en tient lieu. Nous avons mangé de la cuisine préparée avec ce feu d'origine nouvelle pour nous.

Les Stenobothrus viridulus sautent dans les prairies alpines; les Erebia alecto, gorge, et sa jolie variété erynnis volent sous les rayons d'un chaud soleil. Le Cirsium spinosissimum, d'une superbe végétation, borde les sentiers que nous suivons, mais il est de moins en moins avancé à mesure que l'altitude est plus considérable.

L.es Aphodius qui fréquentaient les quinconces des chalets étaient fort nombreux, nous y avons trouvé, ainsi que sous les déjections nouvellement déposées sur le sol et non encore récoltèes, les Aphodius obscurus, atramentarius, alpinus, nivalis, etc.

Les pierres soulevées avec persévérance nous ont fourni les Amara ingenua, picea, les Ilarpales monticoles, et surtout une grande quantité de Forficula bipunctata. Celte espèce est encore plus commune au Lautaret qu'à la Grande. Chartreuse et au-dessus du village d'Huez.

Notre ascension se poursuivant toujours, je trouve l'alpestre Gomphocerus (Stenobothrus) sibiricus. Nous dépassons des creux remplis de neige qqui, en fondant, forme le torrent que nous avons dû franchir au départ. Près de la ncige, nous trouvons les Nebria castanca et nivalis, le Bembidium bipunctalum, puis nous élevant toujours jar des seutiers en zig-zag et à peine tracés sur un sol incliné, 
très garni de menus débris, fort peu commode à gravir, nous touchons au point terminal de notre ascension. Nous sommes sur le faite du Galibier, oủ nous pouvons mettre un pied en France et l'autre en Sardaigne.

Le spectacle que nous avions de ce haut sommet nous dédommageait de nos fatigues. L.e mont Blane apparaissait avec sa large cime neigeuse, le mont Ventoux, le mont Viso, le mont Pelvoux, dominant d'autres pics moins élevés, s'élevaient autour de nous. Sur la petite plateforme où nous étions placés, M. Martin prit une Pieris callidice qui passait à tire-d'aile de France en Piémont. II me montrait aussi, dans sa bolte de chasse, l'Anaitis simpliciaria (1), publiée, comme vous le savez, sous les noms de Magdalenaria et de Pierretaria, et que M. Azambre avait déjà prise sur les hauteurs du Lautaret (2).

N'oublions pas de noter les captures de la Pachyla interrogationis, Luperus viridipennis, Oreina nivalis faites sur les fleurs, à moitié chemin de notre ascension. Nomettons ni Ies plantes que nous avions si près de nous sur le sommet du Galibier, le Ranunculus glacialis, les deux Saussuren alpina et discolor, le Dracocephalus Ruyschianus, le Dianthus neglectus, le Myosotis nana, ni les diverses espèces de Génépi que nous avons trouvées sur notre route. La des. cente fut rapide, chacun allant de son cóté. J'ai suivi dans le bas le sentier qui mène à la demeure des Douaniers, j'y ai pris, au vol, la Cicindela chloris et an bord du torrent, l'Anthrax bifasciata.

(1) Voyez GuÉnée, Ilist. nat. des Lépidopteres, etc., tome X. page $501, n^{\circ} 17522,1857$.

(2) Voyez Annales de la Societé Entomologique de France, 1858 , BulJet. XII. 
Je dois dire que les Tabanus micans et luridus étaient extremement communs et qu'ils n'ont cessé de voler autour de nous, se reposant, s'envolant et revenant se poser encore jusqu'auprès du sommet, pour devenir nos insupportables compagnons jusqu'à la porte du Lautaret.

Nous avons remarqué souvent, sur les gros blocs de rochers éboulés, le Fringilla nivalis et l'Accentor alpinus, qui s'y posent pendant longtemps et qui font entendre un petit cri plaintif et monotone. Des bandes nombreuses de Pyrrhocorax volaient sur les hauteurs, et, le matin, le toit et la cheminée du Lautaret en étaient couverts. Nous les avons aperçus en aussi grand nombre à La Grave.

A près un repas aiguisé par un bon appétit. nos courses recommencent. Autour du Lautaret, je trouve en quantité l'Ocypus picipennis sous des pierres, et je vois là, pour la deuxième fois, des provisions considérables du mème combustible que j'avais trouvé séchant près des chalets.

M. Boisduval ne résiste pas à l'envic de monter sur le Ilaut-Richard, et je l'accompagne. Un petit berger nous guide, et il emmène une chèvre dont l'agilité nous aiguillonne. Cetle course a été moins productive pour l'Entomologie que pour la Botanique; nous n'avons pris que des Coléoptères, quelques Erebia et quelques Géomìtres peu rares pour nous et déjà capturées la veille ou le jour même sur le Galibier.

Dans la soirée, les lépidoptéristes ont pu chasser avec succès au crépuscule. Devant le Lautaret, ils ont pris en grand nombre l'llepialus humuli, dont le vol saccadé est si particulier.

Plusieurs de nos collègues partent le soir pour atteindre Villar-d'Arène. Nous passons une deuxième nuit, dans les 
mimes conditions que la veille, et, le lendemain, de grand matin, nous quittons le Lautaret et retournons a La Grave, en revoyant les sites désolés que nous avions si lentement parcourus à notre arrivéc; vers le milieu du jour, nous étions rendus au Bourg-d'Oisans.

Favorisés par une belle journée et un chaud soleil, nous chassons avec ardeur près de la cascade. Nous nous assurons par nos prises Pandarus tristis, Mylabris variabilis, Satyrus cudora, Rhodocera Cleopatra, que cette localité est très méridionale.

Nous trouvons les chenilles de la Cucullia canina sur la Scrophularia canina, le Syrichthus lavatero, le Lycona dorylas se reposant sur une Toffieldia.

Nous cueillons de belles touffes de la jolie Linaria alpina. Plusieurs espèces intéressantes sont récoltées par nos collègues, entr'autres, les Deleaster dichrous, IIaliplus elevatus, Anthaxia sepulchralis, Syncalypta setigera, Xyletinus pectinatus, Lampyris splendidula, des Cetonia, Hoplia, Anomala, les Otiorhynchus hirticornis, Astynonus griscus, Cryplocephalus bilineatus à taches confluentes, etc., etc.

Dans un champ où l'herbe est clair-semée, je prends en grande abondance la Cicindela germanica el celte fois encore je m'assure qu'elle peut voler, mais peu loin. Au bord d'un fossé, je recueille aussi des Cicindela transversalis; au vol, quelques Diptères, tels que l'Anthrax fenestrata et sinuata, les Leptis lincola et Xylota segnis.

Ce qui m'étonne le plus, c'est de trouver un grand nombre d'Acrydium migratorium à l'état parfait et faisant bruyamment usage de leurs ailes, près du champ où j'ai pris la Cicindela germanica.

Avant de revenir au Bourg-d'Oisans, nous avons mis à mort, sans pitié, une Vipère. Mais, à notre retour, nous 
sommes bien étonnés de voir une immense quantité d'Acrydium à l'état de larve et de nymphe noyés ou écrasés à l'entrée du Bourg, sur la route. Nous apprenons que ces insectes existent par myriades de ce côté de la Romanche, qu'ils n'ont pu franchir. Ainsi m'est expliquée la présence exclusive des individus parfaits de l'Acrydium migratorium, près de la cascade, car ils ont pu traverser la Romanche à l'aide de leurs ailes. Les larves de ces insectes ont déjà produit d'effroyables dégats; les récoltes de céréales ont été détruites sur pied, les végétaux ligneux dépouillés de leurs feuilles, ils attaquent même les Arundo phragmites.

On nous dit qu'un habitant du pays ayant aperçu une sorte de nuage qui arrivait du côté du Sud, fut très étonné de voir, après la chute de ce nuage, la terre littéralement couverte de Sautcrelles. C'étaient les Acrydium qui s'abattaient aux environs du Bourg-d'Oisans. On traita l'observateur de visionnaire, mais il ne s'était pas trompé, il n'avait que trop bien vu.

L'Acrydium, qui a causé les ravages que nous avons constatés au Bourg-d'Oisans, est le migratorium de LiNNÉ ou le Pachytylus migralorius des auteurs modernes. Vous savez, Messieurs, que cette espèce, si anciennement connue, a été plusieurs fois observée en France; et cette année même des milliers de ces Insectes dévastateurs se sont répandus en suisse (1) et dans plusieurs contrées (2).

(1) Voyez un récent travail de N. A. Y. YRSIN, sur le Pachytylus migratorius, publié dans la Bibliothèque universelle de Genève (Arch. Sc. physs. et nat. LXIII année, III, 267, 1858). - Voyez aussi une note de M. le docteur H. Dor, insérée dans ce volume, page ccxxiv du Bulletin.

(2) J.-A. BARRAL, Journal d'Agriculture pratique, 1858, II, $n^{\circ} 15$, page 92. 
Les larves et nymphes, si voraces, étaient ussurément celles de l'Acrydium migratorium. Elles offraient des taches bleuatres très remarquables de chaque coté de leur thorax. Plusieurs larves d'Acrydidre présentent cette livrée pendant les premières périodes de leur existence.

Depuis les dégats des Acrydium, signalés dans plusieurs passages des livres sacrés, ces insectes ont acquis la plus grande et la plus triste célébrité par leurs ravages extraordinaires. Je ne puis, Messieurs et chers collegues, que vous rappeler, à ce sujet, les récits rapportés dans les ouvrages spéciaux. Audinet-Serville, Solier (1), Fischer de Waldheim (2), MM. Brullé (3), Fischer de Fribourg (4), Levaillant, Guyon (5), etc., ont été les historiens de ces calamités, de la destruction des récoltes et de toutes les matières végétales accessibles à la dent meurtrière de ces insectes.

La plupart des bandes de Sauterelles de passage, qui ont paru en Europe à diverses époques, étaient composées de Pachytylus migratorius et parfois de $P$. cinerascens F. L'Acrydium itaticum Lins. est encore une espèce qui a été signalée en Europe comme émigrante (6).

(1) AUd.-SEnvir.Le, IIistoire des Orthopteres, Suites à Bufion, page 555 et suiv. - Solien, Ann. Soc, Ent. de Fr., 1833, 436.

(2) Fiscier de Waddieim, Orthoptires de la Russie, page 21 et pages 293 et suiv.

(3) Audouin et Brulite, Hist. des Insectes, etc., tome IV, p. 199 et suiv.

(4) Fiscien de Fribourg, Orthoptera Europaca, pages 49, 50 , 292 et 293.

(5) Levaillant, Comptes.rendus de l'Acad. des sciences, 1845, tome XX, page 1041.-GuYoN, idem, page 1499, et tome XXI. page 1107.

(6) AUd.-Senville, Orthoptères, page 687. 
Dans le nord de l'Afrique et en Orient, l'Acrydium peregrinum Ouv. est une des especces dont les migrations se renouvellent le plus souvent et qui causent le plus de ravages (1). L'Acrydium lincola $\mathrm{F}$. a été aussi indiqué dans le nord de l'Afrique, comme pouvant émigrer.

Enfin, le Stenobothrus cruciatus Criarp. (Stauronotus cruciatus Fiscir.), est une des espèces émigrantes les plus dévastatrices du nord de l'Afrique.

Vous vous rappelez, Messieurs, les calamités qui suivent l'apparition de ces insectes; la famine obligée, les maladies résultant de la viciation de l'air par les émanations pestilentielles de leurs innombrables corps en putréfaction. M. Guyon (2) a signalé les odeurs infectes répandues par leurs déjections. J'ai été moi-meme étonné de la très grande quantité d'excréments que plusieurs de ces insectes, rapportés vivants à Paris, ont fournie avant de mourir.

Leurs troupes, quoique considérables au Buurg-d'Oisans, n'ont pas, que nous sachions, produits d'autres malheurs que ceux d'une disparition des récoltes. Espérons que ces insectes ne se reproduiront pas en grand nombre, l'année prochaine, dans les contrées qu'ils ont dévastées.

A près une nuit passée à Bourg-d'Oisans, nous rentrons à Grenoble, oủ nous restons une journée avant de regagner Paris.

Avant de quitter cette ville de Grenoble, si intéressante pour nous, nous avons visité ses collections d'histoire natu-

(1) Otrvier, Voyage dans l'Empire Othoman, l'Egypte et la Perse, tome II, pages 424 et $425 .-$ A.-Senvible. Hist. Orth., page 667, et Ann. Soc. Ent. France, 1845, Bull, cxi.

(2) Guyon, Comples.rendus de l'Acad, des Sciences, 1845, tome $\mathrm{XX}$, page 1500 . 
relle, son riche Musée de tableaux, sa Bibliothèque publique, ses monuments, sa Citadelle, etc. Les renseirnements qui suivent sont dignes de fixer votre atiention.

Les collections d'histoire naturelle du Musée sont admirablement tenues. Elles sont classćes et étiquetées avec soin. Les oiseaux des Alpes y sont très completement représentés; les insectes de l'Isère et des Alpes y figurent en assez grand nombre, à part les petites espèces. Les collections de minéralogie peurent etre citees au nombre des plus riches et surtoct des plus remarquables de France pour la beauté de leurs échantillons. Cet établissement fait le pius grand honneur à M. le professeur Bonteille, qui en est le conservateur éclairé.

I.e Jardin botanique pourrait servir de modèle à plusieurs jardins de ce genre. M. le professeur Verlot, qui a l'amour des plantes, apporte à l'arrangement un soin de lous les instants. C'est, sans contredit, l'un des jardins publics de France où les espèces sont le micux classées. Nous regreltons seulement que les serres d'un établissement. aussi remarquable ne soient pas en rapport avec son importance.

L'Ecole d'arboriculture est bien dirigée et nous avons été étonnés d'y rencontrer des arbres aussi bien conduits. Le local servant à la Société d'acclimatation, sous la haute direction de M. Réal, nous a paru beaucoup trop resserré. Il renferme quelques animaux assez précieux qui paraissent bien porlants. Nous avons remarqué, entr'autres, quelques belles races de Poules et une belle paire de Yacks.

Je vous rappellerai, en terminant, que M. Ie Secrétaire général de la Préfecture de l'Isère a consulté votre Prési- 
dent sur les ravages des Acrydium migratorium et sur les moyens à prendre pour y remédier.

Tels sont, Messieurs et chers collègues, les principaux détails de la deuxième session extraordinaire de notre Société. Elle a satisfait tous ceux qui ont pu y prendre part. C'est une joie pour le naluraliste de se soustraire momentanément à la vie ordinaire et aux intérets matéricls dont aucun de nous ne peut etre exempt, de ramasser betes et simples et de se reposer au milieu des Alpes, dans une cellule de la Grande-Chartreuse ou sous le toit du Lautaret.

Il me reste à vous faire connaître les noms des principaux insectes et des plantes qui ont été recueillis pendant nos excursions. Vous y trouverez peu d'espèces nouvelles; le temps nous a été médiocrement favorable, et nous avons parcouru trop vite les meilleures localités.

Mais, pourrions-nous ne pas signaler, avec la GrandeChartreuse et Saint-Laurent-du-Pont, les environs de Grenoble, de Vizille, Séchilienne, le Bourg-d'Oisans, et surtout Li Grave? A ceux qui iraient s'établir pendant une saison convenable dans ces endroits privilégiés, nous pouvons promettre une abondante, une précieuse récolte, aussi leur disons-nous avec le poète :

Les moissons de ces champs lasseront vos faucilles... Et les fruits passeront les promesses des fleurs! 


\section{LISTE DES INSECTES PRINCIPAUX}

Recucillis aux environs de Grenoble, à la Grande-Chartrcuse et dans les Hautes-Alpes (au Bourg-d'Oisans et au Lautaret) pendant la Session extraordinaire de Juillet 1858.

\section{COLËOPTÈRES (1).}

Cicindela sylvicola. -- Grande-Chartreuse.

$$
\text { gallica BnullÉ. - Lautaret. }
$$

chloris DEJ.

hybrida var. riparia. - Route de Bourg-d'Oisans. transversalis.-Gr.-Chartreuse et Bourg-d'Oisans.

Nebria picicornis. - Bourg-d'Oisans, La Grave.

$$
\text { nivalis. - Lautaret. }
$$

Jockischii. - Id.

castanca. - Grande-Chartreuse et Lautaret.

Leistus fulvibarbis. - Grande-Chartreuse.

Carabus monilis var. noire. - Sur toutes les montagnes.

cancellatus var. d'un vert bronzé obscur.-Montagnes d'Huez.

nodulosus. - Chartreuse de Prémolles, VillardEymond.

auronitens. - Grande-Chartreuse.

(1) Cette liste a été rédigéc d'après les notes et les communications qui nous ont été fournies à M. Léon Fairmaire et à moí-même, par MM. Bellevoye, Cartereau, Gougelet, Paul Lambert ct Legrand. 
Carabus violaceus (1). - Grande-Chartreuse.

convexus. - Id.

intricatus. - Bourg-d'Oisans.

Cychrus rostratus (2). - Gr.-Chartreuse, Bourg-d'Oisans.

attenuatus. - Id., id. et Chartreuse de Prémolles.

Cymindis humeralis. - Commune sur toutes les montagnes. axillaris. - Saint-Nizier, Lautaret.

coadunata. - Bourg-d'Oisans et Lautaret.

vaporariorum. - Lautaret.

Dromius fenesiratus. - Grande-Chartreuse.

quadrillum. - Id., Bourg-d'Oisans.

Lebia crux minor. - Bourg-d'Oisans.

Ch!onius tibialis var. à pattes brunes. - Séchilienne, La

Grave.

Licinus cassideus. - Bourg-d'Oisans.

Hoffnanseggii. - Uriage.

Dolichus flavicornis. - Route de Bourg-d'Oisans.

Calathus fulvipes. - Sur toutes les hauteurs, très commun.

micropterus. - Uriage, Bourg-d'Oisans, Prémolles.

alpinus. - Grande-Chartreuse, Huez, Lautaret.

Taphria nivalis. - Grand-Som.

Feronia cuprea var. noire. - Sur toutes les montagnes.

dimidiata. - Grande-Chartreuse.

(1) L.es individus trouvés à la Grande-Chartreuse (à Bovinant) se rapportent parfaitement au Carabus exasperatus DuFTs., qui n'est qu'une variété du C. violaceus Lins., (Faun. Ent. F'r., I, 20). G'est la variété $\mathrm{C}$ du Carabus violaceus décrite par M. Schaum (Naturg. Ins. Deut., J, 154, 1856).

(2) Cet insecte a constamment été pris dans les troucs d'arbres décomposés. 
Feronia lepida var. noire. - Sur toutes les montagnes.

spadicea. - Grande-Chartreuse.

maura. - Grande-Chartreuse, Lautaret.

parumpunctata. - Uriage, Saint-Nizier, Pré-

molles, etc.

Panzeri. - Grande-Chartreuse.

Lasserrei. - Id.

IIagenbachii. - St-Nizier, Grande-Chartreuse.

Honoratii. - St-Nizier, Prémolles, Lautaret.

Prevostii. - Id, Grande-Chartreuse.

externepunctata. - Uriage, Prémolles.

Yvanii. - Grande-Chartreuse, Lautaret.

metallica. - Prémolles, Villard-Eymond.

Amara patricia. - St-Nizier, Prémolles, Lautaret.

ingenua. - Lautaret.

municipalis. - Grande-Chartreuse.

monticola. - Lautaret.

communis. - Grande-Chartreuse.

familiaris. - Id., Lautaret.

curta. - St-Nizier.

picea. - Id.

crenata. - Lautaret.

frufocincta SAHLb. - Montagnes d'Huez.

Y grandicollis Zімм.

Diachromus germanus. - Uriage, elc.

Harpalus rubripes. - Prémolles, Grande-Chartreuse.

patruelis. - Sur toutes les montagnes.

honesius et var. ignavus. - Grande-Chartreuse.

consentaneus. - Id.

hottenttota. - St-Rambert, Grande-Chartreuse. 
Harpalus f fulvipes F. - Grande-Chartreuse.

limbatus GYLL.

(levicollis DurT.-Prémolles, Grande-Chartreuse,

salyrus DEJ. Lautaret.

Trechus arcolatus. - Grande-Chartreuse, Bourg-d'Oisans.

Bembidium 4-signatum. - Bourg-d'Oisans.

\{varium OLIV. - Au bord des torrents, commun,

\{ustulatum FAB. Gr.-Clıartr., B.-d'Oisans, etc.

fulvipes. - Id., Bourg-d'Oisans.

nitidulum. - Id., Grande-Chartreuse.

f fasciolatum. - Bourg-d'Oisans, La Grave, etc., tvar. coeruleum. commun.

tibiale var. - La Grave.

bisignatum. - Conflans.

eques, - St-Laurent-du-Pont, Bourg-d'Oisans.

tricolor. - Bourg-d'Oisans, La Grave.

conforme. - Id., rare.

(Andrea FAB. - Bourg-d'Oisans, etc.

\{ruciatum I)EJ.

femoratum, - Id.

distinguendum. - Bourg-d'Oisans.

rufipes. - Id., commun.

Sturmii. - St-Nizier.

bipunctclum. - Lautaret.

caraboides. - Bourg-d'Oisans.

Agabus guttalus. - Grande-Chartreuse.

Iydroporus Davisii. - Saint-Laurent-du-Pont et dans les bassins du Couvent.

septentrionalis. - St-Laurent-du-Pont, GrandeChartreuse. 
IIydroporus Sanmarkii. - St-Laurent-du-Pont. vittula. - Grande-Chartreuse.

Haliplus elevatus. - Bourg-d'Oisans.

Elophorus elevatus. - St-Laurent-du-Pont, Lautaret.

Hister marginatus. - Grande-Chartreuse.

funestus, - St-Nizier, Grande-Chartreuse.

Saprinus conjungens. - St-Rambert, Grande-Chartreuse.

Silpha nigrita var. alpina. - Gr,-Chartreuse, Lautaret.

Anisotoma rotundata. - Lautaret.

Batrisus formicarius. - Grande-Chartreuse.

Othius alternans, - Id.

Staphylinus hirtus. - St-Nizier, IIuez, etc.

lutarius. - St-Nizier.

chalcocephalus. - Id.

pubescens. - Id.

fossor. - Id., Prémolles.

picipennis, - Lautaret.

fulvipennis. - Grande-Chartreuse.

ater. - Uriage.

Philonthus intermedius. - Si-Nizier.

nitidus. - Grande-Chartreuse.

decorus. - Prémolles.

lucens. - St-Nizier.

Poderus longicornis. - St-Laurent-du-Pont, St-Rambert.

Deleaster dichrous. - Bourg-d'Oisans.

Trigonurus Mcllyi. - Grande-Chartreuse.

Anthophagus armiger. - Id.

alpinus. - Id.

caraboides, - Id.

Thymalus limbatus, - Id. 
Syncalypte setigera. - Bourg-d'Oisans.

Byrrhus signatus. - Grande-Chartreuse.

$$
\begin{aligned}
& \text { ornatus. - Id. } \\
& \text { arcualus. - Id. } \\
& \text { fascialus. - Id. } \\
& \text { varius. - Id. }
\end{aligned}
$$

Parnus striato-punctatus, - St-Laurent, Gr.-Chartreuse.

vicnnensis. - St-Rambert.

auriculatus. - Grande-Chartreuse.

substriatus. - Id.

Elmis angustalus. - St-Laurent, Gr.-Chartreuse.

subviolaccus. - Id.

Heterocerus fossor. - St-Rambert. sericans. - Bourg-d'Oisans.

Ceruchus tarcndus (larve). - Sapins de la Gr.-Chartreuse. Onthophagus nutans, - St-Nizier.

$$
\text { lemur. - Id. }
$$

Aphodius scrututor. - Id.

$\left\{\begin{array}{l}\text { homorrhoidalis. - Id., Prémolles. } \\ \text { var, sanguinolentus IIERBst. }\end{array}\right.$

immundus. - St-Rambert.

\{alpinus Scopol1. - Grande-Chartreuse, Huez, rubens Comols. Lantaret.

bimaculatus var. noire. - Gr.-Chartreuse. $\left\{\begin{array}{l}\text { obscurus FaB. - Sur toutes les montagnes, } \\ \text { sericalus Scrмidr. }\end{array}\right.$ discus. - Lautaret. atramentarius. - Gr.-Chartrcuse, Lautaret. $\left\{\begin{array}{l}\text { carinatus Genm. - Lautaret. } \\ \text { nivalis Mols. }\end{array}\right.$ 
Iloptia farinosa. - Bourg-d'Oisans.

Rhizotrogus cicatricosus. - Id.

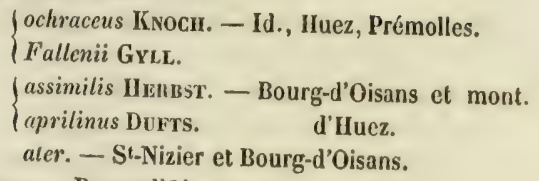

Celonia œnea. - Bourg-d'Oisans.

marmorata, - Id.

Trichius fasciatus. - Grande-Chartreuse, Prémolles, Bourgd'Oisans.

Capnodis tenebricosa. - St-Nizier.

Anthaxia sepulchralis. - Bourg-d'Oisans.

Athous Dejeanii. - St-Nizier, Grande-Chartreuse.

Cryptohypnus rivularius. - Si-Laurent-du-Pont.

Diacanthus ceneus. - St-Nizier, Grande-Chartreuse.

Corymbiles cupreus. - Grande-Chartreuse.

Campylus linearis. - Uriage.

Telephorus albo-marginatus. - Gr.-Ghartreuse, Prémolles.

Rhagonycha abdominalis. - Grande-Chartreuse.

testacca. - Id.

fuscicornis. - Id.

Malachius marginellus. - Prémolles.

ruficollis. - Id.

Colotes trinolatus. - Grande-Chartreuse.

Lampyris splendidula. - Bourg-d'Oisans.

Podabrus alpinus - Uriage, etc.

Ochina sanguinicollis. - Lautaret.

Xyletinus pectinutus. - Bourg-d'Oisans.

Cis nitidus. - Grande-Chartreuse.

Pandarus tristis, - Bourg-d'Oisans. 
Boletophagus freticulatus LINN. - Grande-Chartreuse.

crenalus FaB.

Oplocephala hemorrhoidalis. - Grande-Chartreuse.

Priomychus ater. - Grenoble, bords du Drac.

Pyrochroa coccinea. - Grande-Chartreuse.

Notoxus major. - Bourg-d'Oisans.

$$
\text { cornutus, - Id. }
$$

Mylabris variabilis. - Id.

OEdemera tristis. - Grande-Chartreuse.

Anoncoles adusta: - Id.

Apion meliloti. - Grenoble, bords du Drac.

Sciaphilus viridis (1). - Id.

Chlorophanus salicicola. - Id., Bourg-d'Oisans.

$$
\text { viridis. - Bourg-d'Oisans. }
$$

Gronops lunalus. - Id.

Liophlocus IIerbstii. - Grande-Chartreuse.

pulverulentus. - Id.

ovipennis nov. spec. (2). - Id.

(1) Cette espèce n'a pas encore été signalée en France, à notre connaissance.

(2) Liophlocus ovipennis L. Farrmaine. - Longueur 9 mill. Oblongus, niger, squamositate sat densa cinereo-metallica tectus, capite, rostro prothoraceque dense rugulosis; capile inter oculos foveola signato; rostro crasso, apice latiore et triangulariter impresso, medio vix perspicue carinulato ; antennis nigris, clava fuscopicea, scricea; prothorace lateribus rotundato longitudine dimidio latiore, antice paulo guam postice angustiore, rugoso, medio linea subelevata, postice abbreviata; scutello parvo, angusto, triangulari; elytris breviter ovatis, antice prothoracis basi palum latioribus, medio ampliatis, convexis, sat fortiter punctato-lineatis, interstitiis planis, tenuissime alutaceis, femoribus clavalis, angulatis, anticis fere dentatis, tibiis haud arcuatis. - Grande-Chartrense (L. Fairmaire). 
Barynotus moerens. - Grande-Chartreuse.

Tropiphorus mercurialis. - Bourg-d'Oisans.

Molytes germanus. - Grande-Chartreuse.

Leiosomus ovatultss. - Id.

Phyllobius calcaralus. - Id.

atrovirens. - Id.

psittacinus, - St-Nizier.

Pcritclus mus. - Grande-Chartreuse.

Phytonomus globosus nov. spec. (1). - Lautaret.

Otiorhynchus niger. — Grande-Chartreuse.

$$
\begin{aligned}
& \text { fuscipes. - Id. } \\
& \text { tenebricosus. - Id. } \\
& \text { armadillo. - Id. } \\
& \text { unicolor. - Id. }
\end{aligned}
$$

Obs. Il parait voisin du $L$. lentus, mais, chez cette dernière espèce, le rosire est canaliculé à la base, le corselet presque deux fois aussi large que long, avec une impression transversale en avant, sans ligne élevée médiane, et les elytres ont des stries ponctuées fines; elles sont plus courtes que chez le $L$, mubilus.

(1) Phytonomus globosus L. Fanuv. - Long. 7 à 8 mill. Subovatus, niger, squamulis fuscis griseisque tectus, antennis rufopiceis, rostro crasso, arcuato, sat acute carinato, prothorace lateribus valdè rotundatis, basi rectis, dense ruguloso, medio sæpius linea elevata, parum distincta; elytris ovatis, sat fortiter punctato-striatis, interstitis leviter convexis, cinereo tessellatis, femoribus clavatis. — Lautaret (Bellevoye) ; se retroure aussi dans la Lozère, à Hyères, etc. - Voisin du $P$. salvice, en diffère par le rostre caréné, bien plus allongé, le corselet plus arrondi sur les côtés, non sillonné a la base, et les élytres moins courtes, moins fortement striées.

obs. Cette espèce n'a jamais, que nous sachions, été décrite, nous lui maintenons le nom qu'elle porte dans la collection de M. Chevrolat. 
Otiorhynchus cbeninus. - Grande-Chartreuse.

hirticornis. - Bourg-d'Oisans.

porcatus. - Grande.Chartreuse.

Grypidius equiseti. - Bourg-d'Oisans.

Orchestes sparsus. - Id.

Cionus ungulatus. - Id.

Gymnetron campanula (larve). - Grande-Chartreuse.

Xyloterus domesticus. - Id.

Scolytus villosus. - Id.

Rosalia alpina. - Id.

Criomorphus \{ castaneus LiNN. - Bourg-d'Oisans.

\{aulicus FAB.

Clylus mysticus. - Jd.

Molorchus minor. - Grande-Chartreuse.

Parmena Solieri. - Uriage.

Acanthoderes varius. - Grande-Chartreuse.

Astynomus griseus (1). - Id., Bourg-d'Oisans.

Leiopus nebulosus. - Bourg-d'Oisans.

Pogonocherus fascicularis. - Grande-Chartreuse.

Agapanthia angusticollis. - Id.

Saperda scalaris. - Id.

punctata. - Id., chemin de Fourvoirie.

Rhagium indagator. - Grande-Chartreuse.

Pachyta interrogationis. - Lautaret.

8-maculata. - Gr.-Chartreuse, Prémolles.

virginea et var. corselet rouge. - Gr.-Chartreuse.

Strangalia aurulenta. - Id.

(1) M. Kraaiz a pris un insecte dle cette espèce dans la grande église des Chartreux. 
Lcplura \{ lestacea Lins. - Grande-Chartreuse.

rubrotestacea FAB.

maculicornis. - Id.

rufipennis. - Id.

Anoplodera rufipes. - Bourg-d'Oisans.

Grammoptera levis. - Grande-Chartreuse.

Clythra cyanicornis. - Bourg-d'Oisans.

longimana. - Grande-Chartreuse.

Cryplocephalus imperialis var. - Montagnes d'Huez.

gracilis. - St-Nizier, Grande-Chartreuse,

Bourg-d'Oisans.

bilineatus var. - Bourg-d'Oisans.

Chrysomela limbata. - Montagnes d'Huez.

cacalice. - Grande-Chartreuse.

senecionis. - Id.

vittigera. - Id.

pretiosa. - Id.

nivalis. - Lautaret.

speciosa. - Grande-Chartreuse.

Luperus viridipennis. - Lautaret.

Cassida languida. - Prémolles.

Harmonia impustulata. - Id.

Coccinella labilis. - St-Nizier.

Endomychus coccineus. - Grande-Chartreuse. 


\section{ORTHOPTÈRES (1):}

Forficula biguttata. - Très commune sur toutes les montagnes.

Decticus verrucivorus. - Grande-Chartreuse, très commun. Stenebothrus virilulus. - Lautaret.

bicolor, - Grande-Chartreuse.

\{ scalaris FisciI. WALD. - Gr.-Chartreuse.

$\{$ melanopterus Bonck.

variegatus, - Sur toutes les montagnes.

sibiricus (Gomphocerus). - Lautaret.

Pachytylus migratorius. - Bourg-d'Oisans.

OEdipoda corrulans. - Id., Huez.

\section{LÉPIDOPTÈRES (2).}

Parnassius Apollo. - Sur toutes les montagnes.

Phrebus. - Lautaret.

Pieris Callidice. - Sommet du Galibier.

Rhodocera Cleopatra. - Séchilienne et Bourg-d'Oisans.

Colias phicomone. - Lautaret.

pulono. - Id.

(1) Cette liste a été dressée par M. Louis Brisout de Barneville, sur les quelques Orlhoptères que j'avais rapportés. Je n'indiquerai point les insectes trop peu nombreux des autres ordres, ils ont été mentionnés dans le Rapport.

(2) Cette liste m’a été fournie par MM. Boisduval, Bruand d'Uzelle, E. Martin et P. Millière. 
Polyommatus Eurydice. - St-Nizier, Lautaret, etc.

virgaurca. - Sur toutes les montagnes.

Gordius. - Bourg-d'Oisans.

Lycana Amyntas. - Si-Nizier.

optilete. - Villard-Eymond, Lautaret.

Eumedon. - Id.

orbitulus, - Id.

Eros. - Lautaret.

Pheretes. - Id.

Donzelii (1). - Villard-Eymond.

Damon (2). - Partout.

Alcon. - Basses prairies.

Argynnis Niobe. - Prairies alpines.

Aniathusia. - Chartreuse de Prémolles.

Daphne. - Id.

Ino (3). - Partout, commune.

Pales. - Extremement commune au Lautaret.

Melitaca cynthia. - Lautaret.

didyma. - Bourg-d'Oisans.

Arge var. procida. - Sur toutes les montagnes.

var. leucomelas. - Bords du Drac.

Erebia Cassiope, - Lautaret.

Mnestra. - Villard-Eymond.

Pyrrha. - Grande-Chartreuse.

(1) Pris par M. le docteur Boisduval, dans les localités où il avait découvert celte espèce il y a trente ans.

(2) Il volait par essaims sur toutes les montagnes, autour des places humilles des chemins.

(3) J'ai rencontré à la Chartreuse de Prémolles, près Uriage, de belles $q$ de cette espèce d'une teinte violacée très foncée (E. Martin). 
Erebia Ceto. - Lnutaret.

Stygne. - Grande-Chartreuse.

Alecto. - Sommet du Galibier, Ilaut-Richard.

Arachne. - Villard-Saint-Jean.

ligea. - Grande-Chartreuse.

Gorge var. Erynnis. - Galibier, Haut-Richard.

Manto. - Id.

dromus. - Sur toutes les montagnes.

Satyrus cortula, - St-Nizier et Bourg-d'Oisans.

Ilermione var. Alcyone. - Prairies un peu élevées.

Eudora (1). - Bourg-d'Oisans.

Pasiphae. - St-Nizier.

hiera. - Montagnes d'Huez.

Iphis. - Lautaret.

Syrichtus althex. - Id.

lavaterce (2). - Bourg-d'Oisans.

serratula. - Lautaret.

Deilephila lineata (chenille). - Grenoble, bords du Drac.

hippophaes (3). - Id.

Zygrena Erythrus (4). - Bords du Drac, St-Nizier, etc.

(1) J'ai pris au Bourg-d'Oisans, près de la cascade, des individus de celte espèce, d'une fort grande taille et très caractérisés en dessous. Le type est remarquable (E. Martin).

(2) Cette jolie espèce était assez commune au Bourg-d'Oisans, près de la cascate (E. Martin).

(3) La chrenille de cette espèce était commune sur les bords du Drac, où l'arbrisseau qui la nourrit est très ahondant, $M$. Daube en prit un grand nombre.

(4) Assez commune sur les bords du Drac, à Saint-Nizier et à la Chartreuse de Prémolles. Le type est dans l'Isère, de fort belle taille (Docteur Boistuval et E. Martin). 
Zygcena Minos (1). - Partout, commune.

Sarpedon. - Bords du Drac, St-Nizier.

exulans (2). - Lautaret.

Charon. - Bourg-d'Oisans.

hilaris. - Grenoble, bords du Drac.

Procris infausta. - Bourg-d'Oisans.

Ueterogynis penella. - Lautaret.

Lithosia luteola. - Prairies alpines.

vitellina. - Grande-Chartreuse.

Sctina ramosa. - Villard-Eymond, Lautaret.

Naclia ancilla. - Bourg-d'Oisans.

punctata. - Id.

Nudaria mundana. - Rochers de la Gr.-Chartreuse.

Callimorpha dominula (3). - Grande-Chartreuse.

(1) Nous primes, avec M. E. Martin, au Bourg-d'Oisans, au-dessus de la cascade, sur les lavandes, un joli type de cette espèce, qui ressemble beaucoup, pour la disposition des taches sécuriformes, qui sont très amincies et étroites, à la Zyg. scabiosct, mais qui s"en distingue facilement par les antennes,

(2) Excessivement commune au Lautaret, surtout près de l'hospice, où il était impossible de mareher sans en voir un grand nombre. J'ai pu observer plusieurs fois sur cette espèce, deux mâles accouplés en apparence à une femelle. Un seul, bien entendu, l'ćtait réellement, le second avait l'extrémité de son abdomen fixée, tantôt sur le corps de la femelle, tantôt sur celui du premier male.

J'ai pris une magnificque aberration de cette Zygene avec les points et les ailes inférieures d'un beau jaune (E. Martin).

(3) Je ne cite cette espèce commune que parce qu'clle a été trouvée au-dessus du monastère de la Grande-Charıreuse, a plus de 2,000 mètres de hauteur. 
Nemeophila plantaginis. - Lautaret.

var. hospita. - Id.

Arctia luctifera (chenille). - St-Nizier.

sordida (1). - Route de La Grave.

Ilepialus humuli. - Lautaret.

Typhonia lugubris. - Pariset.

Psyche nitidella. - Grande-Chartreuse.

albida (fourreaux). - Contre les rochers.

febretta (id.). - Id.

Bryophila glandifera. - Vizille.

Apamea captiuncula (2). - Grande-Chartreuse.

Nociua candelisequa (3). - Lautaret.

Erastria candidula. - Environs de Grenoble.

Agrotis (renigera IIUBN. - Grande-Chartreuse.

Polia dumosa Donz. (4).

Plusia circumflexa. - Grenoble, bords du Drac.

(1) La chenille fut trouvée plusieurs fois par des coléoptéristes, sous les pierres de la route du Bourg-d'Oisans à La Grave (E. Martin).

(2) Deux exemplaires de cette rare espèce ont été pris, l'un dans le Couvent même et l'autre contre les rochers qui bordent le chemin de la Grande-Chartreuse, par M. P. Milliere.

(3) J'avais pris autour du saut du Doubs, il y a seize ou dix-huit ans, cette Noctuelle que l'Index de M. le docteur Boisduval et le catalogue de Duponchel indiquent comme provenant d'Autriche et du Valais. Elle figure au catalogue du Doubs, sous le $n^{\circ} 329$ (Bruand d'Uzelle).

(4) C'est en revenant de la Chartreuse à Grenoble, que M. E. Martin a pris près du village du Sappey celte rare espèce que M. Guénée a retiré des Polia pour la placer dans le genre Agrotis. 
Catocala pellex. - Bourg-d'Oisans.

Grammodes geometrica. - Bords du Drac, S'-Nizier.

Metrocampa margaritata. - Grande-Chartreuse.

Nychiodes lividaria. — Citadelle de Grenoble.

Boarmia abietaria. - Grande-Chartreuse.

Gnophos furvata. - St-Nizier et bords du Drac. ophlalmicala (1). - St-Nizier et La Grave.

\{ pullata (2). - Grande-Chartreuse.

impectinata GuÉN. olim.

glaucinata. - Lautaret.

var, citrinata BRUAND. - Gr.-Chartreuse.

Dasydia obfuscata. - Lautaret.

Psodos trepidaria. - Id.

Pygmana venetaria. - Id.

Acidalia confinata II.-S. (3); GuínÉe, tome IX. p. 389.

moniliata (4). - Bords du Drac.

mutata (5). - Contre les rochers.

(1) Trouvéc contre les rochers de Saint-Nizier, par M. P. Millière, et à La Grave, par M. Guénée.

(2) Nous avons pris à la Chartreuse, appliqué contre les rochers, un grand nombre d'individus de cette belle et peu commune Gnophos; le type est très clair et se rapproche beaucoup de la Gnoph. canitiaria Gutenée (P. Millière et E. Martin).

(3) A l'entrée du désert. Nouvelle pour la Faune française (P. Millière).

(4) Cette petite Acidalie était assez commune sur les bords du Drac, près de Grenoble (E. Martin); elle était rare sur les rochers, près de l'entrée du désert (P. Millière).

(5) Prise à Saint-Nizier et à la Chartreuse, par M. P. Millière; elle était commune. 
Acidalia strigaria (1). - Prés de la Gr.-Clıartreuse.

filicata. - Grenoble et Bourg-d'Oisans.

contiguaria. - Pariset.

submutata (2). - St-Nizier.

flaveolaria. - St-Nizier et Lautaret.

rufaria. - St-Nizier, Gr.-Chartr., Bourg-d'Oisans.

perochraria Freyer. - Grande-Chartreuse.

lochrcaria Bov. Ind.

politaria. - Bords du Drac.

suffusata. - St-Nizier.

comparia Her.-Scr. (3). - Gr.-Chartreuse.

argilata Guénée (1). - Bords du Drac.

Stegania permutaria var. commutaria. - Grenoble.

(1) nare (P. Millière).

(2) Prise à l'entrée de la grotte de Pariset (P. Millière).

(3) Cette petite espèce du groupe de l'herbariata FAB, n'était encore connue que de l'Asie-Mincure. M. Bellier l'a trouvée l'année dernière, dans les Pyrénées-Orientales; c'est donc la seconde fois qu'elle est prise en Europe, elle est désormais acquise à notre Faune française. Je l'ai prise dans le monastère même de la GrandeChartreuse (E. Martin).

(4) Cette espèce, encore peu connue, avait été décrite d'après un individu of unique rapporté de la Lozère par M. Bellier de la Chavignerie. M. Delamarche et moi mêne, nous avons êté assez heureux pour capturer quatre of (E. Martin).

M. Lederer de Vienne auquel M. Bellier avait envoyé une de ces Geomètres la reconnut pour la véritable pallidata du WIEN. vERzeicunıss. M. Guénée ayant reçu de M. E. Martin cette espèce en communication depuis la Session de Grenoble, lui aflirma que c'etait bien l'argilat $a$. Après l'avis de ces entomologistes ćminents il est difficile de se prononcer. 
Cabera confinaria Frex. (1). - Prés de la Gr.-Chartreuse. Aleucis pictaria. - Bourg-d'Oisans.

Halia Wavaria. - Iluez.

Tephrina ariesaria. - Bords du Drac.

Numeria capreoluria. - Grande-Chartreuse.

Fidonia atomaria (2). - Bords du Drac.

moniliaria. - Id.

Cleogene \{lutearia FaB. - Lautaret.

Aspilates calabraria. - Bourg-d'Oisans.

Larentia casiala. - Grande-Chartreuse et Prémolles.

cyanata. - Grande-Chartreuse.

infidata DELAH. (3). - Id.

flavicinctala (4). - Id.

tophaceala. - St-Nizier et Gr.-Chartreuse.

\{larentiata (5) Bruand. - Grande-Chartreuse.

Kollararia HERR.-Sch.

frustrate. - St-Nizier et Grande-Chartreuse.

(1) Très rare et nouvelle pour la Faune française ( $\mathrm{P}$. Millière).

(2) Je pris, au bord du Drac, une belle variété à large bordure brune autour des (quatre ailes (E. Martin).

(3) Cette espèce a deux types bien distincts. J'ai trouvé à la Grande Chartreuse des individus dont la bande transversale est d'un jaune safrané, tandis qu'à Prémolles, près Uriage, j'en ai pris un certain nombre à bandes d'un gris très foncé, que j'avais d'abord rapportés à tort à la Lar. flavicinctata HuBN. (E. Martin).

(4) Très commune partout à la Grande-Chartreuse, mais pas plus haut que le couvent ( $\mathrm{P}$, Millière).

(5) Voyez GuénéE, Species général tome X, page 285. Rare, chemin de la Bergerie, dans les sapins ( $\mathrm{P}$. Millière). 
Larentia aptata. - Partout, très commune.

olivata. - St-Nizier et Grande-Chartreuse.

turbata. - Grande-Chartreuse, sapins.

faqueata HuBN.-Route de B.-d'Oisans au Lautaret. lotaria 13pv. Ind. 1625.

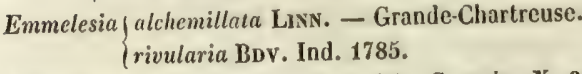

Eupithecia semigraphata BRUand (1); Guenée, X, 310. Rochers de St-Nizier et de la Gr.-Chartreuse.

Thera variata. - Grande-Chartreuse.

Melanipe molluginata. - Id.

Anticlea sinuata. - Chartreuse de Prémolles.

berberata. - Montagnes d'Huez.

Camptogramma scripturata. - Grande-Chartreuse.

riguata. - St-Nizier.

Cidaria aptaria (2). - Id.

silaceata W. v. - Roches de la Gr.-Chartreuse.

capitata Herr.-Scu. - Id., très rare.

Anaitis praformata. - Sapins de la Gr.-Chartreuse.

simpliciala Treirs. - Lautaret.

Magdalenaria BelLier.

Tanagra charophillata. - Sur toutes les montagnes.

Botys sophialis (3). - Grande-Chartreuse.

olivalis. - Id.

(1) Variété caractérisée par la coloration foncće (Bruand d'Uzelle et $P$. Millière).

(2) Type à peu près semblable à celui de la Franche-Comté (Bruand d'Uzelle).

(3) Type blanchâtre, tirant sur le bleı (Bruand d'Uzelle). 
Pyrausla sanguinalis (1). - Bourg-d'Oisans.

Xylopoda pariana. - Grande-Chartreuse.

$$
\text { scitulana. - Bourg-d'Oisans. }
$$

Tortrix dumicolana ZELL. (2). - St-Nizier.

gallicolana IIEYD. (3). - Id.

Scricoris Charpentiana Ifuns. (4). - Id. et Gr.-Chartreuse.

Crambus pyramidellus 'I'neir. (5). - Gr.-Chartr., Lautaret. \{adamantellus GuÉNÉE.

Eudorea ingratella IIER.-ScII. (6). - St-Nizier, Lautaret.

ambiguella H.-ScI. 109 ou 108 ? - Lautaret.

$\left\{\begin{array}{l}\text { muranella H.S. - Grande-Chartreuse. } \\ \text { parella ZELLER. } \\ \text { trumicolella SrAINToN. }\end{array}\right.$ frequentella (7). - Grande-Chartreuse. \{ asphodeliella MAN. - Bourg-d'Oisans. manifesiella IER.-ScH. 104? \{ pyralclla Il uBN. (8). - Bourg-d'Oisans. \{dubitella ZBLLER.

(1) Très commune au pied de la montagne d'Huez.

(2) Espèce non signalée en France jusqu'à ce jour, à ce que je crois (Bruand d'Uzelle); grotte de Pariset, sur des lierres (P. Millière).

(3) Peu rare dans la grolte de Pariset (Bruand d'Uzelle).

(4) Rare, bois de Ilêtres de la Bergerie (P. Millière); à Saint-Nizier (E. Martin).

(5) Commun près de la Vacherie (P. Millière), et au Lautaret (Bruand d'Uzelle).

(6) Sapins de Saint-Nizier, rare (P. Millière).

(7) C'est une variété de cratoggella, suivant Delaharpe (Bruand d'Uzelle).

(8) Dubitella de ZELLER paraît n'ètre qu'une variété de pyralella; du reste, il règne une telle incertitude, qu'Hernich-SCH 
Anacampsis galbanclla FnEY. (1).- Sapins de la Gr.-Chartr. Gelechia peliella. - St-Nizier.

$$
\text { alticartusiella (2). - Grande. Chartreuse. }
$$

Lampros bractella Linn. - Sapins de la Gr.-Chartreuse.

Cochylis magnicitrana Bnusno (3). - Route de St-Nizier.

Tinea \{ Cartusianella Bruand (4).--Rochers de la Gr.-Chartr. var. de fulvimitrella SoDofrskr (II.-S. 283?).

Colcophora $\left\{\begin{array}{l}\text { Constantella Bnuand (5). - St-Nizier. } \\ \text { non Gelechia coronilella Tiscir. } \\ \text { gallipenella Huns, non Tiscir. }\end{array}\right.$

a cru devoir abandonner le nom de pyralclla. C'est ici un des groupes que la Société entomologique devrait bien meltre à l'étude pour ses congrès (Bruand d'Uzelie).

(1) Espèce très commune en cet endroit et nouvelle pour la Faune française (P. Millière).

(2) Entre pisticella Herd., et marmorella HAw., mais le fond des premières ailes entièrement noir. Cette Gelechia ressemble à la Lita decora StepI., que j'ai désignée sous le nom de marmoripennella, et dont elle semblerait n'ètre qu'une variété sans taches jaunâtres au milieu du noir dans les ailes inferieures, qui sont de forme diflérente. C'est une Gelechic et non une Lita (Bruand l'Uzelle).

(3) Rare; c'est la plus grande espèce de Cochylis (P. Millière).

(4) Voisine de fulvimitrella, mais les deux taches du bord bien plus larges, puis quatre ou cinq petits points blancs agglomérés à la côte près du tiers de la longueur et une autre tache dont le centre est marqué de noir près du soinmet apical (Bruand d'Uzelle).

(5) Le nom de coronilella ayant été primitivement appliqué par Tischen à une Gelechia, j’ai dû désigner cette Coleophora sous une autre dénomination; j'ai choisi le nom de mon ani et collègue Constant, lépidoptériste aussi zélé que consciencieux.

Tneirscuxe avait applique à cette Tinéide le nom de gallipennella, mais ce n'est pas l'espèce qu'avait nommée TiscıEn antérientrement (H.-ScH., page 11). (Bruand d'Uzelle.) 


\section{Argyreilhia (spiniella (1). - Bourg-d'Oisans. \\ semitestaceella Cont.}

Pterophorus plagiodactyla FnEY. - St-Nizier.

xanthodactylus ZELL. (2). - Gr.-Chartreuse.

$\left\{\begin{array}{l}\text { adactyla (3). - Bourg-d'Oisans. } \\ \text { var. Delphinensella BRDAND. }\end{array}\right.$

megadactyla HuBN. (4). - Bourg-d'Oisans.

nemoralidactyla. - Id.

tristidactyla ZeLL., IIEn.-Scr. - Id.

$\left\{\begin{array}{l}\text { paludidaclyla. }- \text { Id. } \\ \text { paludum ZELL., Hen.-ScH. }\end{array}\right.$

(1) J'ai reçu d'Allemagne, comme spiniella, une Argyreithia qui se rapporte exactement à celle-ci, mais ce n'est nullement celle d'Henrich-Scir fFFER, figure 648. Elle se rapporterait au contraire à sa figure 603 , qu'il cite comme variété de semilestaceella Cuntrs; j'ai reçu d'Angleterre, de mon ami M. Doubleday, sous le nom de semitestaceclla, l'espèce nommée spiniella par M. Lederer (Bruand d'Uzelle).

(2) Commun près de la Chapelle de Notre-Dame (P. Millière).

(3) Hennich-Scumeren a fait six espèces des variétés d'adactyla (parali $a$, tamaricis, meridionalis, Heydenii, Frankenia et adactyla); on pourrait en faire une septième avec cette variété ci, que j'ai désignée sous le nom de Delphinensella, et qui est plus foncée que toutes celles qu'il a figurées. Elle se rapproche beaucoup de la figure de Duponcues (Bruand d'Uzelle).

(4) Dont gonodactyla Ev., parait être une variêté plus brune (Bruand d'Uzelle). 


\section{PLantes}

Recucillies ou observées pendant la session extraordinaire, clans l'Isere et les IIautes-Alpes.

Nous pouvons vous offrir une corbeille de fleurs alpines extraites des boîtes à herborisation de plusieurs collègues qui cultivent a la fois la Botanique et l'Entomologie. Notre Président, qui visitait les $\Lambda$ lpes pour la cinquième fois, nous a fourni la majeure partie des renseignements et les plus précieuses indications. Cet aperçu vous donnera une idée des richesses botaniques que nous avons observées.

Je diviserai cette corbeille en bouquets séparés de SaintNizier, de la Grande-Chartreuse, de Bourg-d'Oisans et du Lautaret:

\section{Bouguet alpestre de Saint-Nizier de Pariset (1).}

Anemone alpina.

Ranunculus Seguieri.

- montanus.

Trollius europæus.

Biscutella lærigala.

Polygala chamæbuxus.

Dianthus sylvestris.
Silene quadridentata.

Mohringia muscosa.

Geranium sylvaticum.

Ononis minutissima.

Astragalus aristatus.

Dryas octopetala.

(1) Il a été composé uniquement des plantes recueillies depuis la montée de Parisel jusqu'au haut de Saint-Nizier. Lorsq̨ue nous ferons un nouveau Bouqquet, nous ne parlerons plus des mêmes espèces que nous avons retrouvées dans beaucoup d'autres lieux à la mème élévation. 
Valeriana tripteris.

Scabiosa alpina.

Sonchus alpinus.

Centaurea crupind.

Aster amellus.

Achillaca tomentosa.

Vaccinium vitis idea.

Arbutus uva ursi.

Pyrola media.

- chlorantha.

- secunda.

Gentiana acaulis var, angustifolia - verna.

Verbascum chaixi.

Linaria alpina.

Veronica saxatilis.

- urticæfolia.

Euphrasia Jutea.
Thymus alpinus.

Scutellaria alpina.

Globularia nudicaulis. cordifolia.

Polygonum alpinum.

Salix arenaria.

Orchis pallens.

- sambncina.

Allium narcissillorum.

- victoriale.

Luzula nivea.

Phalaris alpina.

Avena pubescens.

Lycopodium selago.

Asplenium Ilalleri.

- viride.

Conopteris fragilis.

Polypodium calcareum.

\section{Bovquiet de la Grande-Chantreuse (1).}

Thalictrum alpinum.

Aconitum paniculatum.

$$
\text { - anthora. }
$$

Arabis serpyllifolia.

Cardamine thalictroides.

Dentaria digitata.

Viola biflora.
Saponaria ocymoides.

Dianthus coesius.

Silene acaulis.

- exscapa.

Arenaria ciliata.

Geranium phæum.

Anthyllis montana.

Spiræa aruncus.

(1) Plantes récoltées depuis Saint-Laurent-du-Pont jusqu’à la Grande-Chartreuse, ainsi que dans les prairies et les montagnes qui environnent le Monastère. 
Potentilla caulescens.

$$
\text { - nitida. }
$$

Sedum rhodiola.

- atratum.

Saxifraga moschata.

- aizooides.

- oppositifolia.

Astrantia minor.

Athamanta cretensis.

- Mathioli.

Lonicera corulea.

Vaerliana montana.

Scabiosa sylvatica.

Prenanthes purpurea.

- tenuifolia.

Leontodon montanum.

Centaurea phrygia.

Carduus personatus.

Cirsium spinosissimum.

Aster alpinus.

Senecio doronicum.

Arnica scorpioides.

Achillsea macrophylla.

Campanula thyrsoidea.

- rhomboidalis.

- latifolia.

Vaccinium uliginosum.

Pyrola rotundifolia.

Gentiana dunctafa.

Veronica aphylla.

- saxatilis.

_ bellidioides.
Bartsia alpina.

Pedicularis giroflexa.

folisoa.

Betonica alopecuros.

Primula auricula.

- integrifolia.

Polygonum viviparum.

Rumex arifolius.

- patientia.

Daphne alpina.

Salix retusa.

Orchis globosa.

Nigritella angustifolia.

Chamorchis alpina.

Lilium martagon.

Anthericum liliastrum.

Toffieldia palustris.

Luzula spicata.

Carex montana.

Lycopodium complanatum.

Botrychium lunaria.

Asplenium fontanum.

Cœnopteris regia.

- montana.

- alpina.

Polypodium phægopteris.

- lonchitis.

- Rhaticum.

Polystichum aculeatum (vrai).

- rigidum.

- oreopteris.

Pteris crispa. 


\section{Bodquet du Boung-D'Oisans (1).}

Thalictrum foctidum.

Anemone vernalis.

Ranunculus alpestris.

- Villarsii.

- thora.

Erysimum strictissimum.

Arabis Halleri.

Cardamine resedifolia.

Biscutella auriculata.

Vesicaria utriculosa.

Iberis nana.

Viola Valderia.

- montana.

Stellaria cerastoides.

Cherleria sedoides.

Arenaria Austriaca,

- Gerardi.

Geranium aconitifolium.

Ononis fruticosa.

Trifolium saxitile,

- alpestre.

Oxytropis pilosa.

Astragalus vesiculosus.

- onobrychis.
Potentilla grandifora,

Geum reptans.

Sibbaldia procumbens.

Paronychia serpyllifolia.

Herniaria incana.

- alpina.

Sedum anacampseros.

Sempervivum montanum.

Saxifraga cuneifolia.

- muscoides.

- exarata.

Buplevrum longifolium.

- stellatum.

Selinum Austriacum.

Laserpitium hirsutum.

Ligusticum apioides.

- mutellinum.

Imperatoria montana.

Lonicera alpigena.

Centranthus ongustifolius.

Eryngium spina alba.

Sonchus Plumieri.

Hieracium aurantiacum.

- cymosum.

- collinum.

(4) Plantes recueillies depuis Séchilienne jusq̨u'au Bourg-d'Oisans, et particulièremeit dans les montagnes de Villard-Eyymond, Villard-Saint-Jean, etc, On ne saurait trop recommander ces précienses localités. 
Hieracium piloselloides.

- fallax.

- cerinthoides.

- prunellafolium.

Serratula rhaponticum.

Tussilago nivea.

Gnaphalium leontopodium.

Artemisia Bocconi.

Inula Vaillantii.

- verbascifolia.

Senecio uniflorus.

- doria.

Achillea moschata.

Phyteuma pauciflora.

- Charmelii.

Pyrola uniflora.

Azalea procumbens.

Veronica Allionii.

Lavandula spica.
Pinguicula alpina.

Betonica hirsuta.

Primula viscosa.

Androsace lactes.

Orchis incarnata.

- albida.

Goodyera repens.

Corallorhiza Halleri.

Carex leporina.

Festuca spadicea.

- violacea.

- pumila.

Poa miliacea.

Lycopodium selaginoides.

- alpinum.

Asplenium septentrionale.

- Breynii.

Woodsia hyperborea.

\section{Bovquet DU LaUtaReT (1).}

Thalicırum aquilegifolizm.

Anemone Halleri.

- Baldensis.

- narcissiflora.

Ranunculus rutæefolius.

- parnassiæfolius.

- glacialis.

Aquilegia alpina.

- viscosa.

Brassica Richeri.
Erysimum ochroleucum.

Sisymbrium tanacetifolium.

- acutangulum.

Arabis bellidifolia.

- corulea.

Draba stellata.

- nivalis.

Dianthus atrorubens.

(1) Formé de plantes recueillies dans les prairies qui entourent l'Hospice et sur les montagnes, jusqu'aux Glaciers. 
Lychnis alpina.

Arenaria biflora.

- linillota.

- recurva.

Geranium nodosum.

Ononis rotundifolia.

Trifolium alpinum.

Phaca alpina.

- frigida.

- australis.

Oxytropis fotida.

Potentilla sabauda.

- frigida.

Geum montanum.

Alchemilla pentaphylla.

Sedum repens.

Saxifraga bryoides.

- biflora.

- retusa.

Buplevrum ranunculoides.

Selinum palustre.

Laserpitium simplex.

Ligusticum meum.

Valeriana Celtica.

- saliunca.

Scabiosa graminifolia.

Hieracium alpinum.

- glabratum.

- Halleri.

- villosum.

- lanatum.

- succisæefolium.

- albidum.

- grandiflorum.

- hlattarioides.
Centaurea uniflora.

Carduus podacanthus.

Cirsium ambiguum.

Saussurea alpina.

- discolor.

Carlina acantbifolia.

Cacalia leucophylla.

Artemisia tanacetifolia.

- mutellina.

- glacialis.

Gnaphalium alpinum.

Senecio incanus.

Arnica bellidiastrum.

Achillea nana.

Campanula barbata.

- spicata.

Phyleuma hemisphærica.

Empetrum nigrum.

Gentiana asclepiadea.

- alpina.

- Bavarica.

- Cenisia.

- nivalis.

- glacialis.

Swertia perennis.

Myosotis nana.

Pedicularis verticillata.

- incarnata.

- rostrata.

- tuberosa.

- comosa.

Dracocephalus Ruyschianus.

Primula farinosa.

Androsace chamœjasme.

Arelia vitaliana. 
Aretia Helvetica.

- alpina.

- pubescens.

Soldanella Clusii.

Salix herbacea.

Nigritella suaveolens.

Narcissus nivalis, n. s.?

Ornithogalum fistulosum.

Allium schœnoprasum.

Juncus alpinus.

Luzula flavescens.
Schwenus ferrugineus.

Kobresia scirpina.

Carex rupestris.

- curvula

- spadicea.

Phleum Gerardi.

Agrostis filiformis.

Avena distichophylla.

- setacea.

Festuca alpina.

- Halleri. 


\section{HISTOIRE DES METAMORPHOSES}

\section{ถข \\ GYMNETRON GAMPANULIE}

Pendant les derniers jours passés à la Grande-Chartreuse, j'avais remarqué et recueilli des pieds de Campanula rhomboidalis dont les fleurs étaient déformées, comme boursouflées à leur partie inférieure. La figure $\mathbf{1}$ de la planche rend cette disposition, elle me dispensera d'une description minulieuse. L'ovaire de la fleur est hypertrophié, gonflé sur un des côtés. Quand on le fend avec précaution, on y trouve une loge habitée par une larve ou une nymphe de Curculionite. Cette excroissance est une galle produite par le séjour de l'insecte parasite. II n'existe point de graines dans la partic occupée de l'ovaire, mais on en trouve le plus souvent dans le point opposé à la loge de la larve.

J'avais emporté à Paris un grand nombre de tiges gallifères de cetto Campanula. Les unes étaient mises dans des tubes de verre de manière à être conservées fraiches aussi longtemps que possible, les autres avaient été déposécs simplement dans des boîtes de carton à couvercle vitré. Jes premières n'ont rien produit; leurs habitants sont morts, tandis que les secondes m'ont fourni leur insecte parfait pendant le séjour que j'ai été obligé de faire au Havre, au mois d'août et de septembre. 
Les insectes éclos ont vécu longtemps (1). Ils appartiennentà une espèce Linnéenne, au Gymnetron campanula. Le male est remarquable par les deux pointes terminant l'abdomen, et la nymphe présente également ces deux appendices.

\section{\$ Ier. Larve. (Voyez fig. 2 à 4.)}

Lanve blanchatre, molle, courbée en arc, composée de douze segments, la tete non comprise, pourvue de pseudopodes ou de mamelons thoraciques.

Tête roussâtre ou brunatre, luisante, lisse, presque cornée, avec quelques poils fins. Un sillon bien marqué en arrière, se divise en avant en forme d'Y, dont les branches se rendent près des mandibules.

Antennes extremement petites, paraissant composées de deux articles (fig. 3 ).

Labre un peu arrondi en avant, cilié; épistôme presque droit.

Mandibules noiratres, fortes, bidentées à l'extrémité.

Mâchoircs à lobe interne arrondi au sommet, muni, en dedans, de poils raides ou en dent de peigne; palpes biarticulés.

Lèvre consistant en un mamelon arrondi à l'extrénité; charnue, soudée au menton, qui est également charnu, formant aver, lui un triangle dont les angles antérieurs sont

(1) Un de ces insectes ne s'est développé entièrement qu'à l'automne, et il est encore visant au moment où l'on imprime ces lignes (mars 1859); il y a, par cousérquent, des éclosions tardives et plusieurs de ces Gymnetron doivent hiverner. 
arrondis; prolongée entre les palpes labiaux, qui sont très petits et composés de deux articles.

Segments thoraciques n'étant pas plus grands que les abdominaux; lo premier, ou prothoracique, portant en dessus une double tache noiratre transversale, et, en dessous, une paire de mamelons rétractiles, de pseudopodes rapprochés. Ils consistent en une surface circulaire, légèrement brunAtre, à centre plus clair et pourvue de quelques poils. Entreles deux pseudopodes du prothorax, on remarque deux points noirâtres et un autre point des deux côtés entre chaque pseudopode et le stigmate (fig. 4, s). Les deuxième et troisième segments thoraciques ont en dessous une paire pareille de pseudopodes, mais plus écartés, et l'ensemble de ces mamelons forme un fer à chieval (Voy. fig. 4).

Segments abdominaux ridés en travers, les derniers moins épais; une double série de bourrelets le long des flancs; un petit mamelon anal, rétractile. A peine existe-t-il quelques poils fins le long du corps, mais la surface tégumentaire, vue au microscope, est chagrinée, couverte de petites aspérités.

Stigmates au nombre de neuf paires: la première paire est située au bord postéricur du prothorax, elle est plus grande, légèrement ovalaire et placée plus bas que les paires abdominales qui se trouvent sur les quatrième, cinquième, sixième, septième, huitième, neuvième, disième et onzième segments. La forme de ces derniers stignmates est à peu près arrondie.

Le point le plus intéressant de la configuration de cette larve consiste dans l'existence des mamelons sous-thoraciques, rétractiles, pouvant être comparés ì des pseudo- 
podes (fig. 4). Mon cher et savant ami M. Edouard Perris en a mentionné d'analogues chez la larve du Tomicus stenographus (Ann. Soc. Ent. France, 1856, 176); Hécger les a observés et figurés pour la larve de l'A pion basicorne li.Ligen (Sitzungsb. der K. Acad. d. Wissenschaften math.-naturw. Classe, xxıv Band, 2 Ileft, 1857). On devine facilement la présence de ces mêmes organes sur les figures de plusieurs larves xylophages dans les Forstinsecten de Ratzeburg.

\section{S II. Nymphe. (Voy. fig. 5 ì 7.$)$}

Nxmpne blanchatre peu après la transformation, devenant plus tard brunatre avec un reflet d'un vert bronzé; courte, voûtée sur le dos et l'abdomen, ce dernier terminé par deux saillies épineuses, recourbées en arrière, plus ou moins marquées et un peu convergentes. Quelques poils blanchatres ou roussatres sur la surface du corps et à l'extrémité des cuisses. Tete fortement fléchie, fourreau du bec arqué. Extrémité du dernier segment abdominal un peu bombée en avant, comme tuberculeuse et pourvue en arrière de deux appendices (fig. 5, 6 et 7 ).

La surface du tégument est finement chagrinée, les bords des segments ont de petites aspérités dirigées en arrière. Je ne sais si toutes les nymphes ont les saillies aussi fortes que celles que j'ai représentées, et qui, peut-etre, appartenaient à des nymphes males.

Le Gymnetron campanulce parait rester quinze ou vingt jours a l'état de nymphe, mais, après sa dernière transformation, il demeure dans sa cellule jusqu'á ce que ses téguments soient raffermis; alors il pratique avec ses mandi- 
bules un trou assez nettement arrondi, par lequel il s'échappe de sa prison (Voy. fig. 1).

\section{$\$$ III. Insecte parfait.}

Gymnetron campanulce LiNwe,, Syst. Nat. I, II, pag. 607, 7 (Curculio).

Schoenhern, Curcul. IV, 773.

Subovatus, niger, subclepressus, pilis brevibus cincreoalbidis adspersus, elytrorum seriatis; rostro elongato tenui; elytris punclato-subsulcatis; femoribus omnibus muticis; ano apice foveolato, maris bidentato. - GYLL.

Le inale est très remarquable par les deux saillies épineuses qui terminent l'abdomen.

Explication des fiqures de la planche.

Fig. 1. Tige de Campanula rhomboidalis portant à droite des fleurs normales, ct, sur la gauche, des fleurs à ovaire gallifère; celle de ces dernières, qui est à la base, est percée d'un trou pratiqué par l'insecte parfait pour sa sortic.

2. Larve grossie du Gymnetron campanula et à colé d'elle mesure de sa grandeur naturelle.

3. Antenne très grossie de cette larve.

4. La mene larve, très grossie, vue par sa partie antérieure pour montrer les six pseudopodes thoraciques. $-s$. Stigmate prothoracique. 
5. Nymphe grossie du meme insecte vue par sa face antérieure et à coté d'elle mesure de sa grandeur naturelle.

6. Celte nymphe vue de profil.

7. Dernier segment abdominal très grossi et vu par la face postéricure, pour mettre en évidence les deux appendices terminaux. 
La Société public chaque année un volume d'Annales composé de 60 à 80 feuilles d'impression et de 16 à 24 planches, dont moitié environ sont coloriées. Le volume des Annales est divisé en quatre cahiers qui paraissent un ou deux mois après le trimestre auquel ils correspondent. Chaque cahier est partagé en deux parties : la première comprenant les mémoires des membres et la seconde le Bullelin entomologique, qui renferme lui-même les procès-verbaux des séances ainsi que les communications verbales faites à la Société.

Le Bureau se compose, pour 1859, de : MM. C. Dumćril, Président honoraire; J. Bigot, Président; docteur Al. Laboulbène,

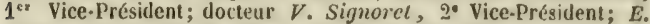
Desmarest, Secrétaire; II. Lacas, Secrétaire-Adjoint ; L. Buquet, Trésorier; L. Fairmaine, Trésorier-Adjoint; A. Doüé, Archiviste; docteur $C$. Coquerel, Archiviste-Adjoint.-Lat Comnission de publication, chargée spécialement de réunir les matériaux qui doivent entrer dans les Annales, est forméc des membres du Bureau et de MM. Amyot, docleur Boisduval, docteur Le Maoul, L. Reiche et J.Thomson.

La Société tient annuellenent deux Congrès : l'un à Paris, le mercredi qui suit Pâques, et l'autre en province dans le courant des mois de juin ou de juillet.

\title{
EXTRAIT DU RìGTEMENT.
}

DE

\section{I.A SOCLETÉ ENTOMOLOGIQUE DE FRANCE.}

\author{
Année 1859. - 28e de sa fondation.
}

Tout entomologiste qui désire être admis dans la Sociêté doit être présenté par un de ses membres. Le Bureau, sur celte présentation, nomme deux conmissaires pour faire un rapport qui doit être lu daus la séance suivante. - Après cetle lecture, la Société se prononce au scrutin secret et à la majorité absolue des membres présents sur les conclusions des rapporteurs.

Le nombre des membres de la Société est illimité; les Français et les Eirangers peuvent également en faire partie. - Le nombre actuel des membres est d'environ trois cents. 
Le montant de la cotisation, pour les membres de la Societé, est, paran, de :

$24 \mathrm{fr}$. pour les membres résidant à Paris.

$26 \mathrm{fr}$. pour les membres résidant en France et à l'étranger.

Les membres residants paient leur cotisation d'avance et par trimestre.

Les membres non résidants doivent faire parvenir la leur au Trésorier de la Société, sans frais, immédiatement après l'annonce de leur nomination, et, pour les antlées suivantes, dans le courant du mois de Janvier.

Les membres de la Société ne reçoivent leurs Annales que par la Socipté. Les numéros auxquels ils ont droit sont envoyés francs de port jusqu'a résidence:

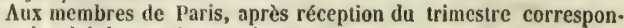
dant à celui du numéro paraissant ;

Aux membres hors Paris, après réception de leur cotisation de l'année courante:

Et francs de port jusqu'à la froutiere, aux membres étrangers, également après réception de leur colisation de l'année courante.

La Société correspond par l'entremise de son Secrétaire, de. son Trésorier et de son Archiviste. Le premier a dans ses attributions la correspondance scientilique; le second, celle qui concerne le recouvrement des cotisations et l'envoi des numéros des Annales, ct le dernier ce qui regarde la bibliothèque. Les lettres et paquets doivent être adressés, francs de port, à M. E. DEsmanest, Secrétaire, rue Sainte-Catherine d'Enfer, 6 ; à M. L. BuQuex, Tré. sorier, rue Hautefeuille, 19; et à M. Doḯ, Archiviste, rue Hautefeuille, 19 , à Paris.

Nota. Pour ne pas éprouver de retard dans l'envoi de leurs Anna. les, il est essenliel que MM. les Membres franfais et étrangers

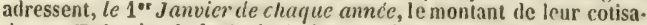
tion au Trésorier de la Société; les premiers par un mandat sur la poste aux leltres; les étrangers, par la voic du commerce.

Chaque auteur d'un mémoire inséré dans les Annales (ì l'exception du Bulletin) a droit gratuitement à un tirage à part de 15 exemplaires (texte ct planches noires). $\Lambda$ u delà de ce nombre et jusfu'à 50 exemplaires, sauf l'autorisation de la Société pour en obtenir un plus grand nombre, le prix des tirages à part est de 5 cent. par feuille d'impression, 10 cent. par planche en noir, et 40 cent. par planche coloriée. L'auteur doit informer le Secrétaire ou le Trésorier de ses intentions en même temps qu'il envoie son travail, et solder les tirages à part aussitôt l'impression du mémoire. 
ANNALES DE LA SOCIETÉ ENTOMOLOGIQUE DE FRANCE (Congres de Cyrenoble)

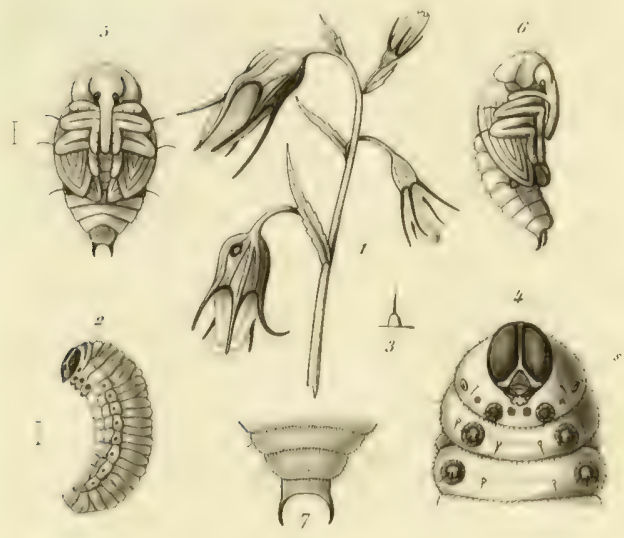

D. A. Laboulbene p?

Rebuffes on

\author{
MÉTAMORPHOSÉS
}

DU GYMNETRON CAMPANULE. 

V.

\section{DESCRIPTION DE UA LARVE DU NOSODENDRON.}

$11 \mathrm{y}$ a plus de vingt ans que je conserve en portefeuille la description et l'iconographie de la larve du Nosodendron fasciculare. Il s'en va temps pour un octogénaire de meltre un terme à celte longanime expectation qui a si souvent échoué, à obtenir la transformation de cette larve en nymphe. $\boldsymbol{\Lambda}$ d'autres l'heureuse chance de compléter l'histoire des métatmorphoses de ce petit Coléoptère.

Tout le monde sait que le Nosodendron vit dans la marmelade de l'ulcère de l'orme, et je l'ai trouvé aussi dans celle du clrêne. Sa larve partage ce même habitat.

Je n'ignore point que Mis. Chapuis et Candèze ont donné, dans leur excellent traité sur les larves des Coléoptères, la diagnose et la figure de cette larve (1). Mais elles laissent quelque chose à désirer, et j'espère que ces savants collègues me permettront de donner une seconde édition de leur travail sur ce point. Le sujet qui a posé pour leur portrait était ou défectueux ou dans une attitude peu favorable. En rapprochant la figure que j'en donne de la leur, on croirait facilement que ce sont deux larves d'espèce différente. Et puis ces savants ne sont pas parvenus a déconvir les stigmates abdominaux que j’ai parfaitement constatés.

Formulons d'abord le signalement de la larve :

LARva hexapoda, cephala, centomnala, oblonga, subdepressa, posticè attenuata, desuper coriacea; pilosa; scymentis abdominalibus margine unilobulato-hispidis, dorso utrinque longitudinaliter bifarium granulatis; stigmatibus luborculo impositis; segmento ullimo a precedentibus distincto, conoideo basi bituberculato; capite magno, lateribus rotundato; occllis quinque distantibus; pedibus brevibus vix cxsertis. - Long. 4 lin.

Hab. in ulccribus Ulmi nec non Quercûs. (Voyez les figures 3 de la planche 2.)

Cette larve, d'un blanc sale en dessous, est d'une teinte obscure en dessus, avec de petites mouchetures plus claires. Le corps est bordé de

(1) Catalogue des larves des Coléoptères, p. 105, pl. 3, fig. 6 (1853). 
poils assez longs, constatables surtout dans l'eau claire après des lavages préliminaires.

Tete remarquable par sa grandeur et sa largeur. Une loupe y saisit quelques granulations faibles et vagues. Orelles non compris dans une orbite, placés latéralement près de l'inscrtion des antennes, disposés sur deux rangées et assez distants. Rangée antérieure de trois, la postérieure de deux.

Je dois à mon ami Laboulbène le dessin de la tête avec la disposition scrupuleuse des ocelles. D'après ce sagace observateur, les ocelles antérieurs seraient bombés en haut et en avant, de manière que la vision ne saurait s'exercer que dans ces deux directions. Les ocelles postericurs placés dans une légère excavation, regarderaient en arrière et non en avant. Je laisse à ce savant toute la responsabilité de cette sorte de strabisme.

Antennes de trois articles, le basilaire court, le second cylindrique, le terminal subuliforme. Chaperon étroit, transversal. Labre demi-circulaire. Faute d'avoir étudié les parties de la bouche, je renvoie à l'ouvrage de MM. Clıapuis et Gandeze. Mandibules courles, mais tranchantes et fortement unidentées.

Des trois segments du thorax, l'antérieur ou prothorax a une largeur double de celui qui le suit. Ges trois segments sont superficiellement et vaguement granuleux, avec quelques granules en sérics aux deux derniers.

pattes courtes, mais débordant un peu le thorax dans leur parfaite extension; composées de trois articles, non compris la hanche et le crochet terminal qui est unique et robuste. L'ambulation de la larve dans son gite ulcéreux est encore assez active.

Abdomen de huit segments. Les sept premiers stigmatiferes, pourvus d'un lobule latéra! arrondi, couronné de longs cils, bien constatables dans l'eau limpide. Ils offrent à la région dorsale, de chaque côté de la ligne médiane, trois rangées longitudinales de trois à quatre granules glabres. Le segment terminal ou le liuitième ne ressemble pas du tout a ceux qui le précèdent. Il est atténué en arrière, avec sa pointe tronquée. On voit à sa base deux tubercules pyramidaux rapprochés, que je ne crois point stigmatiferes. Ce segment est frangé de poils assez fournis.

J'ai complé sept paires de stigmates aux bords latéraux des sept premiers segments de l'abdomen. Tous sont implantés au sommet d'un tubercule pyramidal situé au devant du lobule cilié dont j’ai parlé. Ces orifices respirntoires sont d'une petitesse extrême, ronds, avec un cerceau corné annulaire. La premiere paire, celle du segment basilaire, est fort dificile 
à mettre en évidence par ce qu'elle est cachée, abritée par le bord correspondant du métathorax. Elle n'occupe pas, comme les autres, le bord latéral du segment, mais le disque de celui-ci. Une figure fait voir cette disposition.

Quoique je n'aie pas constaté l'existence de stigmates au thorax, je ne saurais me refuser à croire qu'il n'y en a pas une paire. Quant aux tubercules pyramidaux du dernier segment de l'abdomen, je n'ose point affirmer qu'ils manquent totalement de stigmates. Je lègue à mes successeurs cette double solution.

Explication Des figures $3,3 a, 3 b$ et $3 c$. (Planche $2^{\text {e.) }}$

Fig. 3. La larve fort grossie du Nosodendron fasciculare, et à côté d'elle, la mesure de sa longueur naturelle.

$3 a$. La tete considérablement grossie de cette larve pour faire voir les ocelles, antennes, mandibules, etc.

36 . Les deux premiers segments abdominaux grossis pour mettre en évidence les rangées de granules et le premier tubercule stigmatifere discoïdal; le tubercule stigmatifère marginal; les lobules latéraux ciliés.

3 c. La même larve vue de profil et très grossie. (Voyez p. 149 à 152.) 



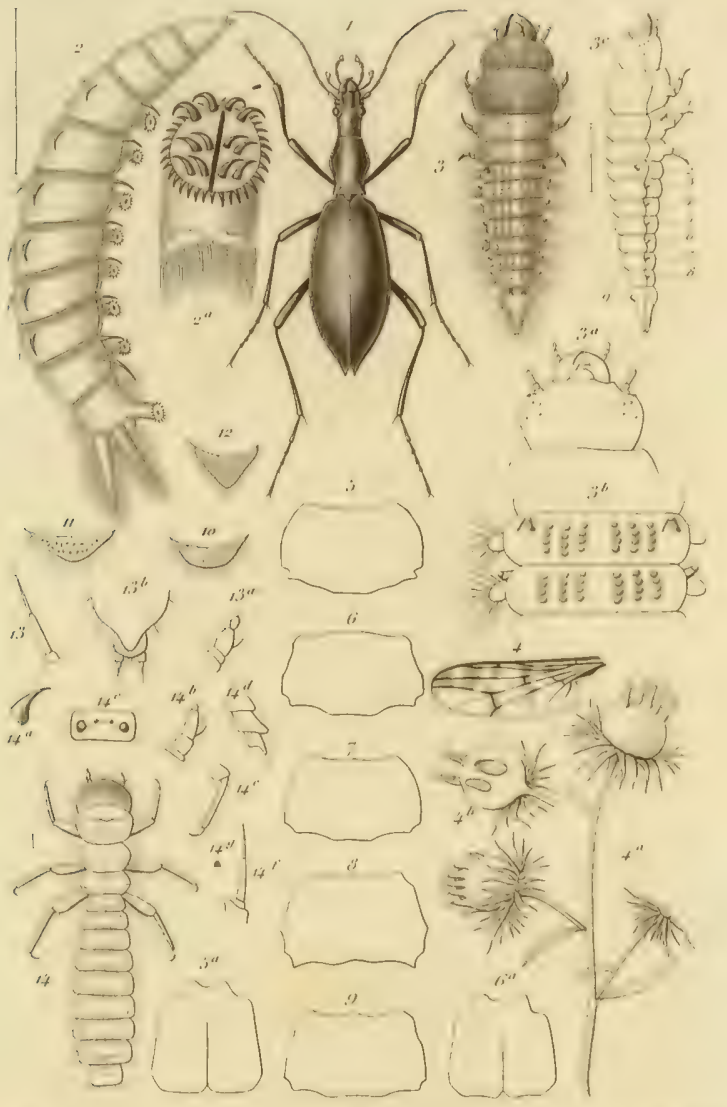

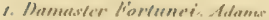

2. Surme angurblipue inditrrmintés.

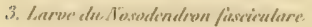

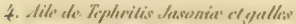
de-latersonia glutinesser.

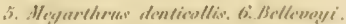

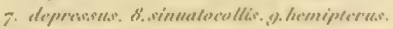

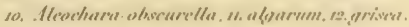

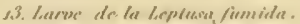

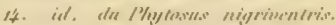





\section{$a 1^{6}, 13$}

\section{HISTOIRE}

D'บ

\section{ICHNEUMOR PARASITE DES ARAIGNEES}

\section{(PImpla Falrmalri1)}

Par M. le D' Alexandre LABOULBËNE.

(Séance du 12 Mars 1858).

Au mois de juin 1856, j'ai trouvé dans le parc de villegenis, sur une feuille de chene tenant encore à la branche, mais sèche et relevée sur les bords, trois larves d'un gris satiné et un peu luisant. Elles se mouvaient lentement au milieu d'une toile blanche d'Araignée, à tissu fin et soyeux, occupant l'espèce de gouttière formée par la feuille. Sur cette toile était l'Arachnide morte, une Clubione holosericea LINNÉ.

Ces larves avaient l'apparence de certains vers de Diptères, mais elles portaient leur tete d droite et à gauche, et paraissaient fixées par des pattes au plan de position. J'en ai sacrifié une pour l'examiner, et, après de longues hésitations, je suis parvenu d̀ reconnaître que les pattes, les pseudopodes existaient, non point sur la face ventrale de la larve, mais bien sur la face dorsale, suivant la ligne médiane du corps. Celte larve singulière se tient, par conséquent, 
su. le dos, renversée, et c'est dans cette position qu'elle marche lentement et qu'elle présente sa tête avec la bouche non point inclince en bas, mais relevée en haut.

On voyait dans l'intérieur du corps des larves une ombre noiratre (pl. 17, no II, fig. 2) qqui m’a paru tenir au tube digestif plein d'aliments. Je ne crois pas qu'il y eut dans l'intérieur de ces larves une autre larve incluse.

De quelle substance ces larves s'étaient-elles nourries pour parvenir d̀ leur croissance complète, au moment où je les ai trouvées? Avaient-elles vécu aux dépens de l'Araignée morte? ou bien celte toile remplissant le fond de la feuille et ayant été filée par la Clubione, renfermaitelle le cocon de ses oufs, et alors ceux-ci avaient-ils servi d'aliment aus larves parasites ? Cette derniere assertion est la plus vraisemblable. L'Araignée dont il s'agit n'a point le volumineux abdomen des Epeira, et il est douteux qu'elle eût suffi à nourrir les trois larves. J'ai trouvé d'ailleurs une coque soyeuse, d'un beau blanc, d'une forme aplatie au fond de la gouttière formée par la feuille; elle ne renfermait plus que des œufs vidés, des pellicules sans contenu. Les larves avaient donc dévoré les cufs de la Clubione.

Ayant placé la feuille supportant les deux larves vivantes, entierement pareilles d celle que j'avais examinéc, dans une boite à observation, j'y ai trouvé, quinze jours plus tard, deux Ichneumons femelles qui y étaicnt éclos et y étaient moris. Ils étaient sortis d'une coque de soie oblongue, fine, blanchâtre, filée sans nul doute par les larves. Il était donc évident que les deux larres étaient celles des deux Iyménoplères parasites que javais sous les yeux, car, je le répète, 
je ne crois pas que ces insectes soient venus d'une larve incluse dans le corps des premières (1).

Le nombre des larves d'Ichneumonides actuellement connues n'est pas très considérable. Plusicurs de celles qu'on a figurées sont remarquables par des mamelons latéraux, quelques-unes paraissent ineme, si on juge par les dessins quelquefois assez imparfaits qui en ont été donnés, avoir des mamelons sur la région dorsale du corps. Toutefois, l'observation pasitive de larves d'Ichneumons, a pseudopodes dorsaux munis de crochets comme les fausses pattes des chenilles, m'a semblé digne d'etre rapportée dans ces Amales. Je l'ai décrite avec soin ct accompagnée de figures.

Je n'ai pas fuit des recherches assez complètes pour pouvoir transcrire ce qu'on trouve dans la science sur toutes les larves des Ichneumons. Un pareil travail ne serait point ici, d'ailleurs, à sa place. Je vais me borner à citer ce qui a trait aux Ichneumons purasiles des Araignées et à leurs larves, puis après avoir décrit la larve de la I'impla Fairmairii, je rapporterai quelques extraits ou opinions d'Auteurs avec les figures où les pseudopodes dorsaux ont élé indiqués ou paraissent exister. Je terminerai en faisant connaître l'insecte Iyménoptère parvenu à l'état parfait.

(1) Jai observé, au mois de juin 1858, dans un lieu sabłonneur, un cocon d'Araignée, arrondi, revètu de sable fin à l'extérieur, et ataché ì une tige de gramince comprise dans sa paroi. L'intérieur était tipissé de soie tiès blanche, il s'y trouvait avec des débris d'culs une larve à pseulopodes dorsaux cini est morte sins se transformer. Mon collegue, M. II. Lucas, pense que ce cocon a eté fait par un Drassus, 
(5) I. Indication de plusienrs Lelmeumons parasites des Araignées.

DE Gíen, dans le tome II de ses Mémoires sur les Insectes, rapporte l'histoire d'un très petit Ichneumon provenant d'une larve parasite qu'il avait vue sur le corps d'une Araignée. Celte Araignée était morte par suite de ce parasitisme et la larve de l'Íchneumon s'était filé une coque oblongue de fine soie, au milieu des fils que l'Araignée avait tendus avant de mourir. Il était sorti de celte coque un très petit Ichneumon noir, à antcrnes filiformes, à deux raies jaunâtres sur le corselet et à patles jaunes (tome II, page 863 et suiv., pl. 30, fig. 1,2 et 3 ).

Grofrnoy décrit un Ichneumon à anneaux sur le ventre et femelle sans ailes. - Long. 2 1/3 lignes. - a Il est sorti l'e nids d'Araignées dont il avait dévoré les œufs. Il parait que cette espèce dépose ses œufs principalement dans ces nids. " (Ilistoire des Ins. des environs de Paris, tome II, 361, 1762.)

Boneman a fait connaitre une Pimpla ovivora; " e nido Araneæ semel specimina septem exclusa. " (En ny art af Insect-slägtet Pimpla hwars law uppehaller sig i Spindelbon. - Kongl. Vetenskaps Academiens IIandlingar, 1821, page 335 , tab. IV, fig. 1 et 2.)

Gravexhorst, en parlant des mours des Ichneumons, s'exprime ainsi : "Vero etiam in nymphas insectorum et in ova Aranearum, seu forsan in coactile densum sericeum quo quadam Aranea ova sua obducunt, Iclineumonides nannulli, v. c. Pimpla oculutoria el Hcmiteles palpator ova 
ponunt; larvæ exclusæ autem substantiam internam ovorum Aranæ comedunt, et in ipso Araneæ nido in nymphas et insecta declarata commutantur. " (Ichneumologia curopaca, 1829, 1, pag. 96.)

En faisant connaitre plus tard (tomes II et III) la Pimpla oculatoria et l'IIemiteles pulpator, Gravenhorst ne décrit point leurs larves, il dit seulement, en parlant de la Pimpla oculatoria, qu'il était sorti le même jour trois Ichneumons de celte espèce, deux ot et une $\mathcal{f}$, d'un nid d'Araignée trouvé dans l'herbe pendant l'automne de l'année précédente. "Larvæ eorum fere omnia ovula comederant, etc. » Il décrit les petites Araignées qui provinrent des œufs épargnés par les larves.

Quant à l'Ilemiteles palpator, il mentionne qu'il lui avait été envoyé comme étant sorti " e folliculo ovis Araneæ cujusdam repleto.,

Dans le supplément du tome IIIc de l'Ichneumologia, GraVENHonst rapporte, page 1096, la description de l'Ichneumon aranearum de Fourcroy, Villers, qui est celui de Geoffroy; il lui donne pour synonyme l'Ichn. audax d'Olivier, Walckenaer; il fait remarquer que le genre de vie de cet insecte est celui de l'Hemiteles palpator.

Gravenhorst dit enfin que l'Ichneumon aranearum d'Olivier et de Walckenaer ne se rapporte pas à l'espèce qu'il vient d'indiquer précédemment sous ce nom.

Davis, en décrivant un nid d'Araignée fort remarquable, signale un Ichneumon aptère qui est parasite à l'état de larve des œufs renfermés dans ce nid (On a beautiful Nidus of a Spider, and a IIymenopterous Parasite found within it. Magasine of Nalural Ilislory, IV, 236, 1831). 
Boucné (Naturgeschichte der Insecten, p. 145, 1834) dit que l'on trouve des larves de la Pimpla rufata pendant lihiver et le printemps, dans les nids de l'Aranea diadema, dont elles dévorent les oufs. Elles se changent en nymphes dans une coque blanche, elliptique, un peu aplatie, et semblable à du papier; ces coques, serrées les unes contre les autres, se trouvent au nombre de 10 à 15 , dans le propre cocon à œufs de l'Araignée. Les insectes parfaits paraissent au printemps.

DILWYNn s'exprime ainsi: "I have frequently observed a small black species successively deposit an egg in the abdomen of two or more spiders on the sand hills, and I doubt whether the spider had in any case arrived at ils maturity. On one of those occasions, I perfectly recollect having seen a young brood of dark-coloured spilers on Cromlyn burrows, and that when the Ichneumon hovered over them, they appeared, and instinctively endeavoured to escapen " (Swansea Colcopt., p. 27, et Westwood, Introd. modern Classif. II, 143).

Walckenaen, dans son Ilistoire naturelle lles Insectes aptères, tom. 1, p. 175, 1837, rapporte ce qui suit sur les ennemis des Araignées. Il ne devait pas connaitre, de visu, les Pimpla dont il parle; ses remarques s'appliquent d̀ de très petites espèces d'Ichncumonides. "Le Pimpla ovivora et le Pimpla arachnitor perçent avec leurs invisibles tarières la tendre pellicule de l'ouf de l'Aranéide, et sans le rompre introduisent leurs propres $œ u$ fs dans la liqueur. . . . I I sort finalement de l'œuf' un insecte ailé, phénomène qui avait fait croire aux naturalistes que les Araignécs potıvaient procréer des mouches à quatre ailes... C'est aussi ce qui a 
fait croire à Aristote que les œufs d'Araignées produisent de petits vers; IIist. An., lib 8, cap 27. ,

Walkenaer avait observé, en outre, une larve très probablement d'Ichoumonide, parasite de la Lyniphia montana (Aptìres, I. II, p. 233). Une de ces Araignées prise par lui sur sa toile dans les Pyrénées avait « une larve blanchatre pareille à une petite chenilie le long de son dos. L'abdomen de l'Araignée avait une ligne et quart de longueur et la larve deux tiers de ligne. " L'Auteur déerit incomplétement cette larve qu’il ne sait à quel insecte rapporter. II hésite méme s'il doit la regarder comme une véritable larve ct se demande si elle ne renfermerait pas une chrysalide incluse (loc, cil, 176).

J. BLAcKWall a fait connaître (Report on the 12 meeting of the British Association, etc., held at Manchester, 1842, p. 68) le parasitisme d'un lchneumon sur plusieurs espèces d'Araignées (Account of a Species of Ichneumon whose larva is parasitic on Spiders). Ces observations établissent que les Ichneumons attaquent, non seulement les œufs d'Arachnides, mais bien les Araignées elles-mèmes. Je transcris textuellement: " Immature spiders of the species Linyphia minute and $\boldsymbol{L}$. pusilla, are frequently infested by the larra of a sinall Ichneumon, which feeds upon their juices and ultimately occasions their death. This parasite is always attached to the upper part of the abdomen, near its union with the cephalothorax, generally in a transverse but occasionally in a longitudinal direction, and, though it proves a source of constant irritalion, is secured by its position from every attempt of the spider to displace it. Being apodous, it appears to retain its hold upon its victim solely by the instrumentality of the mouth and of a siscid secretion 
emitted from its caudal extremity. More than one larva is never seen on the same spider, wich, indeed, could not supply sufficient nourishment for two. " Suit une rapide description de la larve d'une "smooth uniform surface " et qui file ensuite une coque de soic après avoir quitté le corps de l'Araignée. L'Íchneumon sort au bout d'un mois et la femelle pond ses œufs sur le corps de ses nouvelles victimes.

Le MÊme avteun a publié en 1843, dans les Annals and Magazine of natural history, tom. XI, p. 1, sous le meme titre, l'histoire qui précède, mais plus détaillée. Une jeune femelle d'Epeira antriada a été capturée en avril 1838, portant une de ces larves parasites d'Ichneumon; celui-ci s'est développé entièrement le 27 juin. C'était une femelle du Polysphincta carbonaria (il faut lire carbonator) de Gravenhorst.

Il est éclos, le 16 aoùt, le male de ce meme Polysphincta d'une autre Epeira antriada prise le 20 juillet 1838.

Sur une femelle adulte de Linyphia minuta, trouvée le 26 octobre 1811, élait une larve parasite qui est parvenue à toute sa grosseur, en faisant périr l'Araignée. Elle a filé sa coquue le ter février $\mathbf{1 8 4 2}$, mais elle est morte sans s'etre changée en insecte parfait.

On trouve à la fin de ce travail une note que j'ai cru devoir rapporter, car elle mentionne l'existence d'un fait connu de Geoffroy, et que Ratzeburg a plus tard établi, à savoir, que certains Ichneumonides ont des femelles toujours aptères dont on avait fait à tort un genre spécial.

" The Insect is not uncommon in this neighbourhood (Oakland); indeed, the Ichneumonidoe abound throughout the district. Two other species belonging to this family, 
which deposit their eggs in those of spiders, have come under my observation; one is very small and black; the other is small, though larger than the former; and the female, which is apterous, is of orangered colour, with a black head, and a zone of the same hue encircling the abdomen " (loc, cit,, p. 4).

Bote (Entom. Zeitung Stettin, 1846, 292) décrit aussi les mosurs du Polysphincta carbonator, dont il a trouvé les larves sur deux individus jeunes de l'Epcira diadema. Ces larves se tenaient de chaque coté de l'abdomen à des intervalles si réguliers qqu'on aurait pu les prendre pour des taches blanchatres épidermiques. Sur l'une des Araignées, il y en avait deux, sur l'autre trois. Ces larves, comme de vrais vampires, augmentèrent de volume aux déperıs des Araignées qui filèrent incomplétement une toile, et moururent. Deux larves seulement, une sur chaque Araignée, avaient pris leur accroissement. Elles construisirent un cocon d'un gris verdatre et se changèrent en insectes parfaits le 1er juillet. Elles avaient été prises avec les Araignées, le 14 juin, et avaient filé leur coque le 21 du méme mois, au moment de la mort de leurs victimes.

Ratzeburg est l'auteur qui a donné la plus longue liste des Ichneumons parasites des Araignées. On trouve dans ses Ichneumonen der Forstinsecten, pages 261 et 262, 1852, les espèces suivantes dont il a, par lui ou par dautres naturalistes, constaté le parasitisme.

Microgaster aranearum? Hemiteles? palpalor. perspicuus.

Cryptus titillator.

Hemiteles fulvipes.

rufocinctus.

Mesochorus arancarum.

splendidulus. 
P'ezomachus instabilis. Polysphinctu carbonator.

Pimpla angens.

Pteromalus ater. rufate.

punctatus.

Voici quelques détails sur ces divers parasites, d'après l'ouvrage cité de Ralzeburg. Ce savant entomologiste a vu sortir une centaine de Micragaster perspicuus d'un cocon de Sulticus, d'où sont provenus en meme temps des Ilemiteles et des Pezomachus instabilis (page 55). - Le M. araneanum? s'était échilppé d'un nid d'Araignée avec des IItmitcles, des Pezomachus et des Mesochorus splendidulus (p. 55). (Saxesen, Brischke et Reissig.) - Cryplus titillator, deux individus ayant vécu d'œufs d'Araignćes (Rrissig, p. 139). - L'Hemiteles fulvipes avait allaqué les Bombyx pini et dispar, une Colcophora; Brischke l'a ru éclore des nids à œufs d'Araignées ainsi que le Microgaster perspicuus et le Pezomachus inslabilis (p. 151). Ralzeburg prouve que les Pezomachus sont tous des insectes $q$ et les Hemiteles tous des insectes $\sigma^{A}$, d'oú il a conclu (p. 150) que ces insectes ne forment qu'un seul genre.

L'Hemileles rufocinclus est provenu en grand nombre de coques d'œufs d'Araignnéc avec le Pezomachus instabilis, qui est la + de celte espèce (p. 157). - Le Mesochorus aranearum est sorti de nids d'Araignéc (p. 118), ainsi que le Mesochorus splendidulus (Reissig, p. 117), mais ce dernier insecte a pareillement vécu aux dépens de Phalona, Bombyx, Hyponomeuta, Pyralis, Sphinx, Zygona, Papilio, etc. (p. 117). - La Pimpla rufata vit dans les nids d'Araignces (Reissig), mais elle est sortie également de Bombyx, Phalocna, Toririx, Sphinx, Papilio (p. 101). - La Pimpla angens, comme sa congénère, n'altaque pas seulement les 
œufs d'Araignée, mais encore les Geometra, Tortrix et les Tenthredo (p. 101). - Polysphincta carbonator a récu d'œufs d'Araignée (p. 111) à l'état de larve. - Le Pteromalus aler est sorti d'un cocon d'Araignéc vivant sur lo Pin; avec lui étaient des Microyaster (p. 233). - Le P'ter. punctatus a vécu pareillement aux dépens d'une Araignée (p. 237).

En résumé, les Ichneumonides, qui sont, à l'état de larve, parasites des Araignées, ne s'attachent pas tous exclusivement à ces animaux. Ils altaquent aussi les insectes de divers ordres; toutefois, quelques-unes de ces larves parasites nont encore été trouvées que dans les nids des Aranéides.

On a pu croire, et avancer comme règle, que les laries parasites qui nous occupent virent toujours de la substance des œufs renfermés dans les nids. Mais j’ai prouvé, par plusieurs des citations précédentes, que les Araignées ellesmemes portent les larres d'Ichneumon attachées sur leur corps; ces larves, comme des vampires, suivant l'expression de Boie, se nourrissent en aspirant les substances fluides de leurs victimes, qu'elles font mourir d'épuisement.

S II. Description de la larve de la Pimpla Fairmairii.

$$
\text { (Voy. pl. 17, no 11, lig. } 1 \text { dे 5.) }
$$

LARve allongée, un peu courbée (fig. 1 à 3 ), composée de 13 segments, y compris un mamelon terminal, mais la tete non comprise. La coulcur est d'un gris blanchatre, uu peu luisant, satiné. I,e tube digestif parait brunâtre i l'intérieur (fig. 2), et sous l'enveloppe tégnmentaire on 
aperçoit une foule de granulations blanchatres. - Long. 7 millim.

La région ventrale est concave, lisse, sans pattes; les côtés du corps sont fortement arrondis; mais le point le plus important de la configuration de cette larve est l'existence de pseudopodes, de fausses pattes placées sur le milieu de la région dorsole ou convexe, et dont je vais bientot parler.

Tête petite, en triangle curviligne, brunâtre, paraissant munie de deux petites antennes biarticulées (fig. 5 a); d'un labre subarrondi, cilié; de deux marndibules. Les parties de la bouche sont très difficiles à apprécier.

Segments thoraciques les plus grands de tous, arrondis sur les côtés et en dessus.

Segments abdominaux mamelonnés? sur les côtés, les 1 à 70 ayant sur le dos, dans son milieu, de veritables pseudopodes rétractiles entièrement comparables aux fausses pattes des chenilles, ayant comme elles une couronne de crochets qui les fixent solidement au plan de position (Gig. 4). Les deux derniers segments ( $8^{\mathrm{e}}$ el $9^{\circ}$ ) tripézoïdes et formant avec l'appendice terminal un cóne renversé.

Stigmates au nombre de neuf paires. La première situéc au bord antérieur du métathorax, la deuxième sur le premier segment abdominal (quatrième du corps de la larve), Ies troisième, quatrième, cinquième, sixième, septième, huitième et neuvième sligmates sur les deuxième à huitième segments abdominaux. Une longue souche trachéenne règne le long du corps et envoie une branche à chaque stigmate.

La figure 2 représente celte disposition. Les trachées 
sont blanches, argentées sur le tube intestinal, et la dernière ainsi que le stignate correspondant, paraissent noires par la transparence du corps de la larve placée sous la lentille d'un microscope.

La surface du corps de cette larve est très finement ruguleuse ou couverte de très fines rides qui lui donnent un aspect satiné. Je dois faire remarquer les granulations blanchatres, très nombreuses et placées sous le tégument (fig. 2). Des granulations semblables ont été parfaitement décrites par M. Fabre, dans un intéressant travail sur les Sphégides (Annales des Sciences naturelles, Zool., $4^{\text {* }}$ série, VI, 167). Il a démontré que ces grains blanchatres étaient composés par des sels uriques, et servaient d'organe d'excrétion à la larve du Sphex Ravipennis et à plusieurs autres larves.

Dans un travail l'écemment publié dans les memes Annales (Etudes anat. et phys. sur un Diptère Tachinaire, parasite de lo chenille du Sphinx euphorbia, Ann. Scienc, natur., ¿e série VII, 115), M. Barthélemy a constaté les memes granulations blanchatres et leur nature urique sur la larve du Scenometopia atropivora.

J'ai déjà insisté sur le point le plus remarquable que présente la larve de la pimpla Fairmairii, c'est-à-dire sur les pseudopodes dorsaux. Il existe peut-etre des mamelons latéraux sur cette larve, je ne les ai point notés. Je ne crois pas cependant avoir été préoccupé des pseudopodes de la région dorsale, au point d'avoir négligé l'étude des mameIons de la région latérale. S'ils existent, ils ne doivent pas etre très marqués.

Parmi les Auteurs qui ont parlé des pseudopodes dorsaux 3e Série, tome vi. 
ou qui les ont figurés se trouvent Réaumur, Rœsel, Bouché, M. le colonel Goureau.

Réaumur a décrit, dans le III polume de ses Mémoires pour servir à l'llistoire naturelle des Insectes, denx larves trouvées par lui dans les galles ligneuses, en groseilles, venant sur la face inférieure des feuilles du chêne (p. 496, pl. 45, fig. 2, 3 et 4). Elles avaient des mamelons dorsaux et " ressemblant si fort aux jambes membraneuses des fausses chenilles que ce ver parait avoir des jambes presque tout le long du dos. D

Il avait encore observé « que l'intérieur de quelques vers était presque rempli de petits corps ronds qui se touchaient les uns les autres „(XIIe mémoire, loc. cit. 497 ) et il les prenait pour des œufs. C'étaient probablement des granulations graisseuses ou de nature urique.

Réaumur savait que les pattes dorsales n'existent pas chez " les vers de très grosses galles en boutons, les vers des galles ligneuses en boules » (p. 496). Il ne distinguait point toutefois les vers de ces galles en habitants légitimes et en parasites, ces derniers ayant seuls les mamelons ambulatoires sur leur dos. Les observations de Réaumur ont été mal comprises plus tard, par ceux qui les ont copiées sans les étudier suffisamment et sans controle. On troure dans plusieurs ouvrages que les Cynips ont des larves remarquables par des pattes dorsales, suivant Réaumur. Nous voyons ce qu'on doit admettre à cet égard.

Roesel a figuré, dans ses Belustiqungen, tome III, p. 299, Suppl., pl. LIII, fig. $c$, une larve à pattes dorsales, habitant une galle du chene. Elle produit un Misolampus ou Eurytoma (fig. II), d'un vert lloré, à longue tarière. 
Bovcuré, dont j'ai déjà parlé comme ayant observé les mœurs aranéivores de la larve de la Pimpla rufata, décrit (loc. cit., p. 145) cette larve comme ayant des pseudopodes dorsaux incontestables. Sa description remarquable doit être citée en entier: "Die Larve ist halbwalzig, etwas gekrümmt, gelbweiss, weich, fleischig, wulstig gerandet, fein murikat, mit sehr einzeln stehenden kleinen Borsten. Der kleine eiformige Kopf ist blassbraun, und hat einen vorstehenden Hund mit undeutlichen Theile. An den Seiten stehen kleine kegelige, zweigliedrige Fühler. Die kleinen blassgelben Stigmen stehen wie bei den Räupen. Auf dem Rücken der Abschnitte - den Prothorax und die beiden Ilintersleibsabsehnitte ausgrnommen - steht je eine, als Forstbewegungsmiltel dienende Quererhöhung, und darauf zwei, in den Seiten sich vereinigende Doppelreihen kleiser rothbrauner Stacheln. Diese Erhöhungen können eingezogen werden, und bilden alsdann kleine elliptische Vertiefungen, in denen die Stachelreihen stehen. Das Aftersegment ist klein und rundlich. - Lange 3 linien.

Bouché a encore décrit (loc. cit. 144) trois aulres larves de Pimpla. Celle de la Pimpla (Lissonota) setosa a seulement le sommet des segments dorsaux un peu gibbeux " Der Rücken der Abschnitte ist etwas bucklig. " Le méme savant a noté dans la larve de la Pimpla instigator (p. 146) la teinte grise du tube digestif. Il l'aperçevait à travers les téguments et il a vu plusieurs grains (Körnern) blanchatres dans l'intérieur du corps. Il ne parle pas de pseudopodes.

M. le colonel Gouncav a représenté, dans ces Annales (1845, pl. 7, III, fig. 1), la larve d'un Microgasier, qui parait avoir des pseudopodes dorsaux, d'après le dessin. D'antre 
part, le texte ne fait pas mention spécialement de ces pseudopodes dorsaux, mais il fait connaitre sur cette larve des mamelons exsertiles « des jambes qui sortent horizontalement de son corps, au nombre de cinq paires, sur les troisième, quatrième, cinquième, sixième et septième anneaux, et que l'animal fait rentrer et sortir à volonté (loc, cit., 1845, page 357 ). "

Mon savant collègue, M. Gourcau, a eu, en outre, l'obligeance de me communiquer les figures qu'il a fixites, et encore inédites, de la larve de l'Euryloma abrotani Nees D'Esenizck. Cette espèce est parasite d'un Cynips d'une galle du Chene (galle dure en grain de groseilles, ou plutot en pois du chene, se trouvant d̀ la face inféricure des feuilles); cette larve paraît avoir des pseudopodes dorsatux. C'est probablement celle que Réaumur a connue.

Une autre larve, observéc par M. Goureau, vit en parasite dans les Bédéguars, et produit un insecte qui est peutetre, suivant cet auteur, l'Ichneumon parasiticum d'OLIvier, ou l'1. bedeguaris de Founcnoy. Elles est pourvue de deux fortes mâchoires et couchée sur le coté, elle dévore les habitants légitimes de la galle ou bédéguar. Après avoir achevé de manger la larve occupant une cavité, elle passe dans la cavité voisine en détruisant la cloison mitoyenne et dévore le nouvel habitant qu'elle a découvert. Cette larve, sur les dessins que j'ai vus, parait avoir des mamelons dorsaux, mis elle est surtout pourvue de mamelons latéraux.

On a fait remarquer, à juste titre, que les Ichneumonides s'attaquaient aux autres Insectes, sous tous leurs divers états, sans respecter les larres de leur propre famille. Les uns en veulent aux œufs, les autres aux larves, d'autres 
aux nymphes, aux chrysalides, certains aspirent la substances des Arachnides et des Insectes à l'état parfait, on en a la preuve incontestable. Les Ichneumonides sont de la sorte, tantôt parasites internes, tantôt parasites externes. Je me fais un plaisir de citer, à cet effet, la communication suivante de M. Goureau.

Mon savant collègue dit, à propos de l'Ichneumon précité des galles de l'églantier. "L'Ichneumon dont il s'agit est donc un parasite extérieur. Ce fait mérite d'etre signalé, quoique déjà connu, afin que les compilateurs ne disent plus, comme règle générale, que les larves d'Ichneumonides vivent exelusivement dans le corps des chenilles ou des autres larves.

DLeur manière de vivre est variée, puisque nous savons qu'il y en a qui sont parasites, en partie intérieurs et en partie extéricurs. Ces derniers sont plongés à moitié dans le corps de leur victime. J'ai élevé un Cryptus qui a beaucoup d'analogie avec le Cryptus tarsoleucus Grav., dont la larve dévore la chrysalide d'une tordeuse du noisetier, et se tient à moitié plongée dans sa proie. Elle s'y introduit pardessous le fourreau d'une des ailes. »

Il faut remarquer enfin que les larves extérieures, celle que je fais connaître dans ce travail, celles des Pimpla, que Bouché a décrites, etc., ont des stigmates. Les larves qui sont intérieures ne paraissent pas en avoir le plus souvent. On connait les belles observations de Ratzeburg à ce sujet; les faits que j'ai vus me paraissent entièrement les confirmer.

La dépouille des nymphes de la Pimpla Fairmairii ne m'a rien offert de particulier. Je n'en parle que pour mémoire. 


\section{$S$ III. INSECTE PARFAit.}

Pimpla Fairmairii, f. (Voy. pl. 17, no II, fig. 6 à 11.)

Longueur $63 / 4$ mill.; plus la tarière 3 mill.

Tête noire, plus large que le corselet, ayant un point jaune devant la base de chaque antenne (fig. 6). Antemnes plus longues que la moitié du corps, assez greles, de vingtcinq articles environ, le dernier du double plus long que le précédent et arrondi à l'extrémité. Ciouleur brunatre, jaune à la base, surtout en dessous, jaunatre à l'extrémité. Yeux noirs, assez grands, non contigus. Ocelles rougedtres, disposés en triangle presque équilatéral. Labre roussatre. Mandibules noires. Palpes et parties inférieures buccales entièrement d'un jaune clair.

Thorax noir, très finement pointillé et à fine pubescence, varié de :fauve et de jaune. Prothorax noir. Mésothorax noir en dessus, avec deux raies d'un fauve rougedtre foncé, longitudinales; la majeure partie des flancs et le mésosternum sont fauves ou d'un jaune foncé, ainsi que les sutures latérales. Métathorax noir. Région de l'ćcusson d'un jaune un peu fauve, à extrémité d'un jaune clair, suivie de deux traits arqués, à concavité antérieure, jaunatres, répondant à des sulures.

Ailes irisées à base jaunatre. Stigma brunatre. Nervures disposées ainsi que l'indiquent les figures 8 et 9.

Pattes antérieures d'un jaune clair; les intermédiaires également d'un jaune clair avec l'extrémité de quelques articles des tarses à peine obscure; les postérieures d'un jaune foncé à la base, les trochanters blanchatres, extrémilé des cuisses avec un anneau obscur; jambes bianchâtres. 
ayant un anneau près de la base et leur sommet noiratres; extrémité des articles des tarses noiratres.

Abdomen noir, ponctué, pubescent; les segments ont une élévation latérale lisse, luisante, et au bord postérieur une large surface également luisante (Voy. fig. 11). Tarière ayant au moins la longueur des deux tiers de l'abdomen; valves latérales noires, ciliées de noir, portion médiane fauve.

Je ne connais pas le male de cet insecte. Cette description est faite sur deux individus femelles que j'ai déposés dans la collection de mon excellent ami Léon Fairmaire.

La Pimpla Fairmairii est très voisine de ses congénères les Pimpla rufala, angens, oculatoria, ovivora. Elle se distingue essentiellement, et au premier coup d'œil, de la rufata, à laquelle elle ressemble extrémement, et qui a comme elle deux lignes roussatres sur le dos, par la longueur de sa tarière qui chez la rufata est courte, n'égalant que la quatrième partic de l'abdomen.

Elle n'a point la ponctuation abdominale de l'angens; elle est plus fortement punctuée, les espaces élevés sont bien plus marqués; sa tarière est plus longue.

Elle n'a point la coloration rousse du corselet et des anneaux de l'abdomen de l'oculaloria, et sa tarière est bien plus longue, le corps plus grele, etc. La figure me dispense d'autres détails. L'ovivora décrite par M. Boheman s'en distinguerait, au premier coup d'œil, par les taches roussatres du côté de l'abdomen.

Je n'ai pas trouvé, sur ces trois dernières Pimpla, si voisines de la Fairmairii, la cellule aréolaire ouverte ou fermée très obscurément comme dans celte espèce. if 
caractère remarquable se présente dans l'aile des Polysphincta.

Je dirai encore, au sujet des ailes de la Pimpla Fairmairii, que j'ai représenté, chez cet insecte, les crochets de la partie supérieure de l'aile de dessous, ou petite aile (fig. 9 et 10). Ces crochets se retrouvent, comme on le sait, dans presque toutes les ailes des IIyménoptères. Ils sont, dans notre espèce, arqués et simples et au nombre de cinq à six plus ou moins développés.

L'abdomen de la Pimpla Fairmairii est remarquable par les espaces lisses, élevés, qui lui donnent un aspect noueux. La tarière de la femelle a aussi une longueur qui la distingue des espèces congénères, qui lui ressemblent le plus pour la taille et la couleur.

Explication des figures de la planche 17, no II.

Fig. 1. Larve grossie de la Pimpla Fairmairii vue de profil, et à côté d'elle mesure de sa grandeur naturelle.

2. La meme larve, montrant par transparence le tube digestif noiratre sur lequel se détachent en blane les granulalions et, en outre, les trachées et leurs stigmates, qui ont sur la larve vivante un reflet argenté.

3. La même larve, vue par la région dorsale et offrant sur les quatrième à dixième segments des pseudopodes dorsaux médians.

4. Deux segments du milieu du corps fort grossis, 
vus de profil et montrant les crochets des pseudopodes dorsaux.

5. 'Tete fort grossie de cette larve. $a$. Antenne biarticulée.

6. Pimpla Fairmairii , fort grossie.

7. Le meme insecte de grandeur naturelle.

8. Aile supérieure très grossie.

9. Aile inférieure encore plus grossie que la supérieure. On voit, sur le bord supérieur, les crochets qui lient celte aile à la grande aile. Ces crochets sont plus fortement indiqués que lo grossissement ne le comporterait, afin de les mettre plus nettement en évidence.

10. Un de ces crochets extrêmement grossi.

11. Abdomen très grossi. 



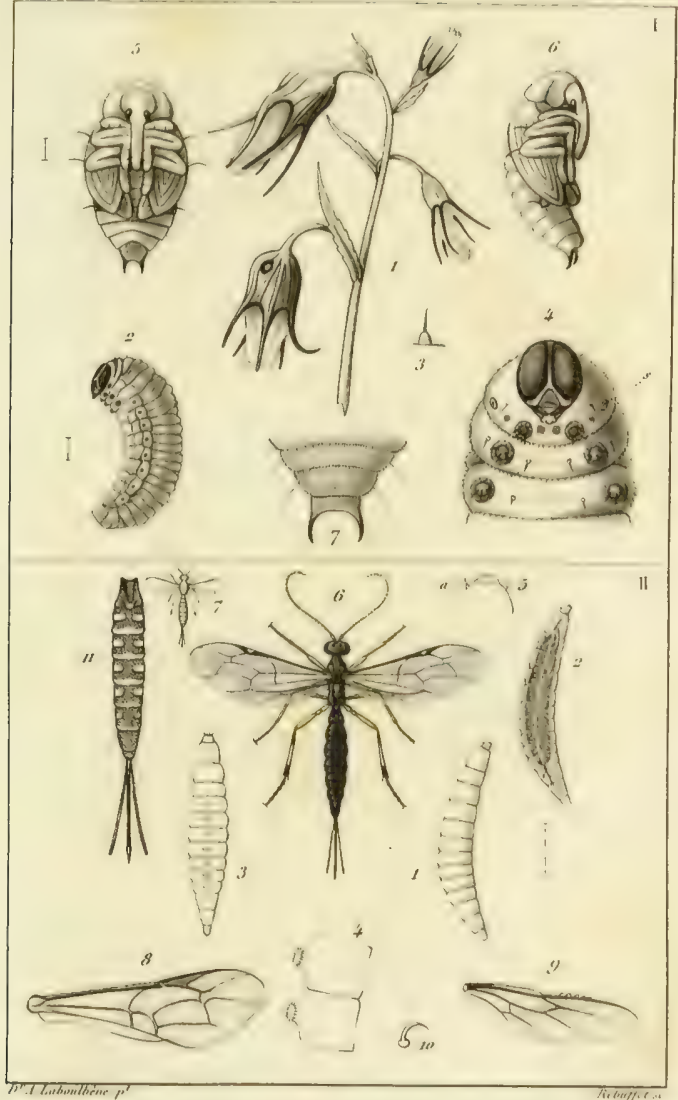

1. Mélamorphasen du Giymenctron Campanula*
II.
de lex l'impla Farmativit. 



\title{
EXAMEN ANATOMIQUE
}

DE

\section{DEUX MELOLONTHA VULGARIS}

\author{
trouvés aceonplé:
}

et paraissant du sexe male,

Par M. le $D^{*}$ Alexandre LABOULBÉNE.

(Séance du 14 Septembro 1859.)

Notre collègue, M. le docteur Puton, m'a fait remettre deux Mclolontha vulgaris qu'il avait trourés accouplés. Ces deux insectes étaient accompagnés des renseignements suivants :

«II s'agit de deux vulgaires Mélolonthes, qui n'auraient rien de bien intéressant si tous les deux ne présentaient les altribuls externes du sexe masculin. Avons-nous affaire à des males véritables, ou bien l'un des insectes serait-il une femelle arec des antennes males? J'ai pensé qu'ils vous intéresseraient et que vous pourriez, en les disséquant, décider la question.

"Je les ai trourés il y a trois ou quatre ans en Normandic. 
dans les environs de Dieppe, et pour les conserver dans leur position exacte, je les ai fait périr sur-le-champ au moyen de la chaleur. »)

Pour résoudre la question poséc par notre collègue j'ai examiné soigneusement ces insectes $1^{\circ}$ à l'extérieur de leur corps; puis j'ai $2^{\circ}$ constaté la nature sexuelle de leur appareil généraleur interne.

\section{Aspect extérieur.}

J'ai tenu à soumettre à la Société, dans sa séance du $2 \nmid$ août, les deux Mctolontha vulgaris accouplés. On a pu constater qu'ils sont de la méme taille, d'une coloration identique; leur fourrure est rare et usée sur le corselet et les élytres. Tous les deux présentent les caractères extéricurs du sexe malc. Tous les deux ont l'épistôme droit, rebordé. Sur les deux parties latérales du corps, leurs antennes ont la massue allongée, composéc de sept feuillets; les pattes antéricures offrent des jambes nettement bidentées en dehors. Le dernier demi-segment dorsal (pygidium) est allongé, prolongé en une longue pointe mousse.

En comparant ces deux Melolontha aux insectes males de la mème espéce faisant partie de ma collection et recueillis par moi aux environs de Paris, je ne trouve entre eux aucune différence appréciable.

La position des Melolontha accouplés est la suivante : L'un d'eux est renversé obliquement sur le dos; l'autre, percé d'une épingle, est horizontal et placé sur la face abdominale. On sait que telle est la position ordinaire des deux sexes accouplés du $\boldsymbol{H}$. vulgaris; la femelle marche ou reste 
fixée sur les feuilles d'arbre tandis que le mâle, renversé, tenant ses pattes relevées contre le corps et paraissant endormi, est transporté par la femelle partout où il plait á celle-ci d'aller.

L'individu renversé sur le dos, occupant par conséquent la place ordinaire du mâle pendant l'accouplement, paraît avoir les organes externes de la génération engagés dans le corps de l'autre insecte placé comme le sont habituellement les femelles.

\section{Examen des organes internes.}

Après avoir fait ramollir dans l'eau froide, puis dans l'eau bouillante ces deux insectes, je les ai dépouillés de leurs élytres, de leurs ailes et j'ai enlevé la face dorsale de l'abdomen.

Il m'a été facile de constater que le premier insecte, ou celui qui élait dans Ia position du male, avait évidemment les organes de la génération, le fourreau corné de la verge tout entier engagé dans le corps de l'autre insecte. Le fourreau ou l'étui corné avait pénétré par l'orifice externe générateur et non par celui qui appartient en propre à l'appareil digestif. L'extrémité de l'étui corné était débordée par une petite masse charnue, plissée, qui n'était autre que la verre membraneuse sortie au dehors et très reconuaissable.

L'autre insecte, remplissant par rapport au premier le role des insectes femelies, ayait comme celui-ci des organes internes mâles. Au-dessous du premier élui corné déjà décrit, il s'en trouvait un second tourné en sens inverse, refoulé dans l'abdomen et appartenant au deuxième insecte percé d'une épingle. L'étui corné avait son aspect ordinaire. sans aucune saillie membrancuse à l'extrémité. 
370 A. LaboulB. - Anatomie de deux M. vulgaris.

Jans la cavité abdominale des deux Melolontha, j’ai trouvé les restes tlétris, racornis, de l'appareil générateur male; les canaux déférents et éjaculateur étaient faciies à reconnaître. Le deuxième insecte ne présentait pas le moindre vestige de gaines ovigères, d'wufs, ni d'aucun organe femelle.

En résumé, il me parait incontestable que ces deux $M l e-$ Lolontha vulgaris appartenaient tous les deux au sexe malle. Le fait de leur accouplement, dont je ne connais pas d'autre exemple authentique, est très singulier. 


\title{
NOTE
}

\author{
sur une \\ MONSTRUOSTÉ DE L'ORYCTES SILENUS,
}

Par M. Ie D* Alexandre LABOULBÈnE.

(Héance du 14 Décembre 1859.)

La collection de mon excellent ami M. Léon Fairmaire renferme un Oryctes (Phyllognathus) Silenus $q$ qui prósente une monstruosité très remarquable. Cet insecte, venant de Sicile, me paraît devoir être décrit, car il est presque identique à un autre insecte $q$ de la meme espèce, pris dans la meme localité et faisant partie de la collection Dejean. Le célèbre entomologiste l'avait indiqué sous le nom d'Oryctes cephalotes dans la $3^{e}$ édition de son Catalogue (page 167).

Cette femelle d'O. Silenus a un aspect extraordinaire. La tete est dilatée sur les côtés, comme boursouflée, gonflée, au point d'etre près de deux fois aussi large que la tete d'unc ơ de la même espéce à l'état normal. Les légères saillies habituelles sont rejetées en avant. Les yeux sont d̀ peine distincts, à première vue; ils se confondent avec la courbure générale supérieure de la tete; leur séparation est à peine marquée, il faut la chercher avec la loupe pour l'apercevoir.

Le corselet est lui-même remarquable par les côtés bien plus arrondis qu'a l'état normal, avec l'angle postéricur plus 
146 Labodrbėne. - Sur une monstruosité de l'O. Silenus.

ouvert, ce qui tient à la couformation des élytres. Ces dernières, en effet, sont étroites à la base et très arrondies sur je côté externe, resserrées en arrière, en commençant à peinc au delà du ticrs antérieur, jusqu’à leur extrémité.

Le pygidium est conformé d'une manière anormale. Il est déjeté à gauche, irrégulièrement sinué, offrant une pointe et de légères tubérosités. L'abdomen, vu en dessous, présente une déviation bien marquéc de la ligne médiane.

Cette description ne me parait devoir laisser aucun doute sur l'existence d'une monstruosité chez cette femelle d'Orycles (Phyllognathus) Silenus. Il en résulte que l'Oryctes cephalotes de Dejean, qui lui est presque identique, mais avec l'abdomen non dévié et régulièrement conformé, ne doit point constituer une espèce distincte qui ne reposerait cn réalité que sur une monstruosité de l'O. Silcnus 우. 


\title{
CONGRESS
}

DE IA

\section{SOCIÉTÉ ENTOHOLOGIQUE}

DI TRSRCI:

\section{TENU A CLERMOND-FERRAND ET EN AUVERGNE \\ EN 1859.}

\begin{abstract}
Procè-verbal de la séance du 27 juin
ET

Rapport sur la SESSION EXTRAORDINAIBE,
\end{abstract}

par M. Emm. MaRTIN,

Secrétaire de l'excursion de la Société.

Extrait des Annales de la Socićté entomologique de France. Anníe 1859.

A PARIS,

CHEZ LE TRESORIER DE LA SOCIÉTÉ 16, rue de Vaugirard. 
Les membres de la Société déjà arrivés à Clermont-Ferrand et qui ont assisté à la séance sont : MM. Bayle, d'Aigueperse; Berce, de Paris; Fallou, de Paris; de Graslin, de Chateau-du-Loir; Guenée, de Chateaudun; Lafaury, de Dax; Dr Laboulbène, de Paris; Gustave Levrat, de Lyon; Lethierry, de Lille; E. Martigné, de Saumur; Martin, de Paris; Remquet, de Brest, et le $\mathrm{D}^{\mathrm{r}}$ Titon, de Chalons-surMarne.

Pans. - Typ, FÉ IX MAI,TESTE ET Ce, 22, rue des Deux-Portes-St-Sauveur. 


\section{CONGRÈS}

DE LA

\section{SOCIÉTÉ ENTONOLOGIQUE DE FRANGE}

TENU A CLERMONT-FERRAND ET EN AUVERGNE

en 1859.

\section{Procès-verbal de la séance du 27 juin $\mathbf{1 8 3 9}$.}

Rédigé par M. MARTIN,

Secrétaire de l'excursion en Auvergne.

Présidence de M. LÉON DE GILAZLLES, maire de Clermont, député au Corps législatif, etc.,

President d'honneur,

et de M. le tocteur AL. LABOULBÈNE,

Président du Conenès.

La Société se réunit à huit heures dans une des salles de la Faculté des sciences, que M. le maire de Clermont a mise avec empressement à notre disposition et préparée à cet effet par les soins obligeants de $\mathbf{1}$. Lecoq, professeur de la Faculté des sciences, membre correspondant de l'Institut.

Plusicurs naturalistes de Clermont assistent à la séance. 
Nous remarquons MM. Léon de Chazelles, le professeur Lecoq, le capitaine Maymat, ancien membre de la Société, Gonod, pharmacien, Vimont, notre colligue M. Bayle, d'Aigueperse, etc.

M. le secrétaire donne lecture de l'ordre du jour de la scssion extraordinaire (conforme à celui qui a déjà été suivi lors des Congrès de Montpellier et de Grenoble), et de la décision prise par la Société dans sa séance extraordinaire du 27 avril dernier, sur la proposition de sa commission permanente, qu'elle se réunirait à Clermont-Ferrand le 27 juin 1859.

Il fait également connaitre la composition du Bureau, qui se trouve ainsi constituó :

M. le docteur Laboulbène, 1er vice-président, remplissant les fonctions de président de la session extraordinaire;

M. Martin, secrétaire;

Mi. Berce, archiviste.

Lecture est donnée de la liste des membres assistants à la séance.

Après cette lecture, $\mathbf{M}$. Ie docteur Laboulbène déclare la session ouverte. Il remercie $\mathbf{M}$. de Chtazelles et M. Lecoq de la bienveillance avec laqquelle ils ont accueillis la réunion de la Société en cette ville et les assure de notre reconnaissance; puis il invite M. Léon de Chazelles, qui s'est autrefois activement occupé d'entomologie, à prendre le fauteuil de la présidence.

M. de Chazelles accepte et remercic en un discours fort gracieux pour la Société ; il déclare qu'il s'est mis à notre disposition avec une grande satisfaction puisqu'il était heureux de voir réunis dans sa ville des hommes s'occupant d'une science qu'il avait aimée. Puis il nous souhaite toutes les chances désirables pour une abondante collecte dans ce beau et intéressant pays oủ il nous promet toutes les jouissances du naturaliste et du touriste. 
Aprés ce discours MI. le président d'honneur ouvre la discussion à l'ordre du jour sur les excursions à faire par la Société pendant son séjour dans le Puy-de-Dòme.

M. Lecoq, consulté par M. de Chazelles comme un des plus aptes à nous renseigner parfaitement à cet égarł, puisque depuis longtemps ce savant professeur a utilisé son zèle pour la science à explorer ce département, nous donne d'intéressants détails sur les endroits à explorer et qu'il considère comme très nombreux; mais, vu le peu de temps que nous comptons consacrer à nos courses entomologiques, il nous indique d'abord comme une des excursions les plus intéressantes celle à faire au Puy-de-Pariou, montagne à peu de distance de Clermont et au pied de laquelle on peut se rendre facilement en voilure.

Le Puy-de-Parion, nous dit-il, est le cône volcanique le mieux conservé de toute la chaîne des mêmes dômes. On y remargue deux cratères dont l'un inférieur, très déformé, a produit la grande coulée de lave qui se partage en deux branches à la Barraque et vient s'arrêter à Nohanent et à Font-Mort. L'autre supérieur, profond de plus de 200 mètres, est régulier et placé au sommet de la montagne. C'est un vrai cratère d'éruption qui a seulement domé issue à des gaz, et qui est parf.itement conservé. Ses abords sont faciles, une jolie pelouse en couvre toutes les pentes, les fleurs en émaitlent le gazon et l'entomologiste peut recueillir aujourd'hui des insectes sur' les scories refroidies de cetle ancienne fournaise ou sur les fleurs qui cachent les parois brûlées du volcan.

Déjà on rencontre ici la végétation des montagnes, l'Arnica mon. tana, la Centaurea montana, garnie de son diadème de fleurons bleus. L'Ancolie y balance ses corolles azurées et le Myrille y montre ses fruits colorés près des frondes légères du Polypodium dryopteris.

Après ces inléressants détails, M. Lecoq nous engage à ne pas redouter une nouvelle éruption de ce cratire, et, pour nous rassurer, nous rappelle qu'avant nous la Société de géologie n'a pas craint, avec raison, de prendre un repas au fond meme du cratère. 
M. Lecoq nous indique comme seconde excursion le Puy-de-Dòme, ce géant des environs de Clermont, et donne les détails suirants :

Cette montagne domine toutes les autres; elle atteint 1,460 mètres d'altitude. C'est un cône presque régulier, mais sans cratèrc. Il est formé dune roche blanchâtre, légère et poreuse, espèce de trachyte, auquel Léopold de Buch a donné le nom de Domic. Si constitution est donc très diflérente de celle du Puyde-Pariou; toutefois, sur le llanc nord du Puy-de-Dôme se trouve accolée une autre montagne toute scoriacée, c'est le petit Puy-deDóme, muni d'un joli cratère arrondi que l'on nomme le Nid de la poule.

La végétation du Puy-de-Dome prélude déji à celles des monts Dore, elle a quelque chose d'alpestre; l'Altium victoriale, le $R a$ nunculus platanifolius, le Moum alhamanticum, le Sonchus plumierii, l'Adenostyles albifrons, le Lilium Martagon et une foule de belles plantes abondent au milieu des graminées. A cette épođque de l'année, la robe de verdure de cetle montagne est émaillée de toutes les lleurs de son printemps.

M. Lecoq termine en nous recommandant un troisième but d'excursion, le bourg de Volvic, pour y visiter le Nugere, un des volcans les plus intéressants du département, et dont la lave remarquable a servi à construire plus d'une ville.

- M. Bayle, d'Aigueperse, prend la parole pour engager vivement la Société à consacrer quelques jours à l'exploration de la chaine des monts Dore, une des meilleures localités du département au point de vue entomologique. Notre collègue, qui a si souvent parcouru ces montagnes, nous donne d'intéressants détails sur les insectes qu'il y a capturés.

M. Lecoq s'unit a notre confrère et nous promet aussi une abondante moisson d'insectes et tout le confortable nécessaire dans celte hospitalière vallée du mont Dore.

M. Ie président remercie MM. Lecọ et Bayle de leurs 
bons renseignements, et la Société décide que les excur. sions seront dirigées d'après ces excellentes indications.

- M. Gonod demande la parole pour appeler l'altention de la Société sur un fait botanique de la vallée de SaintNectaire et qui pourrait aussi etre intéressant au point de vue entomologique. La vallée de Saint-Nectaire, dit-il, est une des plus curieuses de la chaine des monts Dore, et oú crolt, à cause de certaines sources salines, un assez grand nombre de plantes marines; il nous engage vivement à rechercher si ces plantes ne produiraient pas des insectes propres aux bords de la mer.

- M. Berce lit une lettre de notre collègue MI. Bellier de la Chavignerie qui donne quelques curieux détails sur son séjour en Sicile et sur les insectes Lépidoptères qu'il y a recueillis :

Les Diurnes, écrit M. Bellier de la Chavignerie, ne m'ont encore fourni que deux espèces spéciales à la Sicile: l'Arge pherusa et l'Ilesperia Etna, On trouve ici, comme dans le midi de la France, le Salyrus Ida, l'Arge, var. Procida, l'Argynnis Pandora. Il y a fort peu de Nocturnes, je n'ai vu aucune des Zygæna Lavandula, Rhadamantus, occitcnica, hilaris; mais jai pris assez abondamment la Punctum et l'erythrus. Le mème genre Zygona m'a offert aussi une intéressante espèce, l'Oxytropis, que M. Boisluval indique comme propre à l'Etruric; malheureusement quand je fis la découverte de la seule localité où j’ai vu cette charmante espèce, elle était presque entièrement passée. Les chasses de ces derniers jours m'ont fourni quelques jolies Anthophita, plusieurs Sesia, que je ne puis déterminer à première vue, mais qui me sont inconnues; l'Ophiusa stolida et la belle Gcometra chrysitaria, qui habite aussi l'Espagne méridionale. Je puis encore ajouter que j’ai pris les Fidonia semicanaria, Scodiona conspersaria, Emydia coscinia. Psyche villosclla et api,ormis, et les Bombyx Cocles et Spartii.

- M. de Graslin montre plusieurs espèces de Lépidoptères qu'il croit nouvelles :

10 Une Dasycampa dont il a découvert la chenille dans les Pyrénées orientales; 
2. Une Cleophana qu'il a recueillie nux environs de Grenade, en Andalousie, espèce voisine de la C. platyptera, mais qui en serait tris dislincte par son dessin et par le troisième article de ses palpes.

$3^{*}$ Une magnifique Eubolia voisine de l'Eub. bipunctaria, provenant de ses chasses aux environs du Vernet;

40 Une Eupilhecia, montrucuse pour le genre, prise par lui au mont Louis.

II. Guénée prend la parole au sujet de cette communication et fait surtout remarquer l'importante découverte de notre collègue à jropos de la belle Dasycampa qu'il vient de montrer, car ce genre, comme on sait, ne comprenait encore qu'une seule espèce.

- M. Lethierry rend compte d'une excursion qu'il a faite le jour même au Puy-de-Dóme, où, entre autres Coléoptères, il a trouvé la Clylra conculor, une rare Coccinclla et la Ncbria rubripes propre aux terrains humides et qu'il a été surpris de rencontrer dans un sol aussi sec.

II. Lecoq dit à propos de cette communication que quoique le Puy-de-Dóme paraisse etre une montagne aride, les nuagres qui souvent s'étendent sur ses flancs, les brouillards du soir et du matin qui enveloppent sa cime, entretiennent une grande fraicheur et permettent de retrouver quelques especes d'insectes qui aiment les lieux frais et humides.

Le savant professeur engage la Société à rechercher si le sol volcanique qui admet à la fois les plantes des terrains calcaires et celles des sols siliceux, ne serait pas aussi pour les insectes une sorte de terrain neutre qui réunirait à la fois les especces des roches calcaires et celles des roches siliceuses.

La séance est levée à neuf heures et demic. 


\title{
RAPPORT
}

SUR LA

\section{SESSION EXTRAORDINAIRE TENUE A CLERMONT-FERRAND}

\author{
Ca Julu et Julliet 18 8.
}

Par M. EMM. MARTIN.

(Sénce du 26 Oetobre 1859.)

\section{Messieurs,}

Permettez-moi, en commenşant ce rapport, de vous exprimer avec sincérité les appréhensions qui s'emparent de moi quand je considère que nos chers collègues, M.I. Fairmaire et Laboulbène, ont rempli avec talent avant moi, ces memes fonctions, car j'avoue que je ne me sens pas le mérite nécessaire pour vous raconter notre excursion de cette année en Auvergne, aussi bien que mes prédécesseurs l'ont fait de celles de Montpellier et de Grenoble.

J'ai aussi une autre crainte, c'est que le peu de succés de nos recherches me fait appréhender de n'exciter que médiocrement votre intérêt.

Si j'avais la science à mon servire, je pourrais espérer captiver votre attention par l'énumération des merveilles géologiques du beau palys que nous venons de parcourir, mais je ne puis vous raconter que des excursions dans de 
fort belles localités, oủ les insectes nous ont un peu fait détaut, malgré nos nombreuses courses et nos consciencieuses recherches. Nous n'avons recueilli qu'une pauvre moisson entomologique. Je suis done forcé, malgré moi, de vous présenter un maigre rapport; peu nourri de noms d'insectes précieux et d'utiles obscrvations à leur sujet.

La faute en revient à l'année dont la grande sécheresse a sans doute contrarié l'apparition des insectes et peut-ctre aussi à notre empressement qui nous a fait arriver quelques jours trop lôt dans ces belles montagnes.

Je suis donc obligé de compter sur votre indulgence, et, comme je sais qu'elle ne me fera pas défaut, je commence plus hardiment.

Le 27 juin donc, Messieurs, nous étions tous réunis à Clermont. Cette ville avait été bien choisie pour tenir notre session extraordinaire de cette année, car vous savez qu'clle est une de nos cités savantes. Elle possède de honnes Facultés dont les chaires sont très suivies, de riches Mlusées d'histoire naturelle, et sa position au milieu des belles montagnes qui l'environnent et qui ont un si grand intéret pour le botaniste, le gréologue et l'entomologiste devait également nous y attirer; aussi, avant nous, la plupart des sociétés savantes avaient-elles déjà demandé asile à cette hospitalière capitale du Puy-de-Dome.

Notre première journée fut en partie consacrée à visiter les belles collections de M. Lecoq, qui avait été pour nous un guide si obligeant pour préparer et faciliter notre réunion dans la ville, où il inspire avec tant de zèle, par son éloquent enseignement, le goût de l'histoire naturelle.

Je n'entreprendrai jas de vous décrire toutes les richesses que renlerme ce Musée, je vous dirai seulement que ce qui y excite surtout la curiosité et l'admiration, ce sont les collections de coquilles, d'oiseaux et de leurs oufs, celles de géologie et de minéralogie; toutes rangées avec un ordre admirable. Je dois aussi mentionner les insectes qui 
sont parfaitement représentés dans ce Musée digne d'une grande ville.

Plusieurs d'entre nous visitèrent aussi, à la Foculté des sciences, la collection Baudet-Lafarge, riche surtout en Coléoptères d'Auvergne.

Impatients de fouler le sol de ces montagnes volcaniques, que nous apercevions de la ville, nous retournions à l'hòtel de l'Airgle-d'Or, où nous étions presque tous descendus, prendre nos instruments de chasse pour faire une excursion à Gravenoire.

Gravenoire est une montărne pen élevée, couverte de scories de ses pieds à son sommet. Un setnis de pins y a été fait il y a quelques années, et, bien que ce sol brùlé piaraisse ne tevoir rien produire, ces arbres ont furis un ars'z grand développement, et il n'est pas toujours facile de se retirer de leurs touffus épaisses une fois qu'on y est engagé.

Cette montagne n'est qu'à une heure et demie die marche de Clermont, grâce à un élégant omnibus de la grande place de Jaude, qui transporte à peu de frais à l'établissement thermal de Royat.

Ce village est sur la route de Gravenoire et à une demiheure, à pied, de Clermont.

Permettez-moi, Messieurs, de vous arreter avec l'omnibus à ces bains délicieux dans lesquels vos collègues voyagears sont allés plusieurs fois retremper leurs forces, amollies par l'excessive chaleur, dans leurs nombreuses ascensions. I, a vallée de Royat, d'ailleurs, est une des plus jolies vallées des environs de Clermont, en meme tenps que le village se recoinmande par une haute antiquité.

Je ne saurais vous bien décrire la beauté de ce joli villoge, échelonné sur la monlagne et dominé par son arılique clocher, le tout encadré dans une fraîche décoration de vignes el de chataigniers en pleine floraison à celte époque. Un ruisseau limpide anime ce joli paysage et donne à la vé- 
gétation ce bel air de fraîcheur et de verdure. D'ailleurs, Messieurs, vous pourriez m'accuser de m'êtendre trop dans mes deseriptions, je marrete donc. Je vous dirai seulement que, grìce à la facilité de transport et aussi à la beauté attractive de cette riante vallée, nous nous sommes trouvés plusieurs fois entrainés vers ces intéressantes localités.

Je quitte Royat avec regret, mais je suis obligé de vous conduire avec nous sur la route qui mène au but de notre excursion; nous voila done gravissant, le filet à la main, au milicu des scories qui roulent sous nos pieds, et sur lesquelles croissent cependant, jusqu'au sommet de la montagne, d'abondantes toufies du Sedum reflexum, dont la jolic fleur jaune fait un heureux contraste avec la couleur ferrugineuse du sol. Sur les haies, nous faisons envoler quelques petites Géomètres, et les scories nous produisent en les soulevant, divers Colíoptères; mais rien de digne de vous être cité.

Peu après le village dépassé, la grande végétation cesse, je veux parler des magnifiques chataigniers dont quelquesuns atteignent une grosseur colossale. Nous arrivons à cette montagne de Gravenoire, but de notre exploration, nous touchons aux jeunes pins dont j'ai parlé plus haut et qui la couvrent presqu'entièrement jusqu'ì son sommet, qui du reste n'est pas élevé.

Nous comptions sur' une abondante récolte, mais j'avoue que notre espoir a été un peu déçu.

Gravenoire est la patrie favorite, en Auvergne, du $P$ barnassius Apollo; l'abondance des Sedum qui nourrissent sa chenille en est la cause. Il est rare sur les autres montagnes du Puy-de-Dome.

Je ne vous parle du reste de ce Lépidoptère commun que pour vous donner un exemple que je choisis entre beaucoup d'autres, et une preuve malheureusement trop évidente de la paurreté entomologique de cette année. Je vous dirai done que ce Parnassien constituait une véritable 
rareté. Nous désirions en prendre un bon nombre pour notre président, le docteur Laboutbène, qui, comme vous le savez, a si bien commencé l'anatomie des Lépidoptères et, en particulier, celle du Parnassius Apollo, dont il nous a montré de consciencieux dessins.

Sur le flane méridional de la montagne, de belles pentes garnies de Genets nous procuraient la jolie Geometra smaragdaria et quelques autres phalénites plus communes, l'Aspilates Calabraria, d'un fort beau type, la Fidonia concordaria et l'Acidalia decorala; le Botys flavalis élait très aboudant dans les herbes épaisses qui croissent au milieu des Pins.

Sur le sommet, notre collegue M. Lafaury capturait la jolic variété aux ailes inférieures noires de l'Emydia gram. mick.

Nous prîmes également sur ce sommet et au milieu des Pins, quelques Lycœna Bretica, malgré l'absence complète du Baguenaudier qui nourrit sa chenille. C'est donc une preuve de plus que cet arbrisseau n'est pas sa nourriture exclusive.

Le sommet de Gravenoire nous procura une bien douce jouissance, je veux parler de l'admirable vue qui se déroula devant nous en un splendide panorama. La ville de Clermont apparait sur le premier plan majestueusement couronnée par sa belle cathédrale qui se trouve sur le point culminant; au delà, l'immense plaine de la Limagne montre ses riches moissons, et, à l'horizon, les montagnes du Forez ferment ce tableau grandiuse par un pittoresque rideau.

Quittons, Messieurs, cc magnifique spectacle, je craindrais de my arreter trop lontemps pour vous; je vous fais descendre par un joli ravin qui conduit de Gravenoire presque jusqu'i Royat. Ce ravin n'est assurément pas fait pour de minces chaussures un des vêtements de luxe, car l'accès n'en est pas toujours facile et commode; mais 
vous savez que l'entomologiste sait aller à peu près partout où il espère faire quelque bonne récolte, et j'avoue que, chaque fois que nous y avons passé, nous avons été dédommagés de no: insuccès sur les autres parties de la montagne; les petits rochers et les anfractuosites de terrain de cet étroit ravin servaient de retraites à de nombreuses Géomètres; cu les baltant, la Larentia olivafa s'envolait par petits nuages et plus rarement la Larentia frustrata, ainsi que l'Acidalia subsericeala. I.a petite Acidalia holosericala y était aussi assez abondante.

Le lendemain de cette première course, nous partions à six heures du matin dans deux élégantes voitures pour aller au Puy-de-Pariou, que B. Lccoq nous avait indiqué comme une des plus curieuses montagnes de la chaine du Puy-deDôme.

Après une longue montée par une fort belle route, nous arrivames au village de la Barraque, et peu après nous mettions pied à terre ì l'endroit appelé la l'ontaine-du-Berger. Lì, press de cette source fraiche et limpide, se trouve une petite auberge où on nous servit un repas beaucoup moins frugal que nous ne l'aurions supposé au milieu de ces montagnes; puis notre petite caravane se mit en route sous la direction de M. Vimont, naturaliste distingué de Clermont, qui avait voulu nous servir de guide, et auquel je me fais ici un plaisir en meme temps qu'un devoir de temoigner toute notre reconnaissance pour les utiles et intéressants renseignements qu'il nous a donnés, et pour les bons services qu'il nous a rendus dans cette journée et la suivante.

Nous voici donc au milieu d'un col dont les pelouses étaient garnies de Genista sagillalis formant un admirable tapis jaune harmonieusement mélangé d'une fraiche verdure. Nos pieds font résonner ce sol volcanique. Les lépidoptéristes capturaient déjà la Psyche stomoxella, qui volait par essaims sur les gazons, et ils trouvaient, appli- 
quée contre les petils rochers, l'Hadena dentina, d'un beau type foncé. De leur coté, les coléoptéristes faisaient tomber des Spartinm scoparium, le Cryprocephalus coryli; ils rencontraient le Dorcadion meridionale marchant sur les sentiers, le Geotrupes typhecus, qui était fort commun, et plusieurs espèces de Clythra.

La tete de notre colonne nous pressait, car plusieurs d'entre nous voulaient faire, dans la meme journée, l'ascension du Puy-de-Dôme. Il fallut donc, à notre grand regret, abandonner une si belle localité. Nous nous reprìmes à gravir pour atteindre le sommet du Puy-de-Pariou, et nous arrivames au bord de son cratère par une montée assez raide et sur des pelouses littéralement couvertes de Vaccinium.

Je n'essaierai point de vous peinulre l'extase qui nous prit à la vue de ce magnifique amphithéatre de 900 pieds de circonférence et de $\mathbf{4 0 0}$ pieds de profondeur, dont les pentes sont garnies d'une belle verdure, car ma description vous donnerait une faible image de la réalité; d'ailleurs rous avez lu, dans le procès-verbal de notre séance de Clermont, les intéressants détails que M. Lecoq nous a dornés sur cette montagne, et je ne puis mieux faire que de vous $y$ renvoyer.

Ceux de nos collègues qui nous avaient précédés soulevaient les scories au fond du cratère. Les docteurs Laboulbène et Titon y trouvaient les Coléoptères suivants :

L'Otiorhynchus tencbricosus, la Nebria rubripes, type a pattes rouges, et la variété à pattes brunes; les Cychrus rostratus, Byrrhus omatus, Corymbites cupreus, Calathus melanocephalus, variété alpinus; l'Amara picea, la Chrysomela cerealis, etc.

I. Berce capturait aussi, sous les scories, la variété Honoratii du Carabus auraius.

Après un dernier regard sur cet imposant spectacle, nous gravissions le cỏté opposé à notre descente. pour gaguer 
l'immense plaine formée par la coulée de lave de ce volcan, qui est une vaste lande couverte de Bruyères, où se trouvent cependant quelques oasis d'une belle végétation et quelques parties boisées. Nous en profilâmes pour faire à chacun de ces endroits une petite station.

La Gentiana lutea, que nous n'avons guère trouvée en fleurs que la, nous procura cependant peu de Noctuelles; mais, en revanche, elle était couverte d'Atopa cervina.

Nous prîmes également l'Eubolia palumbaria, d'un type jusculudors spécial à l'Angleterre, et l'Herminia tentaculalis, espèce assez rare.

Après avoir atteint le pied du Puy-de-Dôme, nous faisons une longue route sur un chemin couvert de lave et de débris volcaniques, et nous gagnons le village de la Barraque pour reprendre nos véhicules qui nous y attendaient. Nous revenons à Clermont par une pluie assez forte et désagréable pour ceux d'entre nous qui étaient en voiture découverte.

Je passe sous silence l'ascension du Puy-de-Dôme, faite par plusieurs de nos collegues un peu à la hate; par conséquent peu d'insectes y ont été pris. M. Lecoq, d'ailleurs, nous a donné sur cette montagne, comme sur la précédente, d'intéressants détails qui se trouvent aussi consignés dans notre procès-verbal.

l. lendemain, nous retournions à Gravenoire en passant de nouveau par Royat. M. Vimont, notre obligeant guide de la veille, avait bien voulu nous accompagner encore cette journcec. Il nous rappela l'histoire de cet ancien village, en nous faisant remarquer les antiquités et les sites qui nous avaient échappé à notre première visite.

Nous avions à peine atteint le sommet de Gravenoire que la pluie vint nous rendre toute recherche impossible. En vain nous avons attendu le retour du beau temps, blottis dans une petite hutte qui nous contenait à peine et très fréquentée par certains parasites sauteurs. II fallut aban- 
donner le champ de bataille et revenir avec nos boites vides.

Le reste de notre journée, malgré une pluie torrentielle. fut consacré à visiter les curieuses fontaines incrustantes de la ville de Clermont et les monuments de cette cité. Nous la terminions en nous préparant à notre départ pour le Mont-Dore, fixé au lendemain 30 juillet.

Ce jour arrivé, nous prenons tous place dans une diligence retenue par nous.

Par la pluie el un froid très vif, nous parcourons la route du Mont-Dore, qui ne demande pas moins de huit heures de trajet, quoiqu'il n'y ait que 13 lieues de poste, mais elle est toujours ascendante. Le temps nébuleux qui nous enveloppait de toute part ne nous permit pas de jouir de la vue des montagnes au milieu desquelles nous voyagions.

Nous remarquâmes cependant un beau tamnel sous lequel passe la route, et que notre postillon faisait toujours précéder de l'article féminin.

Ce tunnel est à peu de distance de Randanne, ou nous nous arretons pour déjeuner et laisser un peu reposer les chevaux. Après cette réfec'ion, nous reprenons nos places en voiture pour continuer notre voyage par ce qu'on appelle la petite route. Ce chemin était détrempé par la pluie de la veille, et c'est avec peine que nos chevaux parviennent à trainer notre véhicule. Nous mettons souvent pied à terre, et nous soulevons les picres sous lesquelles nous trouvons quelques insectes.

Notre ascension 'sl enfin terminée. Nous arrivons sur l'immense plateau de la Croix-Morand, sur lequel paissent de nombreux troupeaux au milieu de grandes plaines de bruyères ei d'Airelle myrtille.

Mais là un épais brouillard vint nous envelopper et nous priver de la belle vue que donne cette grande élévation, car ce plateau est à 1,300 mètres d’altitude. Après l'avoir fran- 
chi, nous descendons une longue route en lacel, au milieu de belles forets de Sapins, et nous arrivons dans la vallée du Mont-Dnre, ou le soleil nous attendait.

Nous voici donc arrivé au village du Mont-Dore, terme de notre course. Nous débarquons à l'hôtel de France, où M. Lecoq avait eu l'obligeance d'annoncer notre arrivée et de nous recommander aux bons soins de notre hote M. Cohadon-Bertrand; je dois dire qu'ils ne nous ont point fait défaut, car, à cet hotel, les naturalistes sont parfaitement reçus.

Après une courte installation dans nos chambres respectives, nous fîmes une petile excursion, malgré l'heure avancée de la journée, en nous dirigeant vers la grande cascade. Les murs (en pierres sèches) du village étaient presq̨ue tous tap̧issés par la Naclia mundana et les abords de la cascade à laquelle nous parvìnmes, non sans peine. nous procurèrent l'IIepialus Velleda et quelques petites Géomètres spéciales aux montagnes.

Notre première occupation à notre réveil, le lendemain, fut de visiter le village auquel nous étions venus deınander l'hospitalité pour quelques jours.

Le Mont-Dore, vous le savez, jouit d'une trop grande renommée pour qu'on ne fasse pas un peu connaissance avec lui, car de nombreux malades viennent demander leur guérison à ses eaux bienfaisantes.

L.'heure (tait matinale, mais, au Mont-Dore, les malades commencent à prendre leurs bains dìs quatre heures du matin; aussi, a celte heure, tout le village est sur pied.

Le village du Mont-Dore, bati au pied de la montagne de l'Angle qui le domine presqu'à pic, est à 1,046 mètres d'altitude et remonte à une haute antiquité. Les Romains, qui ont laissé de nombreuses traces de leur séjour dans cette vallée, connaissaient déjà les propriétés curatives de ses eaux et y avaient établi des thermes. 
Les calentes baic, dont parle Sidoine Apollinaire, évêque de Clermont du temps de l'Empire romain, désignent les sources du Mont-Dore.

Je n'ai point l'intention de vous faire l'historique de ces eaux, je passe donc de suite à la fin du sičcle dernier, où elles furent l'objet d'un travail important dù à de Brieude. Les maisons ćtaicnt alors mal baties et malpropres, les auberges mal tenues. Les malades n'y trouvaient que peu d'aises, mais telles étaient cependant les propriétés des eaux et leur réputation qu'on y accourait en foule pour les prendre.

Le savant naturaliste Ramond, le célèbre auteur des Voyages au mont Perlu et auquel la science doit tant d'utiles travaux, fut le premier qui s'occupa sérieusement, pendant qu'il était préfet du Puy-de-I)òme, de la création d'un ćtablissement thermal au Mont-Dore.

Depuis cette époque, le villagre des bains a subi une véritable transformation, de beaux hôtels, de larges rues, une jolie promenade publique ornée des débris d'un temple romain, tout, en un mot, a été fait pour rendre aux malades et aux touristes ce séjour agréable et commode.

Aujourd'bui, l'on voit sur l'emplacement même des piscines romaines, s'élever un fort bel établissement de bains, bati en trachyle gris, produit volcanique d'une montagne voisine.

Toutes les sources sortent du pied de la montagne de l'Angle, où elles sont recueillies dans de vastes réservoirs et d'où elles sont dirigées dans l'établissement pour y être prises en hains ou en boissons. Ces sources sont au nombre de huit; deux seulement sont froides et servent peu. Celle dont la température est la plus élevée parmi les six autres est celle de la llagdeleine, qui dépasse 15 degrés centigrades. Elle est en mène temps la plus employée et la plus abondante, car elle fournit 100 litres par minute. Elle est re- 
cueillie dans un aquedue romain et de la dirigée dans les piscines et sous ia galerie de la façade de l'établissement, où elle est prise en boisson. Autrefois, les eaux de cette précieuse source se perdaient au milieu de la place, mais aujourd'hui elles sont soigneusement conservées et ce sont elles qu'on expédie dans toute l'Europe.

Une autre source thermale est digne aussi d'etre mentionnée, c'est celle des bains de César, qui jaillit en bouillonnant dans une grotte, œuvre des Romains; elle est remarquable par la quantité d'acide carbonique qu'elle dégage pendant les temps orageux.

Je ne puis, liessieurs, vous lécrire toutes les sources, cela ne rentrerait pas précisément dans mon sujet, mais la reconnaissance m'oblige de mentionner une source froide, interdite aux malades, dont l'cau, chargéc d'acide carbonique, est comnue dans le pays sous le nom d'eau piquante, car elle nous a procuré a uos repas une bien agréable boisson.

Après cette visite, le benu temps, qui ne devait plus nous quitter, nous engagea à faire l'ascension du pic de Sancy, pic le plus élevé de la chaine des monts bores, et qui compte 1,889 mètres d'élévation.

Il faut, pour s'y rendre, traverser dans toute son étendue la vallée de la Dordogne, ainsi appelée du nom d'un joli cours d'eau qui est alimenté en grande partie par la belle cascade de la Jore, descendant de la montagne qui ferme la vallée. Au pied de cette cascade commence une assez pénible ascension jusqu'au sommet du pic.

Malgré un soleil ardent, les nombreuses prairies de la vallée et les belles pelouses des, pentes de la montagne ne nous ont procuré que bien peu de Lépidopteres. Aucun diurne ne volait, à part quelques Erebia Cassiope.

Grace cependant à un procédé que notre collegue M. de Graslin nous indiqua et qui consiste, dans les endroits dé- 
pourvus d'arbres, à rechercher les Lépidoptères sous les pierres comme des Coléoptères; nous pùmes, en soulevant les débris voleaniques sur les pentes qui conduisent au pic de Sancy, trouver les Agrotis nyctimera, agricola et pyrophila. Ces Noctuelles venaient chercher sous ces abris l'ombre que la végétation leur refusait.

Nous prenions également dans les marais de la Dore, le Silpha alpina, qui est au Mont-I)ore d'une abondance prodigieuse, le Leistus nitidus, l'Amara plebeia, l'Ilarpalus locvicollis, variété Salyrus, le Corymbitc's aruginosus, l'Argutor amaroides et la Feronia femorala, etc.

Nous trouvames aussi les Carabus auratus, auronitens, cancellatus, catenulatus, convexus et monilis, et je ne les cite que pour faire remarquer que dans les montagnes d'Auvergne ils offrent tous des teintes noires ou brunatres remarquables et qui leur donnent un air spécial.

Les fleurs des prairies nous offrirent les Omalisus suturalis, Ebous thoracicus, Cyaniris cyanea, Clythra flavicollis, Pachyla interrogationis variété noire, etc.

Tout en recueillant, nous atteignons le sommet du pic de Sancy, sur lequel nous faisons une halte pour jouir du beau spectacle que l'on a de cette élévation. L'Auvergne entière se déroule autour de nous, nous apercevons la chaîne du Cantal, et, à nos pieds, le beau lac Chauvet. La vue est immense, car, par un temps clair, on peut entrevoir les Alpes dans la direction de Besse.

Nous opérons notre descente vers la plaine de Cacadogne qui donne naissance à la Dogne. Ce ruisseau alimente la Dordogne, qu'clle retrouve dans la vallée après avoir formé la gracieuse cascade du Serpent.

Au bord de ce ruisseau croissent quelques Saules nains sur lesquels MM. Guenée et de Graslin trouvèrent de jeunes chenilles de l'Orthosia cocimacula et de l'Epunda viminalis.

En nous élevant un peu, nous trouvons une vaste pente 
toute couverte de Genista purgans, au milieu desquels la Nemeophila plantaginis et sa variété Ilospita volaient en grand nombre. Ce fut avec l'Eubolia palumbaria, les deux seuls Lépidoptères que nous vîmes parmi ces Genêts qui doivent cependant produire quelques espèces spéciales.

Au-dessous de celte plaine commence une belle forêt de vieux Sapins qui descend jusqu'au fond de la vallée de la Dordogne. En battant les branches de ces arbres séculaires la Thera variala s'envolait par essaims, mais son vol rapide la dérobe facilement à la vue. M. Pallou capturait une remarquable variété de l'Argynmis Euphrosine.

Nous primes aussi la Coremia propugnuta, la Numeria caprcolaria, la Larentia salicala, et plusieurs autres jolies Phalénites.

Les Coléoptères ćtaient assez nombreux, MII. Levrat et Martigné prenaient sur les Sapins morts, mais encore debout, le Dircen discolor Fab., les Pogonocherus ovalis et fascicularis; sous les pierres, prés de la cascade, les Nebria Gyllenlualii et Foudrasii, mais celte dernière plus rarement, et le Pterostichus femoratus, qui est abondant partout au Mont-Dore. Les Oreina superba, ninalis, variété ignila, et la cacalia, très commune sur les Cacalia qui croissent sous les Sapins, furent également rencontrées.

Ilélas, Messieurs! depuis notre retour, et au moment ou j'écris ces lignes, la mort est venue surprendre un de nos chers collègues, M. Levrat, de Lyon, dont je viens de vous prononcer le nom.

Cette perle douloureuse sera vivement sentie par vous tous, mais plus particulièrement encore par ceux qui ont été cette année ses compagnons de voyagre. Entomologiste plein de zèle, cet excellent collègrue avait assisté à toutes nos réunions en province. Celte année encore il était en Auvergne un de nos plus aimables compagnons. Tous ceux qui l'ont connu ont pu juger de son zèle et de son afrabilité. Je sais ctre leur interprète en vous exprimant 
leurs regrets de cette mort prématurée qui laisse dans nos rangs un vide si regrettable.

Le Iendemain de cette longue course, une partie de notre petite troupe bornait son exploration aux forêts de Sapins de la vallée du Mont-Dore, tandis que l'autre, plus intrée pide, affrontait l'ascension de la vallée des Enfers par une chaleur de 30 degrés.

Notre chasse dans les Sapins ne nous valut guère que les espèces que nous avions prises la veille dans la foret à la gauche de la vallée, à part la Cidaria silaceata, qui n'y était pas très rare, mais qui commençait à etre un peu passée.

Le dimanche 3 juiilet, ì nous voir au grand complet, Messieurs, avant cinq heures du matin, sur la porte de notre hôtel, on pouvait facilement soupçonner que nous partions pour une longue excursion; en effet, vos collègues se rendaient au pèlerinage de Vassivières, qui a lieu tous les ans à celte époque, au petit hameau de ce nom, et qui est très célèbre dans cette contrée.

La cuurse devait etre longue, aussi, dès la reille, les meilleurs coursiers da village avaient été retenus pour nous par l'entremise de Jean, notre guide, ce conducteur intelligent de tous les naturalistes qui parcourent ces montagnes. Seize chevaux done à celte heure matinale étaient en ligne de bataille devant notre porte, et chacun choisissait de son micux celui qui devait le porter toute la journée et au dos duquel il devait confier sa personne.

Figurez-vous seize cavaliers défilant un à un à travers les étroits sentiers de la montagne, traversant des ponts de neige et des chemins vertigineux, ayant à leur tète Jean notre guide. Nous arrivons au pied du pic de Sancy, ou nous franchissons le sommet de la châ̂ne des monts Dores pour descendre sur l'autre versant de ces montagnes dont les pentes sont couvertes par le Juniperus sabina. Malgré une assez belle végétation, nous ne vîmes voler sur ces pentes aucun Lépidoptère digne d'être recueilli, ni 
aucun Coléoptère qui puisse vous etre cité. Aussi, Messieurs, je passerai sous silence nos insignifiantes captures de cette journée, que notre position de cavalier, du reste, nous empechait de faire d'une manière fructueuse et suivie.

Je ne vous raconterai pas non plus les divers incidents de notre pérégrination équestre, ni les chutes peu nombreuses et sans gravité de nos cavaliers; je vous ferai arriver de suite à Vassivières, où nous mettons pied à terre au milieu d'une foule compacte déjà réunie autour de la chapelle gothique de ce hameau. C'était le moment oủ les processions arrivaient de plusieurs côtés, avec de nombreuses bannières escortées par ces robustes Auvergnats dont les solides poitrines font retentir l'air de chants patois. Rien n'est plus curieux que ces nombreux costumes de montagnards en habits de fete, que ces ménages entiers montés sur de maigres chevaux dont les jambes plient sous un trop lourd fardeau, que celte collection d'énormes parapluies dont chaque assistant des deux sexes est armé.

Après ce premier coup d'œil, nous nous assurons un déjeuner à une pauvre auberge où le grenier nous servit de salle à manger, et nous allons ensuite assister à la messe solennelle qui se disait en plein air au fond d'un large amphithédre autour duquel cinq ou six mille assistants se pressaient, assis sur un épais gazon.

Vous voyez, Messieurs, que les entomologistes voyageurs ont su accomplir jusqu'au bout leur rôle de pèterins et de patriotes; car, à l'issue de la grand'-messe, nous avons assisté au Te Deum chanté à l'occasion de notre dernière victoire en Italie, le seul peut-être qui ait été, dans une aussi magnifique enceinte, chanté devant un si nombreux auditoire.

Ces cérémonies terminées, nous allons reprendre nos montures pour gagner le lac Pavin. A ce moment, et au milieu de nos chevaux, volait un Ilepialus humuli o* qu'un lépidoptériste s'empressa de recueillir. 
Quelques entomologistes ont prétendu que cette grande Hépiale qui est au crépuscule, dans certaines prairies de montagne, d'une abondance prodigieuse, se cachait tellement pendant le jour qu'il etait alors impossible de la rencontrer. Dans une autre de nos courses, nous avons vu un individu femelle de cette espèce volant également à l'ardeur du soleil. Je leur cite done ces deux exemples comme preuve du contraire.

Une belle route nous conduit au lac Pavin, aussi nos chevaux, mis au grand trot, nous menèrent-ils rapidement, au milieu d'un nuage de poussière, au but de notre excursion. Arrivés au bord de la cliute d'eau formée par le trop plein du lac, nous gravissons à pied un petit chemin boisé, et bientot nous roici au bord de cette belle nappe d'eau dont la beauté sauvage frappe les regards. Ce lac, qui remplit un ancien cratère, est encaissé par des bords sombres et à pic, dominés par le Puy-de-Ilontchalme. Il ne compte pas moins de 96 mètres de profondeur, et son diamètre est dix-sept fois plus considérable.

Sa profondeur, que les habitants du pays supposaient etre incalculable, avait donné lieu à cette croyance, qu'un affreux gouffre se trourait au milieu de ce lac et devait infailliblement engloutir le téméraire qui s'y rendrait en bateau. Depuis la fin du siècle dernier des travaux de sondage y ont été faits, et, dans ces derniers temps, M. Lecoq a renouvelé ces opérations et démontré que l'abìme imaginaire était peu redoutahle.

Depuis un an, un habile pisciculteur de Clermont fait, dans ce lac, un essai d'acclimatation de Truites et de Saumons, car jusqu'alors ces caux n’étaient habitées que par quelques petits poissons. Nous fumes assez heureux pour le rencontrer à notre descente, et il eut l'obligeance de nous proposer de parcourir avec lui ce beau lac en bateau, mais l'heure avancée de la juurnée, et non la peur, ne nous permit point de profiter de celte offre aimable. 
A part une grande Phrygane noire, nous ne vîmes autour du lac aucun insecte.

Nous reprenons encore une fois nos montures pour revenir au villare du Mont-Dore par un chemin différent de celui que nous avions parcouru le matin. Nous laissons la ville de Besse sur notre droite et nous commençons à gravir au travers, tantot de marais tourbeux, tantot d'immenses plaines de Bruyères.

Nous apercevons à distance le lac Chambon, le chateau de Murol et l'entrée de la vallée de Chaudefour. Puis, après une route fort accidentée et des plus pittoresques, nous atteignons le plateau de l'Angle, vaste plaine sur laquelle existent encore les traces d'une belle voie romaine. Après cinq heures de marche, que le peu de souplesse des reins de ros montures nous fit paraitre longues, nous arrivions enfin au village du Mont-Dore, ne nous plaignant pas de notre fatigue en sous rappelant les admirables choses que nous avions vues dans le cours de notre journée.

Le lendemain de cette grande excursion, quoique la raideur de nos jambes eût volontiers sollicité une journée de repos, nous gravissions le chemin qui conduit à la montagne du Capucin pour explorer les forets qui couvrent les pentes de cette montagne presque jusqu'à son sommet. Les Hetres forment la bordure de ces bois, et, quand la hauteur à laquelle ces arbres peuvent végéter est dépassée, ils sont remplacés par de magnifiques Sapins séculaires aux branches desquels pendent le Lichen barbu, Usnea barbata, qui leur donne un air vénérable. Leurs troncs couverts de larges plaques du Lichen pulmonaire attestent leur antiquité.

Ces immenses forêts, où le soleil pénètre à peine sont d'excellentes focalités pour l'entomologiste, les Géomètres y abondent ainsi que les Coléoptères xylophages. Aussi, nous sommes venus plusieurs fois faire en ces lieux quelques fructucuses collectes. Il es vrai que l'ardeur du soleil nous 
engagea souvent d̀ profiter du bienfaisant ombrage de ces splendides forets.

L'Acidalia commutata Freyer (nitidaria Bdv.), volait en grand nombre partout où croit le ilyrtille.

La Larentia cosiata, dont le type est fort beau en Auvergne, était aussi très abondante sous les grands Sapins, ainsi que la Numeria capreolaria. Nous prenions aussi fréquemment l'Ellopia prasinaria, qui jusqu'alors avait été considérté comme une variété de l'E. fasciaria. L'abondance de cette espèce n'est-clle pas une preuve de sa validité, surtout vu l'absence complète de l' $E$. fasciaria, dont nous n'avons pas trouvé un seul individu?

La Thera variata, commune au Mont-Dore, dans toutes les forets de Sapins, nous permettait de prendre sa jolie variété vitiosala Frey. (stragulata Bdv.), mais pas aussi abondamment que le type.

Sur les derniers Sapins de sette montagne, notre collègue M. Guenée prit une belle Agrotis pracox, capture curieuse à cause de son apparition hative, surtout pour un pays de montagnes. 11 avait également rencontré, en commenģant notre ascension, la Lampros nubilosella Ilerr.-Sch., espèce nouvelie et rare.

Ces forets nous valurent quelques Coléoptères. Les Rhagium bifasciatum et indigator couraient en grand nombre, surtout la première, sur les Sapins morts. Nous prenions aussi le rare Campylus rubens et les Pissodes piceee, Leptura cincta, Feronia femorata et Trechus amplicollis.

Nous trouvions de nouveau la Dircea discolor, dont la capture est assez difficile, car, lorsqu'on s'approche pour la saisir, elle se laisse tomber et disparait facilement au milieu des débris que le temps a amassés au pied des vieux arbres qu'elle habite.

Ces magnifiques forêts sont hantées par des myriades de Tabanus et de Culex qui nous faisaient une guerre si 
formidable que le repos nous était impossible; car, aussito̊t que nous restions dans l'immobilité, des essaims de ces importuns insectes venaient nous assaillir.

Ainsi, nous avons essayé plusicurs fois de nous reposer un peu au milieu du salon du Capucin, magnifique salle de verdure entourée de gigantesques Sapins, et oủ la Société de botanique tint une de ses séances lors de sa visite au Mont-Dore, mais nous en étions toujours chassés par ces maudits parasites qui semblaient s'etre donné rendez-vous dans cet admirable site.

Nous avons dépassé la région des Sapins pour explorer les prairies élevées de la montagne du Capucin, mais nos peines furent perdues, car nous n'y primes aucun insecte digne d'etre cité.

A notre descente dans une petite clairière, près le village du Mlont-Dore, nous avons trouvé la jolie Miana fasciuncula sur les fleurs de la Gentiana lutea; la capture de cette belle petite Noctuelle, qui a été considérée comme une variété de la Miana stragilis, et que nous avons rencontrée plusieurs fois, a permis à notre collègue M. Guenée de compléter ses observations à son sujet et de l'ériger en espèce. Il m'a envoyé une intéressante note ì cet égard, que je m'empresse de joindre à la liste des espèces que nous avons prises en Auvergne.

La veille de quitter le Mont-Dore, plusieurs d'entre nous ne voulurent point laisser cette belle vallée sans visiter celle de Chaudefour, que nous avions entrevue au retour de notre course à Vassivières.

Cette dernière course nous procura en abondance la Psodos alpinata $\mathrm{WV.-V}$. (equestrata Fab.), la Nemeophila plantaginis, dont nous primes quelques individus appartenant à la belle variété o aux ailes inférieures presque toutes noires. Le Lycœna Eumedon volait aussi, mais en petit nombre. 
La jolie Agapanthia violacea était asse\% commune sur les nombreuses fleurs de ces riches pelouses.

Ces belles pentes couvertes d'une luxuriante végétation. dont la plupart des plantes sont celles de la flore des Alpes et des Pyrénées, nous promettaient une plus riche moisson. Nous acquérions donc encore une triste preuve de la stérilité de l'année en éprouvant de nouveau une grande déception.

Nous étions partis de grand matin, aussi, à trois heures de l'après-midi, nous étions de retour, grâce aux coursiers que nous avions pris encore pour cette journée afin d'économiser notre temps, car nous devions partir le lendemain de très bonne heure pour Clermont, et it nous fallait auparavant préparer notre maigre butin entomologique et faire notre malle.

Avant de terminer le récit de notre séjour dans la belle vallée du Alont-Dore, je dois mentionner plusicurs chasses de nuit que nous avons faites aux environs du village. Ces chasses n'eurent pas plus que celles de jour de riches résultats, cependant nous primes quelques Nocluelles et Géomètres dignes d'être citées, telles que les Agrotis nyctimera et agricola, Miana fasciuncula, Leucania conigera et Mclanippc alpicolaria Herr.-Sch., espice fort rare et toute nouvelle pour la faune française. C'est sur la route de la 'Tour, dans un champ de Gentianes, que nous prîmes au nombre de trois exemplaires cette belle espèce.

Ces chasses nous procurèrent aussi les Eupithecia venosaria et libanotidata, l'Emmclesia alchemillala Linné (rivulata Wien.-Veri.).

Nos huit jours au Mont-Dore furent bien cmployés; lc succès ne vint pas couronner nos efforts, beaucoup d'espèces ne parurent point cette année dans ces montagnes, et ce fait d'ailleurs s'est présenté dans toute la France, pour les Lépidoptères surtout.

Vous avez pu remarquer que je ne vous ai nommé que 
très peu de Lépidoptères diurnes; c'est que, en effet, ils étaient très rares. Le genre Erebia, par exemple, qui est propre aux montagnes et fort bien représenté en Auvergne, ne nous a fourni que quelques individus des espèces les plus communes, telles que les $E$. Cassiope, stygne, et dromus; il en a été de meme pour tous les autres genres de la grande famille des Diurnes.

Quant aux Zygana, elles sont fort rares sur les montagnes volcaniques. On sait que ce beau genre est propre aux terrains calcaires. Nous avons cependant pris à Gravenoire quelques individus des $Z$. hippocrepidis et lonicerce. Leur petit nombre indique que ce sol ne leur convient pas pour patrie.

Nous avons aussi remarqué que les types d'Auvergne sont tous d'une grande beauté, soit pour la taille, soit pour la coloration. Je vous ai déjà parlé des belles et curieuses variations de tous les Carabes que nous avons rencontrés, et cela peut s'appliquer à tous les ordres d'insectes que nous avons pu observer, car tous, en effet, oifrent une belle modification et des types remarquables.

Malgré notre peu de succès, nous sommes convaincus que, par une meilleure année, les localités que nous venons de parcourir doivent etre excellentes pour l'entomologiste. Rien n'y manque, ni les belles prairies avec une abondante végétation, ni les grandes forets, qui peuvent etre comparées à celles de la Grande-Chartreuse et des autres Alpes.

Le 8 juillet, nous ćtions de retour à Clermont, où notre petite bande, déjà amoindric par le départ de quelquesuns de nos collègues, commença à se disperser (1). Plu-

(1) Plusieurs d'entre nous, après leur départ de Clermont, profitaient de leurs derniers jours de loisir pour aller à Vichy; mais, à part le Lycona boctica dont les chenilles étaient abondantes dans les siliques des Baguenaudiers du parc des Célestins, rien autre chose n'y a êté observé en entomologie qui mérite d’être mentionné. 
sieurs d'entre nous ne pouvant prolonger plus longtemps leur séjour en Auvergne, il fallut se séparer, et je vous assure que ce n'est pas sans un serrement de cœur que nous nous donnions la poignée de mains d'adieu, car une bonne et cordiale confraternité avait toujours été nutre aimable compagne, et nous venions de passer près de quinze jours en une véritable réunion de famille, ayant nos aînés pour pères et chefs.

En effet, Messieurs, que ces réunions sont pleines de charmes pour ceux qui y prennent part et ne serviraientelles qu'à nous procurer de telles jouissances, qu'il nous faudrait souhaiter de les voir se renouveler longtemps encore. Qu'il me soit done permis, Messieurs, d'émettre le vou de voir l'usage de nos excursions en province se continuer et fleurir pendant de longues années. L'entomologic ne peut qu'y gagner, car l'heureuse rencontre de collègues, qui ne se connaîtraient peut-être pas sans ces précieux rendez-vous amènera nécessairement une plus grande confraternité entre les membres de notre Société et sera la source des plus heureux résultats pour notre chère science.

Je sais, Messieurs, etre ici l'interprète de tous nos collègues qui, cette année, avaient le honheur de se rencontrer en Auvergne, car, en nous serrant la main une dernière fois, nous nous donnions tous rendez-vous à notre future réunion de l'année prochaine. 


\section{LISTE DES INSEGTES PRINCIPAUX}

Recucillis aux environs de Clermont et au Mont-Dor'c pendant la Session extraordinaive de Juin-Juillet 1859.

\section{COLẺOPTÈRES (1).}

Nebria Gyllenhalii. - Mont-Dore.

- rubripes et variété à pattes noires. - Puy-de-Dodme et Mont-Dore.

- Foudrasii. - Mont-Dore.

Leistus nitidus, - Id.

Carabus convexus. - Id.

- nodulosus. - Id.

- auronitens. - Id.

Cychrus rostralus. - P'uy-de-Pariou.

Dromius agilis, var. fenestratus, - Mont-Dore.

Calathus alpinus. - Puy-de-Dôme et Mont-Dore.

- gallicus. - Puy-de-Dôme.

Feronia dimidiata. - Mont-Dore.

- erythropa. - Id.

- femorata. - Id.

- amaroides. - Id.

(1) Cette liste a êtê redigée d'après les notes et les communications qui nous ont été fournies à M. le docteur Lahoulbène et à moimème par MM. Berce, Fallou, Lethierry, Nartigné et le docteur Titon. 
Imara plebcia. - Mont-Dore.

- piceu. - Id.

Harpalus honesius. - Puy-de-1)ôme.

- locvicullis et var. satyrus. - Mont-Dore.

- fulvipes. - Puy-de-Dòme.

- subsinuatus C. Rey. - Id.

Trechus amplicollis L. Fairm, - Mont-Dore.

- longicornis. - Id.

Bembidium tibiale. - Id.

- conforme. - Id.

- obsoletum. - Id.

IIydroporus lituratus. - Clermont.

Silpha nigrita et var. alpina. - Puy-de-Dòme, Mont-Dore

- carinata. - Mont-Dore.

Agathidium alrum. - Id.

Staphylinus fossor. - Id.

Oxypoda elongatula. - Id.

Anthophagus armiger. - Id.

alpinus. - Id.

Anthobium montivagum. - Id.

Coxelus pictus. - Id.

Attagenus megatoma. - Clermont.

Byrrhus ornatus. - Mont-Dore.

- fasciatus. - Id.

Sisyphus Schafferi. - Puy-de-Dòme.

Agrilus temuis, - Clermont.

- hirtus. - Id.

Athous subfuscus, - Mont-Dore.

Campylus rubens. - Id.

Limonius Bructeri. - Id.

Elater erythrogonus. - Id. 
Cryptohypnus riparius, - Mont-Dore.

Corymbites cupreus. - Puy-de-Dôme.

- aruginosus. - Mont-Dore.

Diacanthus ancus. - Id.

Atopa cervina. - Puy-de-Dome, Mont-Dore.

Omalisus suturalis. - Id., id.

Telephorus abdominalis. - Mont-Dore.

- tristis. - Id.

- obscurus. - Id.

Malachius pulicarius - Puy-de-Dôme.

Ebous thoracicus. - Id.

Enicopus truncatus L. Fairm. - Mont-Dore.

Dasytes subcneus ơ - - Puy-de-Dôme.

Xylopertha sinuata. - Mont-Dore.

Dirccea discolor. - Id.

Mordellistena pumila. - İ.

Silaria varians. - Puy-de-Dôme.

- 4-pustulata. - Id.

Meloe brevicollis. - Mont-Dore.

- proscarabcus. - Id.

Chrysanthia viridissima. - Id.

Brachytarsus varius. - Id.

Polydrosus undalus. - Id.

- planifrons. - Puy-de-Dôme.

- cervinus. - Mont-Dore.

Liophlocus pulverulenius. - Puy-de-Dôme el Mont-Dore. Molytes germanus. - Mont-Dore.

phyllobius viridicollis. - Id.

Otiorhynchus unicolor. - Puy-de-Dôme ct Mont-I)ore.

- picipes. - Id.

- fuscipes. - Id. 
Otiorhynclus sulcatus. - Poy-de-Dóme et Mont-Dore.

$$
\begin{aligned}
& \text { - } \quad \text { tenebricosus. - Id. } \\
& -\quad \text { monticola. - Id. } \\
& \text { - } \quad \text { rugifrons. - Id. }
\end{aligned}
$$

Pissodes piceo. - Mont-Dore.

Miccotrogus picirostris. - Puy•de-Dômc.

Orchestes fagi. - Mont-Dore.

Cocliodes geranii. - Id.

Acalles Navieresi. - Id.

Rhyncolus chloropus. - Id.

Clyıus rhamni. - Puy-de-Dôme.

Dorcadion meridionale. - Id.

Pogonocherus ovalis. - Mont-Dore.

$$
\text { - fascicularis. - Id. }
$$

Rhagium bifasciatum. - Id.

- indagator. - Id.

Agapanthia violacea. - Id.

Pachyta interrogationis, var noirc. - Jd.

Leptura cincta. - Id.

Donacia discolor. - Id.

- affinis. - Id.

Clythra flavicollis, - Id.

Cyaniris cyanea. - Id.

Cryptocephalus margincllus. - P'uy-de-Dòme, Mont-Dore.

Pachybrachys hieroglyphicus. - Puy-de-Dome.

$$
\text { - histrio. - Id. }
$$

Chrysomela cerealis, - Id.

Oreina vittigera. - Mont-Dore.

- cacalice. - Id.

- nivalis, var. ignita. - Id. 
Calomicrus circumfusus. - Puy-de-Dôme.

Luperus pyrencus. - Mont-Dore.

Crepidodera Modecri. - Id.

Anatis ocellata. - Id.

Mysia oblongo-gullata. - Id.

Sospila tigrina. - Id.

\section{LÉPIDOPTERES (1).}

Parnassius Apollo. - Gravenoire.

Polyommatus Chryseis. - Mont-Dore.

- Gordius. - Prairies du Capucin.

Lyccena Eumedon. - Chaudefour.

- Amynthas. - Prairies du Mont-Dore.

- Boctica. - Gravenoire.

Erebia stygne. - Prairies de la Dore.

- Cassiope. - Id.

- Dromus. - Hont-Dore.

- Manto. - Id.

Sesia tenthrediniformis. - Royat.

- chrysidiformis. - Gravenoire.

Macroglossa fusciformis. - Chaudefour.

- bombyliformis. - Id.

(1) Cette liste a été dressée d'après les notes que MM. de Graslin, Lafaury, Guenée et Fallou ont bien voulu m’envoyer.

Je dois à l'obligeance de $\mathrm{H}$. Giuenée la détermination des espèces difliciles à reconnaitre. 
Emydia grammica. - Gravenoire.

- var. A. - Jd.

Nudaria Mundana. - Partout.

Nemeophila plantaginis. - Partout au Mont-Dore.

- var. hospitu. - Id.

- var. A. - Chaudefour.

Hepiahts humuli. - Mont-Dore.

- Velleda. - Grande cascade.

Psyche albida. - Mont-Dore.

- stomoxella. - Id. et Puy-de-Pariou.

- bombycella. - Mont-Dore.

Leucania conigera. - Id., au crépuscule.

- vitellina. - Id., id.

- Comma. - Puy-de-Pariou.

Miana strigilis. - Mont-Dore, au crépuscule.

- fasciuncula (1) Haw. - ld., id.

(1) Cette Miana est spécifiquement distincte de la strigilis et de la latrancula (qui elles-mêmes, comme je l'ai éprouvé dẹuis la publication de mon Species, constituent deux espèces distinctes). J'ai vu plus de soixante individus de la fasciuncula, qui se prend abondamenent en Angleterre vers la mi-juin et qui, an Mont-Dore, parait en juillet et août, se pose et s'endort sur les fleurs de la Gentiane même pendant le jour, en sorte qu'on peut l'y saisir avec la plus grande facilité. Toutefois les poils du thorax et mème les écailles des ailes sont si peu adhérents chez celte petite espèce, qu'il est rare d'en piq̧uer un individu parfaitement intact. Malgré ces mœurs qui diffèrent complètement de celles des autres Miana, elle ne vole pas moins le soir au crépuscule avec mais un peu avant les autres Noctuelles.

La fasciuncula d'Auvergne est parfaitement identique arec celle des Pyrénées, dont j'ai des individus envoyés par Donzel sous le nom de rubeuncula et aussi avec celle d'Angleterre, mais on trouve dans ce dernier pays une variété d'un brun testacé très pâle qui constitue une petite race à part et dont j'ai vu au moins quinze indiridus 
Agrotis cinerea. - Mont-Dore.

- agricola. - Id.

- pyrophila. - Id.

- nyctimera. - Id.

- precox. - Sapins du Capucin.

Anthocelis pistacina Chen. - Mont-Dore, sur les Gentianes.

Polia cacimacula id. - Saules nains de la Cacadogne.

Epunda viminalis id. - Id.

Hadena Adusta. - Mont-Dore.

- Dentina. - Id.

Plusia iota. - Royat.

Ellopia prasinaria. - Id.

Boarmia repandaria. - Royat.

- rhomboidaria. - Id.

Gnophos furvatu. - Mont-Dore.

Psodos \{ alpinata Wien. v. - Chaudefour.

- equestrata Fab.

Geometra smaragdaria. - Gravenoire.

Nemoria viridata. - Id.

Acidalia contiguaria. - Gorges de Royat.

- herbariata Fab. - Clermont, dans nos chambres.

- microsaria Boisd.

- rusticata. - Royat.

- ossearia. - Partout.

- holosericata. - Gorges de Royat.

bien constants. Cette petite race ne se trouve pas en Auvergne, du moins il n'en a pas été pris dans notre expédition.

La synonymie de la fasciuncula s'établit ainsi :

Fasciuncula Haw., 151. - Steph., p. 15. - Wood, 280. = Rufuncula Steph., p. 14. - Wood, 279 (vix Haw.). = Rubcuncula Donz, Ann. Soc. Ent, 1838, p. 429, pl. 12. - Iler.-Sch., 499, 501. $=$ Strigilis var. G. Spec., v, p. 215.

Guenee. 
Acidalia 'decorata. - Gravenoire.

- submutata. - Id.

- promutata. - Murs de koyat.

- subsericeata. - Ravins de Royat.

- Scommulata Frey. - Forêt du Capucin.

- Initidaria Bdv.

- inornata. - Ravin de Royat.

Pellonia Calabraria. Gravenoire.

Strenia immorata. - Puy-de-Pariou.

Numeria capreolaria. - Forêts de Sapins, Mont-Dore.

- pulveraria. - Id., id.

Fidonia concordaria. - Gravenoire.

- conspicuata. - Id. et Mont-Dore.

Cleogene \{lutearia lab. - Chaudefour.

Larentia rupestrata. - Id.

- cosiata. - Mont-Dore, forets de sapins.

- salicata. - Id., id.

- frustrata. - Ravin de Royat.

- olivala. - Id.

- - pectinataria. - Fuess, forêts de sapins.

- Miaria Hubn.

Emmelesia falchemillata Lin. - Mont-Dore, au crépuscule.

- Yrivulata Wien.-Verz.

- albulata. - Prairies du Mont-Dore.

- Blandiata. - Mont-Dore, forets de sapins.

Eupithecia venosota. - Id.

- libanotidata. - Id., au crépuscule.

- coronata. - Gravenoire.

Thera variata. - Mont-Dore, forets de sapins.

- jvar. vitiosata Frey. - Forets du Capucin.

- Stragulata Bdv., 1794. 
Melanippe iristata. - Mont-Dore.

- montanata. - Royat.

- molluginata. - Mont-Dore.

- galiata. - Id.

- alpicolaria. - Id.

Coremia mropugnata. - Cascade du Serpent.

Scotosia dubitata. - Mont-Dore.

Cidaria Russata. - Id.

- fulvaria. - Id.

- suffumata. Forêt du Capucin.

Eubolia pulumbaria. - Partout.

var. $B$ du Species général. - Puy-de-Pariou.

Anaitis praformata. - Mont-Dore.

Tanagra chorophyllata. - Gravenoire.

Herminia tentaculalis. - Plaine de la Barraque.

Botys flavalis. - Gravenoire.

- hyalinalis. - Id.

Scoparia sudeticalis. - Mont-Dore.

Crambus conchellus. - Foret du Capucin.

- petrificellus. - Id.

Lampros nubilosella Herr.-Sch. - Id.

Scopula opacalis. - Mont-Dore.

Argyroptera Gouna. - Foret du Capucin.

Scraphila cinclana. - Sapins du Capucin.

Adela inauratella. - Id. 


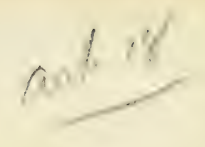

\section{DESCRIPTION}

\section{DES \\ MÉTAMORPHOSES DU DASYTES CGERULESS,}

Par M. le $\mathbf{D}^{*}$ Alexandre LABOULBËNE.

(Séance du 12 mai 1858.)

Au commencement du mois de novembre de l'année dernière, j'ai ramassé, dans le parc réservé de Meudon, des branches mortes, tombées à terre, couvertes de lichens. I.e bois en étuit mou, blanchatre, décomposé; elles étaient faciles à briser. J'en ai rompu un grand nombre et j'y ai trouvé une nymphe placée dans une petite loge oblongue, creusée dans l'épaisseur du bois.

Cette nymphe, que je connaissais peu, a piqué ma curiosité. J'en ai réuni une douzaine et j’ai eu soin de recueillir les dépouilles de larve qui se trouvaient à l'extrémité de leur corps, dans la meme loge. Malgré mes recherches, je n'ai pu me procurer la larve vivante, l'époque de l'année étant trop avancée, et la transformation ayant eu lieu; mais j'ai, dans une loge, pris les débris d'un insecte parfait, enveloppés de moisissure, et j'ai pareillement pris trois larves desséchées, entièrement couvertes de la même production cryptogamique.

Il m'a été facile de reconnaître, dans les débris de l'insecte parfait, un Dasytes, et par sa taille et ses couleurs je l'ai rapporté au cœruleus. D'autre part, j'ai trouvé, le 14 mars 
1858, un insecte éclos dans le vase oủ j'avais placé les morceaux de bois ramassés. Enfin, les nymphes déposées dans la sciure de bois ont produit toutes le meme insecte et, chose peu ordinaire, sans quaucune d'elles fùt piquée par un parasite.

Il n'y a donc pas de doute à avoir sur la légitimité de l'espèce. Quant à la larve, que je n'ai point vue vivante, je l'ai dessinée d'après les dépouilles rejetées au moment de la métamorphose en nymphe et d'après les trois individus débarrassés de leur moisissure.

Les détails que j’en donne sont faciles à apprécier sur les dépouilles, ils sont même d'une netteté remarquable.

Le bois dans lequel cette larve a vécu m'a paru etre du chene.

S Ier. Lanve (voyez pl. 13, no I, fig. 1 à 9).

Larve allongée, élargie en arrière; à peine ou point convexe; composée de douze segments, la tete non com prise, à poils blanchatres, assez longs. D'un blanc jaunatre, avec une teinte rosée ou rougeatre en dessus, la tete et le dernier segment brunatres, une tache latérale de cette couleur sur chaque segment du thorax et une ligne ombrée de chaque colé de l'abdomen (fig. 1).

Tête peu grande, un peı bombée, presque carrée, cornée, brune, en arrière surtout, avec de petits points sans coloration de chacun desquels sort un poil blanchatre; deux sillons peu apparents sur les côtés et réunis en arrière formant une sorte d'Y de couleur claire, blanchatre. Bouche d'un testacé roussatre.

Antennes courtes, composées de quatre articles presque de meme grandeur, le premier large, le troisième suppor- 
tant en dedans un quatrième article allongé, terminé par un long poil et, en dehors, un mamelon très court, ou article supplémentaire (fig. 2).

Ycux situés latéralement, formés par cinq ocelles, très visibles, disposés ainsi que l'indique la figure 3 , qui les montre vus de profil sur le côté gauche de la larve. Ces ocelles ou stemmatcs sont un peu bombés, luisants, dépourvus de pigment sur la dépouille de la larve et entourés d'une ombre brune qui les rend très distincts.

Labre arrondi ou subarrondi en avant, avec des poils nombreux; il est uni avec l'épistôme, en arrière, par une suture bien marquée (fig. 4). Epistôme étroit, presque transversal.

Mandibules ferrugineuses, à peine saillantes, fortes, noiratres ou brunatres à leur extrémité; 4-dentées au côté interne (fig. 5 et 6 ). Les quatre dents sont disposíes sur deux lignes, les supérieures sont les plus fortes.

Michoires allongées, à lobe interne fixe, ayant une lırosse de gros poils au sommet; palpe externe de trois articles, lo premier large, le deuxième arrivant à la hauteur du lobe, le troisième arlicle le plus grêle et le plus allongé (fig. 7).

Lìve infirieure très petite, avec deux très petits palpes biarticulés (fig. 7).

Segments thoraciques presque carrés; le premier le plus grand de tous, trapézoïde, avec plusieurs taches noiratres, les deux suivants ont de chaque coté une grande tache luisante noiratre, en forme de virgule (fig. 1). Chaque segment thoracique porte une paire de palles à peine roussatres ou brunatres aux articulations, de cinq articles, le dernier consistant en un crochet unique corné, ferrugincux (fig. 8). 
Segments abdominaux un peu arrondis sur les côtés, les premiers, à partir du thorax, plus étroits que les suivants; tous offrent de longs poils blanchatres plus marqués latéralement; les premier et huitième ont une tache ombrée, légère, brunatre, de chaque côté de la ligne médiane, elle est moins nette sur le huitième segment. Cette tache est, en outre, comme partagée en deux par un trait transversal, une sorte de pli.

De chaque côté de l'abdomen paraît devoir exister un bourrelet (peu marqué sur les larves que j'examirie), et en dehors, une tache brunatre légère. Le neuvième segment abdominal, qui est le douzième du corps de la larve, a la forme d'une grande plaque brune, cornée, largement canaliculée, couverte d'aspérités, échancrée en arrière, où elle forme ainsi deux crochets convergents, mais dont la pointe est brusquement relevée en haut et d'une teinte plus claire (fig. 9).

Sur la dépouille de la larve, cette plaque brune, ou dernier segment, est fortement appliquée sur la face rentrale, et la tête est repliée de méme, de telle sorte que ces deux parties sont rapprochées.

La tete est fendue ainsi que les segments thoraciques, le premier au moins, el c'est par cette ouverture que la nymphe s'est dégagée. La dépouille chiffonnée de la larve reste ordinairement attachée aux derniers segments de la nymphe qu'elle cache.

Les stigmates sont brunatres. Le premier est très positivement situé en dessous et au bord antérieur du inésothorax (fig. 1, s), les autres, au nombre de huit, sont les six premiers, sur le tiers antérieur des quatrième, cinquième, 
sixième, septième, huitième, neuvième segments; les septième et huitième vers la moitié de la longueur des dixième et onzième segments.

Le dessous du corps de la larve est blanchatre, le dernier segment est brun.

La loge construite par la larve pour y subir ses transformations est oblongue, ovoüde, placée dans le sens de la longueur du bois. Elle est siluée au fond de galeries plus étroites, oú se voit de la sorte une chambre terminalc. L'extrémité des galeries est remplie d'une poussière de bois très finc, et leur orifice est ouvert à l'extérieur par un trou qui paraît anciennement fait.

J'ai trouvé dans plusieurs morceaux de bois des provisions de Diptères de la famille des Tipulaires, accumulés en grand nombre. Ce sont très probablement des IIyménoptères, des Crabronides qui ont amassé ces provisions pour leurs larves, et qui sont les auteurs de la majeure partie des galeries peu sinueuses, presque droites. On trouve dans Réaumur la description de ces magasins de Tipules et de Diptères entassés. La larve du Dasyles cocruleus est peutetre un parasite des larves de Crabronites pendant les premiers temps de sa vie, et, plus tard, clle creuse à l'estrémité des galeries une loge dans le bois décomposé et très friable. Il faut, du reste, que le bois offre peu de résistance à l'insecte parfail et que la sciure ne soit pas trop tassée pour qu'il puisse sortir au dehors. J'en ai aperçu un grand nombre morts au fond de leurs galeries, probablement parce que le bois s'était desséché dans mes boltes et n'avait plus la souplesse qu'il conserve dehors à l'air libre et bumide.

M. le Dr Aubé m'a dit avoir trouvé assez fréquemment. au premier printemps, dans la forêt de Saint-Germain, dans 
des branches de bois de chenc, très décomposées, blanchatres à l'intérieur, des Dasytes cocrulcus, récemment transformés. II a vu, dans ces mèmes branches, des Elatérides, entre autres le Cratonychus brumnipes. Le savant entomologiste croirait volontiers que le Dasytes serait à l'état de larve parasile de quelque Elatíride.

Je dois encore ajouter qu'il y a plusieurs années, j'ai, en compagnie de mon ami Líon Fiarmaire, rencontré dans la meme foret de Saint-Germain, à la mème époque des $\boldsymbol{D} a$ sytes corulcus, récemment éclos dans des branches de bois décomposé. Il y avait avece eux des larves et des nymphes d'Asiliques du genre Laphria.

S II. Nympie (roy. pl. 13, no I, fig. 10 d̀ 13).

Nyurpire très allongée, presque parallèle $\sigma^{*}$, d'un blanc jaundtre et un peu rosé ou rougeatre, avec des poils blanchatres. Deux séries de taches brunatres le long du dos et de l'abdomen, celui-ci terminé par des appendices.

Tête penchée sur la poitrine, offrant les parlies de la bouche étalées.

Yeux noirs.

Antcrnes replićes, longues, se rejoignant en avant.

Prothorax arrondi en avant et en arrière; ailes étroites enveloppant le corps; à peine débordées par les pattes, qui sont minces et ont leurs tarses étendus, articulés visiblement, mais sans saillie des ongles.

Abdomen de huit segments. Chacun d'eux porte sur les côtés et en arrière un bouquet de poils allongés. Des poils semblables existent sur la tete et le corselet. I.e dernier 
segment offre deux appendices très poilus (fig. 12 et 13), épais à la base, terminés par un petit crochet recourbé en arrière, vers la face dorsale de la nymphe. Ces appendices rappellent ceux de la larve situés au mème endroit.

J'ai dit que cette nymphe était presque parallèle, cela est vrai le plus souvent. Quelques-unes cependant sont plus élargies vers le milieu de l'abdomen, et sur ces dernières on trouve à l'extrémité, outre les deux appendices (fig. 12) dont j'ai parlé, deux nouveaux appendices situés en avant des premiers (fig. 13). Je regarde ces nymphes à quatre appendices comme devant produire des insectes femelles, et celles à deux appendices seulement comme appartenant au sexe male.

Je crois aussi que les larves les plus grosses et les plus élargies en arrière doisent appartenir aux femelles, mais je l'admets par hypothèse, sarıs en avoir la preuve directe.

Les insectes parfaits sont écios vers le milieu de mars, et jusqu'a la fin de ce mois dans mes bolles. Peut-ctre l'éclosion est-elle un peu plus tardive au dehors.

\section{\$ III. Insecte panfait.}

Dasytes caruleus, Fabricius, Syst. Entom., p. 70, no 5 (IIispa), 1775.

Anobium cyanœum, FAB., ibid. 63, no 6.

Allongé, un peu élargi en arrière, déprimé et d'un bleu foncé verdatre, ou un peu violet en dessus; d'un vert assez brillant et métallique en dessous. Antennes et jambes noi- 
ratres. Entièrement couvert en dessus d'une pubescence droite et noirdtre; ponctuation forte, surtout sur les élytres, dont l'extrémité est assez arrondie. - Long. 6 mill.

\section{S IV.}

M. Edouard Perris a fait connaitre dans ces Annales $(1854,599)$ la larve et la nymphe du Dasyles flavipes FABricıus. Elle est très voisine de celle que je viens de décrire.

Avant les observations de M. Perris, il n'existait dans la science qu'une description de la larve du Dasytes serricornis, par M. Waterhouse. (Entomol. mag., II, 375, pl. X, fig. 1-2, 1835.)

M. Westwood, dans son Introduction à une classification moderne des Insectes, I, 260, dit qu'Audouin avait trouvé, dans le bois pourri, la larve du Dasyles plumbeus.

Explication des figures de la planche $13, n^{\circ} \mathbf{I}$.

Fig. 1. Larve du Dasyles cocrulcus Fabricius, grossie, et, à côté d'elle, mesure de sa grandeur naturelle.

2. Antenne de cette larve très grossie ainsi que les figures suivantes.

3. Ocelles vus sur la larve, de profil (côté gauche).

4. Labre et épistôme.

5. Mandibule (côté gauche de la bouche) vue en avant après l'enlèvement du labre.

6. La meme mandibule vue en arrière, montrant les deux dents apicales et le condyle articulaire. 
Mélamorphoses du Dasytes cremuleus.

7. Mâchoires et lèvre, vues en dessous.

8. Une palte.

9. Dernier segment abdominal montrant l'extrémité brusquement relevée des deux crochets cornés.

10. Nymphe grossie du Dasytes cerulcus vue par le dos, et, à côté d'elle, mesure de sa grandeur naturelle.

11. La même nymphe vue par la face ábdominale. Cette nymphe est celle d'un male.

12. Extrémité de l'abdomen très grossie de cette nymphe dans le male.

13. Extrémité de l'abdomen fort grossie, d'une nymphe femelle montrant quatre appendices, deux antérieurs et deux postérieurs. 


\section{NOTE}

SUR LES

CARONCULES THORACIQUES OU COCARDES ROUGES

vข

\section{maLACHIUS BIPUSTULATUS,}

Par M. le $D^{r}$ Alexandre LABOULBîne.

\section{Congras de Arenoble.}

(Séance du 7 Juillet 1858,)

Tous les entomologistes et beaucoup de gens du monde connaissent les organes singuliers, les Caroncules ou Cocardes rouges, que les Colćoptères du grand genre Malachius font sortir de leur corps, quand on les saisit. Les altributions physiologiques de ces organes essertiles sont encore un problème, et je ne connais aucun travail spécial qui ait été fait sur leur structure et leur texture anatomiques.

Cette année, pendant l'excursion annuelle de la Société entomolugique de France, qui a cu licu à Fontainebleau le 6 juin, j’ai recueilli, avec l'aide de mes chers collègues, MM. Aubé, Reiche, Léon Fairmaire et Kraatz, un grand nombre de Malachius bipustulatus Fabricios, dans le but d'étudier les organes qui font le sujet de cette note. Je viens actuellement soumettre le résultat de mes recherches à la Société. 
LA DouldĖes. - Carone. thorac, du Mal. bipustulatus. 523

\section{Description extérieure des Caroncules.}

Les Malachius bipustulatus font sortir, de chaque coté de leur thorax, quand on les prend ou quand on les inquiète, des organes rouges, sous forme de prolongements ou de caroncules.

Le point précis de cette exsertion est, en avant, l'angle antérieur du corselet, près de la tete, en arrière le point de séparation du métathorax avec l'abdomen, en empiétant toutefois sur le thorax. L'une des saillies est par conséquent post-céphalique, l'autre anté-abdominale (voyez la figo. 1, pl. 12, no II).

On sait que les téguments des Malachius sont peu cornés avec leurs articulations lâches, mobiles. En ces endroits l'espace articulaire est très élargi, aussi la sortie des caron. cules a-t-clle lieu avec la plus grande facilité.

La forme des deux organes céphalique ou abrlominal différe. La caroncule antéricure, celle du côté de la tête, est trilobée, la caroncule postérieure, située vers l'abdomen, est seulement bilobée. Leur base est largement sessile, les prolongements un peu inégaux. Les insectes ne font pas toujours saillir au dehors ces organes dans leur maximum d'expansion; mais, quand on presse leur corps de manière à produire cet effet, on trouve sur la caroncule post-céphalique la trifurcation $a$ (voy. $6 \mathrm{~g}$. 2) situee en arrière, plus longue que les deux antérieures.

La couleur des organes qui nous occupent est d'un beau rouge, un peu orangé. On remarque (fig. 2 et 3 ), un sillon léger, triangulaire (fig. 2) ou linéaire (fig. 3) sur les caroncules, au point correspondant à leur base. Ces sillons, bien marqués pendant le retrait des organes exsertiles et que j'ai 
représentés ì la place qu'ils devraient occuper, s'effacent pendant la distension extreme.

Si on veut connaître comment les Malachius font sortir les prolongements de leur corps, on s'aperçoit qu'ils cmploient le procédé des Ilelix pour leurs tentacules oculaires. Les insectes refoulent au dehors une sorte d'extrémité de doigt de gant qui serait rentrée en dedans.

Pour savoir si ces organes exhalaient quelque odeur spéciale, j'ai un très grond nombre de fois soumis ces insectes á l'observation directe. Jamais je n'ai perçu d'odeur sortant de leur corps au moment de l'expansion des caroncules. Mes collègues, déjì nommés, n'ont pas trouvé d'odeur sensible en répétant l'expérience.

Les Malachius réunis en grand nombre et bien vivants, dans un tube de verre parfaitement propre, ont été effarouchés, irrités. Ils faisaient fortement saillir leurs cocardes sans produire, pour l'un de nous tous, d'odeur sensible. Cependant, en pareil cas, s'il y avait eu une odeur légère, trop faible pour etre pergue avec un seul insecte, celte odeur très multiplice, accrue par leur grand nombre, aurait dû frapper notre odorat.

Le Malachius bipustulatus n'est pas le seul dont j'aic examiné les caroncules. Le Malachius elegans Ouvien, en possède d'identiques et d'un beau jaume orangé; les petits Malachius pulicarius Fabricies, Anhocomus equestris Fabuicres, Eberus thoracicus Fabrici:3, en ont parcillement et elles sont presque semblables.

Ces organes ont-ils des analogues dans les autres genres d'Insectes Coléoptères. Cela me parait évident. Je citerai les cxemples qui suivent, à l'appui de mon opinion.

Je n'hésite point à regarder comme analogues aux caron. 
cules thoraciques des Malachius les saillies abdominales et si fortement odorantes de la plupart des grands Staphylinides, dont le $S$. olens Linsi, peut etre pris pour type.

Je mets près d'elles les bourses abdominales, en cœeum, décrites par M. Léon Dufour pour les Blaps (Am. Sc. Nat. $1^{\text {re }}$ série, tome viI, p. 18, pl. 20, fig. 9) et celles qu'il vient récemment de faire connaître chez le Misolampus puncticollis (Annales des Sc. Nıl., $4^{\mathrm{c}}$ série, Zool., tome Ix, p. 16, pl. 2, fig. 7 et 8).

Mais, en admettant l'analogie de ces organes divers (1), pouvons-nous préciser leur role physiologique?

Les Staphylinides, et parmi cux les plus odorants, relèvent fortement l'abdomen en faisant saillir leurs bourses, exhalant l'odeur de l'éther, du chloroforme, de l'ammoniaque, etc.; ils les dirigent vers l'objet qui les effraic. Les moins odoriférants se conduisen! de meme. Leurs organes exsertiles paraissent ctre soit des moyens de défense, ou micux encore des moyens d'effrayer ou de produire du dégoût chez leurs ennemis.

Je m'arreterais à ces deux dernières hypotheses pour le rôle physiologique des caroneules ou cocardes des Malachius, ct je ne serais pas surpris qu'il s'échappat de ces organes une odeur insaisissable pour l'odorat liumain, mais sensible pour d'itutres animaux, contre lesquels les Malachius ont à se défendre.

(1) M. de Siebold est incertain s'il faut placer parmi les organes des sens et en particulier du toucher les organes mous, protactiles et souvent d'une belle couleur rouge ou orangée, que les Maluchius possèdent sur les parties latérales du corps (Manuel d'anatomic comparce, Roret, tome ${ }^{\circ e}$, page 565 , note 5). 


\section{Structure et texture des Caroncules.}

Si on détache, au moyen d'un coup de ciseaux, les caroncules au moment de leur extension, puis, si on les place entre deux lames de verre sous divers objectifs d'un microscope, on voit qu'elles sont composées d'une enveloppe complexe et d'un contenu.

L'enveloppe est formée dans sa partic la plus externe par une fine membrane paraissant amorphe, incolore, et sous laquelle est déposée une couche de pigment rouge, sous forme de fines granulations.

Ces granulations pigmentaires sont agitées d'un vif mouvement brownien.

Au point où l'enveloppe ne rentre pas sur elle-même, vers les parties centrales, là oủ se produisent les sillons dont j'ai parlé, on trouve des prolongements de l'épiderme sous forme de poils (fig. 4).

Sous celte enveloppe extérieure existent des faisceaux nusculaires, ayant deux directions principales; les uns transversaux et comme annulaires, les autres longitudinaux se terminant parfois en se croisant en anses avec ceux du côté opposé.

Ces deux ordres de faisceaux, quelle que soit leur direction, sont formés de fibres musculaires, visiblement striées en travers, appartenant à la vie animale et soumises à l'empire de la volonté (voy. fig. 4).

Ces fibres sont fortement marquées à la base des caroncules, où les faisceaux prennent un appui.

En résumé; membrane épidermique, pigment, couches de fibres musculaires formant des faisceaux longitudinaux 
et transversaux, telle est la texture de l'enveloppe des caroncules.

Le contenu est composé par un liquide peu coloré, presque transparent ou hyalin, avec des granulations moléculaires ct des sachets adipeux (1). Y a-t-il un liqquide spécial pour ces organes produisant leur exsertion, ou bien le liquide nourricier y pénètrc-t-il comme dans les autres parties et cavités du corps? J'adopte celte dernière opinion et je crois que la sortie des cœeum des caroncules est due principalcment à la contraction des faisceaux musculaires transversaux ou annulaires. Je pense également que leur rétraction est produite par la contraction des faisceaux longitudinaux. II ne me parait pas nécessaire qu'un liquide spécial vienne distendre ces organes par sã présence et les laisse flétris et rentrés en cux-mèmes par sa disparition.

(1) J'ai vu aussi, à plusieurs reprises, dans ce liquide des corps ovoides ayant une membrane d'enveloppe bien marquée, assez forte, ct un contenu granuleux sous forme de gouttelettes ou de granulations graisseuses, arrondies, offrant laspect, la réfraction ordinaire des corps gras. J'avais déjì, en 1849, en dissérquant des Anobium (voy. Ann. Soc. Ent. de Fr., 1849), trouvé des corps pareils; c'est pour moi le deuxième cxemple de leur présence dans la cavité alb. dominale des insectes Coiéoptères. Je ne sais encore ce que peuvent ètre ces corps ovoïles.

On ne peut les regarder comme des œufs de Malachius, car ils ne sont pas ì la place ordinaire des œufs, ils n'en ont pas exactement la forme et ils existent chez les mâles comme chez les femelles de ces insectes.

Ai-je en sous les yeux les œufs de quelque parasite?

Est-ce une forme particulière de tissu graisseux ou adipeux splanchnique? En ce cas, il serait loin d'oftrir la forme ordinaire du tissu graisseux on adipeux des autres insectes Coléoptères. 
528 A. LA Botlbène- Caronc. thorac. du Mal. bipustulatus.

Explication des figures de la planche 13, no II.

Fig. 1. Malachius bipustulatus Fabnicies, grossi, vu de profil, sur le coté gauche du corps et faisant saillir les caroncules thoraciques. $\mathbf{A u}$-dessous de lui mesure de sa grandeur naturelle.

2. Caroncule antérieure ou post-céphalique très grossie; $a$ son prolongement ou la trifurcation postérieure.

3. Caroncule postéricure ou anté-abdominalc.

4. Caroncule extrêmement grossic, montrant au milieu les saillies piliformes à l'endroit du sillon de rétraction et les faisceaux musculaires striés en travers des prolongements. 


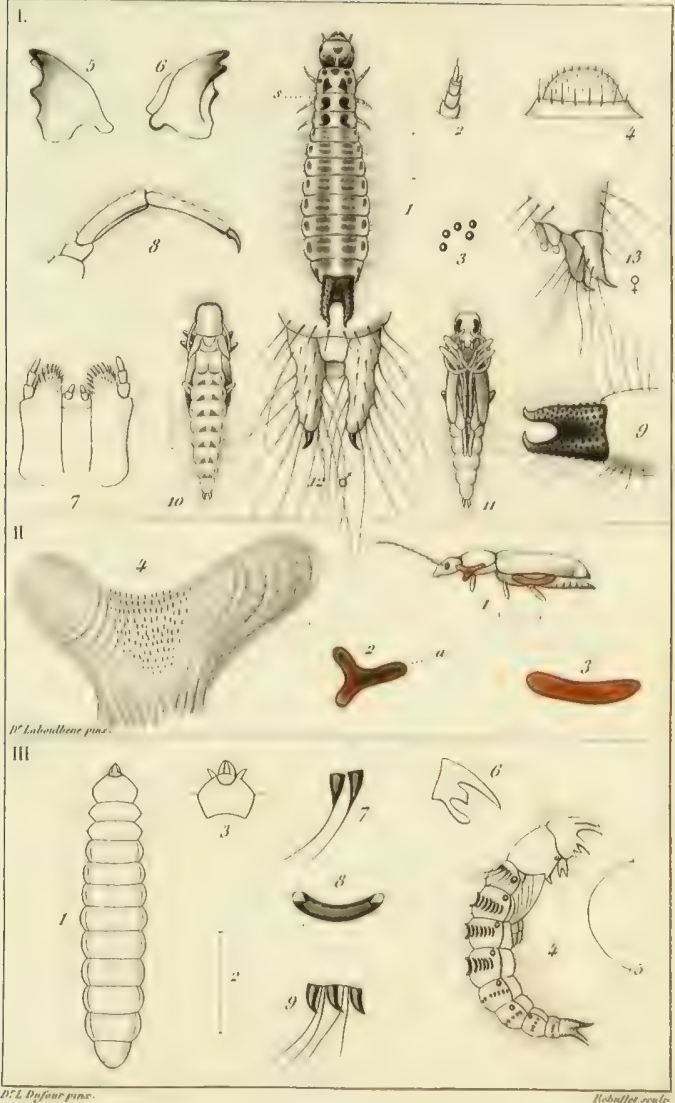

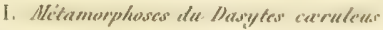

II. Cerroncules thoracigues du Halachiug biplertulutur.

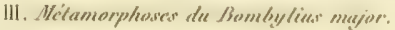





\title{
MÉTANORPIIOSES D'UNE MOUCHE PARASITE
}

\section{Tuchina (Maslcera) vilica.}

\author{
Par M. le Dr AL. LABOULBÈNE.
}

(Séance du 24 Aout 1859.)

Ies insectes parasites qui vivent dans le corps des autres insectes excitent toujours l'admiration du naturaliste. Les lois de pondération des espêces les unes par rapport aux autres, l'accroissement exubérant des individus maitrisé par des ennemis naturels, sont dignes de nos méditations. Malheureusement, l'histoire complete du parasitisme entomologique ne pourra étre établie avant longtemps, quoique la science possède déjà des matériaux nombreux : Le parasitisme de plusicurs familles d'insectes a été constaté rigoureusement; l'étude des mocurs et des mélamorphoses, la vérilable histoire naturelle, telle que l'ont comprise les swanmerdann, les Réaumur, les De Giè, les Léon Dufour, ete., a doté l'entomologic d'inestimables travaux sur ce sujet.

Parmi les parasites, les Diptères offrent à l'observateur un grand nomJre d'espèces vivant à l'état de larve dans le corps des autres insccles. Ia populeuse tribu des Tachinaircs de Macquart présente tout entière ces mours créoplages spéciales, aussi liol)ineau-Desvoidy avait-il créé le nom d'Entomobics pour les Diptères de cette tribu.

Il est très facile de constater le parasilisme des Tachinaires : les chenilles édevées en captivité produisent souvent autant de ces Muscides que de liépidoptères à l'état parfait; les Coléoptères et les Ilyménoptères (1) ne sont point à l'abri de leurs attaques; les Hémiptères (2), les Ortlrop-

(1) Масеиат, Nouvelles observations sur les Diptères d'Europe de la tribu des Tachinaires (Aun. Soc. Lit. France, 1849, p. 355; 1850, p. 437, et 1854, p. 417). - Zejtenstent, Diptera Scandinavia, t. III, 1844. - Voy. aussi Westwoon, An introduction to modern classification of Insects, t. II, p. 567, 1830.

(2) LÉon Dufuæn, Annales des Seiences naturelles, t. X, p. 218, Pl. X1, 1827. - Ann. Soc. Ent. France, 1818, p. 427 et xciv. 
lères (1) cux-mènes ne paraissent point épargnés el probablement les insectes de tous les ordres nourrissent des larves de ces Dipteres parasites.

Mais s'il est facile de constater leur parasilisme, il ne l'est pas autant d'observer l'insecte à l'état de larve, car celle-ci se cache dans le corps de sa victime. A peine cetle larve en est-elle sortic, qu'elle se transforme en pupe avec une étomante rapidité. Le moment opportun pour la saisir est très court.

Je dois à mon ancien collegue $\mathrm{M}$. Villeneuve d'avoir pu éludier la larve de la Tachina villica, espece qui peut rentrer dans le genre Masicorc de Macquart. C'est en faisanl, au moyen d'une serre chaude, éclore prémalurément des Lépidoptères que V. Villeneuve avait remarqué un grand nombre de pupes provenant de chrysalides de la Noctua (IIademu) brassica: LiNw., et il m'avait donné les Diptères qui en étaient éclos. J'engageai M. Villeneuve a rechercher les larves; il s'assura que celles-ci it peine sorlies des chrysalides se métamorphosaient en pupes. Celle transformation s'effectuait même quand on plongeait les larves dans l'alcool. Or, c'était au moment de leur sortie que ces larves adultes ou a leur maximum de développement étaient intéressantes à étudier ; j’ai conseillé à M. Villeneuve de les plonger dans de l'alcool renfermant une pelite quanlite de nicotine el le succès a été complet, les larres sont morles aussitòt sans se transformer.

Je vais décrire successivement les trois élats de la Tachina villica, c'est à dire: $1^{\circ}$ la larve, $2^{\circ}$ la pupe et $3^{\circ} l^{\prime}$ insecte parfait.

\section{S 1. LaRve (Voy, pl, 6 fig, 1 à 8 ).}

LARVA accphala, griseo-albida, cylindrico-conica, pauto incurvalu, anlice subattemuta, postice oblique Iruncatn, glabra, mandibulis nigris, sligmatibus anticis 4-parlitis scu digilatis, haul exserlis, posticis frre rolundatis in cavorna profunda sitis. - Longitudo quinque lincas aquat (11 à 12 millim.).

Inbitat parasitica in tarvis nec non chrysalidibus Noctux (IIadenx) brassica.

IAARVE d'un blanc grisatre ou un peu jaunatre, acéphale ou plutòt pseudocéphalée, cylindrique et un neu conique, légèrement recourbée avee la partie antérieure subatténuée, dirigéc en bas, et l'extrénité postérieure

(1) LÉon bufoun, Souvenirs et impressions de volyage sur des excursions pyrínéennes, etc. (Actes de la Société Linnéenne de Bordeaux, l. XV, 1. 142, 18:7-49). 
obliquement tronquéce et relevée (fig. 1). Corps composé de onze segments, le pseudocéphale non compris. Le vscudocépluale offre 2 mandibules noires souklées à leur partie moyenne, à base divergente dans l'intérieur de la larve, mais dont les deux pointes écartées et aiguès sortent au dehors (fig. 2 et 3 ).

Au-dessus et de chaque côté des crochets mandilubaires est une saillie représentant une antenne ou un palpe et de plus sur la ligne médiane on voit une légère excavation (fig. 3). Le premic) segment renferme de chaque côté contre son bord postérieur, presque dans le pli qui sépare ce segment du $2^{\circ}$, l'orifice des stigmates antérieurs. Les sligmales (fig. 2, 3, ct 6,7,$)$ ont la forme de 4 points ou cercles arrondis quand on les regarde de face, mais de profil (fig. 7) et comprimés entre deux lames de verre, on trouve qu'il se détache d'un trone commun quatre digitations dont l'extrémité est perforée. Les $2^{\mathrm{e}}, 3^{\mathrm{e}}, 4^{\mathrm{e}}, 5^{\mathrm{e}}, 6^{\mathrm{e}}, 7^{\mathrm{e}}$ segments n'offrent rien de special, mais les $8^{\circ}, 9^{\circ}, 10^{\circ}$ ot $11^{\mathrm{e}}$ sont mamelonnes sur leurs hords latéraux, le $11^{c}$ obliquement tronqué d'avant en arrière montre les stigmales postiricurs situc's au fond d'une carerne stigmatique (fig. 4). Ces stigmates sont presque arrondis, légèrement ovalaires ot leur surface prísente à la loupe l'apparence de 3 saillies longitudinales. Un de ces stizmates arraché, rêclé sur la surface adhérente au corps el placé sous la lentille d'un microscope, donne par transparence l'aspect de la figure 8.

On observe enfin, en dessous el bordant la caverne stigmatique, un demi-segment ventral ou une sorte de pannicule disposé en croissant irrégulier et trilobé (fig, 1 el 4 ).

Celte larve est glabre à la loupe, mais a un grossissement plus fort on tronve près des bords anterieur el extérieur des segments el au point un peu renflé où ils s'unissent, des asper rités texminées en pointe mousse, et mèm de très pelits erochets qu'on voit représentés, lig. 5, an bord lateral de's segments. En dessous sur la partie médiane, on trouve des espaces elliplicfues, ou plutôt en forme de navelte de tisserand, qui servent comme les asperites que je viens d'indiquer à la progression de la larve (fig. 5).

L'élude de celte larve est intéressante à plus d'un tilre; je diviserai ce rue j'ai à dire sur son organisation et sur son genre de vie en deux articles distincts.

I. Les larves des Muscides sont acéphates ou privées de tête, par rapport aux larves des Culicides et des antres tribus de Dipteres placées at premier rang de cel ordre d'insectes. On ne leur trouve en ellet que des mantibul's rétractiles el des corps charnus tantòt latcraux, tantòt placés au des:us de celles-ci comme dans notre larve de Trathina. Faut-il 
regarder ces appendices comme labiaux et leurs prolongements comme des palpes parfois bi-articulés. Mr. Léon Dufour est porté à leur donner cette signification (1) et M. Perris les appelle nettement des palpes (2). Doiton y voir l'analogue d'un chaperon et d'antennes rudimentaires ou de màchoires avec leur palne ? Réaumur avait désigné ces corps charnus sous l? nom de cornes mousses.

J'avoue mon embarras à leur égard; on ne peut se dissimuler que dans notre larve les parties en litige sont superposées aux mandibules, mais dans d'autres, décrites par M. Léon Dufour dans son beau mémoire précité sur tes larves fongivores de Dipteres (loc. cit. pl. II, fig. 52 et pl. III, fig. $81)$, les appendices charnus sont sur les parties latérales. D'ailleurs je n'ai pu observer que la larve morte et je n'ai pas pu juger de la position qu'offrent ces organes litigieux pendant la vie. Quoiqu'il en soit, l'expression de larves acéphaties n'est pas absolument exacte et c'est ce qui m’a fail dire le psrudocíphale en décrivant la larve actuelle de Tachina. II. Léon Dufour a lui-mème dans sa description de la larve du Subula citripes (Ann. Sc. nat. $3^{e}$ série, t. VII, p. 6, pl. 17, fig. 13, 1347) employé l'expression de "pseudocéphale. n Dans cet insecte, en effet, les mandibules sont accompagnées d'un museau ou promuscide et d'éminences parliculières. Dans la larve de la Geriu conopsoides (Ann. Soc. Ent. France, 1847, pl. 1, fig. 1 à 3), il parait y avoir quatre appendices jumeaux, palpiformes, tronqués et noirs.

Les mandibules rétractées sont soudées dans l'intérieur du corps et leur hase est très divergente. Celte soudure est-elle intime et $\mathrm{y}$ a-t-il fusion des deux crochets et une tige unique bifide en arrière et en avant ? Il m’a semblé que chaque mandibule était distincte, adossée seulement à sa congénère et attachée contre elie par un ligament très fort et très

(1) I.íox Dufoun, Mimoire sur les métamorphoses de plusieurs larves fongivores appartenant à des Diptères (Ann. des Sc. Natur., $2^{e}$ série, t. XII, П. 14, 1839, et 3e série, t. I, p. 367 , pl. 16, fig. 1, 184i). - Voyez encore diver's Mémoires et leurs figures dans les Annales de notre Societé, 1815, p. 208, pl. 3, fir. 2 a $; ; 18 i 7$, p. 22, pl. 1 , fig. 1 et 3 , etc. Et de plus dans les Miemoires de la Socicté des Sciences, de l.1griculture et des irts de Lille pour l'année 1815, les figures relatives aux larves de l'Eumerus anous et des Drosophila Reaumurii et maculata, p. 197 et suiv., fig. 2, 6, 12.

M. Léon Dufour n'a pas hésité à donnè le nom de lèvre bifide, ayant au còté interne deux palpes bi-articulés, aux corps latéraux charnus de l'apparcil buccal clicz la Sarcophaga hamorroidalis (Études anatomiques et physiologífues sur une Mouche, etc. Mémoires présentés par divers savants à l'Academie des Sciences de l'Institut, elc., t. IX, p. 549, pl. 1, lig. 1 et 2, 1846).

(2) E. PERHus, IVistoire des métamophoses de quelques Diptères (Mémoires de la Société des Sc., de l'Agr. et des Arts de Lille pour l'amée 1850, p. 118 el suiv. et lig. 1 à 21 . 
serré. Je recommande aux observateurs ce point d'étude sur de plus grosses larves. Dans tous les cas les deux mandibules ne jouent pas isolément et clles sont fortement unies l'une à l'autre.

Les stigmales méritent de nous arrèter. Ces organes respiratoires dont on ne peut plus négliger l'étude scrupuleuse depuis que M. Léon Dufour a fait valoir leur variabilité et leur curieuse structure diffèrent heaucoup suivant les espèces. Notre larve a les stigmates antérieurs silués dans la rainure qui sépare le premier du deuxiène segment, il est probable que sur la larve vivante on trouverait que c'est un peu en avant de cette rainure qu'est l'ostiole respiratoire; il en est ainsi dans la plupart des larves de Muscides. Ce stigmate se termine par quatre digitations perforées (fig. 6 et 7). M. Léon Dufour a complé quinze diritations au stigmate antérieur sur la larve de la Sarcophaga hrmorrhoidalis (loc. cit. pl. 1, fig. 3); dix chez. la Piophiln prlesionis (Ann. Sc. nat., $3^{\mathrm{e}}$ séric, t. I, pl. 16, fig. 3). Isa larve de l'Anthomyin metamin a six digitations il claque sligmate antérieur; la larve de l'IIetomyza lineata 12 à 14; celles de la Btephariptera servata et de la Sapromyia blepharipteroides quinze digitations; celle de la Drosophila fasciata offre un faisceau de cinq rayons (Ann. Sc. nat., $2^{\text {e }}$ série, t. XII, pl. 2, fig. 53, 66, 76, 82, 897. M. Edouard I'erris nous a fait comnaitre le curieux stigmate antérieur de la larve de l'Opomy:a gracilis, qui consiste en six papilles déliées, formant une raquetle flabellée portée sur un pédoncule articulé, comme par une sorte de charnière, avec la grande trachée latérale. Il a aussi décril et figuré les sligmates antérieurs cn ratuuté finement créncléc chez la Lucina fasciata; en raquetle pourvue de tubulures longues, nombreuses et paraissant soudées chez la Gymmopoda lomenlosa; en raquelle ovale, ventrue, presque triangulaire, entourée de papilles nombreuses et mullement soudées chez la Ghyliza atriseta.

Le môme observateur nous a encore dévoilé la structure très remarquable des stigmates antérieurs des larves de la Sarcophaga muscariu. Cies stigmates sont recouverts exterieurement, sauf un petit espace circulaire a la base, par de petits appendices comme des papilles ou des écailles, disposés sur trois rangs asse\% réguliers, concentriques ef presque imbriqués, d'un aspect fort élégant (1ém. de la Soc. des Sc., elc. de

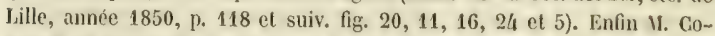
querel en étudiant la larve de la Lacilia hominivorax a trouvé huit éminences moniliformes au stigmate antériem (Amu. Soc. Ent. France, 1859, p. 237. pl. 6, fig. 1, d). Ges éminences ne sont pour moi que l'extrémité de ce sligmate divisé en huit parties.

Voyez combien l'étude de ces stigmates antérieur's des larves est importante et varir suivant les genres et mème suivant les espèces. Entre la 
Phora pallipes (Amm. Sc. nat., 2 série, t. XII, p, 57, pl. 3, fig. 107) dont la larve a le stigmate antérieur simple et l'Aulacigaster meficarsis (Ann. Soc. Ent. France, 1846, p. 457, pl. 11, fig. 4) dont la larve a les stigmates ramifiés de chaque côté le long d'une lige médiane, que de modifications dans ces organes respiratoires.

Les stigmates postérieurs sont légèrement ovales et ne s'éloignent pas beaucoup de ceux que MMi. Léon Dufour et Perris ont représentés dans les Sarcophaga hamorrhoidalis (loc. cit. pl. 1, fig. 5 et 6) et Sarcophaga muscaria (loc. cit. p. 420 et fig. 3-4). Ils different davantage de ceux que N. Coquerel a observés chez la Lacilia hominivorax (loc. cit. pl. 6, fig. 1 b). $\Lambda$ la loupe, on voit l'apparence de trois fentes respiratoires, mais quand j’ai employé le microscope, j’ai été frappé de l'absence de pores ou d'ouverlures à cette membrane tendue et entourée d'un cercle corné; les plis qu'on y décourrait à la loupe ne paraissent plus circonserire ou border une fenle. J'ai représenté l'aspect d'un de ces stigmates de la larve de Tachina villica vu par transparence (fig. 8). On remarquera un endroit très transparent, arrondi, correspondant au point où une grande trachée vient aboutir, mais je n'y ai pas vu, je le répète, de pertuis distinct.

La caverne stigmatique n'offre pas de prolongements sur les bords, on des laciniures, comme dans les Surcophaga himorrhoidalis, (loc. cit. pl. 1, fig. $1 \mathrm{et} 5$ ), Drosophila fasciatu, P'hora prallipes (loc. cil. p). 3, fig. $88 \mathrm{et} \mathrm{107),}$ Drosophila maculata (Mém. Soc. de Lille, 1845, fig. 10), Rhynchomyia columbina (Ann. Soc. Ent. Fr., 1846, pl. 9, II, fig. 2), Trtanocera formeinea (ibid. 1849, pl. 3, 3, fig. 1. et 3) el un grand nombre d'autres; mais lo bourrelet, le pannicule que j'ai eu soin d'indiquer (1) me paraît analogue à ce panneau ou tablier que M. Léon Dufour représente dans la larve de la Surcuphuga hamorrhoitalis (voyez les fig. $20, l, m, \mathrm{pl}$. III, de son memoire jrécité); il dit même que ce panneau ou tablier est trilobé el j’indique moi-mème celle disposition (fig. 4). N'ayant eu que des larves mortes, je J'ai pas vu l'animal imprimant des mouvements à ce pannicule, je n'ai pas pti constater l'expulsion des matières stercorales. J'ai essayé de disséquer la larve pour saisir le point ou finissait le tube digestif, mais je n'aj pu qu'imparfaitement constater qu'il n'arrivait pas à la caverne stignalique. M. Léon Dufour signale avec soin (loc. cit.) que chez la larve de la sarcophaga " un panneau trilobé, un tablier déborde parfois le bout du corps et est destiné à séparer l'anus de la caverne stigmatique; " d'après lui, j'admets que le hourrele trilobé de la larve de la Tachina villica doil

(1) M. E. Perris a trouvé douze lobes dentiformes au dernier segment de la larve de la Sarcophaga muscaria, et sous ce segment, près du bord postérieur, existe une pièce assez volumineuse, bien saillante et ayant qquelque ressemblance avec une enclume renversée (loo, cit., p. 120 et fig. 3 ). 
avoir le même rôle. Cette remarque a de l'importance ainsi que nous le verrons en parlant de la pupe.

Notre larve de Tachina est dépourvue de pseudopodes ou de prolongements latéraux pouvant en tenir lieu; elle n'a que des aspérités rudes ou des spinules, des petits crochets a base très élargie situés autour des segments. Je dois signaler cependant les espaces elliptiques, ou mème en forme de navette, qui se trouvent sur la partie médiane et inférieure des segments, espaces qui doivent aider à la progression. M. Coquerel a représenté une disposition analogue el bien plus accusée dans la larve de la Letcilia hominivorax (Voy. loc. cit. fig. 1).

Malgré l'apparence si complétenent identique des larves des Muscidles, qui a pu faire dire avec justesse à M. Perris "qu'elles semblent toutes taillées sur le meme patron, " ne voit-on pas avec bonheur qu'une étude attentive découvre des différences? Les stigmates antérieurs et postérieurs, la caverne stigmatique, les organes de progression de notre larve n'ont-ils pas leur structure spéciale?

II. Cette structure est appropriée au genre de vie de la larve de celle Tachina destinée à se nourrir. Du corps adipeux de la chenille de la Noctua (IIadcna) brassica, elle n'a jas besoin d'organes de progression énergiques comme la Lucilia hominivorax ou comme les larves d'autres Muscides obligées de se frayer une route dans un aliment solide ou de consistance inégale et non baigné de sucs nutritifs.

Il est probable que la larve aspire l'air extérieur par un des stigmates de la chenille, ou par un trone trachéen, ainsi que M. Léon Dufour l'a démontré pout les larves des Ocypteru (Ann. Sc. nal., t. X, p. 255, 1827) el pour la larve de l'Iyyalomyia dispar (Ann. Soc. Ent. France, 1852, pl. 8, III, fig. 1. et 2). P'eut-etre tient-elle simplement la partie postérieure du corps collée, soit contre une ouverture anormale du tégument, soit simplement contre la peau mince el poreuse de la clienille? Je ne puis émettre qu'une hypothese, n'ayant pas fait d'observations positives at cet égard. Mais ce qui est démontré aujourd'hui, c'est que la larve aspire l'air extérieur par les stigmates, de la caverne sligmatique, ou stigmales postérieurs. I.'exemple des larves d'Ocyptera et d'IIyalomyin dispar greflées sur un sligmate est la pour le prouver. Les larves des Strationydes et des Eristalis observées par Swammerdam (1), par Réaumur (2), et beaucoup de larves de Muscides plongées dans l'eau émergent l'extrémité du corps pour res-

(1) Swammerdai, Collection acalémique, t. v, p. 111 , pl. xxiv el xxv.

(2) Ré..umur, Mémoires pour servir à l'histoire des Insccles, t. IV, n. 445, pl. 30, fig. 1, 1738. Voy. aussi p. 460. 
pirer. L.es larves de Crria conopsoides, d'Aulacigaster ruftarsis, étudiées par M. Léon Dufour et vivant dans la bouillie des ulcères de l'Orme, élèvent leur tube respiratoire caudal au dessus du magma dans lequel elles se nourrissent, afin d'aspirer l'air atmosphérique. Une preuve nous est encore fournie par l'existence des seuls stigmates postériẹurs chez les larres des Tripulaires terricoles (1), Tipula lunata, Ctcnophora atrata, Pachyrrhina maculata, Limnophila dispar, Cylindrotoma mucroptera, che\% la Tetanocera ferruginea (2) et peut-etre de l'IIyalomyia dispar (3). Enfm la disposition anatomique des trachées dans le corps des larves des Muscides est telle qu'elles se dirigent toutes vers la partie postérieure du corps et forment avec les trones trachéens latéraux un angle aigu ouvert en avant, preuve irrécusable de l'arrivéc de l'air par la partie postérieure du corps au moyen des stigmates placés au fond de la caverne stigmalique (4).

La larve de la Tachina villica ne sort pas de la chenille de la Noctuclle, elle reste cachée jusqu'après la transformation de la clienille en chrysalide, et c'est de celte derniere qu'elle s'échappe en pratiquant une ouverture sur des points variables, correspondant peut-ctre aux parties de la chenille oủ elle a vécu et qu'elle a rongées et amincies. J'ai affirmé que notre larve sort sous cette forne et j'ai fait remarquer la surprenante rapidité de la transformation en pupe constatéc par M. Villeneuve. Jamais je n'ai trouvé la pupe dans le corps de la chrysalide de Noctua, et une seule fois j'ai vu une pupe engagée moitié en dehor's moitié en dedans; cette pupe ćlait déformée el serrée dans son milieu. Loin d'en conclure que la pupe est expulsée, j’admets que la larve, n'a pas été assez agile ou assez forte pour quitter la chrysalide de la Noctuclle el qu'elle s'est transformée au passage.

Réaumur (5) a vu sortir des chrysalides les vers de mouches it deux ailes, el il signale (loc. cit. p. 142) la métamorphose parfois très prompte et accomplie en peu de minutes dont il a été témoin. Mais M. Léon Dufour a émis l'opinion que pour les Ocyplera (loco citato) et pour la Ilyalomyia, la pupe élait expulscie dı corps de l'insecte qui les renfermait. Je

(1) Voyez líow Duroun, Mémoires présentes par divers savants à l'Acad. des Sciences, etc., t. 1X, p. 578, note 1, 1846. - E. Perris, Notes pour servir à l'histoire des métamorphoses de diverses espèces do Diptères (Ann. Soc. Ent. France, 1849, p. 344.)

(2) LÉon Dufour, Ann. de la Soc. Ent. de France, 1849, p. 71.

(3) Léon Dufoun, ibid., 1852, p. 113 (Larva... stigmatibus solum posterioribus, binis, tubulosis, exsertis, nudis).

(4) I.Éow Dufoun, Mém. prés. pas divers savants de l'Acad. des Se., elc., t. IX, p. 577, pl. 2 , fig. $17,1846$.

(5) Ríaumur, Mém. pour servir à Thistoire des Insectes, 1. II. n. $\mathbf{4 1}, \mathrm{pl}$. 36 , fig. 1 et 17,1736 . 
dois par conséquent discuter l'assertion de mon cher et vénéré maltre, assertion que je crnis n'être pas entièrement conforme à la vérilé.

M. Léon Dufour dit expressément que " si la larve de ces Ocypterres se transforme en chrysalide (ou pupe) dans la cavité abdominale mème de l'insecte qui la loge... il paraitrait aussi que c'est immédiatement après cette métamorphose que la nymphe est expulsée de l'abdomen. Je n'ai point été témoin oculaire de ce double fait (1). "Les raisons qui suivent ne me paraissent pas convaincantes, mais l'existence de la dépouille caudale trouvée par l'illustre observateur dans l'abdomen de la Pentutome (loc. cit. p. 252) est plus spécieux. Et cependant M. Léon Dufour, avec sa rigueur de description accoutumée, note que celte dépouille se sépare du corps de la larve très facilement : " c'est un mode d'articulation qui semble plutot une espèce d'enchatonnement adhésif, car la larve peut s'en debarrasser sans qu'il se fasse une solution de continuité à l'anneau du corps qu'elle embrasse (loc. cit. p. 252). J'ai constaté ce fait.... Je présume que l'individu approchait de l'époqque de sa métamorphose en chrysalide, et que son corps avait acquis la maturité convenable, car le siphon candal se délacha sans efforts, entránant aulour de sa partie ćvascée quelques lambeaux d'une membrane fine, pellucide, épidermoïle, qui paraissait étrangère au tissu propre du segment abdominal qu'elle recouvrail." Je crois done que la larve de l'Ocyptere, at moment de se transformer, peut ou abandonner, ou bien entrainer avec elle le siphon caudal respirntoire, suivant la plus ou moins grande adhérence de celui-ci, cet appareil ne lui étant plus utile au moment où la métamorphose va s'accomplir. C'est la larve qui sort du corps de la Casside ou de la Pentatome, abanflomant le siphon caudal, et non la pupe. Peut-être M. I.éon Dufour a-t-il été entraine ì croire à l'accouchement, à l'expulsion de la pupe, en sottvenir de ses beaux travaux sur les Dipleres pupipares; mais dans ce cas il s'agit d'un acte physiologique et l'insecte parfait expulse une pupe au moyen d'un appareil et d'organes propres, crécs pour cette fonction et des usages spéciaux, tandis que les victimes ou les hôtes de l'Ocyptera n'ont ‘ucun moyen particulier pour arriver à ce but. Enfin je me suis assuré qu'une pupe même assez molle de Muscidc ne se laisse pas comprimer facilement, etle ćclate et ne samrait prendre la forme de la pupe que j'ai vue à moitié sortie d'une chrysalide de la Noclua brassicx, et c'est pour cela que j'ai admis que dans ce cas, en apparence contradictoire, on devait encore reconnaltre que la larve seule était agile.

M. Leon Dufour ne me parail pas non plus etre dans le rrai, quand en

(1) LÉon Duroun, Mémoire pour servir à lhistoire du genre Ocyptera (Ann. des Sc. natur., t. X, p, 256, 1827. 
faisant connaitre l'Ityalomyia alispa", il se demande si " elle est obligée pour se faire jour sous lı forme de pupe de léchirer les lissus qui avoisinent le rectum (1) ", ou bien en disant: "quand sonne l'heure de la mélamorphose, la larve ayant pris tout l'accroissement voulu se détache, tombe dans la cavité abdominale el se fait de sa propre peau condensée et durcie une coque d'un marron vif, réceptacle de la nymphe ou maillot du Diptère ailé... ", et plus bas, "par quelle manouvre cette mupe incarcérée dans une cavilé sans issue parvient-elle à etre expulsée ?.... Lors de la transition à l'élat de pupe, la larve, qu'une préoccupation instinctive d'avenir entraine irrésistiblement, déchire la paroi membraneuse du bout de l'abdomen du Brachyleres, et suivant toutes les apparences, se loge dans cette breche ou embrasure pour y compléter sa transfiguration en pupe. Lorsque la nymphe incluse reçoit l'éveil de sa prochaine naissance, elle exécute des mouvements obscurs, mais réels, qui ébranlent et font progresser la pupe, en meme temps que les titillations de celle-ci provoquent les efforts expulsifs du Gharançon (2), "

Je crois que le Parasite, l'Ocyptera ou l'IIyalomia, doit sortir à l'élal de larve, du corps de sa viclime; $\mathbf{M}$. Léon Dufour n'a rencontré que la larve et non la pupe lans le corps des insecles altaqués. Si on trouve constamment la pupe dans les boites renfermant les Coléopteres on les llémiptères qui ont nourri la larve, c'est que celle-ci s'est transformée avec une rapidité non moins grande que celle de notre Tachina villica.

\section{\$2. Pupe. (Voy. pl, 7, fig, 9 à 11).}

PUPA nuda, ovato-oblonga, mefo-fusca, obscure undecim-articulala; scgmento primo lateratiler auriculato, segmento quarto tuberculis minulis stigmalifris instructo, segmento ullimo stigmala larva postica cxhibente. - Longit. 4 lin. (9 mill.)

PUPE en forme de barillet; d'un brun rougedtre; ovale, v'ilongue, offrant l'indication des onze segments de la larve. Le pseudocé hale n'existe plus et sur le momicr segment on voit (fig. 10), au milieu et en bas, une petite place luisante, à Jords froncés, vestige de l'ouverture du canal digestif de la larve; de charque côté sont deux petites saillies tuberculeuses et formant deux auricules qui correspondent aux stigmates antérieurs de la larve, el entre ces deux organes vestigiaires (cavité buccale et stigmates) se trouve une élévation transversale qui s'étend sur les deuxième et troi-

(1) L̇́ow Duroun, Sur une IIyalomyia née des entrailles du Brachyderes lusitanicus (Ann. Soc. Ent. France, 1851, p. 65).

(2) Léon Derova, Encore l'Tyalomyia dispar (Ann. Soc. Lint. France, 1852, D. 446 et 447). 
sième segments, et clont la figure 10 exprime le relief. Celle ligne élevée est destinée à l'ouverture de la pupe el c'est quand elle s'est dessondée que la parlie supérieure des trois segments s'enlève el que l'insecte parfait sort de sa prison. Sur le quatriène šgmenı on trouve de chaque côté, près du bord postérieur et un peu en haut (fig. 9 et 10), un tubercule répondant au stigmate thoracique de la nymphe incluse. les segments intcrmédictires entre le quatrieme el le onzième n'ofirent rien de remarquable; le dixième cependant présente en dessous (fig. 11 et 12) les traces d'une ouverture à bot'ds froncés, qui me parait répondre à l'anus de la larve. Le onziòme segment (fig. 9 et 11) montre, vu de face, les restes des organes qui sont dans la caverne stigmatigue, c'est-k-dire les deux stigmates postericurs; il y a de plus, au-dessous d'eux, un point élevé dont je ne comnais pas la signification. Une sorte de hausse-col ayant des angles épaissis et arrondis qui lui donnent un aspect réniforme, représente sur la pupe le bourrelet que j’ai signalé comme bordant en dessous la caverne stigmalique. (Voyez fig. $4 \mathrm{cl}$ aussi fig. 1.)

I. Si beaucoup de lirves de Muscides semblent à premiere vue d'une structure tellement semblable qu'elie a pu paraitre monotone, leurs pupes donnent bien plus cette impression, car elles ont pour la plupart une forme de barillet invariablement stéréotypée. Et cependant, celui qui a reconnu la configuration de la larve et qui l'a séparée par des caractères organiques de ses congénères, retrouve sur la pupe toutes ces modifications. La pupe n'est que la peau épaissie et cornée de la larve; les aspérités, ou les reliels, ou les poils, y sont conservés, et ces pupes d'une forme si peu variée, présentent en réalité un intérèt presque aussi grand que le premier état de l'insecte. Plusieurs d'entre elles d'ailleurs ont de nouveaux organes, car les stigmates de la nymphe qui s'improvisent dans la métamorphose, viennent aboutir dans la région dorsale de la pupe à deux stignates, souvent prolongés comme dans les Ariciu, les Eumerus, les Phora (1) et dans quelques autres genres.

Ia pupe de la Tachina villica a onze segments comme la larve; le pseudocéphale a disparu, mais on voit une place luisante à bords foncés, qui correspond à l'ouverture du tube digestif (fig. 10).

De chaque côté, au bord du premier segment, sont les deux vestiges des stigmates antéricurs disposés comme deux petites oreilles. Audessous de ceux-ci et au-dessus de l'ouverture buccale oblitérée on roit

(1) I,Ĺox Dufoun, Ann. des Sc. naturelles, 2" série, t. XII, p. 57, pl. 3 , fiğ.

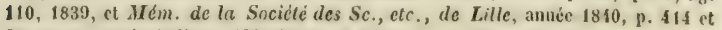
figures; at aunée 1815, p. 199, figures $4,6,10,11$ et 12. - Ca. CoQverer, 4 un. Soc. Ent. France, 1818, p. $190, \mathrm{pl}, 7$, fig. $7 \mathrm{y}$. 
un relief, une côte linéaire, allant de part et d'autre atteindre le lord antérieur du quatrième segment. Ce relief marque la place d'où s'enlèvera comme un panneau, d'où se déboftera une partic de la pupe. Le couvercle se dessoudra, sous les efforts de la Mouche, dans l'étendue occupée par ce relief et par le bord antérieur du quatrième segment. La tete vésiculeuse de la Tachina fera sauter le convercle de sa prison, et c'est quand par un arrêt dans le retrait de la tete, on trouve des Mouches mal venues et à grosse tete, qu'on a cru à des espèces nouvelles. Cette remarque s'applique entre autres au genre Chlorops.

Sur le dernier segment de la pupe on apercoil les deux stigmates postérieurs et au-dessous un point sailiant dont la signification m'échappe, mais que je ne crois pas appartenir a l'anus de la larve. J'ai déjà dit que sur le dixième segment on voit en dessous une place froncée qui me parait répondre à l'oritice anal, je l'ai figurée sous les numéros 11 et 12.

L'extérieur de la pupe est finement ridé en travers quand on emploie un grossissement un peu fort. Cette pupe étant examinéc après que la mouche en est sortie, en trouve les crochets mandibulaires appliqués à l'intérieur sur la face ventrale; on remarque aussi les troncs trachéens sous forme de deux longs traits blanes latéraux.

11. Je point le plus remarquable, à mon avis, de la configuration de la pupe chez notre Tachina, c'est. la présence sur le quatrième segment, en dessus et près du bord latéral d'un tubercule stigmatifere (fig. 9 et 10). C'est là un organe vestigiaire, un représentant des cornes des Phora, des Aricia, etc.

Les stigmates uniques de la nymphe paraissent naitre aux dépens des stigmates antérieurs de la larve, suivant les beaux travaux (1) de M. Léon Dufour; ces stigmales sont thoraciques et leurs grandes trachées s'anastomosent it la partic inféricure du corps (2). Beaucoup de nymphes de Diptères appartenant aux premières trilus, particulièrement celles des Culicides, et pour citer plus particulierement les nymphes que M. Perris a éludices dans nos Ammales, celles des Cylindrotoma macroptcra et Lymmophita dispar (année 1849, pl, 9, 1V, fig. 6, et V, fig. 7 et 8); enfin celle de la Cocidomyia papaveris, que j'ai pareillement décrite et figurée dans ces Amales (année 1857, p. 576, pl. 12, fig. 6 elt 7), el un très grand nombre d'autres offrent à l'observateur ces prolongements dorsaux de leur's stigmates.

(1) Lúox Duroun, Mémoires présentés par divers savants à l'Acarlémie des Sciences, etc., t. IX, p. 573 et pl. 1, fig. 10, 1856.

(2) LÉoN DUEOUR, Ibid., p. 579, et pl. 2 , fig. 18, b, b. 
l3eaucoup de pupes parmi les Musrides en sont privées, MM. Léon 1)ufour el l'erris ne les signalent point dans les Sarcophage qu'ils ont étudiées. C'est pour moi un vrai bonheur de trouver sur la pupe de la Trachina villica, ce vestige d'un organe arrivé au summum de déreloppement pour les Muscides chez les pupes des Phora. Il faut avoir tourné et refourné dans la main ces berceaux d'une simple Vouche, pour comprendre la joie qu'eprouve l'observateur qui finit par découvrir sur ce corps inerte la trace d'un organe dont l'importance physiologique est si haute. Cette petite saillie, ce point élevé, si insignifiant pour le vulgaire, nous révèle le mode de formation des cornes dorsales des pupes chez les Aricia, les Eristalis, les Eumerus, les Phor, etc.

\section{\$ 3. Insegte PARfait. (Voy. pl. 7, fig. 12 à 17.)}

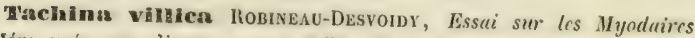
(Mém. prés. par divers savants à l'Acad. des Sciences de l'Institut de France, t. II, p. 188, 1830.) - non Zetrenstedt, Diptera Scandinaviz, t. III, p. 161, 1844, et t. VIII, p. 3248.

Grisca, palpis, scutelli partc postica, alarum basi, rufescentibus; pilosa setiferaque; fascie argenteo-sericen, fronte aurea, intensive o, vilta frontali nigra; thorace nigro qualri-villato, intrnsive of; abdomine albogrisco-micante, segmentis fascia postica ne non liner dorsati nigris. Alis fere diaphanis. - Long. 4-5 lin. (9 à 11 mill.).

IIab. in Gallix campo Lutctiano nec non dicto Saint-Saucur (Ionne).

Gorps gris en dessus, avec les palpes, la partie postéricure de l'écusson et la base des ailes roussatre ou d'un roux ferrugineux. Tike a front doré chez le $\delta$, jaunatre chez la $q$, une raie d'un noir velouké allant des ocelles it la base des antennes, celles-ci noiratres avec quelques écailles grisatres sur le $2^{e}$ article; face d'un beau blanc satiné on argenté; 7 soies au-dessus des antennes, de chaque côté et sur un seul rang ơ (fig. 2 et 4) et 5 soies sur un seul rang atl-ilescous des antennes. T'ète de la f a 2 rangs de soies au-dessus des antennes; une rangée interne composée de 5 , une externe composie de 3 soies (fig. 5), et au-dessous des antennes, 5 soies sur un scul rang. La face est beaucoup plus large chez les $q$ que chez les ô, et les yeux relativement plus petits (fig. 5). La couleur des jeux d'un rouge sombre dans les deux sexes. Corselet presque carré, un peu rétréci en arrière et très légèrement resserré au milieu, grisâtre avec quatre lignes noiraltes, longitudinales; les deux externes paraissent interrompues au milieu. Écusson noiratre en avant, roussatre en arriere. Ablomon d'un noir un peu bronzí, avec la partie antérieure des deuxieme, troisieme et 
quatrième segments d'un blane grisatre, chatoyant, une ligne dorsale's médiane coupant ces bandes transversales. Ventre noir.

Ailes a peine obscures, les grosses nervures brunatres et la base roussatre; cueillerons blancs, bulancirrs d'un brun jaunattre ou jaunatres. Potles assez robustes, noires, la pelote des tarses d'un jaune roussitre.

Le corps est couvert de poils et de soies. Celles de la tête (fig. 2 à 4 ) sont les unes dirigées en arriere, les autres en avant et celles qui sont de chaque côté de la ligne noire veloutée du front s'entrecroisent. Le corselet a, de chaque côté, quatre lignes de points d'ou partent des poils longs, et dirigés en arrière. L'abdomen, plus finement ponctué, est couvert aussi de poils plus fins que ceux du corselet. De forles soies raides se trourent de chaque côté du corselet et autour de l'écusson. L'abdomen a deux de ces soies sur le premier et le deuxième segments à leur partie dorsale, le bord du troisième segment en a 6 chez le ot et 8 chez la 9 . Outre ces soies, il en existe constamment de latérales au bord de chaque segment. Les pattes ont a la fois de fortes soies et des poils, la figure exprime la disposition des premières.

1. La détermination des Tachinaires est extrèmement difficile et les regrets de liobineau-Destoidy à cet égard (1) seront compris par ceux qui essaieront de reconnaitre les espèces de cette populeuse tribu. Le travail de Macquart, inséré dans nos Amnales dès l'année 1845, a contribué à débrouiller ce chaos et à rectifier la synonymic, mais on doit néanmoins convenir que, malgré les œurres de Robineau-Desvoidy, de Macquart, de Zetterstedt, de Rondani, etc., il est presque impossible de déterminer sûrement certaines Tachinaircs, si l'on n'a pas sous les yeux les types auxquels les insectes se rapportent.

Non ami et savant collègue M. J. Bigot possède dans sa riche collection une Tachina villica dont le nom a été écrit par Robineau-Desvoidy, et qui est identique avec le màle de notre espèce. Par conséquent, il ne peut y avoir aucun doute sur la légitimité de celle-ci, el elle doit porter le nom inscrit dans l'Essai sur les $\mathbf{1 1 y}$ yodaires, p. 188.

La question de la détermination rigoureuse de nos Tachina parasites n'est pas entierrement résolue, parce que j’ai pu, grice à la collection de M. Bigot, reconnaitre l'identité de quelqques-unes avec la Tachina villica ớ. Il est éclos des chrysalides de la Noctua brussica un grand nombre d'individus, les uns différant seulement par la taille, les autres d'une coloration plus grise et présentant une teinte moins doréc du front, ainsi que deux rangs de soies de chaque coté de la ligne médiane frontale. Ces derniers

(1) Annales de la Soc, Ent. France, 1848, p. 452 et 4003. 
insectes, tous femelles, et qui pourraient paratre à premiere vue constituer une espèce distincte, ne sont, en réalité, que l'un des sexes de la $T$. villicu. Mr. Bigot et moi ne les asons trouvés décrits nulle part d'une manière reconnaissable et ils rentreraient dans le genre Mesicer't de Jacquart (Diptires, Suites it Buffon, t. 11, p. 118, 1835) et de liondani, si, au lien de les rapporter à la $T$, villiç, j'avais établi sur eux une espèce particulière.

Dans l'état actuel de la diptérologie, on est encore obligé de décrire loutes les différences qu'offrent les individus voisins les uns des autres et que renferment les collections. De lì certainement une trop grande multiplication des espèces établies sur de simples variétés de taille ou de coloration. Je suis méme persuadé que beaucoup d'especes ont les sexes placés dans des genres différents.

Le nombre vaiment prodigieux des Diptiores rend cet ordre le plus peuplé comme individus, de toute l'Entomologie; ces individus si nombreux proviennent de larves inégalement nourries et ils doivent nécessairement varier entre eux. De plus, quand on examine les résultats que l'étude des premiers états a fournis aux observateurs, entre autres à MM. Léon Dufour, l'erris, etc., on remarque que beaucoup d'espèces élevées en captivité ont été désignées par la qualification de dispar; les mâles et les femelles provenant de larves pareilles sont différents. Ne peut-on pas prédire à coup sûr, d'après ces renseignements précieux, que c'est par le contrôle de l'observation des métamorphoses qu'on légitimera l'étalulissement d'un grand nombre d'espèces dans l'ordìre des Dipteres?

Je crois done, en ce qui concerne la Tachina villica, que les individus que j'ai décrits, les uns, tous mâles, plus grands généralement, plus foncés en couleur, à face moins large, à un seul rang de soies frontales, et les autres, tous femelles, plus petits ef plus grisatres, à face élargie et à deux rangs de soies frontales, ne doirent constituer que les deux sexes d'une seule et mème espèce. De plus, ces insectes, offrant dans leurs divers caractères, dans les nervures des ailes, ete, une très grande similitude, pourraient rentrer, les $\uparrow$ surlout, dans le genre .yasiccra de Macquart et de liontani. Disons, toutefois, gue la Tachina tarverum et la $T$. flaticeps sont pour Macqutart ( $1 m$. Soc. Ent. France, 1854, p. 376) de véritables Tachina.

II. Je n'ai que peu de chose a faire remarquer sur les caractères organiques de la Tachina villica. J'ai exposé avec soin la disposition des soies dont la tele et l'abdomeu sont couverts. Ces poils raides ont une destination utile, un but physiologirne et ne sont pas des organes de luxe; plus multiplicis comme cliez la $f$, ils doirent lui ètre útiles au moment oi celle-ci va 
déposer sur le corps de ses viclimes le parasite ou la larve qui les rongera. Ces soies raides el dlastiques anéantiraient les choes résullant des mouvements que doit faire la clıenille de la Noctuelle pour éloigner son ennemi.

Inais qui nous dira les manœuvres de la Tuchina of pour guetler la chenille, pour la joindre et déposer sur elle le germe parasite. Pond-elle un weuf ou une larve vivante? Les recherches de M. Léon Dufour sur l'anatomie des Diplères (1) nous obligent d'admettre gue la Tachina villica est oripare comme l'Echinomyia rubscens, ete. Je dois dire cependant que mon collègue M. Berce m'a affirmé qu'il a souvent vu sur le corps de diverses chenilles des wufs oblongs. Quand il a écrasé ces acufs avec une pince, leś chenilles n'ont pas nourri des larves de mouches parasites, tin̆dis que les mèmes espèces de chenilles qui n’avaient pas été débarrassées de ces euts sont devenues les victimes des Diptères entomobies. liéaumur a constaté les coques des wufs de mouches parasiles sur le corps des chenilles (2).

En terminant cetle histoire de la Tachina villica sous ses trois états de larve, de pupe et d'insecte parfait, je ne puis me défendre d'inviter encore une fois a l'étude des larves et des pupes des Muscides, étude si monotone en apparence, mais en réalité variće et remplie d'intérèt. Én ajoutant une ligne à la connaissance des premiers états des Tuchinaires, je n'ai fait que répondre pour une bien faible partie au veu de notre célèbe et regretté Macquart : "En rappelant la marche progressive des travaux anterieurs sur l'organisation des Tachinaires, nous désirerions pouvoir constater aussi des progrès dans la connaissance des mours parasites et singulières de ces Muscides... Grùce aux investigations de Mis. Léon Dufour, Gourean, l'erris, Herpin, Dagonet et quelques autres, nos connaissances sur le développoment des Diptères de plusieurs familles se sont accrues; il en est de mème résulté plusieurs renseignements utiles à l'agriculture. Nous faisons des vaux pour que les Tachinaires participent à ce progrès. ") (Ann. Soc. Ent. France, 1845, p. 251.)

\section{NOTE ADDITIONNELLE.}

Je consigne ici comme desiderata dans l'histoire de la Tachina villica et des Mouclies parasiles de la Noctua brassica les réflexions suivantes :

En mème temps que les larves et pupes figurées pl. 7, fig. 1 et 9, j'ai vu d'autres larves plus petites et d'autres pupes d'une forme plus étroite

(1) LÉow DUfoun, Recherches anatomiques et physılogiques sur les Diptires (Mémoires présentés par divers savants à l'Académie des Sciences de l'Institut, ete., t. XI, p. 302,1851 ).

(2) Résumur, Mémoires pour servir à lhistoiro des Insectes, 1. II, p. $143 \mathrm{ct}$ 414, 1736. 
el d'une couleur moins foncée (fig. 12). J'ignore si les parasites qui en proviennent sont ou ne sont pas identiques avec ceux que j'ai décrits.

Je ne sais point, de visu, si l'un des sexes a une pupe plus grande que celle de l'autre sexe. Pour s'en assurer, il faudrait séparer les pupes et olsserver les insectes qui en seraient éclos, ce que je n’ai juas été en mesure de faire.

J’ai remarqué, parmi les Mouches qui ont vécu aux dépens de la Noctua brossice, un petit male qui ne diffère de celıi que j'ai décrit et figuré que par sa taille de 8 millimètres $1 / 2$, par conséquent plus petite que dans les individus types ou ou ct ses coulcurs generalement plus claires. Il nous a part, à M. Bigot el à moi, se rapporter à la Tachina flaviceps Maceuart (Ann. Soc. Ent. France, 185/, p). 376). J'ai beancoup de tendance à croire que ce n'est qu'un petit individu ơ de la Tachina villica.

En résume, il reste encore à reconnailte si la Noctuu brussice est allaquée par plusieurs Mouches parasites (comme cela est tres probable) ou si toutes celles qu'on a observées doivent tre rapportées it la seule Tuchinu villica. Mes collègues qui s'occupent de tífidoptimologie pourront léciler cette question.

Jai en le plaisir de déposer dans la riche collection de mon ami ct savant collegue M. J. Jigot les types qui ont servi de base a ce travail.

\section{LXILICATION DES FIGLRES 1 A 18 , TOUTES GROSSIES, DE LA PLANGIIE $7^{\circ}$.}

Fig. 1. Larve adulte de la Tachina villica hobinead-Desvosor, vue de profil, et atl-dessous d'elle mesure de sa grandeur naturelle.

2. Partie antéricure de cetle larée vue de profil, très grossie, ainsi que les figures suivantes, et mettant en évidence les crochets mandibulaires et les stigmates antérieurs.

3. La míme vue de face. On apergoit les parties molles sifuées andessus des mandibules et les stigmates antérieurs placés at bord postérieur du prenier segment.

4. Partic postéricure de la larze vue en dessus el de face. Derniers segments du corps mamelonnés de chaque côté, et dernier segment abdominal surmonté de la portion charnue et trilobée ou d'un croissant irrégulier; caverne stigmatique, stigmates postérieurs situés au fond de celle-ci.

5. Partic médiane du corps de la lurve vue en dessous pour montrer la disposilion des hords latéraux des segments garnis de très fretils crochels, et les espaces mélians en forme de navelle. 
Fig. 6. Aspect des stigmates antérieurs vus de face el extremement grossis; on apercoil l'ouverture des quatre digitalions qui les terminent.

7. Un des mêmes stignates vu de profil et oflrant les quatre digritations écartées.

8. Un stigmate postérieur très grossi, vu par transparence.

9. Pupe de la Tachina villica RoB.-Desv. vue en dessus, el à cóté d'elle mesure de sa grandeur naturelle.

10. La míme pupe très grossie et rue de face par la partie antérieure. On remarque sur le premier segnent deux saillies latérales répondant aux stigmates antérieurs el alt-dessous le vestige de l'ouverture buccale; entre ces parties une ligne en relief qui les sépare el qui se prolonge jusqu'au bord postérieur du troisième segment. Sur le quatrieme segment, de chaque côté et un peu en laut, un tubercule stigmatifere répondant aux stigmates de lat nymphe incluse dans la pupe.

11. Celle mime pupe très grossic et vue de face par la partic postérieure. Le fond de la caverne stigmatique est de niveau, elle offre les stigmates postérieurs et plus bas une place luisante; audessous une plaque réniforme répond au pannicule trilobé de la larve (fig. 4); sur le dixième segment on observe en lessous les lraces d'une ouverture à bords froncés qui me parait répondre à l'orifice anal de la larve.

12. Pupe plus étroite et moins grande que la précédente vue par dessous et dont il a été question dans la note additionnelle (p. 246 et 247 ).

13. Tachina villica Roв.-Desw. ơ, el près d'elle mesure de sa grandeur naturelle.

14. Tête de cette Tachina $\sigma^{x}$ vue de profil et très grossie, ainsi que les figures suivantes.

15. Têle du même insecte ơ vue de face.

16. Tête de la $T$. villica $q$ vue de face.

17. Antenne de la $T$. villica tant ơ que o montrant les articles qui composent cette antenne.

18. Portion de la même antenue extrèmement grossie pour melle en évidence les poils du $2^{\circ}$ article el les deux parties qui comı̨osent Ie style. 


\title{
DESCRIPTION ET FIGURE D'UNE LARVE D'ESTRIDE
}

\author{
Dİ CAYENNE
}

EXTRAITE DE LA PEAU D'UN HOMME.

Par M. le doctcur Alexandre LABOULbise.

(Séance du 27 Février 1861.)

La lare dont je vais tonner la description et la figure provient de Càyenne où elle a été extraite de la peau d'um homme. La deseription gai suit prouvera qu'il s'agit du premier élat d'un insecte l)iptere appartenant ¿t la faunille des orstrides. Après avoir décrit celle larve, je la comparerai avec celles de la mème famille qui ont été observées sur l'Homme dans des ronditions analogues et dans le mème continent.

\section{\$ 1. Larve doestride de Cayenne.}

La larre a les téguments durcis par le séjour dans l'alcool, sa couleur lotale est d'un brun un peu rougeatre, sa longueur est de 22 millimètres, sa largeur de 10 millimètres.

Le corps est composé de dix segments y compris celui qui enveloppe la tète ou plutòt le pseudocéphale; il est légèerement arqué, un peu renflé au milieu, mais à peine atténué en arrière, à peu près elliptique fuand on le regarde en dessus.

Le psculociphate présente deux fubercules ou siillies antemnaires, attdessous desquels sortent deux crochels ou mandibules, distants, peu saillants, un peu arqués et terminés en pointe aiguê.

Ite sixïme segment du corps est le plus grand el ceux qui le précèdent ou le suivent diminuent peu it peu en avant ou en arriere. Le septième segment parait le plus long de tous.

Le momior segment, au milieu ducguel est placé le pseudocephate, nolfre pas d'épines, mais il présente un peu au-dessus des bords latriraux, vers la face dorsale, l'orifice des stigmales antérieurs. J'ai reconnu l'existence de ceux-ci à cinq ou six petits corps, ayant la forme de dentelures jaunitres, silurs dans le repli eulaué au bord postérieur de ce segrnent. Cies pelites dentelures me paraissent ètre analograes à celles qu'on remarque à l'extrémité des stigmates antérieurs cliez beiucoup de larves de biptères. 
Le denxïme segment de la larve, ou le premier qui suit le segment de la tète, et de plus les troisième, quatrieme, cinquiène et sixieme segments portent des épines recourbées ou des crochets arqués, at base large et dont la pointe est dirigée en arrière. Ies deuxième et troisième segments n'ont de ces épines que sur leur bord antéricur, ainsi que l'indique la figure 19, mais les quatrième, cinquième et sixieme offrent, outre la rangée antérieure qui entoure tout le segment en dessus et en dessous du corps, une deuxieme rangée d'épines ou de crochets aigus. Ceux-ci ont leur pointe généralement dirigée en avant, ils sont aussi forts ou plus forts que ceux du bord anterieur, ils occupent le dessus et les còtés du corps, mais ils n'arrivent pas sur la face ventrale de la larve. Le septieme segment offre à peine quelques crochets émoussées ou plutôt des tubercules mutigues, et les trois segments qui suivent (hnilieme, neuvieme et dixieme) son totalement dépourvus de crochets à pointe aiguẻ.

licxtrémité de cette larve est tronquée. Le dernier segment présente une excavation centrale, au fond de laguelle se trouve un mamelon à bords froncés entièrement recouvert d'épines microscopiques. Malgré la rigidité des téguments, je suis parvenu de écarter les bords, revenus sur cuxmèmes, de ce mamelon et à reconnaltre la présence d'une caverne sligmelique, suivant l'expression employée par M. Léon Dufour pour désigner cette disposition.

Au fond de la caverne, il existe deux plaques ovales et un peu réniformes, brunes, qui m'ont paru offrir trois saillies longitudinales. Ces pligues ne sont autres que l'aboutissant des trachées el forment les stigmates postérieurs de la larve. Les bords de la saillie mamelonnaire, en se rap)prochant, peurent donc obturer l'orifice des stigmates, et c'est par l'écartement de ces bords que l'accis de l'air dans les trachées est rendu possible.

Ja larve vue dans son ensemble et en dessus est presque elliptique, tronguée à ses deux extrémités. Elle offre des tubercules médians sur les deuxième, troi iène, quatrième, cinquième, sixième et septième serrments ; latcralement elle offre, de plus, trois rangées de tubercules lisses et larges, dus à des plis du légument. Ėn dessous, les quatrième, cinquième, sixième et seplieme segments ont des rides larges et transversales,

\section{(5) 2.}

Ciette larve a éle présentée a la Société de liologie (Mimoires de ta Socirtć de Biologic, $3^{\circ}$ série, 1. II, p. 161, 1861) par M. L.croy de Méricourt, professeur it l'école navale de Brest. Cet olservateur distingué avait cru pouvoir la rapporter à la Culcrobra noxintis ou au Vor macripue de Crmycmuc. 
In description qui précèle el la fierure 19 de la planche $7^{\circ}$ ne peuvent laisser ancun doute sur l'ordre et la l'amille d'insectes auxquels cette larve appartient; mais est-elle récllement le premier état de la Cutcrebra no.riolis ou du $\mathrm{Vor}$ mucurne proprement dit? C'est ce que je ne saurais almettre.

I'our résoullre en probleme entomologique, j'ai dủ comparer cette larve à toutes celles déjà connues, qui offrent avec elle une analogie de formes ou de moeurs et qui proviennent du même hémisplı̀re.

M. J. cioudot a le premier décril, sous le nom de Cuterrbra norialis, une larve de Diptère qui vivail sous la peau des vaches el des chiens d̀ la Nouvelle-Grenade, et dont il avait lui-mème été altaqué (Voy. Aunales des sciences natarclles, $3^{\circ}$ série, $\mathrm{t}$. III, p. 221, 1845). Ce naturaliste a vu éclote l'insecte parfait des larres recteillies à terre dans un endroil où des vaches infestées de ces OEstrides avaicnt séjourné; ces larves, appelées gusemo ou muche par les habitants du pays, etaient identiques à celles qu“il avait obserreses sur lui-meme et clont il a dome la figure (loc. cil., pl. 4 bis, fig. 5).

In larve qui fait le sujet de celle note differe de la $C$. noxialis de la Nouvelle-firenade décrite par M. Goudol. Sur la figure donnée par cet atuleur, on trouve les trois premiers segments antérieurs chagrinés, el les trois suivants sont les senls qui soient pourvus d'une double rangée d'épines dirigées en arrière; ils n'ont pas de mamelons non plus que les 5 segments qui suivent. Cette larve n'est pas, il est vrai, termine par un atpendice caudal, mais elle est plus atténuce que la nôtre el la forme générale renflée en avant, a partir du troisième segment, n'est pas la mème. Aussi, tout en recommaissant $u$ air de famille entre ces deux larves, je dois dire qu'elles n'appartiennent pas au meme insecte et qu'elles sont d'espèce differente.

M. Leroy de Méricourt avait désigné la larve qu'il a présentéc ì la sociélé de Biologie sous le nom de Vor macripue de Cayenne. Ce nom, donné par Arture, médecin du roi à Gajenne dans le siecle dernier, se trouve dans les Mimoires de l'Acadímio des Sciones de Praris pour l'anné 1753, p. 72. Arture, en effet, avait communiqué a cette célebre compagnie des Observutions sur l'espice de ver nommé macoque, mais il n'avait décrit ni le ver ni la mouche qui en provient.

Mon sayant collegue et ami, M. le docteur Charles Goquerel a éclairci les olservalions d'Arture, gràce à M. le docteur Chapuis, médecin en clief de la marine a la ciuyanne, et il a public dans la Romue of Magusin de Zoologic (2e série, T. II, 356, 1859, et pl. 12, fig. 1), la description et une très bonne figure du Ver macaque de Crmyenne. Ciest à l'aide de ces documents que nous allons pouvoir décider si la iarve que j'ai pu étudier, 
grace il M. Leroy de Méricourt, se rapporte au $\mathrm{V} e r$ macapue proprement dit.

Ce qui frappe le plus dans la description de ce dernier insecle, c'est le prolongement caudiforme ou en queue, des derniers segments du corps el surtout le double bourrelet terminal séparé par un étranglement. Or, rien de semblable n'existe dans la larve, bien plus grande d'ailleurs, el si fortement mamelonnée que j'ai dessinée. Elle n’est donc pas certainement le $V c \cdot$ macaque tel qu'il a été décril et figuré, par M. Ch. Coquerel, avec une grande fidélité (loc. cit., pl. xir, fig. 1 a).

Puisque la larve qui moccupe n'est ni la Gutcrebra noxialis de M. Goudot, ni le Ver macrique proprement dit, il reste encore à savoir si clle ne pourrait point ètre rapportée à une larve d'osstride très curiense, qui vit sur l'houme el en meme temps sur les animatu, le chien en particulier, et que l'on connait au Mexique sous le nom de $\mathbf{V}$ r Moyacuil.

Mis. Cl. Coquerel et Salle, mes chers collegues, ont fait connaitre cette larve qu'ils ont décrite et figurée dans la Rcvue ct magasin de Zoologic, $2^{\text {e }}$ série, t. II, p. 361, 1859 et jl. XII, fig. 4). Celte larve a une incontestable analogie avec celle que je décris moi-mème, mais elle est bien moins grande, elle est alténuée en arière et clliptique; elle est mamelonnée comme elle, quoiqu'à un degré moindre. On verra en comparant les figures que des différences réelles les sépareut, et bien qu'elles aient de grands rapports, je pense que celte larve d'OEstride n'est pas plus le $V c r$ moyacuil que la Culerebra noxialis ou le Vor macaque.

Si je compare enfin cette larve à celles que II. IIope a rassemblées dans son beau travail sur les larves observées dans le corps de l'Ilomme (Trensactions of the cntomological socicly of London, vol, II. p. 256, 1837$1840 \mathrm{et}$ pl. 22), je trouve qu'elle differe de toutes celles que le savant cntomologiste anglais a connues.

Je ferai la même remarque pour les larves signalées dans la Zoologie médicale de MIM. Gervais et Van Beneden.

\section{3.}

11 me paraì inutile de disculer si la larve que j’ai décrite est exclusivement propre à l'homme. Cette question du parasitisme des Otstrides est anjourd'luui résolue et il est prouve que ces insectes altaquent l'homme exeeptionnellement, tandis qu’ils paraissent vivre de préférence sur d'autres espèces de mammilères. I.es observations de Bracy-Clarck, de MII. Roulin, Justin Goudol, etc., rapportées par M. Joly dans ses Recherches chalomiques el physiotogiques sur les OEstrides (Ammales de ta Soc. Hoy. ¿'Agricultur, etc. de Lyon, I. IX, p. 2/16 et suiv., 18\$6), ne peuvent laisser aucun doule; c'est aussi l'opinion de mon savant collegue, M. le: toctenr Gh. Coquerel. On trouve dans la Zuologic médicale de MII. Ger- 
vais el Van Beneden, d'atures faits confirmatifs du parasitisme accidentel des OEstrides che\% l'homme, et M. Duncan, d'Wdimbourg, vient de signaler chez une jeune fille de $\mathbf{1 3}$ ans, la présence de tumeurs renfermant la larve de l'OEstrus ou IIypodorma bovis (Edinturgh velorinary Revirw, 1859).

D'après la discussion à laquelle je me suis livré, je pense que la larve que je viens de décrire est celle d'une Osstride, probablement du genre Cutcrebra.

Elle differe de toutes les larves observées jusquª ce jour dans le corps de l'homme.

Cet insecte n'est pas un parasile exclusif de l'homme, mais comme les Culcrobra déjà observées, il vit sur les animanx domestiques et natlaque l'homme qu'exceptionnellement.

lixplication des figures 19 a 21 de ia plancie 7 .

Fig. 19. Larve d'okstride de Gryjenne, el à côlé d'elle mesure de la grandeur naturelle.

20. Partie antérieure dı corps vue de face et en dessus, montrant les saillies antennaires et les mandibules du pseudocéphale.

21. Parlie postérieure du corps vue de face et en dessous, pour montrer la caverne stigmatique el les stigmates postérieurs. 


\title{
SGCRTIONS IF, MATIER MUSQUEE CIIEZ IES INSECTES.
}

\author{
Par M. le professeur GIRARD.
}

(Séance du 21 Juillet 1861.)

Dans un travail inséré dans le journal le Cosmos el lu dans une de nos séances (11 juillet 1860), j’ai étudié les sécrétions de la matière musquuée chez les animaux et en particulier chez les insectes. J'ai signalé cette sécrétion comme un des caracteres du genre Sphinx et j'ai fait connaitre que le Sphinx ligustri la possède à un moindre degré que le Sphinx convolvuli, espèce ou celle sécrétion musquée est indiquée par les auleurs.

J'ai pu vérifier de nouveau, cette année, sur un exemplaire mâle du Sphinx ligustri, l'existence de la sécrétion de matière musquée, que je regarde comme propre aux males. Seulement ce Sphtinx, éclos le 25 juin 1861, n'a pas oflert inmédiatement la sćcrétion musquée, comme cela s'était présenté pour les mâles de la meme espèce observés l'année précédente. Ce n'est quze cinq jours après l'éclosion que l'odeur musquée devint très sensible el restait alhérente aux doigts. Elle ne fut jamais aussi forte que sur les males des premieres observations of disparaissait par intervalles. Elle était très manifeste, autour de l'orifice génital chaque fois que l'insecte avait volé quelque temps. Eille a persisté plusieurs jours jusqu' mort de l'insecte.

Il n'y a rien d'extraordinaire ì ces variations de la sécrétion musquée clez le Sphinx ligustri ou cette sécrétion est faible, car ces varjations se remarquent aussi sur le sphinx convolvuli oit la matiere odorante est beaucoup plus abondante et se rencontre non seulement sur le male, mais quelquefois sur la femelle, soit qu’elle ait été fécondée, soil par hypertrophie des caracteres habituels.

Je possède en ce moment un Sphinx convolvuli, male, éclos le 21 juillet et chez lequel, depuis plus de trois jours, aucune trace de sécrétion musquéc ne s'est encore manifestée. La sécrétion ne s'est pas produite pendant une semaine où j’ai laissé vivre l'insecte, sacrifié ensuite à diverses expériences. Au contraire, les Sphinx convoteuli mâles, pris sur les fleurs (principalement les fleurs blanches des Petunia nyctaginifora) au mois de septembre, mont toujours offert la matière musquéc à un degré très intense. 

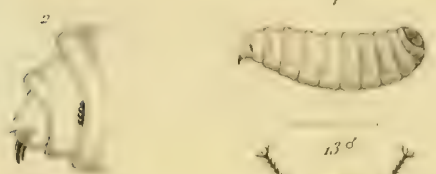

3
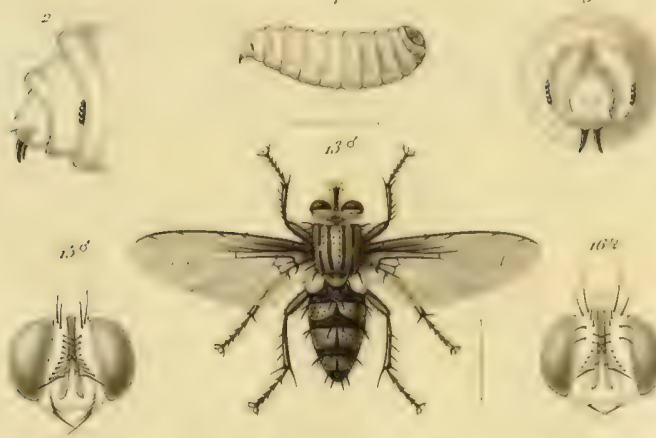

ni'

$1.0^{\infty}$

II
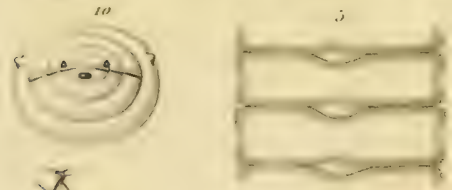

II
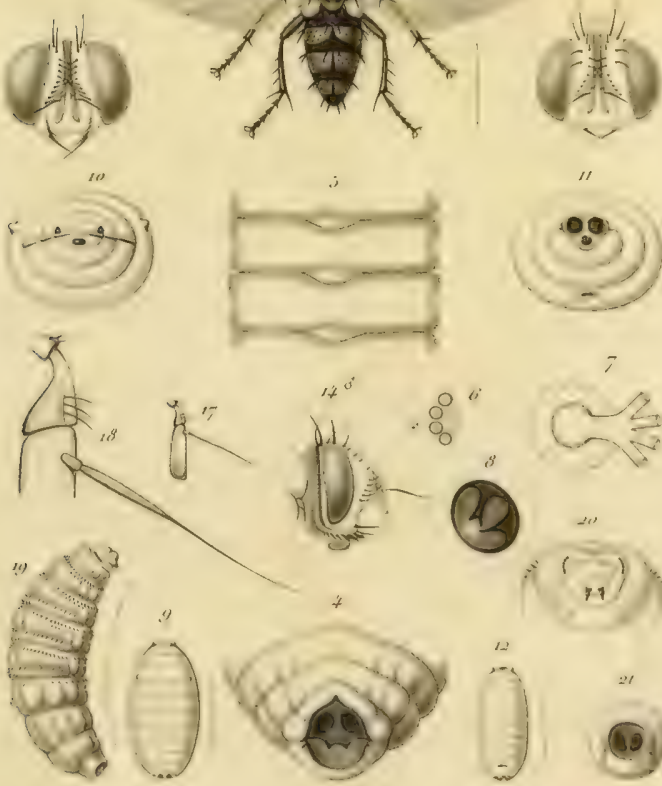

DrA. R.nhoulbrine pint.
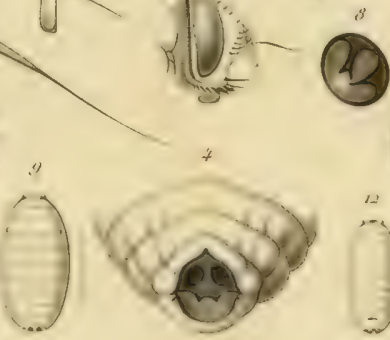

$+0$
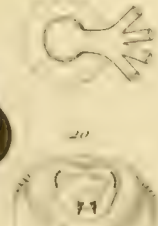

12.

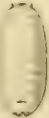

21

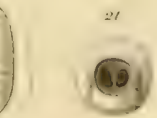

perenes parts

Tachina nillien. 



\title{
Description de la larve du CALLICNENIS LATREILLEI,
}

\author{
Par M. le docteur Alexandre LABOULBÈNE.
}

(SEance du 12 Juin 1861.)

IAAnva incurvo-hamata, segmento ullimo necnom appendice amali maximis; hexapoda, capitata, antemala; luteo-albida, sub lente brviter rufo setosa, pilosaque; capile corneo, rolundo, rufo-pavescente; antemis 5articulatis, angulatis, articulis duobus torminatibus crassioribus; mandibulis duris, nigrescentibus, multi-dentatis; maxillis intus sctosis, ncc haud apice bispinosis, dorso palpigeris, palpis 4-articulatis; labio-subrotundato, palpigcro, palpis biarliculatis; stigmatibus novcm puribus. Longitudo tredecim lineas xquat (28-30 mill.).

Habitat hypogara, ligno pulresecnte depasecns, in arenosis littoribus maris Mediterranei.

LARve d'un blanc jaunatre, fortement recourbée en arc ou en forme d'hameçon, tres convexe en dessus, presque plane en dessous; corps de douze segments, non compris la tete, ni le mamelon ou appendice anal qui est excessivement développé; tégument asse\% ferme et fortement plissé (pl. 16, fig. 5).

Trte d'un jaune-ferrugineux, avec deux lignes fines et plus claires commençant derrière chaque antenne et se réunissant en Y sur le sommet; convexe, trìs rugueuse en avant, moins rugueuse en arrière; bord occipital ou postérieur arrondi; ipistome trausversal et un peu trapézö̈dal; labre presque en demi-ovale, parfois assez netlement droit ct mème échancré en avant chez un individu; bord antérieur b́leve, garni de poils ayant la forme de spinules (fig. $5 d$ ). Marulibules robustes, ferrugineuses, avec l'extrémité noire, la droite (fig. $5 e, f, g)$ tridentie, la gauche bidentée au sommet; toutes les deux présentent un sillon profond et des rides transversales sur leur face externe (fig. $5 \mathrm{f}$ ); la droite offre en declans, et vers la base, une surace rappelant les dents molaires des animaux ruminants, et de plus une dent contoumée (fig. $5 \mathrm{~g}$ ); la surface molaire est moindre sur la mandibule gauche. Máchoires coudees, formees par une 
tige allongée, transversale, supportant, en dehors, un lobe en carré allongé et conique vers l'extrémité. Ce lohe est pourvu de poils spinuleux en dedans et au sommel; on y trouve aussi deux épines, l'une plus forte que l'autre, et bien visibles quand on regarde la machoire en dessus (fig. 5 h); au côté externe lu lobe est un palpe maxillaire de quatre articles bien distincts (fig. 5 h). Licvre inféricure épaisse, arrondie ou un peu quadrangulaire, mais avec les angles arrondis portant deux palpes labiaux formés cliacun de deux articles (fig. 5 h). Antennes de cinq articles, coudées à partir du troisieme article exclusivement, les quatrième et cinquième articles élargis, le premier article gros et court (fig. $5 \mathrm{~b}$ ).

I.es trois premiers segments du corps après la tete sont assez étroits; le prothoracique offere en dessus deux taches roussatres; tous les trois portent en dessous chacum une paire de puttes; celles-ri sont robustes et pourvies d'un ongle terminal peu recourbé (fig. 5 c). Les neuf segments qui suivent grossissent peu ou point de diamètre jusqu'au douzième rgui est le plus volumineux; le mamelon anal est considérable, il a l'air d'un treizième segment. $A$ travers les téguments, ces dernières divisions laissent apercevoir le gros intestin de la larve, rempli du produit de la digestion, ou le sac stercoral, sur la teinte foncée duquel se détachent en blanc nacré des rameaux trachéens. Anus transversal.

stigmates au nombre de neuf paires; la première placée sur un espace d'un jame clair, près du bord postérieur du seginent prothoracique, les huit autres sur des espaces d'un blanc mat, vers le bord anterieur des quatrième, cinquième, sixième, septième, huitième, neuvième, dixième el onzieme segments. 'Tous ces stigmates sont d'un roux vif, ferrugineux, et ont la forme d'un fer à cheval, dont l'ouverture pour le premier stigmate est tournéc en arrière, el pour les huit paires suivantes vers la téte de la larve.

Tout le corps est recouvert, mais principalement en dessus, et sous l'appendice anal, de poils spinuleux courts el fauves, formant brosse. Il y a, en outre, des poils plus allongés et plus mous. res poils des pattes sont forts et assez aigus.

La larve du Cintlicnemis Lutrcillci nous offre les caractères généraux des larves des Coleoplères Lamellicornes et, de plus, quelques traits particuliers de forme et de coloration qui servent a la faire recomaitre. Je vais indiquer les réflexions que m'a suggérées l'étude que j'en ai faite.

Toutes les larves de Lamellicornes sont reconnaissalbles it un air de famille; leur corps fortement recourbé, leurs antennes de cinq articles, leurs pattes ordinairement robustes et trìs développées, leurs stigmates en fer a cheval, la présence d'un mamelon anal, elc, les distinguent des 
larves de Curculioniles, d'A pute, d'Anotrum, dout le corps est igalement argues. On pourra el on devra ajouter it ces caractiones celui d'offrir des antennes coudés. lin ellet, après avoir examiné la larve du Ciallenemis, je trouvais que le caractere le plus sailiant qu'elle présentail étail d'ayoir les antennes coudées, à partir du troisieme article exclusivenent; cette forme des antennes rappelait celle de l'insecte pathait, et le quatrieme et le cinquième article élargis ajoutaient encore a cette ressemblance. Jes divers auleurs qui ont figuré les larves de Lamellicornes ont reprisenté leurs antennes droites ou presque droites, on poura sin assurar en parcourant les ouvrages de N.M. Ratyeburg, Icion Dufour, Perris, Gandeze (1), etc. Or, je le répète, le caractère du coude antennaire étail si marcurí, si apparent, que je l'ai cru particulier à la larve du Cullicnemis; cependant j’ai tenu à être renseigné à cet égard, j’a écrit à mon satant ami M. lid. l'erris, qui possède une très nombreuse collection de larves, de rechercher si les antennes n'élaient pas coudées dans les larves de Lamellicornes qqu’il possédait. Yoici sa réponse :

"Votre question a piqué ma curiositié, et ma collection do larves me permettant de la salisfaire, j’ai passé en revue toutes relles que j’ai de cette famille. Mon examen a porté sur les genres Lucums, Dorrus, Cirmchus, Melolontha, Polyphyllu, Rhizolrogus, Triodonla, Sinodendron, Nestulus, Ochodorus, Aphodius, Cotonia, et daus loutes ces larves j'ai trouvé les antennes plus ou moins coudées à partir du troisième article exclusivement. Le coude m'a paru plus marqué dans celle des Lucrumus, Dorcus, Ceruchus et Assalus, et ces organes sont simplement et faiblement arqués dans celles des Aphodius. La déviation de la ligne droile conslitue done évidemment un caractère de la famille, et vous serez, je crois, le premier qui l'aurez fait remarquer. "

Jl reste donc acquis a la science que les larres de Lamellicornes ont les antennes coudées; les larves des Lucruide ont le coude antemnaire plus prononcé gute les larves des scarabaidex. Les premieres se distinguent peut-être constamment des secondes par le bord postrieur out occipital de la tête trilobes, ainsi que M. Táon Dufour (2) l'a montré dans la

(1) M. Candeze, dans la fignue 3 de la planche $I 1$, de son II istoire des métamorphoses de quelques Coleopteres exoliques (Mém. de la soc. poy. dles scirnces de liége, t. XVI, p. 317 et suiv., représente une antenue pectince et ar.juéc pous la larve de l'Aneylonyeha fuscu, mais il semble y avoir imperfection du dessin, car la figure 3 a est difrérente. Le texte est muet à cet égard.

(2) İéon Dufour, II istoire comparative des métamorphoses et de l'anatomie des Cetonia aurata et Durcusparullelipipedus (Amales des Sciencrs naturelles, 2 e série, $t$. XVIII, p. 162 . pl. 6,1812 ). 
larve du Dorrus, tandis que la larve de la Cotonia a ce bord simplement arrondi, caractère que j’ai déjì indiqué dans la larve du Callicnomis.

On remarquera sur la figure 5 de la planche $16^{\circ}$, l'apparence de treize segments qui suivent la tête, mais il n’y a en réalité que douze segments, plus un mamelon ou appendice anal considérable. La majeure partie des larves de Lamellicornes présente cet énorme mamelon, mais les larves du genre Gétoine en sont privées et n'ont que douze segments. Nous trouvons là le chiffre normal des segments réels des larves de Lamellicornes. Du reste, les larves des Buprestides et des Longicornes offrent pareillement l'apparence de treize segments, due à la présence d'un mamelon ou appendice anal plus ou moins développé; mais toutes ces larres n'ont en réalité que douze segments et je partage l'opinion émise, à cet égard, par M. Edouard Perris (1).

Je n’ai pas trouvé traces d'ocelles sur la larve du Callionomis. On sait que les larves de Trichius ont seules oftert un ocelle à M. Perris (2).

Les parties de la bouche de la larve que j'étudie m'ont offert une particularité singulière. Le labre est le plus souvent arrondi et un peu tuméfié en avant, mais je l'ai vu transversal; je l'ai trouvé même échancré, sur un seul individu, il est vrai, el je me suis assuré que cette larve ressemblail de tous points à celles que j'avais déjà examinécs et ne paraissait pas d'une espèce différente. C'est la première fois que je vois le labre varier de forme dans les larves de la même espèce.

J'ai tenu à mettre en évidence les différences des deux mandibules. Les figures $5 \mathrm{c}, \mathrm{fet} g$ de la planche $16^{\mathrm{e}}$, en diront plus que de longues descriptions. Ia mandihule droite est tridentée, la ganche bidentée à l'extrémité.

L.es palpes maxillaires ont réellement quatre articles, ainsi que l'avait vil De ficer sur la larve de la Gétoine, et non pas trois seulement comme. le pensail M. Léon Dufour (3). Ce nombre de quatre articles aux palpes maxillaires parait constant. Les palpes labiaux n'ont que deux articles.

Les paltes de notre larve sont assez robustes et garnies de piqquants et de poils, la figure $5 c$ me dispense d'autres détails.

Les poils qui revètent le corps sont de deux sorles, les uns courts, épris, spinuleux, à extrémilé un peu émoussée, garnissant le dessus du corps et le dessous du mamelon anal, autour de l'ouverture postéricure

(1) F. Pernas, $\boldsymbol{H}$ istoire des Insectes du Pin maritime (Amules de la soc. Ent. de France, $1856, \mathrm{p}, 480,481$ et note).

(2) E. Pernis, Ann. Soc. Ent. de France, 1854, p. 107 et 108.

(3) De Géra, Mémires pour servir a lhistoire des Insectes, 1. 1V, p. 288, pl, 11, tig. 16, 1771. - I.éon Durovk, Ann. des Sc, nat., 2e série, t. XVIII, p. 164. 
abdominale. Ces poils représentent un "sablé pilifère, un faloule roussatre n suivant l'expression te V. bxon Inufour (1), qui les signale pareilIement chez la Getonia. Il y a, en outre, des poils plus longs, plus flexibles, répandus sur presque tout le corps de la larve du Callicnemis.

Je dois à mon cher collègue, M. Louis lieiche, d'avoir pu étudier vivantes, à Paris, les larves de Callicnemis qui ont servi it ma description. Je l'en remercie sincèrement el je le prie de recevoir, ici, l'cxpression de ma gratitude.

Ces larves ont des mouvements lents; elles se tiennent sur le flanc lorsqu'on les tire du sable dans lequel elles se tronvent. Posées sur une table, elles relevent lentement la tête et la partie supérieure du corps, mais elles retombent bientôt dans le décubitus latéral. facurs antennes sont fortement coudées pendant la vie.

Je ne connais pas d'autres renseignements sur leur manière de vivre que ceux déjà insérés dans ces Annales et qui sont consignés dans lt: Bullctin, pages XY et xvi de la présente année.

M. Reiche avait reçu les larves du Callicnomis Latreiltri de M. l'ablét Chapelier, dont nous déplorons la fin prématurée. Notre malheurenx colliggue les avait trouvées aux environs d'Alger, dans le sable du littoral.

\section{Explication des figunes 5 de iA PIAANGe 16.}

5. Larve grossic du Callicncmis Lalreillei CastelaNaU.

$5 \%$. Hesure de la longueur naturelle de celte larve.

5 b. Antcrne gauche très grossie.

5 c. Palte antérieure droile fort grossie.

5 d. Labre extrêmement grossi.

5 e. Mandibute du côté droit très grossie el fue de profit.

5 f. Ia même mandibute vue sur la lace externe; on y remargue un sillon profond et des plicatures transversales.

$5 \mathrm{~g}$. Mandibute droile examinée par la face interne; on $\mathrm{y}$ troure une: surface molaire et, de plus, une dent saillante et un pen contournée.

$5 \mathrm{~h}$. Machoire gauche offrant un palpe maxillaire de quatre articles, et la Livre inféricure supportant des palpes labiaux de deux articles.

(3) Ann, des Sc. nat., 2 série, t. XVIII, p. 167.

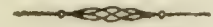




\title{
NOTE POUR SERVIR $\Lambda$ L'IIISTOIRE DES PARASITES
}

\author{
DE I,A
}

\section{Noctun (Madena) Drassica.}

\author{
Par M. le docteur Alexandre LABOULBÉNE.
}

(Séance du 13 Février 1861.)

En donnant l'histoire tes métamorphoses de la Tachina villica dans ces $\Lambda$ nnales (1861, p. 231 et suiv.), j'ai eu le soin de dire que ce parasile ne devait pas etre le seul qui attaquàt la Noctua brassica ct j’ai appelé l'altention sur les autres mouches ou parasites de celte Noctuelle (loc, cit. p. 247). Mon savant collègue, M. le colonel Gourcau, auquel la science est redevable d'un grand nombre d'olservations sur les mœurs et le parasitisme des insectes, a répondu a cel appel; il vient de nous faire part du parasitisme de l'Fulophus ramicornis, dont les larves, au nombre de seize, ont vécu aux dépens d'une chenille de l'Iladena brassica. M. Goureau a vu, de plus, une très grosse larve d'Ichneumonien sortir dı corps de la meme chenille qui avait nourri les seize larves d'Eulophus (1).

Dans un interessant travail sur les lnsectes nuisibles aux arbres fruitiers, aux plantes potagires, aux circules et aux plantes fourragires, que publie la Société des Sciences historiques et naturelles de l'Yonne, M. Goureau décrit une Tachinaire, parasite de l'IIadena brassicx, sous le nom de Tachina Hadma. D'après la description, cette Tachina me parait extrèmement voisine, sinon identique avec la $T$. villica.

Non cher collegue, M. J. Bigot, possede dans sa collection plusieurs T'achinaircs, dont il n'a pas encore déterminé l'espèce, et qui sont sorties des chrysalides de la Noctua (IIadena) brassicx.

Eufin, je puis ajouter que dans un ouvrage posthume du regrettable flobineau-Desvoidy, ouvrage publié par la Société des Sciences de l'Yonne, on trouve que des Tachina Lararum sont sorties, chez M. Bellier de la Chavignerie, des chrysilides de la Noctuelle clont il s'agil et qu'une autre Tachinaire, l'Erigone sedulte R.-I)., est sortie dans les memes conditions des nymphes de la même Noclua brassicx.

Je suis convaincu que cette note ne désigne que très incomplétement les parasiles de li Noctur dont il vient d'être question.

(1) Yoy, dans nos Annales, Bull. vir, 1861. 

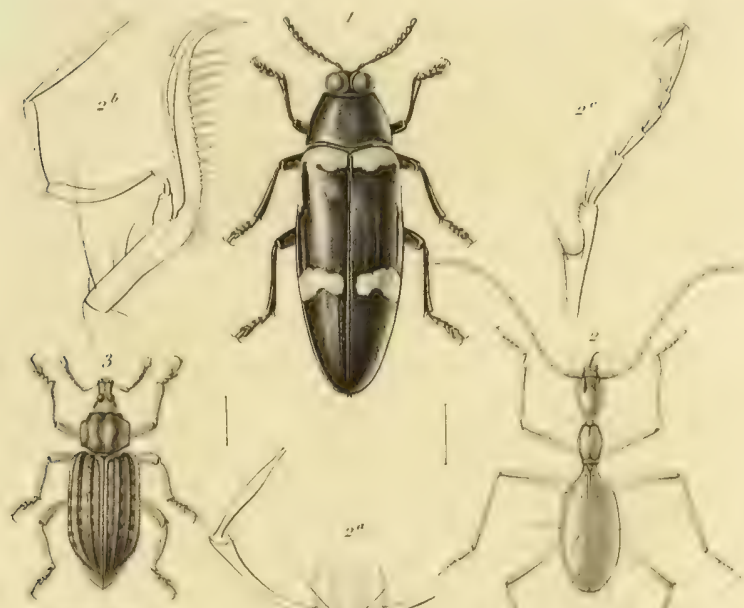

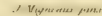
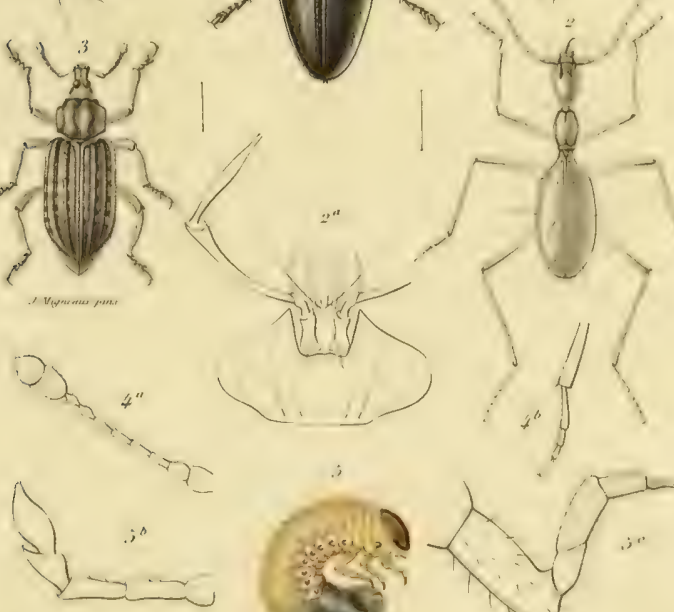

,
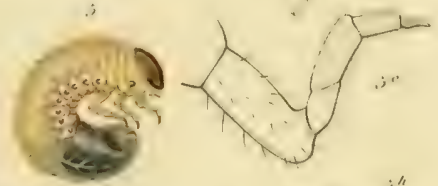

को)
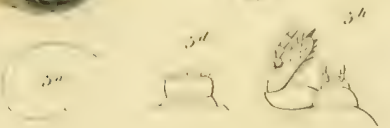

1 liaturatlocine wat

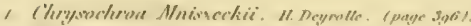

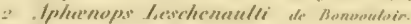

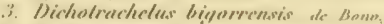

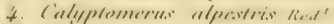

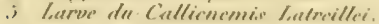





\section{DESGRIPTION}

I)E

\section{l'ACARUS (TYRogLIPIIUS) ENTOHOPIILGUS Lahoullièno}

$\mathrm{xr}$

\section{Observations anatomigines surr le gemre TYROGLYPIIUS}

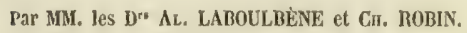

(Séances des 25 Août 1852 et 28 Mai 1862.)

L'Acarien dont la tescription anatomique est l'objet principal de ce travail, a été découvert par l'un de nous et présenté en 1852 à la Société, sous le nom d'Acarus cnlomophagus LiBoulbène. (Annales de la Soc. ent. de France, 1852, bulletin, page urv). Ayant, depuis celte époque, reconnu, en nous communiquant des recherches faites séparément, que nous atrions étudié chacun de notre côté la mème espèce d'Acarim, trouvée dans des conditions analogues, nous n'avons pas hésité, dans l'intér't de la science, à réunir en un seul mémoire les documents et les dessins quue nous possédions sur cette Arachnide et sur le genre Tyroglyphus autquel elle doit étre rapportée.

Le principal résultat de nos olsservalions a été de nous faire reconnaitre que les caractères du genre Tyroglyphus devaient etre notablement modifiés, bien que les limites de ce genre restent les mêmes. Nous nous sommes convaincus, d'autre part, que l'Acarus qui dérore les insectes dans les collections mal soignées constituait une espèce nouvelle, et nous avons vu la confusion qui régnail encore dans les descriptions des especees auxquelles il ressemble. Notre travail sera divisé, en conséquence, de la manière suivante : Enoncé des caractères du genre 'tyroglyphlus, liscussion de ces caracteres; description du Tyroglyphus cntomophagus, remarques analomiques et physiologiques; et enfin exposé succinct de lit synonymic et des caractères des deux especes de Tyroglyph/us les plus communes ( $T$. Sirn et $T$. longior), qui sont restées jus(qu'a ce jour mat ou incomplétement décrites. 
CIAPITRE I'.

Ce premier cltapitre est destiné à l'exposition des caraclères génériques des Tyroglyphus et à la discussion de ces mìmes caracteres.

\section{S 1. Genre TRRZOGETERUS LATREILL.}

Pricis ales caracteres geniriques ates Insceles, etc., in-8 ${ }^{\circ}$, p. 185, Brives, 1797 ('Tupós, fromage et javerà̀s, sculpteur) (1).

Corps ovoüde, allongé, ap̨lati en dessous, un peu allénué en avant, légèrement resserré sur les flancs, ofrant entre la deuxième et la troisieme paire de pattes un sillon circulaire, bien marqué sur le dos. Couleur grisatre, lisse et assez brillante.

Rostre conique, incliné, découvert, d'une teinte rouilléc ou pelure d'oignon, ì palpes étroits, portant trois poils courts. Mandibutes renflées à la base, allongées, didactyles, dentelées.

Epimirs de la première paire de pattes réunis ensemble; les autres épimeres libres. Palles cylindrigues, de mème teinte que le rostre, poilues; tarses sans mamelon, à caroncule membraneuse, onguiculée, sessile.

Amus placé sous le ventre, avec une paire de ventouses copulatrices chez le male.

Vulve longitudinale situce entre les dernières paires dìc pattes, comme l'organe sexuel male.

Males loujours plus pelits et plus trapus que les femelles.

res Tyraglyphus ont acquis déjà huit pattes et commencent ì se reproduire n’ayant encore que la moitié du volume qu’ils peuvent atteindre.

$\$$ 2. Nous derons faire remarguer soigneusement que la forme de ces animaux peut varier un peu dans charue espèce et d'un individu ì l'autre. Ces variations légères ont lieu suivant que la partic du corps siluée au-devant du sillon est rentric ou non tlans celle cui est en arricre; selon que ce sillon est lui-mème plus ou moins profond; suivant que l'Acarien raccourcit son corps en l'élargissant, ou au contraire l'allonge notablement

(1) A. P. Gervais nous parait s't̂tre trompé en disant que "cest au sillon qui sipare le corps (de res animanx) en deux parties n que I.atreille a probablement voulu faire allusion en employaut ancienmement le nom générique de Tyroglyphus

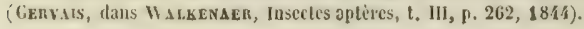


en resserrant ses côtés, surtout près du rostre qui se trouve projeté en avant. Nous indiguons encore l'aspect variable des Tyroglyphus de mème espece quand les poils de l'animal sont inclinés ou redressés et vus par conséquent debout ou dans le sens de leur longueur; suivant que le corps est ou n’est pas déprimé, sous forme d'incisure, au niveau des épimères porlant les deux prenières paires de pittes, et par le retrait de ces épimères. Le sillon circulaire, ou le pli fui existe en arrière de la deuxieme paire de paltes, peut disparaftre plus ou moins complótement daus certains mouvements et lorsque l'animal est gonflé par les liquides dans lesquels on le conserve, tels que l'acide acétique, etc.

La coloration pelure d'oignon, que Limné appelait ferrugineuse, n’appartient qu'aux pièces du rostre, ì celles des épimères et des pièces du squelette exterieur des pattes. Cette coloration est asse\% prononcée pour se réfléter sur l'ensemble du corps lorsque l'animal est vu it un faible grossissement, et en particulier sur les espèces dont les pieces du squelefte cxtérieur sont très-solides, comme clıcz le Tyroglyphus Siro.

\$ 3. Il dait impossible de determiner les caracties répls du geme Tyroglyphus d'une manière rigoureuse à l'éporfue de Latreille ct même plus tard, parce que les rapports qui relient les Acariens en genéral, les Sarcoptides et les Tyroglyphes en particulier, aux autres Araclinides et aux Insectes, n'étaient pas nettement déterminés. Celle lacune est aujourd'hui comblée, et le retard mis à la publication de ce mémoire aura cela d'utile qu'il nous permet de résumer ici les travaux auxquels on doit ec progrès de l'entomologie. Ce résumé servira de complément pour l'intelligence des caractères gónériques qui précèdent et des descriptions zoologiques qui vont les suivre bientôt.

Dans un travail Sur la composition anatomique de la bouche ou rostre des Arachioles de la famille des Sarcoplides (1), à lacpuelle apparlient le genre Tyroglyphus, il a cte prouxd que chez tous les .cariens, le rostre, à tort appelé tête, se compose, comme chez les autres Arachinides : $1^{\circ}$ de deux milchoires ou maxilles, placées en arrière, presque toujours transversales, soudées ensemble sur la ligne médiane; $2^{\circ}$ de demx palpes maxillaires, organes parfois les plus volumineux de tous ceux du rostre dont ils forment les colés, et qui s'étendent de la base au sommet; $3^{\circ}$ d'une lève inférieure membraneuse, plus courte que les palpes, et dont la baso adhère aux mìchoires et au bord interne des palpes; lat livre porte en arriere le menton el au milieu de sa face superieure une languetle ou ligule;

(1) Car. Roвav, Comptes-rendus des séances de l'Academio des Sriences, t. XIIV, p. 294, i:l-40, Paris, 1859. 
$4^{\circ}$ de deux mandibules ordinairement volumineuses et conoides, dont l'extrémité dépasse le bord antéricur de la lèvre, et dont la base adhère au fond du camérostome; elles reposent sur la face supérieure de la lèvre comme sur un plancher, et elles constituent la partic dorsale la plus épaisse du rostre dont les côtés sont bordés par les palpes.

J'organe qui déborde les palpes en dehors dans le genre Sircoptes sous forme de joue, et appelé palpe secondaire ou faux palpe, est un prolongement de f'épistòme ou bord antérieur dorso-latéral du premier anneau céphalo-thoracique. Cet organe n'a aucun rapport d'insertion ni de continuité avec les palpes, non plus qu’avec les mâchoires, et it n'est pas articulé. (Voyez encore les Ircherches sur le Sarcople de la gate humaine, par le $\mathrm{D}^{\mathrm{r}} \mathrm{Ch}$. Robin, Comptes-rendus et Némoires de la Société de Biologie,

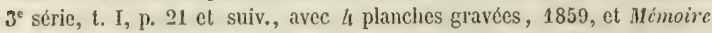
sur une nouvelle espice de Sarcoptes parasite des gallinacis (Sarcoptes mutuns), par Mur. Lanquetin et Ch. Robin, Comples-rendus des séances de l'Académie des sciences, t. XLIX, p. 793, in- $\left.4^{\circ}, 1859\right)$.

Ghez les Sarcoptides (1), et par conséquent chez les Tyroglyphus, on trouve dans toutes les especes cing parties pour chaque patte, comme chez les Insectes. Chacune de ces parties est constiluée sur le même type de la première à la seconde paire de pattes, puis de celles-ci aux deux dernières paires, et enfin d'une espèce à une autre espèce, malgré les différences considérables de forme, d'épaisseur et de longueur de ces organes dans chaque genre. Ce sont: $1^{\circ}$ la hanche ou rotule; $2^{\circ} l^{\text {'exinguinal ou }}$ trochanter; 30 le fémoral (2) ou cuisse; $4^{\circ}$ la jambe; $5^{\circ}$ la pièce solide du tarse ou pied, toujours conique, courbe ou allongée, terminée par deux pointes mousses dans les Sarcoptcs, les Psoroptes, etc., chez lesriuels clle est très courte et à large base circulaire. Le tarse se reconnait aux crochets pectinés ou non, aux caroncules, aux ventouses avec ou sans crochets, ou aux longues soies qu'il porte comme appendices terminaux, et qui sont caduques chez quelques espèces telles que le Sarcoples mutans Lanquetin et Gr. Robin.

Le céphalothorax offre souvent quatre anneaux distincts, au moins à un certain âge. La vulve est toujours portée par le troisième anneau dans le

(1) MÍ́moire zoologique et anatomique sü diverses espèces d'Acariens de la famille des Sarcoplides, par M. Ch. Rolin (Extrait des Mém. de la société impériale des Naturalistes de Moscou, aver 8 planrlies, P. 1 it 110, in-80, Moscou, 1860).

(2) Le fímoral ou cuisse "st divisé en deux piecrs articulées chez les Dermanys sus, ainsi que la jambe, qui alors offre icux articles, ff genual et le tibial; ef qui porte a sept articles les pieces iles paltes de certains Aeariens, nombre qu'om trouve cliez les Aranéides. 
genre Sarcoptes, et elle n'est pas située à l'extrémité postérieure de l'abdomen, tandis que les organes génitaux mâles dépendent du quatrième anneau.

Les saillies tuberculeuses du tégument sont une modification de ses plis réguliers, et ne sont pas analogues aux poils. Les vrais poils ofrent, l'une espèce à l'autre, des différences de distribution sur le corps et sur les pattes, différences qu'on peut ramener cependant à un mème type. Il en est encore de mème pour les épimères (Gu. robin, loc. cil.).

\section{CHAPITRE II.}

Nous allons décrire, dans ce deuxième chapitre, les Tyroglyphus cntomophagus, Siro el longior, en insistant sur leur habital, sur leurs différences spécificques et sur leurs caracteres anatomiques et zoologiques. Nous indiquerons, après la description et les remarques sur le $T$. cntomo.phagus, les meilleurs moyens à employer pour s'opposer aux dégàls qu'il occasionne dans les collections d'Insectes.

S 1. Tyrogiyphus entomophagus NoBis. (Voy. pl. 10.)

Acarus entomophagus Laboulbìne, Annales de la Soc. ent. de France, 1852, Bull., p. 54.

Corps étroit, cylindrico-ovoïde, presque droit sur les flancs, peu rétréci au devant du sillon circulaire; mou, grisatre, lisse et brillant. Rostre peu pointu, court, large, peu coloré, ainsi que les pattes, d'une teinte pelure d'oignon. Pattes semblables dans les deux sexes, grèles, cylindriques, très courtes, moins longues d'un tiers que la largeur du corps; les postéricures ne laissant voir que deux articles courts sur les côtés du corps. Proils postérieurs à peu près de la longueur des pattes.

Nale long de $0^{\text {am }} 12$ a $0^{\text {nus }} 40$ de millimetre, environ d'un cinquième plus petit que la femelle, mais proportionnellement un peu plus large. Tarses de la quatrième paire de pattes dépourvus de tubercules. Organe sexuel situé entre les hanches de la quatrième paire de pattes. inus placé sous le ventre. Ventouses copulalrices siluées à l'extrémité postérieures de l'ouverture anale. Extrémité postérieure de l'abdomen arrondie, bordée transversalement par un prolongoment scmi-lunaire et transparent.

Femcllc longue de $0^{\mathrm{mm}} 16$ à $0^{\mathrm{mm}} 50$ de millimètre, et de moitié environ moins large que longue. Vulve siluée entre les épimères et le premier article de la quatrieme paire de pattes. Anus ouvert au bord postérieur 
même de l'abdomen qui est elliptique en arrière et dépourvu de prolongement terminat.

OEuf régulièrement ovoide, long de $0^{\text {mm }} 10$, large de $0^{m m} 07$ de millimetre.

Nymphrs longues de $0^{\mathrm{mm}} 11$ a $0^{\text {man }} 15$ et larges de $0^{\text {man }} 08$ ì $0^{\text {min }} 11$ de millimètre, dépourvues de pattes postérieures el d'organes génilaux.

Ilabile les collections entomologiques, dans l'interieur du corps des lusectes conservés, ou à leur surface, et enfin dans la poussière qui s'amasse au fond des boltes. Les gros Insectes, a corps plein de parties graisscuses, ceux qui n'ont pas vécu longtemps ou élevés en captivité et qui ne se sont pas accouplés, ceux qui ont tourné an gras, pour employer l'expression ordinaire, sont les plus facilement attaqués. Les Coléoptères de cerlaines familles, les gros Scarbaida, les Orycles el Golrupos, les Lucanida, les Carabidx, les Dytiscida ct les IIydrophilide, les Gerambycidx, les Blaptidie gras ou mal desséchés, sont recouverts ì la surface d'excréments et d'ceufs, sous forme de points blanchâtres, el renferment parfois un nombre considérable de ces Tyroglyphus dans l'intérieur de leur abdomen.

Le corps des gros Lipidopteres, surtout des noclurnes, des Gicadx parmi les Hémiptères, des liorficules, etc., etc., en offre pareillement. Un Acridium migratorium tourné au gras, et des Sesia de grande taille nous en ont fourni une quantité vraiment énorme.

L'un de nous a remarqué la très grande abondance du $T$. cntomophagus dans le midi de la France; les conditions de chaleur et d'humidité sont très favorables à son développement,

On trouse le Tyroglyphus entomophagus courant sur le dos des Insectes morts, et on peut l'apercevoir à l'oil nu. Suivant N. I'erris (1), il ronge le duvet et les poils. Ise plus souvent le $T$. cntomophagus so tient dans le corps des Insectes; il ronge el il dilacere toutes les substances molles ou dépourvies de chitine. En maniant les insectes attaqués par ces Tyroglyphus, on fait tomber les pièces articulées dont les ligaments ont ćté détruits, el il s'éclappe du corps une matière pulverulente dans laquelle fournillent les Acariens vivants. Sous les Insectes altaqués on trouve une poussiere caracteristique el bien differente de celle que produisent les Anthronus et les autres dévastateurs des collections.

fa matière pulvérulente qui s'échappe, quand on secone le corps des Insectes rongés par le Tyroglyphus entomophagus, est composée (voyez

(1) Voyez plus bas la note sur la Cecidomyia entomophila (p.323). 
pl. $10^{\circ}$, fig. 11) : 1. des excréments de ces animaux sous forme de petites masses arrondies et grisitres ; $2^{\circ}$ des aufs en voie de développement et des coques vides ( $l a b$. cil., $a, a$ ) des cufs éclos, ces coques ouvertes el plissées, fendues souvent dans le sens de la longucur; $3^{\circ}$ de jeunes larves et de nymphes toujours plus nombreuses que les animaux adultes; $4^{\circ}$ d'enreloppes tegrumentaires provenant de la mue d'un grand nombre de larves et de njmphes; 50 de débris viscéraux ou musculaires du corps, des morceaux de trachées, de faisceaux musculaires striés, de fragments desséchés, parfois d'ovules non pondus et devenus libres dans le corps des femelles d'Insectes attaqués.

Dans la poussière du fond des boites, parmi les débris de tontes sortes, antennes, pattes, palpes, brisés ou tomjes, on trouve parfois des enreloppes de Gamasus, de Glyciphagus et de Cheyletes, Acariens qui vivent aussi dans les collections. Sur les Insretes cux-menes et derorant les excréments et les dépouilles des Tyroglyp/us, .I. Perris a trouvé, a Montde-Jarsan, les larves de la Cecidomyia critominphila (1).

La marche du T'yrogtyphus entomophagus est lente. Les mâles sont aussi nombreux que les femelles et un peu plus agiles qu'elles. Ce Tyroglyphus marche la tète replice en bas, de manière à laisser voir en ayant le sillon de contact des deux mandibules qui dépassent les poils de la nuque.

Sur l'animal vivant renversé sur le dos, on voit bien la lère et les palpes au-dessus des mandibules, que l'Acarien fait glisser l'une à côté de l'autre. On voit également bien les poils des palpes et leur extrémité mousse, saillante et dépassant un peu la levvre.

\section{Remarques sur la validite de cetle nonvelle espèce.}

Le Tyroglyphus entomophagus est le plus petit de toutes les espices connues de ce genre; it est remarquable par le parallelisme des faces latérales de son corps et par l'aspect cylindrique, par l'étroitesse de co dernier, surtout chez la femelle. Celte étroitesse du corps est due à ce que le rétrécissement du céphalothorax au-devant du sillon transrersal circulaire est moindre dans celte espece que daus ses congénères. La brièveté des patles du $T$. cntomophagus lui donne une physionomie toute particuliere; les paltes postérieures dépassent à peine les côlés du corps, tant les tarses en sont courts.

Ge Tyroglyphus est complétement different de la troisïme espice de Mile te Lyonet (Anatomie de différentes especes d"Insecles, Mém. du Muséum

(1) II istoire des mitamorphoses de rivers Insectes, par M. EDounn PERRIs (Mém. de la Sociéti royale des Scienees de liége, 1855, tirage à parl, p. 46, pl. Y bis, fig, 101 aे 106). 
d'Histoire naturelle, t. XVIII, p. 284, pl. 12, fig. 10, 11 et 12, Paris, 1829). Cette Mite est indiquée dans l'explication des planches de Lyonet comme élant le Sarcoptes destruclor Latreule, ou Acarus destructor Scmink (Enumeratio Insectorum Austriæe indigenoruin, p. 512, No 1057, $\mathrm{Au}-$ gustie Vindelicorum, 1781), et elle est rapprochée des Tyroglyphus par M. Gervais (in Walkenaer, llist. des Insectes apteres, t. III, p. 263, 1844). Il y a la pour nous une double erreur. Lyonet a décrit cette Mite comme un animal blanchatre, un peu transparent, à tele en pointe, brune, émousscé, à partie antérieure du corps plus renfléc que l'autre, ravageant les collections d'fnsectes et surtout de Papillons. Cette Mite se distingue par les longs poils noirs, quoique assez rares, dont elle est hérissée, poils qui, vus au microscope, paraissent pourvus de barbules. Or, la figure 12, qui représente un de ces organes, fait reconnaitre facilement qu'il s'agit d'un poil caractéristique des espèces du genre Glyciphagus (1). La longucur des pattes, leur tarse effile; la longueur et le groupement des poils barbelés, la partic antérieure du corps rentlée et non atténuéc comme clez les Tyroglyphus, sont aulant de caractères qui séparent cette Mite des animaux de ce genre, et qui all contrairc la rapprochent des Glyciphagus d'HFing. Nous avons recouru à l'ouvrage précilé de Scinank, el, pour nous, la description de son Acarts destructor (Modermilbe), p. 512, $\mathrm{N}^{\circ} 1057$, et la figure $\mathrm{I}$, de la planche $2^{\mathrm{e}}$, se rapportent certainement à un Glyciphagus et non à un Tyroglyphus. La disposition des poils postérieurs de l'abdomen et la forme des pattes sont caractéristiques. On n'a qu'à jeter les yeux sur les figures de Glyciphugus données par M. Gervals dans les Annatrs des Sciences naturclles (2e série, tome XV, planche 2, 1841), pour s'assurer de la vérité de notre affrmation.

L'Acarus domesticus de De GÉEr, cité fort souvent comme synonyme du $T$. Siro, ne se rapporte ni à cette dernière espèce, ni à la nôtre. L'íllustre auteur suédois a parfaitement représenté une espèce de Glyciphagus (t. VII, p. 88, pl. 5, fig. 1 à 9), dans ses Mimoires, si riciles de faits bien observés. La pliysionomie de l'Acarien figuré dans DE GÉer, les ventouses terminant les pattes ( fig. 6-7), le prolongement abdominal tubuleux (fig. 8), les poils barbelés (fig. 9), ne peuvent laisser aucun doute à cet égard. La Mite représentée figure $\mathbf{1 5}$ de cette planche est le véritable Acarus farina ou Siro des anciens auteurs. De Géer, qui a parfaitement décrit le Scarcoptes scabici ct l'Acarus farinx, n'a pas connu le Tyroglyphus entomophagus.

5(1) M. Picart, l'habile graveur de notre planche, qui est un enlomologiste zélé, nous a dit avoir observé autrelois dans sa collection un Acarien très poilu. D'après la description qu'il nous en a faite, cet Acarien appartient au genre Glyciphagus. 


\section{Examen anatomique et comparatif des diverses parties du corps du Tyroglyphus entomophagus.}

Le rostre est proportionnellement plus large, surtout à sa base, plus court et plus incliné que chez les autres Tyrogtyphius. Les machoires, placées transversalement, soudées à la lèvre et réunies ensemble sur la ligne médiane, offrent là une dépression postéricure qu'on ne voit pas chez les autres espèces (pl. 10 $0^{\circ}$, fig. 1, 3 et 5 , i). Les palpcs maxillaircs sont relativement volumineux, surtout le premier article, vers sa base. Les deux poils du deuxième article sont longs, ot le piquant ì sommet mousse du troisième article est plus gros et plus courbé que chez les espèces voisines. Les pulpes labiaux accolés, au bord interne des précédents, sont mieux dessinés et plus en relief sur la lèvre que chę le $T$. Siro. Le poil de la base de ces palpes est fort petit; leur sommet porte un piquant mousse très court. (Voy. pl. 10 ${ }^{\circ}$, fig. 5.)

La lère est plus épaisse, plus foncée, à bord libre plissé et mieux limité que sur les autres espèces; elle porte aussi un poil qui n'offre rien de spécial. La languette est remarquable par son épaisseur et par son prolongement terminé par une petite partie élargie en forme de fer de lance; ce prolongement s'avance jusqu'au niveau du bord de la lèv'e et mème le dépasse un peu sur quelques individus (fig. $5,9$. \%

Les mandibules sont, toutes proportions gardées, plus courtes, plus épaisses et plus puissantes que chez les autres espèces connues, el leurs dentelures sont plus rapprochées (fig. 6).

Le bord libre de l'ípistôme est plus foncé, plus épais et un peu plus avancé que chez les $T$. Siro et tongior (fig. 4).

L'anus, chez le mâle de notre nouvelle espece, est situé, ainsi que l'apparcil génilal, un peu plus près du bord postérieur de l'abdomen que chez les autres Tyroglyphus, mais sans atteindre ce bord. Les deux ventouses males propres au male n'offrent rien de spécial; seulement, au lieu de trouver un poil court au-devant d'elles, on y remarque un très court piquant situé en arrière et un autre semblable placé sur leur còté cxterne (fig. 1).

Chez la femelle, l'anus atteint l'extrémité postérieure du corps, ce qui n’a pas lieu dans les autres espèces, et, en outre, l'anus empiète sur la partie dorsale et offre l'apparence d'une incisure rerticale faite en arrière de l'abdomen; ses lèvres minces et saillantes forment un court prolongtment en arrière de l'animal (figo. 3 et 4 ).

$4^{\circ}$ Serie, томе II. 
Les organcs ginitaux eux-mêmes noffrent rien de bien spécial chez le T'yroglyphus cnlomophagus, si ce n'est la petitesse des vcntouses ginilales et l'absence des poils courts qui accompagnent celles-ci chez les autres especes (fig. 1 et 3 ).

Les cpimires nont de particulier que leur pelit volume proportionnel a celui de l'animal. Il en est de même du squelette des pattes. $\Lambda$ joutons que les articles des pattes, et en particulier le cinquième, sont, toutes proportions gardées, généralement plus courts que chez le $T$. Siro et surtout que chez le $T$. longior. Les pattes ne different pas d'un sexe a l'autre; la troisième paire est un peu plus petite que la quatriene, mais non pas d'une manière aussi sensible que chez les deux autres espèces que nous venons de nommer. (Fig. 1 et 3.)

La hanche offre un poil court aux trois prenieres paires de pattes, comme sur le 'T'. Siro ct longior. Comme sur ces deux espèces, l'exinguinat ou trochanter porte un poil, moins gros a la quatrième paire de pattes, mais proportionnellement plus long. Le fímoral de la premiere palte est pourvu de quatre appendices comme chez les autres Tyroghyphus; mais les deux placés au bord supérieur sont des piquants rigides et courts, tandis qu'un seul nous présente ce caractere cliez les $T$. Siro el longior; les deux appendices du bord inférieur sont des poils, mais plus longs dans le ' $T$. cntomophagus que dans les deux autres especes (fig. 7). Le fémoral de la deuxieme patte n'a que deux poils et un piquant rigide au lieu de trois poils comme chez les $T$. Siro et longior (jig. 8). The fémoral des deux dernières pattes est dépourvu de poils (fig. 3), tandis qu'on en trouve deux chez le $T$. longior:

La jumbe du $T$. cntomophagus porte deux poils à toutes les paltes. L'un de ces poils est bien plus long que l'autre, et il dépasse en longueur ceux des T. Siro et longior, sauf à la quatrième paire de pattes (fig. 10); chez ces derniers Tyroglyphus il y a trois poils aux deux premieres paires de pattes.

Le tar'se, plus épais, mais bien plus court que chez les précédents, porte un grand nombre d'appendices. Ce sont: $1^{\circ}$ une spinule courte, assez grosse et assez courbće; on ne la trouve qu’aux deux premières pattes (fig. 7 et 8); $2^{\circ}$ deux poils ou piquants plus courts que la spinule précitée et rapprochés de sa base; ils n'existent qu'a la première paire de paltes; $3^{\circ}$ deux poils courts et fins sur le milieu du tarse, et un autre at son bord libre; ces poils se trouvent sur les quatre paires de paltes, mais chez les $T$. Siro et longior, on en voit le double aux deux premières paires de pattes; $4^{\circ}$ près du bord libre du larse on remarque aux deux premières paires de paltes un long poil (fig. 7 et 8 ), plus grand à la seconde qu'à la première paire; il y a deux poils, placés un peu moins 
pres de ce bord, sur les deux autres paires de pattes; les uns et les autres sont représentés par des poils très fins et très courts chez les T. Siro et longior; $5^{\circ}$ chez les trois espèces, le bord libre du tarse est muni, aux deux dernières paires de pattes, d'un court piquant, difficile à voir (fig. 9 et 10 ), mais le male du $T$. cntomophagus manque des tubercules en forme de ventouse qu'on trouve aux tarses de la quatrième paire chez les espèces congénères; $6^{\circ}$ le tarse est terminé par une caroncule ou vonlouse transparente el membraneuse, semblable chez toutes les especes, ayant la forme d'un fer de lance, mousse quand elle est tout à fait étendue, mais ordinairement à demi rétractéc et alors en forme de cupule ou de godet. Celte ventouse est traversée par un crochct jaunatre, d'une teinte foncée, en forme d'hameçon et dont la partie aiguë et recourbée dépasse la caroncule. Le crochet est volumineux dans notre espèce, si l'on tient compte de la petite taille de l'animal. Notons enfin que la longueur des poils de la jambe et du tarse influe notablement sur l'aspect génèal du $T$. cntomophagus, comparativement aux autres espèces.

Les piquants ou spinules dont nous avons parlé sont aplatis et cunéiformes dans toutes les espèces; ils paraissent mousses et coupés carrément lorsqu'ils sont vus de face, tandis qu'au contraire ils sont très aigus quand ils sont vus de côté.

Le Tyroglyphus cnlomophagus présente, comme ses congénères, à la périphérie du corps : $\mathbf{1}^{\circ}$ une paire de poils entre le rostre et la première paire de pattes; ces poils sont courts, dentelés, difficiles at voir ; $2^{\circ}$ une paire plus grande, recourbée el dentelée, placée au-dessus de la première paire de pattes; $3^{\circ}$ une paire, un peu en arriere du sillon dorsal, et une autre paire, située plus en arrière, vers le point où le corps commence à s'arrondir (lig. 3 et 4 ).

A l'extrémité postéricure du corps, les poils sont moins nombreux que chez les autres Tyroglyphus. On n'en compte que quatre paires: deux paires sont insérées sur la face dorsale et deux sur la face ventrale ffig. 1 , $3 \mathrm{el}$ 4). Les poils qui sont le plus en arriere sont les plus longs; chez le mále, la paire la plus longue est portée par l'expansion membraneuse de l'extrémité postérieure du corps (fig. 1); les poils qui sont insérés sur le dos, près de l'atlache de cette expansion, sont très fins, courts et difliciles it voir (fig. 2). Des poils analogues existent chez les $T$. Siro et longior, qui, en outre, en possèdent de plus courts qu'on ne retrouve pas dans le T. cntomophagus. La face dorsale de l'abdomen de celle espece manque des six paires de poils qui existent chez les espèces précédentes; elle ne porte qu'une seule paire de poils au lieu de deux près du sillon qui sépare le céphalothorax de l'abdomen (fig. lt, a), mais elle en présente une près du bord de l'épistome (fig. $4, d$ ). Tous ces poils sont proportionmellement 
plus longs que chez le $T$, Siro, mais bien plus courts que chez le $T$. tongior.

$\Lambda$ la face ventrale, il y a chez le $T$. entomophagus un poil court entre le premier el le second épimere, un autre entre le troisième et le quatrième, comme che\% les espèces précédentes; mais il n'y en a pas entre le deuxième et le troisième, ni vers l'extrémité des deux derniers épimères (fig. 1 et 3).

Nous devons noter, en terminant cet examen minutieux, mais indispensable, que le petit volume de ces Acaricns du genre Tyroglyphus exige que l'étude des détails de leur organisation soit faite sous le microscope À un grossissement qui ne doit pas être moindre de 300 à 400 diamètres. Nous renvoyons aussi a l'explication des planches pour compléter cet exposé.

Des moyens à employer pour détruire les Tyroglyphus entomojhagus duns les collections d'insectes, el pour prévenir leurs alteintes.

Les Insectes conservés dans les collections sont d'autant plus facilement envahis par le Tyroglyphus entomophagus qu'ils ont éte moins bien desséchés, que les boites dans lesquelles on les renferme sont plus hygrométriques, et surtout que l'appartement oủ ils sont placés est plus humide.

Dès que les Tyroglyphus ont attaqué un Insecte, on s'en aperçoit extéricurement à des petits points blanchâtres qui apparaissent sur le corps des espieces à téguments lisses, ou bien à une espèce de poussière d'un blanc grisiatre, mêlée aux poils des espèces duveteuses ou pilifères. Bientòt, sous l'Insecte envalii ou sur les parois corrrespondantes de la boite, on remarque une matière d'aspect pulvérulent et grisatre, rappelant l'efflorescence des matières salines non déliquescentes. Celte poussière, sur laquelle nous avons insisté (voy. p. 323 et fig. 11), est entièrement différente des débris organiques pulvérulents gui résultent des ravages des larres d'Anthrenus ou de Dermestes; ces derniers produisent une sciure fine, noiràtre ou brunátre, mais sèche et non adhérente.

Les collections du midi de la l'rance, exposées à l'humidité, sont très rapidement envahies par les Tyroglyphus entomophagus. Les moisissures qui se montrent dans une collection doivent faire redouter les $\Lambda$ cariens destructeurs, car la moisissure et les Mites vont presque toujours de comjagnie. L'un te nous a longtemps lutté contre ces deux fléaux des collections en faisant beaucoup d'expériences à ce sujet. Nous allons passer en 
revue les divers moyens auxquels on peut aroir recours pour débarrasser les collections d'Insectes du $T$. entomophagus, et nous insisterons pareillement sur ccux que l'on doit employer pour en prévenir l'apparition.

Quand un Insecte est reconnu attaqué par le Tyroglyphus, le nieux est de l'isoler dans une botte bien sèche. Si l'Iusecte est lisse, on le débarrasse des Acariens qui le recouvrent en le brossant avec un fin pinceau pour l'aquarelle. Si l'insecte est à peine attaqué, s'il a reça seudement la poussière caractéristique qui tombait sur lui en se rendant sur la boite au point le plus déclive, il peut ètre remis en place, à la condition d'être surveillé. Mais le plus souvent on voit reparaitre sur le corps d'un Insecte simplement nettoye on brosse, de nouveaux 1'yroglyphus qui proviennent du dedans ou des cavités splanchniques ou ils sont ramassés en grand nombre. Le nettoyage est done très souvent insuffisant.

On peut avoir recours au calorique et employer la chaleur de l'étuve, celle des nécrentômes de MM. Boisduval, finenée, ele. Ge procédé a de grands inconvéniens quand l'Insecte tourne dejà au gras. D'ailleurs, si les $T$. cntomophagus meurent par l'eflet d'une température élevéc, les acufs résistent ainsi que les larves, surtout quand ils sont situés dans l'intéricur du corps, et les Tyroglyphus repullulent bientôt apres.

L'action de divers liquides offre des avantages plus réels, soit qu'on y plonge les Insectes, soit qu'on emploie seulement la vapeur de ces liquides volatils.

Nous ne dirons presque rien de l'eau pure, car si elle lave l'extérieur du corps des Insectes souillés, elle pénètre dans l'intérieur en laissant une humiditó défavorable au but qu’on veut obtenir.

L'alcool est bon pour tous les Insectes qui peuvent supporter son action sans en etre endommagés, soit pour lcurs couleurs, soit pour leurs poils ou leurs écailles. Il nous est souvent arrivé de placer des Insectes couverts de Tyroghyphus dans un flacon à large ouverture, sans prendre la peine de les nettoyer. On peut piquer au-dessous du bouchon l'épingle qui soutient l'insecte, et le corps trempe alors dans l'alcool sans aller au fond du vase. Une immersion de plusicurs heures ou d'un jour est suffisante. Nous avons employé l'alcool simple et l'alcool dissolvant une petite quantité de sublimé corrosif. $A$ près un bain d'ume heure dans ce dernier, nous lavions l'insecte dans l'alcool pur pour cnlever le sublimé qui, sans cctte précaution, forme un enduit pruineux et altère les épingles (1). Nous ne craindrions pas d'employer de préférence l'alcool arsénié ou saturé de

(1) Voyez une communication de M. Reiche faite à la société en 1835, 3c trimestie, Butl, Lxvrn. 
stryclnine (1) qui, tout en débarrassant les Insectes des Tyroglyphus, aurait l'avantage de les préserver aussi contre les Anthrènrs, etc.

Mais un très grand nombre d'Insectes ne peuvent etre plongés dans l'alcool. Pour tous ceux qui sont dans ce cas, il faut songer à d'autres procédés.

Outre l'alcool, il y a des liquides qui dégraissent parfaitement les insectes, tuent les Acaricns et enlevent leur aliment favori. Ces liquides très utiles sont l'éther, la benzine, l'essence ou l'eau de naphthe.

Quand les insectes peuvent supporter le bain d'éther ou de benzine, le moyen est radical, les Tyroglyphues sont tués, les insectes sont débarrassés des matières grasses et desséchés convenablement. On isole dans une boite hermétiquement fermée les insectes trop délicats pour etre plongés dans la benzine, et on les soumet pendant un jour ou deux à la vapeur de cette substance. L'appareil de MM. Grenier et Aubé, grand necrentôme en fer blanc, à fermeture munie d'une rigole remplie d'cau, oủ baigne l'arête du couvercle, constitue un excellent moyen à employer contre les Anthrenes et les Tyroglyphus cntomophagus.

Le sulfure de carbone (2) ne nous parait pas préférable à la benzine ou à l'eau de naphthe; l'acide sulfhydrique, très toxique, a l'inconvénient majeur de noircir les épingles, aussi ne doit-il pas être employé.

En résumé : $1^{\circ}$ nous conseillons, pour débarrasser les insectes attaqués par le Tyroglyphus cntomophagus, l'emploi de divers liquides : de l'alcool, soit pur, soit additionné de sublimé corrosif, d’arsénic, de strychnine ; de l'éther; et surtout de la benzine. Si on ne peut employer le liquide, on aura recours à sa vapeur dans laquelle les insectes resteront plongés un temps suffisant.

$2^{\circ}$ Nous croyons qu'une collection peut etre mise a l'abri des Tyroglyphus, et rien ne nous paraít meilleur que les bolles en bois sec et léger, bien préférables aux boltes en carton. Ces boites devront être placées dans l'endroit le plus sec de l'appartement. Il sera très utile de les ouvrir et de les ventiler par un temps convenable et de les exposer au besoin à une chaleur douce.

Les insectes ne seront jamais placés dans les boltes que lorscu'ils auront été bien desséchés et au besoin débarrassés des matières grasses viscérales. Cette condition est souvent indispensable pour les espèces élevées en captivité ou gonflées de sucs au moment oủ elles ont été capturées.

(1) Voy dans ces Annales un travail intéressant de M. C.-F. Lepricur (186t, p. 75 et suiv.), et un autre de M. le Dr Sichel (1861, p. 85).

(2) Voyez une Note de M. Girard, à ce sujet, dans nos Annales de 1861, p. 623. 


\section{\$2. Tyroglyphus Siro LinN, LATR.}

Ciron du fromage, Acurus casci antiqui ct Acarus farina Gerrroy, Ilist. abrégée des Insectes des environs de Paris, 1. II, p. 622, 1762.

Acarus Siro (et $\Lambda$. farinx) Lixw. Systema nature, tom. I, pars 1I, p. 1024, edit, duodecima, in-8n, 110lmix, 1767.

Acarus farinx DE GÉER, Mém. pour servir à l'histoire des Insectes, t. VII, p. 97, pl. 5, fig. 15, Stockholm, 1778.

Acarus Siro (Käsemilbe) Scurank, Enumeratio Insectorum Austriæ indigenorum, p. 512, $\mathrm{N}^{\circ}$ 1056, $\mathrm{August}$ Vindelicorum, 1781.

Tyroglyphus Siro LAxR., loc. cit., p. 185, 1797.

Mite du fromage Lyonet, Anal. de différentes espèces d'Insectes (Mém. du Muséum d'Llist. naturelle de Paris, t. XVIII, p. 282, pl. 14, fig. 15, 1829).

Tyroglyphe domestique Genvais, dans Walkenaen, Insectes apteres, t. 1II, p. 261, pl. 35 , fig. 4 (mauvaise), 1844.

Tyroglyphe de la farine Gervais, ibid., t. III, p. 262, № 4 ct pl. 35 , fig. 5 .

Corps resscrré sur les flancs, tronqué en arrière, alténué au devant du sillon circulaire; d'un gris blanchâtre, lisse, brillant. Rostre pointu, large à la base; coloré, ainsi que les paltes, d'une teinte d'un brun-rongeâtre très prononcée, surtout chez le $\delta^{\star}$. Pattes effilécs, mesurant chacune en longueur la largeur du corps, les postérieures laissant voir quatre articles sur les côtés de l'abdomen. Poits dorsaux, latéraux et postérjeurs, plus courts que les pattes.

Mâle long de $0^{\text {nim }} 12$ à $0^{\text {mm }} 42$ de millimètre, le rostre compris; d'un tiers environ plus petit que la femelle. Premieres pattes beaucoup plus grosses que les secondes, et munies, sur le deuxieme article, d'un gros tubercule conique et pointu. 'Tarses de la quatrième paire portant chacum deux tubercules ovalaires en forme de ventouses. Organe sexuel placé au niveau du premier article de la quatrième patte; une paire de ventouses copulatrices situées de chaque côté au niveau du milieu de l'anus.

Femelle longue de $0^{\text {mm }} 18$ a $0^{\mathrm{mm}} 63$ de millimetre, le rostre compris; large de $0^{\text {mm }} 12$ à $0^{\text {nu }} 30$. Penières paltes à peine plus grosses que les secondes et sans tubercule au deuxième article. Vulve située entre les quatre der- 
niers épimères, ne descendant pas au-dessous du premier article de la quatrième patte. $\Lambda$ nus sans ventouses copulatrices.

OEuf régulièrement ovoïle, long de $0^{\text {wam }} 13$, large de $0^{\text {man }} 01$ de millimètre.

Nymphers longues de $0^{\text {mam }} 14$ तो $0^{\mathrm{mm}} 18$, larges de $0^{\mathrm{mm}} 11$ à $0^{\mathrm{mm}} 13$ de millimètre, nettement hexapodes ou dépourvues de pattes postérieures. Une spinule à sommet mousse et un peu renflé, situce au lieu de poil grêle et court entre la première et la deuxième paire de pattes.

IIabite en quantité considérable sur la croùte de presque toutes les espèces de fromages un peu avancés. Ces petits animaux se rassemblent en hiver en groupes, ou par tas, dans les dépressions du fromage et s'y tiennent immobiles; dès que la température s'élève un peu, ils creusent la croûte et la rendent pulvérulente. La poussière qu'on observe alors est formée : $\mathbf{A}^{\circ}$ des excréments des Tyroglyphus Siro ayant l'aspect de pefites boules microscopiques grisatres; $2^{\circ}$ des cufs en voic de développement et des ocufs éclos, de leurs coques vides et plissées; $3^{\circ}$ de nymphes et de jeunes; $4^{\circ}$ d'enveloppes tégumentaires provenant de la mue des larves et des individus plus avancés; $5^{\circ}$ de débris de la croûte du fromage el de nombreuses spores de champignons microscopiques.

Les mouvements de ces animaux sont lents. On trouve beaucoup de femelles trainant après elles un mâle, la tete tournée en sens inverse; celui-ci est fixé par ses ventouses anales copulatrices sur la partic postérieure du corps de la femelle, mais il ne peut y avoir alors aucune jonction entre les organes sexuels. Le male reste longtemps ainsi en attendant le moment oú les lèvres de la vulve se gonflent considérablement et se renversent en dehors; c'est alors que les deux individus male et femelle s'appliquent l'un contre l'autre, ventre à ventre, et que s'opère le coït.

Ce Tyroglyphus se trouvait en quantité considérable dans de la farine de graine de lin très ancienne, répandant une forle odeur d'ammoniaque ct de fromage pourri. Cette farine avait été remise à l'un de nous (M. Ch. Robin) par M. Robinet, pour reconnaitre quel était l'Acrarus qui garnissait les parois du vase. A trois reprises, des Médecins nous ont fait remettre un ou deux de ces animaux, qu'ils avaient recueillis à la surface de plaies sur lesquelles avaient été appliqués des cataplasmes de farine de te graine lin. Une autre fois, un Tyroglyphus de cette espèce avait étẻ trouvé dans l'urine (1).

(1) Sur un Acarus trouvé dans l'urine d'un malade, par le $\mathrm{D}^{\mathrm{r}} \mathrm{A}$. Laboulbène (Comples-Rendus et Miémoires de la Société de Biologie, 2e série, t. V, p. 140 , 1858). 
L'un de nous (M. Ch. Robin) a constaté que le $T$. Siro s'est multiplié en quantité considérable dans de la farine humide répandant une odeur assez prononcéc de matières azotées, sur laquelle il avait placé un peu de poussiere de fromage contenant quelques $T$. Siro.

\section{Remarques historiques et synonymiques.}

Linné (loc. cil., p. 1024), après avoir décrit très exactement cet Acarien sous le nom d'Acarus Siro, cl lui avoir donné comme synonyme l'Acarus farina dont il ne fait pas une espèce différente, ajoule avec raison: "Ilabitat in casco farinaque, Europx, Amcrica. " Mais c'est à tort que ce grand naturaliste a donné comme synonyme des précédents le nom te l'Acurus scabici, et qu'il a ajoute: "Inter Sirones farine, scabici, phtiscos, hemitritai vix ctiamni reperi alias differentires quan à loco petitas. "

Geofrror (loc. cit., t. II, p. 622, 1762) distingue nettement le Giron alu fromage du Giron de la gale, ct il le considere comme étant le mème que celui qu'on trouve dans la farine et dans les vieux pains à cacheter.

C'est par erreur que beaucoup d'auteurs, contrairement à Linné el à Geoffroy, font encore autant d'especes de cet animal (Siron ou Giron) qu'il a d'habitat différents (Acarus Siro ou domesticus ef Acarus farine), parce qu'ils n'ont pas olsservé suffisamment ses caractères.

Audourn dit que l'Acarus domestique (Acarus domesticus DE GÉER) se. trouve ordinairement dans les collections d'insectes et d'oiseaux (Dictionnaire classique d'Jistoire naturclle, t. I, p. 44, in-8\%, ['aris, 1822). Nous avons prouvé (p. 324) que l'A. domesticus de DE Géen étail un Glyciphugus et non pas le Tyroglyphus Siro; le fait signalé par Audouin n'a par conséquent rien d'extraordinaire, prisque c'est dans les plumes et autres objets conservés dans les collections, ainsi que dans les matieres sucrées des fruits desséchés, que vivent les Glyciphagus.

G'est bien le T. Siro de Linné et de Latreilie que Galès a figuré et décrit dans sa thèse célèbre (1) comme ćtant le Ciron de lu Gate humaine. La forme du corps est exactement représentéc; le sillon transversal est seulement trop large et trop prononcé; les deux poils de l'épistôme sont mal insérés, ainsi que ceux des còtés du corps. Lauteur place à tort deux yeux sur la tête. L'insertion des pattes n'est pas exacte, pas plus que la

(1) Essai sur le diagnostic de la Gale, sur ses causes at sur les connaissances médicales pratiques à déduire des vraies notions de cette maladie. (Thèses de la Faculté de Médecine de Paris, $n^{\circ} 151, \mathrm{p}, 23$, in-10, 1812.) 
forme et la disposition des articles, bien qu'au premier abord leur configuration générale se rapproche assez de la nature pour qu'on ne puisse douter de l'espèce qui a été figurée.

Galès ne donne pas de description zoologique de l'animal, et il renvoie à la figure pour qu'on s'en fasse une idée exacte d'après cellc-ci.

Hering (1) a mal représenté le Tyroglyphus Siro ou domesticus quant à la forme du corps, les rapports avec le rostre, l'insertion des poils, l'attache des pattes, la forme du tarse, etc.; mais il a figuré la ventouse anale du mâle, sans s'occuper toutefois en quoi que ce soit de la distinction des sexes de cet animal.

Nous mentionnerons ici, mais pour mémoire seulement, une note de PAGENSTECIER, Einiges zür Anatomic von Tyroglyphus Siro (Zeitschrift für. Wisscnschaftliche Zoologic, t. II, p. 120, pl. XIII, Leipzig, 1861). Nous voulons mettre nos collegues en garde contre les inexactitudes anatomiques et zoologiques vraiment inconcevables que renferment les figures de ce travail, surtout en ce qui concerne les pièces tégumentaires et les appendices.

\section{§ 3. Tyroglyphus longlor Genvals.}

T. longior Gerv. in Walkenaer, Insectes apteres, t. III, p. 262, 184亿.

Seconde espèce de Mitc Lyonet, Anatomie de différentes espèces d'Insectes (Mém. du Muséum d'Iist. naturelle de Paris, t. XVIII, p. 283, pl. 14, fig. 8*, 1829, désignée à tort sous le nom d'Acarus farinx LATR. dans l'explication de la planche de Lyonet, p. 311).

Corps plutôt arrondi que resserré sur les flancs, arrondi en arrière, brusquement rétréci au-devant du sillon circulaire; d'un gris blanchâtre, lisse, brillant. Rostre pointu, peu élargi à la base, à peine coloré en brun-rougeatre pale, ainsi que les pattes, qui sont semblables dans les deux sexes. Pattes grêles, à tarse long, effile, les postérieures un peu moins longues que la largeur du corps, ne laissant voir que trois articles sur les côtés de ce dernier. Poils dorsaux, latéraux et postérieurs, bien plus longs que les pattes el à peu près autant que le corps lui-même.

Male long de $0^{\max } 17$ à $0^{\text {max }} 64$ de millimètre, d'un sixième ou d'un septième seulement plus petit que la femelle. Tarses de la quatrième paire

(1) Die Kritzmilben der Thieve und einigo vertandte Arten (Nova Acta physico-medica Naturx Curiosorum, Yrastislavie ct Bonnæ, t. XVIII, pars secunda, p. $573, \mathrm{pl}, 14$, fig. 12 ct 13, in- 40,1838 ). 
de pattes portant deux tubercules en forme de ventouses; ces tubercules très petits. Organe sexuel situé au niveau de la hanche de la quatrième paire de pattes. Anus placé immédiatement au-dessous de lui, avec les ventouses copulatrices situées à l'extrémité inférieure de l'ouverture analc comme dans le $T$. entomsphagus.

Femelle longue de $0^{\text {min }} 20$ at $0^{\text {min }} 75$ de millimètre, large de $0^{\text {maw }} 44$ à $0^{\mathrm{mm}} 39$. Vulve placée entre les épimères et les hanches de la quatrième paire de pattes; anus séparé d'elle par un intervalle marqué.

OEuf régulièrement ovoïde, long de $0^{\text {man }} 45$, large de $0^{\text {mm }} 09$ de millimètre.

Nymphes longues de $0^{\mathrm{mm}} 16$ a $0^{\mathrm{mm}} 18$, larges de $0^{\mathrm{mm}} 10$ de millimètre.

Ons. Les oufs et les nymphes sont petits, relativement à l'animal adulte ct à ceux des autres espèces.

Nous ferons observer que, chez le 7 . longior, les poils dorsaux du corps, tous plus longs, plus gros et d'une couleur plus foncée que chez le $T$. Siro, sont tous très finement dentelés, mais seulement à un très fort grossissement de 500 diamètres réels. Les poils des Glyciphagus montrent leurs dentelures avec un faible grossissement de 60 diamètres.

Dans les gros individus du T. Siro, les poils de l'épistôme et les deux qui se trouvent au devant du sillon transverse sont légèrement dentelés, mais sculement à un grossissement de 500 diamètres.

Les poils courts de la face ventrale du corps sont lisses dans les espèces de Tyroglyphus dont il vient d'etre question.

IIabite avec le précédent, mais on en trouve à peine un pour cent sur Ic Scmoncel, huit ou dix pour cent sur le Roquefort, et un peu plus sur le vieux fromage de Gruyère. Il est très agile, le mâle surtout; la rapidité de ses mouvements, par rapport au $T$. Siro, le fait distinguer facilement. La taille plus considérable, la longueur des poils brillants, dressés et qui hérissent la surface du corps, donnent à cette espèce un aspect frès remarquable.

Des Tyroglyphus de cette espèce ont été placés sur de la farine en voic de putréfaction, en même temps que des $T$. Siro dont il a été question (p. 333), et avec lesquels ils vivaient sur du fromage de Roquefort. Les Tyroglyphus longior ne s'y sont pas multipliés comme les $T$. Sire, et ils sont morts après un ou deux jours. Cette expérience a cu lieu au mois d'avril; nous l'avons répétéc au mois de juillet, et nous devons dire que nous avons constaté la multiplication du $T$. longior, dans ces conditions, sur de la farine aussi bien que sur le fromage, mais cependant avec un peu plus de lenteur. 


\section{EXPLICATION DES FIGURES DE LA PLANCIE $10^{\circ}$.}

Fig. 1. Tyroglyphus cntomophagus NoBis, mále, vu ch dessous, ì un grossissement de 100 fois en diamètre. On remarque à la partic postérieure une bordure semi-lunairc, caractéristique du sexe male. $\Lambda u$-rlessus de cette bordure on voit la fente longitudinale de l'anus avec ses deux ventouses copulatrices anales et leurs deux pelites spinules; au-devant de l'anus, l'appareil génital externe du màle avec ses deux paires de ventouses genitales, une paire de chaque coté.

On observe encore de chaque coté un poil très court entre chaque paire d'épimères, c'est-à-dire entre la première et la deuxième, el entre la troisième et la quatrième. On ne voit pas au-devant du troisième épimère une paire de poils semblables comme dans les $T$. Siro et longior.

Fig. 2. Portion de la bordure scmi-lumaire postérieure de l'abdomen du même Tyroglyphus male, grossic 200 lois et vue en dessus, pour montrer l'insertion des deux poils dorsaux postéricurs vers la jonction de cette bordure avec l'abdomen.

Fig. 3. T. cnlomophagus femelle vue en dessous, à un grossissement de 100 fois. On ne trouve pas à la partie postérieure la bordure semi-lunaire. L'anus est terminal et sous la forme d'une fente avec deux lèvres saillantes; une paire de poils sur les còtés, et une autre paire au-devant de lui. La vulve est placée entre les quatre pattes postérieures et représente un V renversé; les deux paires de vontouses gínilales se montrent de chaque côté, mais clles sont dépourvues des poils que l'on trouve dans les T. Siro et longior.

Fig. 4. Le mème individu femelle vu en dessus. On remargue à la partie postérieure la fente anale prolongée sur la partie dorsale de l'abdomen, avec une longue paire de poils sur ses côtés, un à droite et un à gauche (ce dernier n'existe pas sur la figmre), et une autre paire plus courte, en avant et en dehors. Le dos est dépourvu des poils que l'on trouve dans les autres espèces, mais les côtés de l'abiomen offrent les deux paires de poils qu'on trouve ordinairement che\% les autres Tyroglyp/us; ces poils sont dans le $T$. cntomophayzs plus longs chez le màle que cliez la femelle (comparez les fig. 1, 3 et 4).

a. Poit unique inséré au-devant du sillon séparant le céphalothorax te l'abdomen; il y a deux de ces poils, de chaque côté, dans les aulres espèces. (Voy. l'OBs, sur ces poils des $T$. longior et Siro, p. 335.)

6. Poil barbclé inséré au niveau de la première paire de pattes. 
c. Très petit poil spiniforme insćré entre la première paire de pattes et le rostre; il est lisse dans notre espèce, mais finement dentelé chez le T. longior.

d. Poil inséré près du bord de l'épistôme; au-devant de ce bord on aperçoil le rostre dépassé sur le côté par le palpe maxillaire.

Fig. 5. Moitié tatérale gauche du rostre, privée de ses mandibules et montrant en dessous la lève, les máchoires et le palpe maxillaire, vue a un grossissement de 500 diamètres.

c. Le menton, subdivisé en pièce continue arec la lèvre; f. Poil labial; g. La languctte; h. Palpe tabial, avec un poil court à sa base. Le sommet du palpe est surmonté d'une courte spinule mousse et dépasse le sommet plissé de la lèvre.

$i j$. La machoire soudée à sa congénère sur la ligne médiane en $i$, et formant une seule piece transversale.

$j m$. Le palpe maxillaire vu dans son ensemble; $j$. Articulation du premier article de ce palpe sur la máchoire; $k$. Premier articte du palpe maxillaire soudé sur toute la longueur de son bord interne avec la lèrre; ce premier article porte un poil vers le milien de sa longueur; $\iota$. Deuxième article du palpe maxillaire portant deux poils; l'un des deux est plus long que l'autre et inséré sur le bord antérieur; on remarque, de plus, que ce poil est au moins du double plus long chez le màlc que cher. la femelle (comparez les fig. 1 et 3 ); $m$. Troisième article du palpe maxillaire, plus grêle que les précédents, portant, près de son extrémité, une courte spinule mousse.

Fig. 6. Mandibule droite vue par la face interne renversée et grossie 120 fois. Son onglet supérieur est continu avec le bord correspondant et convexe de la base. L'onglet inférieur est nobile, denté en sens inverse du précédent et un peu plus court que lui.

Fig. 7. Première patte, grossie, comme les suivantes, 200 fois. C'est sur' ta hanche que se trouve inséré le premier poil de la patte (voyez fig. 1 et 3$)$.

Fig. 8. Deuxième patte, un peu plus grêle que la précédente. Le poil du deuxième article, ou exinguinal, est un peu plus court que sur la première patte. Le bord du troisieme article ou fémoral ne porte qu'une seule spinule mousse au lieu de deux comme sur la première patte (comparez ces spinules et leurs tubercules basilaires, fig. 7 et 8). Le long poil du quatrième article ou jambe est plus court que celui de la première patte. On remarque l'inverse pour le poil du tarse ou cinquième article. La spinule de ce tarse n'est pas accompagnée des deux spinules plus courtes qui se trouvent sur la première palte. 
Fig. 9. Troisieme patte, jambe et tarse et leurs poils. Les deux articles précédents manquent de poils. (Voyez fig. 3).

Fig. 10. Quatrième patte, jambe et tarse. Le poil postérieur de la jambe est beaucoup plus court que le poil correspondant de la troisième patte. On remarque une disposition inverse sur les deux longs poils du tarse. Le bord antérieur et inférieur des dernières paltes se termine par une pointe courte et aiguẻ.

Le fémoral de la quatrième patte manque de poils; le trochanter en offre un très court, mais la lianche en est dépourvue à la quatrième patte, tandis qu'elle en porte un sur la troisieme. (Voyez fig. 3.)

Les quatre pailes offrent a l'extrémité du tarse une caronculc membraneuse avec un crochet corné disposé en hameçon, à pointe tournée en bas et en avant.

Fig. 11. Poussière recueillie au fond d'une bolte ravagéc par le $T$. cntomophagus, vue à un grossissement de 40 diamètres.

On remarque en bas un Tyroglyphus cntomophagus vu de côté; dans le haut de la figure, un autre individu de petite taille vu sur la face dorsale. On observe à gauche les derniers articles d'une antenne du Bembidium lamprosi IIERnst, celere FAB. (Faune entomologique française, I, 173). On voit encore les dépouilles de larves et de nymphes de Tyroglyp/ius, et enfin des filaments végétaux qu'on trouve dans beaucoup de poussières et qui proviennent en majeure partie dans les boites, soit des fibrilles qui ont servi à la confection du papier qui recouvre le fond, soit des linges avec lesquels le fond de ces boites a été essuyé.

aа. Coques plissées des aufs éclos du Tyroglyphus entomophagus. 


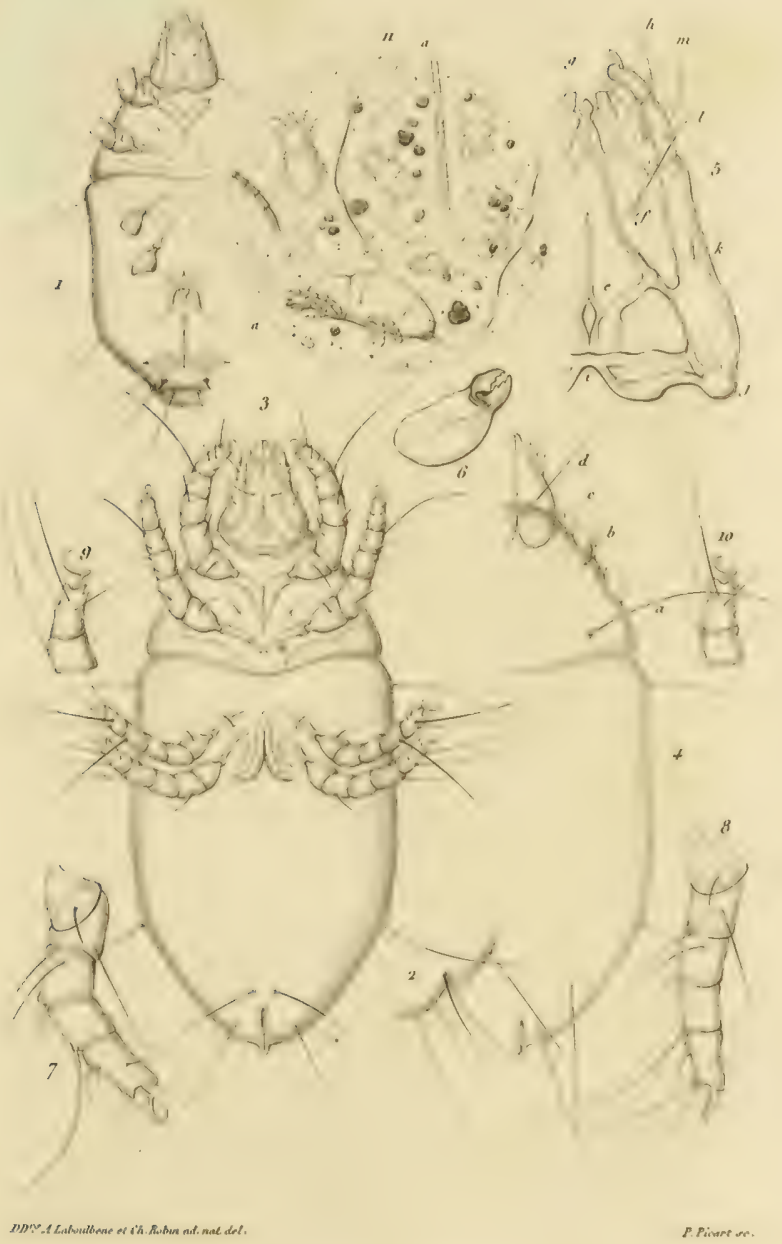

Tigroglyphus entomophusus 



\section{DESCRIPTIONS}

\section{DE \\ Plusieurs Larves de Coléptères, avec Remarques}

Par M. le docteur Alexande LABOUlbéne.

(Séance du 11 Juin 1862.)

1. Deseription de la larve du Staphylinus chloroplerus P'axzer.

(Voy. planche 13e, fig. 1 à 7.)

Lanva hexapoda, capitatu, clongata, coriucce, sctifcra; capite majore, rufesconte, antice denticulato; antennis 4-articulatis, luteo-albidis; stemmatibus quatuor; mandibutis apice brunneis, arcuatis, haud dentatis; maxillis lobo interno conico, articulato, palpis catcrnis elongatis, 4-articulatis; labio clongato, palpigero, palpis 2-articulalis; segmentis thoracis anco-brunneis, nitidis, mothorace magno; scgmentis abdominis mollioribus, suma coriaccis, obscuris, postice lateratiterque lutes-albido marginatis, scgmento ultimo longe bicandato; pedibus lutcis, valuli spinosis, tarsis unizngulatis. - Longitude septem linens aquat (15-16 millim.).

IIabilat in sylvis Fonlis-Belluquei, inter assulas recous sectas ad radices arborum ocissime currens.

IARVE allongée à grande tète rouge, à llıolax d'un brun luisant, un peu bronzé, avec la bouche, les antennes et les pattes d'un jaune blanclıitre: abdomen mobile, recouvert de plaques d'un gris noiratre. Corps couvert de poils sétiformes, prolongements du dernicr segment abtominal très longs et pourvus de 5 soies.

Téte grande, d'un fauve rougeatre clair, avec une ombre noiritre en avant entre les yeux, une ligne blanchatre el fine nait de part et d'autres derrière la base de chaque antenne, puis va en s'arrondissant s'unir à celle du côté opposé, et enfin se prolonge en arrière en forme d'Y grec; une autre pelite ligne blanchatre existe de chaque coté de la tèle (Gig. 2). $\Lambda$ n- 
tennes et parties de la bouche d'un jaune blanchâtre. l'artie antérieure de la tète élargic, còtés arrondis; épistome et labre confondus; bord antétéricur offrant neuf dents inégales, une médiane très petite, une autre très grande de chaque côté de celle-ci el 3 autres moyennes et à peu près égales, à droite et à gauche (fig. 2). Antennes longues, grẻles, formées de 4 articles, le $1^{\text {er }}$ très court, le $2^{\circ}$ allongé, plus court cependant que le $3^{\circ}$ qui est renflé à l'extrémité et taillé en biseau au bord interne, où il porte un atticle supplémentaire, le $4^{\circ}$ petit offrant des poils que la figure représente, ainsi que les poils du $3^{\mathrm{e}}$ article (fig. 2). Mandibutrs longues, arquées, d'un brun noirâtre, surtout à l'extrémité, aiguês, inermes. Machoircs à lige peu épaisse et insérée en dehors, au-dessous el près des mandibules, ćlargie à son extrémité; lobe grèle, un peu conique, dirigé en dedans, court, l'extrémité n'atteignant pas la moitié du $2^{\circ}$ article; palpe maxillaire de 3 articles, le $2^{\mathrm{e}}$ plus long que le $1^{\mathrm{er}}$, le $3^{\circ}$ le plus long de tous, très conique et pointu (fig. 3). Licrre allongée, terminéc par une languette petite et triangulaire; palpes labiaux greles, biarticulés, le $\boldsymbol{1}^{\text {or }}$ article le plus long (fig. 3). Cette lève est supportée par un menton un peu cordiforme, bordé par un trait corné et d'un brun roux.

Yeux formés de 4 ocrltes placés sur le côté et derrière la base des mandibules (fig. 2 et 4 ), le plus inférieur est le moins grand de tous.

Thorax d'un brun clair un peu bronzé el luisant en dessus. Prothorax th còlés arrondis, plus grand que le mésolhorax et celui-ci que le mélathorax. Chacun des segments thoraciques porte une paire de pattes jaunatres, de 5 articles, à jambe et tarse garnis de 2 rangs d'épines, et terminées par un onglet unique, lisse, pourvu de deux petites épines sur sa partic dorsale (fig. 5).

Segments abrominaux all nombre de neuf, les derniers diminuant de largeur, $3^{\mathrm{e}}, 4^{\mathrm{c}}$ et $5^{\mathrm{c}}$ les plus grands; le $9^{\mathrm{e}}$ segment of rrant en dessus deux prolongements biarticulés, et en dessous un pseudopode anal. I'rolongensent a $1^{\mathrm{er}}$ article muni de 5 soies (fig. $6 \mathrm{el} \mathrm{7}$ ), le $2^{\circ}$ article ayant à peine un poil très court, est terminé par une longue soic. Le dessus de tous les segments abdominaux présente deux plaques d'un gris noiràtre, maculées de traits noirs et séparées par une ligne médiane dorsale, blanchâtie, qui est la continuation de la ligne fine el blanchatre du vertex qu'on retrouve avec de l'attention sur le thorax. En dessous, l'espace thoracique compris entre les pattes est blanchatre, les segments abdominaux offrent des plaques grisâtres, le pscudopode anal est formé par l'anus prolongé en tube et articulé sur le $9^{\mathrm{e}}$ segment (fig, 6).

Sur les cotés du corps on trouve une plaque étroile, grisatre, longitudinale et pilifêre, et au-dessous un autre espace coriacé, ou sont insérés de nombreux poils (fig. 6). 
Sligmates at nombre de 9 paires, la $1^{\text {re }}$ situese sur la membrane d'union dì prothorax avec le mésothorax, elliptique, grande, transversale, les huit autres arrondies, placées assez près du bord antérieur des $1^{\mathrm{er}}, 2^{\mathrm{e}}, 3^{\mathrm{e}}$ et $4^{\mathrm{e}}$ segments alddominaux; elles gagnent le tiers antérieur vers les $5^{\mathrm{e}}$ à $8^{\mathrm{e}}$ segments. Péritrème roussâtre. Tous les stigmales ablominaux sont situés au-dessus de la plaque longitudinale supérieure qu’on voit sur la larve examinée de profil (fig. 6).

Les poils sétiformes dont cette larve est revètue se trouvent sur la tête entre les dentelures de la partie antérieure, aux antennes, ainsi cque l'indique la figure 2 , et autour de la tête. $\Lambda$ u thorax on observe 3 poils principaux de chaque côté des segments; sur l'abdomen deux poils principaux dorsaux sont placés en avant et en arrière de chaque plaque grisatre dorsale, le postérieur et externe est très longr, d'autres poils plus petits s'élèvent sans disposition bien régulière; si l'on considere de chaque côté de la ligne médiane, on trouve une rangée de 3 poils, obliqute d'avant en arrière et de dedans en dehors, et un poil plus petit se voit entre le dernier poit de la rangée oblique et la ligne blanche dorsale. De chaque côté dı corps, il y a deux poils sur la plaque grisatte longitudinale supérieure et 3 à 5 sur l'espace grisâtre inférieur. En dessous, les poils sont disposés à pent près comme en dessus. Le pseudopode anal est garni en dessous de 4 rangées de poils, les 2 rangées internes sont les plus fortes.

La NYMPIE qui provient de cette larve m'est inconnue.

Remarque. Gette larve, d'une rare ćlégance de formes, ofire tous les caractères des larves de la famille à laquelle elle appartient. Elle est beaucoup plus svelte que celle du Staphylinus olcns représentie dans les Forstinsecten de liatzebung, planche ${ }^{\mathrm{re}}$, fig. 14, B.

Elle a été découverte pendant la promenade annuelle de la Société, faile celle annec ì Fontainebleau te $\mathbf{4}^{\text {er }}$ juin. J'en ai pris un indivilu, et deux autres ont été capturés par M. Martin. Mes cher's collègues, Mu. Reiche, Coquerel, Fairmaire, Javet, Raris, de Bonvouloir, de Barneville, etc., qui faisaient partie de l'excursion, étaient présents à notre découverte. C'est parmi les copeaux de bois recourrant les racines des hetres récemment abattus que courait avec une très grande agilité la larve que je viens de décrire, en compagnie du Staphylinus chloroptorus PAxzer (i'aune Entomologique française, I, 506). Or, la présence de ce seul et bel insecte, de ce rare staphylin à habitudes speciales, avec la larve adulte, et de plus un air de ressemblance qui attire les yeux les moins prérenus, nous ont tous porté a la considérer comme devant appartenir à cet insecte. 11 y a de ces inspirations, de ces appréciations qui ne trompent pas, el iri le jugement a été unanime. 


\section{Description de la larve du Calathus gallicus Farnm. el Lanour.e.}

$$
\text { (Pl. 13e, fig. } 8 \text { ì } 15 \text {.) }
$$

LARva hexapoda, capitata, cylindrico-clongala, nigra, glaberrima; supra coriace', linea dorsali impressa; segmento ullimo brhamato; capite corneo, depresso; antennis 4-articulatis; stemnatibus sex; mantibutis unidentatis; muxillis luteo-griscis, lobo interno palpiformi, biarticulato, palpis externis 4-articulalis; labio palpigero, palpis biarticulatis; pedibus rufo-brunneis, spinosis. - Novem lineas paulò superat (21-22 mill.).

IIabitat in sylvis Fontis-Bellaquei.

LArve noire, allongée, cylindrique, da antennes, máchoires et lèvre d'un gris jaunatre; dernier segment ayant deux crochets; pattes d'un brun ferrugineux.

Tŕle trapézoüde, avec un sillon arque de chaque côté et une place élevée, luisante au milieu (fig. 9). lipistome soudé avec le labre; bord antérieur de la tête avancé sur la ligne médiane oủ il est légèrement échancré, formant de chaque côté un prolongement triangulaire, faiblement arrondi à l'extrémité. Anternes assez courtes, d'un gris jaunatre, composées de 4 articles, le $4^{\text {er }}$ court, le $2^{\text {e }}$ le plus long, le $3^{\text {e }}$ un peu élargi à l'extrémité, le $4^{\circ}$ le plus petit; pas d'article supplémentaire inséré sur le $3^{\circ}$ article (fig. 9). Mandibules noires, longues, aiguès, falciformes, ayant au tiers inférieur une dent crocliue, arquée et recourbée en arrière (fig. 9). Machoires d'un gris jaunatre ainsi que la lèvre; tige maxillaire un peu élargie au sommet, ciliée à la parlie interne, avec une très petite épine terminale; lobe palpiforme formé de 2 articles, le $1^{\text {er }}$ plus court que le secotod, l'extrémité de celui-ci dépasse à peine le milieu du $2^{e}$ article des palpes maxillaires; ces palpes sont longs, 4-articules, le $\mathbf{1}^{\mathrm{er}}$ article est deux fois plus petit que le suivant, celui-ci est le plus long de tous, les $3^{e}$ et $4^{\circ}$ articles sont presque égaux (fig. 10). Lìre triangulaire, clargie en haut, languctle peu saillante el arrondie. Palpes labiaux de 2 articles, le $2^{\mathrm{e}}$ plus grele que le $1^{\mathrm{er}}$ et faiblement élargi à l'extrémité (fig. 10). Ocelles au nombre de six, situés près de la base des antennes sur un espace elliptique, transversal et un peu élevé; ils sont disposés sur deux rangées, ainsi que l'indique la figure 11 ; le plus petit est l'interne de la $2^{\mathrm{e}}$ rangée.

Prothorax allongé, à peine trapézoide, plus élevé en arrière qu'en arant, côtés faiblement arrondis en avant; mésothorax un peu plus grand que le métathorax (fig. 8). Les segments thoraciques ressemblent aux sfgments abdominaux qui les suivent; ceux-ci, au nombre de 9 , sont presque égaux en 
longueur, le $9^{e}$ est échancré el terminé par deux appendices arqués, relevés en haut et un peu en dehors, non articulés, finement granuleux, munis de 2 saillies mamelonnées et de quelques longs poils (fig. 8, 12 et 13). Un sillon médian peu profond s'étend sur toute la partie dorsale du corps. Les segments sont finement bordés par une ligne enfoncée qui se prolonge au bord antérieur (fig. 8 et 12).

Dessous du corps peu bombé, presque plan. Dessous de la tête séparé en deux moitiés par un sillon profond (fig. 10), chacune représente un ovale d'un brun rougeâtre luisant bordé de noir. Prothorax très fortement échancré, ayant en avant une sorte de hausse-col ou de plaque noiràtre, en croissant; le mésothorax et le métathorax n'offrent que quelques points ou taches noirâtres entre les pattes. Le $\mathbf{4}^{\text {er }}$ segment abdominal montre 4 taches ou plaques carrées et juxtaposées; les $2^{e}$ et $3^{e}$ segments en ont d'autres disposées suivant la figure 14 ; les $4^{\circ}$ et $5^{\circ}$ en offrent d'à peu près semblables; celles des $6^{\circ}$ el $7^{\mathrm{C}}$ segnents n'ont pas la plaque postérieurc divisée perpendiculairement; $8^{\circ}$ segment avec une plaque simple sans division transversale ni verticale; $9^{\circ}$ segment pourvu d'un pseudopode anal, tubuleux (fig. 12). Chacun des segments du thorax et de l'abdomen a sur les côtés des plaques latérales, celles de l'abdomen sont allongées (fig. 12).

Pattes robustes, d'un brun ferrugineux, a cuisses fortes, les 3 derniers articles très épineux en dessous à leur partie inférieure et offrant une couronne de piquants aigus à l'extrémité inférieure de ces articles (fig. 15). Tarses avec 2 rangées de ces piquants. Ongles doubles, presque droits.

Stigmates au nombre de 9 paires : la $1^{\prime}$ 'transversale, grande et elliptique, située au bord antérieur du mésothorax; les autres paires arrondies et placées près du tier's antérieur de chaque segment abdominal de-

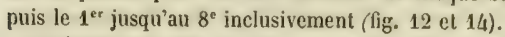

Quelques poils longs et roussàtres existent au bord antérieur de la tête, et une paire à droite et à gauche; le prothorax a aussi deux poils de chaque còté; les derniers segments abdominaux en offrent pareillement, ainsi que les appendices ou crochets arques et le pseudopode anal.

NrMpis inconnue.

Remarque. Cette larve est certainement celle d'un Carabique; je crois inutile de discuter ses caractères, tant ils sont évidents. Je noterai l'ahsence d'un article supplémentaire aux antennes, silué d'ordinaire à l'extrémité et en dehors du $3^{\text {e }}$ article. J'ai eu soin de figurer la disposition d'un crochet terminant l'abdomen (fig. 13) et de représenter les plaques rentrales des $3^{\mathrm{e}}$ et $4^{\circ}$ segments rus en dessous; on trourera, je pense, dans ces derniers organes, des traits caractéristiques quand l'étude des larves cles Cưrabiques sera plus avancée (fig. 14). 
J'ai pris celte larve à Fontainebleau, dans la même journée où a été capturée la larve du Staphylinus qui précède. Elle courait sous les détritus végétaux, les morceaux de bois humide et la mousse, en compagnie du Calathus gallicus (Faune Entomologique française, I, 71). J'ai cru devoir la rapporter à cet insecte dont l'habitat est assez spécial.

III. Remaryues sur les palpes maxillaires et labiaux de la larve de l'A Eus Robinii Laboulbène.

Mon ami M. le docteur Ch. Coquerel, en faisant connaltre dans nos Annales (année 1850, page 529) la larve de l'Xspus Robinii qu'il avait découverte à Brest dans l'Anse des gardes-marines, dérrivit de la manière suivante les parties de la bouclie: "Mandibules très fortes, pointues, recourbées, tranchantes, armées d'une dent pointue, très forte, à leur partie interne. Machoircs próminentes, plus longues que les antennes, surmontées de deux palpes de trois articles terminés en pointe. Livve inféricurp un peu allongée. Palpes de trois arlictes, plus courts que les maxillaires. "(Loc. cit., p. 532.)

Depuis cette époque, M. Édouard Perris a completé par les larres des Dromius 4-notatus Duftscr., et Bembidium (Tachys) nanum Gru,Lnir, son admirahle travail sur les Coléoptères qui vivent sur le pin maritime (voyez nos Annales, 1862, p. 172 et 175). Au sujet de ces larves, il a résumé les caractères que présente à l'observateur la bouche des larves des Carabiques; et il doute que la larve de l' Aspus offre des palpes maxillaires de 3 articles et des palpes labiaux également de 3 articles. Dans un langage mesuré, ainsi qu'il convient dans une discussion vraiment scientifique et entre collègues qui s'estiment, il émet l'ilèe que M. Coquerel a été induit en erreur en comptant les articles des palpes chez la larve de l'Epus, et il demande une vérification nouvelle. (Ioc. cit., p. 177-178.)

En apprenant la demande de M. Perris, j'ai pensé que je pourrais y répondre, quoique d'une manière indirecte. En effet, j'ai prouvé (Anmules de 1858, p. 83) que M. Westwood, au lieu de décrire la larve de la Micralymma brcvipenne, avait eu en sa possession celle d'un Espus : par conséquent les figures qu'il en avait données pouvaient servir à élucider la question. En jetant les yeux sur la figure $3, \mathrm{C}$ de la planche $2^{2}$, où j'ai rapporté la figure donnée par M. IVestwood, on voit quatre articles aux palpes maxillaires et trois articles aux palpes labiaux. L'opinion de 
M. Perris, au sujet des palpes maxillaires, était donc vérifiée et se trouvait juste.

Je puis ajouter, pour compléter ce renseignement, que sur des larves d'Espus que M. Ch. Javet possède dans sa collection, M. Ch. Coquerel s'est assuré, avant son départ pour l'île Bourbon, que les palpes maxillaires avaient 4 articles. M. Javet $m$ 'a obligeamment donné une de ces larves et j’ai moi-mème complé ce nombre; il n'existe que deux articles aux palpes labiaux.

\section{Deseription de la larve et de la nymphe}

de l'A pion violaceum KurBY. (Voy. planche 13e; fig. 16 à 22.)

LARva arcuala, lutco-athida, clongata, paulis plicata, mollis, capitala, apoda, fere glabra; capite cornco, subrolundo, rufo-flacescente; antennis brevissimis, biarliculatis; stemmate singulo, nigro; mandibulis duris, bidentatis; maxillis intus stosis, dor'so palpigrris, palpis biarliculatis; labio cordiformi, palpis bierliculatis; stigmatibus novcm paribus, fore inconspicuis. - Bis lineam cum dimidia a'quat (5 1/2 millim.). - IIabilat in caulibus Rumicis acetosie hortensis, medullam edens.

Nyмpн clongata, nuda, obvoluta; albida, oculis obscuris; postice attenuata, nec non appendices duas gerens. - Lineam, terque linex terliam partem, aquat (4 millim.).

LARve allongée, arquée peu fortement, atténuéc en arrière, très peu plisséc, d'un blanc jaunatre; tête d'un jaune lauve avec l'extrémité des mandibules brune et un ocelle noir (fig. 16).

Títc offrant en dessus deux traits clairs et en forme d'Y sur le vertex; bord antérieur échancré, portant en dehors les deux antcmes biarticulées et très difficites à voir (fig. 18). Un gros ocelle noiràtre. Épistome presque droit; labre arrondi, avec huit poils courts sur les bords. Mandibules fortes, bidentées (fig. 19). Machoirrs à lobe interne muni de poils courts et larges, arrondi, et portant au côté externe un palpe de 2 articles, le $1^{\text {er }}$ large et court, le $2^{\mathrm{e}}$ conique (fig. 20). Liwe épaisse, presque cordiforme, arrondie en haut avec 2 très petits palpes biarticulés (fig. 21).

Les trois scgments thoraciques ressemblant beaucoup aux neuf scgmon/s abdominutu, à peine plus épais, ayant en dessous 3 espaces de chaque côté, six en tout, discoïdaux, un peu saillants sur lat larve virante, munis de 3 petits poils. Le corps est très peu plissé, mesque glabre. Les mamelons latéraux sont très peu marqués. Anus ayant la forme d'une fente transversale (ig. 16). 
Stigmates très petits, très difficiles à voir, le premier situé au hord postérieur du prothorax, les autres sur les $4^{\circ}-11^{\circ}$ segments.

Le corps montre, à un très fort grossissement, de fines aspérités sur le dos des segments, et quelques rares poils courts; quatre à cinq poils assez longs se trouvent sur la tète.

Je dois faire remarguer la ressemblance te cetle larve avec celle de l'Apion curvirostre Sciroenir. et de l'A. basicorne Ildigen, qu'Héeger a représentées (Sitzungsberichte $d e$ K. Akademie der Wissenschaften Wien, math.-naturwiss. Classe, B. XIV, IIeft 2, 1854 et B. XXIV, Ieft 2, 1857). Ces deux dernières larves ont le corps peu plissé, les stigmates extrêmement petits, par exemple la larve de l'A. basicorne, ou lléeger n'en représente que 6 paires, à tort, sclon moi. Les stigmates ne sont pas figurés pour la larve de l'A. basicorne, et le texte n'en fait pas mention.

L'ocelle unique de la larve de l'A, violaceum, observé à un trìs fort grossissement, offre les apparences de la figure 22 ; je l'ai vu clair au centre avec 8 à 9 prolongements formés par des granulations pigmentaires. Dans un autre examen, je l'ai trouvé disposé en croissant et non en cercle. La vision doit etre fort imparfaite avec un pareil organe.

NyMpite blanchâtre, allongée; yeux noirâtres; six poils sur le prothorax, ayant ì leur base un petit renflement ou une petite tubérosité. Antennes noueuses avec de petites saillies surmontant les articles; un poil épais et recourbé à l'extrémité de chaque cuisse, en dessus. Abdomen terminé par deux appendices clivergents et recourbés en arrière (fig. 17).

J'ai déjà figuré les poils des cuisses pour la nymphe de l'Orchestes rufus (Annales de 1858, pl. 7, III, fig. 10). On les retrouve chez plusieurs des nymphes représentées dans Ratzebung (voy. Die Forst-insecten, Kæfer, Taf. IV et V).

Je dois la connaissance des premiers états de l'Apion violaceum à M. Picart, qui les a si bien gravés sur la planche $13^{\circ}$. Il m’a envoyé les larves, les nymphes et l'insecte parlait récemment éclos qu'il avait trouvés aux mois de mai et juin dans les tiges d'Oseille (Rumex acclose L). La larve se creuse des galeries en vivant aux dépens de la moelle des tiges de l'oseille commune des jardins, et elle se change en nymphe sans préparation autre que d'amincir un point de la tige pour favoriser la sortie de l'insecte parfait.

Apion violuceum Ktrby, Trans. Linnæan Society, I. IX, p. 65, pl. 1, fig. 16 (1808). 


\section{Description des métamorphoses de l'A pion hematocles Kırny.}

(Voy. planche 13e, fig. $23 \mathrm{el} 24$. .)

LARva incurvo-hemuta, aurantiaca, crassiuscula, plicata, apoda, fore glabra; capile ut in larva $\Lambda$ pionis violacei. - Lincem cum tertia parte xquat (3 millim.).

IIabilat in foliis nec non petiolis Rumicis acetosellæ, gallas producens; Campo Lutetiono, Clamart dicto.

Nrмpна aurantiaca, crassiuscula.

Cette larve ressemble à la précédente, majs elle s'en distingue au premier coup d'œil par sa belle couleur orangée, par sa forme plus ramassée, les segments du thorax plus épais, à pseudopodes plus saillants; par son corps plus plissé, nettement mamelonné sur les côtés. Les antennes sont plus faciles à voir que sur la larve de l'A pion violaceum; mais j'ai à peine entrevu les stigmates, ce qui tient évidemment ì ce que leur péritrême est peu coloré et se confond avec la teinte du corps. Les téguments sont très finement couverts d'aspérités au microscope, et ils offrent des poils très courts et très rares sur le dos des segments.

La NYmpie est d'une couleur orangée comme la larve, et offre les caracteres de celle de l'Apion violaçum. Elle esł un peu plus ramassée. Je me suis assuré qu'elle porte à l'extrémilé du corpss deux prolongements arqués et divergents et des nodosités sur chaque article des antemnes, etc.

J'ai constaté sur cette larve, ainsi que sur plusieurs autres diversement colorées, que la couleur tient à un pigment sous-jacent, ou à la teinte des parties profondes. Quand celtc larve ou sa nymphe ont été plongées dans un liquide qui resserre les parties internes, celles-ci se détachent de l'enveloppe qui se montre alor's telle qu'elle est, c'est-i-dire tout a fait incolore et transparente.

Mon cher ami et collegue le doctenr' Signoret m'envoya, l'année dernière, des feuilles de Rumex acolosellu qu'il avait trouvées dans les clairières du bois de clamart, et (qui présentaient sur la nervure médiane et parfois sur les pétioles des renflements insolites (roy. fig. 24). Ces feuilles renfermaient dans ces renllements des larves d'un jaune orangé; je les plaçai dans des conditions favorables pour oblenir l'éclosion de l'insecte qu'elles nourrissaient, et j'en vis éclore l'Apion hamulodes KinBX, Trans. Linnaan Society, t. IX, p. 76 , pl. 1, fig. 16 (1808). - A. frumentarium PмҮкuL..

Celte année, au commencement du mois de juin, j’ai été faire arec mes 
collegues MM. les $D^{r}$ Signoret, $\Lambda$ ubé et Grenier, une bonne provision de fevilles de Rumcx acclosetla $\mathrm{L}$. allaquées, et j’ai décrit leurs habitants.

L.es renflements des feuilles et des pétioles sont de véritables galles constituées jar un grand épaississement ou une hjpertrophic du tissu végélal autour de la larve qui en habile la cavité. Quand on fend la partie renflée, on y trouve une larye ou une uymphe au milieu d'une petite loge de longueur variable. l'arfois deux larves habitent une grosse galle.

La couleur de ces galles est ordinairement jaune on d'un vert jaunatre qui tranche sur la teinte verte de la feville. Il n'est pas rare, quand la galle est anciennement formée, qu'elle prenne une teinte rougeatre surtout en dessous, au point où la nervure est devenue très saillante.

La nymphe reste peu de temps sous celte forme, et l'insecte parfait, que j'ai trouvé mou et récemment éclos dans la galle, en sort par la partie inférieure de la fenille, c'est-it-dire en dessons, après avoir praticué un trou au moyen de ses mandibules.

La larve de l'Apion hamutodrs n'est pas toujours sente dans sa cellule. J'y ai vu auprès d'elle une larve grisatre et luisante, à petites saillies dorsales qui doil appartenir à un de ses parasites et qui m'a rappelé les larves observées par héaumur dans les galles du chêne. J'ai mentionné ces larves remarquables en donnant l'histoire de la Pimpla Fairmairii (Anuales de 1858 , p. 810 et suiv.).

VI. Remarques sur les palpes maxillaires des larves

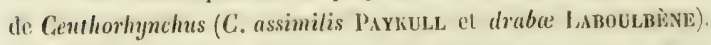

(Voy. planche 13e, fig. 25 à 28.)

Il parail établi aujourt'hui, et M. P'erris a mentionné le fait avec son exactitude ordinaire, gue les larves des Curculiomiles ont tes palpes maxillaires de deux articles et des palpes labiaux éralement de deux articles (Annales de 1856, p. 4377).

Je viens récemment de vérifier cette intéressante question sur les larves du Geuthorhynchus assimilis PAYK., et j'ai représenté planche $13^{\circ}$, figr. 25 a 28 , la bonche de ces larves. Il est hors de doute que les palpes naxilliares n'ont que deux articles; le dernier est termine par des poils très courts, le lobe interne offre des poils en dents de peigne. Ia mêne remarque s'applique a la larre de mon $C$. drabe, ainsi que je m'en suis assuré. J'avais dit, du reste, que je n'avais " jamais trouvé que 2 articles a contours nets aux palpes maxillaires " (voy. nos Annales de 1856 , 
p. 157-158); mais javais admis à tort un $3^{c}$ atticle basilaire el rétractile, qui en réalité n'existe pas. M. E. Cussac avait décrit 3 articles aux palpes maxillaires de la larve du C. ruphani (Annules de 4855, p. 242), mais cet honorable colleguc les a certainement mal vus ou mal comptes.

VII. Description des mótamorpheses da Phylonomus meles lisBi. var. trifolii IIEnBst. (Voy. planche 130. fig. 29 à 33.)

LARva clliptico-oblonga, lutra seu virili-lutea, sine viridis, capile brunneo vel nigro, minuto, subrolundo; supra fusciis dubus viridi-brunncis longiludinalibus. Corpus valde plicatum, lateraliter nec haul infre mamillarum tribus striebus instructum. Antcmua brever, biarticulate. Stem-

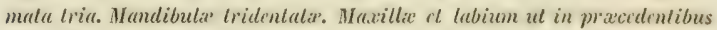
Ipionum lervis. Stigmata novem utringue. - Longitudo tres lincus arfuat. (7 millim.).

IIabilat in pratis super Trifolii pratensis foliu et flopers replans.

Nympia folliculala, ovala, crassiusculu, postice atlomuta, parce pilosa.

Folbiculus reticulatus, ovalis, formosus; griseo-albus, interdum vix. aurulentus.

LARve allongé, clliptique, ressemblant berucoup à une chenille; couleur verte ou jaunatre, tète noiratre ou brune, plus ou moins loncéc ; deux lignes longitudinales brunes ou d'un rert fonce sur le dos, segments poinlillés de noirâtre en traver's, el pourvus de poits courts, claviformes.

Tŕte jaumatre en dessous; horil antérieur jresque droit, côtés arrondis: un trait de couleur claire partant de chaque côté derrièe les antennes el allant se réunir en arrière en formant un Y. Intemes très petites de 2 articles, insérées contre le bord antérieur de la tele près de la partie externe (tig. 31). Épistome transtersal el trapézollde; labre un peu échancré en arant, muni de 8 poils courts et gros (fig. 31). Uandibutes assez forles, tridentées, brunàtres, noirâtres à l'extrémiti. Mâchoires à lobe arrondi, ayant au côté interne des poils en dent de peigne; leurs palpes sont netlement biarticulés. Livre inféricure épaisse, cordiforme, avec 2 petits palpes de 2 articles. Youx constiués par deux ocelles placés l'un auelessus de l'autre (fig. 31); j'ai plusieurs tois vérifié ce nombre.

Thorax formé de trois segments à peine plus épais que le reste du corps. Prolhorax ou $\mathbf{1}^{\text {er }}$ segment oflrant une teiute brunatre ou noiratre de chaque côte, interrompue sur la ligne médiane et n'alteignant pas le bord 
externe (fig. 29). Les deux autres segments sans taches noires transversales. Pas de pattes, mais en dessous des psendopodes sous forme de mamelons ou de disques ayant 2 poils ou 3 poils à leur surface (fig. 30 ).

Segments abdominaux au nombre de neuf, d'une couleur qui varie du vert jaunatre ou du vert clair au jaune sale. De chaque còté de la ligne médiane, en dessus, on voit une bande brunâtre ou d'un vert foncé (fig. 29) et une autre ligne plus étroite sur le bord des segments, attenant aux bourrelets latéraux. Le fond des plis que présente la larve est aussi de la même teinte brunatre ou d'un vert sombre.

Les scgments thoraciques sont plissés et divisés en deux parties comme dans la plupart des larves de Curculionites, et les segments abdominaux offrent en dessus à l'exception du dernier, deux plis transversaux qui divisent le dos de chaque segment en trois bandes transversales (fig. 29 et 32); le premier pli est interstigmatique, le second est recourbé aux extrémités, et remonte vers le stigmate; le $1^{\text {er }}$ espace est glabre, le $2^{\circ}$ offre 6 points bruns de chaque côté de la ligne médiane, 12 en tout; le $3^{e}$ espace est en forme de navette et ofre 2 points bruns, un de chaque colé. De chacun de ces divers points bruns part un poil court et claviforme, ainsi que je le dirai plus bas. Le $12^{\circ}$ segment est tronqué en arrière ct porte un psendopode gros et charnu, formé par l'anus tubuleux.

Sur les côlés du corps, on trouve 3 sérics de mamelons ou bourrclets, d'une couleur verte ou jaune; la $1^{\text {re }}$ ligne ou série de mamelons est tout a fait latérale, les deux autres appartiennent à la face ventrale de la larve, la

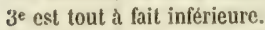

Stigmates au nombre de 9 paires, situés de chaque côté au-dessus de la $1^{\text {ro }}$ série de mamelons (fig. $29,30 \mathrm{et} 32$ ). La $4^{\text {re }}$ paire est placée très près du bord postérieur du prothorax, les 8 autres paires vers le bord antérieur, vers le quart ou le cinquième environ des $4^{\mathrm{e}}$ à $\mathbf{1 1 ^ { \circ }}$ segments. Péritrème arrondi, d'un brun noiratre ou noir.

Les poils de la tête sont longs et assez gros, contournés et non sétiformes; l'antenne est placée derrière un long poil. A la partie dorsale du corps, chaque point brun a un poil claviforme (fig. 30 et 32 ); en arrière les 6 points bruns ne pouvant pas tenir sur une rangée, deviennent alternes, ainsi que les poils claviformes (fig. 29). Le $10^{\circ}$ segment a deux longs poils de chaque côté, le $11^{\circ}$ segment deux également el le $12^{\circ}$ quatre poils allongés. Les mamelons ou bourrelets latéraux ont un poil sur le thorax, mais sur les segments abdominaux les mamelons de la $\mathbf{1}^{\text {re }}$ séric ont deux poils (fig. 30). Chaque mamelon de la $2^{\circ}$ série a 3 poils sur le prothorax; sur le méso et le métathorax, mais sur les segments abdominaux chaque mamclon n'a qu'un poil. Les mamelons de la $3^{\mathbf{e}}$ série sont tout à fait inférieurs et oflrent 2 it 3 poils au prothorax, 1 à 2 sur les segments abdo- 
minaux. Ces mamelons sont de vrais pseudopodes. J'ai dejà dit que l'anus était lui-même prolongé en forme de tube et constituait un pseudopode puissant (fig. 30).

Le Cocon (fig. 33) (1) est réticulé, en forme de réseau ou de filet, et il est remarquable par ses mailles lâches; il ressemble à de la dentelle ou du lulle. Sa forme est ovoïde ou ovale; sa coulcur blanche ou, au plus, légèrement ambrée.

La. Nympiz n'offre rien de particulier. Elle présente les diverses parties de l'insecte parfait et des poils en avant sur la tête, sur les còtés du corps et à l'extrémité de l'abdomen.

Les larves des Phytonomus déjà décrites ont toutes un air de famille, et de Géer, Iléeger, MiM. Goureau, Perris, etc., qui nous les ont fait connaltre, ont insisté sur leur corps multisegmenté, leurs poils nombreux, leurs mamelons latéraux et leurs mamelons inférieurs qui servent de pseudopodes. Iréeger, en représentant la larve du Phytonomus maculatus RED'TENB. (Silzungsberichte der Kais. Akademis der Wissenschaften Wien, math.-naturw. Classe, 1851 ; lirage à part, page 23, pl. X, fig. $10 \mathrm{ct} \mathrm{11),}$ a très bien signalé les poils claviformes dorsaux et les aspérités du tégument. M. Perris n'en a pas fait mention dans son travail si remarquable d'ailleurs sur la larve du Phytonomus vicix GyLL. (2).

J'ai déjà dit que les ocelles de la larve que j'étudie sont au nombre de deux de chaque côté. Hécger en a décrit et figuré trois (loc, cit., tab. $\mathrm{X}$, fig. 3) chez la larve du Phylonomus maculatus; $\mathbf{H}$. Perris n'en a compté que quatre en tout (loc. cil., p. 94) sur la larve du I’vicir. La tète des larves les moins colorées du phyionomus meles offre bien trois points ou trois taches noirattres à partir des antennes el derriere ces organes, mais il n'y a, en réalité, que deux petites saillies bombées ou deux petits tubercules convexes, vérilables ocelles; la tache noire la plus reculée en arjière n'est que pigmentaire et ne présente pas de cornéule. Sur la tète des larves les plus fortement colorées, et ou la couleur brunatre de la tele rend ces taches noires indistinctes ou peu marquées, il n'y a que deux tuhercules noirs, bombés, rappelant la forme des anciens verres de montre. La position exacte des deux ocelles latéraux est la suivante : le premier ou l'antérieur se trouve très près de l'antenne dont il est séparé par le trait clair de la tête qui va de l'antenne au vertex et se prolonge en arrière comme

(1) Je dois cette figure à mon collègue M. J. Migneaux; je n'ai pas hésité à remplacer celle que j'avais faite par celle-ci, tout aussi fidèle mais bien plus artistique.

(2) Édouarn l'erais, Notes pour servir à l'hisloire des Phytonomus et des Phylobius (Mém. de l'Icad, des sciences de Lyon, nouv. série, l. I, P. 93 ct suiv.,
1851). 
un Y. Le second ocelle ou le postérieur est placé laléralement (fig. 31). Le premier ocelle regarde surtout en avant, le sccond sur le côté. Pour bien se rendre compte de la position de ces deux ocelles le microscope est nécessaire, la loupe ne suffit pas.

J'ai trouvé abondamment celte larve, il y a plusieurs années, au mois de juin, à Villegenis, ancien domaine du prince Jérôme. Elle vivait sur le Trifolium pratense $\mathrm{L}_{\mathrm{L}}$, et ressemblait beaucoup à une chenille. Les capitules du Trifolium, les bractées et les feuilles de cette plante sont les endroits où on la trouve de préférence; elle place sa coque, soit entre les fleurons, soit à l'aisselle d'une feuille ou d'une bractée.

En renfermant dans une boite ab observation des larves et des coques présumées de Phylomomus meles, j'ai trouvé, an bout d'une quinzaine de jours, les insectes parfaits éclos, la plupart très mous et peu colorés, et j'ai vu leurs parasites. J'ai de plus constaté que les larves incluses dans les cocons à point de dentelle ou de gaze étaient identiques avec celles que j'avais observées, rampant sur le Trifotium et se glissant entre les fleurons du capitule.

J'ai plusieurs fois cherché à voir comment cette larve fabriquait son cocon; mal servi par les circonstances, je n'ai jamais pu y parvenir, nais j'affrme qu'elle n'a pas de filière. Il est extrêmement probable qu'elle s'y prend de la méme manière que celle du Phytonomus vicix Grlennal, dont M. Perris nous a raconté l'histoire avec un talent consommé (loc. cil., p. 100).

M. le colonel Goureau croit que les larves des Phytonomus marchent et s'appliquent sur le plan de position au moyen des ventouses qui leur sont fournies par les pseudopodes ou mamelons inférieurs. M. Perris a combattu celte ilée en attribuant la fixité des larves à une humeur particulière qu'elles sécrètent et qui fait adlıérer le dessous de leur corps au plan de position, ainsi que de Géer et M. Iacordaire l'avaient admis. M. Goureau n'a pas été convaincu, et en parlant des métamorphoses du l/hylonomus fuscescens Schoenir, il reproduit l'opinion qu'il avait dejà émise (voy. nos Annales, 1856, Bull. XVIII).

Tout ce que je puis dire, c'est que la larve du Phytonomus que j'ai étudiée n'est pas recouverte par une humeur visqueuse el paralt asse\% seche; il est vrai qu'elle n'a pas à vivre sur un feuillage très mobile et qu'elle se glisse en rampant sur une plante peu élevée et à feuillage ramassé; mais ayant mis celte larve dans des tubes en verre, elle a rampé le long des parois en laissant une trace humide; it travers le verre on voyait une couche de liquide épais, faisant adhérer le dessous du corps au point où il se trouvait.

Les larves du phytonomus meles doivent être très voisines des petites 
larves vertes vivant sur la Luzerne et qu'Audouin avait observées dans les nids de l'Odynerus spinipes, à Choisy-le-Roi. Ces petiles larves vertes avaient donné naissance au Phytonomus variabilis Iterbst-SCHOENI. J'ai tenu à rappeler ce fait peu connu (Amatcs des Scicnces naturclles, $2^{e}$ série, t. XI, p. 107, 1839). La larve du Phytonomus mel's, vivant sur te trefle, est peut-être attaquée par quelque IIyménoptère fouisseur; elle a d'aillcurs des parasites directs, qui sont des Iclnemmoniens, ainsi que j'ai pu m'en assurer.

Cette larve, je le répète, est très commune aux environs de l'a:is, je l'ai retrouvéc cetle année à Bourg-la-Reine. Je la signale à ceux de nos collègues qui passent les mois de mai et de juin à la campagne; ils pourront compléter son histoirc. J'ai décrit l'anatomie extérieure de la larve, d'autres plus heureux nous feront connattre sa physiologie, of observeront la fabrication de sa coque si élégante.

Phylonomus meles Fabricies, Ent. System. I, II, p. L66, 1792 (Curculio). - Var. Curculio trifolii IIEnBst, Natursystem der Insecten, Kixler, VI, 266, tab. 80, fig. 5 (1795).

Cette variété du phytonomus moles est curieuse par la teinle roussitre du corps et les séries de lignes blanchàtres des élytres. Jaai fait remarquer combien la couleur de la larve était variable, il n'y a rien de surprenant à ce que l'insecte parfail varie beaucoup lui-mème pour la coloration.

\section{EXPLIGATION DES FIGURES DE LA RLANCIE $13^{\circ}$.}

Fig. 1. Larve du Staphylimus chloropterus L., el à côté d'elle mesure de sa grandeur naturelle.

2. Tete fortement grossie de cette larve, vue en dessus, montrant les dentelures du bord anterien, les antemes et les mandibules.

3. Trite de la même larve vue en dessous, pour montrer: Jes màchoires, à lohe interne articulé, conique; les palpes maxillaires de 3 articles; la lèrre avec ses palpes labiaux biarticulés.

4. Ocelles au nombre de 4 et extrêmement grossis.

5. Palte intermédiaire droite, très grossie.

6. Extrimité postéricure du corps, fortement grossic et placée de profil. On voit la position des stigmates et des appendices du dernier segment. 
Fig. 7. Appendice gauche très fortement grossi représentant les 2 articles de ce prolongement, le poil terminal et les 5 soies latérales.

8. Larve du Calathus gallicus Farra. et LAB., et à côté d'elle, mesure de sa grandeur naturelle.

9. Tite grossie, vue en dessus, montrant les antennes et les mandibules.

10. Tête de la même larve, un peu plus grossie et vue en dessous, montrant : les máchoires à lobe interne de 2 articles, les palpes maxillaires de 4 articles; et la levre offrant 2 articles aux palpes Jabiaux.

11. Occlles au nombre de six, frès fortement grossis.

12. La même larve grossie vue de profil, pour meltre en évidence la position des stigmates.

13. Grochet corné droit, terminant l'abdomen en dessus, très grossi. On y remarque deux saillies principales, l'externe plus forte que l'interne; la surface est rugueuse et granulée.

14. Troisième et quatrième segments abdominaux fortement grossis, vus en dessous, pour montrer la disposition des plaques qui les recouvrent et la situation des stigmates.

15. Putte intermédiaire, très grossie.

16. Larve de l'Apion violaceum KirBY, el à côté d'elle mesure de sa grandeur naturelle.

17. Nymphe du même insecte, et idem.

18. Labre, épistome et bord antéricur très grossis de la tête de la larve. On remarque une très pelite antenne, biarticulée, de chaque còlć du bord antérieur, en delors.

19. Mandibule droite de cette larve.

20. Machoire gauche. Le palpe maxillaire est biarticulé.

21. Livrc avec deux palpes labiaux très petits ef biarticulés.

22. Occlle de la mème larve.

23. Larve de l'Apion hiematodes KinBY, el à côté d'elle mesure de sa grandeur naturelle.

24. Deux feuilles du Rumex acelosella $\mathrm{L}_{*}$, de grandeur naturelle, et ofirant des renflements anormaux, ou des galles, ou vil et se développe cette larve.

25. Labre et bord de l'ópistome très fortement grossis de la trorve du Geuthorhynchus assimitis PAYKOLL.

26. Mandibule droite de celte larve. 
27. Machoire gauche. Palpes maxillaires bjarticulés.

28. Lievrc offrant deux palpes labiaux ayant chacun deux articles; audessous deux poils divergents.

29. Larve du Phytonomus meles, var. trifoli vue en dessus, et à cótć d'elle, mesure de sa grandeur naturelle.

30. La même larve grossie, placée de profil, pour montrer la disposition de ses plis transversaux, de ses bourrelets latéraux et des divers poils qui la recouvrent.

31. Labre légèrement échancré, épistome et bord antérieur de la tête, très grossis. De chaque cóté de ce bord on aperçoit une petite antenne, de 2 articles, et derrière elle, les deux ocelles.

32. Deux segments du corps, vus en dessus et très grossis pour meltre en évidence les taclies brunes et les poils claviformes qui en partent.

33. Coque réticuléc el à jour, grossie, fabriquée par la larve du Phytonomus meles; on voit à travers son tissu la nymple incluse de cel insecte. 


\title{
NOTE
}

SUI DES

\section{HELMINTHES PARASITES DU GENRE MERMIS}

\author{
SORTIS DU CORPS
}

du Gryllus domesticus et du Dytiscus marginalis.

Par M. le docteur Alexande LABOULBËE.

(Séance du 9 Avril 1862.)

$\$ I^{\text {er. }}$.

Le Mermis sorti du Gryllus a été pris à Agen (Lol-el-(aaroune) dans .es conditions suivantes. Une personne apereut un Grillon qui courait sur te plancher el fut firappée do la grosseur insolite de l'ablomen de cet insecte. En l'examinant avec plus d'altention, clle fut très surprise de voir une pointe jaunàtre qui faisait saillic sur un des côtés du corps. Ayant tiré sur celte saillie anormale, elle anena an dehors un ver qui sortit de l'insecte sons la forme d'un long filament. Le parasite vécul hors du corps de son hòte, car il se roula et se replia sur lui-même pendant longtemps et à plusieurs reprises. M. Adolphe Magen, secrétaire de la société d'Agricullure, et M. Goux ont été témoins de la sortic, ou pour parler plus exactement, de l'extraction du parasite hors du corps du Gryllus domesticus.

Le Mermis conservé dans l'alcool offre une coloration d'un blane jaunailre; il est replié trois fois sur lui-mème à la manière des serpents. Sa longueur est de 173 millimètres; sa grosseur est de un millimètre dans son plus grand diamètre. Le corps va en diminuant de volume vers les deux extrémités; la plus effilée est noiràtre, avec un rebord aninci el plus clair; elle répond évidemment ì la lontche, car l'animal vivant porte en avant cette partie du corps en l'agitant en tous sens, el c'est elle 'qui progresse la première. L'autre extrémité est bifide, formant deux prolongements ou lobes latéraux, un peu plus foncés que le reste du corps; entre 
ces deux lobes, en observe une pointe mousse dépendant de l'appareil génital.

Le Gryllus domesticus n'était point parvenu à l'état parlait, mais seulement à l'état de nymphe. Il ofrrait des moignons d'ailes au thorax, et l'extrémité clu corps était dépourvue des caracteres sexuels de l'insecte parfait, soit male, soit femelle.

Je dois a mon collègue M. Gustave Le Grand le Dytiscus marginulis ơ, attaqué par les Mrrmis, et les belminthes parasites au nombre de sept qui sont tous sortis du corps de plusieurs Dytiscus de la mème espèce capturés par ce zélé entomologiste. Je prie M. Le Grand de recevoir l'expression de ma reconnaissance.

Des sept Mermis, six appartiennent au sexe male, un seul au sexe femelle. La taille des màles est variable. Le plus long a environ 37 centimetres de longueur, les intermédiaires de 30 à 32 centimètres, le plus court 24 centimètres. Tous ces Mermis sont atténués vers l'extrémité buccale et vers l'extrémité postérieure, mais plus fortement vers la bouclıe. L'enroulement de l'extrémité postérieure ou génitale se fait en volute, et il est caractéristique, ainsi que la présence de deux lobes latéraux cntre lesquels je n’ai pas nolé la saillie d'un organe copulateur màle.

La couleur varie du blanc jaunatre au brun foncé; l'extrimite buccale est constamment noiratre, les lobes de l'extrémité postérieure sont й peu plus foncés que la couleur dominante du corps. De plus, deux lignes brunes ou noiratres s'étendent dans toute la longueur du ver, en dessus et en dessous, c'est-à-dire sur la convexité et au milieu de la concavité du corps enroulé. Il est facile de s'en assurer à l'extrémité postérieure, car les lignes brunes ront se rendre au milieu de l'espace compris entre les lobes latéraux écartés en forme de $\mathrm{V}$.

L'un de ces Mermis mâles est noué en 8 de chiffre, et ce nœud parait s'être produit pendant la vie de l'animal.

Le Mermis o est long de 255 millimetres (entre 25 et 26 centimètres); l'extrémité antéricure est eflilée, la postérieure ne l'est pas, celle-ci est neltement terminée en bout arrondi, sans enroulement en volute. Lá grosseur du corps est peut-être un peu plus forte qque celle des malles, eu egard a la moindre longueur relative. La coloration est jaundire avec les lignes brunes longitudinales et l'extrémité buccale noiràtre.

Mais la particularité la plus curiense et la plus intéressante que nous 
fournit le Dytiscus marginalis donné par M. Le Grand, c'est la présence d'au moins un $\mathbf{M}$ crmis dans la cavité de l'abdomen. A travers la pelluci dilé des téguments du ventre, on distingue déjà ce ver enroulé sur luimême; quand on soulève les élytres et les ailes, on trouve lis paroi dorsale de l'abdomen en partie détruite, et on voit un Mermis blanchâtre ou à peine jaunatre, enroulé ou pelotonné. Le nombre des replis est tel qu'il y a peul-etre deux parasites dans l'abdomen. C'est un point qu'un examen ultérieur décidera.

J'avais remarqué, comme M. Le Grand et comme M. Fairmaire, que l'un de ces vers parasites était encore engagé en partie sous les élytres du Dytiscus, c'était même le moins coloré de tous. Ne peut-on pas en conclure que les Mermis, qui sont blanchatres dans le corps de l'insecte, se colorent et deviennent brunatres ou noiratres par suite de leur exposition à l'air ?

Le Dytiscus marginalis male dont il s'agit nous a offert l'exemple extrémement remarquable d'au moins deux helminthes du genre Mcrmis qui ont vécu dans son corps. L'examen de cet insecte ne laisse aucun doute sur le parasitisme des Mermis dans la cavité abdominale des Dytiscus. 

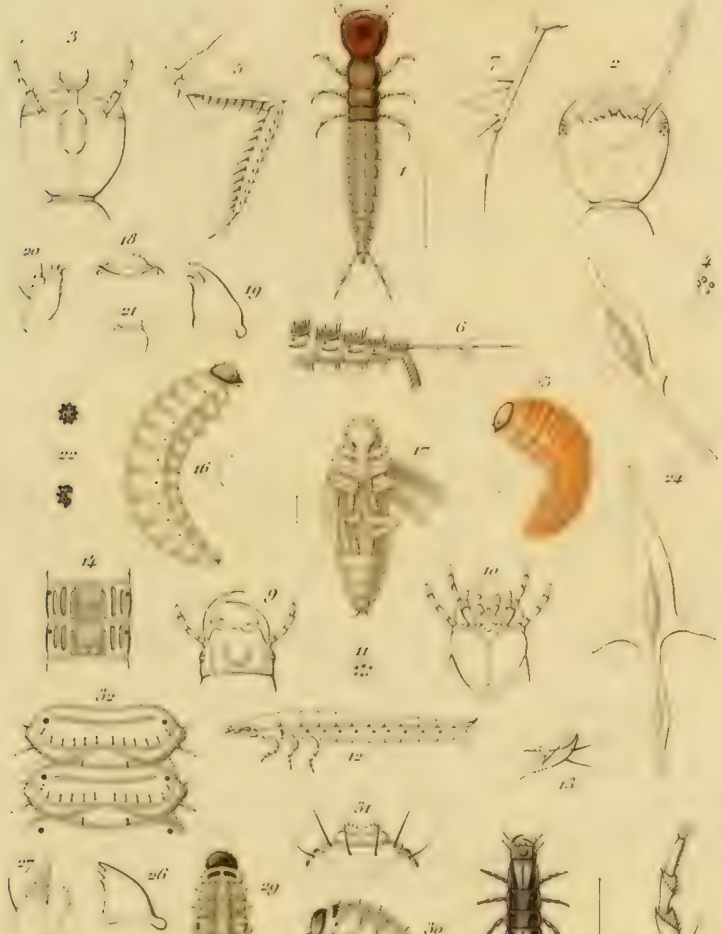

3.3
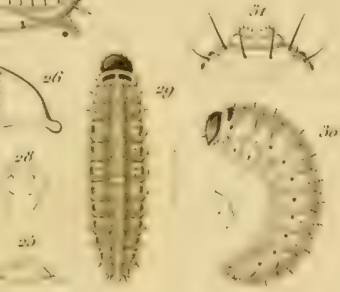

firt bithulsine pine.
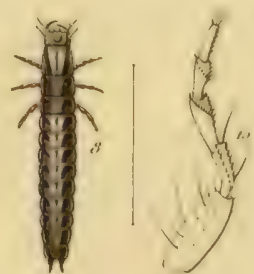

Plivere stivilp

\section{Larues de Colioptires.}

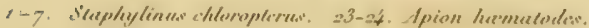

$8-15$. C'elnehur gallicus.

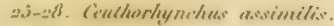

tri-s.:. Apion violuerem.

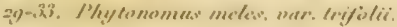





\section{OBSERVATIONS}

SUR LES

\section{INSECTES TUBÉRIVORES}

Avec réfutation de lerreur

qui, attribuant les Trufres à la piqúro d'un Inseoto.

108 a fait assimiler aux Galles végótales

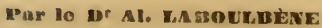

Professeur agrégé à la Faculté de Médecine de Paris, Médecin des IIopitaux,

ancien Président de la Société Entomologique de France, etc.

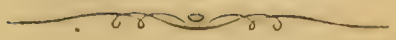

\section{PARIS}

'TrPOGRAPHE E' LITHOGRAPHIE FÉLIX MALTESTE ET Ci॰,

22, rue des Deux-Porles-Saint-Sauveur. 


\section{Exxlrait des Anaales dy la Société cnlomologique de France, $4^{\bullet}$ série, tome IV, pages 69 et suiv.}




\title{
OBSERVATIONS SUR LES INSECTES TUBÉRIVORES,
}

\author{
Avee réfutation de verreur qui, attribuant les Truffes à In \\ piquire d’un Insecte, les a fait aksimiler aux Gulles végétales,
}

Par M. le docteur Alexandne LABOULbENE.

Les naluralistes ont signalé a plusicurs reprises les Inscctes tubérivores, c'est-ì-dire seux qui se nourrissent de lit substance des Truffes, soit à l'état de larve, soit à l'état parfait. néaumur a indiqué dans ses Mímoires les vers des Truffes qui se métamorphosent en Mouches à deux ailes; M. Léon Dufour leur a consacré un long article dans ses tetudes sur les larves fongivores de Diptères. Robineau-J)esvoidy, Mar. Goureau, Lucas, Guérin-Méneville, etc., ont fait au sujet de ces insectes d'intéressantes remarques ; jaurai soin de les rappeler.

Les malériaux dont j'ai eu plus particulièrement à disposer pour ce travail proviennent de plusieurs sources. Il m'est très agréable d'en parler tout d'abord. M. le docteur $\Lambda$. Gubler, mon collègue de la Faculté et des hôpitaux, m'a remis, au relour d'un voyage dans le Midi de la France, avec sejour à Cannes, des Nouches auxquelles on altribuait dans ce pays la propriété d'indiquer sûrement le gisement des 'Truffes (1). Mon savant maitre M. le docteur $\Lambda$ ubé a bien voulu me donner une grande quantité de 'Truffes attaquées par des larves et qu'il tenait d'un marchand de comestibles. Ces Truffes provenaient du département des Basses- $\Lambda$ lpes ; placées dans un pot à fleurs rempli à moitie de terre, il en est sorti une grande quantite de Dipteres divers pendant les mois de mai et juin 1863 (2).

Enfin pendant un séjour d'une semaine auprès de MM. Léon Dufour et Perris, j'ai pu consulter leur collection et connaitre les espèces vivant dans les Truffes qu'ils avaient décrites ou qu'ils possétlaient.

Ce Mémoire est divisé naturellement en deux parties : la première comprendra l'étude des insectes tubérivores, en insistant sur ceux qui ont été soumis à mon examen; Ia deuxième renfermera une discussion sur la véritable origine, sur la nature spéciale et incontestable des Truffes.

(1) Voyez le Bulletin de la société Bulanique de France, 1. VIIT, p. 235, 1861.

(2) Annales de la sociélé Entomologique de France, 1863, Buil. p. xxvin. 


\section{CIIAPITRE I"er.}

\section{Des divers Insectes titherivores.}

Je vais successivement passer en revue dans ce clapitre les insectes de tous les ordres qqui ont été trouvés dans les Truffes. Je commencerai par les Diptères, j'examinerai ensuite les Coléoptères, et je signalerai en terminant un Lépidoptère et des Myriapodes.

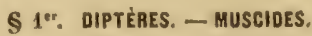

\section{GenTe HELOMYZA.}

\section{IJ. LINEATA.}

Les insectes dipteres que M. Ie docteur $\Lambda$. Gubler m'a remis se rapportent tous à l'IIctomyza lineata de Robineau-Desvoidy. Ces insectes étaient au nombre de huit, tant males que femelles, les premiers reconnaissables au dernier segment ahdominal recourbé en dessous, les secondes à leur oviscapte pointu et allongé. La taille, la forme et la coloration de ces Mouches se rapportaient parfaitenent ì un individu pareil et conservé dans la collection de M. Bigot sous le nom de 11 . lincata, donné par Robineau-Desvoidy lui-même. J'ajouterai, quan à la coloration, que plusieurs Mouches, ayant été ramollies à la vapeur de l'eau froide, ont pris une teinte beaucoup plus foncée, presque rougeâtre, el que les lignes dorsales du corselet sont devenues très apparentes et brunâtres, surtout la ligne médiane.

Les métamorphoses de l'Ilelomyza lineala ont été observées par M. Léon Dufour, qui les a très soigneusement décriles dans les Annales des Scienceg naturelles (1). Ce vénéré måtre a fait ressortir les caractères distinctifs de cetle espèce d'ilélomyze, caractères tirés de la plumule antennaire, des raies dorsales thoraciques, des ailes sans taches, etc. Je renvoie ì sa description si consciencicuse el si complète (2), me bormant à reproduire

(1) Ménoire sur les métamorphoses de plusieurs larves fongivores appartenant à des Diplères, 2c série, I, XH, P. 4i, tig. 59-68, 1839.

(2) Loc, cit, P. 45-16. 
ici sa diagnose laline, et en priant le lecteur de jeter les yeux sur la figure onzieme de la planche.

II. Inneata RoB.-DEsv., Essai sur les Myodaires (Mém. présentés par divers savants à l'.1cadémie des sciences de l'Instilut, I. II, P. 6ł5, 1830). - L. Dur., Annales des Sciences naturelles, $2^{e}$ séric, t. XII, p. 4l, 1839.

Testaceo-pallida, antennis formgincis, thoracis dorso rufescente linris tribus intensioribus vix distinctis, alis subfumosis immaculalis; tarsis apice obscuris. - Long. 3 lin. (6 $1 / 2$ à 7 mill.).

LARva acephala, albida, cylindrico-conica, postice truncala, integra; labio cmarginato, angulis intus palpigeris; sligmalibus anticis pubcllatis, exscrtis. - Long. $31 / 2$ lin. (8 mill.).

\section{II abilat in Tubere cibario, metanosporo?}

PUPA nuda, ovalo-oblonga, glabra, fusca; segmentis duobus anticis doclivis, tandem ulrinque longitudinaliter impressis; postice convexiuscula, minute bituberculata. - Long. 2 1/2 lin. (5 mill. 1/2).

L'Ilctomyza lincata parait propre au midi de la France; il est douteux pour moi que l'exemplaire appartenant à Dejean, et sur lequel RobineauDesvoidy a fait sa description, ail été pris dans le Nord ou aux environs de Paris.

J'ai, en étudiant cetle espèce d'llélomyze dans la collection de M. Léon Dufour, dessiné la paletle antennaire et la soie plumeuse que je représente sur la planche (fig. 13). J'ai vu aussi la pupe, qui est d'un marron clair et qui atteint cing millimetres et demi. J'aurai soin de la comparer avee eelle de l'Il clomyza luberivora el d'en faire ressortir les différences.

Réaumur a connu l'IIclomyza lincuta sous sa forme de larve et de pupe. M. Léon Dufour a mis ce fait en lumière. Comparez, en effet, les figures données par liéaumur et ses descriptions (1) avec les détails minutieux et l'iconographic du Mémoire précité des Ammales des Scienees natureltes, et vous trouverez une identilé à peu près complète.

M. Gubler m'a dit que l'IIclomy:a lincata volait au-dessus des endroits ou l'on trouve les Truftes et se posait par groupes sur la terre gui recourre ces tubercules si estimés; cette Mouclie indique de la sorte les gites aux chercheurs de 'Truffes ef clle s'en éloigne très neu. Il est bien prouré pour nous, d'après les observations de Réaumur et de M. I.eon Inufour, que sa larve vit dans les Truffes, et puis s'enfonce dans la terre pour prendre la forme de pupe. Linsecte parfait prend son essor trois mois après.

(1) Rídunur, Mémaire's pour servir a P'llistoire des Insectes, t. IV, p. 372 et 373 , pl. 27, fig. $13,11,15$ et 16,1738 . 


\section{llelomyza PENICILLATA.}

M. Líon Dufour a vu éclore dans son cabinet, le 16 avril 1839 , une autre espèce d'Ilélomyze dont les larves se trouraient dans les Truffes avec celles de la précédente espèce. Cette Hetomyza, à laquelle il a donné le nom de penicillata, a de grands rapports avec l'II. affinis MEig.; elle est plus grande, presque de la taille de l' $I I$. tubcrivora, ses ailes n'ont pas de taches, non plus que le dos du thorax. L'Jl. penicillala, que j'ai étudiée arec M. Perris, nous a paru une espèce distincle dont le style des antennes est brièrement velu (fig. 14), et M. Perris m'a appris qu'ayant celte amnée élevé des larves vivant dans les 'lruffes gâtées, il avait obtenu les insectes parfaits qui se rapportaient a l'Ilclomyza prnicillata, pareils en tous points aux types de la collection de Saint-Sever que nous avions sous les yeux.

Voici la diagnose que M, Léon Dufour a donnée de cette espèce :

11. penachinara Léon Dufour, Annales des Sciences naturelles, $2^{\circ}$ série, t. XII, p. 48, 1839.

Trstacca, nigro-pilosa, antemna arliculo ullimo ovalo-oblongo, slylo breviter villoso; thoracis dorso minutissime forruginco punctato; fomoribus subtus densius villosis; trochanterum intomediorum articulo basilari sclis nigris rigidis penicillalo, alis subfumosis norvis transversis nigro marginatis. - Long. 4. lin. (9 mill.).

\section{LARVA habitat in Tubere cibario, metanosporo?}

La pupe que j'ai sous les yeux, et que je dois a l'obligeance de M. Perris, ressemble beaucoup plus à celle de l'II. luberivora gu'd celle de l'II. lincala. J'en parterai plus tard, en faisant leur examen comparatil (royez p. 12-13).

\section{IJELOMYZA TUBERIVORA.}

Robineau-Desvoidy avait fonde sur celle espece le genre Suillia dans son Essai sur les Myodaires des environs de Paris. C'est bien cette Hélomyze que j'ai vue provenir en si grand nombre des larves et pupes données par Ar. le docleur Charles Aubé. Dès que j'avais eu les Truffes peuplées de larves, je m'étits empressé de recueillir celles-ci en assez grand nombre et de les immerger dans l'alcool, les $12 \mathrm{cl} 13$ avril 4863 . Pressé à cette époque par divers travaux, je n’ai pu étudier ces larves que longtemps apres et lorsque les insectes parfaits d'especes diverses avaient paru. C'est alor's que je me suis assuré que toutes les larves recueillies 
appartenaient à une seule ct même espèce, cl en les comparant aux figures

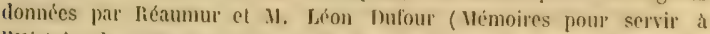
l'llistoire des Insecles, t. V. p. 63 et sujv., [1. 8, fig. 1-2, el Ammales des Sciences naturelles, $2^{\circ}$ série, t. XII, p. 48 , deuriöme obscration), j’ai acquis li: conviction que j'avais trouve les larves de l'Irlomy:a tubcrivora et manqué celles de la Curloncera stabulans.

J'ai eu a ma disposition une très graude quantite de pupes de liJ Iotomyza dont il s'agit, et d'après la configuration de ces pupes, jantais pu decripe presque à coup sûr les formes de la larve; on "n jugera par les descriptions qui suivent :

LARva acrphala, grisro albida, cylindrico-conica, anticc allcnuata, postice oblique truncata; mandibulis nigris, labio patpiforo; stigmatibus anticis octodigilatis, posticis fore rolundatis pauto crserlis ; sublus lateraliterque mamillis ambulatoriis uncimuliforis instructr. - Longiludo qualuor lincas rquat aut supcrat (9 à 10 mill.).

\section{IIabilat in Tubere melanosporo.}

I.ARve (royez figg. 1 à 6) allongéc, blanchatue ou d'un blanc gristilre, cylindrique, mais alténuée en avant et recourbée quand on la roit de profil (fig. 1, a), la partie antérieure étant dirigéc en has, l'extrénité postérieure un peu relevée.

Corps composé de onze segments, non compris le pseudocéphale. Celui-ci avec deux mandibules noires, recourbées et une levre ayant deux paipes courts biarticulés. Promicr sigment offrant de chaque côté un stigmale placé près du bord postérieur, de couleur jaunallre, et composé de huit digitations partant d'une base renfléc. Les premier, deuxième et troisieme segments présentent seulement au bord antéricur une rangée étroite de Irès petites aspérités. Mais les segments suiwanls, jusqu'au dixième, ofrent en dessus un ruban étroit formé par de petites aspérités disposćes aux bords antéricur et postérieur, de telle sorte qu'elles se joignent presçue les unes les autres aux plis des segments, ce pli ne faisant qu'une ligne médiane enfoncée entre les deux bordures. En dessous, sur lous les segments du qualrième jusqu'au dixiènie, on remarque en avanl du bord postérieur, formé par le pli segmentaire, une ligne étroite constituée par de peliles aspérités; mais pris du bord antérieur de chaque segment, on voit une rangie de mamelons ambulatoires, ovales et disposés en travers, interrompus au milieu el recourerts d'asperilt's spinuleuses. Sur les côtés on trouve enfin, faisant suile à la ligne intersegmentaire, une surface rétractile el peu recouverte d'aspéritis spinuleuses, lien moins que les sriries ou paires de manclons plicés en dessous. Ces surfaces élevées 
forment néanmoins une série de vérilables mamelons ambulatoires laléraux (fig. 1). Le dixième segment est, en dessus, fortement granuleux et couvert de spinules.

L'cxtrimité posicricure (onzième segment), vue de face et en dessus, présenic huit petites saillies épineuses, brunàtres, peu marquées, visibles cependant sur toutes les larves conservées dans l'alcool qua j'ai observées et disposées de la manière suivante (fig. 2) : quatre situées en bas el sur une mème ligne, deux latérales très marquees, deux médianes plus petites, deux supericures asse\% marquées, deux autres faibles sur la mème ligne que les stigmates postérieurs. Toutes ces saillics sont entourées par des reliefs cutanés (fig. 2). Enfin les stigmates sont gros, d'un brun noirittre, presque arrondis, el ont sur leur milieu trois plis, ou reliels, transversaux élevés. Au pourtour de l'orifice anal, par conséquent en dessous du corps, on observe quatre saillies un peu épineuses, deux grosses et fortes au bord marginal, et deux autres plus retites contre le bord inférieur anal (fig. 1).

Tout le corps de la blarve est glabre entre les lignes rugueuses et les espaces que j'ai indiqués, en dessus el sur les còtés, comme étant des mamelons ambulatoires munis d'aspérités. Celle apparence de rugosités, appréciable arec la loupe, llevient tout autre avec le secours du microscope. On voit alors de férilables crocliets ou des spinules recourbées, surtout en arrière, et disposées avec un ordre remarquable, leur crochet étant dirigé tantòt en arrière et tantôt en avant (fig. 4). J'y reviendrai plus bas (royez p. 9).

Les larves dont je viens de donner la description étaient conservées dans l'alcool et je ne les ai pas étudiées vivantes; je n'ai pas vu les parties de la bouche en mouvement, pas plus que les mamelons ambulatoires. Les palpes m'ont paru de deux articles, et altachés sur une partie inférieure aux mandibules que j'ai considérée comme étant la lère. Les stigmates ont nettement huit digitations; je dois dire cependant qu'une fois j'ai trouvé neut digitations d'un côté et luuit de l'autre sur la même larve. M. Léon Dufour a signalé sur la larve de l'rr. lineata un fait analogue, car sur un même individu il a trouvé douze digitations au stigmate gauche et qualorze au droit (loc. cit., p. 46).

Le stigmate est renflé et pédiculé (fig. 3) dans la larve de l'IIclomyza tuberivora, comme dans sa congénère l' $I 1$. lincata.

Les mamelons ambulatoires inférieurs, disposés par paires, et les mamelons latéraux sont remarquables sur notre larve; ils sont munis de petits crochets ou de petites spinules recourbées. Pour bien apprécier la disposition des aspérités et des crochets, j'ai pratiqué une incision dorsale; j'ai vidé le corps de tous les organes inclus, puis étendant la peau 
bien nelloyée, je l'ai placée entre deux lames de verte. De celte manière, j'ai acquis la certitude que les dispositions des figures 5 et 6 sont exactes, et j'ai vérifié la direction des crochets en avant ou en arrière, déjà étudiée au microscope sur la larve non vidée et placée de profil. Sur les deuxième et troisième segments on trouve, seulement au bord antérieur, des aspérités qui au microscope représentent des rangées de luuit à dix spinules très petites et placées côte à côte; â un grossissement failıle, on voit des dents de peigne imbriquées et alternées sur trois ou quatre rangs (fig. 5). Celle apparence de rangées spinuleuses imbriquées existe encore en dessous du corps sur la ligne, ou série, placée au bord postérieur des segments, en avant du pli intersegmentaire $\Lambda$ un fort grossissement (objectif $n^{\circ} 5$ de Nachet), les spinules se montrent sous la forme de crochets juxtaposés mais distincts, et leur pointe est dirigée en arrière, au bord antérieur des deuxième et troisieme segments et même de tous les segments suivants (fig. 4). Au bord postérieur, au contraire, à partir du quatrième jusqu'au dixième segment, les crochets sont dirigés en avant (fig. 4); sur le onzième, les crochets forts et gros sont dirigés en avant.

En dessous, sur les mamelons ambulatoires, ces crochets ont une disposition verticillee; ils sont dressés au milieu; leur pointe regarde en avant à la partic antéricure et en arrière a la partic postérieure.

J'ai représenté, figure 6 , la forme des crochets de diverses grandeurs; on verra que quelques-uns sont doubles, mais cette disposition est rare. Je n'ai pas vu de crochets au fond du pli intersegmentaire.

L'extrémité postéricure de la larve de l'It. tuberivora ofre des épines ou des pointes nues recourbées que j'ai décrites et figurées, tant en dessus qu'au pourtour de l'orifice anal.

Ces appendices sont très importants cliez celte larve, puisqu'ils la différencient de sa congénère $I$. linertu, dont la troncature postéricure est sans aucune saillie ou épine. M. Léon Dufour est très explicite à cet egard (1); d'autre part, la figure 14 de la planche 27 qu'on trouve dans Réaumur indique ce fait pour la larve vivant dans les Truffes et décrite dans le neuvième Mémoire du lVe volume (2). Ces caractères analomiques distinguent au premier coup d'nil les deux larves des IIclomy:a tubcrivora et lincate.

On remarquera pareillement que la larve de l'H. tubcrivora a ordinairement huit digitations aux stigmates antérieurs, tandis que la larve de l'H. lincuta en a quinze d'après $\mathbf{M}$. Léon Dufour. La saillie des sligmates (1) L.éon Dufoun, Annales des Sciences naturelles, 2e série, t. XII, p. \$6, pl. 2 ,
ng. $63,1839$. 1738 .

(2) RéA aมun, Mémoires pour servir à l'Histoirc des Insectes, t. IV, p. 372 ct 373 , 
postérieurs est plus forte chez la tubcrivora; aucune des deux larves n't de caverne stigmatique.

De plus, il est probable que la larve de l'Ir. lincata doit avoir les mamelons ambulatoires et les aspérités des bords antérieur el postérieur des segments plus marqués que dans l'H, tubcrivorn, à en juger par la figure de profil (loc. cit., pl. 2, fig. 63) donnée par M. Léon Dufour. La pupe de cette espèce nous offrira deux reliefs élevés, très marqués sur chaque segment et bien plus forls que dans l' 1 . tubcrivora.

Quant it la larve de l'rl. penicillatu, que je n'ai pas vue, elle doit ctre intermédiaire aux deux espèces dont il s'agit. Je ne serais pas surpris qu’elle offrit ì l'extrémité postéricure de légères saillies ou des pointes très petites.

La larve de l'Helomy:a tubrivora se distingue des larves de la Curloncera stabudans clécrite par M. Léon Dufour (1) par les digitations plus nombreuses du stigmale antérieur, qui sont au nombre de six dans la Curtonerra, et par ses mamelons ambulatoires qui paraissent manquer dans celte dernière.

Voici la deseription de la pupe de l'IIclomyza Iuberivora :

Pura muda, ovalo-oblonga, mfosecns sen rufo-fusca, antice segmentis primis dectivis, utrinque linca longiludinali impressis; latcribus crassioribus; poslice convexiuscula valde bitubcrculata; segracnto primo biauriculato, segmento quarto luberculis mimutissimis fore inconspicuis instruclo, segmenlo ultimo vix spinas larva cxhibcnte. - Longiludo tres lineas aquat ( 6 1/2 à 7 mill.).

P'ure (voyez fig. 7 et 8) oblongue, avec la partie antérieure déprimée, comme si elle eût élé pressée entre les doigts, sur les deux premiers segmenls, qui sont fortement épaissis el rebordés sur les côlés. Couleur d'un fauve vif ou parfois d'un brun rougeatre. La forme de la pupe ést un peu élargic vers le quatrième segment sur plusieurs individus; chez d'autres, celte légère dilatation n'est pas marquée.

Le pseudocíphate est à peine indiqué, et l'ouserture buccale occupe un espace brunâtre et foncé, situé sur le plan inférieur de la pupe. Le mrmicr scgment porte deux pelites pointes ou auricules, une de chique côté, divergentes et répondant aux stigmales antérieurs de la larve. Le hord anterrieur de la pupe est irrégulièrement découpé et offre des élevures ou saillies longitudinales entre les deux pointes auriculaires stigmatiques. Toute la surface du deuxième segment est très rugueuse en travers et elle est déprimée; en dehors, une ligne enfoncée détermine un fort bourrelet

(1) Voyez plus bas, page 18. 
qui se continue en se portant sur le troisième segment; celui-ci est également déprimé et très ruğteux. Le quatrième segment est moins rugueux en travers que les deux précédents, et sur son bord postérieur on trouve de chaque còté une très petile saillie qui répond aux stigmates thoraciques de la nymplie incluse dans la pupe (fig. 7 et 8). 'Tous ces segments olirent, a partir du pseudocéphale, une ligne élevée, exactement latérale, luisante el qui vient passer sur le dos de la pupe en suivant une direction un peu oblique et en enlevant juste les saillies des deux stigmates thoraciques. Les figures indiquent celte disposition répondant exactement au panneau gui se dessoude et s'enlève pour donner passage à la Mouche lors de son éclosion.

En dessous, le prenier et le deuxième segment sont trìs rugueux en Iravers; le troisième l'est beaucoup moins.

Les segments intermidiaires n'offrent rien de particulier dans leur forme. En clessus, ils présentent, en avant et en arrière de la ligne de séparation des segments, une bordure finement rugueuse : c'est un petit ruban placé à la fois sur le bord postérieur du segment qui est en avant el sur le bord antérieur du serment qui le suit, de sorte que l'intersection segmentaire ne fait que les séparer. En dessous, on voil une ligne rugueuse très étroile située au bord postérieur très près de l'intersection des segnents, puis une large bordure rugueuse, transversale ovale, interrompue au milieu, répondant aux pseudopodes de la larye et siluce près du bori antérieur des quatrième jusqu'au dixième segments.

Sur les côlés enfin, on remarque un espace un peu rugueux qui se conlinue arec la ligne intersegmentaire, et qui répond aux mamelons latéraux de la larve (comparez les figures 7 et 8 ).

Le dixiome ssgment est très fortenent ruguetx en dessus. I, on:iöme srgment est pareillement rugueux, les stigmales postíricurs s'en detachent nettement sous l'aspect de deux pelites cornes noires; au-dessous d'elles le segment est arrondi, et au pourtour, arec beaucoup d'allention, el sur les pupes fauves el peu épaisses, on trouve les saillies et les épines décrites dans la larve. Ces saillies sont bien plus difficiles à reconmaitre ou meme n'existent pas sur les pupes les plus brunes et les plus coriacées. Enfin on voit en dessous le reloord froncé de l'orifice anal très maqué et très apparent.

Dans un autre travail (1), j'ai fait ressortir l'importance de l'éfude des pupes des Muscides, en insistant sur ce fait capilal qu'elles reproduisent les caractères des larves, puisqu'elles sont constituées par le tégument

(1) Mélamorphoses d'une Mouclie parasile (Amnales de la Société Entomologique de France, 1861, D. 2\$1! 
propre de ees dernières qui s'est épaissi et durci. Les pupes de l'Iletermy a tubrivor viennent confirmer l'opinion que j'ai soutenue; elles different beaucoup de celles de la Trahina villica, elles different meme des pupes du meme genre que j'ai sous les yeux, de celles de l'II. lineala et de l'H. penicillale.

Le pseudocéplaale est denticule sur la pupe de l'Hrlomyza tubcrivora, l'ouverture buccale froncée se trouve sur le plan inférieur de la pupe; la ligne élevée qui indique l'endroit de dessoudure par où s'échappera la Mouche occupe tout a fait le bord lateral : cette ligne dlevée se continue en avant du pli segmentaire sur le dos du segment, et enléve juste les deux très légères saillies révélant les stigmates thoraciques de la nymphe (royez Ann. Ent. Fr., 1861, p: 240) (1).

Les dépressions des premier, deuxième et troisieme segments et le bourrelet latéral si épais paraissent caractéristiques dans les pupes du genre Iletomy:a. Tous les traits que jai longuement signalés pour les séries transversales d'aspérités el de spinules erochues chez la larve sont bien indiqués sur la pupe. Les stigmates antérieurs ont pris la forme d'auricules divergentes, les stigmates postérieurs se sont détachés et forment deux petites cornes sur le plan supérieur. Le onzieme segment est bombé et non aplati comme dans les pupes venant de larves pourvues d'une caverne stigmatique; enfin sur les pupes ambrées, sur celles qui ne paraissent pas avoir, au moment de leur formation, trop dilaté la peat de la larve, on voit très manifestenent les restes des pointes terminant le dernier segment.

Sur beaucoup de pupes, l'extrémilé postérieure étail garnic de terre, celle-ci adhérait fortement à l'orifice anal.

I.es pupes de l'II. tuberivora élaient enfoncées à une profondeur variable dans la terre meuble oủ les Truffes avaient été posées; la plupart deg pupes étaient à un, deux ou trois pouces de profondeur; quelques pupes etatient restées dans le milieu des Trulfes, surtout les pupes ambrées ou d'un marron clair.

Si je compare la pupe que je viens de faire connaltre avec celle de l'Ilelomyza lincata décrite par M. Léon Dufour et que j'ai étudiée de visu,

(1) Les pupes de la Phora pallipes Latr. et des Phora nigra Mrigen et helicivora J.. Duy., qui sont pourvues de petites cornes allungées, formant le prolongement des trachées et des stigmates thoracigues, offrent pareillement une dessoudure dorsale des premiers segments, et cette partie qui s'enlève comprend dans son aire les cornes stigmatiques répondant aux petits lubercules de l'Ilelomyza lineala. (Voy. Annales des Sciences naturelles, 2e série, t. XII, p. 57, pl. 3, fig. 150, et liecherches sur les Métamorphoses du gente Phora (Mémoires de la Société des sciences, cle, de litle, p. 414, fig. 4, 10, 11 et 12, année 1840). 
je trouve de nolables différences, indépendamment de la taille. La pupe de $1 ' 1$. lincala offre, en avant et en arrière de chaque pli intersegmentaire, un relief très marqué et bien prononeé qui lui donne un aspect caractéristique (1); la saillie des stignates postérieurs n'est pas aussi forte que dans la pupe de l'If. tubrivora, au-dessous de ces stigmates on ne voil aucune trace de pointes épineuses. Sur le troisième segment thoracique et en dessus on ne trouve rien qui indique la place des stigmates thoraciques. Enfin la coloration des pupes de l' 11 . lincata est constamment fauve ou d'un marron clair.

La pupe de l'II. menicillata, intermédiaire pour la grandeur entre les deux dont je viens de purler, se rapproche davantage de la tuberivora. Comme dans relle-ci, la pupe de l'II. penicillata offre deux rangées juxtasegnentaires moins élevées que dans la lincata, les saillies des stigmates thoraciques manquent ou ne sont pas apercevabies à la loupe. Les stigmates postérieurs sont assez avancés; enfin sur les huit pupes de celte espèce que j'ai examinées, quelques-unes ont des vestiges de pointes mousses au bout renflé postérieur. La coloration est d'un marron peu foncé.

I'examen comparatif de ces trois pupes me ramene aux considérations que j'ai émises au sujet des larves. Il cût êté bien difficile d'admettre à miori les différences que nous avons trouvées; on dislinguera sûrement et facilement au premier coup d'œil une pupe d'IIctomy; lineatı d'une pupe d'Ilclomyza tubcrivora. Je le répète, l'étude des pupes ne doit point être négligée.

IT. Iuberivora RoB.-DEsv., Mémoires présentés par divers savants A l'Académic des sciences de l'Institut, t. II, p. 642, 1830. - Macecant, Ilist. natur. des Ins. Diptères, t. II, p. 410 (Suites à Buffon, Roret, 1835).

Testacra pilis nigris, frontc antcnnisque fulvis, scth anlcmnanum pilis longissimis plumata; thorace brunneo-rufo maculato nec non menclato; alis costa nrrisque nigro-brunnris, maculis infuscatis; pedibus lutcis; frmoribus maris inflatis. - Longiludo tres cum dimidia usque ad quatuor lineas requat ( 8 à 9 mill.).

Ilabital in sylvis; super oblegrntem Tubera terram volitans (voy. fig. 9).

Corps d'un jaune d'ocre, à poils noirs. Tétc avec la face, les palpes et la trompe d'un jaune d'ocre clair ; joues un peu fauves; face presque glabre. Antennes à palette d'un fauve rougeatre foncé, ovale, largement arron-

(1) M. léon Dufour (loc. cit., p. 46 et fig. 67) a indiqué ce caraclère. Réauunur l'a connu et parfailement représenté (loc. eit., pl. 27, fig. 16), et c'est pour cela que je rapporte, arce M. Líon Dufour, la ligure 16 à l'a. lineula. 
die el déprimée vers l'extrémité; style allongé, plumeux, à poils très longs, au nombre de neuf à dix, de chaque côté (fig. 12). Front d'un beau roux fauve; vertex d'un roux blanchattre, avec la base des poils entourée d'un cercle d'un gris blanclıttre ainsi que le bord du triangle formé par les stemmates. Ycux d'un rouge sombre à reflets verdatres, non velus; ocelles d'un rouge clair. Les poils de la parlie supérieure de la tetre sont ainsi disposés : deux dirigés en arant et placés entre les ocelles postérieurs et l'antérieur (fig. 10); deux dirigés en dehors, placés sur la ligne de l'ocelle antérieur el sur les côtés des précédents; six sur le vertex et près de son bord postéricur; deux internes sitnés plus en arrière et entrecroisés; deux latéraux ì base asse\% rapprochée mais divergents au sommet (fig. 10) : ces derniers poils sont suivis de deux rangées de poils petits et contournant les yeux.

Corselet d'un jaune d'ocre, finement mouchelé de brun fauve avec des lignes de poils noirs entourés à leur base d'un cercle brunatre; les mouchetures et les petits points rapprochés forment une ligne médiane brunatre; chaque petite moucheture brume donne naissance à un petit poil noir et couché. Une série de cinq longs poils noirs, dressés (fig. 10), dirigés en arrière, existe de chaque còté de la ligne médiane; deux nouvelles séries longitudinales de poils noirs se trouvent de chaque côté, l'une sur le bord latéral du corselet forméc de trois poils et l'autre tout à fait sur le côté, allant vers la racine de l'aile et n’ayant que deux poils (fig. 10). Écusson triangulairc, moucheté de brun comme le corselet, mais ì la ligne médliane jaunâtre, quatre longs poils noirs, un de chaque côte sur les bords et deux vers l'extrémité. Flancs d'un jaune d'ocre à reflets soyeux, sans taches. Ailes un peu enfumées, còte ou bord supérieur brunatre ou noirattre, garnie de poils noirs; nervures noiritres avec un point marginal et deux taches enfumées ou noiratres; l'extrémité des nervures, au sommet de l'aile, est souvent entourée d'une tache noiratre (fig. 9). Balanciers d'un blanc jaunàtre.

Abdomen composé de sept segments, à extrémité globuleuse et recourbée en dessous, ơ; piane, lerminée par un oviducte, biappendiculée, of; d'un jaune d'ocre avec le bord postéricur des segments un peu plus foncé, et des bordures de cing à six longs poils de chaque côté de la ligne médiane et au bord postérieur, deuxième segment ayant une rangie supplémentaire el antéricure de deux poils latéraux; dessous de l'abdomen du ơ avec de longs poils mous et assez serrés.

Pattes très différentes dans les deux sexes; cuisses grosses et arquées chez le $\sigma^{x}$, do grandeur ordinaire et droites, 우. Chez le ox, les cuisses antêrieures ont des poils mous et allongés silués en dessous el disposés sur deux lignes, lunit longues soies raides ot noires siluées en dessus; les 
cuisses interméliaires ont en dessous seize à dix-sept soies, tont six plus longues et plus fortes vers la base, de plus une rangée latérale de quatre soies noires; les cuisses postérieures ont des poils mous et allongés en dessous, avec l'extrénité brunàtre, el six à huit sojes sur le bord latéral. Tous les tibias arqués, avec l'extrémité un peu brunâtre chez le ô; de plus un anneau brunatre, pres de la base, aux tibias postéricurs. I.es trochanters des cuisses postéricures sont garnis d'une forte rangée de poils noirs, dressés el arqués. Chez la q, les cuisses antéricures seules présentent un léger renflenrent et sont légèrement arquées, les autres droites, les intermédiaires sans la série de soies raides et placées en dessous; trochanters avec des poils noirs, simples. Dans les deux sexes, les cuisses et les tibias sont couverts de poils fins el noirs, couchés. Les tarses ont leurs trois derniers articles noirtires, surtout chez les ơ, qui ont de plus et constamment le dernier article du tarse élargi, ainsi que la double pelole tarsienne qui est fauve en dessus, l,lanche en dessous; les ongles sont grands, saillants et divergents. Chez la $q$, les tarses ne sont pas fortement élargis à l'extrémilé, la pelote peu grande ainsi que les ongles.

En dessous, l'abdomen du màle est garni de poils moelleux et allongés, noiratres.

L'llclomyza lubcrivora, rapporlée par Macquat a l'II. gigantea de Meigen, en différe spécifiquement d'après M. Loew, à qui j'ai montré plusicurs des insectes que j'ai recueillis. Suivant ce savant diptérologiste, il serail éclos des Truffes données par M. Aubé, outre l'IIclomy:a lubcrivora ơ et + , des individus de l'Ilelomy:a hispanica Loew a hypopygium beaucoup plus grand. Je crois pouvoir dire que l'II. hispanica n'est qu'une variélé remarquable de la tubrivora, car sur le tres grand nombre d'insectes éclos chez moi, je trouve les passiges de l'une à l'autre de ces deux espèces (1).

L'Iletomy: tuberivora, que je viens de déerire sous ses trois états de larve, de pupe et d'insecte parfait, a été observée certainement par Réaumur. Ce grand naturaliste avait connu la Mouche et il l'a représentée,

(1) Voici les caractères reconuus par M. Loew à la nouselle espèce qu'il a élablie sur un seul individu malle, pris dans le midi de l'Espagne, le 21 septembre, par M. Staudinger.

II. Lispaniea LoEw, Ueher die curopaischen Ilelomyzidac, etc. (Zeilsclırift für Entom. des Vereins für schlesische Insektenkunde zu Dreslau, tiroge ì part, p. 27, 1859).

Ex fusco testacea, hypopygio permagno, flavo, setỉ antennarum pilis longissimis plumatu, pleuvarum dimidio superiore undo, femoribus intermediis infra setas aliquet validas gerentibus, $-1.0 \mathrm{n}_{5} .31 / 4$ lin. (7 1/2 mill.). 
planche 8, figures 1 et 2 du deuxième Mémoire (tome $\mathrm{V}$ ); mais il n'avait pas connu la larve, et il était resté indécis sur la pupe dont l'Hélomyze était sortie (1). Je puis aftirmer aujoard'hui que c'est de la pupe qu'il a représentée figure 6 de la planche 8 , car celte pupe se rapporte bien à celles que j'ai étudiées.

Mon savant collègue M. le colonel Goureau a consigné dans nos Annales (2) les observations qu'il a faites sur les larves de l'Helomyza tubcrivora. Ces larves sont extrèmement pernicieuses pour la Truffe, elles la corrompent très promplement en rendant par l'anus une matière blanchâtre qui, dit-il, en provoque et achève la décomposition. On reconnalt par le tact les Truffes attaquées, car celles qui cèdent sous la pression du doigt contiennent des larves et ne tardent guère à tomber en bouillie épaisse et fétide. Ces larves croissent rupidement et se clangent en pupes soit dans la Truffe même, soit dans la terre environnante. L'llélomyze s'envole dès le commencement de septembre et parait jusqu't la fin d'octobre; elle est commune dans les bois où se trouvent des Truffes, et sa présence y décèle l'existence de ces dernières.

L'Hclomyza tuberivora parait répandue dans plusieurs parties de la France; M. Goureau l'a prise à Santigny dans le département de l'Yonne, Réaumur avait reçu du Dauphiné les Truffes d'où cette espèce était sortie. J'ai déjà dit que les larves que j’ai étudiées provenaient du département des Basses-Alpes.

Cetle IIclomya a a deux générations dans l'année, puisque MI. Aubé el moi l'avons vue éclore au printemps et M. Goureau pendant l'automne.

\section{Helomyza pallida et ustulata.}

Ces deux espèces, prises dans le midi de la France, ont été déterminées par M. Lucas (3), et elles sont signalées par MM. Tulasne comme faisant partie des Mouches ou Mouscos des Rabassiers provengaux. M. Tulasne a remarqué dans ces Truffes des larves et des nymphes, mais il n'a pu obtenir des insectes parfaits; il a $\mathrm{u}$ dans les environs de Rians (Var), au commencement de décembre 1847 , l' $I$. pallida voltigeant f̧à et la solitaire, et paraissant se poser sur les gisements des Truffes plus volontiers qu'ailleurs. Réchaufrée par les rayons d'un soleil brillant, cette Mouche était très agile. M. Tulasne a pu prendre au rol plusieurs indivi-

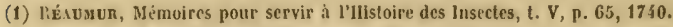

(2) Annales de la Société Entomologique de France, 1852, Bull. r.xxv. - Voy. aussi la note rectificalive de $\mathrm{N}$. I.éon Dufour, Annales de 1853 , p. 383 et suiv.

(3) H. Lucas, Annales de la Sociétć Entomologique de France, 1818, Bull., p. z. 
dus de l'II. paltida; ils exhalaient une odeur extrêmement pénétrante analogue à celle du Salyrium hircinum, et ils la conservaient longlemps après leur mort (1).

L'IIclomyza uslulata vole, comme l'espèce précédente, au-dessus des terrains ou l'on trouve des 'Truffes. Mi. Citienne Bonnet, d'Apt (Vaucluse), s'est assuré que les truffières des environs de cette ville sont fréquentées vers la fin de l'hiver par l'II. astulala. Mar. liequien, Leveillé el 'Tulasne ont pris ou observé cette espèce d'Ilctomyza dans ces mèmes localités.

E. Dadilda FaLLe., Heterom, 3, 1. - Meigen, System. Beschreib. der bekannten curopaischen zweiflugelingen fnsecten, C. VI, p. 50, 1830 (2).

Pallida, incisuris ablominis tenuiler fuscis; alis immaculatis; sclu antennarum breve plumata. - Long. $31 / 2$ lin. (8 mill.).

II. ustulata MEIGEN, loc. cit., VI, p. 54.

Forruginosa, hypostomate albo, polibus rufis, tarsis anticis maris cilialis; alis nervis transversis apicrque fuscis, macula trigona apicali albu. - Long. 4 lin. (9 mill.).

\section{HELOMYZA (indétermince).}

On trouve dans l'ouvage précité de Mu. Tulasne sur les Champignons hypogés, page 164, la mention d"une Mouche de coulcur joune, observée par eux dans les Truffes, et que je rapporte sans hésiter au genre IIflomyza. La lave de cette Mouche s'était nourric avec la substance des Tuber astivum et mesentericum trouvés au bois de Vincennes a la fin de l'automne.

\section{Genre GURTONEVIA.}

\section{C. stabUlans.}

Celte Mtuscide, très commune, est éclose en grand nombre chez It. Aube el chez moi des Truffes gàties provenant du departenent des Basses-Alpes.

(1) L.-R, et C. Tutasve, Fungi hypogai, p. 161, 1851.

(2) M. Loew, dans son excellent mémoire sur les I/ Elomyzides d'Europe, publii dans le journal d'entomologie de Breslau, place le nom d'Il elomyza pallida comme synonyme de l' $\boldsymbol{H}$. olens Mcrese (tirage a part, p. 40). J'ai maintenu le nom d' $\boldsymbol{H}$. pallida, uniquement parce que les Muscides déterminérs par M. II. lucas lui ont paru exactement se rapporter a la deseription de Meigen qur j'ai cilée. 
M. Léon Dufour en a observé les mélamorphoses (1). Je n’ai pas vu la larve ni la nymphe de celte Curtonevra, et je me borne à reproduire les diagnoses données par mon vénéré maitre en rappelant les descriptions de Bouché :

Curtonovra ntabulans FALLEN, Musc., 52, 32. - MeIGEN, Syst. Beschr. der europ. zweiflugeligen Insekten, t. V, p. 75 (Musca).

Cincreo subcrsia; facic albido-argentca; thorace villis quatuor nigris ; abdomine maculis cincreo-micantibus tesselato; palpis, sculclli apire pedibusque forrugincis, tarsis fomorumque basi nigris. - Long. 4 lin. (9 mill.).

II abilat in domos nec non arborum truncos foliague in umbrosis; frequens.

LARVA accphala, cylindrico-conoidea, glabra, albida, postice truncata, truncuturx margine supero integro; infero scxdentalo; mamillis ambulatoriis sex paribus; stigmatibus posticis simplicibus, anticis flabelliformibus sex-digitatis; labio bifudo. - Long. 4-5 lin. (9 à 11 1/4 mill.). (Vid., loc. cit., pl. 3, fig. 16).

Habitat in Tubere melanosporo (Ch. Aubé, Laboulbène), in Agarico aurantiaco, Boleto eduli, etc. (L. Dufour).

PCPA muda, intense castanca, lævis, ovato cylindroidca, poslice rolundato truncata, stigmatibus vix prominulis; incisuris punclato aspcrulis. - Long. 3 1/2 lin. (8 mill.). - (Vid. loc. cit., pl. 3, fig. 19-20.)

Bouché (2) mentionne chez la larve de la Muscr stabulans des stigmates a neuf divisions, et indique des saillies charnues qui se voient dans le jeune age de la larve et disparaissent plus tard. Il dit aussi que la larve se change en pupe sous terre, dans une petite cavité formée de bave et de mucosité.

M. Léon Dufour (loc. cit.) a remarqué une sorte de cocon formé par les larves de la C. slabulans (loc. cit., t. XIII, pl. 3, lig. 20). Je dois dire que j'ai trouvé moi-même, dans la terre sous-jacente aux 'Truffes, des coques à mailles très làches qui doivent avoir élé produites par les larves des Mouches de cette espèce écloses dans mon cabinet.

Enfin M. Goureau a vu cetle année (1863) sortir de Truffes noires très parfunices ( $T$. melanosporzm?), récoltées à Santigny, une variété de cetle

(1) Annales des Sciences naturclles, 2e série, t. XIII, p. 157, 1810.

(2) P.-Fr. Boucux́, Naturgeschichle der Insekten, etc., p. 67, 1831. 
Ciurtoncura dont le $\delta^{x}$ a le second anneau de l'alodomen taché de roussattre. Les larves de la Gurtonevra s'élaient développées dans la Truffe souterraine el y avaient remplacé l'lletomyza luberivora trouvée quelpues années auparavant par M. Goureau dans les mêmes localités.

\section{Genre ANTHOMYIA.}

\section{A. GaNigulaRis.}

Celte espece, extrêmement commune, est apparue en grant nombre, comme la précédente (Gurtoncora stabutans), parmi les insectes tubérivores que j’ai élevés ainsi que M. le docteur Aubé. Sa larve a été connue de De Gécr (1), et avant lui peut-être de Swammerdam (2).

Bouché, qui nous a donné tant de détails précieux sur les premiers élats des insectes, a longuement décrit la larve de l'Anthomyia canicularis (3), et il l'a représentée. Cette larve differe de ses congénères par les poils longs et harbelés du bord latéral des segments du corps, par les dentelures de ceux qui sont placés sur la partic dorsale de chaque côté de la ligne médiane, et par ses stigmates très saillants et fortement trilobés.

Je n'ai pas observé celle larve, je n'ai recueilli que la pupe dont bouché n'a dit que deux mots. En voici la description; je l'ai dessinée figures 15 el 16 .

PUPA sordide lutescens, srgmentorum interstitiis bruncis; ovalis, antice altenuata nec haud dectivis, spinis lamelliformibus, basin denticulatis, latcralibus dorsalibusque scriebus duabus disposilis, postice valde clongalis; stigmatibus posticis inxqualiter trilobatis; segmontis anticis quatuor cvamidis. - Longitudo dues cum dimidia lincas xquat (5 1/2 mill.).

Larva habilat in Tubere molanosporo pulrescente; pupa in terra subjacet.

Pope ovale, allongée, atténuée en avant et aplatie sur les premiers segments (fig. 15 et 16), bordè de poils allonges, surtout it la partie postérieure du corps, surface des téguments un peu granuleux. Couleur dim gris sale un peu roussatre, interville des segments brunàtre. Le promior

(1) DE Gíkn, Mémoires pour servir à l'llistoire des Insectes, I. VI, p. 26, th $^{\circ}$ (Musca domestica minor), 1777.

(2) J. Swamendu, Biblia nalura, t. II, pl. 38, fit. ut et iv, 1738.

(3) P.-Fr. liovenE, Naturgeschichte der Inschten, etc., P. 89, pl. vi, fig. 3-6, 1831. 
segment après le pseudocéphale, qui est rentré en declans et qui a de ha sorte disparu, porte deux soies dirigées en arant et sur les côtés les vestiges des deux stigmales antéricurs; le deuxième offre un poil raide, non dentelé; les suivants, du troisième au dixième, ont tous une longue épine à buse élargie el denteléc répondant à des appendices frangés de la larve : ces appendices s'observent au bord latéral des segments tant dorsaux qu'abdominaux. L'ne série des mèmes ípines à base dentelie, mais courtes et dirigées en arrière, existe de chaque côté de la ligne médiane du corps, du deuxiene au dixicme segment. Le dernicr segment est grand et en demi-cercle, avec trois appendices très longs placés de chaque côté; l'intermédiaire plus raccourci. Stigmates postíricurs saillants et irrégulièremens trilobés (fig. 17). Bords latéraux des segments dorsaux pourvus de peliles épines.

Celte pupe est recouverte d'une croủte épaisse de malière brunatre; ce n'est qu'après une macération prolongèe et un nettoyage complet qu'on peut se rendre bien compte de sa forme et de ses carnetires. Lors de l'éclosion, les quatre premiers articles dorsaux s'écartent doucement en se dessoudant et restent peu éloignés des segments ablominaux. La Muscide a un passage suffisant pour s'eclapper, d'autres fois le panneau dorsal tombe en entier (fig. 16).

D'après cette description, on peut reconnaître la configuration de la la larve qui, ainsi que Bouclé l'a indiqué, doit etre pourvue sur les côtés ct sur le dos d'épines allongées, surtout al la partie postéricure du corps. Toutes ces épines sont élargies à leur base qui est denticulée, le bork des segments porte de petites épines, les stigmates postérieurs font saillie et sont très fortement trilobés.

Cette larve est par conséquent extrêmement voisine de celle de l'Anthomyia paradoxalis Durour (1); elle en differe surtout par la longueur plus considérable des épines postérieures du corps et par sa taille moindre. Elle est beaucoup plus éloignée des larves de l'Anthomyia manicata et scalaris, dont les appendices latéraux sont pinnatifides et plusicurs fois divisés. Enfin, la larve de l'Anthomyia melania s'en distingue par les séries dorsales de ses poils simples et non dentelés à leur base.

On voit que malgré la ressemblance très grande de ces diverses larves on arrive, avec une attention soutentic, a les differencier, cl que leurs pupes different comme les larves elles-mêmes.

(1) M. Léon Dufour a décrit plusieurs latves fongivores du genre Anthomyia ayant tontes de longs poils dentelés : ce sont les larves des Anthomyii melania DUF., manicala Meıgex et paradoxalis Dur. (Voy. Amales des Sciences ualureiles, 2 e sévie, $t$. XII, p. $35, \mathrm{pl} .2$, fig. 50 , ct t. XIII, p. $152 \mathrm{rt} 155, \mathrm{pl} .3$, fig. 5 ('t 11.) 
La larve et la pupe de l'Anthomyia canicularis, ayant le corps aplati et garni de claque còté de longs filaments dentelés à la base, rentrent dans le genre Homalomyia, que Bouché avait établi pour distinguer des $\mathbf{A n -}$ thomyia ordinaires, celles dont les larves sont ainsi configurees. Beaucoup d'auteurs ont déerit de ces larves, et plusieurs fois elles ont été rejetées du corps par le vomisscment après avoir causé des accidents plus ou moins graves à des malades (1).

Bouché dit que la larve de l'Authomyia(IIomalonyiur) cunicular is parait deux fois dans l'année, et vit dans les végélaux pourris et dans le fromage. Il est très probable pour moi que cette larve, comme ses congéneres, doit se nourrir de différentes substances putréfices, et que les 'Truffes gâtées n'ont èté pour elles qu’une occasion favorable de développement.

Enfin, pour dire toute ma pensée, je suis très porté à croire que les larves qui ont produit les Anthomyia canicutaris que nous arons recueillies avec M. Nubé provenaient d'œufs poidus à Paris par les insectes parfaits, si communs dans les maisons, et déposés dans les Truffes déjà décomposées, oủ fourmillaient les larves des Hetomyza plus spécialement tubérivores. La mème remarque pourrait ètre appliquée aux Curloncrra stabutans; mais ces dernicres pondent très certainement dans les Truffes sous les chênes, ainsi que l'a observé M. Goureau (2).

Anthomyla canicularis LinN., Fauna Suec., 1841. - Meigev, Eur. zweiflug. Insekten, V, p. 143.

Thorace nigricante, lincis tribus obscuris; abdomine clliptico, cincreo, linea dorsali incisurisque nigris, scymentes anlicis flazo diaphanis (Mas). Obscure cinerea, thorace trilincato, abdomine unicolore (Femina). - Longitudo 1 1/2 lin. (3 1/2 à 4 mill.).

\section{ANTHOMYIA BLEPHARIPTEROIDES.}

M. Léon Dufour a étudié les métamorphoses de cette petite espèce de Mouche, qu'il a trouvée dans les Truffes noires et dans les diverses especes d'Agaries et de bolets. Il a décrit la larve, la nymphe et l'insecte parfait de l'Anthomyia blophariploroidss, en donnant les figures de l'insecte sous

(1) 1.-0. Westwoon, An Introduction to the modern classification of Insects, 1. II, p. $570-571,1810$.

(2) Voyez plus haut les pages $19-20$. 
ses divers états de transformation (1). On remarquera combien la larve differe de celle de l'Anthomyia canicularis et des autres larves fongivores de ce genre décrites par M. Léon Dufour (voy. p. 20, note 1).

\section{Gente CIIEILOSIA.}

réaumur a signalé, dans le deuxiême Mémoire du tome $\mathrm{V}$, des pupes tres petites, portant de petites cornes antérieures "placées comme le sont celles des coques des vers à queue de rat; le bout de clracune de ces coques avait une sorte de courte queue. 1) Ces pupes provenaient des Truffes envoyées du Dauphiné au commencement de juillet (2).

M. Goureau a observé des pupes du mème genre, provenant de larves d'une taille assez, forte, remarquables par le tube caudal qu'elles portent, par deux petites cornes charnues situées au-devant de la tête et par les rides transversales de leur corps. La pupe est lisse, avec un tube caudal comme la larve.

Il est sorti de ces pupes, vers le 9 septembre, une espece de Cheilosia dont te male a de l'analogie avec la $C$. mutabilis Mageuart, et la femelle

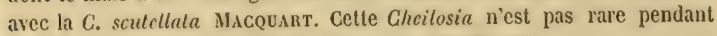
tout l'automne dans les bois produisant des 'Truffes (3).

M. Ićcon Dufour a fait remarquer à ce sujet que les espèces observées par Réaumur et M. Goureau doivent etre distinctes de la Chcilosia scutcllata dont il a étudié les métamorphoses. La lave de la $C$. scutcllata, qui vit dans le Boletus bovinus, est couverte de duvet ainsi que la pupe, tandis que la pupe de l'espèce observée dans les Truffes est lisse (4).

\section{Genre IHORA.}

\section{P. PALLIPES.}

Parmi les larves qui vivent dans les Truffes, il y a celle d'une espece de Phora dont II. Léon Dufour a suivi les métamorphoses, la $P$. pallipes de

(1) Annales des Scicnces naturelles, 2 e série, t. XiI, p. 42, pl, uIr, fig. 69-79, et t. XIII, p. 162, liectification.

(2) Réauxun, Mémoires pour servir à l'llistoire des Insectes, t. V, p. 65, pl, vir, fig. 1 et 5,1740 .

(3) Govne.xo, Inrales de la Société Entomologique de France, 1852, Bull. Lxxv.

(4) Léon Durour, Annales de la société Entomologig̨ue de lrance, 1853, p. 385. 
Latneilte (1), espece fort commune. La larve de cette Phort se nourrit indifféremment de diverses matières azotées : Champignons putréfiés tels que $A$ garics, Bolets et 'Truites, de fromage pourri; elle est sortie de clnysalides du Sphinx Atrepros qui avaient mal tourné, etc.

M. Goureau a observé une Phora dont la larve suçait la bouillie fétide des Truffes décomposées, el dont la pupe offrail Ies cornes dorsales si remarquables dans ce genre de Diptères. M. Gourcau a fait remar(puer les petites pointes charnues ou mamelons ambulatoires sortant de chaque rôté du corps de ces larves de rhora et les faisant paraitre festonnées (2). M. Léon Dufour avait soigneusement représenté celte disposition des anneaux du corps chez la larve de la $P$. pallipes.

\section{TIPULAIRES FONGICOLES.}

\section{Genre SGIALA.}

\section{S. INGENUA.}

On aurait une idéc bien incomplète des Diptères tubérivores, si l'on croyait que les espèces dont je viens de donner l'énumération sont les seules qui vivent dans les Truffes et qui voltigent au-dessus des truffières. Bosc a signalé des Tipules qui probablement appartiennent au genre Sciara (voy. plus las, p. 31); faridel et le comte de Borch ont peut-être parlé d'insectes de cetle même famille.

M. Léon Dufour a vu sortir des Truffes gatées une espece de Sciura qu'il a décrite sous le nom d'ingcmua, et dont il a suivi les métamorphoses. Voici la description de cette pelite Tipulaire fongicole :

\$. Angenua Léon Dufour, Ann. Sc. natur., 2e série, t. XII, p. 29, pl. 1, 1839.

Atra, thorace nitidiore, palpis perlibusque obscure litidis, abdomine nunc nigro unicstore, munc livido rufescente, tarsis nigris, alix vix fumosis. - Long. 1 lin. (2 1/4 mill.).

LARva cephala, haud oculata, albida, postice rolunduta, capile atro ni-

(1) Léox Devrour, Amnales des Sciences naturelles, 2 e séric, t. XII, p. 5 s et 56 , pl. $\mathbf{x y}, \mathbf{n g}, 107$ et $110, \$ 839$.

(2) Gonresu, Ammales de la Société Futomologique de France, 1852, Bull., p. Lxxyi. 
tido ovato-subtriangulari, occipite unilobato fisso, mandibulis oblongis subbifidis, mamillis ambulatoriis novem paribus pilis punctiformibus vage mulliseriatis. - Long. 1 1/2 lin. (3 1/2 mill.).

IIabitat in variis fungis, Tubcre, Boletis, Agaricis. (Pl. 1, fig. 23, 25.)

NYMPIA folliculata, oblonga, albida; oculis rolundatis, fuscis, subgranulatis; pedibus abdominis longitudine. - Long. 1 1/2 lin. (3 1/2 mill.). (Pl. 1, fig. 26.)

Foldiculus ovato-oblongus, albidus, opacus, mucoso-sericcus. - Long. 2 lin. (4 1/2 mill.). (Pl. 1, fig. 28:)

Les vers a tete noire trouvés dans les Truffes par Réaumur (t) se rapportent sûrement à une Tipulaire fongivore. M. Léon Dufour a signalé ces vers, qu'il a parfaitement reconnus et dont il a lait l'anatomie, mais il n'a pu en obtenir la transformation (2); enfin moi-meme j'ai observé, parmi les Diptères sortis des Truffes que M. Aubé avait mises à ma disposition, une petite espece du genre Sciara nettement caractérisée par la nervulation des ailes.

M. Goureau a vu sortir une pelite Tipulsire entierement noire du magma fétide des Truffes décomposées, c'était une espèce de Sciara; mais il n'a pas pu distinguer sa larve pour la décrire (3). M. Léveillé, qui a beaucoup ćludiẻ les végélaux inférieurs, mentionne les larves de Tipules et de Mouches de differentes especes parmi les insectes qu'on trouve dans la substance des Truffes (4).

\section{\2. COLÉOPTÈnES.}

\section{Genre ANISOTOMA (LEIODES).}

\section{A. CINNAMOMEA.}

L'Anisotoma cinnamomę a été si souvent observéc dans les Truffes, qu'on devait présumer que sa larve se nourrissait tle la sulıstanee de ces

(1) Résunur, Mémoires pour servir d l'histoire des Insectes, t. IV, p. 37\%, 1738.

(2) I.. Dufoun, Annales des Sciences naturelles, 2 éérie, t. XII et pl. $x$, fio. 1 d 4 , explication de la planche, p. 58, 1839.

(3) Goureau, Annales de la Société Entomologique de France, 1852, Bull., p. LXXYi.

(4) LÉveıLı̇, Dictionnaire universel d'Jlistoire naturelle, d'Orbigny, I. XII, p. 723, 1818. 
tubercules. Je viens changer cette présomplion en cerlitude, et je vais bientôt décrire la larve qu'on ne connaissait pas encore.

Les botanistes ont, comme les entomologistes, signalé la présence de I'A. cimamomea dans les Truffes. M. Léreillé (1) et M. Passy (2) désignent experessément ce Coléoptère; Ilenslow parle d'une espèce de Lciodes devorant les Truffes comestibles qu'on récolte en Angleterrn (3), et John Gurtis représente cette Lriodes, qui n'est autre que l'A. cinnamomea, en plaçant à coté d'elle une Truffe noire (4).

Iarva/hexapoda, capilala, crassa, paulo clongata, parce pilosa, sordide grisea; capite majore, stemmatibus nullis: antennis 4-articulatis, lutcoalbidis; mandibulis robustis, rufescentibus apice brumeis, forliler dentatis; maxillis tobo setifero, palpis triarliculatis; labio quadrato, palpigero, palpis biarticulatis; segmento ultimo biappendiculalo, appendicibus biartirulatis, minimis; stigmalibus notrm paribus. - Longitudo frre tres lincas attingit (6 1/2 mill.). (Voy. fig. 18 ò 27.)

\section{Habitat in Tubere melanosporo.}

LARVE d'un gris sale, a tète grande, avec le corps épais et assez court, les paltes courtes et l'abdomen terminé par deux appendices très petits. Point de stemmates (fig. 18).

Tếte presque carrée, un peu élargie en arrière; angles postérieurs arrondis, épistome prolongé en avant. Anternes d'un jaune blanchâtre, de quatre articles (fig. 20) : le premier gros, arronli, les deuxieme el troisième allongés, épais, le quatrième petit; un article supplémentaire, sous lorme d'un tubercule, place en dedans du dernier article sur le troisieme. Labre avancé au milieu, a peine echancré en avant, presque droit arec huit poils inégaux (fig. 21). Mandibutes épaisses, roussàtres, croclues à l'extrémité qui est brune, fortement dentées au sommet et à la partie interne vers leur base (fig. 22). Machoires d'un gris jaunatre ainsi que la levre, lobe interne arqué avec de longues soies; palpe de trois articles, le premier long, le deuxiène très court, le troisieme grèle et plus allongé (fig. "23). Livre infóricure d languette carrée, soudée au menton; palpes de deux articles, le premier épais, le deuxième conique, allongé, petit (fig. 24).

(1) LéveıLLé, Dictionnaire universel d'Histoire naturelle, article Mycologie, t. VIII, p. 474,1816 . - Faut-il lui rapporter la petile espece de Neomida à èlytres rouges dont il est question dans le mẻme ouvrage? (Voy. t. XII, p. 723.)

(2) Bulletin de ta socićté Botanique de France, t. VII, p. 232 et suiv., 1861.

(3) Voy. L.-3. et C. Turisse, Fungi hypogeei, p. 164 (Berk, in Hook., Engl. Flor., t. V, pars II, p. 228).

(1) J. Curtis, British Entomology, t. VI, fig. 251, 1829 (The Trume Beetle). 
Prothorax élargi sur les cótes, plus grand que les deux segments qui suivent et qui ressemblent, du reste, aux segments abdominaux suivants, car ils sont arrondis comme cux sur les côlés (fig. 18). Pattes assez courtes terminées par un ongle unique (Gg. 25).

Sogments abdominaux un peu élargis vers les trois quarts postéricurs du corps, le huitième segment abduminal plus petit, trapézoïde, le neuvième en demi-cercle et avec deux petils appendices biarticulés convergents et terminés par un poil court (fig. 27).

Stigmates petits, aı nombre de neứ de chaque côté; la première paire est placée à droite et à gauche au bord postérieur du prothorax et en dessous, les huit paires suivantes près du loorl supérieur des quatrième à onzième segments du corps (fig. 18). La forme de ces stigmates est très simple: ils consistent en un cercle bien arrondi et roussatre d'où part un gros tronc trachéen (fig. 26).

Le corps n'offre que de faibles poils roussatres, un de claque côté du corps sur chaque segment, d'autres en arrière, et six sur chaque segment en dessus, quelques poils pareils en dessous.

Je dois dire que M. Aubé a remarqué dans l'intérieur d'une Truffe une petite cavité ovalaire dans laquelle une de ces larves vivante était renfermée. De mon cóté, j'en ai découvert une autre. Ces larves avaient pris la forme très bizarre représentée figuro 19 , c'est-à-dire qu'elles étaient renversées sur elles-memes, le corps reployé, non en dessous, mais en dessus. Elles sont mortes sans se transformer en nymphe, el cette derniere mest inconnue.

La description qui précède est faite sur ces deux larves conservées dans l'alcool. La couleur est pâlie ; on observe des points noiratres sur chaque segment postérieur et une ombre de chaque cóté du prothorax, de plus une série médiane de petiles taches rousses. Ces macules sont-elles plus évidentes pendant la vie? Gela est probable; je me contente de les noter ici.

Je rapporte sans hésitation cette larve de Coléoplère à l'Anisotoma ferruginea PANzer (Faune Entomologique française, I, 314). J'ai pris de nombreux débris de cet insecte dans diverses Truffes, et il est probable que la larve, après avoir pratiqué une cavité dans la substance propre de ces Truffes, y subit ses transformations.

Cette larve est, du reste, fort remarquable par l'ensemble de ses caractires; elle s'éloigne beaucoup de la larve de la Leiodes humeralis décrite par Erichson, et de celle de l'Agathidium sominulum décrite par M. E. perris (voy. Cuapuis et Caxdize, Catalogue des larves des Coléoplères, p. 67 et 69,1853$)$. 


\section{ANISOTOMA FERRUGINEA.}

Daprès M.M. Tulasne, M. Ltienne Bonnet s'est assuré que les truffières des environs d' $\Lambda$ pt (Vaucluse) sont liabitées, ver's la fin de l'hiver, par l'Anisotoma ferruginea (1).

\section{ANISOTOMA PICEA.}

Vitladini, dans sa Monographie des Tubéracées, dil que le Iscoides picca dévore fréquemment, principalement à l'état de larve, toutes les Truffes, et surtout le Picoa juniperi (2).

\section{COLÉOPTÈHES OE DIVERSES ESPĖCES.}

Je réunis sous ce titre plusieurs coléoptères observés dans les Truffes, mais dont les uns ne s'y trourent pas ordinairement et dont les autres n'ont été déterminés que d'une maniêre approximative et seulement générique.

M. Guérin-Méneville a dit ì la Société entomologique de France que le Bolboccras gallicus a été pris en grand nombre, principalement par Allibert, dans l'intérieur de la Truffe; M. Guérin-Méneville en a conclu que cc Coléoplère pourrait aider à la recherche des Truffes en indiquant leur gite (3). Je ferai remarquer la rareté du Bolboccras, qui doit être plus difficile à trouver que les Truffes elles-mêmes; mais il n'est pas moins prouvé que le Bolboceras est tubérivore.

Deux autres Coléoptères de la famille des Scarabéides ont été rencontrés dans les Truffes, suivant M. Léveille (4). Ce sont les Ilannetons solstitial et horticole (R/hi:otrogus solstitialis et Phylloperta horticolu).

(1) I.-R. et C. Torasie, Fungi hypogai, p. 161. - Je pense que celte espèce d'Anisotoma doit être rapportée à l'A. calcarala li.rger-Enicuson, qui a pour synonyme 1'A. ferruginea scumor. (Vuy. Faune Entomologiqque française, t. 1. p. 317 .)

(2) Can. Vitranivi, Monographia Tuberacearum, Mediolani, 1831. - In Tuberibus omnibus ast precipue in Picoa juniperi observandum occurrit... cujus pareuchyma ab Insectorum (Lejodes pice( 1 ) larvis passim erosum (p. 81, note 1).

(3) Anuales de la Société Entomolngique de France, 1852, Bull., p. Lxxvi.

(1) Léveılue, loc. cit., article Tubéracées, t. XII, p. 723, 1898. 
Leur présence me paratt devoir y etre tout à fail accidentelle. J'en dirai autant du Bostriche capucin (Apate capucina) mentionné par le même auteur (1).

Dans un Mémoire sur la production spontanée et artificielle des Truffes, il est dit que M. Vincent $\Lambda$ moreux (2) a observé un Tembrio parni les insectes qui vivent aux dépens de ces précieux tubercules souterrains.

Je dois rapporter ici une espece d'llomulota très voisine, d'après M. Aubé, de l'autumnalis, et que M. le colonel Goureau a trouvée dans une bolte où il avait renfermé des Truffes gâtées. Cet insecte parait à M. Goureau etre né dans celte boite et y avoir subi ses transformations.

Enfin plusieur's petits Coléoptères, non déterminés, sont mentionnés par MI.M. Tulasne comme vivant dans les Truffes (3), et M. Léveillé signale le Gibbium scotias comme tubérivore; mais je dois faire observer qu'il s'agil de 'Truffes desséchées et renfermées dans les collections bolaniques (4).

\section{\$ 3. LÉPIDOPTẺAE. - TINÉIDE.}

MM. Tulasne, dans leur ouvrage sur les Champignons hypogés, page 16/, ont signalé dans les Truffes d'êté et mésentériques du bois de Vincennes, récoltées à la fin de l'automne, la présence d'un petit Lípidoptìre du genre des Tcignes, Ils ne parlent pas de la chenille ni de la chrysalide.

\section{\$ 4. MYRIAPODES.}

On trouve, d'après M. Léveillé (5), dans la substance des 'Truffes, et surtout quand elles commencent à se gàter, des Scolopendres et des Iules.

(1) Lévérulé, loc. cit., t, XII, p. 723.

(2) Bovenet-Doumence, Nouvelles observations sur la production.... des Trufies (Bulletins de la Société d'agriculture du département de l'Ilérault, $29^{\mathrm{e}}$ année, p. 301 et 305,1842 ).

(3) Fungi hypogai, p. 164.

(4) LéveILlé, loc. cit., t. VIII, p. 473. - Voici l'indication : in Fungis exsiccatis præesertim in Tuberibus.

(5) I.ÉveH..é, Dictionnaire universel d'Histoite naturelle, 1. XII, p. 723, 1848. 
En résumé, nous sommes autorisés à dire, par ce qui précède, que les Truffes nourrissent un grand nombre d'especes d'insectes, principalement de Diptères, dont les larves ont été rencontrées tour à tour dans plusicurs especes de Ghampignons et meme dans d'autres matieres riches en azole (Phora). Le genre Hctomyza est surtout tubérivore, mais il ne l'est pas exclusivement (1), et nous voyons qu'il en est de mème pour beaucoup d'autres genres qui sont plutôt fongivores que tuberivores; nous trouvons enfin des insectes Coléoptères, Lépidoptères et des Myriapodes vivant dans les Truffes comme dans d'autres substances azolées. Ce point établi, nous devons maintenant prouver que s'il y a beaucoup de Mouches et beaucoup d'autres insectes tubérivores, aucun de ceux qui ont été observés, el que nous avons examinés, n'est organisé pour produire les Truffes, et partant que les insectes prétendus truffigines n'existent pas.

\section{CHAPITRE II.}

\section{Refutation de l'erreur gui a fail attribuer les Truffes d) la piquire d'un insecte.}

Ia réfutation suivante semblera peut-ctre inutile à mes collegues; mais je les prierai de remarquer combien il est important de détruire une erreur qui s'appuic sur un fait observé par des personnes de bonne foi. L'interprétation seule de ce fail n'est pas exacte, elle est mème complétement fautive (2). Jespere d'ailleurs en finir avec cette question ct apporter la conviction dans les esprits, en fournissant aux cultivateurs de Trufles les données entomologiques invoquées par eux à plusieurs reprises.

(1) M. I.éon Dufour at observé que "l'espèce de larve varie dans le même Clampignon suivant la salson et l'age de celui-ci ; ainsi en septembre le Boletus pinelorum nourrit une quantité prodigiense de larves d'une Muscide du genre Helomyza, et en décembre il est peuplé de celles du Mycelophila inermis, qui est une Tipulaire. (Annales des Sciences naturelles, loc, cit., t. XII, p. 8.)

(2) Je recommande la lecture d'un bon travail de M. D. Cros combattant ectte erreur : Origine des Champignons; la Truffe et sa culture (Revue de l'Académie de Toulonse, livraisen d'avril 1858, tirage à part en brochure in-8n, 12 pages). 
Depuis très longtemps on s'est aperçu que des Mouches volligent audessus des terrains ou les Truffes se sont développées. Les ouvriers trulfiers ou rabussiors connaissent, sous le nom de Mouscous des Rabassos ou Mouches des 'Truffes, diverses espèces d'Ir lomyza (1). La présence des insectes tubérivores sur les gisements des Truffes ou dans l'intérieur de ces tubercules a été constatéc par des naturalistes éminents; les citations suivantes le prouvent d'une manière catégorique.

Garidel (2), qui professait d l'ícole de Montpellier au commencement du siecle dernier, dit expressément, après avoir indiqué la manière de chercher les 'Iruffes avec les pourceaux ou les truies: "Il y a une autre manière de découvrir les Truffes qui est connue de peu de gens et que j'ai moi-meme observée : c’est lorsque le jour est serein et calme et que le soleil reluit sur ces endroits, on s'aperçoit d'une nombreuse quantité de Mouclierons qui s'clevent, de l'endroit où est cachéc la Truffe, à la hauteur de deux ou trois pieds. Si l'on creuse justement au point de la terre d'où s'élèvent les Moucherons, on decouvre ordinairement la Truffe, qui est assez souvent gatéc : c'est ce qui m'oblige de croire que les vers que l'on trouve ordinairement dans les Truffes que l'on creuse l'élé sont les cufs éclos de ces insectes. Ces vermisseaux, qui sont d'une couleur blanche, sortent dans la suite des trous de la'Truffe et de la terre en forme de Moucherons. Les Truffes où l'on trouve ces vers n'ont ni l'odeur ni le goùt des autres : je parle de celles de l'été sur lesquelles j’ai fail plusieurs fois ces observations. ")

Ia justesse des réflexions de Garidel est frappante; il avait très bien apprécié la présence des Moucherons au-dessus des Truffes dont ils étaient sortis; il croyait que les $\alpha u f s$ éclos de ces Moucherons produisaient des vermisseaux qui se changeaient cnsuite en insectes ailés. Quant à savoir à quelle espece appartenaient ces insectes, il est permis de conjecturer qu'il s'agit peut-etre d'une Tipulaire vivant dans la Truffe d'été?

Le comte de Borch, dans sa deuxieme lettre sur les Trufles du Piémont, adressée au comte Morozzo, a parlé de deux espèces d'insectes (3) qui

(1) Les Truffes sont appelées Rabassos par les Provençaux; les ouvriers truffers portent lo nom de Rabassiers ou Rabassaires, et les Mouches des Truffières celui de Mouscous des Rabassiers ou Rabassaires.

1.es ouvriers qui récoltent les Truffes dans le Poitou sont conus sous la désignation de Trupleurs ou de Truffiers.

(2) Garnder, Histoire des plantes qui naissent aux environs d'Aix et dans plusicurs autres endroits de la Provence, $1 . \mathbf{4 7 4}$ et $\mathbf{4 7 5}, \mathbf{1 7 1 5 .}$

(3) De Borcu, Lettes sur les Truffes du Piémont, Milan, 1780. 
indiqueraient la présence des Truffes. "Lorsque les Truffes sont mùres, on voit voltiger alentour de l'endroil qui les produit des Mouches bleues; mais lorsqu'elles sont dans un élat de putréfaction, ces Mouches disparaissent et sont remplacées par d'autres tout à fait noires. J'ai eu occasion d'examiner ces insectes dans ces diférents étals..... " ( $($. 34.)

"Les Mouches bleues proviennent d'un petit ver blane ayant une tete noire et deux poils loruns à l'extrémité; le nid de cet insecte se trouve dans la Truffe même, au milieu d'une petite cavité noire qui recèle son germe. En grandissant, ce ver change plusieurs fois de couleur : de blanc il devient couleur de café au lait, puis brun rouge, ensuite il passe a l'état de chrysalide et s'enferme dans une coque blanche qu'il s'ourdit lui-meme, enfin il sort de ce cocon en forme de Mouche bleue. " (P. 34 et 35 ,)

"Les Mouches noires doirent leur naissance à un ver brun, qui noircit toujours plus en avançant en age, qui dans l'état de clirysitlide se revet d'un cocon brun à peu près comme celui des Teignes, et puis, au moment de sa métamorphose, reparait sous la forme d'une longue Mouche noire. n (P. 35.)

Le comte de Borch renvoie à la planche 3 qui accompagne ses Lettres; mais le dessin très imparfait et l'enluminure grossière des figures ne permettent pas de reconnaitre les insectes dont il a voulu parler. Bosc a rapporté la Mouche noire ( $F$ et $G$ de la planche 3 ) à une Tipule; je n'oserais le faire avec certitude.

Quant à la Mouche bleve, le doute est encore plus grand. Le ver $(A)$, s'enveloppant d'un cocon et vivant dans une cavité de la Truffe, rappelle, par sa couleur et son extrémité pourvue de deux poils, la larve de l'Anisolome; mais il n'est pas fait mention des pattes, et la figure de l'insecte parfait $(C)$, d'un bleu cendré avec deux gros points rouges sur les côtés de la tête, est, à mon avis, intraduisible. On dirait une Jouche mal venue ou un Coléptère à élytres courtes, et on comprend que M. Villadini, dans sa Monographic si estiméc, ait regardé ces figures comme imaginaires. Pour moi, je suis convaincu que le comte de Borelt parle d'un fait rai, mais qu'il a très mal représenté les insectes dont il fait mention.

Bosc, lorsqu'il demeurait sur la chaine calcaire situee entre Langres et Dijon, avait souvent reconnu la place où se trouraient des Truffes mùres, vers la fin de l'aulomme, à la présence de petiles Tipules : "Quand le soleil luil et à neuf heures du matin, il faut, dit-il, se pencher et regarder horizontalement la surface de la terre pour voir une colonne de ces 
petites Tipules, a la base de laquelle on n'a qu'a fouiller avec une pioche pour trouver les Truffes d'où elles sortent (1). n

J'ai noté précédemment les observations de MM. Tulasne, Léveillé, Gubler (2), etc., signalant les Mouches du genre IIclomyza qui se plaisent dans les départements méridionaux du Vaucluse, du Var, des Basses-Alpes et des Alpes-Naritimes, sur la terre ou sont les Truffes et qui en indiquent le gisement aux gens du pays. M. Goureau a fait des remarques analogues à Santigny, dans le département de l'Yonne, pour l'Ilelomyza fubcrivora (3). M. Ravel, de Montagnac, lans les Basses-1lpes, insiste beaucoup, dans deux mémoires que j'aurai à discuter, sur la présence des Moucies au-dessus des truffieres. "Ces Mouches voltigent constamment à la hauteur de 30 à 40 centimètres, au plus, au-dessus du sol, et ne craignent pas le froid (4); depuis des siècles, les paysans sont guidés dans la recherche des Truiles par ces Mouches (5). "

D'après cet exposé, il me paraft hors de toute contestation que des insectes, et notamment des Dipteres, voltigent au-dessu; des truffèeres dont ils sont sortis ou qu'ils recherchent pour aller y déposer leurs œufs. J'ai déja dit qu'un auteur célebbro, M. Vittadini, a soutenu que les insectes des truffières ne sont pas spéciaux et ne differrent point de ceux des autres Champignons; il nie que ces insectes aient l'habitude de se réunir en essaim, et il affirme que les Milanais ne clierchent point les Truffes sur leur indication : les figures publiées par le comte de Borch lui paraissent tout à fait imaginaires (6). Je ne puis accepter celle opinion dans sa rigueur, car les espèces d'IIclomyza dont nous connaissons les larves sont tubérivores; et d'ailleurs, en supposant que les insectes dont les larves vivent dans les Truffes se nourrissent aussi dans d'autres matières azolées, il n'en reste pas moins prouvé que ces insectes indiquent les truffières, ainsi que liosc et beaucoup d'autres l'ont constaté. Par conséquent, la présence des insectes au-dessus des gisements de Truffes est incontestable; mais c'est le seul fait vrai dont on ait pu déduire une interprétation

(1) Bose, article Truffe du Nouveau Dictionnaire d'Histoire naturelle, t. XXXIV, p. 558 , Paris, Déterville, 1824.

(2) Bulletin de la Société Botani, ue de France, t. VIII, p. 235, 1861.

(3) Gourfav, Annales de la Société Entomologique de France, 1852, Bull., p. 1.xxv.

(4) Ravec (de Monlagnac), Culture de la Truffe, deux Mémoires publiés à Paris en 1857; Jer Mémoire, p. 11, et 20 Mémoire, p. 8.

(5) Raver, 20 Mémoire, p. 11.

(6) C. Viтtapinı, Monographia Tuberacearum, p. 87, note 35, 1831. 
crronce du rôle des insectes par rapport aux 'Truffes, car ces insectes, loin de les produire, ne font que s'en nourrir. Pour le prouver, je vais examiner successivement les questions auxquelles cetle présence des insectes dans les truffières a domé lien, el discuter : 1" Si les insectes tubérivores peuvent provoquer le developpement des Truffes et s'ils sont gallicoles? $2^{\circ}$ La Truffe est-elle une galle vézétale? $3^{\circ}$ Enfin, si la Truffe n'est point une galle végétale, qu'est-elle réellement?

\section{- Ees Insectes qui vivent dans lew Truffes Nont-ils gallicoles et peuvent-ils provoduer le développement d'uns Truffe commo colui dyne Gallo végétale?}

Si les insectes tubérivores ont fixé l'attention depuis des siecles, suivant l'expression de M. Ravel, depuis un temp̨s très reculé aussi on a fait jouer aux insectes un rôle plus ou moins bizarre ou hypothétique dans la production de ces tubercules.

Dumont (1), dans l'exposé de ses voyages, publiés en 1699, rapporte l'opinion d'un sieur clary, avocat provencal. Les Truffes sont "un amas d'un certain sue de la terre... eltes se pourrissent dans la terre au commencement de l'été, et de leur corruption s'engendre toujours une frande quantilé de papillons d'une espice parliculire " qui servent à la gínération de nouvelles T'ruffes. "Cela arrive par le frai de ces animaux dans de cerlaines fentes qui se tont en terre au lieu ou les I'ruffes avaient pourri... Aussitòt après, les crevasses se referment et les Truffes y viennent une autre fois. $)$

Quels sont ces papillons d'une espece particuliere? Faut-il y voir quelque Tiníile analogue à celle observéc par M. Tulasne, ou cst-il siniplement question d'une Mouche colorée, d'une IIclomyza? Quoi qu'il en puisse être, on voit que ce n'est point d'hier qu'on a pensé à attribuer, en Provence, la production des 'Truffes a l'influence des insectes.

En 1847, M. Robert crut reconnaitre que la Truffe se formait sur les racines des chênes "à rextrémité des filaments devenus capillaires et imperceptibles. " Ne pourrait-on pas admettre, pensait-il, que les Truffes sont des noix de galle souterraines, qu'elles doivent leur origine " à une circonstance a peu près pareille à celle qui donne lieu sur la feuille de

(1) Dewont, Voyages en France, en Italie, etc, p. 114 et 145, 1699. 
certains chènes blanes à celte espèce d'excroissance d'où résultent les noix de galle, c'est-î-dire à la piquure de quelque insecte (1). ")

N. Bavel, sans connaitre le travail de M. Riolsert, a eu la nuime jelée, ef il a pensé que la Truffe était une galle végétale. N. liavel a basé sur cette domnée une culture de la Truffe, car celte dernière "n'est autre chose qu'un accident produil dans la végétation du chène par la piquùre d'une Mouche qu'il appelle truffigène (2). " La Truffe ne pourrait exister, pas plus que la noix de galle, si l'insecle qui la produit n'existait point. " La galle et la Truffe sont toutes les deux l'ouvrage d'un insecte qui a voulu mettre sa couvée à l'abri et préparer une pature à ses larves (3). "

On voit nettement quelle est la croyance de Mu. Robert et Ravel sur la production des Truffes. Leur manière de voir a été partagée par d'honorables agriculteurs, mais peu familiarisés avec les études entomologiques et botaniques, et récemment M. Valserres (4) a reproduit les opinions de MM. Robert et Ravel en leur accordant toute créance et en appelant sur elles une sérieuse attention.

Nous trouvons, dans les deux Mémoires de M. Ravel sur la culture de la Truffe et dans le compte rendu de M. Valserres, les assertions qui leur ont fait altribuer les Truffes à la pigûre d'un insecte. M. Ravel dit qu'il y a autant de variétés de Vouclies qu'il y a de variétés de Truffes, mais il n’a pas déterminé ces diverses variétés de Nonehes. "Il existe plusieurs espèces de Mouches truffigènes, el celle qui produit la Truffe noire n'est certainement pas la meme que celle qui produit la Truffe blanche (5). "

"Méconnaissant le rôle capital, dit M. Valserres, que la 'lipule joue dans la production de la Truffe, c'est a peine si les naturalistes nomment ce Diplolèpe dont les espèces varient comme les Truffes elles-mêmes. Aussi, en cet important sujet, l'histoire naturelle est-elle complétement à refaire (6). n

Je réponds que la détermination des espèces d'insectes qui vivent dans les Truffes et qui se nourrissent de leur substance est aussi précise que ossible. Les mœurs de ces petits animaux sont parfaitement connues, insi que je l'ai démontré. Je puis affirmer que parmi ces insectes il n'en

(1) Rовект, Apreçu sur l'histoire naturelle des Truffes et leur mode de production. (Comptes Rendus des séances de l'Académie des sciences, t. XXIV, p. $66 \mathrm{el}(67,1817$.)

(2) Raver, De la culture de la Truffe, ter Mémoire, p. 7.

(3) Raver, loc. cit., 1er Mémoire, p. 7 et 8.

(4) Valsernes, Annales de l'agriculture française, se série, t. XXI, p. 184 et suiv., 15 mars 1863.

(5) Raver, loc. cit, ter Mémoire, p. 10.

(6) Vausernes, loc, cit., p. 190. 
existe aucun qui soit l'artisan ou l'auteur d'une galle végélale, il n'y a aucun IIyménoptère gallicole, aucune Jiplolèpe; la seule Mouche à quatre ailes sortic des Truffes est un parasite des autres Dipteres, un Ichneumonien.

M. Goureau a fort bien établi ce fait en indiquant les insectes qu'il avail observés dans les Truffes, et en signalant une espece d'Alysia parasite des autres larves lubérivores (1).

Eutrons au coeur mème de la discussion el prourons que pas un seul des insectes vivant dans les Truftes n'est gallicole. La Tipule dont il est question dans le deuxième Mémoire de M. lavel el dans le compte rendu de $\mathrm{H}$. Valserres est une espèce de Tipulaire fongivore appartenant au genre Scirra. Il est probable aussi que la petite Tipule que Bosc avait remarquée se rapportait à ce genre. Or, ces Tipulaires ne sont pas gallicoles comme les cécidomyies et les Lasioptères, car elles se développent dans les matières végélales en décomposition, dans le fumier, dans les Champignons de diverses espèces, elc. J'ai décrit récemment les premiers états de la Sciara Bigoti (2), dont les larves se trouvent par milliers dans le fumier aux environs de Paris.

Les Coléoptères olıservés dans les Truffes ne sont pas gallicoles; on sait qu'un petit nombre de Ceutorhynchus et de quelques autres genres ıle Curculionites peuvent produire, rarement, des galles sur les vẻgélaux qu'ils habitent; mais ni l'Anisotoma, ni le Bolboceras, ni aucun des Coléoptères tubérivores, n'est gallicole. Les cavités creusées dans la Truffe, soit par la larve précitée du comte de Borch, soit par la larve de l'Anisoloma, sont élablies dans un tissu déjâ formé; ces cavités sont entièrentent semblables à tous les trous, à toutes les galeries creusées dans le bois et dans les végélaux par les vers ou par les insccles parfaits, et personne n'a jamais pensé que les loges oil les Xylophages se mélamorphosent fussent des galles. L'entomologiste, s'occupant des mours des insectes, est obligé d'admeltre comme vérité démontrée l'absence complète d'un insecte gallicole trouré dans les Truffes.

M. Ravel affirme que les Mnuches volligent sur les truffières l'été comme l'hiver: "Ce qui la dislingue de la Mouche ordinaire, c'est qu'elle ne craint pas le froid et résiste a une température assez élevée en se blottis-

(1) Gocresu, Annales de la Société Fntomologíque de France, 1852, Bull., p. Lxxvi.

(2) Annales de la Société Enlomologique de France, 1862, p. 105 et suiv., pl. 2, fig. 5 . 
gant sur la terre (1). "On verra " an coeur de l'hiver les Mou es truffigènes, pleines de force et de vilalité, se mouvoir en tous sens sur l'emplacement des trufticres; il n'y a qu'un vent violent et un froid sec qui les engourdissent et qui les fassent blottir sur la neige, car la plus forte couche de neige ne les fait point périr (2). "

Il s'agit évidemment de Mouches d'espece et même de genre très différents qui vivent daus les Truffes pendant l'été et pendant l'hiver; les insectes mentionnés par Garidel dans la Trufte d'été ne sont pas les mèmes que ceux observés pendant l'antomne par M. Goureau dans la Truffe noire. M. Ravel a lui-mème signalé la différence des larves "qui, vers la fin de mars et d'avril, dévoreront les Truffes complétement el ne laisseront at la place du précieux tubercule qu'une matière noire semblable a du charbon pilé (3), " et celles de la Truffe blanclie d'été "qui se contentent de la sillonner dans tous les sens et d'y pratiquer une infinité de pelils trous, comme on le remarque en la coupant en tranches..... (i). Ia génération de la nouvelle truffigène n'est arrètéc que par le délat de chaleur pour l'éclosion de la ponte; mais une fois commencese clle continue pendant cing, six et sept mois de l'année, et celte multiplication d'insectes devient innombrable (5). " Celte durée illimite et celte diversité inexplicable dans la Mouche prétenduc truffigène n'avait pas ćchappé à .I. Valserres, qui s'étonne de "cette pérennité contraire à toutes les rigles de la science, " et "d'une exception faite en laveur de la ripule non soumise à la loi qui régit les ères inférieurs (G). " Mais, qu’on renille bien se le rappeler, il y a diverses espèces, un grand nombre d'espieces de Mouches vivant dans les mênes Truffes et se succédant tour à tour dans leur éclosion.

Les IIclomyza, les Curtonevra et autres Muscides à larves pseudociphalées et à pupe formée de la peau même de la larve, n'ayant que des allures généralement peu agiles, paraissent deux fois dans l'annice et volent sous les rayons les plus chauds du soleil; elles ne forment pas d'essaim. Les Tipulaires vraies, si differentes à l'état de larve et de chrysalide, sont d'abord souts l'aspect de vers blanchatres à tête d'un noir de jais, puis revêtues d'une enveloppe extérieure munie de saillies et rappelant

(1) Ravez, ter Mémoire, p. 11.

(2) Raver, 2e Mémoire, p. 8.

(3) Raver, 2。 Mémoire, P. 8.

(4) Ravic, 2e Mémoire, p. 9.

(5) Ravel, ter Mímoirc, p. 9.

(6) Valserreg, loc, cit., 191. 
celle des Lépidopteres diurnes; ces Tipulaires hibernent assez facilement. Elles forment des essaims; on les voit pendant les journées les plus froides, mais sereines, tourner, s'elever, redescendre; elles ont des habitudes spéciales : ce sont les Mouches choraras agmles de Linnée. Ces diverses especes ont leurs mocurs particulières et se reproduisent à leur maiere dans les Truffes, tant qu'elles en trouvent; à défaut de Truffes elles choisissent d'autres matiores arotées, et elles ne sont pas plus gallicotes ou gulligines les unes que les autres, elles ne sauraient lietre cu aucune façon.

Voici comment se produit la Truffe suisant M. liavel : "La Nouclse truffigene, que l'on remarque voltigrant constamment en hiver sur la place des truffieres, aulour des chènes producteurs des 'Truffes, pénètre dans la terre, atteint les racines chevelues et les pique à leur extrimite pour déposer ses ocufs; la pigùre délermine le jet d"une goulte lailense.... La Truffe étant formée, les racines piquées par la truffigine meurent et la Truffe, abandounéc it clle-mème, grossit et se développe avec le secours de la lerre el de l'air. Vaili pourqunoi ceux qui se sont occupés de la Trufte n'ont jamais pu y reconnaitre ni germe, ni radicule, ce qui prouve qu'elle n'est pas un produil vígétal (1). " J'ai reproduit intígralement ce passage qui renferme deux exreurs, à savoir : le rúle de la Mouche et celui de la nature de la Truffe. Je ne répondrai actuellement qu'a la premiere, en rétablissant les faits relatifs à la Motrche prétendue truffigène. Quand les Mouches femelles pénetrent dans le sol apris en etre sorlies au moment de leur éclosion el s'elre accouplées, c'est pour aller y pondre sur les Truffes; mais ces insectes, dépourvus de farière analogue a celle des Ibiplolepes, des Tentluredines, etc., et n'ayant pas d'oviscapte pour entailler une racine si minime qu'on la suppose, ne peuvent absolument. pas piquer le tissu vererdal ou les ralicules fibrillaires du chène.

Gombien Garide! et Bosc, ces observateurs consciencieux et ne voulant pas torturer les fails pour les plier à une lluéorie, araient mieux jugé la question! Jous arrivons après eux ì conclure surement que lo seul fail réel parmi toutes ces assertions étranges, c'est la presence des Mouches dans les fruffières, parce que ces Mouches recherchent les Trufles pour y déposer leur's cul's.

(1) RAvex, les Mémoire, p. 8 . 


\section{La Trufro n'est point une Galle végétale.}

Après avoir démontré à nos honorables adversaires, par l'cxamen rigoureux des insectes dits truffigènes, que pas un seul d'entre eux n'est gallicole, il nous sera facile de prouver que la Truffe n'est point une galle.

Notre vénéré maitie 3 . Léon Dufour, dont l'autorité dans ces questions complexes est si grande comme entomologisle et comme botaniste, a voulu combattre celte erreur. Nous ne pouvons mieux faire que de résumer ce qu'il a dit :

"Une galle, pour mériter ce nom, a non-seulement besoin d"être fixée au végétal dont elte emprunte les sucs nourriciers.... mais la larve ou les larves qui en provoquent la formation, et dont l'existence iniliale coincide avec cette galle, s'établissent dans une ou plusieurs loges ou coques particulières..... (1).

" hien de semblable ne s'observe dans la Truffe, à quelque age que vous en étudiiez la structure intime. Demandez plutôt at fin gourmet, à l'artiste culinaire s'ils ont jamais trouvé des rers dans les Truffes fermes et parfumées mème les plus grosses, ils vous diront: non. Mais s'ils rencontrent un tubercule mou et infect, ils le repoussent bien loin, et ce tubercule fait la fortune de l'entomoplile. ")

La Truffe n’offre ni les caractères extéricurs, ni les divisions ou les cavités intérieures d'une galle végétale. Elle re ressemble en aucune manière aux galles des Diplolèpes, ni à celles des Coulorhynchus, ni à celle des Cicidomyies ou des Aphidiens. On connait, depuis longtemps déjà, la galle souterrine des racines dlu chẻne produite par le Cynips aptera F.ıB. (2). Уоуеz combien clle differe de la Truffe : elle est ligneuse, avec une cavité où est éclos le Jiplolepe gatlicole, et elie n'a aucune espece de rapport avec la masse charnue du précieux tubercule. L'une est dure, constituée par du tissu hypertrop̣hié, par des cellules végétales et des clostres ou vaisseaux aériens du chene; l'autre renferme des utricules spéciales de tissu cellulaire, et dans les sinuosités qui la parcourent se déposent des germes particuliers, des spores, corps reproducteurs de la 'Truffe. Les œufs et les larves d'insectes ne font jamais partie intégrante, ou nécessaire, d'une Trufre normale. Leur présence y est accidentelle.

(1) I. Duroun, (utrlịue chose sur les Truffes, (Comptes Rendus des séances de l'Académic des sciences, t. XLIII, p. 1031, 1856).

(2) Vuyez une note de M. 11. T.ucis dians res Aunales, année 1861, Bull., p. cav. 
$3^{0}$ La Truffe est un Cunmpignon hypogé.

Si la Truffe n'est habitéc par aucun insecte gallicole, si clle ne peut être produite par aucun de ces mèmes insectes qu'on y rencontre a l'état de larve; si la Truffe, en definitive, n'est point une galle virgétale, qu'estelle done? La réponse est des plus faciles, des plus calégoriques dans l'état actuel de la science : la Truffe est un Champignon souterrain ou, en d'autres termes, un Champignon hypogé.

Ce serait être bien injuste et bien peu reconnaissant envers les savants dont les cuvres resteront comme un modele que de ne pas citer ici les magnifiques travaux de MM. Vittadini, Léveille el Tulasne, car on y trouve la démonstration la plus complète que la Truffe est un Champignon. Fille l'est par son organisation et mème par son mode de développement. C'est pour n'avoir voulu apprécier que certains états de son évolution, par exemple l'àge adulte ou de maturité, que les auteurs anciens ont soulevé des controverses fort vives. Mais déjà l'analogie aıce les Clıampignons était prouvée : les insectes viennent la confirmer. Car les mèmes espèces dévorent à la fois les Truftes et les Champignons aériens ou croissant à la surface du sol, et on sait quel est le tact botanique des insectes qui, ne trouvant pas la plante dont ils se nourrissent, ront s'établir daus une espèce du mème genre ou, à son défaut, dans une plante de la même famille, et cela avec une sùreté qui fait l'admiration du naturaliste (1).

puand on coupe une Truffe parvenue à l'époque de sa maturité, on voit qu'clle est forméc d'une partie charnue intérieure parcourue par des veines sinueuses el dont la direction varie suivant les especes. Dans la Truffe plus jeune, ces mêmes veines sont larges et forment des cavités sinueuses très irrégulières; on peut s'assurer que ces veines ou cavités communiquent entre elles et aboutissent finalement à une ourerture unique ou à une dépression; d'autres fois les reines répondent â plusicurs orifices situés à la surface. En comparant les deux Truffes jeune et à l'état de maturité, on s'assure que les cavités de la Trufie jeune se sont amoindries quand elle s'est développée, parce que les cloisons de ces cavitès se sont épaissies; il s'est formé là un tissu qui finalement a produit à la sur-

(1) Voy. Léox Doroun, Amales des Sciences naturelles, ze série, t. v, p. Đ, 1816.

- E. Penris, Annales de la Société Entomologique de France, 1863, p. 465. 
face interne des filaments et les corps reprodncteurs de la Trufe: les thèques et les spores développées dans les thèrques (1).

Nous ne trouvons dans la Truffe, si extraorlinaire en apparence, qu'une structure analogue en réalité à celle d'autres Champignons, car c'est une masse charnue, ou glebre, dont la surface externe forme une cnveloppe, ou un peridium, renfermant des eavités étroites, sinueuses el revètues d'un tissu spécial, tissu dont les cellules peurent produire dans leur intérieur les corps reproducteurs ou spores.

Que le lecteur nous prète encore une attention soutenue, et veuille bien réfléchir que la structure de la Trufée ne peut etre bien appréciéc que par la comparaison de ce Cryptogame souterrain avec les autres Cryptogames vivant it la surface du sol. Or, tout Champignon (et par exemple le Champignon cultivé) résulte d'un myceliume ou thallus végćtant sous terre ou sous les écorces des arbres, etc. Ce mycélium, qui ressemble à un feutre, à un amas de filaments blancs, forme le blanc de Chempignon dans .es couches où pousse l'Agaric comestible des marchés. On peut comparer ce mycélium, eet amas byssoïde, ces filaments, à la racine souterraine de certaines plantes, et le champignon lui-mème n'est en réalité qu'une production finale de ce mycélium, production comparable à certains fruits composés et renfermant les spores.

Mais, dira-t-on, la Truffe n’a pas de mycélium, elle se développe par les spores qui grossissent et elle differe de tous les Cryptogames sous ce rapport. Erreur, la nature a été prise sur le fait, et c'est à M. Tulasne que la science est redevable de celte observation si remar(quable (2); ce savant botaniste s'est assuré que le sol des truffières du Poitou élait, au mois de septembre, traversé par des filaments blancs, cylindriçues et byssoïdes, ayant trois à cing millièmes de millimètres de diamètre. Ces filaments se continuaient avec un mycélium cntourant les jeunes Truffes, grosses comme une noisette ou une noix, et formaicnt autour d'elles un feutre blane très dense de un à trois millimètres d'épaisseur. Il faut lire dans l'ouvrage de M. Tulasne celte observation si concluante recueillie sur la Truffe noire des gastronomes. Je me contente de dire ici que le fait est probant: la Truffe jeune est entourée d'un mycélium et provient de ce mycélium tout comme les autres Champignons des genres Balsamia, Terfezia, Delestria.

(1) I.,-R. et C. Tulasne, Fungi hypoger, Histoire et Monographie des Champignons hypogés, p. $2 f$ et suiv., 1851. - Voyez aussi le Rapport de M. Ad. Brongniart (Comples Rendus des séances de l'Académie des sciences, t. XXXI, p. 876).

(2) L.-R. et C. Tulasse, Fungi hypogæi, p. 59 et 60, 1851. 
En résumé, la Truffe est un végélal isolé, à l'éporque de la maluritr. au milieu du sol; mais dans sa jeunesse elle est entourée d'un mycélium d'où elle provient; les organes reproducteurs sont placés dans l'intérieur cle sa masse cliarnue, el les spores, très petites, ayant de deux ì quatre dixiemes de millimetre de longteur, se développent quand la Truffe pourrit el se décompose. Ces spores donnent naissance at mycélium. (oue deviennent devant ces faits irrécusables les assertions dont j'ai pronis de montrer ie peu de fondement et l'erreur manifeste? (loyez plus haut, pages 33 et suiv.)

MIM. Tulasne n'ont pas seulement porté beaucoup plus loin gu'on ne l'avait fait avant eux la connaissance de la structure interne el des organes de reproduction des Clampignons hypogés, mais ils ont décrit un grand nombre d'espèces nouvelles et qu'ils ont répar ties dans trente-deux genres. Ils ont fait voir que le genre Tuber proprement dit renferme vingt ef une espèces soigneusement distinguées les unes des autres. En France, quatre de ces especes sont comestibles et bien souvent confondues sous le nom de Truffe noire. Deux de ces espèces mutrissent en automne ef sont récoltées à la fin de cette saison, et sturtout en hiver : ce sont les Tuher lirumule el mclanosporum; deux autres espèces acquièrent tout leur développement en élé : ce sont les $T$. astivum et mrsentericum. Ces Truffes d’été sont moins estimées que les précédentes et s'exportent en quantités parfois considérables, quand clles ont été desséchées, après aroit été coupées par tranches, La Truffe blanche, $T$. Magnatum, se trouve aux environs de Tarascon et en Provence; elle est très estimée en Pitimont. Les autres especes de Truftes frangaises ne sont pas comestibles (1).

J'ai tenu à donner ces délails, rui ne nous éloignent pas des insectes tubérivores, pour appeler de nouvelles recherches et pour fournir à mes collegues ou aux observateurs favorisés par les circonstances les noyens de connaftre sûrement les especes de Trufies qu'ils auront trouvies et les insectes qui les habitent (2).

(1) Fungi hypogri. Voyez pl. vi, If Tuber Magnutum, el pl. vit, Ies $T$. brumale, melanosporum, mosentericum et cestivum.

(2) Tuber brumale Vitrumis, Monogi. Tuberacearum, p. 37. - Tuliswe, Fungi lypogavi, p. 135. - T. globosum plus minus regulare, nigrum, verrucis polygoniis aspera'um, taniem glabrum nudumque; pulpo frurtifora matura vinereo-nigrescente, venis albis marmorata; sporangiis creberrimis $1-6-5 p 0-$ ris; sporis oblongo-ellipticis spinulisque rigitlis echinatis.

Espèce Irès abondante, à la fin de l'automne et en hiver, dans les truffières de la France et de l'llalie, très commune sur les marchies. Poilou, en octobre; Provence, 
Une derniêre question se présente enfin, e'est de determiner le róle que peuvent jouer les insectes dans la dissémination des spores de la

Avignon, Apt, Riaus, novembre et décembre. Edule, odeur forte ot un peu alliacée (odor ligni corni sanguinece, Vittadini).

Cette Truffe porte le nom de Truffe punaise ou fourmi aux enirons de Turin, ct de Truffe puante ou pudento dass le Midi de la France près de Nérac (Lesp̧iault); jenne et croissant encore, elle est d'une couleur rouge ferrugineuse. Ces jeunes Truffes sont apnelées rougeottes en Provence.

T. melanosporum Vitrud, Monogr. Tuber., p. 36. - Tulasve, Fungi liyp., p. 136. - T. nigro-rufescens, verrucosum, verrucis polygonis maculis rubiginosis notatis; pulpa matura saturate rubeo-s. violaceo nigrente; venis albidis utrinque linea pellucida marginatis tandemque subrubidis; sporangiis 4-6-sporis, sporis elliptico-oblongis, echinatis, opacis.

Abendante en France el en ltalie et vendue sur les marchiés avec la prérédente, quỉ est moins estiméc. Poitou, automne el hiver, Civray, Coulé, Vérac, Ingrande; Provence, Avignon, Apt, etc.; l'are aux environs de Paris, parc de Viucennes, coteau de Beauté, terrasse de Charenton-le-Pont, an pied des bouleaux et des chênes au commencement de décembre (Tulasne). Angleterre, rare, Odeur et saveur spéciales, odor saporyue gratissimi.

C'est la Truffe violette ou du Périgord et la plus reclierchée. Flle se distingue de la précédente par son volume ordinairement plus considérable, la couleur noire on violacée de sa chair, ses veines blanchatres fincs et nombrenses, jar unc videur et une saveur plus agréables. Ia pulpe de la Truffe puante des Condomois, on T. brumale, est grise ou bistrée, marbrée de veines plus rares, nettes et d'un blane mat, les speres en sont de couleur roussitre et semi-transparentes (Lespiault).

T. restivum Viтtad., Monogr. Tuberac., p. 38. - Turasse, Fungi liypogæi, p. 137. - T. albidum Fries. - T. rotundato-difforme, majus nigro-brunneum, colato-verrucosum; verrucis maximis polygoniis pyramidatis transversimque striatis; venis numerosissimis, obsoletis, in carnem e variis superficiei punctis dendritice immissis; sporangiis 4-6-sporis; sporis cllipticis brunneis reticulato-alveolatis, alveolis amplis paucis.

Juillet et août dans les forêts de chênes, où elle croft rassemblée en grand nombre et parfois très près de terre; Paris, au pied des bouleaux près de la Marne, Charenton, Nogent, en automne et en hiver; Poitou, Croutelle, Ingrande; Avallon, Falaise; Nérac, rare au pied des pins. Odeur aromatique de ferment; bien moins estimée pour la savear que les deux précédentes.

On la désigne en Poitou sous le nom de Truffe de la Saint-Jean, mais it est probable que sous ce nom on désigne aussi toutes ies Truffes non mûres et de diverses espèces récoltées à partir du mois de juin. Le $T$. cestivum est, suivant M. Tulasne, la seule Truffe qu'on ait encore rencontrée en Normandie. II croit souvent dans les Truffières de la France moyenne et méridionale avec le $\boldsymbol{T}$. brumale, dont il se distingue très facilement, ainsi que du $T$. melrnosporum, par ses spores réticulésalvéolés et non simplement hérissés de pointes, et au premier coup d'œil par la couleur păte, d'un jaune d'argile ou bistre clair de sa chair. 
Truffe. M. Ravel a cllleuré ce problème; je vais le discuter. On me rendra, je l'espère, cette justice que je n'ai reculé devant aucune des idées émises au sujet des insectes tubérivores, et que sur loutes j'ai donné mon as is impartial el motivé.

"Lors mème, dit M. Ravel, qu'il serait reconnu que la Truffe, au lieu d'ètre le résultat de la piquâre d'un insecte, n'est, comme le champignon, que le produit de spores ou d'oufs atlachés a des filaments; que la (Mouche) Iruffigène n'a d'autre rúle dans l'acte de la reproduction que celui de porter en terre les spores ou oufs appelés à être fécondés par le contact du chevelu des racines, ou peut-ètre encore d'onvrir seulement la terre

T. menendericum Vitad., Monogr. Tuber., p. 40. - Tulasve, Fungi liyp,, p. 139. - T. glolosum, mediocre, atrum, exasperatum, vermcis angulosis media magnitudinis; carne griseo-fusca, variegata, venis lineisque obscuris mire insimul gyrosis; sporangis 4-6-sporis; sporis ellipticis reticulato-alveolatis brunneis.

Commune aux environs de Paris, en automne et cn liver; Vincennes, terrasse de Charenton, Nogent, auprès des bouleaux avec la Truffe d'été. Forèts montagneuses de chènes du nord de l'ltalie, dans la campagne autour de Milan en octobre. Odeur forte; sa saveur la met sur la même ligne que la précédente.

Dans le Condomois, celte Truffe est confondue avee la Truffe d'été sous le nom de 'Truffe samaroquo; en Bourgogne et aux cmvirons de Paris, on l'appelle Truffe grosse foune et petite fouine. Cette espece et la précélente s'avanent le plus vers le Nord; c'est à elle qu'il faut rapporter la majeure fartie iles Truffes comestibles d'ingleter re, de Bohême et de l'Allemagne centrale et du norl. le $T$. mesentericum est très voisin du $\boldsymbol{T}$. astivum; il s'en distingue par une clatir plus olsscure, d'un gris fuligineux et par d'abondantes lignes noirittres étroites ou nuclíiformes qui, au milieu de la pulpe fruclifère, dicrivent de's tours nombreux et irréguliers parallèlement aux veines blanches. Cette Truffe présente aussi très souvent vers sa base une large anfractuosité qui semble caractéristique.

T. Magnatum Pico, Meleth., p. 79 (sub nota). - Tulasne, Fungi hyp., p. 150. - Truffe grise DE Borcir. - T. ochracco-pallens $v$. dilute virescens, subleve aut minutissime papillosum, difforme, globrso-angulosum et varie lobatum, basi obconica instructum; venis aeriferis tenuissimis, reticulatis ; ascis 1-3-sporis; sporis fuscis elliptico-rotumlatis et alveolato-reticulatis, retis alveolis amplis.

Croit solitaire, rarement mu groupes, pès tes cliênes, des peupliers, des saules, parfois dans les champs cullivés. Trés commune dans l'ltalie sepientrionale a la fin de l'automne; Tarascon en novembre. Odeur alliace ou rappelant celle de certains iromages.

Truffe lhanche des Piementais; elle se dessèche facilement. T.es jeunes Trufés ricoltées a la fin de juillet sont les Fioroni des Italiens. La savear de cette Trufle crue est peu agréible et comue savonnense, mais elle devient délicieuse par direrses prếparations. On sait que Napoléon Ier préférait celle Truffe aux espèces noires. 
pour laisser pénétrer ses semences, ma théorie n'en resternil pas moins la mème : la truffigene serait alors, comme le disent les naturalistes, la cause el le résultat de la production. Chacun sait, en effet, que la fécondation des fleurs a souvent pour agent un insecte à abdomen chevelu qui, ouvrant le calice de la fleur, y dépose le pollen des ctamines.

" De mème aussi la Mouche tu uffigène porterait du gland aux racines la semence de la 'Truffe, ce qui rentre toujours dans l'esprit de ma découverte (1). "

Je ne m'arreterai point à faire remarquer la différence complèle qu'il y a entre la fécondation d'une fleur femelle par le pollen d'une fleur male apporté par un insecte, et la semence de la Truffe portée du gland aux racines; je ne relèverai pas les expressions de spores et d'culs données conme synonymes, mais je poserai le probleme sur ses donnes les plus larges en disant: Les insectes vont pondre leurs aufs dans les Truffes et leurs larves s'en nourrissent; d'autres insectes à l'état parfait mangent les Truffes mûres, ils sont en contact arec les spores; les insectes peuvent-ils aider à la reproduction et, par conséquent, à la culture des Truffes?

Disons-le tout de suite, ce rôle des insectes nous parait très secondaire; il nous semble douteux qu'en détruisant la pulpe charnue du précieux tubercule, les larres respectent les thèques et les spores. Nous ne pensons pas que les Houches diverses ou les colcoptères qui vont pondre leurs œufs sur les 'Truffes ou qui les dérorent emportent sur leurs corps beaucoup de germes reproducteurs. Ce fait n'est pas impossible, et nous ne le nions point; toutcfois il nous parait être cxtrèmement limité dans ses résultats.

En admettant que les larves tubérivores respectent les spores des Truffes, on pourrait dire qu'en hâtant la décomposition de la pulpe elles aident à la dissémination des corps reproducteurs; mais de là au transport lointain et dans un terrain favorable de ces memes germes reproducteurs il y a bien loin.

fes insecles ne nous paraissent devoir aider à la dissémination des spores de la Truffe et des Champignons en général que pour une très faible part. Il en résulte nécessairement que les insectes seront des auxiliaires peu actifs tans la culture de la Truffe, et, pour dire toute notre pensée à ce sujet, nous crojons plulôt à la production ou, si l'on veut, à la culture indirecte de ce précieux et si recherché Cryptogame qu'd sa culture directe. Les essais tentés par Bradley, de Borch, Alexandre de

(1) Raveu, 1er Mémoire, p. 32. 
Bornholiz, de Noé, clc. (1), avec des composés terreux ou avec des Truffes coupées par fragments, n'ont réussi que dans des limites restreintes. D'autre part, Bouchet-Isoumencq et Léopold 'trattinick ont énerģiquenent nié ou regardé conme chimérique la culture artificielle de la Trulfe comparée à celle de l'A garicus camprstris ou Champignon de couche.

Mais it nous semble que c'est aller beaucoup trop loin, et que dans cet ordre d'icleces it est acquis aujourd'hui que si l'art n'a que peu de part à Ia production directe des 'Truffes, cependant on doit admettre, à moins de nier l'évidence, que l'on a déterminé la production des Truffes par la création de truffières artificielles. C'est en plantant des cliênes, en semant des glands dins des sols calcaires pareils d̀ ceux ou les Truffes se plaisent que l'on a pu rícolter de ces tulierenles là oủ l'on n'en avait jamais vu, où l'on ignorait leur existence antérieure, aux environs de Loudun, par exemple (2). Il est reconnu que les Trufies comestibles ne végètent bien, surtout les Tuber metanospornem et brumate, qu'au milieu des racines chevelues des arbres, surtout des chènes; or il y a trois espectes de chènes répandues dans notre pays : le chène ordinaire à feuilles marcescentes, le chene vert ou yeuse, et le chène kermès. Ce sont les glands de res chènes qu'il faut semer, et surtout, d'après a. Ravel (3), les glands du chène blane non pédonculé, a l'exception des autres. Je dois dire eependant que M. Auguste fiousseitu (de Carpentras) a trouvé que les Truffes noires étaient plus abondantes, plus égales et plus parfumées au pied des chènes verts qu’au pied des chènes ordinaires, et quu'il récoltait toujours des tubercules an pied des arbres qui en avaient domné les années précédentes. Quant aux consilerations sur la nature du sol propre aux Truffes comestibles, son exposition, les condilions de sécheresse et d'lumiclité, les labours superficiels, la préraution de ne pas déposer de fumier sur les truffières, mentionnée par de Borch (4) et affirmée de nouveau par M. Ravel (5), elles ne peurent trouver place dans ce travail, non plus que les diverses manicires de croitre des Truffes, considéries dans l'ensemble du genre $(6)$.

(1) Josipu fiogues, IIistoile des Champignons comestibles et rénéneux, p. 155, 1832. - Voy. alissi Turasve, Fungi hypogai, p. 166 et suiv.

(2) Voy, Turasse, Fungi hypogai, p. 166.

(3) Raver, ter Mémoire, p. 15, et 2* Mémoire, n. 5 .

(4) De Bonch, Lettres sur les Truffes du Piémont, 2 e lettre, p. 37.

(5) Rayes., ter Mémoire, p. 17 et 25.

(6) On se tromperait fort si on croyait que toutes les espèces du genre Tuber. wu 'Truffe ne peuvent croltre que sous les chènes on sous d'iulres arbres et arbustes: M. Léveillé a trouvé pendaul le mois de mai des Truffes aux environs d'orange dans un endroit où n'y avuit pas d'arbres (Ilictionnaire universt'l d' histoire naturelte. 
La saveur des Truffes a la plus grande importance dans l'arl culinaire, mais elle n'est point un caractere botanique de premier ordre; telle plante exlalera ou produira un parfum péncitrant sur un sol aride et moutueux, une labiée, par exemple, qui sera bien moins odorante dans un sol humide et argileux. Le Tuber melamosporum sera attaqué par les insectes tubérivores dans tous ses gisements, soit qu'on le rencontre au pied du charme, du hètre, du noisetier, du chataisnier, du pin d'Alep, du marronnier, du lilas, elc. Dans ces divers endroils, celte Truffe offre toujours les rềmes caractères botaniques, mais elle n'aequiert jamais le délicieux parfum qu'elle possìle lorsqu'elle a végélé entre les racines des chenes.

Qu'on ne croie pas, du reste, que celle culture indirecte de la Truffe soit presque stérile ou de peu d'importance dans ses résultats. Notre savant maitre et ami M. Ie professeur Charles Martins a montre, dans une intéressante étude sur le mont Ventoux (1), tout le parti que la plantation de mauvais terrains avec des essences de chene pouvait donner en rendements, d'abord en taillis et plus tard en grands arbres. On arrive de la sorle it former des forêts, à retenir la terre végétale, on résout le difficile problème du reboisement, et tous ces avantages sont obtenus en sus du produit des Truffes qui est considérable (2).

Dans celte culture de la 'Truffe, on voit que les insectes n'ont pas une part bien active; ce sont principalement des mangeurs de Truffes, mais il faut le savoir et l'admeltre.

Nous arrivons à la fin de la tache que nous nous sommes imposée, celle de réduire à ses véritables proportions le rôle iles insectes tubérivores, qui sont en réalité fongivores et rien de plus. Si l'on nous reprochait d'avoir insisté sur une vérité démontrée depuis longlemps, celle de la nature végétale de la Truffe, nous pourrions dire: il y a de ces vérités qu'il faut répéter plusieurs fois, on trouve encore trop de personnes qui,

d'Orbigny, t. XII, p. 715,18 i8). M. I.éon Dufour dit qu'une grosse Truffe blanche, fort insipide du reste, croit dans le sable des landes à un kilomètre de loute espèce d'arbre (Comples Rendus de l'Acadimie des seiences, t. XI.IHI, p. 1032, 1856).

(1) Cur. Mantiss, le mont Vintoux en Provence (Revue des Deux-Mondes, seconde période, t. XLIV, p. 624 et suiv., avril 1863).

(2) Cir. Mantins, Joc. cit., p. 626. - II. Augnste liousseau a pu récolter sar un terrain calcaice siliecux, planté de chìnes blanes et de clienes verts, une grande quantité de Truffes, et l'hertare de ce maurais terrain lui a donné lie la sorte un produit de 740 franes; peu de cultures donnent des résultats semblables avee aussi peu de soins.

Une intéressante discussion sur la culture de la Truffe a en lien a la Suciété Botanique de Franer (royez le liulletin de la Société Botaniqque de France, 1. II, 1. 777 et suiv., 1855). 
suivant une heureuse expression, prisent la Truffe sans trop savoir ce qu'elles mangent, ou qui veulent la cultiver sans se rendre comple de sa nature spéciale. L'ouvrage de .1. Tulasne date de 1851 ; croirait-on que l'article que j'ai dù combattre sur la culture de la Truffe ait paru dans le Journal d'Agriculture pratique le 15 mars 1863 ? Et, bien avant toutes les publications des Vittadini et des Tulasise, le fondateur du Jardin des plantes, le vénérable Guy de la Brosse, n’avait-il pas dit : "La Trufle... qui a embesogne beaucoup de persomnes a luy assigner rang au nombre des choses naturelles, car plusieurs ont douté qu'elle fust plante et qu’elle eust vie... est de nécessité plante... el cela se pronue parce que les Truffles croissent, comme il est très cognt de ceux qui les fouillent, les rencontrant de plusieurs grosseurs selon leurs aages (De la Nature, vertu et utilité des Plantes, p. 172 et 173, 1628), "

\section{Expligation des figures de la planche.}

Fig. 1. Larve de l'Iletomyza luberivora RoBneac-Desvordy, grossie et vue en dessous. -1 , a. La mème larse de grandeur naturelle et placée de profil.

2. Extrémité postéricure très grossic de cette larre, vue de face et en dessus.

3. Stigmate antérieur flabelliforme, extrèmement grossi, pour meltre en évidence ses huit digitations.

4. Bords des $3^{\mathrm{e}}, 4^{\mathrm{e}}, 5^{\mathrm{e}}$ et $6^{\mathrm{e}}$ segments dorsaux, très grossis et vus de profil pour montrer leurs crochets; le $3^{\mathrm{e}}$ n'en a point au bord postérieur, les autres en ont aux bords anterieur et postérieur. Les crochets ont la pointe tournée vers la partic médiane du segment.

5. Quelques-uns de ces crochets faiblement grossis et disposés en séries alternes imitant des dents de peigne.

6. Disposition des crochets de la partie postérieure du corps, extrèmement grossis.

7. Pupe grossie de l'Ilelomyza tuberivora, vue de face.

8. Une autre pupe vue par la partie latérale.

0. IIclomyza tuberivora ơ, grossic, el auprès d'elle mesure de sa grandeur naturelle. 
Fig. 10. Thte el corselet tris grossis, pour montrer lit disposition des taches et les divers poils qui revitent ces parties du corps.

11. Iflemy: linculu lobinasu-Desvorny, grossie, $\mathrm{cl}$ a cole diclle, mesure do sa grandeur naturelle.

12. Antenne arec la palette et le style plumeux de l'Inclomyza tuberivora, très grossie.

13. Antenne avec la palelte et le style plumeux de l'II. lincaln, tres grossic.

14. Antenne avec la palette el le style plumeux de l'II. ponicillata, très grossie.

15. Pupe de l'Anthomyia conicularis Mergen, grossie et rue par la face dorsale; auprès d'elle, mesure de sa grandeur nalurelle.

16. La mème pupe, vue de profil; le panneau supérieur a élé cnlevé.

17. Stigmate postérieur gauche très grossi.

18. Larve de l'Anisoloma cimamomer P.Ixzin, grossie, et ì sòté d'elle, mesure de sa grandeur naturelle.

19. La mème larve repliée sur elle-mème.

20. Antesme droite de celte larve, très grossie comme les figrures suivantes.

21. Labre de la même larve.

22. Mandibule gauche, vue en dessus.

23. Nachoire du côté droit, vıe en dessus.

24. L.evre inféricure et palpes labiaux, vus en dessus.

25. I'alte posterieure ganche délachée du tronc et renverséc.

26. Un des stigmates extremement grossi.

27. Extrémité postérieure de la mêne larve très grossie, pour montrer la disposition du dernier segment et les appiendices dont il est pourvu. 


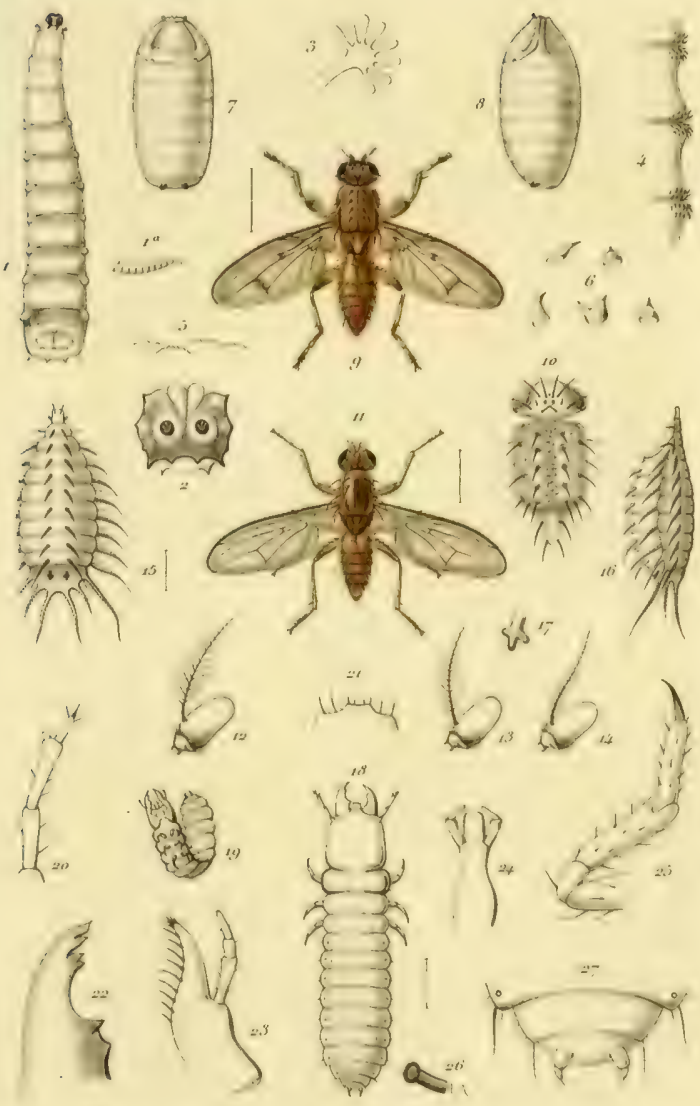

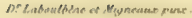

Inipetos tuberiuores.

1-10. Helomyxa Luberivora. 15-17. Anthomyiu varicularis. 



\section{DESCRIPTION FT FIGURE:}

\section{D'UNE}

\section{Chenille mineuse des reullies du Bouleru,}

Par is. le Dr ALexande LABOULBENE.

(Séance du 27 mai 1857.)

Après une longue attente de plusieurs années, je me décide à publier la description et la figure d'une larve mineuse des feuilles du Bouleau. J'ai trouvé pour la première fois cet insecte au commencement du mois de mai 1857 et j'en ai communiqué verbalement les caractères à la Société, après avoir signalé les Galles du Calligonum comosum.

Depuis celte époque reculée, j’ai, à la fin de chaque hiver, recueilli ces larves et j'ai cherché à les élever. J'ai constamment échoué dans mes tentatives; je n'ai jamais pu obtenir l'état parfait. Espérant que d'autres seront plus heureux que moi, je vais indiquer la diagnose de l'insecte que je désire faire connaître.

LARVA acpressiuscula, clongata, capilala, apoda, glabra, sub lentcleviter asperula, luteo-albida, scu grisea; capite minore; anternis brevibus, triarticulatis ; mandibulis duris, tridentutis ; maxillis lobo interno spinuloso, palpis externis biarticulatis; labio palpigero, ligula scricaria instructo, palpis elongatis, biarticulatis; stigmatibus novem preribus. - Longitudo vix quatuor lineas xquat (8 à 9 millim.).

Vlabitat in foliis Betulæe albæ, campo Lutcliano.

LARve a'un blanc jaunatre, parfois d'une teinte grisatre et un peu ardoisée (planche $\mathbf{1}^{\text {re }}$, fig. $1, a, b$, et c). Tète noiràtre ou d'un jaune fauve. Deux taches superposées sur le prothorax en dessus et en dessous, noirátres ou d'un jaune fauve; de plus un espace blanc ayant la forme indiquée (fig. 1, h), oblique de haut en bas ot de dedans en dehors sur le mésothorax et le métathorax et enfin deux autres lignes blanches, transversales sur chaque segment abdominal, formant une ligne blanche interrompue au milieu. 
d'autres larves mineuses de coléoptères. J'en altendrais une espece de Curculionite.

" Si votre dessin avait appartenu à mes études ordinaires d'entomologie je vous aurais prié d'en faire une copie; mais puisqu'il me. parait se rapporter à un Coléoptère, je ne rous en donncrái pas la peine. "

Ainsi donc, au lieu de la solution que j'attendais, je me trouvai dans un extrème embarras. Mr. Perris, dont je connais le tact entomologique si sùr, croyait que ma larve mineuse était une chenille, et M. Stainton, le microlépidoptériste si habile, la rapportait à un coléoptère, probablement de la famille des Curculionites. Je gardai les réponses contradictoires de mes obligeants et savants collègues, et je me promis de recourir au moyen par excellence, a l'éducation de cette larve si litigieuse que je jugeais, de prime abord et non sans raison, très difficile à élever complétement.

En 1859 et 1860, j’ai recueili des feuilles minces du I3ouleau, dans les bois de Meudon et de vincennes. Je constatai que les larves vivaient presque toujours solitaires dans chaque feuille, rarement au nombre de deux, mais jamais dans la mème place minée, toujour's séparément. Ces larves étaient très voraces et croissaient fort vite. L'époque de leur apparition était celle du développement des feuilles, e'est-it-dire de la fin d'avril au 15 mai, suivant la précocité du printemps.

La sortie des larres a toujours eu lieu par la face inféricure de la feuille par un trou très facile à trouver. Cette sortie m'a paru avoir lieu de préférence par un temps pluvieux. Les larves étaient fort agiles, couraient it la surface de la terre et s'y enfonçaient rapidement. Une seule larve fila un cocon de soie entre une feuille el la paroi d'un bocal en verre, mais la moisissure s'empara du cocon, sans doute par un excès d'humidité.

En 1861, je m'adressai ì M. Fallow et ce zélé collegue mit me grande complaisance à venir récolter arec moi des larves mineuses, dans le bois de Meudon, te 5 mai. La neige grui nous surprit ne nous empecha pas de faire une provision aloondante, et M. Fallou disposa les branches de Bouleau ou se trouraient les feuilles et leurs mineuses dans des boites spéciales, garnies de terre de bruyere tamisée, de feuilles sèches, elc., rappelant la disposition de la terre ou croissaient les jeunes Bouleaux. Dans ces bonnes conditions, les larves quilterent les feuilles en les trouant sur la face inférieure; elles s'enfoncerent en terre et jusqu'au printemps de 1862 ne donnèrent plus signe d'existence. Quand la fin de mai arriva, perdant l'espoir de voir éclore l'insecte parfait, nous recherchámes dans la terre et ¿t la profondeur de un à deux pouces environ, nous avons trouvé les coques en cocons représentées fig. $1, i$. Ces coques renfermaient les larves re- 
plices et encore vivantes; aucune des coques ouverles ne nous offrit de chrysalide ou de nymphe.

Enfin au mois de juin, je recherchai de nouveau les roques, mais toutes les larves élaient mortes et desséchies dans les cocons, aucune ne s'élaił mélamorphoséc. Je trouvai deux parasiles, deux Chatidites desséchés et encore dans leur enveloppe de nymphes, mais je Ie répète, je n'apercus ni chrysalide, ni nymplıe qui pût trancher la question de l'insecte parfait.

Le cocon, revêtu à l'extérieur par une conche de terre, est formé à l'intéricur par un tissu de soie blanche, très résistante et très lisse. Sa longueur est de 4 ì 5 millimetres. La larve y est replićc sur elle-mème ainsi que je l'ai dit et figuré (fig. 1, i).

On a dû se convaincre, par ce qui précède, de la difficulté que présente l'éducation de cette larve. A défaut de renseignements plus complets. puis-je décider à quel ordre l'insecte parfait doit apparlenir ?

pour moi cet insecte doit ètre un Microlípidoptere et la larve est une chcnills. Je partage l'opinion de $\mathrm{H}$. P'erris, mais je comprends que la ressemblance de la larre arec celles des coléoplères ait pu dicter le jugement de M. Stainton dont je me plais à reconmaitre le mérite scientifique et dont japprécie infiniment les travaux. Te me fonde pour étayer mon appréciation sur la forme des antennes, des mandibules tridentées, des màchoires à palpe biarticulé, et surtout sur l'existence de la filière. Eu un mot les caractères de la bouche me paraissent indiquer une chenille et c'est pour cela que j'ai précisé cette dénomination sur le titre du jrésent Iravail.

Je termine en laisant des voux pour que l'histoire de cette chenille soit prochainement achevéc par un collègue qui pourra obtenir la transformation en chrysalide, et enfin l'éclosion de l'insecte parfait.

\section{Lixplicatiox DES fIGURES $1^{\text {res }}$ DL LA PLAXGIE. $4^{\text {se }}$.}

Irig. 1. Fenille de Bouleau (Betulu alba) de grandeur naturelle, avec une chenille mineuse, el les excréments allongés ot disposés en filaments, rendus par cet insecte.

1, a. Chcnille mincuse grossie, vue en dessus, non allongce et contractée; ì côlé d'elle, mesure de sa grandeur nalurelle.

1, b. La même chenille vue de profil. 
104 AL. Laboulbìnf. - Chenille mineuse des fouilles du Bondeau.

Fig. 1, c. La même rhenille mineusr vue en dessous, allongée et non contractée.

1, d. Antenne droite, très grossie comme les figures suivantes.

1, e. Labre muni de quatre poils courts.

1, f. Mandibule gauche tridentée.

1, g. Machoire avec son palpe biarticulé; levre el filiöre, palpes labiaux de 2 articles.

1, h. Deux segments du corps extremement grossis, vus en dessus. Le premier est le mitathorax; le second ou postérieur, le $t^{\text {er }}$ segment abdominal.

1, i. Cocon ouvert, revêtu de terre à l'extérieur, tapissé de soie blanche à l'intérieur, laissant voir la larve incluse; à côté, mesure de la longueur naturelle de ce cocon. 


\title{
DESGRIPTION
}

DU

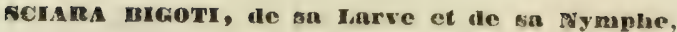

\author{
Par M. le D' Alexandne LABOULBbine.
}

(Séance du 23 Juillet 1862.)

Dans un pot à fleurs, rempli de fumier ordinaire, peuplé de larves d'A phodius el donné par mon cher mattre M. Gharles subé, j'avais remarqué des vers filiformes, blanchàtres, à tète d'un noir luisant et qui ne pouvaient appartenir qu'à un Diptère. L'éclosion des Aphodius fimctarius, si vulgaires, et provenant des premières larves qui m’étaient signalées, m'intéressa bien moins que le développement des sccondes; c'est un bonheur inespéré de trouver ce qu'on ne cherchait pas et ce bonheur n'est pas rare quand on étudie les métamorphoses des Insectes.

Ces vers blanes et allongés, mis à découvert, s'agitaient avec vivacité; leur corps visqueux devenait, quand on les avait saisis, raidi el redressé combue une baguette. On les voyait fréquemment agglutinés au nombre de trois à einq et pius, les uns contre les autres, dans le sens de leur longueur; ils se plaisaient dans les endroits oủ le fumier était le plus humide.

Les larves qui m'ont été données le $\mathbf{4} 4$ mai 1862, se transformèrent en nymphes ou chrysalides vers la fin de juin. Pour subir cette métamorphose elles ne s'enfoncèrent pas plus profondément dans le fumier et ne construisirent pas de coques; enfin une nuce de petiles Mouches en sortil du 15 au 20 juillet.

Je vais exposer successivement les caracteres de la larve, de la nymphe et de l'insecte parfail que j'étudie dans ce travail.

\section{S1. Larve. (Planche $2^{\circ}$, fig. $5, a, b, c_{\text {. }}$ )}

IARVA capitata, haud oculatr, elongata, postice rotundata; albida, capite atcrimo, nitido, minuto, occipite haud fisso, integro; ano cxerto, pedi adsimiti. - Longitudo tres lincas aqquat (6-7 millim.).

II bitat in stercoribus, campo Lutetiano. 
LAnive vermiforme, allongée, blanchatre, à tète petife el d'un noir luisamt. Corps formé de 12 segments grossissant peu à peu et légèrement renflé aux $2 / 3$ postéricurs, dernier segment arrondi, terminé en dessous par un pscudopode clarnu, formé par l'anus saillant, ćtalé, et rappelant la ventouse postérieure des sangsues (fig. $5, c$ ).

Títc composée d'un labre transtersal, de deux mandibules à 4 ou 5 dents, de deux máchoires et d'une lèvre peu distincles. Scgments du corps très glabres, et n'offrant pas en dessous de pseudoprodes ou de séries de poils courts, placés en travers.

Stigmatrs très petits, pet visibles, au nombre de 8 paires, la $1^{\text {re }}$ sur le $i^{\text {er }}$ segment, les suivantes sur les $4^{\circ}$ à $10^{\circ}$ segments; le péritrème noirâtre et situé en dessous du corps.

Cette larve a pendant la vie les téguments translucides, et on apercoit all travers, les organes digestits sous forme de traits brunatres ou foncés. Quand elle a été conservéc pendant quelque temps dans l'alcool, la transparence disparalt et la teinte est plus uniformément blanchâtie.

La larve du Sciara Bigoli a les plus grands rapports avec celle du s. fuscipes de Meigen, décrite par Ernst Héeger dans les mémoires de l'Acatdémie de Vienne (Sitzungsberichte der lais. Akad. der Wisscnchaften Wicn, Malh.-nalurw. Classe, XI Band, I IJeft, 1853, tirage ì part, page 6, pl. II, fig. 2) ; elle n'en differe guère que par le dernier segment qui n'est pas exactement arrondi. Elle ressemble aussi a celle du Sciara ingenua dont M. Léon Dufour a fait connaitre les métamorphoses dans les Annales des Sciences naturelles (Mimoire sur les métamorphoses de plusicurs larves fungivores appartenant à des Diptercs, $2^{\circ}$ série, $\mathrm{t}$. XII, pages $29 \mathrm{et}$ 30 , pl. 1, fig. 20 à 29), mais elle n'a pas comme cette dernière le bord occipital de la tête prolongé au milicu et bilobé ; en effet, la tête de la larve du S. Bigoti a le milieu du bord occipital à peine saillant et très largement arrondi. M. L. Dufour a représenté 13 segments au corps de la larve du S. ingenua (loc. cit., fig. 23).

La tête des larves du genre Sciarı est d’une étude fort difficile. Je me suis assuré que les antennes et les yeux font défaut chez celle du S. Bigoti; j'ai vu dans sa bouche un labre, des mandibules munies de 4 à 5 dents, des mâchoires et une lèvre; mais je ne puis en préciser exactement la configuration. J'ai tout lieu de croire cependant que ces parties diverses doivent être conformées à peu près comme celles de la bouche de la larve du Sciara fuscipes qu'Héeger a très soigneusement décrites et figurées (loc. cit., prag. 7 et 8, pl. II, fig. 3 à 7). Bouché avait donné quelques détails sur la bouche de la larve du Sciara vitriponnis Merg. (Naturg. der Insecten, etc. p. 38, pl. III, fíg. 10 et 11); M. Léon Dufour a dit aussi 
que la larve du $S$. ingcuua lui avait offert des mandibules petites, étroites, oblongues, bifides à la pointe; mais aucun auteur, a ma connaissance, n'a décrit aussi scrupuleusement qu'Héeger la bouche des larves de Sciara. Les observateurs qui pourront étudier les grandes larves de ce genre etabliront d'une manière définitive le nombre el la disposition des parties buccales.

Il m'a été impossible de trouver des fausses pattes, ou des organes en lenant lieu, soit des mamelons rétractiles, soit des séries de poils ou d'aspérités transversales placíes sous les segments du corps. Mais le pseudopode anal de la larve du Sciara Bigoti est considerable et aide a la progression d'une manière efficace lorsqu'il est mis en jeu ; il s'étale et rappelle alors la ventouse postérieure des Hirudinées. MM. Léon Dufour, Bouche, Westwood et Héeger ne mentionnent rien de semblable dans les larves ๆ u’ils ont eues sous les yeux.

Iléeger avoue qu'il n'a pas pu trourer des stigmates chez la larve du Sciara fuscipes; mais M. Léon Dufom a parfaitement décrit ceux dn Sciura ingenua comme " d'une telle exiguité qu'il faut le secours d'une. forte lentille d'un microscope pour en constater l'existence " (loc. cit., p. $30 \mathrm{et} \mathrm{pl.} \mathrm{1,} \mathrm{fig.} \mathrm{23).} \mathrm{J'ai} \mathrm{vu} \mathrm{facilement} \mathrm{pendant} \mathrm{la} \mathrm{vie} \mathrm{des} \mathrm{trachées} \mathrm{bril-}$ lantes dans le corps de la larve du s. Bigoti, mais après la mort leur constatation est presque impossible. Les stigmates sont extrêmement petits, il faut les chercher, non en dessus, ou sur le plan latéral du corps, mais en dessous, comme l'a remarqué .I. L.éon Dufour. On les trouve alors sinon

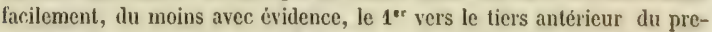
mier segment, les autres près du bord antérieur des $4^{\mathrm{c}}, 5^{\mathrm{e}}, 6^{\mathrm{c}}, 7^{\circ}, 8^{\mathrm{c}} 9^{\mathrm{c}}$ et. $10^{\circ}$ segments, les derniers sont un peu plus éloignés de ce bord que ceux des $4^{\circ}, 5^{\circ}$ et $6^{\circ}$ segments.

Pour terminer ce que j'ai à dire de la larve du Sciara Bigoli, j'ajouterai que l'habitude qu'elle a de se grouper avec ses pareilles ne lui est pas particulière. On sait que des larves de ce genre ont étẻ quelquefois trouvées en quantité innombrable collées les unes contre les autres et formant une sorte de long serpent ou de cordon monstrueux.

\section{\$1. NYMPLE. ([?], 2*, fig. $5, d_{0}$ )}

AxMru. muda, oblonga, pallide mescens; oculis rotundatis, subgranulatis; thorace gibbo; prdibus coarctatis, abdominis bis tertiam partem attingcntibus. - Longit. 1 1/2 à $13 / 4$ lin. (3 à / millim.).

Ceite nympix placéc à nu, c'est-à-dire sans cocon d'enveloppe, est oblongue, peu recourbée, d'un blanc jaunâtre et ambré ou d'un roux 
pâle, avec ta tîlc et le thorax plus foncés que l'abdomen, qui est plus blanchitre. Yeux noirttres. Les antennes, les rites rudimentaires, les pattes sont bien distinctes; l'extrémité des pattes ne dépasse pas les deux tiers de la longueur de l'abdomen; celui-ci est bifide à son extremité. Segments abdominaux avec de fines aspérités microscopiques.

Au moment de l'éclosion le corselet se fend sur la partie dor'sale el médiane. Presque toujours l'extrénité abdominale renferme une goultelette de liquide blanchâtre que l'insecte parfait a rendu avant de quitter sa dépouille.

Cette nymphe differe de celle du $S$. ingenua $L$. Dufoun, par les patles qui n'alteignent pas l'extrémité de l'abdomen el par l'absence de cocon; elle ressemble beaucoup à celle du $S$. fuscipcs qu'Iléeger a représentée (loc. cit., fig. 8), mais elle n'a point de bourrelets latéraux aux segments du ventre, ni d'appendices divergenls à l'extrémité de l'abdomen. Les yeux me paraissent avoir été figurés trop petits sur la nymplı précitée el étudiée par Héeger.

\$II. INSECTE PARFAIT. (P]. $2^{\circ}$, fig. $5, e, f_{0}$ )

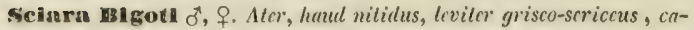
pile nigro; antennis fuscescentibus, longioribus ot, 15-aticulatis ; palpis lividis, thorace ferc unicolore; abdominis segmentis nigro-obscurioribus, basi luteo-pallidis, latcribus pallidis ; pedibus tutco-pallidis ò, obscurtrufescentibus $q$, tarsis obscuris; alis fumosis, violacec-miccentibus + , vix. fumosis, fore diaphanis $\delta^{x}$. - Longiludo unam lineam arqual $\delta^{*}$; lineam cum dimidia xquat aut vix suprrat f (2 mill. à 2 mill. $25,0^{x}$; 3 nill. 25 à 3 mill. 50, ).

Noit. T'r̂le ovale; ycu.x grands, noirs, fortement réticulés, à peine séparés dans les deux sexes; 3 ocelles très pelits el disposés en triangle. Antennes assez longues, de 15 articles, le premier grand, cupuliforme oै, en carré allongé o ; les suivants, en carré allongé presque égaux, le dernier à peine plus grand que le pénultième, pas de verticilles de poils ; couleur plus claire chez. le ð', d'un brun jaunatre ou d'un roux très obscur. P'alpes d'un jaune livide, de 3 articles, le dernier claviforme.

Corsetet rribbeux, noirtre avec trois bandes fines et grisatres, formes par des poils, une médiane et une autre de chaque côté épaules et flanes du métathorax d'un lestacé roussatre.

Ailes ^ base jaunatre, à limbe d'une couleur à peine rembrunie el irisée, $\sigma^{t}$; manifestement obscures el à reflets irisés violets $q$. Nervures 
disposées suivant la tigure 5, la nervure interno-mediaire incolore, indiquée par un pli ; frange alaire pas très fournie, assez làche.

Batanciers à pédicelle allongé, à bouton ovale et pyriforme; d'un blane jaunatre, plus blanc à l'extrémité.

Patles longues, assez greles, d'un jaune livide of, d'un roux obscur lal'ses bruns.

Abdomen d'un noir brunatre en dessus, un peu allongé, très finement velu, terminé par un épais forceps ${ }^{*}(f i g .5$, c); par une série conique de trois tuyaux engainés of (fig. $5, f$ ). Bords des segments d'un jaune roussitlre chez les $q$ ayant l'abdomen volumineux; côtés d'un roux pàle ou livides, dessous d'un roux obscur.

La détermination précise de celte espèce m'a beaucoup embarassé, je n'ai pas su la trouver dans Meigen, Macquart, Zetterstedt, elc. Mon sayant ami M. Bigot n'a pas été plus heureux, el dans l'implossibilité oì je suis de reconnattre avec les anteurs le Sciara que j'ai étudié, je lui donne le nom du cher collegue, auquel la Diptérologie est redevable de consciencieux et nombreux travaux.

Le Sciara Bigoti ơ, est roisin du S. hyulipennis de MeIgen (Systcm. Beschreib. der Eur. zarriflüg. Inssklon, 1. 1, p. 285, spec. 21), mais cet atuleur n'a décrit de cet insecte que le sexe femelle; d'autre part le s. Bigoli of a des rapports avec le $S$. picipes de ZetTenstedr (Diptera Scandinaviz, t. X, p. 3722, sp. 12), mais les descriptions de Mcigen et de Zetterstedt ne concordent pas parfaitement avec la mienne et arec la figure $\mathbf{1}^{\text {re }}$ de la planche $2^{\circ}$. Je dois ajouter que les insectes à pattes claires et a ailes à peine rembrunies élaient tous des màles, et que parmi les autres beaucoup plus nonbreux a ailes rembrunies, et fortement irisces en violet, il n'existait pas un seul mâle, tous appartenaient au sexe femelle. J'en ai dû conclure qu'ils formaient une seule el meme espèce provenant de larves jdentigues et dont j'avais les deux sexes sous les yeux.

néeger a représenté 17 articles à l'antenne du s. fuscipes of (loc. cit., fig. 10); je n'en ai trouvé que 15 aux deux sexes du s. Bigoti, l'arlicle basilaire est gros et noueux chez le $\sigma^{x}$, il est en carré long chez la q. Tout le corps du s. Bigoti est quand l'insecte vient d'éclore, revetu d'une très fine pubescence courte et grisatre, formant trois petites bandes sur le thorax.

Les paltes sont assez longues, les tarses constamment brundtes, it 5 articles serrés, décroissant de longueur jusqu’au dernier, terminés par deux ongles très petits, à peine saillants.

Les parties genitales males et femelles du Sciura que je fais connaitre, ressemblent beaucoup a celles du $s$. ingcnua l. Durocr (loc. cil., fig. 21 et 22) ; mais elles different de celles du $S$. fuscipes figurées par Héeger 
110 Laboulbixz. - Larve, Niymphe el Insecle parfail du S. Bigoti.

(loc. cit., fog. 11 ơ, et 12 \%). 11 est probable que l'examen de ces orgames sexuels fournira des caractères pour l'étude si difficile des petiles Tipulaires et en particulier de celles du genre Sciara.

Je n’ai point ru les œufs du S. Bigoti; Héeger représente (loc. cit., fig. 1) ccux du $S$. fuscipemis sous la forme d'un petit carré allongé a angles arrondis et légèrement resserré dans le milieu.

Explication des figures 5 dE LA planche 2 .

Fig. 5. Sciara Bigoti ㅇ, vu de profil, très grossi, et at1-dessous, mesure de sa grandeur naturelle.

5, a. Larve de cet insecte vue de face et sur le los, et à côté, mesure de sa longheur.

5,b. Extrémité de l'abdomen de cette larve vue de profil et très grossie.

5, c. Cette mème extrémité vue en dessous, pour mettre en évidence l'anus exsertile et élalé, formant un pseudopode à la volonté de l'animal.

5, d. Nymphe du S. Bigoli vue de côté, auprès d'elle, mesure de sa longueur naturelle.

$5, \epsilon$. Extrémité de l'abdomen, extrêmement grossie, du Sciaru Bigoti $\delta^{*}$, \&l l'état parfait, pour montrer le forceps copulateur.

$5, f$. Extrénité de l'abdomen de la femelle, pour faire voir la disposition des trois tujaux engainés terminaux et les appendices biarticulés qui se trouvent sur le dernier. 


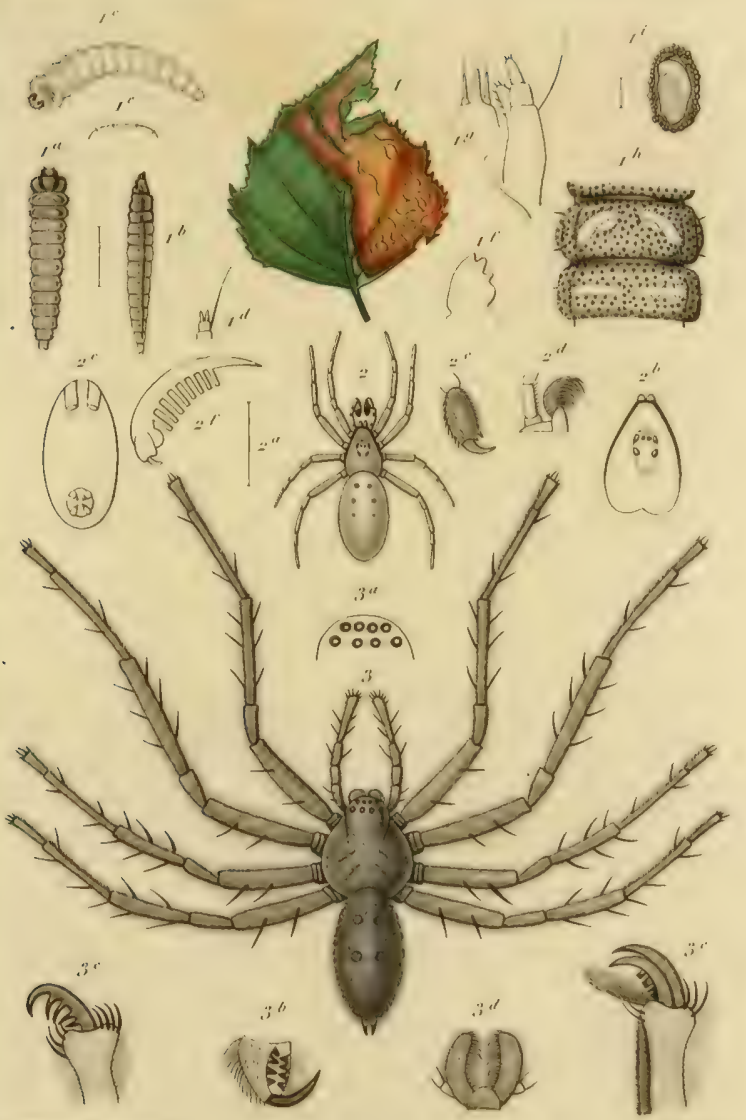

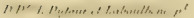

1. Chenille minsuse du boulerue Aabentbione.

2. Kicobies nigripalpis 2. Dufour.

3. Sparvastes Ammanila. I. Dufour. 



\section{ANNALES}

DE LA

\section{SOCIÉTÉ ENTOMOLOGTQUE DE FRANCE}

\section{NOTICES ENTOMOLOGIQUES}

(Suite) (1).

Par M. LÉON DUFOUR, Président honoraire.

(Séance du 13 Août 1862.)

I.

\section{Sur trois ARANÉtDes de Guerrera,}

AU SUD DE R'ATGÉRIE.

(Eresus Guerinii Lugas, E. acanthophilus $\mathrm{L}$. Durour, OFcobius nigripalpis L. DUFOUR.)

Au commencement de 1861, mon ami, le docleur lieboud, médecinmajor à Djelfa, m'expéclia, dans un flacon à alcool, trois espèces d'Aranéides qu'il avait prises at Guerrera pendant une expédition militaire. Ce n'est que récemment que j’ai exhumé de leur réceptacle mortuaire ces Aranéides pour les étudier. Ce sont :

$1^{\circ}$ Six individus femelles de l'Eresus Gucrinii LvG. (2). Gelte grande et belle espece, d'un brun noir uniforme, mesure un pen plus d'un pouce de longueur. D'après les renseignements pris sur les lieux, cette Aranéide se trouverait dans l'intérieur les maisons, habitat qui n'est point celui des diverses espèces d'Errsus que j’ai observées en Espagne, nolamment de l'imperialis qui a toute la tournure du Gucrinii et qui habite les lieux déserts du royaume de Valence, à la vérité, sous les pierres.

(1) Voyez les Annales, 40 série, 1861, tome ler, pages 5 ì 16, et 1862, tome II pages 131 à 118.

(2) Lucas, Arachn. Alg., P. 133, pl. 4, fig. 10.

$4^{\circ}$ Sirvie, томк III. 
L'Eresus Gucrinii est réputé venimeux chez les indigènes. Ils lui donnent le nom de Boulukas. Ce terme est vraisemblablement commun aux grosses Araignées noires qui, en Afrique comme en Europe, cansent de l'eflroi et par conséquent sont accusées de venin. C'est aussi sous ce mème nom de Boulakas que, suivant M. Reboud, le voyageur anglais Shaw les désigna dans son ouvrage à la dale de 1724.

$2^{\circ}$ Plusieurs Eresus acanthophilus en tout semblables à cenx que je lécourris, il y a plus d'un (lemi-siècle, en Espagne.

$3^{\circ}$ Une Aranéide nouvelle dont je vais donner la description et la figure:

OECOBIUS NigRipalpis L. Duf. (Pl. $\left.\mathfrak{1}^{\mathrm{re}}, \mathrm{fig}, 2.\right)$

․ Pallide rufescens, abdomine pallidiore, ovalo-oblongo, nitente, glaberimo; cephatolhorace antice altenuato-obluso, maigine temiler nigro; pulporum articulo terminali ovoideo-nblongo, nigorrimo; fusulis inconspicuis. - Long. 5 lin.

IIab. in domibus Gucorra Algcria moridionalis (heboud).

En retirant celte $A$ ranéide de l'alcool je crus d'abord avoir affaire à un Dysacra à cause de sa forme, de sa couleur et de ses six yeux; mais je fus vite détrompé.

En consultant les Arachnides algériennes de M. Iucas, je me décidaí, malgré de notables différences, at la rapporter au genre OEcobius de cet auteur (1). Toutefois, il faudra non-sculement modifier mais refaire la diagnose générique, car, indépendamment de ce que ma nouvelle espèce a une taille de beaucoup supérieure à celle des deux Olicobius de M. Lucas, son céphalothorax, quoique atténté en avant, n'est pas pointu et les filières placées loin du bout de l'abdomen ne sauraient jamais dépasser ni méme atteindre ce bout.

Dans la classification des Aranéides on doit attacher une valeur de première importance au nomble des stigmates, it celui des yeux ainsi qu' leur position respective el à leur siége sur le céphalothorax, a la force et à la direction des mandibules, à la longueur comparative des membres, etc.; mais il est imprudent de descendre si loin dans une diagnose trop détaillée ¿̀ l'occasion d'un genre fonde sur deux especes seulement. En procédant ainsi on s'expose à tomber dans des caractères purement spécifiques qui ne donnent plus acries dans le genre à de nouvelles especes.

Notre OEcobius nigripalpis est un géant comparativement aux deux espèces de M. Lucas, qui n'ont pas plus de deux millimètres de long. Son céphalothorax est ovale-oblong; par conséquent il n'est pas plus large

(1) Iucas, loc. eit., p. 101, pl. 2, fig. 1-2. 
que long ainsi que celui des OEcobius Luc.; il se prolonge en avant de l'éminence oculifère, en se rétrécissant un peu, mais sans se terminer en pointe. Dans les deux individus femelles que j'ai eus a analyser, l'un, plus grand que l'autre el paraissant adulte, a en juger par la grosseur du ventre, a les bords du céphalothorax, sauf le dernier tiers, avec une fine bordure bien noire qui ne s'observe pas dans le plus pelit individu. Je remarque que M. Lucas signale une semblable bordure noire dans son OE. domesticus.

L'éminence ocellifère de notre Orcabius est tout ì fait abrupte en avant et les six ocelles y sont fort rapproches. Quatre d'entre eux forment une série antérieure transversale. Les latéraux de celle série sont plus grands, ovalaires, d'un blanc opalin chatoyant, obliquement placés. Les intermédiaires sont petits, ronds et noirs. Les deux ocelles postérieurs sont oblongs, plats et opalins comme les latéraux de la série antérieure avec lesquels ils forment un carré. M. Lucas a représenté ces ocelles postéricurs hémisphériques.

Il doil y avoir entre les yeux ovales, déprimés, opalins et les pelits yeux ronds et noirs des différences fonctionnelles quant à la vision. Je pense que les ocelles opalins sont des yeux de nuit.

Les pattes de moyenne longueur et grosseur ressemblent à celles des Dysdera, Segestria, Mygale, dont notre OEcobius pourrait bien partager les habitudes sédentaires et le genre de vie. Ces pattes sont à peu près égales entre elles: toutefois la troisieme paire est un peu plus courle comme dans la plupart des Aranéides.

Les ongles courts et noirs ne sauraient être mis en évidence que par une compression expulsive du bout du tarse. Cliacune de ces griffes vues à une puissante lentille du microscope offre un peigne à huit dents droites, égales. Elle s'insère sur un talon ou onglet armé d'un crochet presque droit, pouvant faire la pince avec deux ou trois spinules sous-jacentes. Ces ongles ne sont point mentionnés par .II. Lucas sans doute à cause de la petitesse de ses espèces. Les peignes de notre OEcobius me donnent la certitude qu'il doit ourdir une toile ou des fourreaux comme les petites espèces de M. Lucas. L'existence du talon armé fait présumer un instrument de préhension et de vulnération pour sa proie.

Les palpes de notre espece sont remarquables, malgré le sexe femelle, par la grosseur de son article terminal ovoïde-oblong, d'un noir ardoisé, revétu de poils couchés. En pressant entre deux lames de verre cet article on détermine la saillie d'un crochel corné, noir, simple, à peine arqué qui en se ployant fait la pince avec deux petites dentules situées à l'angle d'un sinus peu profond. C'est un organe de préhension et de lacération.

Ie plus long article basilaire de ce palpe, abstraction faite de celui très 
court inséré a la mâchoire, est garni à son bord interne d'une série de spinules assez raides et ravissantes.

La lère est ovale-oblongue, étroilement enclavée entre les mâchoires. Celles-ci très inclinées ont leur bord externe avec une échancrure angulaire et le palpe s'insère en arrière de l'échancrure. Les mâchoires sont garnies d'une scopule à soies incurvées grisâtres.

L'abdomen est ovale-oblong, d'un luisant satine, san s apparence de duvel. La moitié antérieure de sa région dorsale of̂̃re quatre points ombiliqués, disposés en carré et deux autres infiniment petits en arrière de ceux-ci.

L'appareil de filature est placé à une certaine distance du bout du ventre. c'est un écusson rond el, dans le repos, les quatre filières sont couchées, et forment à peine relief.

EXPLication Des FigdoRes $2^{\text {e* }}$ DE LA PLANCIE $1^{\text {to }}$.

Fig. 2. OEcobius nigripalpis L. Duf.

$2 a$. Mesure de sa longueur naturelle.

2 b. Céplaalothorax fort grossi, pour mettre en évidence la forme et la disposition des ocelles, ainsi que sa bordure noire.

2 c. Aidomen vu par sa face ventrale el fort grossi, pour faire voir les stigmates pulmonaires et l'écusson des filières distant du bout du ventre.

$2 d$. Màchoire grossie, avec la lèvie et l'insertion du pálpe.

$2 c$. L'article terminal du palpe avec son crocliet saillant.

2 f. Une griffe des tarses considérablement grossie 


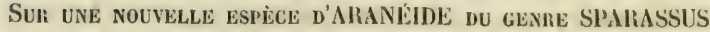

(Sparassus ammanita).

Dans le siècle actucl latreille, Savigny, Walckenaer, Sundeval, Lucas, de Ilaan, s'élevant au-dessus des préjugées, ont donné une puissante impulsion à la recherche et à l'étude sérieuse des $A$ rachnides. J'ai aussi cherché à seconder cette impulsion, par des investigations spéciales, soutenues pendant plus d'un demi-siècle avec un zèle passionné.

Sans contredit ces animaux sont les plus intelligents, les plus industrieux de la grande classe des articulés. La Providence semble avoir voulu compenser par cette haute intelligence l'espèce d'arersion que produisent sur des yeux prévenus leurs longues pattes, leur corps velu et leurs couleurs généralement rembrunies.

Les quatre individus femelles de la grande espèce de Sparassus WarcK., Micrommata Larr., que je vais faire connaitre, mont été apportés de Saigon (Cochinchine), par mon fils Gustave Dufour, médecin-major dans cette lointaine expédition. Malgré les difficultés et les dangers de la siLuation, son amour filial ne s'est point démenti et je lui dois une foule d'ohjets d'histoire naturelle qui deviendront plus tard, je l'espère, l'objet de nouvelles publications.

J'ai vainement cherché celte forte Aranéide dans les Olius, les Spurrssus de Walckenaer, qui a mentionné plusieurs grandes espèces exoliques, ainsi que dans les Philodromus de Savigny et de Jucas. Elle constitue une espece nouvelle pour la science. En roici la diagnose:

\section{Sparassus amanita L. Duf. (1P. $1^{\text {ro }}$, fig. 3.)}

Mugnus, uniformiter grisio-murinus, pubescons villosusque; pedibus hunc inde spinulosis; thorace orbiculato; rabdominc ovato-oblongo; fusulis vix exsertis. - + . Long. 12-13 lin.

IIab. in Saigon Cochinchincnse (G. Dufour).

te m’étonne qu'aucun des auteurs précilẻs n'ait point mentionnẻ un Irail de structure des tarses des Spurussus (qui a, relatisement aux habiludes de ces Arancides, une signification pliysiologique incontestable. Cetle structure, du moins dans les trois especes que j'ai plus particulière- 
ment étudiées it savoir les $S$. argclrs, S. spongilursis (1) el le $S$. ammanitı actuel, consiste dans l'existence, à la face inférieure de toutes les pátes, d'un duvel serré, velouté, comme spongieux, d'une tciute ardoisée qui, durant la vie et à certitin jour, brille d'un vert métallique. Je ne doute point que ce même reflet n'existe aussi dans l'espece cochinchinoise. Celte curieuse brosse a, comme les plus minimes structures bien comprises, une mission physiologique. Elle exerce sur les surfaces les plus lisses, les plus verticales, une action préhensive qui permel ì ces Araneides de courir, de glisser avec une étonnanle prestesse ou pour suive une proic ou pour éviter un ennemi.

A en juger par la forme el la structure des diverses parties du corps, le $S$. ammanila doil avoir les habitudes du $S$. argelas, marcher comme lui toutes les pattes transversalement élendues et se livrer aux mèmes mitnouvres. I,cs $S$. ammanitu que m'a apportés mon fils ont été pris daus l'hôpital même de Sä̈gon. Celui-ci est entouré d'une forêt d'Aróquicrs, palmier dont le trone lisse et droit doit être fréquenté par cclle Aranéide. Il n'existe point de rochers dans cette localité.

Passons à la description sommaire de l'espèce :

Céphalothorax grand, plus large que l'abdomen, orbiculaire, très modérément convexe, un peu plus relevé à sa partie céphalique, oflrant quelquues vagues empreintes rayonnantes qui correspondent aux origines des palles. Duvet collé, presque imperceptible. Disposition des yeux suflisamment cxprimée par la figure; les deux centraux de la série postéricure un peu plus petits que les autres.

Mandibules courtes, robustes, tombant perpendiculairement, velues, garnies au côté interne de scopules roussitres. Crochel fort el noir reçu dans une coulisse armée de chargue còté de quatre dents pour enserrer et déchirer sa proic.

Màchoires presque droites, largement distantes lune de l'atulte, oblongues, obluses, velues, garnies d'une brosse on scopule ì soies rousràtres fournies et incurvées.

Lèvre trois fois plus courte que la michoire, demi circulaire, velute.

Palpes longs, velus el spinuleux : article terminal à bout un peu renflé. couronné de soies assez raides et recélant dans le repos de l'organe un harpon à cing crochets, dont jusqu't̀ ce jour je ne connaissais aucun exemple el dont la configuration n'est signalée dans aucun auteur. Ce

(1) J'aỉ déjà, à l'oceasion te ce $S$. spongilarsis (Ann. Soc. Ent., $2^{\text {r }}$ série, tome $\mathrm{X}$, Bull., p. XuI, 1852), réfulé l'opinion erronée de Walchenaer el de Dugès, fqui n'ayant pas connu l'espiece, l'ont soupçnnaéc d'illégitimité. 
harpon rétractile, peu facile à mettre en évidence, a sa pointe courbée en bas ainsi que les deux crochets suivants, tandis que les deux basilaires sont it peu près droits. Qui nous dira quand et dans quel but ce terrible larpon entre en exercice?

Je m'abstiens de décrire les patles dont j'ai scrupuleusement représenté el la longueur respective el la villosité et les spinules. Je ne reviendrai pas sur les brosses sous-tarsiennes. Quant aux spinules qui toules sont dirigées d'arrière en avant, et qui, au gré de l'animal, peuvent se redtesser sur leur bulbe, je ferai observer qu'elles manquent entierement à l'arlicle du tibia représentant la rotule el que les cuisses n'en ont que deux. Tout cela doit avoir' sa raison d'ètre, parce que la Providence n'a rien créé sans un but fonctionnel.

Les ongles des tarses de notre $S$. ammanila méritent de nous arrèter un inslant. Binaires comme ceux de toutes les Aranéides, ils sont rétracliles et si profondément situés que, dans l'état de repos, ils demeurent totalement invisibles, dissimulés qu'ils sont par de petites spinules qui couronnent le bout tarsien un peu renflé. Une macération préalable permel à une compression expulsive de les mettre en saillie. On constate alors que chacun de ces ongles a deux fortes dents plates, en carré-oblong, et à la suite de celles-ci deux ou trois dents fort petites. Ia base de claque ongle repose sur une grande houppe de fines soies que l'animal peut épanouir à volonté en une sorte de ventouse ou de pelotte creuse qui lui sert à se fixer sur le support. De semblables houppes ont été parfaitement figurées par Savigny dans ses Philodromes égyptiens qui ne sont sans doute que des Sparussus.

Jes peignes ongulaires des Iractinides oflrent d'excellents caractères spécifiques trop négligés par la plupart des Arachnologisles, mais auxquels Savigny a accordé la valeur qu'ils méritent. Ces peignes sont des instruments de tissage. Les dents carrées du s. ammanila font présumer la fabrication d'un mode particulier de tente, de coque ou de toile difrérentes de celles de nos especes curopéenmes. Encore un coup la nalure n'a pas domé it notre Ammanite trente-deux dents carrées, toutes semblables entre clles sans leur avoir assigné des attrilutions spéciales. A nous de constater ou de deviner celles-ci.

Abdomen ovale-oblong, du moins dans la femelle, d'une teinte gris de souris uniforme, fincment feutré. I) ux paires de filières superposées, dont la supérieure dépasse seule le boul de l'abdomen. Qualre points ombiliqués à la moitié antérieure de la région dorsale. Ite scalpel a dèmontré que ces points dans les Artuchnides chaient dus à l'altache des muscles perforants qui traversent de part en part le loie. 


\section{EXPLICATION DES FIGURES $3^{\text {es }}$ DE LA PLANGHE $1^{\text {te }}$,}

Vig. 3. Spurassus ammanilu $f$ L. Duf. nexcedant que d'une ligne la longueur naturelle.

$3 a$. Disposition des yeux.

3 b. Nandibule grossic, pour faire voir les quatre paires de dents de la coulisse interne.

3 c. Extrémité fortement grossie, pour mettre en évidence le harpon rétractile.

3 d. Màchoires el lère grossies.

$3 e$. Bont fort grossi d'un tarse, pour meltre en relief les ongles, lit houppe sous-ongulaire el la brosse veloutée ou spongieuse du bord du tarse.

\section{III. \\ Note JUSTIFICATIVE SUR LE MGROMYRMA PYGMLA.}

La critique est aisée, mais l'art est difficile.

11. lioger (Journ, d'entom, de Berlin, 1862), dans un article qui trate de nouvelles Fourmis exotiques, en a pris occasion de défendre mon Micromyrma contre la critique de M. Mayr. Je l'en remercie. D'après cel article, dont mon ami le $\mathrm{D}^{\mathrm{r}}$ Sichel $\mathrm{m}^{\text {'a }}$ transmis la traduction, M. Mayr, auteur des Formicides d'Europe, non-seulement conteste la légitimite du gene Micromy'me, mais l'espèce ne serait suivant lui qu'un individu tres petit du Tapinoma erraticum. Je ne releverai pas les termes peu mesurés de la critique de M. Mayr. De son propre aveu, il n'aurait eu à consulter qu'un spécimen très mutilé de mon Micromyrma pygmara. P'our couper court at toule polémique, je prends sur moi d'acepter pour excuse celte circonstance.

M. lioger me rend la justice de croire que mon espece n'est point te Tapinoma rrralicum el il adople le genre Hycromyrma pour une espece cxotique sur laquelle je dirai bientôt quelques mots. 
Je déclare à MM. hoger et Mayr que le principal caraclère générique du Micromyrma est un trait négatif qui a mes yeux a une grande valeur: c'est l'absence complète, absolue, d'une écaille au pétiole de l'abdomen. Il n'y a là ni vestige, ni soudure. Je les prie de croire qu'avant de me décider à publier ce nouveau genre j'ai constaté cette absence d'écaille non seulement avec le secours d'une puissante loupe, mais a une forte lentille du microscope. Je renvoie donc ces savants lintomologistes a ma première notice sur le Micromyrmu dlont je maintiens comme conformes à la vérite et la description et la figure. Je ne saurais en retrancher un iolu.

Depuis 1856, malgré des recherches réitérées dans l'intérét de mes amis je n'ai retrouvé nulle part ce Micromyrma, et tout récemment je viens de partager avec M. Sichel les trois ou quatre individus qui restaient encore dans ma collection.

Que M. Roger me permette de lui soumettre quelques observations sur Ic Formica melanocephala Fab. (Ent. Syst.), petite espèce de Gayenne qu'il croil appartenir au genre Micromyrma et que je ne connais point.

Fabricius décrivit celte Fourmi dans la collection de Bosc at Paris. Coquebert, dans ses Illustrationes iconographice, presque exclusivement consacrées aux espèces nouvelles inscrites par Fabricius dans cette collection, en a donné une figure. Or, celle-ci, toule défectueuse qu'elle puisse être, ne saurait, par sa forme allongée et sa physionomic, se rapporter au Micromyrma.

Plus tard l'Entomologiste de Kicl colloqua (Syst. Piez.) ce méme molanocophute, sans y ajouter la moindre observation, dans son genre Lusius où il le jeta sans doute au hasard. Or, les Lasius ont, suivant Kabririus, une écaille au pétiole de l'abdomen et trois ocelles au vertex. Cos deux caractères n'existent nullement dans mon Micromyrmu.

Latreille (Itist. nat. des Foumis) mentionne lat melmocrphatu et cite lit ligure de Cognebert, mais il parail qu'il n’a fats va par lui-mème l'espéce, puisqu'il n'ajoute pas un mol au lexte de Fabricius et qu'il ne dit rien str l'analogie qu'elle pourrail atroir avec sa Formicu mygmaxa. 


\title{
SUR DES LARVES DE DIPTERES
}

TROUVÉES

\section{Dans les tunlques de l'estomac, Ies replis péritouéaux et lat parol abotominate}

\author{
CHEZ DES GRENOULLES.
}

Par M. le docteur Alexandre LABOULBENE.

(Séance du 22 Avril 1862.)

Les larves qui font le sujet de celte Nole ont été trouvées par non ami, M. Ie $D^{r}$ Vulpian, au commencement du mois d'octobre, dans des firenouilles vertes et un Crapaud commun, servant, au Jardin-des-Plantes, a des expériences physiologiques. En examinant les viscères abdominaux, l'attention fut attiréc par des taches noirâtres et disséninées sur l'estomac, la plupart sous-péritonéales, d'autres plus profondément situées. En cherchant quelle était la cause productrice de ces taches, on rencontra de petits corps allongés, noirâtres, qui m'ont été soumis ct dont je vais apprécier les caracteres. J'ai reconnu qu'il s'agissait de larves de Diptères, mortes depuis longtemps, enkystées, d'une teinte noiratre et d'une opacité très marquée, rendant leur ćtude fort difficile. Je les ai placées dans l'acide acélique, qui a fail pailir beaucoup les parois ou elles étaient enkystées, dauns la gljećrine, l'éther sulfurique, la benzine, etc.

Voici la description de ces larves :

Lance d'un gris noiratre ou ardoisé après la mort, mais très probablement d'un blanc grisûtre pendant la vie; pseudo-cephalée; ordinairement déformée, comme ratatinée et aplatie quand elle est au milieu des fibres musculaires et enkystée. La forme de cette larve est allongéc, cylindrique, lorsqu'elle est moins déforméc ou plus réecmment morte ; la partie antéricure est atténuée en pointe; la partic postéricure est tronquée.

Corps formé de onze segments, le psculo-céphale non compris; celui-ci offre deux mundibules rapprochées, accolées entre elles, longues, noires, crochues à l'extrémité antérieure, ou, en d'autres termes, terminées pał un erochet arnuć, obscurement articule avec la tige mandibulaire. Partic dorsale de chaque mandibule avec un prolongemenl supérieur el arqué, 
prolongé en arrière plus bas que la lige elle-mème. Il m'a élé impossible de saisir les vestiges de palpes ou d'uutres organes sur le pseudo-céphate, vu l'état avancé de décomposition ou plutôt de déformation de ces parlies si délicates.

Les segments du corps sont à leur maximum de développement sur le milieu de la larve : ils vont en diminuant de diamètre, soil en avant, soil en arrière. Le bord antérieur de clıque segment est muni de crochels très petits el remarquables, qu'on retrouve aussi sur les boris de la troncature postéricure du corps. Ces crochets ont une forme crochue ; leur base est plus ou moins épaissie, leur onglet est dirigé en arrière. Les segments antéricurs du corps sont pourvus de quatre rangées de croclicts, les segments postérieurs n'en ont que deux.

Dernier segment de la larve tronqué, bordé de crochets; on y distingue toujours soit un, soil deux traits bruns ou noiràtres et longitudinaux; ces traits m'ont paru être les aboutissants des stigmates postéricurs el constitués par de grosses trachées.

Je nai pu trouver aucune trace de stigmates antérieurs (Voy. Mém. de la Société de Biologie, $3^{\circ}$ série, t. III, p. 329 et pl. vi).

La longueur du corps varie d'un millimètre et demi à deux millimèlres, el jusqu'à quatre millimètres.

Ces larves se trouvent surtont dans les parois de l'estomac, où clles sont tantôt rapprochées de la membrane muqueuse, tantòt parmi les fibres musculaires, tantôt tout à fail sous-péritonéales, dans le mésentère, enfin sous le péritoine de la paroi abdominale gauche. lies dimensions el lapparence mème des larves variaient suivant le point qu'elles occupaicnt. Ilus petites, d'un noir ardoisé, daus les parois sous-muqueuses de l'estomac, elles élaient plus longues et moins noires dans les repplis du péritoine.

Ces larves élaient enkystées et elles adhéraient asse\% intinement aux tissus voisins; parfois il clail fort difficile de les extraire el on ne pouvatit les retirer que par fragments.

Je rapporte les larves que je viens de faire connaitre à la famille si nombreuse des Muscides: la forme du corps, des mandibules et de l'extrémité postérieure de l'ablomen ne saurait laisser de doutes a cel égard. Mais il serait très difficile de les rapporter ì un des genres de cette famille, car, dans l'état actuel de la science, la connaissance des larves est encore trop peu avancée pour autoriser une hypothèse soutenable. W'autre part, je pense qu'il s'agit d'une larve jeune, dont le developnement n'est pas complel; j'ai fait remarquer le volume plus considerable de l'animal à mesure qu'il se rapproche des luniques les plus extérieures de l'estomac. 0 r. 
l'histoire descriptive et iconographique du développement des larves des Dipleres est encore à faire presque complétement.

l'insiste d'une manière toute particulière sur les différences qui dislinguent le fait que je signale de ceux que la science possède déjà. On comnait, en effet, les dégàts ocensionnés par des larves de Muscides dans l'estomac de lieptiles malades qui les avaient avalées pour s'en nourrir. Les larves que jai décrites étaient mortes, les (rrenouilles paraissaient en parfaite santé, et loin de causer leur mort, ces larves n’avaient agi que comme corps étrangers inoffensifs, en s'enkystant dans les parois de l'estomac.

Voici les faits relatifs aux ravages causés dans le tube digestif par des larves de Mouches. M. IImpolyte Lugas a relaté, dans les Annales de la Socicti cnlomologique de France (année 1851, Bull., p. Lxi1), que des larves de Galliphora futvibarbis et vomitoria ont été trouvées en grand nombre dans l'intérieur du corps d'un P'latydectylus muratis que M. Emile Blanchard élevait au laboratoire d'entomologie. Les larves de Calliphor seraient provenues d'œufs sortis des Mouches femelles avalées par le Sattrien, et ces larves une fois écloses auraient vécu aux dépens, non seulement de l'estomac et des intestins du Platydactylus, mais encore de son loic et de ses poumons.

M. Eugtine Desuarest at mentionné dans nos mèmes Amuales (année 1851, Bulletin, p. LXI11), que M. Gratiolet, voulant conserver des Lézards verts, avail cherché à les nourrir au Muséum avec des larves de Calliphora vomiloriu vivantes. Quelque temps après avoir pris celte alimentation, ces Lézards grossirent considérablement vers la région ventrale, et ils ne turdèrent pas a périr. $\Lambda$ l'autopsic on trouva, dans l'intérieur du corps, des lan ves encore vivantes qui avaient perforé les parois du tube digestif. 

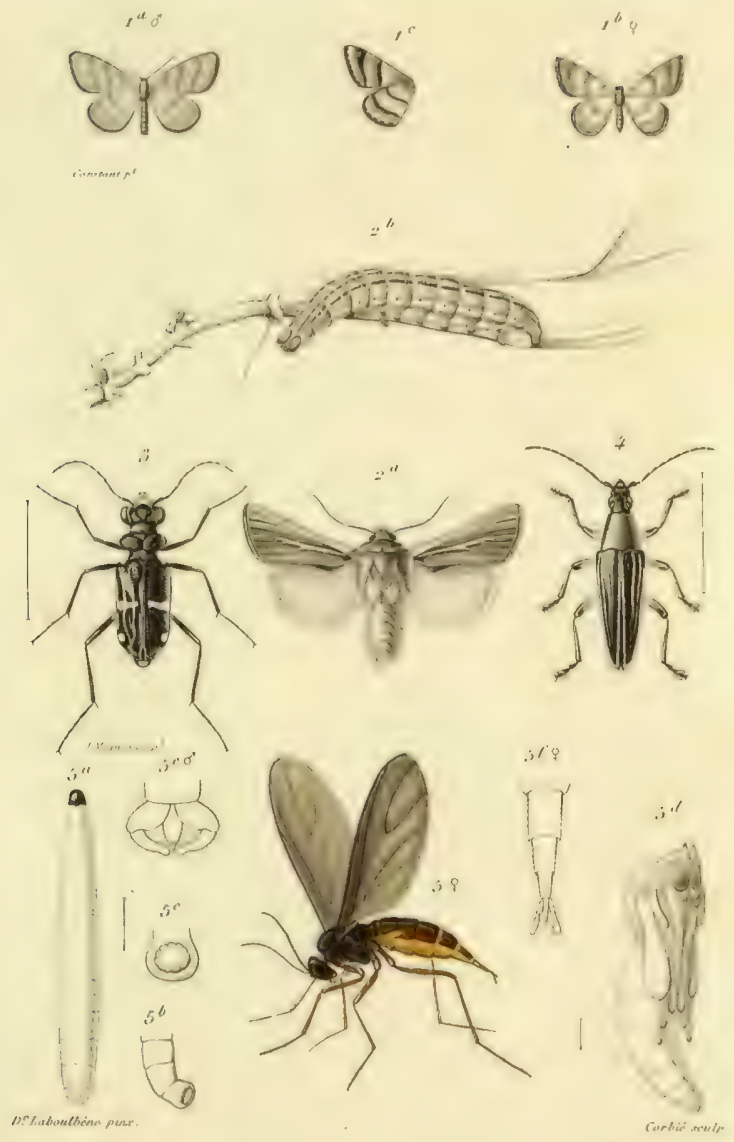

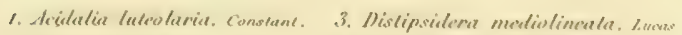

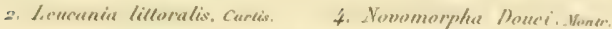

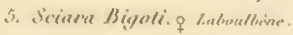





\title{
NOTE
}

SUR LA

\section{Phosphorescence des larves el des nymphes du $G^{\text {re }}$ Lampyris,}

\author{
Par M. le $\mathbf{D}^{\mathrm{r}}$ Alexaydne LABOULBÈNE.
}

\section{(Séance du 8 Juillet 1863.)}

Le but de celle note est d'appeler l'attention sur un fait déjà observé par De Geer et que j'ai pu confirmer á plusieurs reprises : la pliosphorescence des larves du Lampyris noctiluca et d'autres especes de ce genre. En causant avec plusieurs entomologistes d'un grand mérite, j'ai été surpris du doute qui s’élevait dans leur esprit quand je leur signalais la phosphorescence de ces larves. Un de nos collegues, M. le docteur puton, de Remiremont (Vosges), a remarqué, pour la première fois, vers la fin de l'année dernière, cette propriété des larves de Lampyris; il en a été très étonné et il m'a fait part de ce qu'il croyait avoir découvert en m'envoyant les insectes à l'appui.

"Le 10 octobre 1862, dit notre collègue, en passant dans une petite prairie enclavée dans le bois, je vis le gazon constellé de milliers de vers luisants. Le Lampyris noctiluca, sans etre rare à Remiremont, n'est pas très abondant, et je ne l'avais jamais trouvé que vers le mois de juillet. J'en ai amassé une douzaine, et le lendemain, les examinant avec soin, j'ai reconnu que ce n'étaient que des larves. Je n'ai jamais vu indiquer cette propriété lumineuse des larves du Lampyre; croyant celle faculté phosphorescente destinée à altirer le $d^{x}$. je ne me l'explique pas dans la larve. Les insectes que j'ai pris ont conservé leur phosphorescence pendant trois ou quatre jours; vous trouverez sur ceux que je rous envoie les derniers segments abdominaux blanchatres comme chez les ․ "

L'observation de M. Puton était exacte et ronforme à ce que j'avais déjà vu moi-même soit dans le midi de la France, soit aux environs de Paris, près du chateau de Meudon en particulier, sur diverses espèces de larres de Lampyris.

Je termine celte note en rendant à DE GÉer la justice qui lui est due. Ce grand entomologiste nous apprend, en décrivant la larve du $L$. noctiluca dans le $1 V^{*}$ volume de ses précicux Mémoires, que les $9^{e}, 10^{*}$ et $11^{e}$ segments (fig. 28) sont en dessous d'un blanc verdâtre et que c'est de cet endroit que part la lumière que la larve fait paraitre dans l'obscurite; c'est là qu'est placée la matière phosphorescente qui la produit (loc. cit., p. 38). Plus bas De fièer ajoute : Le même soir où la nymphe eut quitté la peau de larve, je lui vis répandre une lumiere très vive et très brillante qui avait une teinte d'un beau vert (p. 44 ); et il conclut que le Lampyre luit dans son état d'enfance, dans celui de larve, et encore après aroir pris la forme de nymphe (loc. cit., p. 44). 
Les Gampronuinus dans les Amentacées cupuliferes (Chene).

Les Coentodes sur les Géraniẻes (C. geranii, etc.) les Labiécs (G. lamii) et les Urticées (C. 4-maculaius).

Les Mononycuus, du moins le Pscudo-acori, sur les Iridées.

Les Ceutonnyncrus sur les Grucifères (G. erysimi, etc.), les Borraginées (G. asperifoliarum, elc.), les Labiées (C. lycopi, etc.), les P’apavéracées (G. Raphaclensis, ctc.), les Ericinées (G. forrugalus, ctc.), les Urticées (C. pollinarius).

I.es Crovus sur les feuilles des Verbascées et des Scropluulariées.

Les Granztron sur les Campanulacées (G. campanula), les Verbascées (G. ascllus, etc.) et surtout les Scrophulariées (G. villosulus, linariz, clc.).

Les Mlecinus sur les Plantaginées (.1\% pyrasler et circulatus).

Ies Naxopnyes sur les Lythrariées ( $N$. lythri, elc.), les Tamariscinces (N. pallidulus, etc.), les Crassulacćes (N. umbitici nov. sp.) el les Éricinées ( $N$. siculus).

Les Sitopinues dans les grains de certaines Graminées.

Les Cossoncs, Mesites, Pinloropingus, Riryncolus el Dryopithorus, dans le bois des Amentacées et des $\Lambda$ biétinées. 


\title{
SUR L'ORGANE PIUSICAL DE LA CHELONIA PUDICA,
}

\author{
Par M. le Dr Atexanone LABOUlabenE.
}

(Séance du 23 Novembre 1864.)

C'est dans le premier volume de nos Annules que fut signalé pour la première fois le bruit musical produit par un charmant Lépidoptère du midi oriental de la France, la Chclonia pudica Espen. L'indication doit nous être précieuse, puisqu'elle se rattache étroitement au bercenu de notre Société et qu'elle nous rappelle le nom de de villiers. Depuis cette époque déjà reculée et glorieuse pour l'entomologie, les auteurs ont parlé du travail primitif, mais sans rien y ajouter de nouveau. M. Guenie, étudiant en 1861 le genre Sctina, découvrait un organe spécial situé de chaque côté du thorax, et, assistant l'année dernière à l'Excursion qui a eu lieu a Zermatt, dans le Valais, il constatait un bruil musical che\% plusieurs especes de ce genre. Notre savant collegue nous a domné un excellent mémoire à ce sujet, mais il s'est borme à lappeler le bruit indiqué pour la Chelonia pudica.

Je chercherai d'abord à établir l'élat de la science sur le sujet qui va m'occuper, puis j'essayerai d'y joindre le résultat de mes recherclıes.

De Villiers s'exprimait ainsi : J'ose me flatter d'avoir découvett le premier un fait extraordinaire, el je présente le fruit de mon observation aux entomologistes qui, plus instruíts que moi, peuvent la faire toumer au profit de la science, en les invitant à en vérifier l'exaclitude que je garantis.

Ein chassant aux Lépidoptères dans le midi de la France, je métais aperçu que dans les belles soirées d'ete, si communes aux environs de Montpellier, l'Écaille pulique faisait, en volant autour de moi, entendre un petit bruit que je ne peux mieux comparer qu'ì celui d'un métier de fabricant de bas. Ce bruit étail même si lort que, guidá par loi, j’ai souvent pris celte belle licaille au vol et sans l'apercevoir. Ĺtonné de cette 
singularilé, unique peut-être dans le mécanisme du vol des Lépidoptères, j'ai cherché à décontvrir quelle pouvait en être la cause, et je l'ai enfin trouvée.

L'Écraille pudique a de chaque côté de la poitrine, à la naissance des ailes inférieures, un espace profondément sillonné et creux, tapissé par une pellicule blanche et très dure et recouvert hermétiquement par une autre petite peau épaisse, luisante, bombée et bordée de poils, dont la partic la plus large est situe vers l'endroit où le corps se joint à l'abdomen. Cette peau, qui m’a paru pareille à celle qui compose les timbales des cigales, ne tient au corps qu'ì la naissance de l'aile inférieure; et lorsque l'insecte vole, ćtant mise en jeu par les muscles qui font agir cette aile, elle presse fortement l'air renfermé dans la cavité et produit le bruit dont j’ai parlé. Cette singulière propriété est commune aux deux sexes; seulcment, comme dans cette espèce, ainsi que dans toutes ses congénères, le mâle vole beaucoup plus que la femelle, j'ai été plus à portée d'olserver celui-ci que l'autre, mais tous les individus femelles que j’ai disséqués m'ont offert le mème appareil, seulement plus petit (1).

Solier, at la fin d'un mémoire sur la stridulation des insectes, observe qu'il a été sourent intrigué, dans les soirées d'été, par un bruit très fort et très remarquable produit par un insecte qu'il ne pouvait saisir. Je ne savais, dit-il, si je derais l'attribuer at un Orthoptère, et je penchais pour cette opinion; mais j'ai su depuis que l'insecte que je cherchais a connaitre n'était qu'un assez faible papillon, la Chiclonia pudicu.

Ignorant si ce fait avait été observé, j'en fis part à M. 1)uponclıel, c’t ce savant me marque, dans une lettre, que déjà $\mathrm{M}$. de Villiers en avait parlé dans le prenier volume des Amales de la Socielté entomologique de France. J'ai vu alors que $\mathrm{N}$. de Villiers attribuait ce bruit à deux creux situés de chaque côté de la poitrine, à la naissance des ailes iuferieures, ces creux étant tapissés d'une pellicule blanche et recouverte hermétiguenent par une autre petite peau épaissc.

J'ai vainement cherché ces organes dans la poitrine de l'insecte, dit Solier, mais j'ai découvert à chaque hanche postérieure une grande vessie qui la déborde. Les deux lanches précilées étant appliquées contre le corps, ces deux vessies paraissent, au jremier aspect, appartenir à la poitrine, ct c'est peut-etre ce qui a trompé l'observateur que j'ai cité. On

(1) DE Vur.uns, Observations sur l'Écrille pudique de Godarl, genıe Eyprepria dOchsenheimer (.1nnates de la Société entomologique de France, ire série, t. I, page 203, pl. vi, fig. 9, $a, b, 1832$ ). 
peut se convaincre que ce n'est qưue illusion : car en dútachant une des pattes postéricures, l'on verra que la vessie correspondante appartient réellement à ha hanche. Ge corps vésiculeux est déprimé et d'une forme subtriangulaire. It présente a la surface inférieure du côté interne, des côles élevées, courtes et transverses, subparallèles, dont quelques-ınes plus grosses et plus longues. La face verticale interne a deux sillons longitudinaux laissant entre eux un gros pli dans le mème sens. La parlie de cette vessie oủ sont situées ces côtes s'engage sons les hanches intermédiaires. Ces dernières m'ont paru réunies et fixes (ce que je n'oserai cependant assurer, n’ayant étudié que sur le sec), et elles sont ciliées de brossas de poils au côlé exlérieur, correspondant aux petiles côtes de la vessie. Il me parait done tris probable que lorsque l'insecte veut produire sá stridulation, il fait mouvoir les hanches postérieures contre les brosses des intermédiaires, qui, passant sur les côles élevées de lat vessie, font vibrẹ celte derniere el produisent le son remarquable: que ce papillon fait entendre en volant. Cos ressies seraient done deux especes de violons dont les hanclies intermédiaires seraient les archets. Ce que l'on peut assurer, c'est que la stridulation n'a lieu que par la volonté de l'insecte, et qu'elle n'est point le résultat forcé du vol, puisque je l'ai vu souvent agiter avec une très grande vilesse ses ailes sans produire d'autre son que le lourdonnement naturel dù à l'agitation de l'air que ces ailes mettent en mouvement (1).

V. le colonel Goureau, apres avoir expliqué la stridulation de l'Acheruntia Alropos, se contente d'ajonter : On cite encore comme Lépidoptere bruyant la Ghctonia pudica male. Je n'ai jamais possúdé cet insecte vivant et je ne l'ai jamais entendu; en conséquence, je ne puis rien dire sur ses organes vocaux (2).

UII. Westwood (3) et Siebold (4) rappellent Ies travaux de de Villiers et de Solier, mais sans commentaires.

(1) SoLna, Observations sur quelques particularités de la stridulation des Insectes ( $\mathrm{Am}$. de la societé entom. de France, 1re série, t. VI, p. 215, 1837).

(2) Govnew, Essai sur la stridulation des Insectes (1mu. Soc. cut. France, $1^{\text {re }}$ série, t. VI, p. 69, 1837).

(3) Westwoon, An Introduction to the modern Classification of Insects, t. II, p. 383,1810 ).

(4) Siebozd el Stansius, Anatomie comparie, éd. Encjclopédie Roret, in-18, t. I, p. 551 , note 3,1850 . 


\section{Examen unatomique rt physiologique de lorgane musical de la Chelonia pudica.}

Vers la fin du mois d'octobre dernier, mon ami et collegue M. Enmanuel Martin m'apporta deux individus de li Chclonia pudica, nouvellement éclos chez lui, à Paris, de chrysalides rapportées du midi de la France. Malheureusement les ailes de ces deux Lépidoptères étaient avortées. .1. Martin m'engagea ì examiner l'organe musical, et, en pressant faiblement l'insecte entre l'extrémité du pouce el de l'index, de chaque cóté du thorax, il me fit entendre un bruit particulier. Répétant moi-même cette petile manourre et approchant l'insecte de l'oreille, j'entendis également un son, comparable at celui d'un papier sec et mince froissé rapidement entre les doigts. Les insectes, placés sur une table, ont agité leurs moignons d'ailes et produit un bourdomnement léger, mais sans que le bruit spécial ou particulier fût perceptible pour nous. Les mêmes insectes, posés sur le dos, essayaient de se redresser en donnant de petits coups de pattes, on plutôt en rapprochant vivement et en ccartant les pattes du corps, contre lequel battaient leurs genoux. Placés au bout du doigl, its faisaient frémir leurs ailes et essayaient de voler. Je les ai souvent exanines, et de toules les manieres, de jour comme de nuit, pendant une semaine environ, mais je n'ai jamais pu saisir de bruit particulier rendu par l'insecte et semblable à celui que produisait la pression des doigts sur le thorax.

Les deux insectes remis par M. Marlin élaient deux femelles, ainsi que l'indiquaient les antennes filiformes, les taches des ailes inférieures en miniature el la disposition de l'extrémité de l'ablomen. Jai fail des expériences sur l'organe spicial thosaciquer pendant la vie de ces deux femelles, puis j’ai étudie cet organe sur un grand nombre d'individus, tant males que femelles, de la belle collection de notre collegue M. Fallou, auquel je me plais ici ì témoigner ma reconnaissance pour sa complaisance inépuisable.

1. Élude anatomique. L'organe musical de la Chelonia pudica differe, pour la grandeur, suivant le sexe. Il est plus volumineux chez le male, ainsi que de, villiers en avait fait la remarque.

En examinant l'insecte place de profil (planche $10^{\circ}$, fig. 4), on trouve que l'organe vésiculiforme est situé sur le thorax, à la partie postérieure, 
el qu'il fait partie do métathorax. La forme est che\% le mâle celle d'une large saillie vésiculaire et triangulaire, plane en dehors arec les borts un peu convexes el réfléchis el les sommets largement arrondis (fig. $4, \|\rangle$. Ia partie supérieure, ou base du triangle, est presçue horizontale; le côté antérieur est très oblique d'avant en arrière et de haut en bas; le cóté posterieur est presque vertical et son bord arrondi est très ćpais. Chez la femelle, le triangle est plus petit, et de méme le côté supérieur ou base est presque horizontal, inais plus étroit que chez le o, le còlé antérieur oblique ct le côté postéricur presquue vertical au point oủ il confine it l'abdomen. La face extérieure, plane ou un pel bombée sur le vivant, offre sur la partic antérieure, c'est-ì-dire vers la tète, un pli irrégulier parallèle au côté ou bord antérieur. Ce pli résulte de la convergence de petites lignes transversales élevées, très légèrement arquées el interceptant de petits sillons. Ces lignes sont au nombre de 16 à 20 chez le ơ, les unes plus fortes que les autres. Ce nombre est seulement de 8 a 10 chre\% le femelle. Ces plis et ces rides transversales exprimés par la figure 4 , sont bien plus margues chez le màle que chez la femelle.

Les côtes de la vésicule sont épais, surtout chez le ơ, en arrière, et sur le pourtour, et vont s'altacher au thorax en formant un rebord, ou si l'on veut une sorte de cadre sur lequel la membrane extérieure est tendue. Ce rebord est généralement lisse el dépourvu de saillies ou de rugosités. Sur le côté antérieur, on trouve à peine une goultière et une ligne élevée qui la borde. Solier avait évidemment exagéré la disposition de cette ligne ćlevée et en avait même admis đleux. De Villiers l'a mal représentée. Iu reste, en comparant les figures que j’ai dessinces avec celles de la planclie $6^{e}$ du $f^{e r}$ volume de nos Annates, on verra que les figures a et $b$ de cette planche $6^{\circ}$ ont phlutôt l'air d'etre théoriques on schématiques que faites d'après nature, et l'aspect de la membrane tendue au-dessus du calre extérieur n'est point rendu exactement.

La couleur de l'organe vésiculiforme est d'un blanc grisitre el transparent. Chez les insectes tres frais, on trouve at la partie supericure des touffes de poils rouges ou rosis; vers la partie postérieure, ou juxta-abdominale du bord, d'autres poils longs; enfin sur le disque lui-mène, surtout en arrière, des écailles d'un gris satine et rosi. Sur les insectes très frais, ces ecailles on squamules sont assez abondantes, et l'endroit oì se reploie la patte postéricure contre le corps est seul légèrement dipouills. Chez les insectes qui paraissent avoir vole, les poils ecailleux on les squamules ont disparu, la membrane est lisse et glabre. J'avais d'abord cru que l'organe vésiculeux était ordinatrement lisse, mais l'examen des insectes très frais m'a prouvé le contraire, el les poils élargis, les squa- 
mules qui le recouvrent in'ont rappete le fait, encore trop peu connu, des écailles si rapidement enlerees, ou si caducues, des Macroglossa fusciformis el bombyliformis. Chez ces Sphingides venant d'éclore, la surface médiane des ailes est garnie d'écailles brunatres, mais si promptes à se détacher, que l'on n'en trouve presque point ou pas du tout chez les insectes qui ont volé depuis quelque temps.

L'organe vésiculiforme examiné en dedans, c'est-ì-dire en détachant la surface extérieure de la vésicule avec une lancelte bien coupante ou de fins ciscaux, offre une cavité triangulaire avec un relicf oblique et à peu près médian séparant la cavité en deux parties. Ce relief, bien plus prononeé sur les insectes desséchés, n'atteint pas la membrane externe et il en est assez éloigné. La cavité est tapissée par une membrane blanchâtre et lisse.

La partic interne de la vésicule n'offre point de prolongement ou d'arrière-cavité; elle ne présente pas de pore ou d'ouverture allant dans l'intérieur du corps. D'autre part, il n'existe point de saillic interne autre que celle que j’ai indiquée précédemment; il n'y a pas, je le répète, d'adhérence entre le fond de la cavité et la face postéricure de la memlurane tendue, rien, en un mot, qui rappelle un muscle ou un tendon pouvant lirer la membrane, rien qui ressemble à un battant, à un narteau, ou it un corps percutant situé à l'intérieur.

J'ai placé sous l'eau l'organe vésiculiforme de l'insecte frais, et en pressant le corps entre les mors d'une pince, je n'ai vu aucune bulle d'air se légager des parois.

Les rapports des pattes avec l'organe vésiculeux sont les suivants : le genou des pattes intermédiaires du mâle alteint et dépasse mème le côté supérieur ou base du triangle vésiculeux; mais la palte postérieure est adaptéc d’une façon admirable avec la vésicule; le bord antérieur de la dernière cuisse se loge contre la ligne ou aboutissent les reliefs élevés transversaux; le genou de cette patte postérieure arrive presque au bord supérieur du triangle, mais ne l'atteint pas; la cuisse et la jambe, repliées et en place, occupent la partie moyenne de l'organe musical et y déterminent une dépression pareille à celle qque j’ai vue sur plusieurs insectes à l'état sec. Cette adaptation si parfaite de la cuisse postérieure avec l'organe musical de la Chelonia pudica ô se retrouve sur les Setina. La souldure des hanclics intermediaires admise par solier n'a aucun rapport avec l'organe vésiculiforme.

Une particularité intéressante et dont je dois parler ici est la suivante. thans les lemelles vivantes que j'ai olsservées, grâce ì M. Martin, les cuisses 
thes jambes des patles, surtout des posterieures, étaient arques.es. J'avais cru d'abord at la possibilite d'un rapport de celte coubure anec la fonetion de l'organe misical. Je me suis convatinen plus tard qüil n'en itait rien. Les paltes des cifurtonir purlica of ou of at l'état normal, ne sont pas courhées. Lette dernière disposition est morbide ou maladive, elle sp lie it l'avortement des ailes; l'insecte a des patles rachitiques, il est mal conformé. J'ai retrouvé sur plusieurs espèces écloses en captivité avec les ailes avortíes (V. Corvini) cette curieuse disposition. de l'ai vue aussi sur des Sctina à ailes ì demi avortées (s. aurita) et dont les jambes étaient devenues arquées à un degré fort prononcé.

Après avoir examiné cet organe sur deux insectes femelles, à l'élat frais, el sur un grand nombre d'insectes des deux sexes conservís en collection, j'ai reconnu que par l'inspection seule de l'organe musical, on pouvait dire le sexe, el, répétant plusieurs fois l'épreuse avec xul. Fallon, je ne me suis jamais (rompé. De plus, j’ai tenu a voir si, dans un certaiı nombre d'espèces voisines de la Cheloniu pudica, je ne trouscrais point un organe analogue it celui qu'ofire celte espice. Mu. Fallon perre et fils mont aide pour cela de leurs yeux et de leur collection.

l'ai examiné dans ce but les espèces suivantes appartenant it divers genres:

\section{Genre Chclonia LATreille.}

Cheloniu Qurnsclii PaYk. ôt, q. P'oint d'organe vésiculiforme.

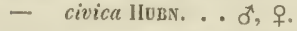

Id.

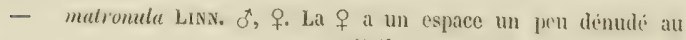
métathorax, mais it n'est point recouvert d'une membrane perforable, il n'est point vide en dessous.

- villica Linn. . o o f. Point d'organe vésiculiforme.

- Latreillci God. . of ㅇ.

Id.

- fasciata lispen . of 오.

Id.

- Ravie kisper .. o. Le ot a un espace un peu dénudé au métathorax, fléchissant un peu sous la pointe mousse d'une aiguille, mais sans cavité remarquable.

- caja Linn. . . . ๙ + +o l'oint d'organe vésiculiforme.

$\perp$ llebe Linn. . . . o o g.

Id. 
Genre Nemeophila Stepinens.

Nimrophila russula LiNN. . . . o̊, f. l’oint d'organe vésiculiforme.

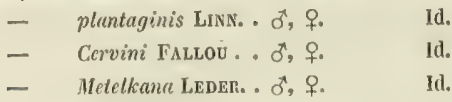

Genie Callimorpha Latreille.

Callimorpha dominulı Lins. líen d’appréciable, comme organe vésiculiforme, au thorax.

- hera LiNN. . Id.

Genre Naclia Borsduval.

Naclia ancilla Lrwn. . . đૅ, ․ Point d'organe vésiculiforme.

- punctata FAB. o o, q. Id.

Genre Nudaria STEPIENS.

Nudaria mundana Lins. . . ơ, q. Point d'organe vésiculiforme.

Genre Trichosoma liambur.

Trichosoma hemigomom Grasuin . ox, ․ Point d'organe vésiculiforme.

Genre Arctia LATREILLE.

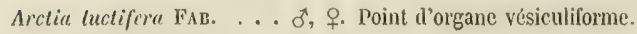

- menthastri FAB... ox, o. Id.

- intercisa Treits... o, 요 Id.

11 nous reste enfin à préciser quelle est la signification, au point de vue de la philosophie analomique, de l'organe vésiculiforme de la Gheloniu 
pudica. De Villiers le rapportait ì l'attache des ailes inférienres, cl solier le croyait une dilatation de la branche. Nous allons démontrer qu'il est indépendant de l'une et de l'autre.

En observant une Chclonia purtica màle, on ne se rend pas un comple exact de la partie thoracique d'où provient la vésicule énorme rqu'on a sous les yeux. L'insecle femelle est plus favorable, car l'organe, par ccla même qu’il est moins développé, a refoulé à un degré, moindre les parties environnantes. Il convient toutefois d'enlever soigneusement les poils et les écailles qui recouvient les parties contiguès et qui enveloppent l'organe vésiculilorme. Apres avoir nelloyé les flanes de l'insecte, on s'assure que la lanche du métathorax fait suite a la vésicule et qu'elle la prolonge ver's le bas. Derrière la vésicule est une partie allongée qui de mème va s'unir avec le pourtour de la hanche. Or, on sait que dans les répidoptères la lanche est très allongéc et que l'articulation de la cuisse est beaucoup plus bas que le point ou commence la hanche proprement dite.

La vésicule bordant le mésothorax et ayant derrierw clle l'épimère ne peut être autre chose que l'ópisternum du milathorax. Lne autre considération vient prèter son appui à celte manière de voir : c’est que, sur les Callimorpha hera et dominula, on trouve, après avoir enleve les poils et les écailles des flancs đu métathorax, les épisternum du mélapectus strićs en lravers et à la partie antérieure comme le sont les enormes bésicules de la Cholonia mulica. Ces Callimorphes nous doment done lat preuve que nous cherchions, et fixent la détermination anatomique de l'organe musical de la Chelonia pudica.

Les conclusions suivantes résument l'élude analomique it laquelie je me suis livré :

Il existe de chaque côté du mélathorax, chez la Chctonie mulica, un organe spécial, vésiculiforme ou tympaniforme, constitue par une cavité à bords élevés et arrondis, cavité recouverte d'une membrane lendue, mince, seclie, et pouvant vibrer.

Get organe a une forme triangulaire; il est locancoup plus considerable shez le male; il ofre a la partie antérieure une séric de seize à vingl lignes élevées, transversales ot parallètes chez le mâle, el seulement de huit ì dix chez la femelle.

L'organe vésiculiforme est forme, au point de vue des modifications anatomigues, par le développenent considérable de l'épisternum tu dessous du métathorax, ou métapectus.

2. Elude pliysiologique. J'ai llejà dil qu'en pressant douement entre les doigls le corselet de la Chertoniz vivante, et en rapprochant l'insecte 
de l'orcille, nous crimes entendre, M. k. Martin 't moi, um Joruit comjarable an froissement d'un papier sec. Je tois ajouler qu'en faisant flechir la surface externe de la memurane tympanilorme sous la pointe mousse d'une aiguille, je suis arrivé au même résultat. Le gratlement de la partie striolée et anterieure de la membrane tendue donne, aussi un Jruil, mais de ráclement et d'un timbre different.

te n’ai pu, sur les deux insectes vivants, entendre que ce que j’ai noli; j'ai examine deux femelles, et elles ne pouvaient voler à eause de l'avoltement des ailes.

Je n'ai rien perru qui rappelat le bruit d'un métier à labriquer les bas (de Villiers), ni un bruit très fort (Solier) indigné pour la Chrloniu purdicu volant en liberté dans les belles soirées d’été, par un temps calme.

Quand j'ai percé d'un trou assez fort la membrane externe des vésicules tympaniformes chez l'un de's insectes vivants, le bruit n'a plus cu lieu; il al cessé pareillement par ła section simple et un peu étendue de la menbrane pratiquée sur l'autre insecte.

Après avoir fait ramollir des chectonia medicu ot et $q$, j'ai essayé de presser leur thorax entre les doigts, et j'ai très flistinctement entendu un bruil qui me rappelait celui des insectes vivants. Le son rendu par les mâles citait plas fort. Les dernières pattes s'étaient placres d'elles-mêmes comme je l'ai dit en parlant de leurs rapports avec la face extérieure de l'organe musical. J'ai essayé de presser sur la partic antériente de lit vésicule, et je n'ai pas produit de bruit. En comprimant l'insecte, a la fois sur la tete et sur l'abtomen, l'avant en arrière pour faire agir la partie antérieure da thorax sur la postérieure on, en un mol, en pressant la vésicule entre la tète el l'abdomen, l'insecte est resté muet.

Telles sont les expuriences que j’ai tenties. D'après elles ct d'après les faits anatomiques, fu'est-il permis d'admettre sur la physiologie de lat vésicule tympaniforme de la Chelonie medice? Plusieurs opinions ont été émises lant sur cet insecte que sur les Sctima. P'assons-les tour à lour en revie en les discutant.

Je ne crois pas au bruit produit par les hanches des euisses intermithaires frottant contre le bord antérieur on bien aux pattes qui passeraient sur les rugosités it la manière d'un archet. Liexplication de de villiers ne me parait plus soutenalłe aujonrd'hni. Les cuisses of les jambes que j'ai examinées sur le ot la f sont mutiques, les poils sont très fins el ue sauraient racler la face anterieure ou le côté externe à la manière d'un archet. D'ailleurs, l'organe musical tes Selina est prirlailement lisse. Ce n'esl point par le mecturisne de lit stridulation des ciriquets ou des cirittons que te bruit peut se manilester chez nos Lépidoptères. 
Il n'est pas possible de s'arevter un instant it la formation ilu son pall un muscle interne firant sur la membrane, comme cela a lieu jour les Cigales.

Je ne pense pas que le vide puisse etre produit dans la vésicule tympaniforme suivant la manière indiquée par M. Guenée (loc. cit. 186\%, p. 401), ef que l'insecle soit doué de la faculté d'aspirer une partie de l'air conŁenu, of rui ferail rentrer la mem]sane, puis de la gonfler de noureau par une cxpiration subite. Il $\mathrm{n}^{9} \mathrm{y}$ a point de communication appréciable avec un système de trachées ou un récipient capable d'amener ce résultat. Gelle lrypolhèse ingénieuse me scmble devoir ètre rejetée.

Il y aurail la stridulation par pioulement, si Jien étudiée par M. Coureau (1), et alors l'insecte, à la maniere des Diptères syrphictes, ferail vibrer rapidement les ailes et le corps, et la vésicule tympaniforme renforcerait le son, comme cela a lien chez la Syrilla pijpicns et le cimysotoxum arcutum. Mais rappelons-nous les intermittences, soil du bruit naturel observé par de Villiers el comparé à celui d'un métier à fabriquer les bas, soit du bruit provoque produit dans mon cabinet entre mes doigts. liappelons-nous encore la stridulation des Selina imilant un peu, stfvant M. Guenée, le tie-tac d'une montre ou les pulsations des Anobium. In tel truit ne peut etre assimile au piaulement de certains piptères; il ne peut etre produit par les mêmes causes.

liapportons une opinion de M. Ciuenée. La membrane qui recouvie l'organe est mince et flexible, on la fait fléchir à rolonté, ct dès que la pression cesse elle reprent par son ćlasticite propre la position primitive. L'insecte, en contraclant les organes pectoratix, en pressant arec les cuisses intermediaires sur la partie antericure du rehord, ploierail el déploierait alternativement la membrane. Cela riest point impossible.

Il reste enfin un dernier mode de production du bruit musical, et c'est lui qui me parât rendre comple du phénomene. Je crois que l'insecte stridule par suile de petits coups donnés au moyen des pattes sur la membrame tendue, ou par des pressions latérales rapides au moýen des genoux. Ia cherlomir puedicu et les Sclime auraient, de la sorte, le mème morle de stridulation, ce seraient des insectes timbaliers. Lat percussion interue ne peut ète possible, puisque je u’ai va aucun corps pouvant pereuter de dedans en dehors la membrane tendue; c'est du dehors que vient le coup sec qui fail vilurer la membrane sèche et parcheminec, tendue sur la vésicule remplie d'air.

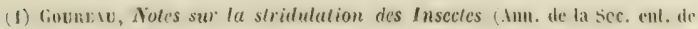
France, 1837, ए. 398). 
La fenelle de la Chrlonia pudica produit-elle un Irruil identigute a celui de l'insecte mate? C'est ce que je ne puis dire, et de: Villiers et Solier ne sont pas explicites à cet égard; ils pensent que la femelle stridule, mais ils ne le disent point de auditu.

L'opinion que j'ai émise me parait la plus probable; toutefois j'y renoncerais sans peine s'il m'était démontré qu'elle n'est point la vaie. Mon amour de la science el de la vérité prime loute consideration persomnelle, et j’adjure mes collègues des départements méridionaux de faire de nouvelles recherches sur l'organe nusical de la chelonio pudica, tant mile que femclle.

11. Comparcaison de l'organe musical de la chelonia pudica avec celui des espices du genre Setina.

La stridulation spéciale des Setina a élé signalée pour la première fois, à ma connaissance, par llaldeman. Il s'agit d'une espece de lithoside americaine qui doit certainement être rapportée au genre précils. L'auteur donne une brève mention du bruit et du nouvel organe du son (1), mais il ne décrit point eet organe. Il ajoute que l'A cherontia Atropos peut produire le bruit qui lui est propre par un mécanisme analogue, ce qui est une erreur.

M. Gitené, dans la monographie des Lithosia publice dans nos Amutes de 1861 (2), a fait connaitre un caractère différenticl excellent du goure Sctinu, caractère établi sur un organe particulier. cet organe consiste en deux larges vésieules tympaniformes situées dans la région pectorale de ces derniers insectes.

J'ai déjà dit que notre savant colliggue avait constate, pentant l'Exenision provinciale de la société dans la province de Zermatt, que les Sirtinu produisent des sons faciles it percevoil. lin pressant doncement l'insecte entre le pouce et l'index, suivant la manière dont on ie saisit dans le filet

(1) Ie dois à notre collègue M. Guérin-Mténetille la eommunication de la nole suivante :

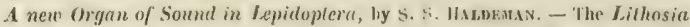
minula kingx (Fauna Bor. Im., p. 305), or an allied species, produces an andible strilulation by vibrating the pleura beneath the wings, this part being marked in recent specimens by parallel lines, apparenlly imdirating the position of the muscles. It is possible that the european .leherontia .Ltropos may produce ils preculiar sound in a similar manner (The ameriean Journal of Science ant Arts, ly Selsiman, 2 series, $n^{\circ} 15$, page 435 , mai 1848 ).

(2) Guenée, Eludes sur le genre tithosia (Anu. soc. ent. France, 1861, p. 11). 
de chasse, et en l'approchant de l'orcille, on entend une sorte de crépitation (1). Le mate senl parait apte at prodtuire ce bruit, daprès M. fitcuéc, au travail durquel je renvoie pour de plus amples détails. Je dois toutefois dire que M. Fallou, qui a très attentivement écoute de près les Srlinz ramosa volant en liberté sur les hauts sommets alpestres, n'a pu parvenir i leur entendre produire une crépitation. Ce bruit doit ètre tout à fait dépendant de la volonté de l'insecte. C'est un chant d'appel amoureux et probablement aussi un cri plaintif.

Aucune figure n’ayant encore eté donnée de l'organe musical des Sctina, je l'ai représenté sur la planche $40^{\circ}$. On voit la s. aurita ô de profil (figg. 5) et auprès d'elle la vésicule tympaniforme très grossie $(5, a)$. L'asplecl esl cclui d'un triangle irrégulier, it sommets très largement arrondis. Lit surface ne présente pas de rieles transversales ou de rugosités; la loupe n'y découvre aucune saillie ; elle est pirffailement lisse. A peine sur l'insecte dessiché voit-0n une dépression anguleuse ì sommet supérieur ct répondant exactement à l'empreinte des pattes postérieures, le genon repusant sur la dépression. Chez les femelles, cet organe est réduit extrêmement, au moins dans la plupart des espèces.

Dans aucune des Setina que j'ai examinées, je n’ai trouvé de poils squimeux ni d'écailles à la surface des vésicules tympaniformes; au plus ai-je. pu noter deux faibles rangées de poils jaunatres fort espacés. el seulement sur des insectes très frais.

L'interieur de cel organe est creux; une legère cloison le divise en deux parties, suivant la juste deseription de M. fiuence (tue, cil., p. 101); nulle part on ne trouve de point d'atlikche entre le fond el lat membine extérieure. Il n'existe pas de corps interne qui puisse agir à la manire d'un marleaul.

V'après mes observalions réitérées laites dans la collection te V. Fallon sur un grand nombre d'indivitus, voici le demré de developpement de l'organe musical clıez plusieurs espèces de Setina :

\section{Genre Śclina SCHRanck, Borsduval.}

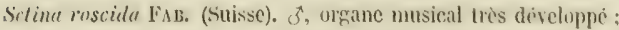

f, organe presque aussi développé que clıez le $\sigma^{x}$ (j'ai vu deux femelles de eclie espèce).

(1) Guxnie, Vules sur te genre betina (Amu. suc. ent. France, 186i, p. 39? et suiv.). 
s. irrora IIubN. (Paris). ơ, organe très développé, mais moins que clic\% le ơ de la S. aurita;

, organe très peu développé.

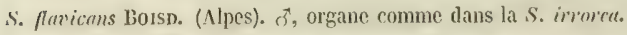

s. merila Esper (valleses du lihône el des Alpes). ô, organe extrèmemenl développé;

†, organe très peu développé.

S. ramosa Fad. (IIauls sommels des Alpes). ơ, organe tries développé, mais moins que dans la $S$. aurita; q, organe très peu développé.

S. Andreggii IlenR.-SCH. (Hauts sommets dles $\Lambda$ !pes). of et $q$, comme dlans l'espèce précédente.

'Toutes ees diverses espèces du genre sirlina m'ont offert l'organe musical lisse el non strié, on rajé en travers, comme dans la Chelonia mudica; cel organe est bien plus volumineux dans les Selina, par rapporl au corps de l'insecte. La surface lisse de la membrane extérieure el l'absence de lout marteau intericur, ponr me servir de l'expression de N. Guenée, me sont très précieuses a constater, car chez les Sitina, bien moins encore que chez la C. pudica, il n'est pas possible t'invoquer une place rugueuse sur latguelle frotterail $u$ archet. J'ai élabli que la chéloniu mudicu étitit un insecte timbalier frappant à l'aide de ses patles sur une peau lendue ol vibrante, et les sirtinu confirment entierement, ce me semble, ma manière de voir. I,eur appareil musical comparé à celui de la C. pudica fail rneore mieux comprendre la physiologie de ce ternier; leur étude se complète l'une par l'autre.

11. Guenée, dans ses études sur le grenre Lithosia, publiées dans nos Annales, indirque des vésieules recouverles d'écailles et siluées à la base de l'ahdomen che\% un grand nombre de Callimorphides (Amatrs de 1861, p. (11). Nolse savant collegue a bien voulu me donner de précieux détails sur ces vésicules abdominales; elles existent non seulement dans nos Callimorphu hro el dominula indigenes, mais aussi chez les Sitina ellesmèmes; elles sont tout à fait indépendantes de l'organe musieal qui fait le sujet de mon travail, puisqu'elles sp rencontrent au plus haut degré de développement chez des espèces dépourvues des timbales thomaiques, it elles ont probablement une destination toute spéciale.

Le lopidoptire qui les possède at maximum de développement est lit

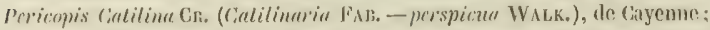
Inne ande Callimorphide du Brćsil, l'liphestris melorantha HuBs., jatune 
$\mathrm{rl}$ noire, at les veisicules abulominales fort déploppeses, quoigue moins sail-

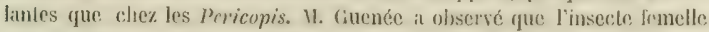
a des vésicules comme le inile; mais il est bien eturieux le roir ces organes, arrivés au plus haul point de diveloppement diez certaines Gallimorphides (Poricopis Calilina, Isse, Bicolora, Pyloris ; Composin Sybaris; Eucyane glauca, ele.), se supprimer chez une espece nouvelle très voisine de la $P$. Isse, el que M. Ciuenéc a nommée IIcticonir ditns sa collection.

L'anatomie et la physiologie des vésicules abdominales des Callimorplides sont encore à éludier. Esjẻrons que M. Guenée nous les fera connâ̂tre. On voit combien elles different de l'organe musical de la c'fertonin pudica.

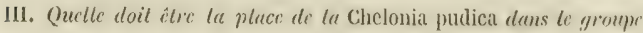
des Chelonides?

A mon avis, Jasé sur les considérations qui précèdent, la Chulunia pudicu represente un lype particulier dans te groupe des liyprepun d'Ochsenmemer, ou des Chélonides de M. Boispuval.

celle espèce est remarquable, non sculcment à l'élat parfail, mais cneore a l'élat de chenille. Le papillon, mâle el femelle, est pourun de l'organe curieux el spécial que jai chudié; la coupe des ailes le distingue des vraties Cihclonin. el dans toutes les collections il se sépare au premiet coup d'ocil des autres especes ol surtout des Arrtiu oil le plareut MrM. Staudinger el WVocke. I'ai la conviction gu'on trourera de bons rararlieres diflérentiels daus d'autres parties du corps de cel insecle qui fail le passage des Chilonides aux Lilhosides; c'est pour moi un lype de

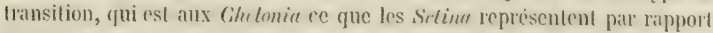
aux Lilhosir.

La chenille de la Chetonia madica s'éloigne buancoup des autres clie-

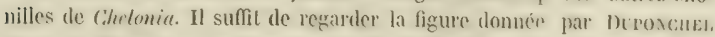

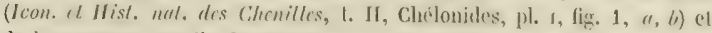

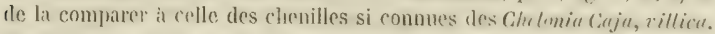

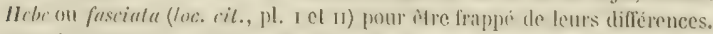
l'our la rhenille de la C. medica, des bouquets de poils courts ol raides; pour celle des chertomia caja, IIrbe, rillica, des fascienles de poils allongis et soyeux.

de conseille is l'auleur du Speries des Leipideptires, dont nous altentons

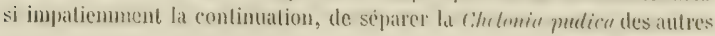


Chelmides, au mémo litre que les Sthinu des vrairs Lithosirs, quand il traitera ce groupe intéressant de Lépidoptères Hétérocères. Je propose de. former, avec la $(.$. pmulica, une coupe générique sous le nom de Trmpano-

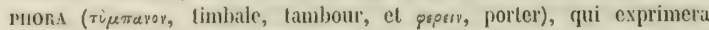
parfailement le caractere organique le plus saillant de col insecte remarquable.

\section{Expligation des figures 4 et 5 de la plancie $10^{\circ}$.}

lig. 4. Cikclonia mulica ơ, we de profil, pour montrer l'organe musical; les ailes gauches sont enlevées.

1, ". Organe musical, délaché, vu de face of très grossi, de cet insecte.

5. Sctiun anerila ơ, vue de profil; les ailes gauches ont été arritchices.

5, 1. Organe musical, vu de face el très grossi, de celle espiece de Selina. 


\title{
Recherches sur I'ANURIDA IMARITIMA,
}

\author{
INSECTE 'IIIYSANOURE DE LA FAMILLE DES l'ODUIIURS,
}

Par M. Ie Dr Alexayde LABOULBÈNE.

(Séance du 28 septembre 1864.)

I ans l'explication des planches annexée à l'Jconographic du Br'gm animal de Cauvier, on trouve la premiere mention de l'insecte qui fait le suję de ce travail. M. Guérin-.léneville, après avoir prarlé du sousgenre Achorutcs, formé aux dépens du vieux genre Podura, s'cxprime de la manière suivante : Nous avons trouvé au 'Tréport, en Normandie, près de l'embouchure d'une petile rivière, dans la partie couverte par les eaux de la mer it chaque marée, une innombrable quantite de petites P'odures de ce sous-genre Achorules, qui ne sautent pas el qui couraient la vase dès que la mer étail retirée. Comment ces petits animaux viventils quand il y a cinq ou six pieds d'eau de mer au-dessus des lieux où ils se tiennent? Peut-être retiennent-ils l'air nécessaire à leur respiration au moyen des poils qui couvrent leur corps. Cette petite espece est noire, et longue de press d'une ligne; nous la nommerons Achorutes marilimus (1).

M. Paul Gervais, en rédigeant la suile des insectes Aptères de M. le baron Walckenaer, décril ainsi l'Achorutes maritimus: Noir; long de près l'une ligne. P'uis il ajoute : c'est une espèce incomplétement commue. Celte espèce ne saute pas. Est-ce bien un Achorule? C'est ce que le peu qu'en a dit M. Guérin ne nous permet pas de décider (2).

Linfu, M. Nicolet, qui n'avait point connu cet insecte quand il publia ses belles Recherches pour servir at l'histoire naturclle des Podurclles, l'a

(1) Iconographie du Règne animal de G. Cuvier, texle explicalif, t. II!, p. 11, 1829-1844. (I.a figure $2 \mathrm{e}$ i laquelle le texte se rapporte porte la date de décembre 1836.)

(2) Histoire naturelle des Insectes Aptères, tome III, p. 139 (Suiles a Buffon, Roret, 1844). 
indigné plus land dans son Essai sur me olassification des inscetes Aplions de l'ordie des Thysunues. M. Nicoled le place dans le genre dnonere sous

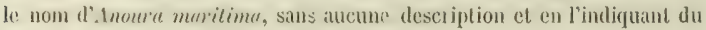
'Tréport (1).

Arant de remonler aux sources bibliorraphiques, je pensais que l'insecte maritime qui va moccuper était parfaitement comnu; je croyais que les caractères specifiques rn étaient tracés, el qu’il avait éte facile de le rapporter à un genre rigoureusement defini. Iles collegru's ont pu voir qu'il n'en ciait point ainsi, el la suite leur prouvera que tout ou presrpue tout restait encore à faire d̀ cet égard.

11 y a dijàt longtemps que je me suỉs altaché à l'átude des insectes sousmarins, en décrivant tout à tour l'Acpus (Trohus) llobinii (2); les Gamasus salinus, maritimus, hatophilus (3), et les moeurs et l'anatomie te lit Micralymme brevipene (1), sous les divers itats de Iarve, de nymplie et d'insecte parfait. L'étude de codernier insecte n’a pu ètre completée qu'apres divers stjour's faits au Iavre pendant trois annés consécutives. pendant que je recherchais la Micralymma, j'avais trouvé constamment l'Arhonutrs murilimus, signalé par M. Guérin; cet insecte ćlait derenu pour moi une commaissance personnelle très facile a rencontrè, je l'avais recueilli en griand nombre, je l'avais dessiné de profil et de lace, en dessus el en dessous, j'avais entrepris l'étude de ses viscères intérieurs, el j'avais chte surpris de l'extrime difficulté de cette étude.

Quand j'ai voulu revoir mes notes et mes dessins, j'ai éte effrayé des drsidcralu que je constatais. Les insectes conserves daus l'esprit-de-vin ure m'étaient que d'un secours médiocre, je demandais de nouveaux Achomtes vivants it tous les colleggues qui allaient an bord de la mer. N. sules Migneatx entendit mon appel ch, dans le mois d'aôt 1863, il m'envoya une petite provision d'insectes vivants, blotlis sous les debris de roches él entourés de plantes marines. Que ce cher collegue regoive ici mes remerciments pour son dévouement que j'ai bien souvent mis it l'épreuve, et qui jamais ne m'a fait défaut.

Il me restait encore certains points d'anatomie à élucider, ou plutôt quelques doutes it relaircir ; aussi pendaul l'automne de 1864, j'ai, avec mon ami le doctour 'Titon, exploré la còte du Calvados et daus un séjour

(1) Annules de la Sociéti entomologique de France, 1877, pase 388.

(2) Voyez nos Annales de 1849, p. 23-37, [1. 2, no 1.

(3) Annales de 1851, p. 295-299, pl. 9.

(4) Annales de 1858, p. 73-110, pl. 2 et 3. 
¿t Arromanches, localité déjì explorée par แII. Aube el Signoret (1), j’ai recueilli en quantité consitérable l'Achorutes marilimus, de lous les dges, vienx et jeunes, weul's el déponilles laissées pendant lat mue.

Soit au Havre, soit à Arromanches, cet insecte est excessivement commun. Il est très facile à tronver à la mare basse, dans les conditions suivantes :

$1^{\circ}$ En cherchant dans les fentes des rochers que la mer laisse à découvert, au pied des falaises, et en faisant iclater la pierre au moyen d'un ciscau a froid, ou d'une lame de fer, introduit dans les fissures, on voil les $\Lambda$ chorutes maritimes rassemblées en grand nombre. lilles sont les compagnes habituclles des Micralymma, mais elles sont bien plus répandues partout.

En même temps qu'on trouve les Achorules adultes ct d'un beau bleu ardoisé, on en voit aussi de très petiles, qu'on doit considérel comme les larves des premières, et dont le tégument est blanchàtre ou jaunâtre. On remarque encore les oufs, gros et jaunes, disposés en plaques, ou ('n petits monceaux, el enfin des trainées blanches ayant l'aspect d'un mycelium, et qui ne sont autre chose que les enveloppes cutanies, ou les dépouilles formées par la peau ratatinée et déposée à clıaque mue pa: ces insectes.

Les Achorutes mangent évidemment des petits Mollusques, si abondants sur les rochers submerós à la maréc haute, car lorsque j'écrasais un de cos Mollusques pendant mes chasses, je voyais, au bout de cinq ou six minutes, un bon nombre d'Achorutes qui se réunissaient sur cette proie, el, par ce moyen, je pouvais en prendre jusqu'i une douzaine at la fois.

$2^{n}$ Auprès des fissures ou des fentes des roches, on trouve ordinairement des Achorules, marchant Ientement, en appuyant altermativement leurs antemnes pour palper le sol sur lequel elles s'avancent. Toutes celles qui sortent de leurs retraites sont des individus ardoises ou d'un teinte foncée.

$3^{\circ}$ En fouillant et en cherchant dans les plantes marines dépostés sur le rivage ou le flot les a rejetées, on tronve encore des Ac/mrutes, mais en moindre quantite qu'au bord des fissures des roches, el strtout que dans les fissures ou fentes profondes el argileuses, leur gile habituel.

L'humidité est absolument nécessaire ì ces insectes pour l'entrelien de

(1) Annales de 1863, Butl., p. xxxy. 
la vie; placés dans un air sec, ils stuccombent rapidement. L'air cliarçí de vapeur d'eau et l'atmosphère saline, voila les conditions de leur existence. J'ai pu conserver, pendant plusieurs semaines, un grand nombre de ees animaux placés dans des tubes de verre avec des plantes marines; je les ai gardés ainsi à Paris pendant 22 jours au maximum. Ises Achorutes se rassemblaient en orand nombre contre le bonchon ou sur un point de la paroi des tubes de verre. Quand j'avais jeté ces insectes dans l'eau de mer ou l'eau douce, ils n'étaient nullement mouillés, ils surnageaient aussitot et marchaient assez vite à la surface du liquide. Loin de s'éviter les uns les autres, ils ne tardaient pas à se joindre, ì s'argolomérer et à former un petit rassemblement irès pressé.

La Poduride que j'ai observéc au Havre et sur les côtes du Galvados appartient-elle ì la mène espèce que celle découverte par M. Guérin-Méneville au 'Tréport? Je n'ai point exploré cette dernière localité; mais, pour éviter la création d'un nom spécifique nouveau, j’ai conservé la désignation si caractéristique de maritima à l'insecte que j'ai pris at Ilavre et qui est juentiqgue avec celui des côtes du Galvados.

\section{Description de t'andrida maritima.}

Plumbca, velutine carulescens, albido pilosa; stemmatibus quinqur, nigris; larsis albicantibus.

Longitudo bis tertiam linex partem usque ad tineam icquat, aul paulluto cxcrdit ( $13 / 4$ a 2 millimètres ơ; 2 a 2 1/4 et 2 1/2 millim. of).

llabitat in saxosis Occani littoribus, astu decedente cmbulans (IIavre, Calvados, etc.). - Vulgarissima.

Corps d'une teinte ardoisée, avec des reflets bleuatres et d'un aspect velouté (planche 11, fig. 1). Le dessous parfois d'une teinte plus claire, avec un fond un peu rougeatre ou jaunatre.

Trle triangulaire arec ume partie élevée, irrégulièrement polygonale, situce en avant et domnant allache aux antennes sur les côtes; un pli transversal en arrière, el sur lequel se rendent deux sillons perpendiculaires (fig. 2 et 4); Antcnues épaisses, courtes et enchâssées à leur base dans un repli du tégument; composées de quatre articles à peu près d'égale longueur, le premier le plus épais; le quatrième, pelit, arrondi à l'extrémité, mais n'ćlant pas très petit (fig. 5 et 10). Y cux formés de chaque 
còté par cinq stemmates ou cornées lisses, distantes et disposées suivant la figure 6 qui les reprisente pour le côlé droit. En avant des yeux un argane anti-oculaire ou pro-stemmatiqur, composit chez l'adulte de sept "spaces ovoüles, arrondis, très noirs, entourés clacun d'une fine ligne. claire, et laissant à leur centre commun unc partic claire; a leur sommet interne, après avoir enleve la teinte pismentaire noire, on remargue $m$ pelit cercle clair et arrondi (fig. 7 et 8).

Bouche fortement armée, constiluée par un labre arrondi, des mandilules, des màchoires, el une lère inféricure (iig. 12). Ouverture buccale. n'ofliant point de saillies particulières. Mondibules paraissant agir latéralement, mais profondément cachées dans la bouclie, ayant me loase en Jorme d'arneau allongé, et un sommet large et fortement denti (fig. 11).

Mêchoires pouvant sortir séparement de la cariti buccale, â mourements lirigés d'arrière en avant, formées d'une hase composin de trois articles. dont l'interne s'appuie sur la lère, dont l'externe s'arlicule avec une

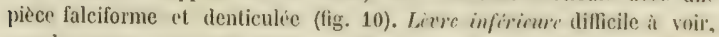
membraneuse, composec de deux lobes, entre lesquels on apercoit une languette en forme de $V$ irregulier (fig. 13). Menton charnu fermant la bouche en dessous, à la manière du labre, en dessus.

Thora.r constitue par trois segments; prothorax très étroit (fig. 2, is el 4); mélallorax lo plus grand des segnents thoraciques. Chaque segment porte en dessous une paire de pattrs; chacune de celles-ci, formé par cinq parties : une hanche courte, grosse, charmue, appliquée contru le corps; une cuisse ou fémur; une jambe ou tibia ; et un tarse d'un seul article, constitur par un crochet recourbé, pointu, lissı sur les hords (lig. 14 et 15 ).

Abdomen paraissant comprose de six segments tant en dessus qu'en dessons; le quatrieme demi-segment le plus grand en dessus et plus grand encore en dessous. En dissus, les segruents ofrient tous des plis lateraux, et d'antres transversaux en avant of en arriere de claaque segment (fig. 1, 2 et 1); on trouve aussi des poils bariahles de longueur et irréguliers, sur les còtes, en dessus et en dessous du corpe; cependant quatre séries, deux de chaque côté, de poils égaux el plus grands 'xistent sur le dessus des segrments. lin dessous, le premier segment prisente sur la ligne médiane une fonte longiludinde disposée en boutomière, et hordée par deux lères laterales, accolées ei fort épaisses (fig. 3 el /1). Le cinquiène: segment est profondément échancré en atrière. On ne trouve aucun restige d'appareil saltatoire, de fourche ou de repli articule, sur aucun segment (fig. 3).

L'OEuf est arrondi, tres gros par rapport au volume de linsecte adulte. $4^{\circ}$ Série, tone JV. 
a peu près régulierement arrondi, non ovoüde arec une extrémité phus petite. Couleur d'un bean jaune de soufre (fig. 19).

L'insecte très jeune est blanchatre, très petit; les jeunes sont jaunatres ou orangés; les dépouilles des mues d'un blanc mat et ratatinces ou plissées sur elles-mèmes.

La grandeur tes individus les plus potits est de trois quarts de millimetre au plus; les jeunes colorés en jaune ont de trois quarts de millimère à un millimetre entier; cenx qui ont la couleur ardoisés bleuatte, mais encore privés d'organes génitaux internes, atleignent un millimetre et demi. Les adultes, que je regarde comme des males, ont un millimetre trois quarts à deux millimetres; enfin les femelles alleignent do deux millimètres jusgu'à deux millimètres et demi.

Examinons présentement les caracteres speciaux que nous offre cet inscetr. dans les diverses parties du corps, comparons-les à ceux des espèces voisines; nous serons alors en mesure de les apprécier à leur valeur, et de placer celte Porturide dans le genre qui lui convient lo mienx.

Io corps, avons-nous dit, offre un aspect velonté et d'une teinte ardoisce à reflets bleus. Io tegument est par lui-même incolore, et la coloration est due à un pigment dépose dans l'intériem du corps sur la face interne de la peau. Ce pigment est granulenx, un peu moins aboudiunt en dessous qu'en dessus; c'rst a son alsence qu'est due la teinte blanchatre ou jaunatre des plis inter-segmentaires, et à sal quantité moindre que les tarses doivent leur coloration moins foncée.

Les trìs jeumes insectes riont pas de pigment, ot les visecres blanchutres sont aperçus librement à travers la peati ; les individus plus degés sont jammities ou d'un jame orange. Celte couleur provient de nombreuses goultelettes de matière grasse, ayant une belle teinte jaume ou orangée, goutlelettes répandues dans toul l'intérieur du corps, et formant le tissu adipeux splanchnique.

Le tegrument rost très finement grenu it la surface extérieure; la figure 8 represento cette disposition. Pour bien voir ce détail de structure, il est indispensable d'enlever le pigment interne. On y parvient en ecrasant l'insecte, et en pressant le corps pour classer les visceres, puis en lavant la clépouille a grante eau. Les dépouilles des mues sont très favorables pour éludier ces fines élévations arrondies ou ces granulations ulı légument.

On peut voir les ocelles ì la lumiere réfléchie el avec une forle loupe, mais on les leconnait bien mieux avec le microscope, après avoir viche la 
tête aplatie entre deux lames de verre, et on apprécie seulement alors lat disposition du singulier organe que fappelle pro-stemmalique ou antéoculaire. Cel organe est formé par des espaces colorés tels fue les représente la figure 7 ; leur couleur est très noire. Le nombre des cercles rapprochés varie de 7 à 8 , le plus ordinairement il y en a 7 , mais je dois noter que j’en ai trouvé parfois 8 d'un cólé el 7 de l'antre. Sur les jeunes individus, la disposilion est trés curiense, lit figure 9 en dome une idée; il existe alors 22 it $2 /$ espaces comprimés al serrís les uns contre les autres, avec III espace central libre; le tout rappelle la forme du fruil che\% les plantes malvacfes indigenes, entre antres les Malva et les Althar. Ouelque soin que j’ais: mis à chereher si du point central il naissail un poil allongé on toute atutre production dermique, je dois dire que je n'en ai point trouvé. On ne peut se dissimuler, loutefois, que cet organe antéoculaire ressemble beaucoup a ceux que M. Nicolel a décrils, et figures daus ses belles ficcherches sur les podurelles (1), et qui, placés sous la peau, servent de base aux gros poils qui se trourent sur l'A Inoun luturezlata (Achorutes tubcriatatus Nicor.s, olim). N. Nicolel ignore completement, dit-il, l'usage de ces organes; je me borne a faire remarquer qum je n'ai pas trouvé de poil qui en jartit; de plus, que le nombre des cercles est variable avec l'age; enfin, que l'organe que je fais comnaitre n'est point sous-cutanc. La comparaison des dessins de Ir. Nicolet aver les miens fera comprendre toutes ces differences.

Le résultat le plus facile a obtenir dans l'étule do l'A, marilimu est la mise cu évidence d'organes buccaux. Des mes premieres recherches, j'avais vu les insectes de differents tges imeltre par lorifice Junceal, lantôt une, lantôt deux pointes, qu’ils faisaient mouvoir avec ritpielité. be ces pointes aigues a la houche toul à fait inerme, ou forme seulement par une ouverture silué il l'extremiti d'une tromper conique, houche qui caracterise ce genre Inowra, it y arait bien loin (2). Mais si l'existenee de ces parties saillanles est tris facile a constater, il n'en est point ainsi du reste de lappareil inceal. Il fiut employer la dissection el surtout prendre des individus adultes et d'autres jeunes, leur feraser rapirlement la tele, vider celle-ci du pigment interme, faire agir un liquide alcalin, l'eau distillée chargén de soude ou de potasse; et alors, apres avoir sacrifié un grand nombre d'individus, on acfuiert li cerlitude que

(1) II. Niconet, Recherches pour servir il l'histoire nalurelle des Podurelles, 1. 24, pl. 2, fig. 14 et 15 (In Neuen Denkschriften der allgent. Sweizerischen Cipsellschaft für die gesammleu Naturwissenschaften, Neufchatel, Band 11, 1812. - I.

(2) Anuales de la Socicté entomolorique de France, 1847, p. 386. 
non seulement la bouche de l'A. moritima n'est pas inerme, mais qu'elle est très compliquée.

En définitive, on trouve des mandibules (fig. 11), des michoires que je regarde comme telles à cause de lcurs connexions (fig. 10), une lève pourvue d'une languelte (fig. 13). Cette dernière ne devient netlement visible qu'après avoir fait sortir au dehors les organes internes buccaux dans une préparation heureuse et après les avoir fait baigner dans une solulion alcaline, en faisant pénétrer le liqguide entre les deux lames de verre. Les especes voisines du genre Anoura ont-elles la bouche constituée de même? je l'ignore; des recherches ultérieures décideront; j'appelle l'attention sur les différences que j'observe entre la bouche des podurelles, représentée par $\mathrm{M}$. Nicolet (loc. cit., pl. 4, fig. 5, 8), et celle le mon insecte.

Le premier segment ablominal présente che\% tous les individus en dessous une ouverture longitudinale. En plaçant l'insecte de côté et en l'impreignant d'une solution alcaline de polasse, on voit les bords de la fente médiane se gonfler ct prendre une leinte rosée. On s'assure ainsi qu'il y a en cet endroit un pertuis a deux lèvres. Je n'en ai point vu sortir d'organe allongé pareil à celui des Smynthurus, ni même le cylindre blanchatre signalé par M. Waga chez l'Achomutes bictanensis (1). Notre insecte est dépourvu par conséquent du tube gastrique (Bourlel) décrit par M. Nicolet, el dont les fonctions sont encore fort obscures.

Le dessous du troisième segment est priwé de tout vestige d'appareil saltatoire. Il n'y a plus rien qui rappelle les organes si remarquables ¿les Orchesella, Degeria, et ceux des Podura, des véritables Achorutes, ni enfin ceux à létat vertigiaire des Anurophorus (2).

Les poils qui revêtent le corps de notre insecte sont blanchatres el peu allongés. Les uns, plus courts, sont placés sans ordre; mais deux séries de poils plus grands sont disposeies sur les segments thoraciques et abdominaux (fig. 2). Il y aurail it la fois che'z l'A. marilima la disposition des poils épars, réunie à celle des poils sirlaux, si bien figurées toutes deux

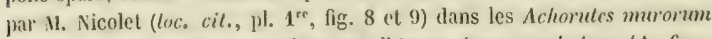
(Podure similata Nicotex, olim), et l'Anurophorus ambulans (A. fincIurius NicoLet, olim). (Voyez pour la synonymie nos Annales de $\mathbf{1 8 4 7}$, p. 377 et 384.$)$

Il m’a été impossible de distinguer sûrement, et a l'aide de caractires

(1) Waga, Description d'un Insecte aptere qui se trouve en quantité aut environs de Varsovie (Ann. Soc. ent. France, 1847, p. 267).

(2) Niculet, loc. cil., pl. 3, fig. 10-18, 1841. 
extérieurs précis, les màles des lemelles. J'ai compris el longtenps parlagé les hésitations que M. Nicolet à exprimérs à ce sujet (loc. cil., p. 42 et 44). Je me contente de dire ici que les individus les moins grands sont presque toujours des males, mais on ne peut avoir de certitude qu'en ouvrant leur abdomen.

Avant d'aborder la constitution anatomique de notre insectc, nous devons maintenant à l'aide des cutracteres fournis par l'extérieur dı corps décider à quel gene il appartient. La tâche n'est point exempte de difficultés.

En prenant your guide le dernier travail de M. Vicolet sur la classification des Thysanures (Annales de 1847, p. 383), nous devons nécessairement nous restreindre an groupe des Lipurefles. La vraie Podurn aquatica et les vrais Achorutes de 'Templeton auxquels it ressemble ont un appareil saltatoire très reconnaissable et du reste santent fort bien.

Les Lipurelles comprennent les deux gentes Amurophorus et Anoura. Les premiers ont un organe saltatoire rudimentaire et impropre au saut, leur bouche est armée, l'organe rétractile du ventre existe, mais il est court. Tous ces caracteres, a part la complication buccale, manquent chez notre insecte. Je ne m'arrête ni au nombre des ocelles, ni à la forme des antennes qui sont variables d'espèce ì espèce, el par conséquent u’ont pas de valeur générique. Les Anoura indiquées seulement par M. (iervais (1), mais caractérisées par M. Nicolet, auraient quatre ocelles de claque cóté de la téte et la bouche inerme. Notre insecte a cing stemnates et surtout la bouche fortement armere. re plus, les Anoures sont solitaires, les femelles pondent des ouls isoles sur plusicurs points differents, et ne les réunissent jamais comme les Achorutrs. Or notre poduride est eminemment sociale et pond ses aufs en les reumissant en grand nombre.

On voit done que nous sommes obligés de faire une coupe générique pour notre insecte qui ne peut rentrer dans aucun des groupes élablis. Je propose de former pour lui le genre Imuridu, qui rappelle sa ressenblance avec les Anowra.

1) Innales de la sociétc entomologique de France, 18\{2, bull, p. xwr1, o Iistoire naturelle des Insectes Apteres, 1. III, 1. 142, 184. 
(iente ANURIDI.

(Anoura de $x$ privalif, ovpe, queue, appareil du satut, el udos, forme, aspect.)

Corpss allongi, un peu dilaté on arriere, pru velu et non poureu de y.os momelons. Antennes de qualre arlictes it peu pris igan $x$, plus courtes que la têle. Stemmales visibles, au nombre de cinq. Bouche pourvue de mandibules ol de mâihoires. P'as d'organe vilraclile abdominal. Pas d'organe sallatoire ni de raimure ventrate. Paltes courles, tormintes par an seul ongle.

Tels sont Jes caractères du geme qui me parait devoir être ctabli pour l'espece remarquable qui la premièe vient y prendre place, el dont l'anaIomie viscerale vit nous offrir des particularilés aussi curieuses qu'inatlendues.

\section{I. Arulomic de l'ANURIDA MARITIMA.}

Il est trìs diflicile d'étudier les viscères internes ou la splanclmologie de l'Anurila; la peau, revêtue de pigment à l'intérieur, ne permet pas de recomnailtre les apparcils renfermés dans les cavités dı corps; les très jeunes individus seuls, dépouryus de pigment, laissent apercevoir patr transparence l'aspect du tube digestif; mais comme ils n'ont point encore l'organes génitaux déxeloppés, ees derniers organes ue peuvent etre appréciés que sur les adultes et seulement quand les tiguments ont ite divisés, excisés on déchirés.

Apress avoir fixe la lìle de l'Amuride at moyen d'une fine épingre piquée sur une platque de liégr, et avoir de même immobilisé le train poslírieur du corps, il convient de pratiquer une section latérale des téguments soil avec de fins ciseaux, ou avec une lancette bien coupante, ou une aiguille à cataracte. J'ai pu aussi, en tenant l'insecte avec les doigls, enlever d'un coup tle ciscaux un lambeau tantót dorsal, tantôt ventral. D'autres fois, il convient mieux d'aracher la tete pour avoir le tube digestif qui reste atlache dans une asse\% grande étendue. Au contraire, on arrachant l'extrémité abelominalc, on amene les organes génilaux. Mais je dois noler que c'est à travers des tliflicultés persistantes qu’on 
parvient à saisir la configuration des organes internes; l'insecte par la mollesse des parties du corps, la facilité aver laquelle il se rélracte el change de forme, soumet la patience de l'investigatem it de rudes ejreuves. linfin l'immersion des organes dans de l'eau pure ou dans d'autres liquides est indispensable pour aider à l'examen microscopique.

Je vais exposer successivement le résultat de mes recherches sur les appareils de la digestion, de la reproduction, de la respiration, et enfin sur le système nerveux de l'Anurida maritima.

1. Apparcil digestif. J'ai dejàt insisté longnement sur la forme des organes buccanx. I la cavilé buccale succèle un asophage grẻle, dilaté postérieurement en uв jubot (firg. 16). Le ventricule chylifurue est tres longr, la surface en est lisse, non mamelonne. L'intestin grite est très court; puis on trouve le gros intestin dont la partie supérieure, on cocum, est dilatéc, et l'inferieure ou rectum très conte (fig. 16). Je n'ai point vu de vaisscau de Matpighi; à mon avis, ils mancjuent totalement, je n'en ai apergu aucun vestige dans les lit's nombreux insecles que j'ai ouverts, ni sur les jeunes individus que j’ai examinés pir transparence.

11. Waga (1) avait indiqué la maniere dont l'Achorulcs biclancnsis fail sorlir de temps en temps, et avec une grande vilesse, les parties interieures de la bouche. Je me suis assuré que ce sont les michoires qui ont ce mouvement d'avant en arrière. J'ai represente les pieces que je regarde comme mandibulaires (fig. 11 et 12) tolles que les préparations les montrent. 'tontelois, je crois que leur position est dérangée, elles sont renverscies très probablement dans cet élal. Je m'explique difficilement le jeu de ces olyanes, mais leur exislence est incontestable, et ils s'éloignent des mandibules courtes et très fortement denties, représentées par M. Nicolel sur une Podurelle qu'il ne fait pas connattre (2).

On comprend que l'Amerida recherche les pelits animaux écrasés, les Mollusques morts; la conformation de sa bouche lui permet de se nourip de ces animaux, el rend comple de ses iustinets carnassiers. I) nouvelles investigations, fue jappelle de lous mes veux, nous apprendront si les vaies Amoura ont une houche inerme, el consistant seulement en un siphon aspirateur on si, comme notre insecte, elles sont pourves d'organes compliqués, mais cachés dans la prolondeur d'une cavilé burcale.

Le. lube digestif presque droit, peu contoume, dépassant à peine lit

(1) WAGs, loc. eit. (Ann. Soc. ent. France, 1812, p. 266).

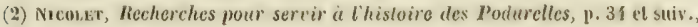
pl. 4, tig, 6,7 et 8 . 
longucur du corps, indique un insecte carnassier. L'absence des vaissinux: at Malpighi montre une dégradation organique remarquable. On trouve peu d'exemples de celle absence dans la série entonologique; les Itémiplères des genres Coccus, Chrrmes et les Aphidirns ont seuls élé trouvés dius le même cas par U. Léon Intour; M. de siebold a constaté le manque de ces vaissa aux chez les Strésiptères (1); M. Nicolet a représenté six vaisseaux de Nalpighi chez l'Achorutes murorum, qui est sa l'odure similut olim (2). Je ne puis m'expliquer, chez des insectes aussi voisins que l'Ach. murorum el l'Amurida maritima, la présence de's vaisseaux che\% l'un et leur absence chez l'autre; je me borne a la constater.

2. Apparcil de la génération. S’il m’a été impossible de distinguer extirieurement les màles des femelles des Amurida, je n'ai pu, par la dissection, que difficilement reconnattre la forme des organes génitaux internes. J'ai examiné ces insectes à la fin de l'été ou pendant l'automne : aurais-je eu plus de faciliti au printemps? Je signale celte lacune du temis d'observalion, en rappelant que M. Nicolet n'a jamais pu parvenir à se rendre comple des organes génitaux des porlurclles.

A. Les insectes les plus grands, ayant l'abdomen forl développé el qui après l'incision des téguments offrent des wufs dans la cavité abdominale, sont de toule évidence des femelles. Les oufs se détachent avec une extrème facilité. Jamais ils ne sont très nombreux, 3,4 ou 5 au plus de chatque côté. Je suis parvenu it voir que chaque ocuĺ est placé dans une Irès fine membrane d'enveloppe (lig. 18). Il y a done lat whe grame ovigire à 3 , h ou 5 loges au plus el terminée par un filament suspenseur reuni a celui du côté opposé. Plusieurs fois j’ai trouvé, an lieu de l'aspect moniliforme des gaines dû aux wufs superposés, une gaine à loges sessiles el vi le jaune de l'œuf, ou vitellus, oceupait une place centrale dans claque loge (voye\% la gaine ovigère gauche sur la figure 18).

l.es deux galnes ovigeres couvergent vers le bas et se reunissent pour former un oviducte: il má été impossible de trouver sur celui-ci la moindre trace de poche copulatrice ou de glandes annexées à ce conduit.

L'orifice vulvaire s'ouvre après le $6^{\circ}$ segment; il y a entre l'orifice générateur el l'ouverture anale une petite pièce segmentaire ou urite. l'oint de trace apercevable d'armure génitale. Nofre Poduride est bien loin de présenter la complication de l'armure génitale des Thysanoures placées en lùte de l'ordre, armure décrite et figuréc avec soin par

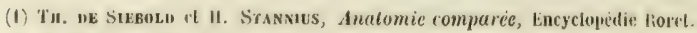
L. Ier, 2e prartic, p. 605 , note $2,1850$.

(2) Nicouet, loc. cit., pl. 4, fig. 2. 
II. Jatcaze-i)uthicrs, dans les Annales des sciences nalurelles (Zoologic, 30 série, L. XIX, p. 37, planche 2, fig. 13 et 14, 1853).

L'auf de I'Anurala marilima est gros, d'un beau jaune, lant dans les ovaires que lorsqu'il a élé pondu. $\Lambda$ ussi cette couleur jaune, jointe à celle du lissu adipeux splanchnique (fig. 20), plus particulièrement jaune chę les femelles, fait-elle penser que les insectes dont les plis intersegmentaires présentent celte coloration sont des femelles.

En écrasant les aufs, on les trouve remplis de globules vitellins le nature graisseuse; ceux qui sont les plus avancés depuis la ponte renferment de jeunes Amrida dont les parties principales du corps sont reconnaissables ainsi que les pattes. Ces embryons, après être sortis de l'œuf ouvert, exécutent quelques mouvements très lents.

B. I.es insectes les plus petits, virement colorés d'une belle teinte ardoisée bleuâtıe, sont presque toujours des màles. A l'ouverture du corps on voit deux cocuns blanchitres, de volume variable remplissant la cavité ablominale. Ces deux coecums convergent vers l'exirémité du corps; je les regarde comme les testicules (fig. 17).

Ia réunion des deux testicules, dont la surface est un peu aréolaire ol comme marbrée, constilue immédiatement un canal déférent sans aucune vesicule séminale annexée; je n’ai pu voir ni verge, ni aucun organe copulateur. L'ouverture sexuelle male est placée cxactement comme l'ouverlure génitale de la femelle que jai décrite. Enfin, je me suis assuré que les organes de la génération, tant màles que femelles, nont aucune connexion avec l'ouverture siluée sous le premier segment abdominal et dont j'ai parlé en décrivant l'insecle (royez pages 709 et 712).

Dans les testicules, je crois avoir vu, mais a deux reprises seulement, des spermatozoüdes; j'ai regret de ne pas les avoir dessinés. J'ignore comment a lieu l'accouplement de l'Anurida maritima.

3. Appurcil respiratoire. Jusqu’ì présent j’ai pu, quoiqu’avec difficulte, reconnatre el decrire les divers organes internes des deux grands apparcils qui précèdent; mais jarrive à une conclusion inaltendue el extraordinaire au sujel de l'appareil respiratoire.

L'Anurida maritima ne présente aucune rachée, ni mecune ouecrlure stigmatique.

Je supplie mes collègues de ne pas penser que j'agis à la légère en leur affirmant un fail aussi insolite. J'ai examine un bien grand nombre d'insecles de loutes les lailles; je suis toujours arrivé au mème résullat négalil. J'ai envoyé à mon sayant matie ol ami, le professeur charles liobin, 
des Anurida vivantes, en le priant de me dire comment élaient faites el disposées les trachées, et cet anatomiste hors ligne, après un cxamen prolongé, m'écrivait en 1863: "Je n'ai pas vu de trachies, je n'en trouve pas de traces; vous pouvez affirmer qu'elles n'existent point chez cel itrsecte. "J'ai prié mon collègue le docteur Grenier, fort incrédule au sujet de l'absence des trachées et surtout des stigmates che\% l'Amurida, de regarder de près l'insecte vivant et puis de l'examiner intus el cxlra. Il s'est retiré, après une longue stéance d'élude, convaincu qu'on ne pouvail les reconnaître.

Ainsi, pendant plusieurs amnées j'ai vainement cherclıé un tube tratchéen dans te corps de l'Amurida, et cela sur plusieurs centaines de ces insectes. La difficulté de l'observation est grande sans doute, mais elle n'empecherait pas de meltre les trachées en évidence. M. Nicolet est parvenu a les voir dans l'Achorutes murorum (Podura simitata, olim) (1).

J'adjure les anatomistes qui observent au bord de la mer de rechercher les organes respiratoires de l'Amrida marilima, sans oublier les vaisseaux de Malpighi.

1. Appareit de l'innoreation. Il ne m'a point été difficile de reconnaitre les gauglions nerveux qui comprosent avec le cerveau l'appitreil de l'innervation de notre insecte. hes ganglions sont at nombre de trois, deux thoraciques, l'autre abdominal, et ce dernier, fort gros, est en rapport avec les fonctions de la reproduction (2).

II me reste, avant de terminer ces recherches sur le curicux insecte que j’ai étudié avec insistance, ì parler de l'aclion que divers liquides exercent sur ses téguments; le plus souvent cette aclion est négative : l'.luwida marilima est certainement l'insecte le plus difficile à mouiller qque j’aie vu jusqu'à présent.

Licau douce ou salée n'adhère en aucum point du corps; l'insecte qu'on cherche at y plonger est entouré d'une grosse butle d'air, el cela aussi bien sur les pattes our sur les antennes que sur le dos on le ventre. lait glycrine ne monille pas ou mouille tres peu l'Anevide; la frrbenthine est dlans le mime cas, ainsi qque les vornis à l'essence. L'acide aciliquer agit peu at peu; l'atcoot très rectilié mouille assez bien le corps; la solulion atcaline de polasse ou de soude n'arlhère pas de suite, mais l'action

(1) Nirolet, loc, cit., p. $47, \mathrm{pl} .3$, lig. 3 et $\mathbf{1}$.

(2) Au moment de la correction des éprenves, j'ai comaissance par le dernier Bericht über die Entomologio, publié pate V. Gerstaecher, de deux travaux analomiçues sur les Poderide, l'un de M. J. Lubburh, I'autre de M. L. von ollers. de regretle de n'avoir pu en profiter pendant la rédaction de ce travail. $-\Lambda$. I. 
ne larde pas à se manifester. L'óther est de lous les liquides celui qui mouilie le mieux le corps de l'insecte. Je ne fais que mentionner la teinture d'iode qui m'a été utile pour reconnaitre les parties très pàles de lit bouche, mais qui agit trop fortement sur les autres endroits du corps, après un contact assez prolongé.

Il me parait résulter de l'étude qui précède que l'Anuridı maritima est un insecte des plus curieux par son organisation; e'est le représentant le moins compligué dans ses organes de la famille des Thysanoures. A côté d'une armure buccale imapercue, il manque de vaisseaux de Malpighi; ses trachres et ses stigmates sont invisibles; il est doué d'un tégument impernéable à lit plupart des liquides qui s'altachent si rapidement aut corps des autres insectes. J'ai expliqué jadis (Amales de 18.19, p. 28) le mode de respiration des insectes sous-marins, ct .I. Coquerel a vérific l'exactilude de mes prévisions; mais en présenee de l'Anurida sans trachées el sans stigmates, je suis très embarmassé el réduit à admeltre là respiration par la peau, ou par l'enveloppe cutanéc. Il y aurait enrore bien des suppositions à faire et toute une thérie à clablir sur le curieus animat dont j’ai essiye de faire connailre l'organisme; mais je crois devoir m'arrèter ici, car j'aumis peur de me faire dire : assez d'hypotheses; contentez-vous de nous exposer ce que vous avez observé.

LXPLICATION Des Figures DE LA P'LANCIIE 11.

Fig. A. Amovilu marilima fort grossie, et, à côte d'elle, mesure de sa longueur naturelle.

2. Le meme insecte, encore plus grossi el ru en dessus.

3. Le même, vu en dessous.

1. Le mème, vu de profil.

5. Anteme tres grossie, ainsi que loules les figures suivanles.

6. Ocelles du cold droil; on voil toul a fait en avant lorgane prostemmatique.

7. Organe prostenmatique ou antioculaire dessiné sur l'insecte adulte, ayant le pigment sous-culané.

8. Le mime organe après l'enlevenent du pignent ; on troure en dessous, à droite, la cornée d'un stemmate. 
Fig. 9. Organe prostemmatique d'une Anurida maritima très jeune.

10. Tète de l'insecte adulte, pour montrer la disposition des deux mâchoires et la manière dont elles peuvent se mouvoir isolément, d'arrière en avant.

11. Mandibule détachée et isolée.

12. Ensemble de l'appareil buccal extrêmement grossi ; on aperçoit en dehors les matchoires, puis les deux mandibules, et au milieu la lèvre inféricure.

13. Lère avec sa languetle ayant la forme d'un $V$ irrégulier:

14. Une des pattes de l'Anurida maritima.

15. Extrémité terminale de la jambe, et crochel unique représenlant le tarse, extrèmement grossis.

16. Appareil digestif de l'Amurida maritimu. OEsophage court, dilaté en un jabot a la parlie postérieure. Ventricule chylifique lisse, suivi d'un intestin grêle très court, puis d'un cocum assez volumineux, enfin du rectum.

17. Apparcil générateur ơ du même insecte, vu en dessus. Il consiste en deux gros coecums blanchâtres.

18. Appareil générateur $q$, représenté en dessous. On voil dans l'ume des gaimes ovigères quatre oufs de volume dilférent et arrondis, enseloppés d'une fine membrane terminée clie-nème par un filament suspenseur. L'autre gaine renferme des loges sessiles et des vitellus espacés.

19. OEuf de l'Anurida maritima.

20. Granulations composant le corps graisseux splanchnicue, vues a un fort grossissement. 


\title{
NOTE
}

sug $\operatorname{te}$

\section{HELMINTHE PARASIIE DÜ GENRE MERMIS}

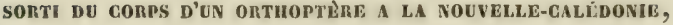

\author{
Par M. le $D^{r}$ Alexixdne LABOULBENE.
}

(Séance du 22 Janvier 1862.)

Notre savant archiviste et ubligeant collegue, M. Doủé, m'ayant remis le Ver parasite signalé à la Société par le li. père Montrouzier (vop. Annates de 1862, Bull., Iv el v), j’aj examiné cet IIelwintlıe après l'avoir fait préalablenent tremper dans de l'eau pure pendant plusieurs jours.

Ce parasite est long d'au moins vingt-trois centimetres; sa grosseur est d'environ trois quarts de millimetre, dans le milieu du corps. L'une des extrémités est prolongée en ligne droite, épaisse de un demni-millimètre et taillee en biseau sur un angle de 30 degrés; je suis porté à croire que cette disposition est accidentelle. Lautre extremite est arrondie, contournée et épaisse d'un tiers de millimète seulement.

La couleur est noirattre, ou d'un brun noirâtre et rongeatre par places. Ge Ver était replié plusienrs fois et relent par des épingles; les endroits oì le corps était contourné ne sont pas revenus it la dimension du reste du corps, ils sont restés repliés el aplatis, malgré une macération assez prolongée.

1.e père Montrouzier nous apprend que cet Helminlhe, qui parait appartenir au genre Mormis ou au genre Gortius, a été tronvé dans une Mantis, remarquable par sa forme raccourcie et deux taches dun violet sombre au coté interne dles hanches antérieures. Le fer parasite est si commun dans les Orthopleres précités rue les incligènes de Víle des Pins disent, arec la meilleure foi du monde, que ce sont les Mantes qui produisent les anguilles dont aboudent les lacs situés sur les montagnes.

Il résulte pour nous de ces données que le parasite dont il s’agit est très abondant a lit Nouvelte-Caledonie, el que son parasilisme est analogue ì celui des especes europécnnes, dont il diflere toutefois au premier abord. Je pense que l'individu que j'ai examiné est une femelle, et M. Inavaine, si compétent eu pareille matière, partage mon opinion (rojez nos Amnales de 1862, p. 576 et suiv.).

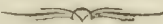


M. Ginarn. - Sur la chaleur de la Galleria revella.

8 octoble.

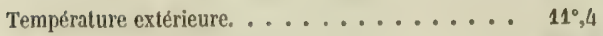

Id. intérieure............... $35^{\circ}, 6$

Différence, $24^{\circ}, 2$.

9 oclobre.

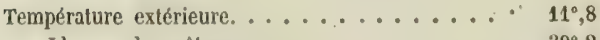

Id. des gateaux. ............. $39^{\circ}, 2$

Différence, $27^{\circ}, 4^{\text {. }}$.

11 octobre.

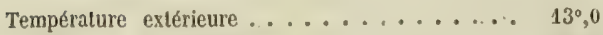

Id. des galeaux. ............... $36^{\circ}, 9$

Différence, $23^{\circ}, 9$

12 octobre.

Température extérieure. ............... $14^{\circ}, 0$

Id. des gâteaux ............ $38^{\circ}, 4$

Différence, $24^{\circ}, 4$.

Jes larves sont nourries avec d'abondantes doses de circ fragmentée Il me parait probable que le frottement actif el réitéré de ces petits animax contribue pour une certaine part à ces excès si considérables de température et très sensibles à la main. La nature chimique de la cire, substance sans azote, la parfaile vitalité des larves, l'alsence de toute odeur anmoniacale, font voir que des phénomènes de fermentalion putride ne peuvent pas être invoqués ici. Si, d'autre prart, on considère la grande combustibilité de l'aliment, on est frappé de la preuve manifeste que celleobservalion apporte a la théorie de Lavoisier, que la chaleur animale résulte seulement de la combustion respiratoire, disséminée dans tous les tissus, théoric, au reste, généralement admise aujourd'hui, et pouvant rendre compte de tous les faits de chaleur animale. C'est l'opinion soutenue par un des membres les plus éminents de notre Société, M. Milne-Edwards (Leçons de physiol. et d'anal., t. VIII, 1863, p. 84 et 90). 


\title{
SUR UN IABITAT REMARQUABLE
}

DE I.A

\section{Chenille de l'EPHESTIA ELUTELLA,}

\author{
Par M. le docteur Alexindre LABOULBÉnE.
}

(Séance du 14 Décembre 1864.)

La manière de vivre de l'Ephestia elutclla sous sa premiere forme de chenille a été signalée par plusieurs entomologistes. Bruand d'Uzelle, dont la science déplore la perte, avait noté, dans sa Monographie des Lépidopteres nuisibles (1), que la chenille de la Phycide effacie est polyphage et vit dans une foule de provisions de bouche, comme aussi de fruits verts et même de substances animales. Il l'avait trouvée tour à tour dans du chocolat, du pain d'épice, des rayons de miel, des amandes sèches, des raisins de caisse, des noix verles, et mème dans une boîte de Lépidoplères, où elle se nourrissait du corps d'une Ilcpialus humuli morte et conservée en collection depuis dix ans. Cette chenille, dit-il encore, attaque le cuir et les matières grasses, à défaut d'autre aliment.

M. le colonel Goureau a vu éclore l'Ephestia clutclla de chenilles qui mangeaient les dattes conservées (Annates de 1859, Bull., p. vii). Enfin, M. Stainton a constaté que cette mème chenille se nourrit de fruits desséchés, de café, de figues, de raisins, de noisettes, de baies de lierre, etc.

Je puis ajouter un nouvel habitat à cette lisle déjà étendue. Un de nos collègues, M. Léveillé, m’a remis un petit Lépidoptère dont la chenille rongeait l'écorce siche de racine de Gronadicr, conservée dans les officines comme anthelmintique. Ce Lépidoptère n'est autre que l'Ephlıstia clutella. Cette espèce est du reste commune en France, malgré l'assertion de Duponchel, que Bruand avait rectifiée (2).

(1) Monographie des Lipidoptires nuisibles, 6r livaison, p. 56 et $57, \mathrm{pl}, 6$, fig. 3 , ave.

(2) Ephestia (Tine.1) elutella HuвnEn; Phycis clutella Dupoxcre, His1. nat. des Lépid. de france, $t, X$, p. 20\%, pl. 279, fig. 8, 1836. - Bruand, loc. cit., p. 58,1855 .

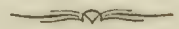




\title{
Notice nécrologique sur GABRARL DR BARAN,
}

\author{
Par M. E. ALLARL.
}

(Séance du 28 Décembre 1864.)

Messieurs,

Vous avez bien voulı me charger de rédiger une courte notice pour fixer dans les Annules de la Sociélé cotomologique de France la mémoire de notre collègue de Baran, décédé il y a quelques mois. Je vous remercie de celte mission qui, si elle est triste a remplir en rappelant la perte douloureuse d'un des meilleurs d'entre nous, me donne au moins la donce satisfaction de signaler au public entomologique une pure et noble existence que la pratique de nos chères études a largement contribué à rendre digne de nos souvenirs.

Gabriel de Baran est né à Paris, le 5 aoút 1830. Je sais pen de chose de sa jeunesse. D'une grande modestie, il parlait très rarement de luimème; mais pour qui l'a vu aux prises, dans son petit appartement de la rue de Vaugirard, arec les problemes que soulevait frécfuemment son esprit sérieux, il est facile d'élablir qu'il avait fait de lsonnes ćtudes.

Membre des Sociétés de Botanique, d'Horticulture, d'Acclimatation, indépendamment de la nôtre, ses goûts le prortaient vers les sciences naturelles, et il avait une aptitude particulière pour améliorer les procédés qu'elles meltent en cuvre. Aussi a-t-il créé plusieurs appareils ingénieux, soit pour la chimie, soil pour la plıysique, soit meme à l'usage des entomologistes, et on cite de lui un nouveau modèle de machine pneumatique qu'il a imaginé et fait exécuter alors qu'il n'avait que dix-sept ans.

Mais ce n'est pas tout, sa riche organisation lui pernetlait d'autres jotrissances : il se délassait des travaux sérieux par la culture des deux arts qui, peut-être, parlent le plus à l'imagination, la peinture el la musique. Quelques heures avant de se mettre au lit, étant déjł soufrant, il improvisait à son piano une de ces mélodies touchantes comme les mou- 


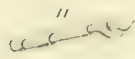

1.3
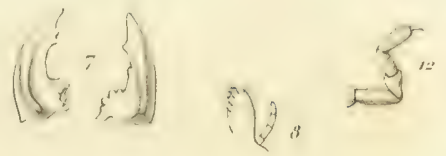

(1.3)<smiles>c1ccccc1</smiles>
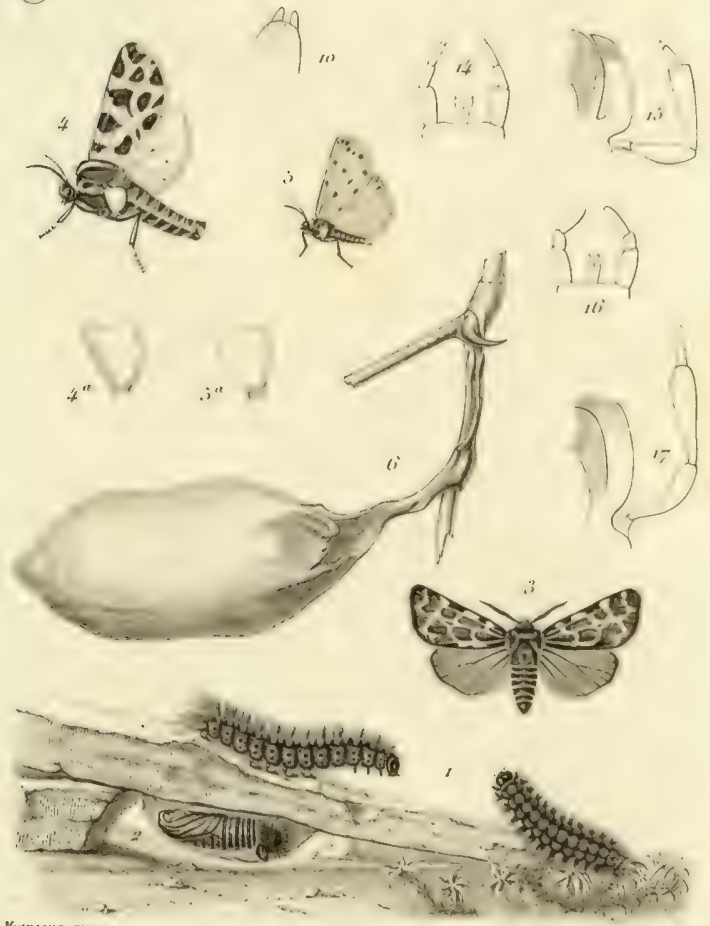

1. Hesmontare mur

1-3) Nemeophila C'revine.

7-4" Chelonsir putiont. 8".

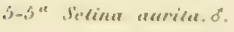

(i. Soturnet Banhiniar, Surr. 7-1.3. Sirvive holessericed.

44-15. Dinuser hicromblymilama.

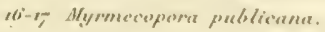




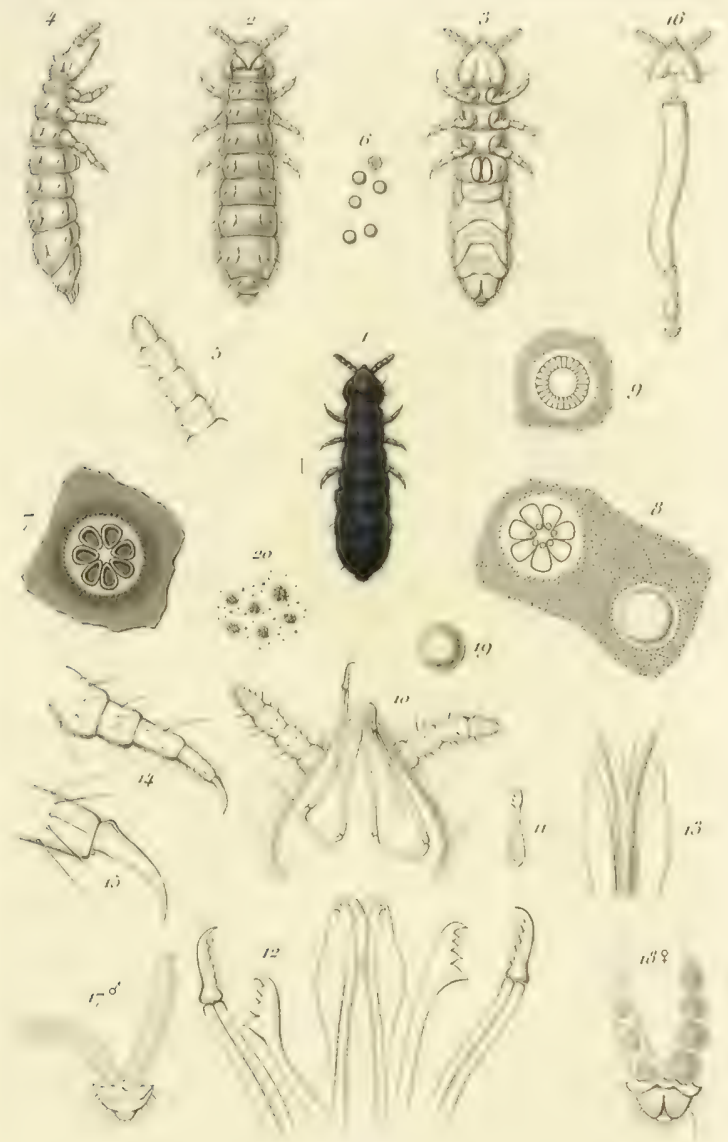



\title{
FUNÉRAILLES DE M. DUMÉRIL.
}

\section{DISCOURS prononcé par M. HILLNE EDWARDS}

\author{
Au nom de l'Académie des sciences.
}

\section{Messieurs,}

La mort vient d'enlever, au milieu de nous, un des derniers représentants d'une époque gloricuse pour les sciences, celle oú la France, rajeunie et reprenant possession du riche héritage que lui avaient légué les siècles passés, s'appliqua de nouveau aux travaux de l'intelligence et donna de dignes successeurs à Descartes, à Pascal, à Réaumur, à Lavoisier et à Buffon. Ce temps est déjà loin de nous; mais, hier encore, l'Académie voyait dans son sein un des contemporains de cette phalange nouvelle d'hommes de génic, un médecin qui avait été l'émule de Bichal, l'illustre fondateur de l'anatomie générale, un naturaliste qui fut l'ami et le collaborateur du grand Cuvier, lorsque celui-ci, au début de sa carrière, posait les premières bases de la zoologie moderne et prenait rang dans la science à côté de Geolíroy Saint-IIilaire, d'Haüy, de Laurent de Jussieu, de Berthollet, de Monge, de Lagrange et de Laplace.

En eflet, M. Duméril, né à Amiens le 1er janvier 1774, et déjà prévôt d'anatomie à l'école de Rouen en 1793, eut le 
rare bonheur de pouvoir aider au monument intellectuel qui, malgré le bruit des armes et les enivrements de la victoire, marqua en France les premières années du XIX $^{\circ}$ siècle.

En 1801, M. Duméril fut chargé de l'enseignement de l'anatomie à la Faculté de médecine de Paris, et pendant sa longue carrière il occupa successivement plusicurs chaires dans celte école, dont la célébrité est si légitime. Il consacra aussi une partie de son temps à l'exercice de la médecine, et, en 1805, on le vit dans le midi de l'Espagne, affrontant les dangers d'une épidémic cruelle pour contribuer aux progrès de son art. Mais il aimait trop la culture des sciences naturelles pour s'en laisser détourner par le soin de sa fortune, et, tout en remplissant avec zèle les charges de ses fonctions, il ne cessa jamais de s'occuper d'études zoologiques. Ses premières publications eurent pour objet la classification naturelle des insectes; elles datent de 1797, et, soixante-trois ans après, peu de jours avant sa mort, nous l'avons vu poursuivant encore avec une ardeur juvénile des travaux du meme ordre.

En 1800, M. Duméril rédigea, sous la direction de Cuvier, les deux premiers volumes des Leçons d'anatomie comparée de ce grand naturaliste, et ce ne fut pas seulement de sa plume qu'il contribua à cet ouvrage qui fait époque dans la science: Cuvier se plaisait à reconnaître que M. Duméril l'avait activement secondé dans ses investigations, et qu'il devait à la perspicacité de ce collaborateur zélé une multitude d'observations curieuses.

Ainsi, M. Duméril fut le premier à entrevoir l'analogie de structure qui existe entre les vertèbres et les os du crane. On peut donc le considerer comme un des fondateurs des théories anatomiques qui, depuis quarante ans, exercent une puissante influence sur la direction des étades du naturaliste.

Vers la meme époque, II. Duméril succéda à Cuvier 
comme professeur à l'Ecole centrale du Pauthéon, oủ il avait pour collègue un géologue illustre dont le nom est également cher à l'Académie, Alexandre Brongniart. Puis, en 1802, Lacépède lui confia, au Muséum, le cours d'erpétologic et d'ichthyologie. Pendant plus de cinquante ans, M. Duméril a rempli cette mission, d'abord comme suppléant, ensuite comme professeur titulaire, et le Muséum lui doit la création, non seulement de la plus belle collection erpétologique qui existe, mais aussi d'une ménageric pour les reptiles, chose qui n'avait été tentée par aucun naturaliste, et qui est considérée aujourd'hui comme une partie nécessaire de tout grand établissement zoologique. Enfin, les études persévérantes faites par M. Duméril sur celle partie du régne animal lui ont permis d'écrire, en collaboration avec son disciple, M. Bibron, l'ouvrage d'erpétologie le plus complet et le plus important que l'on possède.

Tant de zèle pour le service de la science, une instruction si variée et des droits fondés sur divers travaux zoologiques dont l'énumération serait trop longue ici, ne pouvaient manquer d'etre appréciés par l'Académie, et, longtemps avant la publication du grand ouvrage que je viens de citer, M. Duméril obtint de ce corps sivant la récompense que tous les hommes voués ì la culture des sciences ambitionnent le plus:

En 1816, il fut élu, par le suffrage de ses pairs, membre de l'Institut de France.

Ce n'est pas sur les bords d'une tombe encore entrouverte qu'on peut analyser froidement les ouvrages d'un confrère qu'on vient de perdre, et d'ailleurs c'est à ses secrétaires perpétuels que l'Académie donne mission de juger les travaux de ses membres décédés. Mais, s’il m'était permis de chercher à caractériser en peu de mots les écrits de II. Duméril, je dirais qu’à certains égards ils réunissent les caractères propres à ceux de l'école de Linné et des disciples de Cuvier. En effet M. Duméril s’appliquait toujours à don- 


\section{MiLne-Edwands. - Funérailles de M. Duméril.}

ner à ses classifications la précision, la netteté si précicuses des systèmes linnéens, tout en les rendant l'expression de l'ensemble de nos connaissances sur le mode d'organisation des animaux, ce qui est l'objet principal de la méthode de Cuvier. En marchant dans cette voie, ses efforts ont été souvent couronnés de succès, et son nom ne sera pas oublié par les historiens de la science.

Du reste, ce n'est pas seulement comme savant que M. Duméril sera regretté de l'Académie. Par son caractère loyal et ferme, sa franchise naïve, son désintéressement, la douceur de son commerce et li solidité de ses amitiés, il a su conquérir le respect et l'affection de tous ses collègues, et ces sentiments, il les inspirait à tous ceux qui le connaissaient. Sa vie fut calme et heureuse; il goûta toutes les joies pures du cœur que la piété filiale pouvait lui offrir, et, en allant rendre comple à Dieu de l'emploi de ses jours nombreux, sa confession sera facile, car il pourra dire: " Ma conscience a toujours été la règle de ma conduite, et j’ai constamment cherché à agir envers autrui comme j'aurais voulu que l'on agît envers moi. ,

En effet Duméril fut, avant tout homme de bien. 


\title{
ALLOCUTION prononcée par II. le Dr LABOULBìnE
}

\author{
Ie 16 Aott $\mathbf{1 8 6 0}$
}

Au nom de la Société entomologique de France.

\section{Messieurs,}

$\Lambda$ près les éloquents témoignages de regret que vous venez d'entendre, permettez-moi d'apporter à Celui que nous pleurons tous, l'expression de l'aflliction la plus vive, au nom de la Société entomologique de France, dont il était le président honoraire et vénéré.

Pendant le cours de sa longue existence, si noblement et si bien remplic par le professorat et par les publications les plus importantes sur les sciences naturelles, M. Constant Duméril eut toujours pour l'entomologie une grande prédilection. Il étudia arec une admirable sagacité l'organisation et les mœurs des insectes; il les distribua, comme Latreille, en familles naturelles auquelles il donna, le premier, des noms particuliers. Le Tablean synoptique de la Classification des Insectes en familles naturelles, qui a été imprimé en 1800, commença la carrière scientifique de M. Duméril, l'Entomologie analytique, ou l'Ilistoire naturelle générale des Inscctes, publiée il y a quelques mois à peine, vient de la terminer. Dans l'intervalle qui sépare ces deux ouvrages, c'est-i-dire pendant phus d'un demi-siècle, M. Duméril s'est associé à tout le mouvement scientifique de notre époque, et parfois il l'a dirigé; il a fondé la plus belle collection de Reptiles vivants et le plus beau Musée erpétologique qui soient au monde. Médecin, il a été plein de dévolsement pour les malheureux, et il a instruit une longue suite de générations médicales. 
Pour nous, Messieurs, que les liens d'une affection r'espectucuse et presque filiale, attachaient ì M. Duméril, ce n'étaient pas l'éclat de sa juste renommée ni son titre de doyen de l'Institut de France qui nous le faisaient surtout chérir et vénérer. Au milieu de nous, il avait déposé la toge professorale, il n'avait voulu d'autre autorité que sa belle couronne de cheveux blancs.

Et, en effet, Messieurs, le professeur du Muséum et de la Faculté de médecine, Ic membre de l'Institut et de toutes les Académies de l'Europe savante, n'a manqué aux réunions d'une Société qu'il aimait quue lorsque ses forces ont trahi sa volonté. Entouré de nos respects, l'ami de coeur de Cuvier, de Latreille et de Léon Dufour, a pris part a tous les travaux de la Société cntomologique de France; il y apportait, il y a peu de jours encore, cette ardeur et cet amour constant de la science qui ne l'ont jamais abandonné, il nous témoignait une bienveillance que notre reconnaissance a pu scule égaler.

Son souvenir vivra dans nos cocurs! Il nous a légué le plus bel exemple d'une existence tout entière consacréc à la science, car il lui est resté fidèle, il l'a aimée jusqu'au dernier jour!

Au nom de la Société entomologique de France, je viens apporter sur volre tombe, vénéré Maître et vénéré Président honoraire, l'hommage de notre profonde douleur et notre supreme adieu! 


\section{$n+40$}

\section{LIS'T E}

\section{IIS \\ Travaux d'Entomologie publiés de $\mathbf{1 7 9 3}$ it $\mathbf{1 8 6 0}$.}

PAR M. C. DUMÉRIL (1).

1. Dissertation sur l'organe de l'odorat et sur son existence dans les Insectes. - Magas. encycl., tom. 2, p. 436, an 111 (1795).

I. Id. sur la génération des Vers intestinaux, en réponse à l'ouvrage de M. Bloch. - Mag. encycl, tom. 5, p. 435, an $\mathrm{V}(1797)$.

II. Exposition d'une méthode naturelle pour l'étude el la classification des Insectes (2).-Magas. encycl., tom. 4, p. 433, an vi (1798).

iv. Dissertation sur les moyens que les Insectes emploient pour conserver leur existence.- Magas. encycl., tom. 1, p. 7, an vir (1799).

v. Remarques sur les Vers intestinaux trouvés dans le corps des animaux. - Magas. encycl., tom. 5, p. 438 (1799).

(1) Cette liste a élé dressée, sur la demande de la Société, par H. H. Lucas, secrétaire-adjoint.

(2) Aucher-Eloy a publié en 1827 un ouwrage ayant pour titre : L'Entomologie ou l'histoire naturelle des Insectes, enseignée en 15 leçous.... ourrage daus lequel on a suivi la méthode de classifi. cation de M. Duméril. 
v. Traité élémentaire d'histoire naturelle, 1 vol. in-8o (par demandes et réponses). - (1801).

Le même ouvrage (tiré sans demandes et réponses). (1804).

L.e même ouvrage, $2^{\circ}$ édition, augmenté d'un vol. avec 33 planches. - (1807).

Le même ouvrage, $3^{\text {e }}$ édition (Eléments des sciences naturelles) 2 volumes. - (1825).

1.e même ouvrage, 4e édition, 2 volumes. - (1830).

Le même ouvrage, je édition avec figures nouvelles, 2 volumes in-12. $-(1846)$.

vir. Observations sur le Lombric marin ou arénicolc. Magas. encycl., tom. 3, p. 407, an xil (1805).

vıir. Zoologie analytique on méthode naturelle de la classification des animaux, 1 volume in-80. - (1806).

IX. Exposé des particularités que présentent les Insectes sous le rapport de la génération. - Tirage à part de l'article Accouplement (Entomologie) du Diction. des Sc. nat., lom. 1, p. 121 à 128 (1816) (1).

$x$. Tous les articles d'Entomologic du Dictionnaire des sciences naturelles en 60 volumes. - (1816 à 1830). (Voir la note ci-dessous.)

(1) Les cinq premiers volumes de cet ouvrage furent publiés dans l'intervalle de 1804 à 1806 . On en fait la remarque ici pour ne pas être accusé de donner comme nouveau un ouvrage qui ne l'est pas. C'est par des suppléments successifs gue les cinç premiers volumes ont été ramenés au niveau des contaissances actuelles, et ces suppléments se trouvent placés à la fin de chacun des volumes auxquels ils se rapportent.

(Note de l'ćditeur du Dictionnaire.) 
xI. Considérations générales sur la :lasse des Insectes, 1 volume in-80, avec 60 planches. - (1823).

xu. Rapport sur deux mémoires de MM. Audouin et MilneEdwards, contenant des recherches anatomiques et pliysiologiques sur la circulation des Crustacés. Ann. des sc. nat., 1re série, tom. 10, p. 394 (1827).

xIII. Id. fait à l'Académie des sciences sur un mémoire de M. Bretonneau, docteur-médecin, intitulé : Notice sur les propriétés vésicantes de quelques Insectes de la famille des Cantharides. - Ann. des sc. nat., 1re série, tom. 13, p. 75 (1828).

xıv. Id. fait à l'Académie des sciences sur un mémoire de MIM. Audouin et Milne Edwards, ayant pour titre: De la respiration aérienne des Crustacés, et des modifications que présente l'appareil branchial chez les Crabes terrestres. - Ann. des sc. nat., fre série, tom. 15, p. 85 (1828).

xv. Lettre au Secrétaire de la Société entonsologique à l'occasion de sa nomination comme membre honoraire de cette Société. - Ann. Soc. Entom., t. 1, p. 18 (1832).

xvı. Compte-rendu au sujet d'une réunion de naturalistes qui a pris le titre de: Société entomologique de France. - Journal le Temps, 22 juin (1832).

xvir. Rapport sur un mémoire de M. Guérin-Méneville, concernant les métamorphoses des Círatopogons et la découverte de deux nouvelles espèces de ce genre d'Insectes aux environs de Paris. - Extrait du journal le Temps, 20 mars, p. 182 (1833).

xvilr. Rapport sur un mémoire de II. Audouin, relatif aux métamorphoses d'une chenille du genre Dositheca, et sur une larve d'Irhneumon qui vit dans son intérieur. - Ann. des sc. nat., 2e série, tom. 1, p. 122 (1834). 
xix. Doutes exprimés sur l'opinion émise par M. Fourcault, que les larves développées dans l'épaisseur de la peau d'un enfant appartiennent à l'espèce de la mouche commune. - Comptes-rendus de l'Institut, tom. 1, p. 197 (1835).

xx. Id. Sur une monographie du genre Clyius, par MM. F. de Laporte, comte de Castelnau, et Gory.- - nnn. des sc. nat., tro série, tom. 5, p. 56 (1836).

xxı. Id. sur plusieurs mémoires ou notices concernant diverses espèces d'Insectes, par $\mathbf{M}$. le docteur RobineauDesvoidy. - Ann. des sc. nat., 2e série, tome 6, pag. 360 (1836).

xxir. Idéc générale de l'ouvrage adressé à l'Académic pour concourir au prix de Physiologie fondé par M. de Montyon, et ayant pour titre : Recherches anatomiques et physiologiques sur les Orthoptères, les Hyménoptères et les Névroptères, aver, un Atlas composé de 270 dessins d'anatomie sur 25 planches in-folio, par M. L. Dufour, correspondant de l'Académie (extrait du rapport de M. Duméril).-Comptes-rendus de l'Institut, tom. 2, p. 48 (1836)

xxuI. Rapport sur un mémoire de M. Lefebvre, relatif à un nouveau groupe d'Insectes Orthoptères de la famille des Mantides. - Id. id. id., tom. 2, p. 169 (1836).

xxiv. Remarques sur un Cryptogame qui se développe quelquefois sur l'abdomen des Mouches. - Id. id. id., tom. 2, p. 436 (1836).

xxv. Rapport sur le ter volume du Species général des Lépidoptères, par M. Boisduval. - Id. id. id., tom. 3, p. $32(1836)$.

xxvı. Id. sur un mémoire de M. L. Dufour, relatif à quelques Entozoaires et larves parasites des Orthoptères el des Ilyménoptères. - Id. id. id., t. 3, p. 750 (1836). 
xxvir. Id. sur un mémoire de M. Robineau-I)esvoidy, ayant pour titre : Sur des chenilles qui ont vécu dans les intestins de l'homme, qui y ont subi leur mue et qui en ont été expulsées vivantes par l'estomac. - Id. id. id., tom. 3, p. 753 (1836).

xxvir. Id. sur un ouvrage de M. Percheron, intitulé : Bibliographie entomologique. - Id. id. id., tom. 1, p. 195 (1837).

xxix. Id. sur un mémoire de M. Audouin, relatif à un nid d'une Araignće maşonne de la Nouvelle-Grenade. - Id. id. id., tom. 5, p. 110 (1837).

xxx. Id. sur un mémoire de M. Audouin, relatif aux ravages faits dans les vignobles d'Argenteuil, par la Pyrale. - Id. id. id., tom. 5, p. 110 et 311 (1837).

xxxr. Id. sur un manuscrit de M. Macquart, de Lille, contenant la description el les figures des Insectes exoti. tiques à deux ailes. - Id. id. id., tom. 3, p. 896 (1837).

xxxır. Id. sur une collection d'échantillons de Vers ì soie malades et sur un mémoire explicatif de ir. Bourdon. - Id. id. id., tom. 6, p. 318 (1838).

хxхи. Id. sur le second volume de l'ouvrage de M. Lacordaire. intitulé: Introduction à l'En'omologic. - Id. id. id., tom. 6, p. 349 (1838).

xxxiv. Id. sur un mémoire de M. P. Gervais, relatif aux Insectes Myriapodes. - II. id. id., tom. 9, p. 530 (1839).

xxxy. Id. sur diverses communications relatives à des tissus fabriqués par des Insectes. - Id. id. id., lom. 9, p. 533 (1839).

xxxvı. Id. sur plusieurs lettres de Mr. Vallot, relatives a l'Entomologie. - Id, id. id., tom. 9, p. 534 (1839). 
xxxvu. Indications d'observations anciennes relatives à la phosphorescence des Lombrics pendant une certaine saison. - Id. id. id., tom. 11, p. 747 (1840).

xxxvir. Rapport sur la partic entomologique des Collections de M. Ad. Delessert. - Id. id. id., tom. 11, p. 388 (1840).

xxxix. Id. sur un mémoire de MM. Perrotet et GuérinMéneville, relatif aux ravages que fait dans les caféieries des Antilles une race d'Insectes Lépidoptères et une espèce de Champignon. - Id. id. id., tom. 14, p. 750 (1842).

xน. Id. sur un manuscrit de M. Guérin-Méneville, portant le titre de : Texte explicatif de l'Iconographie du Regne animal de G. Cuvier. - Id. id. id., tom. 15, p. 937 (1842).

xLr. Remarques à l'occasion d'une note de MM. Dumas et Milne-Edwards, sur la production dela cire des Abeilles.

- Id. id. id., tom. 17, p. 537 (1843).

xL.II. Rapport sur un travail de M. P. Gervais, concernant l'histoire des Phrynéides, Scorpionides, Solpugides, Phalangides et Acarides. - Id. id. id., tom. 18, p. 649 (1844).

xı.1I. Id. sur un mémoire de M. E. Blanchard, ayant pour titre : Recherches anatomiques et zoologiques sur l'organisation des Insectes. - Id. id. id., tom. 23, p. 396 (1846).

xurv. Allocution sur la tombe de Duponchel. - Annales de la Société entomologique, $2^{e}$ série, t. 4, Bulletin, p. vur (1846).

xLv. Lettre d'envoi en faisant parvenir à la Société une Notice sur la vie et les ouvrages de Duponchel. - Id. id. id., 20 série, t. 4, Bulletin, p. xcy (1846). 
xuvi. Notice sur la vie et sur les ouvrages de Duponchel (Ph.-Aug.), membre de la Société entomologique.-Id. id. id., $2^{\circ}$ série, t. 5, p. 5 (1847).

XLvir. Rapport sur un mémoire de M. Boursier, relatif á des wufs d'un Bombyx du Mùrier qui furent fertiles sans avoir été fécondés. - Comptes-rendus de l'Instilut, t. 25, p. 422 (1847).

xLvur. Lettre sur la petite Araignée des murs (Theridion civicum Lucas). - Ann. Soc. entom., 2e série, tom. 8, p. 1 (1850).

xux. Rapport sur deux mémoires de M. Guérin-Méneville, l'un sur la Muscardine, l'autre sur les Vers rongeurs des Olives. - Comptes-rendus de l'Institut, tom. 32, p. 792 (1851).

น. Remarques sur les bourses formées par les chenilles de la Processionnaire du Pin (Pityocampa). - Id. id. id., tom. 33, p. 100 (1851).

L. Rapport sur une note présentée par M. Bourguignon, comme complérment à ses recherches sur l'Acarus de la gale de l'homme. - Id. id. id., tom. 33, p. 443 (1851).

LiI. Id. sur les recherches de M. Laurent, concernant les animaux nuisibles aux bois de construction, en réponse a une demande de $\mathrm{M}$. le ministre de la marine. - ld. id. id., tom. 34, p. 631 (1852).

uir. Id. sur la mission relative à des recherches sur la production de la soie, dont avait été chargé M. GuérinMéneville. - Id. id. id., tom. 36, p. 714 (1853).

Lrv. Remarques à l'occasion d'une communication de M. Ie maréchal Vaillant, sur l'introduction du Ver à soic du Ricin en Algérie. - Id. id. id, tom. 39, p. 707 (1854).

Lv. Note sur les particularités offertes par les cocons du Bombyx mylitta Latr. - Id. id. id., t. 41, p. 365 (1855). 
น.vı. Rapport sur un Insecte trouvé vivant dlans l'intérieur d'une pierre. - Id. id. id., tom. 11, p. 778 (1855).

Lvir. Remarques sur des sécrétions abdominales de quelques Insectes. - Id. id. id., tom. 43, p. 123 (1856).

Lvıı. Remarque à l'occasion des faits mentionnés dans une note de $M$. de Siebold, sur la reproduction de certains Insectes sans fécondation. - Id. id. id., tom. 43, p. 637 (1856).

LIx. Rapport sur un mémoire manuscrit de M. Leprieur, ayant pour titre : Essai sur les métamorphoses du Trachys pygmea. - Id. id. id., tom. 44, p. 314 (1857).

Lx. Id. sur l'instinct et sur les mœurs des Sphégiens, par II. Fabre. - Id. id. id., tom. 44, p. 318 (1857).

LXI. Etudes historiques sur les Insectes qui perforent le plomb. - Id. id. id., tom. 45, p. 361 (1857).

LxiI. Rapport sur un mémoire de M. Fabre, ayant pour titre : Sur l'hypermétamorphose et les mœurs des Méloïdes. - Id. id. id., tom. 46, p. 553 (1858).

Lxu1. Remarques concernant une note de M. Ducommun, sur les Insectes qui produisent les maladies de la Vigne. - Id. id. id., tom. 46, p. 1259 (1858).

Lxıv. Histoire de la caprification. Remarques présentées par M. Duméril, à l'occasion d'une communication faite par M. Leclerc. - Id. id. id., t. 47, p. 361 (1858).

Lxy. Rapport sur un mémoire de M. Ch. Lespès, relatif à l'appareil auditif des Insectes. - Id. id. id., tom. 47, p. 681 (1858).

Lxvi. Note sur la substance médicinale connue sous le nom de Trehala, produite par une coque du genre Larinus. - Annales de la Société entomologique, 3e série, t. 6 , Bulletin, p. cxvir (1858).

Lxvi. Note sur des balles de plomb perforées par l'Uro- 
cerus juvencus. - Id. id. id., 3e série, Bulletin, p. cxvıx (1858).

Lxvin. Allocution de M. Duméril en remerciant la Société entomologique de sa nomination comme Président honoraire. - Id. id. id., 3e série, t. 6, Bulletin, p. cxLII et CXLIII (1858).

Lxix. Remarques sur la mue d'un Phalangiım. - Id. id. id., 3o série, t. 6, Bulletin, p. GLXX (1858).

Lxx. De l'éducation et de l'introduction des Bombyx arrindia et cynthia. - Id. id. id., 3e séric, t. 7, Bulletin, p. CxCIV (1859).

Lxxi. Sur le rang que les Insectes paraissent devoir occuper parmi les autres animaux. - Comptes-rendus de l'Institut, t. 48, p. 601 (1859).

uxxur. De la fonction génératrice chez les Insectes. - Id. id. id., tom. 48, p. 705 (1859).

Lxxır. Rapport sur deux mémoires de M. L. Dufour, relatifs à l'anatomie des Insectes. - Id. id.id., t. 49, p. 65(1859).

uxxiv. Remarques à l'occasion d'un tableau imprimé, ayant pour titre: Classification naturelle des Insectes d'après la méthode analytique, offert à l'sicadémie des sciences.

- Id. id. id., tom. 49, p. 228 (1859).

xxxy. Plan de l'ouvrage intitulé : Entomologie analytique. Id. id. id., tom. 49. p. 653 (1859).

Lxxvi. Sur une demande de M. L. Dufour, relative à son ouvrage sur l'anatomie des Galéodes. - Id. id. id., t. 19, p. 848 (1859).

Lxxvir. Entomologie analytique : Histoire générale, classification naturelle et méthodique des Insectes, 2 rol. in- $\mathbf{4}^{0}$ avec figures dans le texte. - Extrait des mémoires de l'Académie des sciences, tom. 31 (1860).

3e Série, томе vи. 
662 Travaux entomologiques de M. C. Duméril.

Lxxvir. Note sur son ouvrage intitulé : Entomologie analytique. - Comptes-rendus de l'Institut, t. 50, p. 272 (1860).

Lxxix. Communication concernant son Entomologie analytique, en présentant une Notice historique sur cet ouvrage extraite des $\Lambda$ nnales de la Société entomologique (voir no LXXI). - Id., id. Id., t. 50, p. 659 (1860).

Lxxx. Réponse de M. Duméril à des Remarques de M. Valade-Gabel, sur la notice concernant l'Entomologie analytique. - Id. id. id, t. 50, p. 799 (1860).

Lxxxx. Remarques sur la classification naturelle et métho. dique des Insectes, à l'aide de tableaux synoptiques, on Notice historique sur son Entomologie analytique, présentées à la Société entomologique de France. $\Lambda \mathrm{nn}$. de la Société entom., Bullet., $3^{\mathrm{e}}$ série, tom. 8, p. $1(1860)$.

Parmi les manuscrits laissés par M. C. Duméril, se trouvent :

10 Une traduction française complète de l'ouvrage de Fabricius, intitulée : Philosophia entomologica. Celte traduction a été faite en $\mathbf{1 7 9 5 .}$

$2^{\circ}$ Les Insectes rangés par familles naturelles. Ce travail a été présenté à la Société philomatique dans sa séance dı 3 brumaire an 9 et paraphé sous le numéro 414 par Al. Brongniart. 


\section{FUNERAILLES DE N. LEON DUFOLR.}

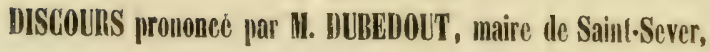

le 20 avril 1865 ,

au nom de la ville de Saint-Sever.

Illustre vieillard, c'est un jeùne homme à qui incombe lat difficile el douloureuse mission de vous adresser un dernier adieu; c'est le fils d'un confrère, c'est l'ami de vos fils, c'est le représentant de la cité en deuil, qui, obéissant au sentiment de sa profonde vénération pour vous, de sí vive aflection pour les vôtres, doil dire sur vos clépouilles, an milieu des larmes et des regrets, ce que vous avez fail, ce que rous avez été.

Quelle noble existence vient de s'éteindre, Messieurs ! Encore un témoin de toutes nos révolutions qui n'est plus! El cet homme fut aussi un soldat, qui, mêlé à nos terribles guerres, portail le secours, le soulagement, la vie sur le clamp de bataille; et cet homme fut un savant naturaliste dont la célébrité, rayonnant aux quatre coins de l'Europe, attirait le regard des savanls sur notre ville si fiere de celui qui les lui valait.

En 1808, le dosteur Léon oufour étail altaché, comme médecin ordinaire, au quartier général du maréchal Suched, dans les provinces d'Aragon el de Valence. Lì, pendant six années consécutives, malgré les fatigues incessantes dues aux marches des régiments, au service des hôpitaux, oủ il faillit lui-même succomber au typhus, il occupe ses loisir's avec ses études favorites; il cherche, aver, l'ardeur de l'artiste, les beautés secretes de la nature, qu'il dépeint, en poèle toujours inspiré, dans leur germe el leur développement. Sur son chemin, il noue avec les ofliciers 
de l'armée, avec les Bugeaud, les Ilarispe, de ces grandes et solides amitiés dont il a été le dernier survivant. Quand la paix succède à la guerre, ce n'est pas à Paris, où l'attend une haute position au Val-1le-fráce, qu'il continuera ses travaux, c'est à Saint-Sever qu'il se retire; et lui, que ne séduira pas l'offre de la chaire laissée vacante au Muséum d'histoire naturelle par Latreille et par Audouin, ne résiste pas à l'honneur d'etre fait médecin de l'lıspice de sa ville natale, et de devenir ainsi le médecin de nos pauvres. Quel rare exemple de désintéressement, de modestic, de fidèle attachement à la famille, aux lieux de l'enfance! Quel dédain pour le bruit et la vanité du monde! "Vanitalem longe fac ì me, "écrivail-il comme épigraphe en tête d'un volume de ses nombreuses notes. Quelle fermeté de pratique! quelle rigoureuse observation de la règle qu'il s'est traccée! Et lorsque la société, en proie à une fière qui l'emporte vers l'affranchissement de toutes les entraves, semble vouloir briser le culte des traditions et des souvenirs, combien l'esprit honnête contemple avec bonheur ces figures pures d'ambition, altachées ì leurs principes, accomplissant leur destinéc dans le calme et sans ostentation !

Dans sa paisible retraite, le docteur Léon Dufour partage son temps entre son inaltérable sollicitude pour l'humanité qu'il soulage, et ses considérables travaux sur la botanique et l'entomologie, qui altirent successivement sur sa poitrine les croix de clevalier et d'officier de la Légion d'honneur. Il correspond avec les Académies de France ot de l'étranger, est admis dans leur sein, compte un ani partout où un lomme étudie la nature; il est élu membre correspondant de l'Académie des sciences sur la proposition de Cuvier lui-meme, comme si ce grand homme avait eu le pressentiment de la récompense destinée au modeste savant des Landes, qui devait être le premier Franģais couronné du prix Cuvier. I.es mémoires qu'il rédige sont étincelants de verve, d'espril, d'entrain, de poésie; il analyse, il dissèque, il décrit l'infiniment pelit avec autant de gràce que de justesse. Chez lui, jamais le travail ri'engendre la lassilude, conme l'ige n'a janais amené la vieillesse. Sa vigoureuse constitution lui permet de croire qu'il peut commander aux forces, à la santé, et les tenir sous sa main en dociles esclaves. Yoyez-vous ce souriant octogénaire, ì la tête encadrée dans une magnifique chevelure blanche, gravir le flanc des Alpes et les crètes des Pyrénées; il lorave le froid, la chaleur, la ncige ; il est ì pied, sans bâton à la main, l'œil sur la plante, l'œil sur l'insecle; ses compagnons le regardent, l'admirent, l'interrogent, consultent son immense savoir, et demandent merci quand lui marche et cherche sans repos : c'est le docteur Dufour. 
$\Lambda$ près ces pénillles el fréquentes excursions où l'entraînail une curiosité toujours avide, jamais satisfaite, il rentrait dans ses foyers, plus riche de gaiclé, parce qu'il était plus riche de science, parce qu'il avait enlevé un secret de plus à ce petit monde qui échappe au vulgaire, el dans lequel il découvrait les plus belles harmonies de la nature. Alors, dans son commerce intime où l'entourait un si affectueux respect, il se livrait, avec l'esprit le plus vif, le plus séduisant, le plus aimable, à ces intéressantes conversations qui tenaient ses auditeurs sous un charme ineffable. Ses longues et laborienses recherches lui avaient montré Dieu dans son infinie providence, et avaient affermi dans son cour les sentiments les plus sincèrement religieux. Il y a huil jours a peine, il priait encore dans notre église; an moment oú unc crise imprévne allait l'entever dans la plénitude de ses facultés, e'est à la religion qu'il faisait un dernier appel.

Tel fut, Messieurs, le docteur Léon Dufour. Peu de temps avant sil mort, il s'adressait en loute vérité, avec la franchise qu'impose le pressentiment de l'heure supreme, ces paroles que peu d'hommes ont le privilege de se dire à cux-mèmes: "Si j'avais à recommencer ma vie, je vivrais comme j’ai vécu. ") Vénérable el si regrelté docteur, c'est en sage que vous avez vécu, Dieu vous récompensera en sage! 


\section{Paroles d'adieu adresseces a II. Lion DuFoun,}

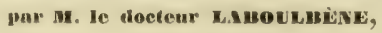

le 20 avril 1865 ,

au nom de la Socield entomologique de France.

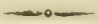

Messicur's,

Si le devosi ne me faisait surmonter une poignante douleur, je scrais resté accablé el sans parole devant cette tombe ouverte, le cour rempli, comme vous, des plus tristes pensées et des plus vils regrets, el contondant mes larmes avec les vôtres.

C'est aujourt'hui, Messieurs, un jour de deuil pour la cilé el pour le pays. Vous vene\% d'entendre décerner l'hommage le plus vrai, le plus mérité et le plus grand, au citoyen éminenl, au médecin dévoué el à l'homme de bien. Peut-etre plusieurs d'entre vous connaissent-ils seulement à celte heure loute l'étendue d'une perte irréparable, car la modestie. de M. I éon Dufour n'a eu d'égale que son mérile, el l'infatigable travailleur, le savant au renom européen, mettail ì taire ses travaux el ses succès le soin que d'autres meltent à les proclamer.

pendant bien longtemps, Messieurs, Saint-Sever a w tour à lour les célébrités scientifiques visiter le grand naturaliste qui avait voulu y vivre; les Academies ont couronné ses travaux et publié ses auvres, el M. Jéon Jufour a élevé à la science, qu'il aimait tant, un monument impérissab)le sur l'anatomie et la pliysiologie des insectes.

Au nom de vos disciples el des admirateurs de volre génie, je viens élever la vois, Maítre vénéré, pour vous adresser un adieu suprène.

La Société entomologique de France, qui vous conféra la présidence d'honneur comme à Latreille el comme à Duméril, doil être ici la première ât expriner ses regrets. C'élail pour vous la société choisic el dẹpo- 
silaire de vos découverles. Chacun de ses membres vous connaissail, vous aimail el vous vénérait; tous porteront pieusement votre devil.

Et, comme la sociêté entomologique, vénéré Maàtre, les Académies des sciences et de médecine, les Sociétés philomatique, botaniqque de France et de biologie, déploreront l'immense perte qu'clles ont faite. Vos collègues des Académies de Stockholm et de Madrid, et des Sociétés savantes de Londres et de Berlin, regretteront en vous le savant illustre; mais nous, cher, excellent et vénéré Maitre, nous qui naguère encore nous réjouissions de votre verte vieillesse, qui trouvions votre esprit si vif, si jeune et si aimant, qui étions associés à vos pensces pour l'avancement de notre clière science, nous ne pouvons nous consoler et nous pleurons en vous le Maftre et l'Ami.

oui, votre vie fut longue el glorieuse; nous ne pouvons accuser la divine Sagesse, la Providence infinie, qui vous donna de si rares facullés et des jours nombreux. .... Nous pleurons!

Nous pleurons, car cetle voix aimée qui nous enscignail el nous encourageait, nous ne pourrons plus l'entendre; ce ceur si ardent el si généreux a cessé de battre; cette main qui a produit des chefs-l'œurre de science et de sentiment et qui pressait la nôtre avec tant de bonté, tant d'affection, cette main est glacée pour toujours !

Au nom de la Société entomologique de France, atu nom de tous vos disciples, je vous adresse, vénéré Maître, le ternier adieu. liẹnosez en paix. Votre souvenir vivra dans nos caurs..... lincore adicu! 


\title{
LISTE
}

DES

\section{Travaux d'Eutomologie publiés de 1811 à 1864}

\author{
Par M. LEON DUFOUR.
}

La Société entomologique de France a bien voulu me charger de dresser la liste des travaux d'Entomologic de notre vénéré Maitre et Irésident lionoraire; je me suis efforcé de remplir cette tàche avec tout le soin dout je puis être capable; mes collègues trouveront cette liste plus nombreuse et plus complète que celle donnée par M. IIagen dans sá Bibliotheca cntomologica.

Gette énumération des travaux ne renferme pas les mémoires de botanique, de Météorologie ou d'Agriculture, ni toules les relations de voyage de M. Isen Dufour; j'ai donné place seulement à celles des excursions pyrénéennes oủ la botanique et l'entomologie se trouvent mêlécs, comme elles l'ont été si souvent dans les éludes du savant Maître dont elles occupaient tous les loisirs.

Le litre des ouvrages est rigoureusement exact; les notes sont de moi el indiquent les espèces nouvelles, ou bien qui ont servi aux recherches analomiques, ou enfin celles dont les meurs ont été observées. J'ai été extrèmement sobre d'appréciations; j’ai noté sculement les rectifications synonymiques faites par M. Léon Dufour sur les especes qu'il avait déjá décrites et au fur et à mesure de ses travaux.

L'immense perte que la science a faite est trop récente, et pour moi les regrets sont trop présents, pour que je puisse encore avoir la force d'ana- 
Iyser de sang-froid les travaux considérables de M. Léon Dufour. Un jour viendra, je l'espère, où j'arriverai à fixer la synonymic des especes Dufouriennes, avec l'aide de mes amis M.M. P'erris et P'srez, et oì je pourni rendre à cette chère el vénérée mémoire l'hommage qui lui est dû, en m’inspirant de l'esprit du Maitre pour coordomer son weuvre impérissable.

\section{A. LABOUlBène.}

1. Mémoire anatomique sur une nouvelle espèce du genre Brachine (1).

(Annales du Muséum d'Hist. nat. de Paris, t. XVHI, p. 70-81, pl. v, fig, 1-5, 1811.)

2. Recherches anatomiques et observations sur le Scorpion roussatre (2).

(Journal de Physique, de chimie et d'Ilistoire naturelle, 1. LXXXIV, p. 439-455, avec 1 planche et 8 figures, 1817.)

3. Recherches anatomiques sur les Scolies et sur quelques autres Insectes hyménoptères.

(Journal de Pliysique, t. LXXXVII, ]. 178-188, avec 1 planche et 12 figures, 1818.)

4. Observations sur l'organe digestif de quelques Diptires.

(Journal de Physique, 1. XC, P. 345-352, avec 1 planche et 5 figures, 1820.)

5. Description de six Arachnides nouvelles (3).

(Anmales générales des Scien es physiques, t. IV, p. 355-369, pl. Lxix, fig. 1-6, Bruxelles, 1820.)

(1) Le premier Insecte publié par M. I.én Dufour est le Brachinus displosor.

(2) Scorpio occitamus, de la basse Catalogne et de Valence, en Espagne.

(3) Theridion lugubre, montagnes de la Catalogne, sous les plerres; Eresus imperialis, royaume de Valence, montagnes arides; Epeira opuntice, royaume de Valence et Catalogne, au milieu des feuilles de l'A gave et de l'Opuntia; Selenops omalosoma, rochers du royaume de Valence; Palpimanus gibbulus, montagnes de Moxente, sous les pierres; Mierommata spongitarsis, Barcelone, daus un jardin. 
6. Description d'une notuvelle espèce de Galiode (1).

(Annales génér. des Sc. physiques, t. 1V, p. 370-374, pl. Lxıx, fig. 7, Bruxelles, 1820.)

7. Observations sur quelques Arachnides quadripulmonaires (2).

(Ann. génér. des Sc. pliysiques, t. V, p. 96-116, pl. Lxxir, fig. 1-7, Bruxelles, 1820.)

8. Description de cing Arachnides nouvelles (3).

(Ann. génêr. des Sc. physiques, t. V, p. 198-209, pl. Lxxvi, fig. 1-5, Bruxelles, 1820.)

9. Olservations générales sur les Arachnides et description de quelques espèces nouvelles ou peu connues (4).

(Ann. génér. des Sc. physiques, t. VI, p. 289-306, pl. xcv, fig. 1-5, Bruxelles, 1820.)

10. Description de dix espèces nouvelles ou peu connnes d'Insectes recueillis en Espagne (5).

( $\mathrm{nn}$. génér. des Sc. plyysiques, t. VI, p. 307-317, pl, xcvi, fig. 1 8, Bruxelles, 1820.)

(1) Galeodes intrepidus, t'Espagne, environs de Madrid et coleanx arides de Paterna, près de Valence.

(2) Mlygale Valentina, de Moxente, Espagne; M. Sauvagesii Latr, de Corse et d'Italie; $\boldsymbol{M}$. carminans I.ATR., de France el d'Espagne; $\boldsymbol{M}$. camentaria LATR., d'lispagne et du midi de la France; Atype Sulzeri Latı., de Saint-Sever; Dystera erythrina LATR., de France et d'lispagne; $D$. parvula, des montagnes de Moxente.

(3) Uroctea 5-maculata, du midi de la lirance et d'Espagne; Scytodes rufescens, des montagnes du royaume de Valence; Dolomedes spinimanus, des montagnes du nord de l'Espagne; Thomiseus bufo, des montagnes de l'Espagne; Pholeus caudatus, des montagnes du royaume de Valence.

(4) Drassus segestriformis, sous les pierres, dans les Pyrénées, région alpine; Micrommata A rgelasia Latr., d'Espagne; Eresus acanthophilus (E. lineatus I.ATn.), sur les arbusles épineux dn royaume de Valence; Epeira fusciata LATn, dans les buissons, pendant l'automne.

(5) Clythra pubescens, d'Fspagne et du midi de la France (description de la larve et le la coque); C. 9-punctata; Asida gigas; P'edinus pruinosus; P. pulescens; Broscus stultus; H. patruelis; Gryllus umbraculatus; G. pipiens; Forficula pallipes; Scolopendra semipedalis; S. viridipes. 
11. Observations sur quelques Cicindritetrs et Garabiqurs oloservés en Espagne (1).

(Ann. génér. des Sc. pliysiques, t. VI, p. 318-331, Bruxelles, 1820.)

12. Anatomic de la Ranalre lincire el de la Nipe cendrif.

(Ann. génér. des Sc. plıysiquues, I. VII, p. 194-213, pl. cv, cri et cvIr, 1820.)

13. Descriptions de six especes d'Insectes nouveaux (2).

(Ann. des Sc. physiques t. VIII, p. 358-361, pl. cxxx, fig. 1-7, 1821.)

14. Recherches anatomiques sur le Lithobius forficatus el la Scutigert lineata.

(Annales des Sciences naturelles, $1^{\text {re }}$ série, t. II, p. 81-99, pl. V, fig. 1-5, 1824.)

15. Description d'une nouvelle espèce de Coccus (3).

(Ann. des Sc. naturelles, $1^{\text {re }}$ série, 1. II, p. 203-205, pl. x, fig. 1, 1824.)

16. Description et figures de quelques Arachnides (4).

(Ann. des Sc. naturelles, Te $^{\text {re }}$ érie, t. II, l. 205-211, pl. $\mathrm{x}$, fig. 2-6, 1824.)

(1) Cicindela paludosa; C. sinuata Panz.; C. maura I.INN.; Brachinus displosor; $\boldsymbol{B}$. bellicosus; Lebia pubipennis; $L$. cyanocephala Liтn.; $L$. anthophora; L. turcica I,ATR.; L. corticalis; L. lineola (Cymindis); $\boldsymbol{L}$. rufa (Cymindis); Zuphium fasciolatum Latr, ; Scariles gigas; S. sabulosus 0ur.; S. terricola Bonneltr; Aristes bucephalus IATR.; A. culydonius LATR.; A.trogositoiles; Harpalus decipiens; $\boldsymbol{H}$. fulgicollis (Chlewius): $\boldsymbol{H}$. pubiger; II. cinctus LATR. et vestitus IATR.; $\boldsymbol{H}$. terricola LATR.; $\boldsymbol{H}$. cristatus (Pterostichus); II. lavigatus; Licinus agricola Latn,; Panagu'us crux-major LATR.; Calosoma sericeum LATR.; Nebria arenaria LATn,; Omophron limbatum Larn.; Bembidium ripicola; B. atroviolaceum; A potomus rufus Ilorw. .

(2) lispèces rapurortées de Galam, dans le sénégal : Mololontha Senegallia (Anoplognatha); Scarabaus nitidulus; II arpalus Dusaultii; Cicindela asperula ; Cantharis vestita; C. Dusaultii.

(3) Coccus Zea Maidis.

(4) Epeira quadrata FABr, -IVAlkeN., Saint-Sever; Epcira conica l.ATr, , de France et d'Espagne; Segestria cellaris IATn, S. perfidı W ALKex, de lirauce : Theridion dispar ơ, + , d'Espagne. 
17. Recherches analomiques sur les Carabiques et sur plusicurs autres Coléoptères (1).

(Ann. des Sc. naturelles, $1^{\text {ro }}$ série, t. II, p. 462-482, pl. xx et xxI; id. t. III, p. 215-242, pl. X-xv et p. 476-491, pl. xxIX-Xxxi, 1824; id. t. IV, p. 103-425, pl. V-vin ; t. V, p. 265-283; t. VI, p. 150-206, pl. IV-1x et 427-468, pl. xvir-xx, 1825 ; id. t. VIJ, p. $5-54$, pl. $\mathrm{xIX}-\mathrm{xxI}$ bis, 1826.)

18. Notice sur les cocons ou les oufs du Lombric terrestre.

(Ann. des Sc. naturelles, $\mathbf{A}^{\text {'e }}$ série, $t . V$, p. 17-21, extrait d'une lettre aux rédacteurs des Annales, 1825.)

19. Recherches anatomiques sur les Cigales.

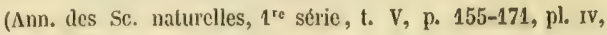
fig. 1-8, 1825.)

20. Recherches anatomiques sur l'hippobosque des chevaux.

(Am). des Sc. naturelles, $1^{\text {ro }}$ série, t. VI, p. 299-322, pl. XII, fig. 1-5, 1825.)

21. nescription et figure d'une nouvelle espèce d'Ornithomyic (2).

(Ann. des Sc. naturelles, $1^{\text {re }}$ série, t. X, p. 243-248, pl. XI, fig. 1, $\mathrm{n}-\mathrm{c}, 1827$.

22. Mémoire pour servir à l'histoire du genre Ocyptera (3).

(Ann. des Sc. naturclles, $1^{\text {ro }}$ séric, I. X, p. 248-260, pl. XI, fig. $2, \mathrm{f}-0$, el $3, \mathrm{p}-\mathrm{s}, 1827$.)

23. Description d'un nouveau genre d'Insectes de l'ordre des Parasiles (4).

(Ann. des sc. naturelles, $1^{\text {re }}$ série, t. XIII, p. 62-66, pl. IX, B, fig. 1-4, 1828.)

(1) On trouve dans ce grand travail anatomique la mention de plusieurs espèces nouvelies, citées pour la première fois ou déja indiquées : Anobium fascialum; Staphylinus punctatissimus; Akis hispanica : Asida gigas (voyez $1^{0} 10$ ); Cistela badiipennis; OEdemera calcarata.

(2) Ornithomyia biloba.

(3) Ocyptera bicolor et 0 . Cassida.

(4) Triungulinus Andrenetarum, C'est une jeune larve d'ume espèce de Meloe. 
24. Notice sur la Filaria Forficulix, espèce de Ver trouvée dans l'alsdomen du Perce-Oreille.

(Ann. des Se. naturelles, $1^{\text {re }}$ série, I. XIII, p. 66-68, pl. IX, c, fig. 1-2, 1828.)

25. Recherches anatomiques sur les Labidoures ou Pcrer-Oreilles, precédées de quelques considérations sur l'établissement d'un ordre particulier pour ces Insectes (1).

(Ann. des Sc. naturelles, $\mathbf{1}^{\text {re }}$ série, t. XIII, p. 337-366, pl. xıx, $\mathrm{Xx}, \mathrm{XxI}$ et XXII, 1828.)

26. Note sur la Grigarine, nouveau genre de Ver qui vit en troupeau dans les intestins de divers Insectes (2).

(Ann. des Sc. naturelles, tre série, t. XIII, p. 366-368, pl. XxiI, fig. $5, \mathrm{a}, \mathrm{b}, \mathrm{c}, \mathbf{1 8 2 8 .}$ )

27. Nouvelle notice sur les œufs du Lumbricus terrestris, accompagnée de figures.

(Ann. des Sc. naturelles, $1^{\text {re }}$ série, I. XIV, p. 216-219, pl. xir, B, fig. 1-4, extrait d'une lettre aux rédacteurs, 1828.)

28. Description et figure de l'apparcil digestif de l'Anobizm striatum.

(Ann. des Sc. naturelles, $1^{\text {re }}$ séric, I. XIV, p. 219-222, pl. XII, A, fig. 1-2, 1828.)

29. Olservations sur une nouvelle espèce de Vers du genre Filaria (3).

(Amn. des Sc. naturelles, $\boldsymbol{I}^{\text {re }}$ séric, L. XIV, p. 222-224, pl. XI, c, fig. $1-4,1828$.)

30. Description et figures de quelques Aruméides nouvelles ou mal con-

(1) Forficula lividipes. (C'est la $F$, pallipes olim, (Voyez $\mathrm{n}^{\circ} 10$. )

(2) Gregarina ovata.

(3) Filaria tricuspidata. Ln note : Filaria filaria. C'est, d'après de Slelsold, un long cordon d'oufs agglutinés par ute substance albunineuse, et placés bout à bout.

$4^{*}$ Sirie, томе V. 
nues, et procédé pour conserver à sec ces Invertébrés daus les collections (1).

(Ann. des Sc. naturelles, $1^{\text {re }}$ séric, t. XXII, p. 355-371, pl. $\mathrm{x}$ et $\mathrm{xI}, 1831$.

31. Description et figure de la Nyctéribic du Vespertilion, et observations sur les stigmates des Insectes pupipares.

(Ann, des Sc. naturelles, t, XXII, p, 372-384, pl. xum, fig. $4-10$, 1831.)

32. Descriplion el figures de quelgtes espèces du genre Phalangium, observées en Espagne (2).

(Ann. des Sc. naturelles, $1^{\text {re }}$ séric, t. XXII, p. 385-388, p]. X, fig. 4 et 5,1831 .)

33. Descriptions et figures de deux espèces nouvelles du genre $L \ell-$ pisma (3).

(Ann. des Sc. naturelles, $1^{\text {re }}$ série, t. XXI, p. 419-421, pl. xrr, fig. 1 et 2,1831 .)

34. Description et figure du Xylocoris rufpennis, Ilémiptère nouveau.

(Ann. des Sc. naturelles, 1." série, t. XXIf, p. 423-426, pl. xun, fig. 3, a-d, 1831.)

35. Description et figure du Tetramychus lintearius, Arachnide nouvelle de la tribu des $\Lambda$ carides.

(Ann. des Sc. naturelles, $1^{\text {re }}$ séric, t. XXV, p. 276-283, pl. Ix, fig. 4-5, 1832.)

(1) Aranea coarctata, d'Esprane ; A, macullulata, du royaume de Valence; A. spinicrus, des montagnes de Moxente; Dolomedes errans, des lords de la mer, a Valence; Epeira apoclysa Whiken., de France; $\boldsymbol{E}$. umbraticola L.str., France, sous les écorces; Salticus biritlatus, Espagne, vieux trones d'olivier; Dysdera parvula, Espagne, sous les pierres.

(2) Phalangium tricuspidutum, des environs de Batcelone; $\boldsymbol{P}$. crassum, sous les pierres, dans le royaune de Valence; et $P$. lineola, monlagnes du milli du royaume de Valence.

(3) Lepisma aurea, . Vavarre, Catalogne, royaume de Valence, e! $I$. ciliata, des environs de Murviedro et de Moxente. 
36. Description et figure du Cacculus rchinipes, Arachnide nouvelle.

(Ann. des sc. naturelles, $1^{\text {re }}$ série, t. XXV, p. 289-296, pl. IX, fig. 1-3, 1832.)

37. Description ef figure du Pleroptus Vrspertilionis, insecte nouveau de la famille des Tiques.

(Ann. des Sc, naturelles, $1^{\text {re }}$ série, t. XXVI, p. 98-102 et pl. IX, fig. 6 et 7 du t. XXV, 1832.)

38. Extrait d'une lettre à M. Audouin, sur le Pteroplus Verpertilionis.

(Ann. des Sc. naturelles, $2^{2}$ séric t. XXVi, p. 257-260, 1832.)

39. Description de quel(ues Insectes Diptères des genres Astomilla, Xrstomyzu, Plors, Anthrux, Bombylius, Dusypogon, Laphria, Sepedon et Myrmemorpha, observés en Espagne (1).

(Ann. des Sc. naturelles, $1^{\text {re }}$ série, t. XXX, p. 209-221, pl. xvir, A, fig. 1-8, 1833.)

40. Recherches anatomiques et physiologiques sur les Himipteres, accompagnées de considérations relatives it l'histoire naturelle et à la classification de ces Insectes (2).

(Mémoires prisentés par divers savants à l'Acadimie des Sciences de l'Institut de France, t. IV, p. 129-461, pl. I-xix, 1833, et lirage à parl, un vol, in- $4^{\circ}, 333$ pages, xIx planches, 1833.)

(1) Astomella curviventris, des envirous de Madrid; Xestomyza culiciformis, sur les fleurs des collines arites; Ploas rhagioniformis, sur les fleurs, aux environs de Madrid; Anthrax margarilifer, pen rare, sur les collines arides; A. bombyciformis, id., mais rare; Bombylius evertebalis, des rivirons de Yalence; Dasypogon senes, des environs de Tudela ; D. nigriventris, Madrid ; D. ripicola, des lnrds de l'Elre; Laphria lanigera, Tudela; $L$. coarctata, Madrid; Sepedon ferrugineus, d'lspagne et de France; Myrmemorpha brachyptera, Briviesca.

(2) Description de toutes les espèces disséquies ot de plusieur's regardćes comme nouvelles; quelques-unes sont figurées.

Pentaloma aparines (Edessa marginata lis.), de Saint-Sever, vit sur le Grateron (Galium aparine Lıys.), dont elle pique et suce les fruits; Corcus chloroticus, de Saint-Sever, de Provence et d'sspagne, sur le buis, le Myrthe; Coreus Panzeri (C. crassicornis PAnz. non Fank.), Saint-Sever; Alydus geranii, figure 16, de Saint-Sever, sur les Geranium, dans les près et les jardins; Alydus apterus, fig. 18, sur le's Graminées; Lyg̨eus lagenifer, lig. 23, Saint-Sever, sur les fleurs; Hiris nankinea, prés et bruycres; Hiris coccinea, prairies; Iradus 
41. Hémoire sur les genres Xylocoris, Liplopus et Velia (1).

(Annales de la Société entomologique de France, 1833, p. 10द118, pl. vi, B, fig. 1, 2 et 3.)

42. Observation sur une nouvelle espèce d'Anoplius qui n'offre qu'un seul ocelle $(2)$.

(Ann. de la Soc. ent. de France, 1833, p. 483-485.)

43. Recherches anatomiques el considérations entomologiques sur quelques Insectes Coléopteres compris dans les familles des Dermrstius, des Acanthopodes et des Lcplodactyles (3).

(Ann. des Sc. naturelles, $2^{\circ}$ série, I. I, p. 56-84, pl. 11, ni el ir, 1834.)

44. Résumé des recherches anatomiques et physiologiques sur les It:mipteres (4).

(Ann. des Sc. naturelles, $2^{*}$ série, t. I, p. 232-239, 1834.)

45. Description el figures de trois llimiptires européens noncaux ou mal connus (5).

(Inn. de la soc. enl. de lrance, 1834, p. 341-357, pl. v, ^, B, c.)

46. Consultation sur un Cruslacé lluvialile voisin du genre Pendalus.

(Ann. de la Soc. ent. de France, 1834, p. 477-478.)

avenius fig. 36, et sa larve, fig. 41, sous les icorces; Nabis dor'salis, fir. 55 , sur les Graminées; Gerris canalium, + , lig. 59 (Cimex najax, var. aptera De Géer, ex Latreille), sur l'eau des fossés ou des canaux; Naucoris aptera (N. maculata FAB.); Saint-Sever, dans les caux stagrantes; Corixa hieroglyphica, Saint-Sever, idem; Cixius 5-costatus, ju's secs; Aphis longipes, fig. 116, antenue, vil sur les sommités du Chêne tauzin et rouvre; $\mathbf{A}$ phis pini maritima, vit sur les sommités du Pin maritime.

(1) Les espèces d'ilémiptères décrites sont le Xylocoris rufipennis, les Jeptopus liltoralis Litr., $L$. echinops et Velia pygmaa.

(2) Cet Ilyménoptère a été nommé, jar M. I. Dufour, Anoplizs uniocellatus.

(3) Description du Byrrhus pyranuzes el de la Gregarina caudata.

(4) Voyez le 11040.

(5) Cephalocieus histerodies; Prostemma brackelytrum; Leptopus littoralis LAтณ. Leplopus lanosus. Jans une lettre reclificative anuexée, le Prostemma urachelytrum est reconnu pour un jeune lieduvius guttula. 
17. Observations sur la Tarentule (Lycosa Tarantula), aver la figure de cette Aranéide (1).

(Ann. des Sc, naturelles, $2^{\circ}$ séric, I. III, p. 95-108, pl. v, A. fig. 1-4. 1835.)

48. Deseription el figure d'une nouvelle espèce d'Eprire (2).

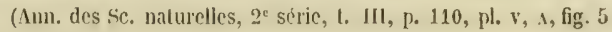
el 6, 1835.)

49. Recherches anatomique's et considérations entomologirgues sur les Insectes Coléoptères des genres Marronyque el Elmis (3).

(Ann. des Sc. naturelles, $2^{\circ}$ série, t. III, p. 151-174, pl. vi et VII, 1835.)

50. hecherches analomiques et physiologirues sur les orthopteres, les IIyminopteres et les Nivroptires (extrait) (4).

(Ann, des Sc. naturelles, $2^{\mathrm{c}}$ série, t. 11', p. 238-243, 1835.)

51. Lettre sur te mouvement observé par 31. Behn, dans les pattes des IIydrocorises.

(Comptes-liendus hehdomadaires des séances de l'Académic des sciences, t. J, p. 334-338, 1835. - Voyez aussi Ann. des sc. naIurelles, t. IV, p. 313-316, 1835, el les . $\mathrm{mm}$, de la Soc. ent. de France, 1835, Bull, p. LXXIII-LXXVI.)

5y. Description el iconographic de trois especes du genre Philoptcus, parasiles de l'Albatros (5).

(.Inn. de la soc. ent. de Flunce, 1835, \%. 669-680, pl. xxi, fig. 1-4.)

(1) Descliption des Lycose (Aranea) turantula lins, el Lygensa fasciitentris; cetle derniere a été tronvere sur Ies montagnes arides de Murvietro, dans le royaume de Valence.

(2) Epeira spinivalva.

(3) Stenelmis canaliculatus et consobrinus,

(1) Voyez les $110 \mathrm{~s} 81$ et 82.

(5) Philopterus diomeda, brevis el pederiformis. 
53. Recherches sur quelques Entozoaires et larves parasiles des Insectes Orthopteres et IIymenopteres (Extrait) (1).

(C.-li. hebdom. de l'Acad. des Sciences, t. III, p. 20-21, 1836, et $\Lambda \mathrm{nn}$. des Sc, naturelles, $2^{\circ}$ série, t. VI, p. $55,1836$. )

54. Letlre a M. le 1) Grateloup, sur des excursions au pic d'Anic el au pic Amoulat, dans les Pyrénées (2).

(Actes de la Société Linnéenne de Bordeaux, t. VIII, p. 53-102. 1836.)

55. Notice sur les dévastalions de la larve du colaspis ba ba'a.

(Ann. de la Soc. ent. de France, 1836, p. 371-372.)

56. Observations sur la Filistata bicolor (3).

(Ann. de la Soc. ent. de France, 1836, p. 527-535.)

57. Recherches sur quelques Enlosorires et larves parasites des Insectes Orthopteres et IIymenopteres (4).

(Inn. des sic. naturelles, t. VII, p. 5-20, pl. 1, fig. 1-16, 1837.)

58. Némoire sur tune galle de la Bruygre ì batais et sur les Inscetes qui l'habitent (5).

(Ann. de la Soc. ent. de France, 1837, p. 83-91.)

59. Iiecherches sur l'histoire naturelle du Tridaclyle pranachí.

(1nn. des Sc. naturelles, $2^{\circ}$ séric, I. IX, p. 321-334, 1838.)

60. Observations sur le genre Stizus (6).

(Ann. de lit Soc. ent. de France, 1838, p. 269-279, pl. Ix, fig. 1 et 2.)

(1) Voyez le $\Perp^{\circ} 57$.

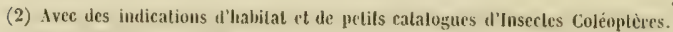

(3) Description des deux sexes et des mours de cette Aranéide.

(1) Descriptions et tirtures de la Filaria locuste livdocim, M. Irufour y rapporte ses Filaria forficula el tricuspidata (voy. nos 24 et 29); $\boldsymbol{F}$. sphecodes; Oxyuris gryllotalpa; Spharularia bombi; Ciregarina spherulosa; G. soror; G. ovata; (i. conica; $\boldsymbol{G}$. hyalocephala. - Dix larves et chrysalides parasiles.

(5) Cecidomyia erica-scoparia ; Euloplus erice et E. verbasci.

(6) Stizus Perrisii et nigricornis. 
61. Hecherches sur l'Indrur lagopus de Latreille (1).

(Ann. de la soc. ent. de France, 1838, p. 281-289, pl. Ix, fig. 3.)

62. Notice sur l'Ammophila amata de Latreille.

(Ann. de la Soc. ent. de France, 1838, p. 291-292.)

63. Note pour servir à l'histoire des Gícidomyies et description d'une nouvelle espèce de ce genre de Diptères (2).

(Ann. de la Soc. ent. de France, 1838, p. 293-296.)

64. Observations eritiques sur quelques espènes de Corabro (3).

(Ann. de la Soc, ent. de lrance, 1838, p. 409.)

65. Mémoire pour servir it l'histoire de l'industric el des mélamorphoses des Odynires, et description de quelques nouvelles espèces de ce genre d'Insectes (4).

(Ann. des sc, naturelles, 2e séric, 1. Xl, p. 85-103, pl. v, fig. 1-7, 1839.)

66. liévision et monographie du genre ciroplutus (5).

(Anu. des Sc. naturelles, $2^{\mathrm{c}}$ série, t. XI, p. 193-213, pl. v, fig. $8-25,1839$.

67. Description el figure de quelrues parasites de l'ordre des Lrariens (6).

(Ann. des Sc. naturelles, $2^{\mathrm{e}}$ séric, I. XI, p. 274-281, pl. viIr, (ig. 1-7, 1839.)

(1) C'est la Megilla labiata de Fabricius, d'aprés M. I.éon Dufour.

(2) Cecidomyia pini marilima.

(3) L.e Tyreus vexillatus (त) et le Solenius lapidarius (f) sont les deux sexps l'une même espèce d'Hyménoptère.

( 1 ) Odynerus Reaumurii; O. consobrinus; O. cognatus; O. rubicola.

(5) Ceroplatus tipuloides Bosc ; C. dispar; $r$. Recummurii; C. testaccus DALx; C. carbonarius Bosc.

(6) Pteroptus limosina; Pteroplus sciara: Trichodactylus osmiar; IIyppus sapromyzarum. 
68. Description et figure d'une nouvelle espece de Thrips (1).

(Ann. des Sc. naturelles, $2^{\circ}$ série, t. XI, p. 321-324, pl. vir, fig. 8-13, 1839.)

69. Mémoire sur les métamorphoses de plusieurs larés fongivores appartenant à des Dipteres (2).

(Anu. des Sc. naturelles, $2^{\mathrm{c}}$ série, t. XIl, p. 1-60, pl. I, II et III, 1839.)

70. Quelques observations sur une note de M. Doyère, relative au tube digestif des Cigales.

(Ann. des Sc, naturelles, $2^{\circ}$ série, I. XII, p. 287-289, 1839.)

71. Observations sur le Sibistroma Infourii Mac(. (3).

(Ann. de la Soc. ent. de France, 1839, p. 129-181.)

72. Notice sur la Nomil diversipes Latr. (4).

(Ann. de la Soc. ent. de France, 1839, p. 583-586.)

73. Second mémoire sur les mélamorphoses de plusieurs larves fongivorcs appartenant à des Diptères (5).

(Ann. des sc. naturelles, $2^{\circ}$ série, t. XIII, p. 148-163, pl. III, fig. 1-26, 1840.)

74. Hémoire sur les mélamorphoses el l'analomie la Pyrochroa coccinra.

(Ann. des Sc. naturelles, $2^{\mathrm{c}}$ série, t. XIII, p. 321-343, pl. v et v1, 1840.)

(1) Thrips aptera, trousé sur un vieux piquet de bois de Pin maritime.

(2) Fispèces décrites : Macrocera hybridı MElG.; Mycetophila amabilis; $\boldsymbol{M}$. hilaris; $\boldsymbol{M}$. modesta; $\boldsymbol{M}$. inermis ; Sciophila melanocephala ; Sciara in-

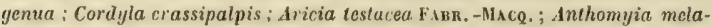
nia; Blephariptera serrala Linn.; Sapromyza blepharipteroides; II elomyza lineala lion.-1)Esv.; II. penicillala; Drosophila fusciata Pennis; D. maculata; Limosina lugubris; Phora pallipes IATR.

(3) Description des deux sexes de ce Dintère.

(4) C'est I'Andrena humeralis de Jurine, Description des deux sexes,

(5) Fspèces décrite's: Cheilosia scutellata Far.ev, M.tce.; Anthomyia manirata; A. paradoxalis; Curtonevra stabulans Merg.; C. fungiuora MAce.; Platypeza holosericea Meic.; Anthomyia boletina. La Sapromyza blepharipteroides est une Anthomyia. (Voyez $\mathrm{n}^{0} 69$. ) 
75. Histoire des métamorphoses de l'Elato rhombrus oliv.

(Ann. des Sc. naturelles, $2^{\text {c }}$ série, t. XIV, p. 41-45, pl. III, fig. 1-5, 1840.)

76. Histoire des métamorphoses du Buprestis chrysostigmu (1).

(Ann. des Sc. naturelles, $2^{\circ}$ séric, I. XIV, p. 111-116, pl, II, fig. 6-12, 1840.)

77. Ilistoire des métammrphoses el de l'anatomic dles Mordrltes.

(Ann. des sc. naturelles, $2^{c}$ série, 1. XIV, p. 225-240, pl. xi, fig. 1-20, 1840.)

78. Hecherches sur les metamorphoses du genre phor" el description de deux espèces nouvelles de ces Itiptères, avec figures (2).

(Mémoires de la société des siciences, de l'igriculture el des Arls de Lille, aunée 18,0, p. 414-424, avec une planche et 21 figures.)

79. Mémoire sur les Insectes Hyminoplerrs qui nichent dans l'intérieur des tiges siches de la Ronce (3).

(Ann. de la soc. ent. de France, 1840, p. 1-49, pl. I, jt el j11.)

80. Description des mélamorphoses du Stcnocurus inquisitor:

(Inn. de la soc. ent. de France, 18'10, p. 63-67, pl. v, ligr. \{-7.)

81. Recherches anatomiques et physiologiques sur les Orthoptires, les Hyminopteres el les Nivropteres (4).

(Mémoires présentés par divers saranls à l'I Icadémie des Ściences de l'Institut, t. VII, p. 265-647, pl. I-XII, 1841.)

(I) Il s'agil du Buprestis (Chysobothrys) affinis, ainsi que je l'élablirai plus tard.

(2) Phora helirivora; $\boldsymbol{l}$, sordidipennis. B arve de la Phora nigra Mercex.

(3) Hyménoptère's niditiants : Osmia parvulu; $O$. tridentatu; $O$. ruborum; 0. aculicornis; Ceratina carulen VII.I. ; C. albilabris SPIx.; Odynerus rubicola; O. industrius: (). hospes; Solenius rubicola; S. vagus; Tryporyion figulus.

Ilyménoptères parasites: Stelis mimula, ENcצct. méru.; Prosopis signata; Stigmus ater; P'emphredon unicolor; Chrysis obtusidens; C. intigoten: C. cyanea ГАвк. Hedychrum minimum: Ichreumon gyrator; $I$, alloriforator; I. odynericilus; Anomalon mandibulator: Pintula ephippiatora: $r$. marginellatoria: Formica truncata.

(1) M. léon Dufour avait dérrit un grand nomber d'esjèces nouvelles dans ce 
82. Explications, notes, erralit el addenda coneernant les Recherehes anatomiques et physiologiques sur les Orthoptires, les HyminopLirrs et les Nívruplires, faisant partic du VII ${ }^{e}$ volume des Mémoires de l'Académie des Sciences (1).

(Un mémoire in- $\iota^{\circ}$ de 36 pages, implimé à Sainl-Sever, 18ఓ1.)

83. Études anatomiques el physiologirues sur une Mouche, dans le but d'éclairer l'histoire des mélamorphoses et de la prétendue cireulation des Insectes (2).

(Ann. des Sc. naturclles, $2^{\circ}$ série, $t$. XV , p. 5-14, 1841.)

84. Observations sur les mélamorphoses du Coreris bupresticida el sur l'industrie et l'instinct entomalogigue de cel Hyménoptère (lettre adressée ì Audouin).

(Ann. des Sc. naturelles, ${ }^{\circ}$ seiric, t. XV, p. 353-570, pl, XI, A, fig. 1-6, 1841.)

liecherches; coll voici l'indication sommaire. J'ai uoté d'un astérisque les Ilyménoptères qui ont la mention : Lepecetren inéd.

Orthoptères: Gryllus hirticollis (voyez If $\mathrm{n}^{\circ} 82$ ); Ephippigera diurna; $\boldsymbol{E}$, vespertina.

Uyménoplères: Saropoda Ravilabris; S. albilabris (voyez le no 82 pour celte espèce et plusicurs des suivantes); Encera difficilis: Nucera faseiatella "; Macrocera pollinosa *; II. meridiana *; II riades ranunculi'; Megfachile cristata; Calioxys rufescens "; Crorisu ramosa ; Melectu vidua *; Nomada consobrina; N. sericea; Indrena nitidiventris; A. violaceipennis; A. fulvirrus ; Formica Rediana; Stizus nigricornis (voyez $\left.n^{\circ} 60\right)$; Crabro quadrifer ; C. tetra'drus; Lysson Dufourii'; Corceris cristata; Pompilus iracundus; Diapria glabra; Eulophus verbasci (1oy. nos 58 et 119); Ichneumon amonus; Banchus pictus *; Peltastes flavipalpis.

Névroplères: Ephemera flavipennis; E. nigrimana; Dodecatoma flava Fourc.; Phryganea viridiventris; $P$. aurovitata; Hydropsyche cxocellata.

(1) Rectifications de synungmie faites par 3. I.eon Dufour : (iryllus hirticollis = Nemeobius lineolutus Awb. -Srry. (pagr 11); Saropoda relbilabris =Anthophorn linotala Lner. (pige 21); II arrorera meridiana $=\boldsymbol{M}$. salicaria; Heriades ranunculi $=$ Chelostoma maxillosa I. itn, ; Megachile eristata $=M$. Mufourii I.FEl., Andrena nitidientris n'est pas l'A. milida Fab1., malgré l'avis de Lepeletier (pare 24); Indrena violareipennis $=1$. vollaris LEPEL. Crabro quadrifer est la of du ('. voxillatus (voyez no 61 ); Cerceris buprestiride remplace le nom de $C$. cristata (page 28 et $n^{u} 84$ ).

(2) Voyez le $\mathrm{n}^{\mathrm{n}} 11 \%$ 
85. Histoire des métamorphoses des fócidomyirs du Pin marilime el du Peuplier (1).

(Ann. des Sc. naturelles, $2^{\mathrm{e}}$ série, L. XVI, p. 257-263, pl. xvi, A, fig. 1-16, 1841.)

86. Nole sur la larve du Pachygorster moromeles, insecle be l'ordec des Diptères.

(.Mm, des Sc, nat!relles, 2e séric, L. XVI, p. 264-266, fig. 17-19, 1841.)

87. IIstoire des métamorphoses du Sciophiln strintu.

(Mém. de la Soc. des Sc., de l'Agric. el des Arts de Lille, année 1841, $1^{\text {re }}$ partie, J. 201-207, avec une planche et 4 figures.)

88. Histoire des métamorploses d'une (Hidimire (2).

(Ann. de la Soc. ent. de France, 1841, p. 5-10, pl. 1, nº fig. 1-9.)

89. Ilistoire des métamorphoses des Cihalcis el description d'une espèce peu connue de ce genre d'llyménoptères (3).

(Ann. de la Soc. ent. de France, 1841, p. 11-19, pl. I, $\mathrm{I}^{\circ} \mathrm{II}$, fig. 1-5.)

90. Apercu sur un ouvravge relatif à l'anatomic des Insectes Dipliors.

(C.-Ii. hel)d. de l'dead. des sciences, I. N1X, 1). 675-678, 18/12.)

91. Histoire comparative des mélamorphoses el de l'anatomie des Cetonio aurula et Dorcus parallelipipedus (4).

(Inn. des Sc. naturelles, 2e seric, I. IVIII, p. 162-181, pl. IV el $v$, fig. 1-19, 1842.)

(1) Cecidomyia pini maritime; C. jopuli; Lasioptera saliciperda (en nole, p. 262).

(2) OEdemera dispar. C'est l'OE. calcarata des Recherches sur les Colcopleres (voyez $\mathrm{n}^{\circ} 17$ ).

(5) Chalcis Fonscolombei (C. podagrica hossi, non Fis.).

(1) Il est très-probable qu'il s'agit de la larve de la Cetonia speciosissima. Celle tétermination sera discutée et précisée plus tard a l'aide des manuserits et de la colJection de M. I.ẻon Dufour. 
92. Histoire des mélamorphoses du Triplax nigriponis.

(Ann. de la Soc. ent. de France, 1842, p. 191-196, pl. vi, n 11 , fig. 1-6.)

93. Nole anatomique sur la question de la produclion de la cire des Abcilles.

(G.-R. hebd. de l'Acad. des Sciences, L. XVII, p. 809-813, 1843.)

9 . Nouvelles recherches sur l'anatomie l'Abcille et la production de la Give.

(C.-li. hebdom. de l'Acid. des Sciences, t. XV11, 1). 1248-1253, 1843.)

95. Mémoire sur les vaissenur biliaircs ou le foir des Insectrs.

(Ann. des Sc. naturelles, $2^{\circ}$ séric, t. XIX, p. 145-182, pl. vi, vir, viri et Ix, fig. 1-33, 1843. - G.-R. hebd. de l'Acad. des Sciences, t. XVI, p. $34-38,4843$.

96. Histoire des métamorphoses de l'Etrdona agmicicola Latr.

(Ann. des Sc. naturelles, 2 série, 1. XX, 12.284-289, pl. Xir, B, fig. 1-9, 1843. - C.-k. liebd. de l'.lead. des Sciences, t. XVII, p. $1046-1047,1843$.

97. Histoire des métamorphoses du Diuperis boleti.

(Inn. des sc. naturelles, $2^{\circ}$ séric, 1. XX, p. 290-292, pl. xu, B, fig. 10-15, 1843.)

98. Excursion entomologique dans les montagnes de la Valle d'Ossan (1).

(Bulletin de la Sociélé des Sciences, Jeltres el drts de Jau, annéc 1843, p. 5-118.)

(1) Espèces décrites comme nouvelles : Carabus pyrenonus; Pristomyrhus p!lrenuts: Feronia Boisgiraulii: $F$. monticola: Amura amica; Bembidium atroviolaccum (B. siculum I'Ex.); B. puncticolle; Blemus acuticollis ; Staphylinus punctatissimus (S. nigripes I) $\mathrm{x}$.); S. Iavipennis ; Tantholinus frigidus; Stenus bisclosus; Elater canus; $E$. difficilis; $N$. mandibularis : E. humeralis; Malachius nigritulus; Anobium fust ialum; A. declire; 1. I. atreillei ; Byyrhus pyrenaus: Elmis Perrisi: IIydrobius pracox; A nisotomet rufomaryinatum: Anthicus occipilalis; OEdemera dispar (o celadonia 11.2. . ? ruficollis 
99. Note sur la composition segmentaire de quelques larves de Cotioplires.

(Ann. de la Soc ent. de France, 1843, p. 253-256.)

100. Histoire des métamorphoses du Choragus shuppardi et du Xylıtimus hederix.

(Ann. de la soc. ent. te France, 1843, p. 313-328, pl. xi, fig. 1-27.)

101. Note sur la prétendue circulation dans les Inscclcs.

(C.-13. hebdom. de l'Acal. des siciences, t. MIX, p. 188-189, 1844.)

102. Etude anatomique et physiologique sur les Insectes Dipteres de la famille des Pupipares (Extrait).

(C.-li. hebdom. de l'Acad. des Sciences, 1, XIX, p. 1345-1355, 1844.)

103. Anatomie générale des Diptères (Extrait) (1).

(Ann. des Sc. naturelles, $3^{2}$ série, t. I, p. 244-264, 1844.)

104. Ilistoire des métamorphoses et de l'anatonie du Piophilu prtusionis.

(Amn. des Sc. naturelles, 3 e sirie L. I, p. 365-388, pl. xv, D, el xvi, fig. 1-20, 1844. - C.-Ii. hebdom. de l'Acad. des Sciences, l. XVIII, p. 233-238, 1844).

105. Deseription de deux espèces nouvelles d'dradus des I'yremines, of remarques sur les ilémiptères de ce genre (2).

(Ann. de la Soc, ent. de France, 1844, p. 447-454, pl. x, fig. 1-6.)

Ouv.); Apion ulicis (A. canescens IEJ.); Otiorhynchus granuligerus ; 0 , obsimulatus; Plinthus costalus; Larinus lineola; Cleopus uncinalus (C. scolopax DEs.); Nanodes cricetorum ; Calandra uniscriala; Rhyncolus pyrenu us, Bostrichus hysterinus; $B$. villifrons; Plalypus oxyurus; Cis bostrichoides ; Rhizophagus variolosus; Leptura diversiventris; Timarcha pyrenaica; Galleruca salicarix; Cryptoceplalus cristula; Coccinella apicalis. (Voyez. pour lit synonymie, le no 171.)

(1) Voyez le no 166.

(2) Aradus dilatatus et elliptieus, sous les écorces des Sapins. 
106. Rectification relative à la composition de la bouche du Choragus Sheppardi (1).

(Amm. de la Soc. ent. de France, 1844, Bull., XLs)

107. Sur les galle's du Vrrbascum et de la Scrophulariu el sur les Insectes qui les habitent, pour servir à l'histoire du parasitisme el de l'instinct de ces animaux (Extrait) (2).

(C.-li. hebdom. de l'^ead. des Sciences, t. XXI, p. 1134-1140, 1845.)

108. Étude anatomique et physiologigue sur les insectes Diptères de la famille des Pupipares (3).

(Ann. des Sc. naturelles, $3^{\text {e }}$ série, l. III, p. 49-95, pl. II el 11i, fig. 1-38, 1845.)

109. Hisloire des métamorphoses de l'Eumcrus ancus Macquart.

(Mém. de la Soc. des Sc., de l' $\Lambda$ gric. el des $\Lambda$ rts de Lille, année 1845, p. 197-200, avec planche, fig. 1-4.)

110. Ilistoire critique des métamorphoses de la Drosophizla Rcammurii, et description de la larve de la Drosophile maculata (4).

(Mém. de la Soc. des Sc., de l'Agric. et des $\Lambda$ rts de Lille, année 1845, p. 201-208, avec planclie, fig. 5-12.)

111. Etude sur la Mouche des cerises (Urophora cerascrum).

(Mém. de la Soc. des Sic., de l'Agric. et des $\Delta r$ ts de Lille, année 1845, p. 209-21/4.)

112. Mémoire pour servir à l'histoire des métamorphoses les Tipulaires du genre Lasioptera (5).

(Mém. de la Soc. des Sc., de l'Agric, et des Arts de Lille, année 1845, p. 115-222, avec une planche el 5 figures.)

(1) Voyez le no 100.

(2) Voyez le no 119.

(3) L'Ornithomyia biloba ne narait pas diférer de l'O. viridis (voyez $\|^{\circ} 21$ ).

(4) Voyez le $n^{\circ} 09$ (note).

(5) Lasioptera picta MEIGEx. 
113. Ilistoire des métamorphoses de la Lacilia dispar.

(Aun. de la soc. ent. de France, 1845, p. 205-21/4, pl. $\mathrm{nI}, \mathrm{n}^{\circ} \mathrm{I}$, fig. 1-10.)

114. Observations sur les mélamorphoses du cirralopogon grniculatus Guérin.

(Ann. de la Soc. ent. de France, 1845, p. 215-223, pl. III, n" II, fig. 1-6.)

115. Nouvelle espèce d'Aradus (1).

(Ann. de la Soc. ent. de lirance. 1845, p. 225-226, pl. III, n" III, fig. 1-3.)

116. Encore une notice sur la composilion segmentaire de quelques larves de Colioptires et sur la position des stigmales thoraciques (2).

(Ann. de la Soc. ent. de France, 1845, p. 493-498.)

117. Études anatomiques et physiologirques sur une Mouche, dans le but d'éclairer l'histoire des métamorphoses et de la prétendue circulation des Insectes (3).

(Mémoires présentés par divers savants à l'Acad. des śc. de l'Institut, t. IX, p. 545-628, pl. I-III, 1846.)

118. Sur une colonie d'insectes vivant dans l'ulcire de l'Ormeru (4). 1846.)

(C.-R. hebdom. de l'icad. des Sciences, l. XXII, p. 318-319,

119. Description des galles du Verbuscum el du Scrophuturia, el des Insectes qui les habitent (5).

(Ann. des Sc. naturelles, $3^{\circ}$ série, I. V, p. 5-24, pl, II, fig. 1-30, 1846.)

(1) Aradus Perrisii.

(2) Voyez le no 99.

(3) Cetle Mouchic est la Mouche carnassière d'Onvin, la Sarcophaya hatmorrhoidalis de Fatren et de Macquant.

(4) Indication de onze espères, dont trois sont nouvelles: Apototomella impressifrons; Drosophila pallipes; $D$. niveopenctata.

(5) Cecidomyia verbase: ValLoT; Misocampus (Diplolepis) nigricornis FABR.; Eulophus verbasci Valiot; Slomortea pallipes (nov. gen. et sper.). 
120. Histoire des métamorphoses du Srathopse noir de Geolfroy.

(Ann. des Sc. naturelles, $3^{\circ}$ série, t. VI, p. 37/1-383, pl. xvi1, fig. 1-11, 18/6. - C.-H. hebrlom., de l'Acad. des sciences, t. XXIII, p. 1058-1060, 1846.)

121. Ilistoire de la galle de l'Eryngizun et des divers Insectes qui l'habitent (1).

(Mém. de la Soc. des Sc., de l' $\Lambda$ gric. el des Arts de Lille, année 1846, p. 121-127, avec une planche et 11 figures.)

122. Histoire des métamorphoses de la Drosophila pallipes.

(Ann. de la Soc. ent. de France, 1846, p. 321-326, pl. Ix, n" เ.)

123. Histoire des métamorphoses du Rhynchomyia columbina.

(Inn. de la Soc. ent. de France, 1846, p. 327-330, pl. Ix, $n^{\circ}$ Ir.)

124. Sur les métamorphoses et le genre de vie des Brris picinus et cuprivostris.

(Ann. de la Soc. ent, de France, 1846, p. 453-454.)

125. Nétamorphoses de l'Aulatcigaster rufitarsis et observalions critiques sur ce genre de Muscides acalyptérées.

(Ann. te la Soc. ent. de France, 1846, p. $455-463, \mathrm{pl}, \mathrm{xI}, \mathrm{n}^{\circ} \mathrm{I}$. )

126. Nole sur la Fulgora obliqua de Panzer (2).

(Ann. de la Soc. ent. de France, 1846, Bull., xLV-XLVIr.)

127. Quelque chose sur le Brachyopa bicalor et le Subularia citripes.

(Ann. de la Soc. ent. de France, 1846, Bull., xivit.)

128. Note sur le Rhyngia femorala (Musca femorata Panzer.)

(Ann. de la Soc. ent. de France, 1846, Bull., Lvi-Lvir.)

129. Un mot sur la Sigara minuta Fabr.

(Ann. de de la Soc. enl. de France, 1846, Bull. xcin-xciv.)

(1) Lasiopler'a eryngii; Misocampus sapphirinus Foxsc.; Eulophus eryngii.

(2) Dans une note au bas de la page est l'indication de la Tettigometra impressopunctata. 
130. Nolice sur les Zones rntomologiques de nos Pyrínes (1).

(C.-R. liebdom. de l'Acad. des Sciences, t. XXIV, p. 833-836, 1847.)

131. Histoire des métamorphoses du Trtanocrru frrmeginea (Extrait).

(C.-R. helodom. de l'Acad, des Sc., I. Xxiv, p. 1030-1034, 1847.)

132. Histoire des métamorphoses du Subula citripes et de quelques autres espèces de ce genre de Diptères (2).

(Amn. des Sc. naturelles, $3^{\text {e }}$ série, 1. VII, p. 5-14, pl. xvir du tome VI ${ }^{\circ}$, fig. 12-21, 1847.)

133. Histoire des mótamorphoses du Casside maculata.

(Ann. des Sc. naturelles, $3^{\circ}$ série, t. VII, p. 1/4-20, pl. xvir du tome VIe, fig. 22-25, 1847. - Extrait dans les C.-R. heldom. de l'Acad, des Sciences, t. XXIII, p. 653-657, 1846.)

134. Description et anatomie d'une larve à branchies externes d'Hydropsyche.

(Ann. des Sc. naturelles, $3^{\mathrm{c}}$ série, t. VHII, p. 341-354, pl. xv, fig. 1-13, 1847.)

135. Notice sur le Misocampus stigmatisans (Ichncumon stigmatisans Fabr.).

(Ann. de la Soc. ent. de France, 1847, p. 441-444.)

136. llistoire des métamorphoses de la Ceria conopsoides.

(Amm. de la soc, ent. de firance, 1847, p. 19-27, pl. 1, nº 1.)

137. Eludes pour servir à l'histoire du Nematus ribis.

(Ann. de la Soc. ent, de trance, 1847, p. 571-581.)

138. Dissertation sur le Nematus De Geeri.

( $\Lambda \mathrm{mm}$. de la Soc. ent. de France, 1847, p. 583-589.)

139. Sur le Cyrtonus Dufourii.

(Anm, de la Soc. cnt. de France, 1847, Bull., p. ciri-civ.)

(1) Voyez le $n^{\circ} 171$.

(2) Description et figure de la pune du Suluala marginata Veigen, p. 12.

$4^{\circ}$ Sirie, томе V. 
140. Sur la respiration branehiale des larres des grandes libellules comparée à celle des Poissons.

(C.-F. hebdom. de l'Acad. des Sciences, t. XXV1, p. 301-303, 1848.)

141. Recherches anatomiques sur la larve à branchies extériemres du Siatis lutarius.

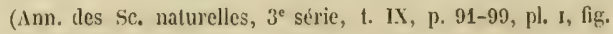
$1-10,1848$.

142. Uistoire des métamorphoses du Brachyopa bicolor.

(Ann. des Sc. nalurelles, $3^{\circ}$ série, t. IX, p. 199-204, pl. xVr, fig. 1-5, 1848.)

143. Histoire des métamorphoses du Cheilosia ærra.

(Ann. des sc. naturelles, $3^{c}$ série, t. IX, p. 205-209, pl. xvr, fig. $6-10,1848$.)

144. Recherches sur l'anatomie el l'histoire naturelle de l'Osmylus mar'zlatus.

(Ann. des Sc. naturelles, $3^{\circ}$ série, t. IX, p. 344-357, pl. xv1, fig. 11-29, 1848. - C. - h. heblom, de l'icad. des siciences, t. XXVII, p. 77-79, 1848.)

145. Souvenirs et impressions de voyage sur des excursions pyrénécnnes, à Gavarnie, Héas, Pic du Vidi, Montagnes maudites, I'íc d'Ossau, Lac Bleu, adressés à M. Massey.

(Actes de la Soc. Limnéeme de Bordeaux, I. XV ( $2^{\circ}$ série, t. V), p. 69-151, 1847-1849. Le lirage à part de 83 pages porte la date de mars 1848.)

146. Nole pour servir à l'histoire des mélamorphoses du genre 1 husiu.

(Inn. de la sioc, ent. de lirance, 18/18, p. 427-428, el Bull., p. XCIV.)

147. Sur la circulation dans les Insecles.

(C.-Rr. hebdom. de l'Acad. des siciences, I. XITII, p. 28-33, 1849.)

Sur la circulation dans les Insectes (Deuxieme parlic).

(Idem, t. XXVII, p. 101-104, 1849.) 
Sur la circulation dans les Insectes (T'roisïme partie).

(Idem, t. XXVIII, p. 163-170, 1849.)

148. Oloservations sur l'organe digestif du Galeode.

(C.-1i, hebdom. de l'Acad. des Sciences, t. XXVIII, p. 340-3द2, 1849.)

149. Sur l'appareil digestif du Scorpion el du Galiode.

(C.- R. hebdom. de l'Acad. des sciences, 1. XXViII, p. 523-528, 1849.)

150. Des diver's modes de respiration ruquatique dans les Insectes (1).

(C.-R. helylom. de l'Acal. des Ściences, 1. XXIX, p. 763-770, 1849.)

151. Sur (quelques IIymónopterrs nouveaux ou peu connus de l'Espagne (2).

(Ann. des Sc. nalurelles, $3^{c}$ série, I. XI, p. 91-98, pl. v, fig. $1-26,1849$.

152. Sur une nouvelle espèce du genre Dycliophora (3).

(Ann. des Sc. maturelles, $3^{\circ}$ série, 1. XI, p. 98-105, pl. v, fig. 27-38, 1849.)

153. Nole sur Irois espèces du genre Anthicus (4).

(.Inn. des Sc. naturelles, $3^{\mathrm{e}}$ série, I. XI, p. 229-230, pl. v, fig. $(12-49,1849$.

154. Note sur le Buprestis putchra Nab.

(Anu. des Se. naturelles, $3^{\circ}$ série, I. XI, p. 231, pl. v, fig. 3941, 1849.)

155. Sur la circulation dans les insectes.

(Acles de la soc. Liméenne de Bordeaux, I. XVI (2 série, I. VI), p. 5-42, 1849.)

(1) Le Phytobius hydrophilus itudié dans ce travail loit ètre mapporté au Phylobius velatus ScHöNu.

(2) Cerceris A-maculata; C. tenuiviltatı; C. dorsalis; Sapyga 8-gultatu, s. fiduciaria; Brachymeria peclinicomis: Lithurgus nasutus.

(3) Dycliophora longipes; D. Genei.

A. Anhicus renator; A, amicitice; A. pallicrus, tous lis trois d'E-pagme. 
156. Histoire des mélamorphoses du Telanocra fornginea.

(Ann. de la Soc. ent. de France, 1849, p. 67-79, pl. Iur, nn in.)

157. IIistoire des métamorphoses du Rhyphus fencstralis et du Mycrtobia pallipes.

(Ann. de la Soc, ent. de France, 1849, p. 195-210, pl. vir, $n^{\circ}$ III.)

158. Note sur un fait remarqubble de géographie entomologique, relatif à une chenille d'Hydocampa.

(Ann. de la Soc. ent. de France, 1849, Bull, p. rxxi-Lxxit.).

159. Recherches pour servir à l'histoire des métamorplıoses des Asiliques (1).

(Ann. des sc. naturelles, $3^{\circ}$ série, t. XIII, p. 14l-158, pl. v, fig. 1-32, 1850.)

160. Quelgues mols sur l'organe de l'Odorat et sur celui de l'Ouir dans les Insectes.

(Anu. des Sc, naturelles, $3^{\text {e }}$ série, L. XIV, p. 179-184, 1850.)

161. Quelques mots sur l'organe de l'Odoral et sur celui de l'Ouie dans les Insectes.

(Actes de la Soc. Linnécnne de Bordeaux, t. XVI ( $2^{e}$ série, t. VI), p. $260-266,1850$.)

162. Description et iconographic de quelques Diptives de l'Espagne (2).

(Ann. de la soc. ent. de France, 1850, p. 131-155, pl. v et vi.)

(1) Res espèces spècialement éfudiées sont : Asilus forcipatus l.ixs.; Laphria

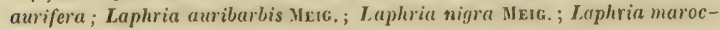
cana FAB, ; Laphria atra Lisx.

(2) Astomella curviventris ; Nemestrina Perezii; Testomyza (Tipula) chrysanthemi FAB. (ancien Ploas rhagioniformis); Anthrax Hiegii; A. fasciata; A. bombyciformis; Mydas lusilanicus Me16; M. Rulviventris : Ortalis (Oscinis) maculipenmis I.ATn.; Dioctrin chalcogastra; D. melas: Millogramma aurifrons; Sarcophaga tertripunctata; Fallenia fasciata; Lampromyia funebris (voyez no 177); 
163. Note sur la chrysalide du sccmopimus fencstratis et sur le poste de ce biptere dans la classificalion.

(.Imn. de la Soc. ent. de France, 1850 , p. 493-496, pl. xvi, $\mathrm{n}^{\circ}$ IV,)

164. Nole sur le Xylograp/hus bostrichoides et sur ses métamorphoses.

(Ann. de la sioc. 'nt. de France, 1850, p. 549-554, pl. xvi, n v1.)

165. Sur le Callicnemis truncalifrons.

(Ann. de la Soc. ent. de lirance, 1850, Bull., p. LIV-LV.)

166. liecherches anatomiques et pliysiologiquns sur les Diptires, accompagnées de considerations sur l'histoire naturelle de ces Insectes (1).

(Hémoires présentés par div. sarants à l'.lead. des Sc, de l'Inslitut, t. XI, p. 171-360, pl. I-1X, 1851.)

167. Sur l'anatomie du Scorpion.

(C.-R. helodom. de l'icad, des sciences, I. Xx.II, p. 28-33, 1851.)

168. Sur le Parasilisme.

(C.-li. heblom, de l'Acal, des sciences, t. XXXIII, P. 135-139, 1851.)

169. The la circulation el de la nutrition clez les Insectes (Extrait).

(C.-11, hebdom. de l'.1cakl. des Siences, t. XXXIII, p. 542-543, 1851.)

170. Olsservations sur l'anatomic du Scorpion.

(1mn. des Sic. naturelles, $3^{e}$ sirie, 1. XV, p. 249-255, 1851.)

(1) L.es espèces nouvelles citées dans ces Riecherches ont presque toutes été décrites daus divers travaux. Voici les noms des Insectes et lindication du mémoire descriplif : Mycetophila amabilis et M. hilaris (voyez $n^{\circ} 69$; Ceroplatus dispar (roy. $\mathrm{n}^{\mathrm{n}}$ 66); Sciara ingenua (voy. $\mathrm{n}^{.69}$ 69; Dioc ria nigritarsis; Pegomyia blepharipteroides; Piophila pelasionis (voy. 110 104); Phora sordidipennis et $P / h$. helicivora (voy, no 73). 
171. Des Zones entomologínues dans nos pyrinies occidentales cl désignation des Insectes qui les habilent (1).

(Actes de la Société Limméenne de Borleatux, l. XVII (2 série, 1. VII), p. 304-364, 1851.)

172. De la circulation du sang el de lit nutrition chez les Insecles.

(Actes de la Soc. Limnécnne de Bordeaux, I. XVII (2 ${ }^{e}$ série, t. VII), p. 373-381, 1851.)

(1) Il y a dans ce travail un grand nombre d'especes nouvelles et les rectifications de synonymie, la plupart fournies à l'auteur par .I. Ie docteur Aubé. J'indique les synonymes par le signe $=$ qutand $M$. Léon Dufour les adopte sans contestations; je mets au contraire le mot serait pour exprimer que M. L.én Dufour conservait des doutes sur l'identité des espèces.

Zone sous-alpine. - Pristonychus pyrenarus serait $P$. terricola DEs.; Feronia Bualei; $\boldsymbol{F}$. Audouini; Bembillium puncticolle serait B. elongatum DEs., $\boldsymbol{\Pi} \boldsymbol{y}$ droporus bimaculatus; Xylobius humeralis; Elater canus; Elater mandibularis; E. testaceipennis; E. lujubris ; E. Panzeri; E. lavistrialus; E. filicornis; $\boldsymbol{E}$. difficilis; $\boldsymbol{E}$. suturalis; Tclephorus unicolor; Malthinus unicolor; Dasytes pectinicornis; Anobium fasciatum $=$ rillosum Bonru.r. A. declive: Byrrhus pyrencus serait B. scabripennis Sterr.; IIeterocerus nenicolor; Hydrobius pracox; Aphodius ruffrons; Anisoloma rufo-marginatum; A. succineum; Hycctochares bifoveolata; Cistela denticornis; Anthicus occipitalis $=$ punctatus Des.; OEdemera dispar $=$ OE. celadonia of, ruficollis 우 OLIV.; OE. aurulenta; Apion cynare; Barynotus umbilicalus; B. unipunctatus; Otiorhymehus nitidicollis; $O$. granuligerus; 0 . obsimulatus; $O$. costipennis : O. parvulus; Plinthus costatus; $\boldsymbol{P}$. imbricalus; $P$. 7-carinatus; Gymnatron uncinatus = scolopax DeJ.; Baris brassicarius; r'eutorhynchus cruciger ; C. rufulus: Acalles clavuliger; Nanodes cricetorum - siculas DEJ.; Calandra uniseriata $=$ Baris punctatissimus DEx,; Rhyncolus crassirostris = porcalus MUน.; R. myrencus; Bostrichus hysterinus; B. rillifrons: Platypus oxyurus; Cis bostrichoides; hhizophrqus variolosus appelé depuis $\boldsymbol{R}$. rersus ERıchs.; Gracilia rufipennis: Pogonocherus Schlumbergii; l.eplura diversiventris; Galleruca rugipennis (Adimonia); Galleruca salicaria serait une varlété de G. Lythri GyL..; Timarcha pyrenaica; T. monticola: Chrysomela stenomera; C. fulgens; Altica lavicollis; Rachnephorus Schlumbergii; Cryptocephalus cristula; Agathidium magnum; Tenthredro speciosa.

Zone alpine. Foronia Boisyiraudi $=F$. Dufourii I) 3. ; Staphylinus frigidus =Othius pilicornis РАук.; Elophorus inalpinus; Otiorhynchus monticolu. - lovigalus GYLENH.L. 
173. Mélanges entomologiques.

(Ann. de la Soc, ent. de France, 1851, p. 55-70.)

1. Etude de l'Entomologic (p. 55-56).

2. Ilabitat du Serenthia lata (p. 56-57).

3. Sur l'Issus grylloides de Fabricius (p. 57-58).

4. Sur une nouvelle especr de Gelonitrs (C. dispar) (p. 58-61 ct pl. III, $\mathrm{n}^{\circ} \mathrm{j}$ ).

5. Lemarques sur la famille des Masarides (p. 61-63).

6. Sur une Myalomyia nee des entrailles du Brachyderes Lusitanicus (p. 63-67).

7. Sur la Musca vitripennis (D. 67-68).

8. Sur l'Otiles putchelle Macquart ( $\Gamma$. 68-70).

174. Description et figure d'une nouvelle espèce de Lygeile, le Rhyparochromus brachiidens.

( $A$ nn. de la Soc. de France 1851, p. 317-328, pl, xi, n" แ1.)

175. Iperçu analomique sur les Insectes Lipidoptires.

(C.-li. hebdom, de l'icad. des Sciences, t. XXXIV, p. 748-754. 1852.)

176. Etudes anatomiques el physiologiques ef observations sur les larves des Libellules.

(.1mn. des sic. nalurelles, 3e série, t. XriI, p. 65-110, pl. ni. IV, v, fig. 1-33, 1852.)

177. J)eseription el iconographie de quelepues Diptires de l'Espagne (1).

(Ann, de la Suc. ent. de France, 1852, p. 1-10, pl. I, 17 I.)

178. Mélanges entomologiques.

(Ann. de la Soc. ent. de France, 1852, p. 443-461.)

9. Encore l'Iyulomyia dispar (p. 443-447, pl. vi1, n 111).

(1) Nemotelus cingulatus: N. lateralis; Anthrax nebulosa; A. trinotata; 1. formosa; Bombylius funosus; Ploas macroglossa; P. fuminervis; Dioctria ochrocera (voyez no 162). 
10. Encore Masaris el Celonites (p. 448-449).

11. Sur les coques de Cryptocephatus et de Clythra (p. 450-453).

12. Les Hetérocives (p. 453-458).

13. Ichneumons, mode descriptif (p. 458-460).

14. Lucilia dispar Duf. (p. 460-461). (Voyez le $n^{\circ}$ 113.)

179. Mélanges entomologiques.

(Ann. de la Soc. ent. de France, 1852, Bull., p. xuII-xLvi.)

15. Sur la Micrommata spongitarsis (p. XLII-XLIV).

16. Sur les deux sexes de la Mutilla arenaria (p. XLIV-XLV).

17. Sur la Macrocera ruficollis Brullé (p. xLv).

18 Sur l'Eucera grisea Fabricius (p, XLV-XLVI).

19. Sur l'Eucera numida Lepeletier (p. xLvi).

180. Mélanges entomologiques.

(Ann. de la Soc. ent. de France, 1852, Bull., p, Lxxxv-Lxxxvi.)

20. Un dernier mot sur les coques de Clythra el de Cryptocephalus (p. Lxxxv). (Voyez $n^{\circ} 10$, note, et $n^{\circ} 178,11$.)

21. Note sur le Ctenocrus Klugii Dahlb, - Clavelia pompiliformis Lucas (p. Lxxxvi).

181. Un mot et un portrail sur la fenelle du farleodes barbara Lucas.

(Ann. de la Soc, ent. de France, 1853, p. 5-8, pl. III, $\mathrm{n}^{\circ}$ I.)

182. Signalements de quelques espèces nouvelles ou peu connues d'Hyminopterss algériens (1).

(Ann. de la Soc. ent. de France, 1853, p. 375-382).

183. Mélanges entomologiques.

(Ann. de la Soc. ent. de France, 1853, p. 383-388.).

(1) Sphex pubescens FAв, ; S. niveala; Tachytes ruforus; Dinctus niger; Bembex galactina; Palarus humeratis; Cereris elegans; C. niyro-cincta ; Phitanthus ecoronatus; Odynerus rhombiferus : Inthidium coronatum : AnIrena Doursana. 
22. Reclamation sur les métamorphoses des genres de Diplères IIelomyza, Cheilosia, Phora, Sciara (p. 383-385).

23. Masaris, Celonites, Ceramius (p. 385-386).

24. Jes deux sexes de l'Inthophor' crassipes (p. 386-388).

25. Pangonia atervima Duf, (p. 388).

26. Cerceris straminca Duf. (p. 388).

184. Recherches anatomiques sur les Hyménoplères de lit famille des Uroceratcs.

(. Inn. des Sc. naturelles, $4^{\circ}$ série, I. I, p. 201-236, pl. 1V, lig. 1-22, 185/. - Extrait dans les $C_{\text {. }}$-li. hel,dom. de l'. 1 cad. des Sciences, t. XXXVIII, p. 484-488, 1854.)

185. Excursion cntomologique aux dunes de Biscarosse et d'.lrcachon, avec indication de quelques manœuvres insecticeplologicues et Ieflexions (1).

(Actes de la Soc. Linnécnne de Bordeaux, t. AIX (2érie, t. IA), p. $283-318,1854$.)

186. Métamorphoses de la Lycoperdinu bovistx.

(Ann. de la soc. ent. de France, 1854, ]) 647-651, pl. xix, n 1 II.)

187. Métamorphoses du Nanodes hxmisphericus.

(Anu. de la Soc. ent. de France, 1854, p. 651-656, pl. xis, $\mathrm{n}^{\circ}$ 111.)

188. Métamorphoses du Lixus verustulus.

(.1mn, de la Soc. ent. de France, 1854, p. 656-663, pl. xxx, $\mathrm{n}^{\circ}$ IV.)

(1) Fspèces técriles rares cu nouvelles, - Coléoplères: Tyletinus rufithornx Ins:yne; Xyletinus holosericeus, - Hyménoptère : Halictus semipubescens. Névoptère : larve đu Myrmelen occilanirum. - Diptères : Dasypogon hirtellus Mese.; Leucopis maritima; L. lusoria; Rhuphium odontocrrum; R. oceanum: n. squamipalpum; Odhiphila maritima; i phrozela (PERnus, nov. gen.) cincrea; Meromyza smaraydina; Terellia eryngii: Aricia maritima. - Irachnile: Epeira thomisoides. 
189. Aole sur l'absence dans le Nemoptera lusitumicu d'un sjstème nerveux appréciable.

(Inn. des Se, naturelles, $4^{\circ}$ série, L. IV, 1). 153-158, 1855. C, -R. hebdom, de I'Acad. des sciences, I. XLI, P. 1204-1206, 1855.)

190. Quelques mols sur les Cerceris de M. Falore.

(Inn. des sic. naturelles, $4^{2}$ série, I. IV, 1. 261-263, 1855.)

191. Idditions d̀ la note sur l'alosence dans le Nimoplere d'un systeme nerveux appréciable.

(Ann. des Sc. naturelles, $4^{\circ}$ séric, L. IV, p. 263-264, 1855.)

192. Description de deux espèces nouvelles d'Aramides (1).

(Ann. de la Soc. ent. de France, 1855, p. 5-14, pl. v, fig. 3-14.)

193. Histoire anatomique el physiologique des Scorpions (2).

(Mémoires présentés par div. sarants à l'Acad, des Sc, de l'Institut, t. XIV, p. 561-657, pl, I-IV, 1856.)

194. Quelque chose sur les Truffes.

(C.-11. hebdom. de l'Acad. des Sciences, L. XIIII, H). 1030-1032, 1856.)

195. Madrid en $\mathbf{1 8 0 8}$ et Madrid en 1854; excursion dans les Gastilles el les montagnes de Guadarrama.

(Ictes de la Soc. Linnéenne de boldeaux, I. XXI (3e série, (. 1), p. 115-151, 1856.)

196. Nole sur la Formica barbara.

(Ann. de la Soc. ent. de France, 1856, j). 341-343.)

(1) Epeirn thomisotdes, des randes, près de l'océan; Theridion ardesiacum of, 우 de Saint-Sever.

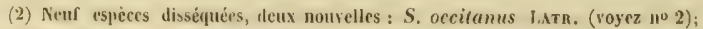
$S$. palmalus IIEnr.; $S$, australis SAvisy ; 5 , nigrolincatus, tes Indes orienlales; S. leioderma, Malabar; S. ufer I.ıNı.; S. biaculealus I.,trn.; S. longicauda LaTR.; S. europaus ScHRANCK. 
197. Sur IIn habilat curieux du Stcmus resticus rassemble en grand nombre.

(Ann. de la Soc, ent. de France, 1856, Bull., p. xci.)

198. Note sur un nouvel habilat du Carabus hispanus.

(Ann. de la Soc. ent. de France, 1856, Bull., po. xcv.)

199. Fragments d'anatomie entomologique.

(Inn. des Sc. naturelles, $4^{e}$ série, I. VIII, p. 5-17, avec une planche et 7 figures, 1857.)

1. Sur l'appareil digestif et les ovaires du Nomoplera lusitanicin (p. 5-10, pl. 1, fig. 1-5).

2. sur le systeme nerveux du Brochyderes lusilamicus (p. 11-17, pl. I, fig. 6-7).

200. Fragments anatomiques sur quelques Blutrides.

(Aun. des Sc. naturelles, $4^{\circ}$ série, I. VIII, p. 365-372, pl. viı, fig. 1-9, 1857.)

201. Note sur le Melandrya serrata.

(Ann. des Sc. naturelles, qe série, 1. V'III, 1). 373-374, 1857.)

202. Note sur le Cebrio Carrenoi.

(Inn. des Sc, naturelles, /i série, L. VIII, p. 37/4-376, 1857.)

203. Fragments d'anatomic entomologique sur les Buprestides.

(Archives entomolowiques de Thomson, ᄂ. I, p. 373-381, pl. . (ig. $1-5,1857$.)

1. Sur l'appareil digestif du capmodis tenebrionis (1).373-376, lig. $(-2)$.

2. Fragment anatomique sur te eanal digestif du Dicure armo (p. 377, fig. 3).

3. Sur l'appareil génital male du Corabus bifusciulus ( $p .378$. 380 , fig. 4-5).

204. Nouvelle espèce de Cychrus (1).

(.1rchiv. entom. de Thomson, 1. I, p. 382-383, pl. xr, fig. 6-7, 1857.)

(1. Cychrus spimicollis d'Espagne, La figure porte par erreur is nom de Cychrus aculicollis. 
205. Mélanges entomologiques.

(Ann. de la Soc. ent. de France, 1857, p. 39-70.)

27. Sur une nouvelle espece de Pliylomy: neuse des fevilles du Troprolum aduncum (p. 39-47, pl. II, $n^{n}$ 1) (1).

28. Ilistoire des mélamorphoses du Trphrilis jucex el de l'Urophora quedrifasciata ( $\mathrm{p}_{0} 48-59, \mathrm{pl} . \mathrm{II}, \mathrm{n}^{\circ} \mathrm{II}$ ).

29. Sur le Hicromyrma mygmaa, nouveau genre de lormicide (p. 60-64, pl. IV, $\mathrm{n}^{\circ} \mathrm{I}$ ).

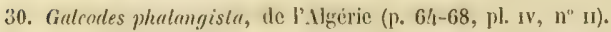

31. Sur quclques especes algériennes du genre Ophthalmiczs (p. 68-70) (2).

206. Fragments anatomiqques sur quelques Coléoptères.

(Ann. des Sc. naturelles, $4^{\circ}$ série, to IX, p. 5-22, avec une planche et 9 figures, 1858.) (Voyez $\mathrm{n}^{\circ}$ 199.)

3. Sur lappareil génital femelle du Iroplia farinosa (p. 5-6).

4. Sur le Lagria lala (p. 6-11, pl. II, fig. 2-4).

5. Sur le Tillus transversalis (p. 11-13, fig. 5).

6. Sur le Misolampus puncticollis (p. 13-17, fig. 6-9) (3).

7. Sur le Spondylis buprestoides (p. 17-20, fig. 1).

8. Sur le Nephodes villiger (p. 20-22).

207. liecherehes anatomiques el considéralions entomologiques sur les Ilémipteres du genre Leplopus (4).

(.Inn. des sc. naturelles, $l^{\circ}$ séric, l. $x$, p. 343-36/, pl. xxis, fig. 1-15, 1858. - Extrait dans C.-ri. heblom. de l'Acat. des Sciences, t. XLVIII, p. 681-687, 1858.)

(1) Phylomyza tropaoli.

(2) Ophthalmirus erythrops, emirous de Bone; (). boops, id.; (). orcipilalis, environs d'Alger.

(3) Gregarina longicuuda (10.17).

(4) Leptopus lanosus; $\boldsymbol{L}$. boopis Foercrox; $\boldsymbol{L}$. cchinops. 
208. Sur le Drassus segestriformis.

(Ann. de la Soc. ent. de France, 1858, p. 255-261, pl. vi, n ${ }^{\circ}$ II.)

209. Histoire des métamorphoses du Bombylius major.

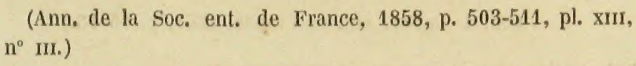

210. Sur l'habitat de la Pimelia corsnata.

(Ann. de la Soc. ent. de France, 1858, Bull., p. Xcr.)

211. Note sur une nouvelle espèce d'Hippobosque (H. camelina).

(Ann. de la Soc. ent. de Fiance, 1858, Bull., p. cirr.)

212. Recherches anatomiques sur l'Ascalaphus meridionatis.

(Ann. des Sc. naturelles, $4^{*}$ série, t. XIII, p. 193-207, pl. I, fig. 1-11, 1860. - C.-R. hebdom. de l'Acad, des sciences, t. LI, p. $232-233,1860$.)

213. Impressions d’un voyage botanique aux Alpes du Dauphiné.

(Actes de la Soc. Linnéenne de Bordeaux, t. XxIII ( $3^{\text {e }}$ série, I. III), p. 225-246, 1860-1861.)

214. Notices entomologiques.

(Ann. de la Soc. ent. de France, 1861, p. 5-14.)

1. Sur l'Epeira sericea et le Pompilus croceicornis, avec quelques considérations sur leur habitat géographique (p. 5-7, pl. I, fig. 1-2, ㅇ).

2. Euchalcis Miegii, nouveau genre et nouvelle espèce de Chalcidite, et sur quelques autres Hyménoptères de ce même genre (p. 7-11, pl. 1, fig. 4-10) (1).

3. Sur une nouvelle espèce d'Astata (p. 11, pl. I, fig. 11-12) (2).

4. Sur une nouvelle espèce de Bembex (p. 12, pl. I, fig. 13-15) (3).

(1) Euchalcis hematomera ; E. velusta; E. Dargelasii I.ATr,

(2) Astata Miegii.

(3) Bembex bipunclata. 
5. Sur une nouvelle espèce de Cephus (p. 13, pl. I, fig. 16, ठ) (1).

6. Sur une nouvelle espèce de Phalangopsis (p. 13-14) (2).

215. Leltre à la Société entomologique de France, au sujet de sa nomination à la Presidence honoraire (3).

(Ann. de la Soc. ent. de France, 1861, p. 15-16.)

216. Notice nécrologique sur le professeur Mieg.

(Ann. de la Soc. ent. de France, 1861, p. 17-20).

217. Des cocons de la Puce.

(Ann, de la Soc. ent. de France, 1861, p. 255-258).

218 Note à l'occasion de l'histoire des métamorphoses du Trachys pygmæa de $\mathrm{M}$. Leprieur.

(Ann. de la Soc. ent. de France, 1861, p. 467-468.)

219. Un mot sur la galle de la Ronce.

(Ann. de la Soc. ent. de France, 1861, p. 572.)

220. Anatomie, physiologie et histoire naturelle des Galéodes (4).

(Mémoires présentés par div. Savants à l'Acad, des Sc, de I'Institul, t. XVII, p. 338-446, pl. I IV, 4862.)

221. Etudes sur la larve du Potamophilus.

(Ann. des Sc. naturelles, $4^{\text {e }}$ série, t. XVII, p. 162-173, pl. I, fig. 1.9, 1862.)

222. Notice sur une larve présumée du Macronychus.

(Ann. des Sc. naturelles, $4^{\circ}$ série, t. XVII, p. 226-228, pl. r, fig, 10-11, 1862.)

1) Cephus nigripennis SICHEL.

(2) Phalangopsis Linderi.

(3) Le commencement de cette lettre a été aulographié et placé dans ce volume avec le portrait de M. Iéon Dufour.

(4) Description de onze espèces, dont huit sont nouvelles: Galeodes barbarus Lucas; G. Dastuguei; G. intrepidus; G. Lucasii; G. melanus Oxv.; G. phalangista SAvienY; G. brunnipes; G. quadrigerus; G. nigripalpis. En supplément : $G$, ochropus; $G$, curlipes. 
223. Notices entomologiques.

(Ann. de la Soc. ent. de France, 1862, p. 131-148.) (1)

7. Consultation sur une larve aquatique (p. 131-138, fl. II, fig. 2.)

8. Note critique sur le Scorpio Savignyi Duf. (p. 139-140).

9. Note sur la Formica Savignyi Duf. (p. 141-142).

10. Description de la galle de la Jasonia glutinosa et du Tephritis qui la produit (p. 143-145, pl. II, fig. 4) (2).

11. Description de la larve du Nosodendron (p. 146-148, pl. II, fig. 3).

224. Nolices entomologiques.

(Ann. de la Soc. ent. de France, 1863, p. 5-13.)

12. Sur trois Aranéides de Guerrera, au sud de l'Algérie (Eresus Guerinii Lucas; E. acanthophilus L. Duf,; OEcobius nigripalpis L. Duf.) (p. 5-8, pl. I, fig. 2).

13. Sur une nouvelle espèce d'Aranéide du genre Sparassus (S. annamita) (p. 9-12, pl. I, fig. 3).

14. Note justificative sur le Mycromyrma pygmæa (p. 12-13).

225. Essai monographique sur les Bélostomides.

(Ann. de la Soc. ent. de France, 1863, p. 373-400.)

226. Recherches anatomiques et physiologiques sur les Lépidopteres (Extrait).

(C.-R. hebdom. de l'Acad. des Sciences, t. LIX, p. 65-67, 1864.)

227. Ma dernière ascension au Pic du Midi de Bagnères et mon ultime adieu aux Pyrénées.

(Actes de la Soc. Linnéenne de Bordeaux, t. XXIV, tirage à part 15 pages, 1864.)

(1) Voyez $\mathrm{n}^{n} 214$

(2) Tephritis jasonice; Eulophus stenostigma. 
228. Notice sur une noouvelle espece de Gallinsecte (Aspidiotus luzulx).

(Ann. de la Soc. ent de France, 1864, p. 207-209, pl. v, fig. 4.)

229. Note sur une nouvelle espèce de Fourmi (Formica Vinsonella).

(Ann. de la Soc. ent. de France, 1864, p. 210.)

230. Description el figure du Cryptostemma alienum.

(Amn. de la Soc. ent. de France, 1364, p. 211-212, pl. v, fig. 3.)

231. Description du Siphonura gallx quercus, nouvelle espèce de Chalcidite.

(Ann. de la Soc. ent. de France, 1864, p. 213-214.)

232. De la direction à donner aux études entomologiques.

(Anin. de la Soc. ent. de France, 1864, p. 567-628.)

I. Généralités (p. 567-571).

II. Arachnides (p. 572-577).

III. Coléoptères (p. 578-586).

IV. Labidoures (p. 587),

V. Oithopteres (p. 588-591).

VI. Nevroptères (p. 592-594).

VII. Hyménoptères (p. 594-607).

VHI. Hémiptères (p. 608-612).

1X. Lépidoptères (p. 612-613).

X. Dipleres (p. 614-628). 